\title{
Next Generation Nuclear Plant Intermediate Heat Exchanger Materials Research and Development Plan
}

J. K. Wright

April 2008
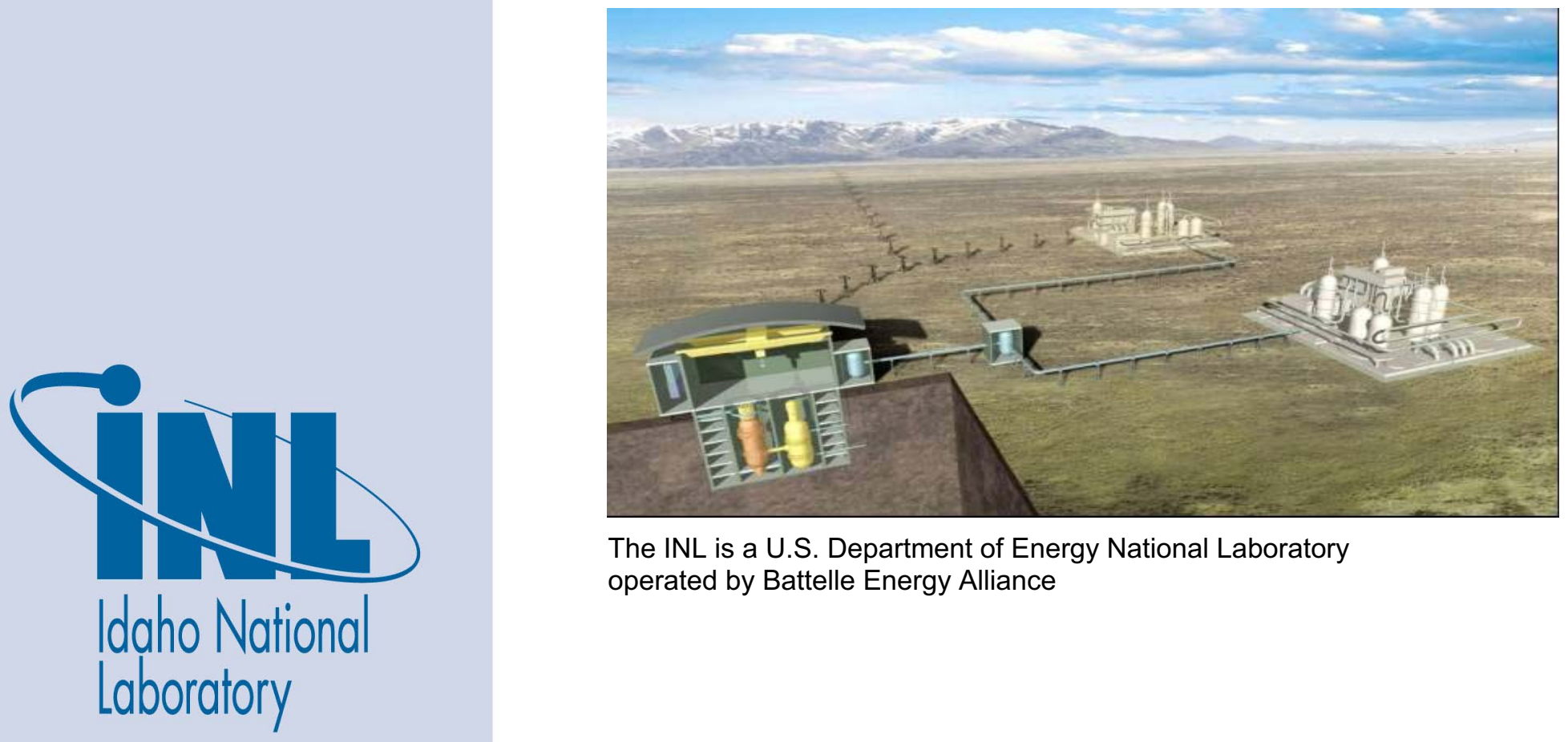

The INL is a U.S. Department of Energy National Laboratory operated by Battelle Energy Alliance 
INL/EXT-08-14107

PLN-2804

\title{
Next Generation Nuclear Plant Intermediate Heat Exchanger Materials Research and Development Plan
}

\author{
J. K. Wright
}

April 2008

Idaho National Laboratory Idaho Falls, Idaho 83415

http://www.inl.gov

Prepared for the U.S. Department of Energy

Office of Nuclear Energy Under DOE Idaho Operations Office

Contract DE-AC07-05ID14517 


\section{DISCLAIMER}

This information was prepared as an account of work sponsored by an agency of the U.S. Government. Neither the U.S. Government nor any agency thereof, nor any of their employees, makes any warranty, expressed or implied, or assumes any legal liability or responsibility for the accuracy, completeness, or usefulness, of any information, apparatus, product, or process disclosed, or represents that its use would not infringe privately owned rights. References herein to any specific commercial product, process, or service by trade name, trade mark, manufacturer, or otherwise, does not necessarily constitute or imply its endorsement, recommendation, or favoring by the U.S. Government or any agency thereof. The views and opinions of authors expressed herein do not necessarily state or reflect those of the U.S. Government or any agency thereof. 

NEXT GENERATION NUCLEAR PLANT

INTERMEDIATE HEAT EXCHANGER

MATERIALS RESEARCH AND DEVELOPMENT PLAN
Identifier: PLN-2804

Revision: $\quad 0$

Effective Date: $04 / 30 / 08$

Page:ii of xix

Materials Properties and Engineering

Plan

eCR Number: 560588

\section{REVISION LOG}

\begin{tabular}{|l|l|l|l|}
\hline Rev. & Date & Affected Pages & \multicolumn{1}{c|}{ Revision Description } \\
\hline 0 & $4 / 30 / 08$ & All & New document \\
\hline & & & \\
\hline & & & \\
\hline & & & \\
\hline & & & \\
\hline & & & \\
\hline & & & \\
\hline & & & \\
\hline & & & \\
\hline & & & \\
\hline & & & \\
\hline & & & \\
\hline
\end{tabular}


NEXT GENERATION NUCLEAR PLANT

INTERMEDIATE HEAT EXCHANGER

MATERIALS RESEARCH AND DEVELOPMENT PLAN
Identifier: $\quad$ PLN-2804

Revision: $\quad 0$

Effective Date: $04 / 30 / 08 \quad$ Page:iii of xix 


\begin{tabular}{c|lll|}
\hline $\begin{array}{l}\text { NEXT GENERATION NUCLEAR PLANT } \\
\text { INTERMEDIATE HEAT EXCHANGER }\end{array}$ & Identifier: & PLN-2804 & \\
MATERIALS RESEARCH & Revision: & 0 & \\
AND DEVELOPMENT PLAN & Effective Date: & $04 / 30 / 08$ & Page:iv of xix \\
\hline
\end{tabular}

\section{EXECUTIVE SUMMARY}

DOE has selected the High Temperature Gas-cooled Reactor (HTGR) design for the Next Generation Nuclear Plant (NGNP) Project. The NGNP will demonstrate the use of nuclear power for electricity and hydrogen production. It will have an outlet gas temperature in the range of $900^{\circ} \mathrm{C}$ and a plant design service life of 60 years. The reactor design will be a graphite-moderated, heliumcooled, prismatic or pebble-bed reactor and use low-enriched uranium, TriIsotopic (TRISO)-coated fuel. The plant size, reactor thermal power, and core configuration will ensure passive decay heat removal without fuel damage or radioactive material releases during accidents. The NGNP Materials Research and Development (R\&D) Program is responsible for performing R\&D on likely NGNP materials in support of the NGNP design, licensing, and construction activities.

Today's high temperature alloys and associated American Society of Mechanical Engineers (ASME) Codes for reactor applications are approved up to $760^{\circ} \mathrm{C}$. However, some primary system components, such as the Intermediate Heat Exchanger (IHX) for the NGNP will require use of materials that can withstand higher temperatures. The thermal, environmental, and service life conditions of the NGNP will make selection and qualification of some high temperature materials a significant challenge. Examples include materials for the core barrel and core internals, such as the control rod sleeves. The requirements of the materials for the IHX are among the most demanding.

Selection of the technology and design configuration for the NGNP must consider both the cost and risk profiles to ensure that the demonstration plant establishes a sound foundation for future commercial deployments. The NGNP challenge is to achieve a significant advancement in nuclear technology while at the same time setting the stage for an economically viable deployment of the new technology in the commercial sector soon after 2020.

A number of solid solution strengthened nickel-based alloys have been considered for application in heat exchangers and core internals for the NGNP. The primary candidates are Inconel 617, Haynes 230, Incoloy $800 \mathrm{H}$ and Hastelloy XR. Based on the technical maturity, availability in required product forms, experience base, and high temperature mechanical properties all of the vendor preconceptual design studies have specified Alloy 617 as the material of choice for heat exchangers. Also a draft code case for Alloy 617 was developed previously. Although action was suspended before the code case was accepted by ASME, this draft code case provides a significant head start for achieving codification of the material. Similarly, Alloy $800 \mathrm{H}$ is the material of choice for control rod sleeves. In addition to the above listed considerations, Alloy $800 \mathrm{H}$ is already listed in the nuclear section of the ASME Code; although the maximum use temperature and time need to be increased.

The highest priority research and development tasks that have been identified in this Technology Development Plan are generating sufficient information to develop a code case for inclusion of Alloy 617 in the nuclear 


\begin{tabular}{c|lll|}
\hline NEXT GENERATION NUCLEAR PLANT & Identifier: & PLN-2804 & \\
INTERMEDIATE HEAT EXCHANGER & Revision: & 0 & \\
MATERIALS RESEARCH & Effective Date: & $04 / 30 / 08$ & Page:v of xix \\
AND DEVELOPMENT PLAN &
\end{tabular}

section of the ASME Code. Specific weaknesses in understanding properties of this material were identified in comments received on the draft code case and through more recent discussion with ASME. Greater understanding of the creepfatigue behavior of the alloy and weldments has been ranked as the highest priority for generating additional information prior to submitting an updated code case.

The NGNP project has also identified a number of areas where additional characterization of the behavior of Alloy 617 is required for high temperature design. These include constitutive models for behavior of the alloy in tensile loading at elevated temperature, for creep and for creep-fatigue. These data are needed for both as-received material and after long-term aging. Note that because of the design of NGNP, the heat exchangers will not experience irradiation and no testing of irradiated Alloy 617 is required.

In addition to the requirement for inclusion of Alloy 617 in the ASME Code, it has been determined that additional scoping studies of potential degradation of the properties of this material due to high temperature interaction with the anticipated NGNP helium environment are required. Phenomenological models for environmental degradation and greater understanding of the kinetics of degradation are needed to help bound the requirements for control of impurities in the primary and secondary helium during operation of the NGNP. Tests are specified to determine environmental effects on microstructure and properties.

Although Alloy $800 \mathrm{H}$ is included in the nuclear section of the ASME Code, requirement for some additional characterization has been identified in this Technology Development Plan. Some information on changes in properties of Alloy $800 \mathrm{H}$ under irradiation are available, however, additional scoping studies are specified to characterize the irradiation behavior of this material at higher temperatures than currently available. Mechanical property characterization for this material after long-term aging is also required.

A large matrix of required testing to support design and licensing of the NGNP has been developed as part of this Technology Development Plan. Investment in additional testing capabilities and development of a long-term aging facility will be necessary to accomplish all of the required tests. The abbreviated table below outlines the scope and cost of the research. If sufficient funding is available, completion of the necessary research and development can be accomplished to support the NGNP schedule. 
NEXT GENERATION NUCLEAR PLANT

INTERMEDIATE HEAT EXCHANGER

MATERIALS RESEARCH AND DEVELOPMENT PLAN
Identifier: PLN-2804

Revision: $\quad 0$

Effective Date: $04 / 30 / 08$

Page:vi of xix

\begin{tabular}{|l|l|c|}
\hline \multicolumn{1}{|c|}{ Activity } & \multicolumn{1}{|c|}{ Detail } & Cost (\$) \\
\hline Raw Materials \& Consumables & $7500 \mathrm{lbs}$ & 700,000 \\
\hline Machining Specimens & & 328,125 \\
\hline Materials Subtotal (With Adder) & & $1,336,563$ \\
\hline Mechanical Properties & 2785 specimens & $6,155,100$ \\
\hline Corrosion & & 500,000 \\
\hline Irradiation & & $1,000,000$ \\
\hline Physical Property & & 500,000 \\
\hline Testing Subtotal & 11 load frames, fixtures, furnaces + other & $7,155,100$ \\
\hline Equipment Purchases \& Upgrades & analysis, modeling, code support, etc. & $4,322,500$ \\
\hline Post-Test Labor & constitutive modeling & $4,800,000$ \\
\hline Subcontracts & & $1,100,000$ \\
\hline QA \& Program Management & & 3942833 \\
\hline Total & & $23,656,995$ \\
\hline
\end{tabular}


NEXT GENERATION NUCLEAR PLANT

INTERMEDIATE HEAT EXCHANGER

MATERIALS RESEARCH AND DEVELOPMENT PLAN
Identifier: $\quad$ PLN-2804

Revision: $\quad 0$

Effective Date: $04 / 30 / 08 \quad$ Page:vii of xix 


\section{ACKNOWLEDGMENTS}

The authors gratefully acknowledge the assistance of the following: D.S. Vandel, J.R. Cox, D.C. Kunerth, from INL and W.R. Corwin, D.F. Wilson, J.P. Shingledecker, R.L. Battiste, M.L. Santella, and Z. Feng from ORNL. We would also like to thank R.I. Jetter, Chair, ASME Boiler and Pressure Vessel Code, SCD, Subgroup Elevated Temperature Design; R.W. Swindeman of Cromtech Inc.; K.P. Walker of Engineering Science Software, Inc.; V.K. Vasudevan, Professor, Department of Chemical and Materials Engineering, University of Cincinnati; and W.J. O'Donnell of O'Donnell Consulting Engineers, Inc. 
NEXT GENERATION NUCLEAR PLANT

INTERMEDIATE HEAT EXCHANGER

MATERIALS RESEARCH AND DEVELOPMENT PLAN
Identifier: $\quad$ PLN-2804

Revision: $\quad 0$

Effective Date: $04 / 30 / 08 \quad$ Page:ix of xix 
NEXT GENERATION NUCLEAR PLANT

INTERMEDIATE HEAT EXCHANGER

MATERIALS RESEARCH AND DEVELOPMENT PLAN
Identifier: $\quad$ PLN-2804

Revision: $\quad 0$

Effective Date: $04 / 30 / 08$
Page:x of xix

\section{CONTENTS}

EXECUTIVE SUMMARY iv

ACKNOWLEDGMENTS viii

ACRONYMS xviii

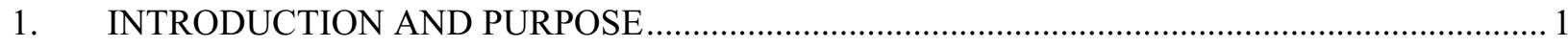

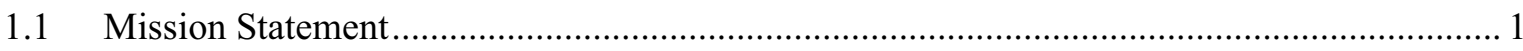

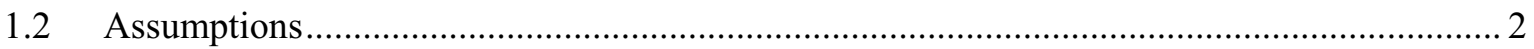

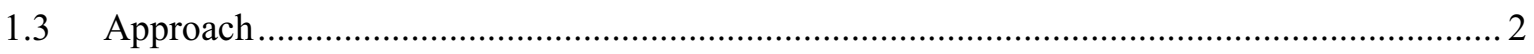

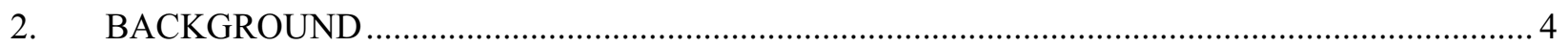

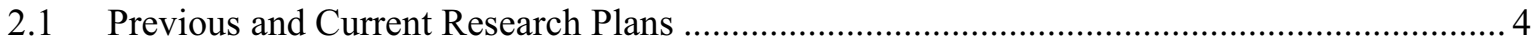

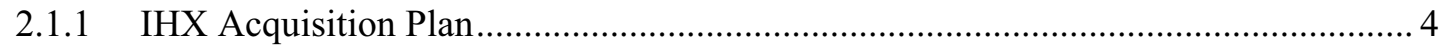

2.1.2 FY-07 Research and Technology Plan (Preliminary) ................................................. 4

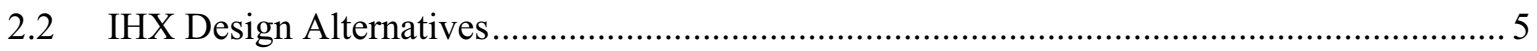

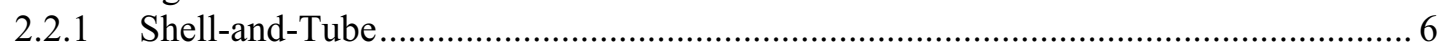

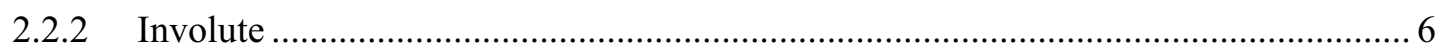

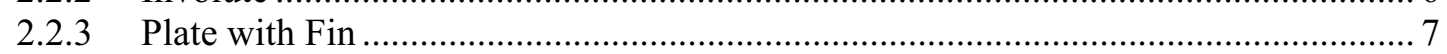

2.2.4 Etched Plate ......................................................................................... 7

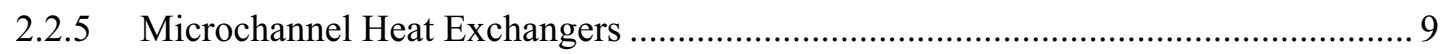

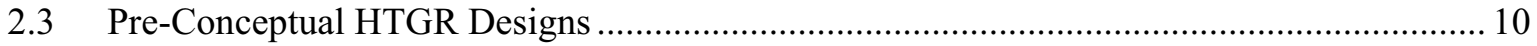

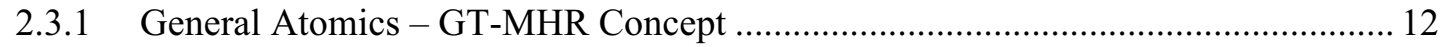

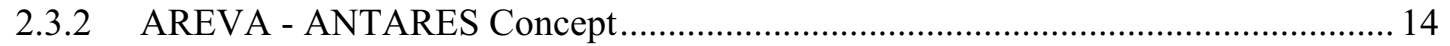

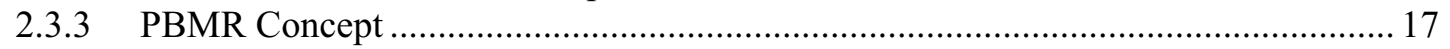

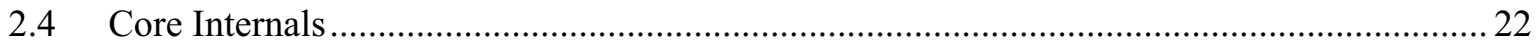

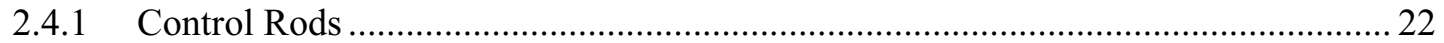

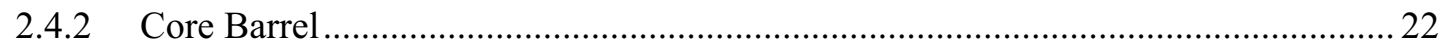

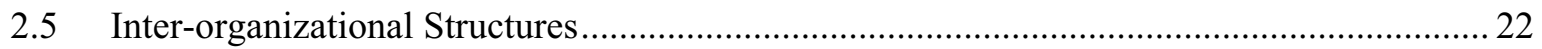

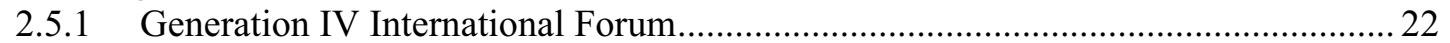

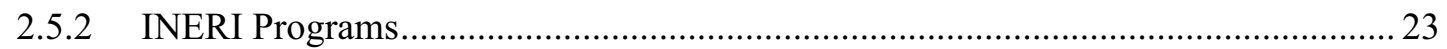

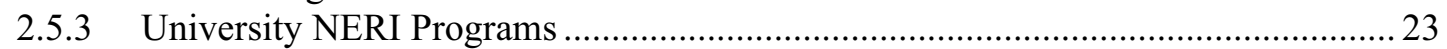

2.5.4 The Independent Technical Review Group............................................................ 23

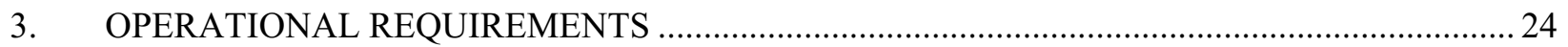

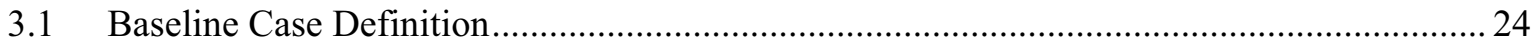

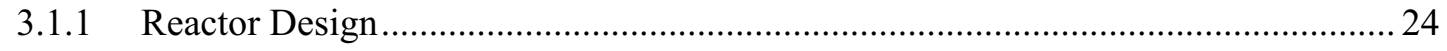

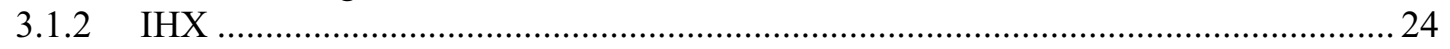

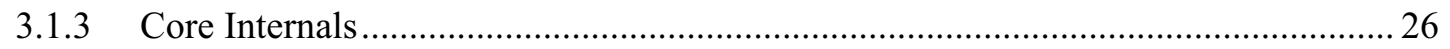

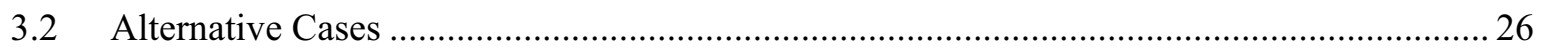

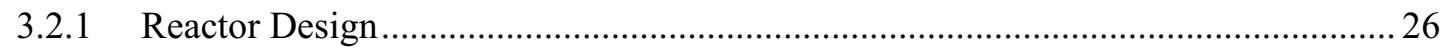

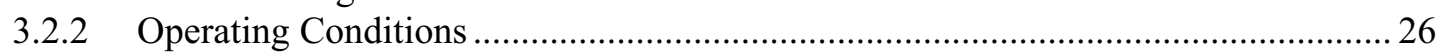

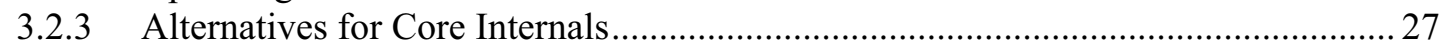

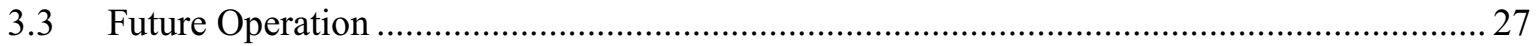




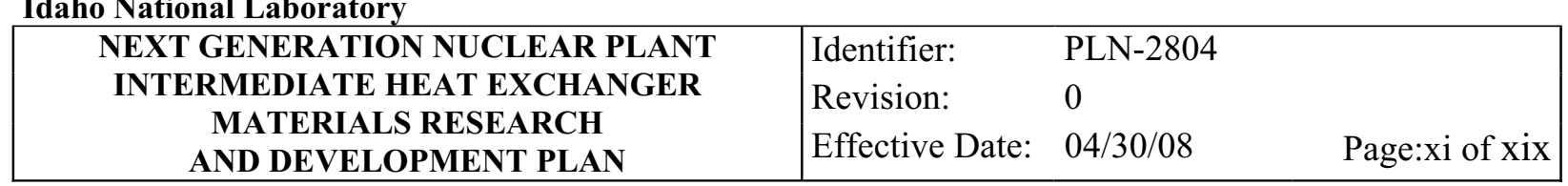

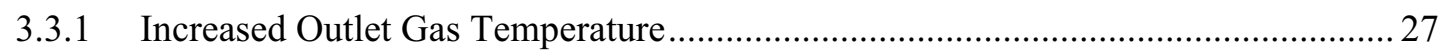

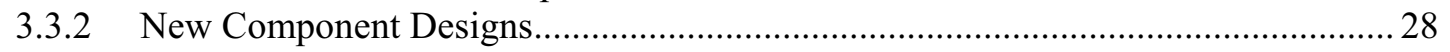

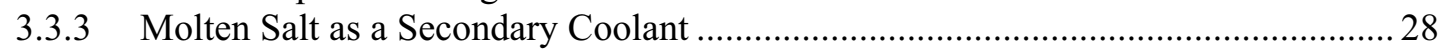

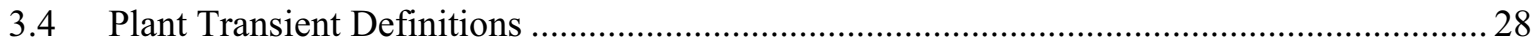

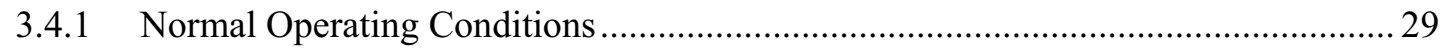

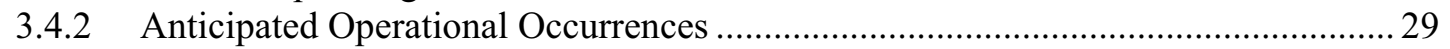

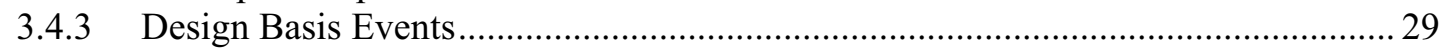

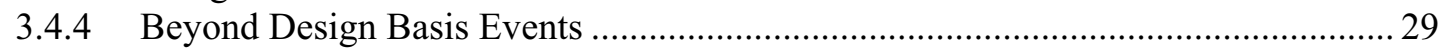

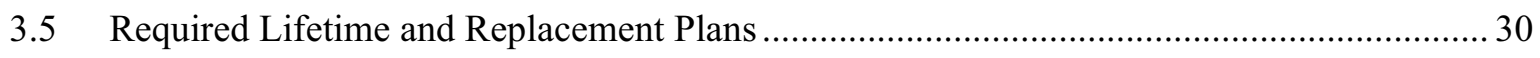

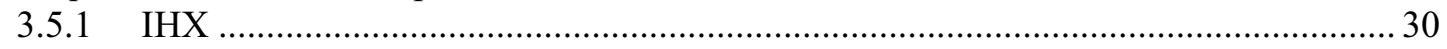

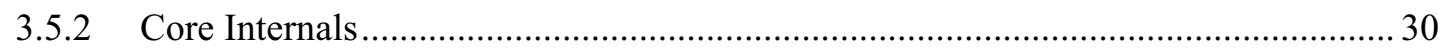

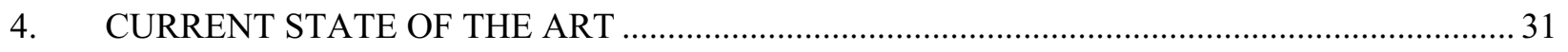

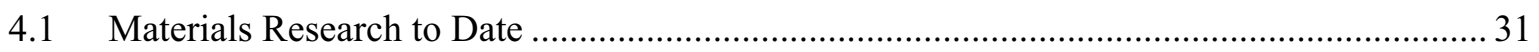

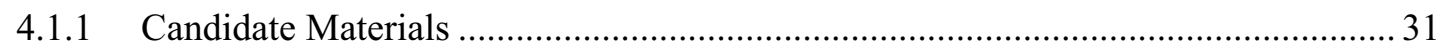

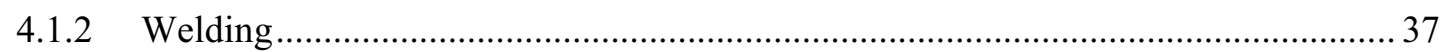

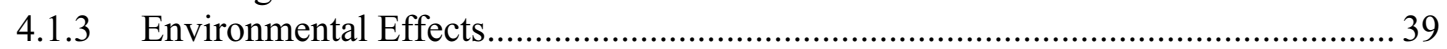

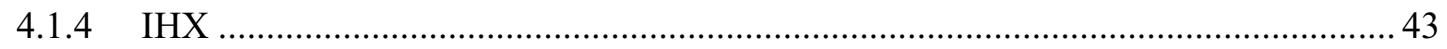

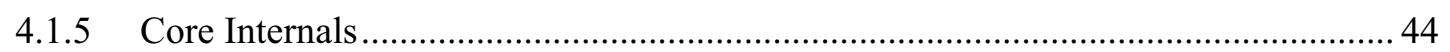

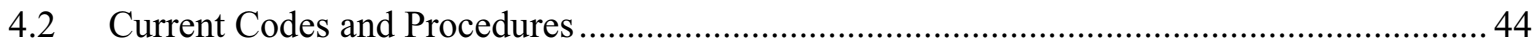

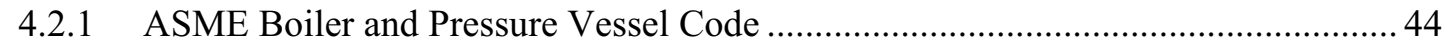

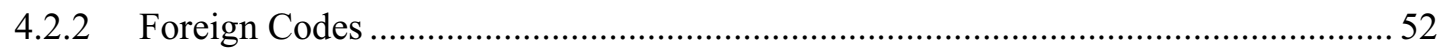

4.2.3 DOE Initiative to Address ASME Code Issues for Gen IV Reactors ........................ 53

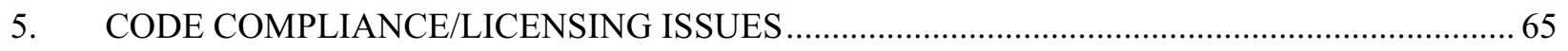

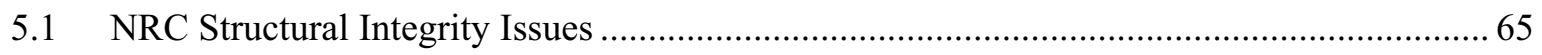

5.2 Strategy to Support Code and Licensing Needs........................................................... 72

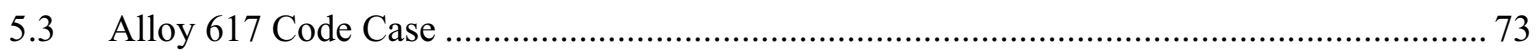

5.3.1 Actions for 617 Code Case (Standard Grain Size) .................................................... 73

5.3.2 Implication of Code Class Designation for Alloy 617 Code Case ............................ 74

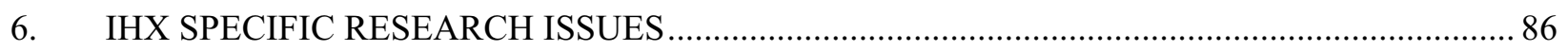

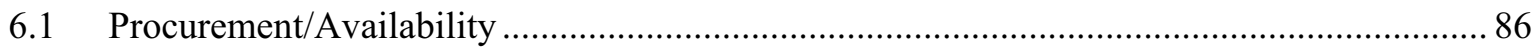

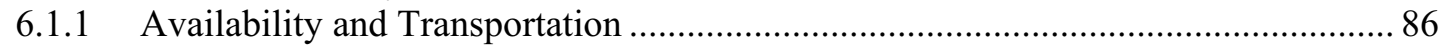

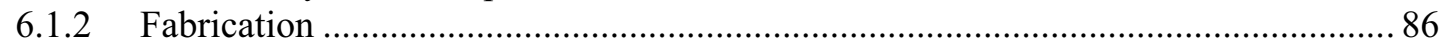

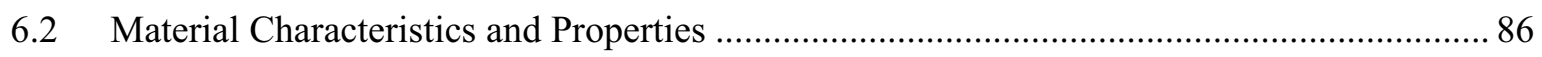

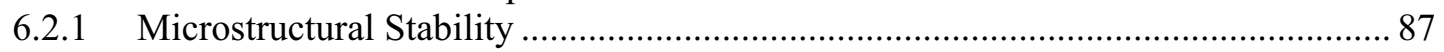

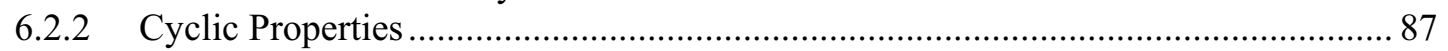

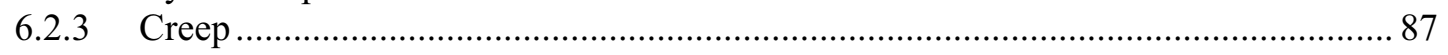

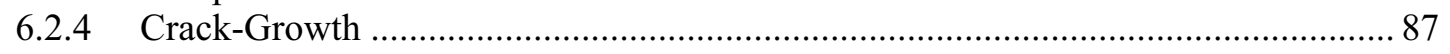

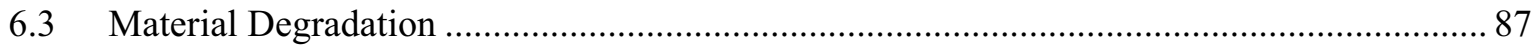

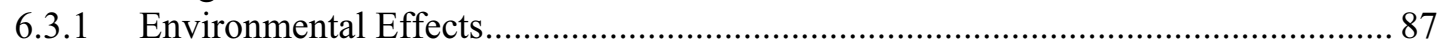

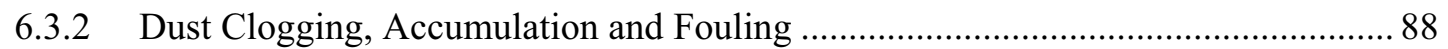

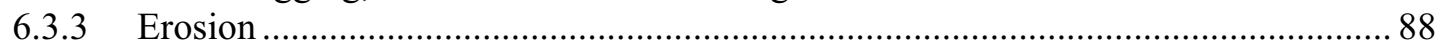

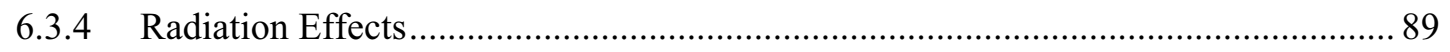




\begin{tabular}{|c|c|c|c|c|}
\hline $\begin{array}{r}\text { NEX' } \\
\text { INT } \\
\end{array}$ & $\begin{array}{l}\text { GENERATION NUCLEAR PLANT } \\
\text { RMEDIATE HEAT EXCHANGER } \\
\text { MATERIALS RESEARCH } \\
\text { AND DEVELOPMENT PLAN } \\
\end{array}$ & $\begin{array}{l}\text { Identifier: } \\
\text { Revision: } \\
\text { Effective Date: }\end{array}$ & $\begin{array}{l}\text { PLN-2804 } \\
0 \\
04 / 30 / 08\end{array}$ & Page:xii of xix \\
\hline 6.4 & 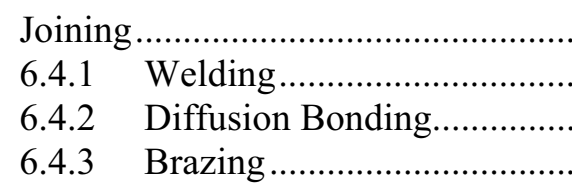 & . & & 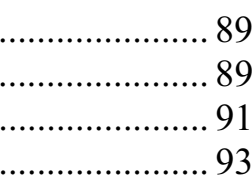 \\
\hline 6.5 & 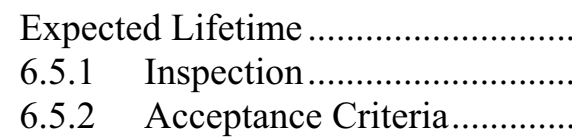 & & 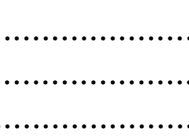 & 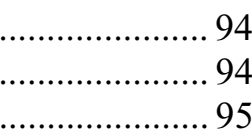 \\
\hline
\end{tabular}

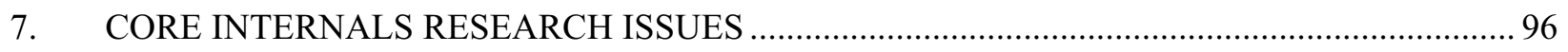

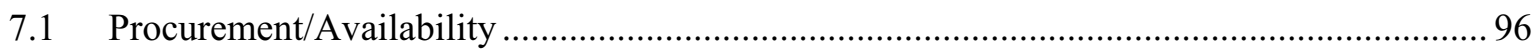

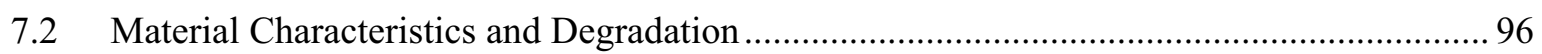

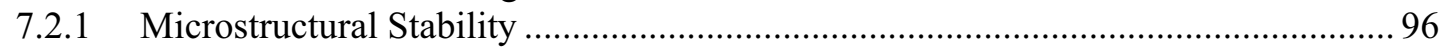

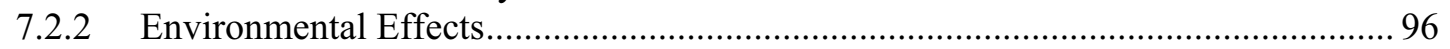

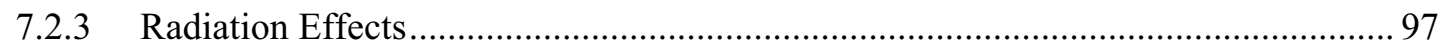

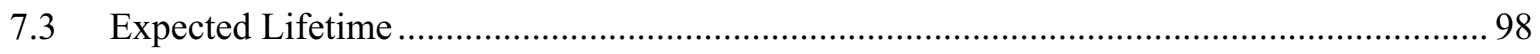

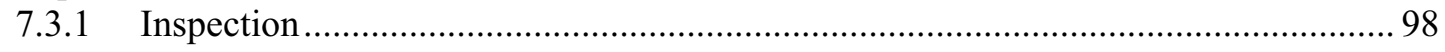

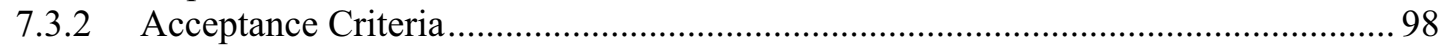

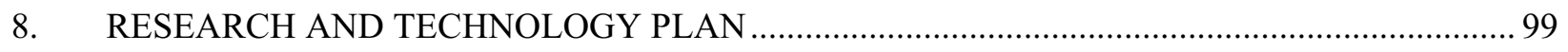

8.1 Required Actions for Code/Licensing Issues .................................................................... 99

8.1.1 Issues Originally Identified for Draft Alloy 617 Code Case..................................... 102

8.1.2 Data Needs Originally Identified for Draft Alloy 617 Code Case ............................... 104

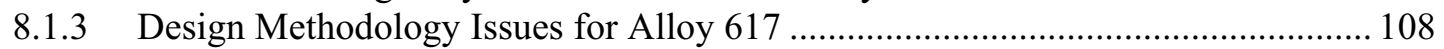

8.1.4 Additional Issues to Update Alloy 617 Data for Subsection NH............................ 119

8.1.5 Significant Recently Emerged Issues for Alloy 617 .............................................. 128

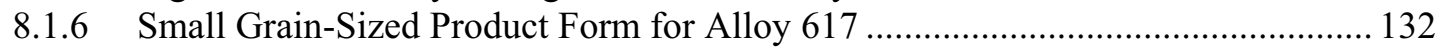

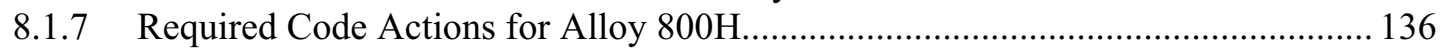

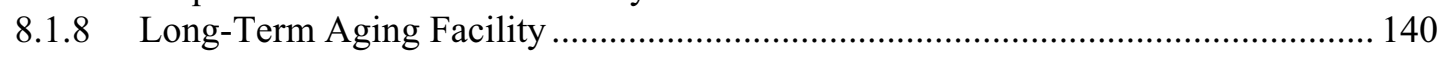

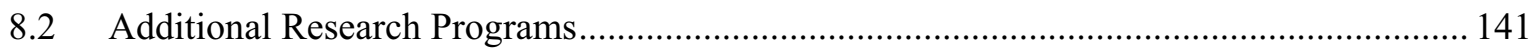

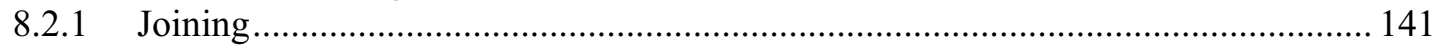

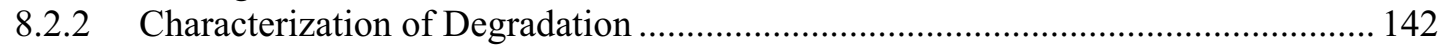

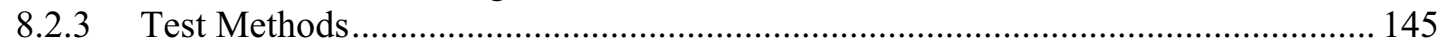

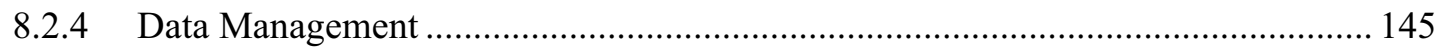

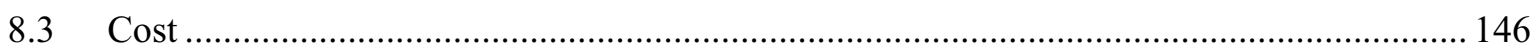

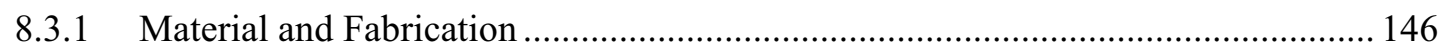

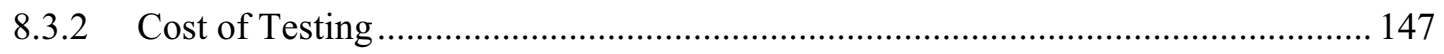

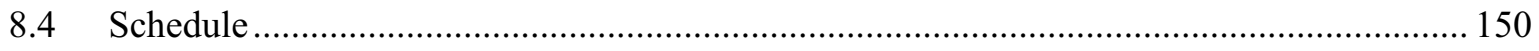

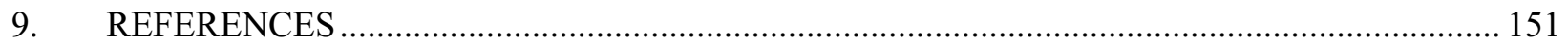

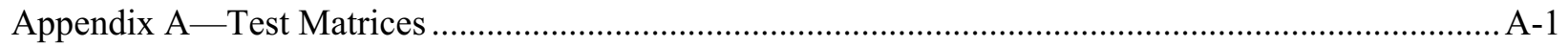




\begin{tabular}{c|lll|} 
NEXT GENERATION NUCLEAR PLANT & Identifier: & PLN-2804 & \\
INTERMEDIATE HEAT EXCHANGER & Revision: & 0 & \\
MATERIALS RESEARCH & Effective Date: & $04 / 30 / 08$ & Page:xiii of xix \\
AND DEVELOPMENT PLAN &
\end{tabular}

\section{FIGURES}

Figure 1. Involute Heat Exchanger viewed from several perspectives. 6

Figure 2. Unit Cell Heat Exchanger (a) primary side plate, (b) the unit cell showing countercurrent flow. 7

Figure 3. The diffusion-bonded heat exchanger in the foreground undertakes the same thermal duty, at the same pressure drop, as the stack of three shell and tube exchangers behind. 8

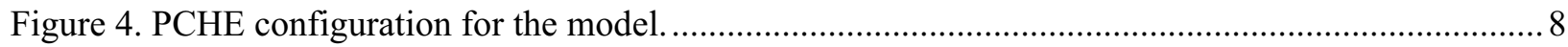

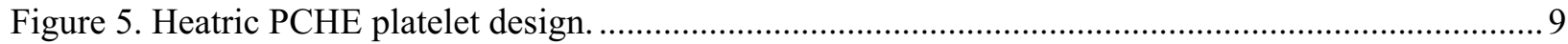

Figure 6. Section of Velocys heat exchanger showing layers of corrugated sheet. ..................................9

Figure 7. GT-MHR reactor system cutaway showing the metallic internals structures, core, control rod guide tubes and cross vessel (labeled as hot duct). 12

Figure 8. NGNP configuration as proposed by General Atomics....................................................... 13

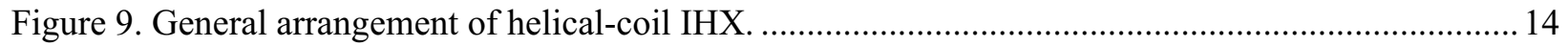

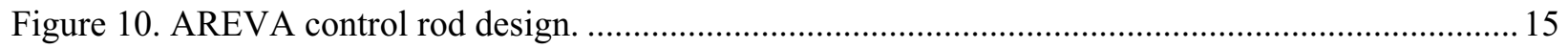

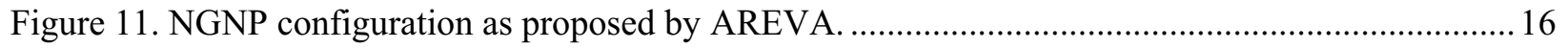

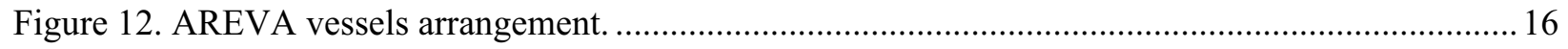

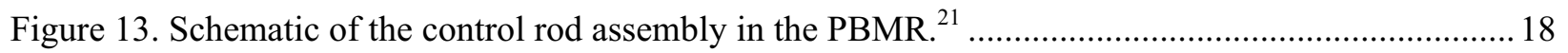

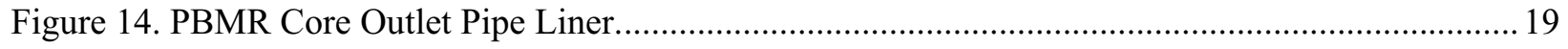

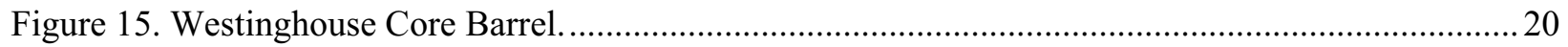

Figure 16. NGNP configuration as proposed by Westinghouse ........................................................2

Figure 17. Proposed layout of the reactor unit system in relation to the PHTS, SHTS, SG and

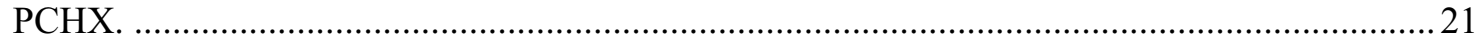

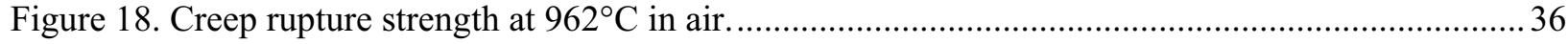

Figure 19. Isothermal oxidation behavior after $800 \mathrm{~h}$ exposure at $950^{\circ} \mathrm{C}$ in helium environment.............36

Figure 20. Mass change as a function of time in $\mathrm{H} 2-5.5 \% \mathrm{CH} 4-4.5 \% \mathrm{CO} 2$ carburizing environment

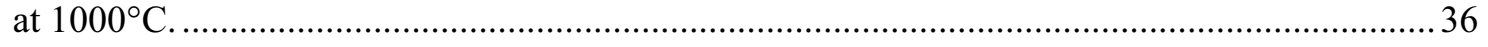

Figure 21. Allowable stress for heat exchanger materials for plate, sheet and strip forms......................36

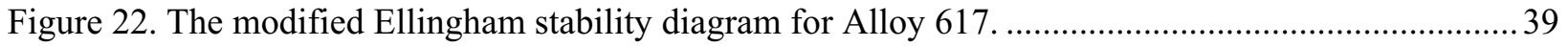

Figure 23. Schematic of the current configuration of the INL controlled chemistry high

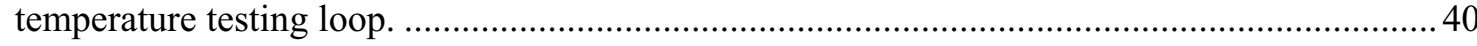

Figure 24. Optical micrographs of cross-sections through (a) Alloy 617 and (b) Alloy 230 for the $1000^{\circ} \mathrm{C}$ experiment under oxidizing conditions.

Figure 25. Optical micrographs of cross-sections through (a) Alloy 617 and (b) Alloy 230 for the $1000^{\circ} \mathrm{C}$ experiment under carburizing conditions.

Figure 26. Optical micrograph of carbides in the center of the Alloy 230 coupon after carburizing exposure at $1000^{\circ} \mathrm{C}$ 
NEXT GENERATION NUCLEAR PLANT

INTERMEDIATE HEAT EXCHANGER

MATERIALS RESEARCH AND DEVELOPMENT PLAN
Identifier: $\quad$ PLN-2804

Revision: $\quad 0$

Effective Date: $04 / 30 / 08 \quad$ Page:xiv of xix

Figure 27. Tensile data for irradiated $800 \mathrm{H}$ (a) yield strength, (b) total elongation. ................................97

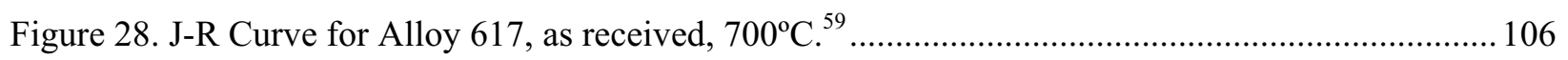

Figure 29(a). Values of $\mathrm{J}_{0}$ and (b). tearing modulus for Alloy 617, as received

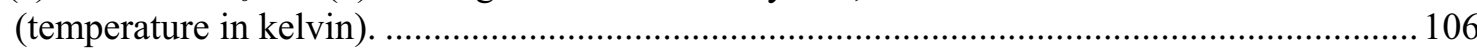

Figure 30. Room-temperature CVN energy of Alloy 617 after thermal exposure. ................................ 107

Figure 31. CVN energy at room temperature and aging temperature after thermal exposure................. 107

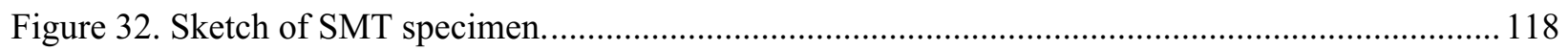

Figure 33. Thermal aging effect on room temperature yield strength. ................................................ 124

Figure 34. Thermal aging effect on room temperature tensile strength............................................ 125

Figure 35. Effect of aging at $871^{\circ} \mathrm{C}$ on strengths and elongation of Alloy 617..................................... 125

Figure 36. German creep-fatigue data for Alloy 617 in impure helium at $950^{\circ} \mathrm{C}$............................... 130

Figure 37(a). Preliminary INL creep-fatigue data for Alloy 617 in air at $800^{\circ} \mathrm{C}$. ................................ 130

Figure 37(b). Preliminary INL creep-fatigue data for Alloy 617 in air at $1000^{\circ} \mathrm{C}$.............................. 130

Figure 37(c). Preliminary INL creep-fatigue data for Alloy 617 in vacuum at $1000^{\circ} \mathrm{C} \ldots \ldots \ldots \ldots \ldots \ldots \ldots \ldots . . . . . . . . . .130$

Figure 38. Creep curves for (a) HR-120, and (b) Alloy 230 ........................................................... 133

Figure 39. Strengths comparison of service-exposed (73,500 hours) and laboratory-exposed (18,600 hours) Alloy $800 \mathrm{H}$. 


\begin{tabular}{c|lll|} 
NEXT GENERATION NUCLEAR PLANT & Identifier: & PLN-2804 & \\
INTERMEDIATE HEAT EXCHANGER & Revision: & 0 & \\
MATERIALS RESEARCH & Effective Date: & $04 / 30 / 08$ & Page:xv of xix \\
AND DEVELOPMENT PLAN &
\end{tabular}

\section{TABLES}

Table 1. Properties of heat exchangers as presented by Velocys...................................................... 10

Table 2. Key operating parameters for the NGNP designs and the Fort St. Vrain HTGR...................... 11

Table 3. Material selections for elevated temperature components in the PBMR-DPP.......................... 18

Table 4. Current estimated operating conditions for NGNP control rods for outlet gas of $950^{\circ} \mathrm{C} \ldots \ldots \ldots \ldots . . .28$

Table 5. Chemical Composition (wt. \%) of Alloy 617. ........................................................................... 31

Table 6. Prediction and Observations of Second Phase Precipitates in Alloy 617................................... 32

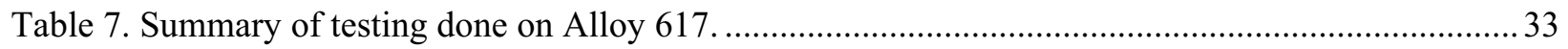

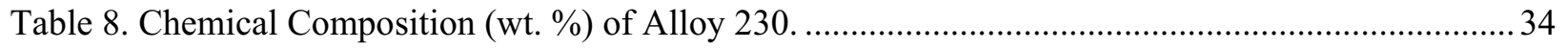

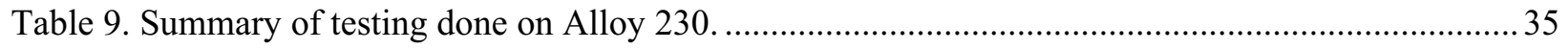

Table 10. Room-temperature tensile properties of joints in as-welded condition. ................................... 37

Table 11. Tensile properties of 230 base and weld metals. ................................................................... 37

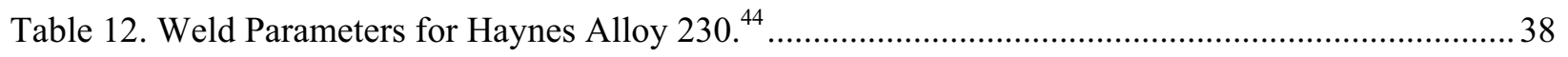

Table 13. Comparison of PCHE and shell-and-tube IHX designs....................................................... 43

Table 14. Definition of B\&PV Codes for Subsections in Section III Division 1. .................................... 45

Table 15. Section III, Division 1 Code cases developed for elevated temperature service. ....................... 45

Table 16. Materials specified in NH for elevated temperature service in nuclear applications................. 48

Table 17. The temperature and time limits for $\mathrm{NH}$ code materials for bolting........................................ 48

Table 18. Summary of licensing concerns based on elevated temperature structural integrity issues........56

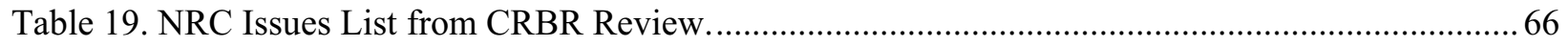

Table 20. Issues originally identified for the Draft Alloy 617 Code Case................................................ 75

Table 21. Additional issues to keep current with Subsection NH........................................................... 79

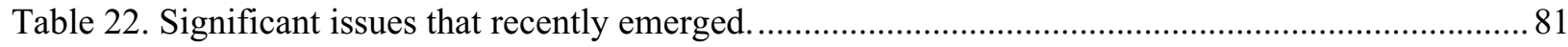

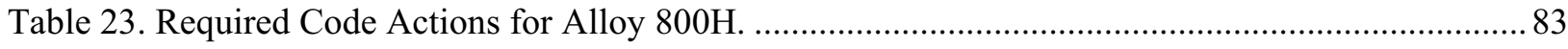

Table 24. Summary of testing required to address code and licensing issues. ...................................... 100

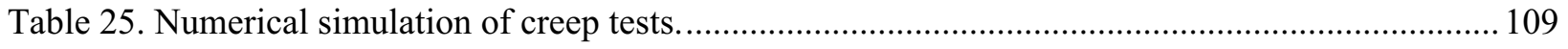

Table 26. Deformation/microstructural behaviors to be modeled by unified constitutive equations. ...... 110

Table 27. Huntington Alloys creep rupture data for Alloy 617 in air................................................... 120

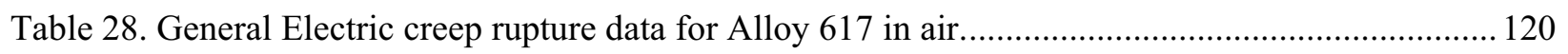

Table 29. ORNL creep rupture data for Alloy 617 in air.................................................................. 121

Table 30. European Creep Collaborative Committee creep rupture data for Alloy 617 in air. ............... 121

Table 31. Petten creep rupture data for Alloy 617 in air................................................................... 122

Table 32. Creep rupture data for Alloy 230 tube and foils. .............................................................. 133 
Identifier: $\quad$ PLN-2804

Revision: $\quad 0$

Effective Date: $04 / 30 / 08 \quad$ Page:xvi of xix

Table 33. Grain sizes specified for various sheet and strip thicknesses in ASME SB-168..................... 135

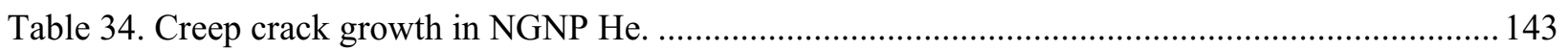

Table 35. Cost Breakdown of Mechanical Property Testing. …........................................................... 148

Table 36. Cost breakdown for high temperature materials R\&D plan................................................... 149 
NEXT GENERATION NUCLEAR PLANT

INTERMEDIATE HEAT EXCHANGER

MATERIALS RESEARCH AND DEVELOPMENT PLAN
Identifier: $\quad$ PLN-2804

Revision: $\quad 0$

Effective Date: $04 / 30 / 08 \quad$ Page:xvii of xix 


\begin{tabular}{|c|lll|}
\hline NEXT GENERATION NUCLEAR PLANT & Identifier: & \multicolumn{2}{l|}{ PLN-2804 } \\
INTERMEDIATE HEAT EXCHANGER & Revision: & 0 & \\
MATERIALS RESEARCH & Effective Date: & $04 / 30 / 08$ & Page:xviii of Xix \\
AND DEVELOPMENT PLAN &
\end{tabular}

\section{ACRONYMS}

ACRS

AOO

ASME

ASTM

AVR

B\&PV

BDBE

$\mathrm{C}_{\mathrm{f}} / \mathrm{C}$

CRBRP

CT

DBE

DCC

DOE

ETD

GA

GIF

GT-MHR

HFIR

HTE

HPCC

HTGR

HTR

HTTR

IHX

INERI

INL

ITRG

LBE

LMFBR

LPCC

LWR

NE

NERI

NGNP

NRC

ODIN

ODS

ORNL

PBMR

PCHE

PBR
Advisory Committee on Reactor Safety

Anticipated Operational Occurrence

American Society of Mechanical Engineers

American Society for Testing and Materials

Albeitsgemeinschaft Versuchsreaktor

Boiler and Pressure Vessel

Beyond Design Basis Event

Carbon/Carbon Composite

Clinch River Breeder Reactor Plant

$\mathrm{X}$-ray Tomography

Design Basis Event

Depressurized Conduction Cool-down

Department of Energy

Elevated Temperature Design

General Atomics

Generation IV International Forum

Gas Turbine-Modular Helium Reactor

High-Flux Isotope Reactor

High Temperature Electrolysis

High Pressure Conduction Cooldown

High-Temperature Gas-cooled Reactor

High-Temperature Reactor

High-Temperature Engineering Test Reactor

Intermediate Heat Exchanger

International Nuclear Energy Research Initiative

Idaho National Laboratory (formerly the Idaho National Engineering and Environmental Laboratory)

Independent Technical Review Group

Licensing Basis Event

Liquid Metal Fast Breeder Reactor

Low Pressure Conduction Cooldown

Light Water Reactor

DOE Office of Nuclear Energy

Nuclear Energy Research Initiative

Next Generation Nuclear Plant

Nuclear Regulatory Commission

Online Data \& Information Network

Oxide Dispersion-Strengthened

Oak Ridge National Laboratory

Pebble Bed Modular Helium Reactor

Printed Circuit Heat Exchangers

Pebble Bed Reactor 


\begin{tabular}{|ll|ll|}
\hline \multicolumn{1}{|c|}{$\begin{array}{c}\text { NEXT GENERATION NUCLEAR PLANT } \\
\text { INTERMEDIATE HEAT EXCHANGER } \\
\text { MATERIALS RESEARCH } \\
\text { AND DEVELOPMENT PLAN }\end{array}$} & $\begin{array}{l}\text { Identifier: } \\
\text { Revision: } \\
\text { Effective Date: }\end{array}$ & $\begin{array}{l}\text { PLN-2804 } \\
0\end{array}$ & \\
PCS & Power Conversion System & & Page:xix of xix \\
PCU & Power Conversion Unit & & \\
PHX & Process Heat Exchanger & & \\
PMR & Prismatic Modular Reactor & & \\
QA & Quality Assurance & & \\
RCS & Reactor Control System & & \\
R\&D & Research and Development & & \\
RPV & Reactor Pressure Vessel & & \\
SiC $/$ SiC & Silicon-Carbide Fiber/Silicon-Carbide Composite & \\
SI & sulfur-iodine & & \\
SS & Stainless Steel & & \\
SSC & Safety Significant Components & & \\
TDP & Technology Development Plan & & \\
THTR & Thorium Hochtemperatur Reaktor & & \\
TRISO & Tri-Isotopic (fuel) & & \\
UT & Ultrasonic Testing & & \\
\end{tabular}




\begin{tabular}{c|lll|}
\hline NEXT GENERATION NUCLEAR PLANT & Identifier: & PLN-2804 & \\
INTERMEDIATE HEAT EXCHANGER & Revision: & 0 & \\
MATERIALS RESEARCH & Effective Date: & $04 / 30 / 08$ & Page: 1 of 156 \\
AND DEVELOPMENT PLAN &
\end{tabular}

\section{INTRODUCTION AND PURPOSE}

The Department of Energy (DOE) has selected a High Temperature Gas-cooled Reactor (HTGR) as the basis for the Next Generation Nuclear Plant (NGNP) Project. The NGNP will demonstrate the use of nuclear power for electricity and hydrogen production. The reactor will be a graphite-moderated, heliumcooled, prismatic or pebble-bed, thermal neutron spectrum reactor. The NGNP will use very high burnup, low-enriched uranium, Tri-Isotopic (TRISO)-coated fuel and have a projected plant design service life of 60 years. The HTGR concept is considered to be the nearest-term reactor design that has the capability to efficiently produce hydrogen. The plant size, reactor thermal power, and core configuration will ensure passive decay heat removal without fuel damage or radioactive material releases during accidents.

The basic technology for the NGNP was established in former high temperature gas-cooled reactor plants (e.g., DRAGON, Peach Bottom, Albeitsgemeinschaft Versuchsreaktor [AVR], Thorium Hochtemperatur Reaktor [THTR], and Fort St. Vrain). These reactor designs represent two design categories: the Pebble Bed Reactor and the Prismatic Modular Reactor (PMR). Commercial examples of potential NGNP candidates are the Gas Turbine-Modular Helium Reactor (GT-MHR) from General Atomics (GA), the High Temperature Reactor concept (ANTARES) from AREVA, and the Pebble Bed Modular Reactor (PBMR) from the PBMR consortium. Furthermore, the Japanese High-Temperature Engineering Test Reactor (HTTR) and Chinese High-Temperature Reactor (HTR) are demonstrating the feasibility of the reactor components and materials needed for NGNP. (The HTTR reached a maximum coolant outlet temperature of $950^{\circ} \mathrm{C}$ in April 2004.) Given this strong base of technology development, the NGNP is focused on building a demonstration plant, rather than simply confirming the basic feasibility of the concept.

The operating conditions for the NGNP represent a major departure from existing water-cooled reactor technologies. Although a significant assortment of materials and alloys for high temperature applications are in use in the petrochemical, metals processing, and aerospace industries, a very limited number of these materials have been tested or qualified for use in nuclear reactor-related systems. Today's high temperature alloys and associated American Society of Mechanical Engineers (ASME) Codes for reactor applications have been approved for use up to $760^{\circ} \mathrm{C}$, but some primary system components for the NGNP will require use of materials at higher temperatures. Few choices exist for metallic alloys for use at NGNP conditions and the design lifetime considerations for the metallic components may restrict the maximum operating temperature. Code qualification of materials for successful and long-life application at the high temperature conditions planned for the NGNP is a large portion of the effort in the NGNP Materials Research and Development (R\&D) Program.

Selection of the technology and design configuration for the NGNP must consider both the cost and risk profiles to ensure that the demonstration plant establishes a sound foundation for future commercial deployments. The NGNP challenge is to achieve a significant advancement in nuclear technology while setting the stage for an economically viable deployment of the new technology in the commercial sector soon after 2020.

\subsection{Mission Statement}

The objective of the NGNP Materials R\&D Program is to provide the essential materials R\&D needed to support the design and licensing of the reactor and balance of plant, excluding the hydrogen plant. The materials $R \& D$ program was initiated prior to the design effort to ensure that materials $R \& D$ activities are initiated early enough to support the design process. The thermal, environmental, and service life conditions of the NGNP will make selection and qualification of the high temperature 


\begin{tabular}{c|lll|}
\hline NEXT GENERATION NUCLEAR PLANT & Identifier: & PLN-2804 & \\
INTERMEDIATE HEAT EXCHANGER & Revision: & 0 & \\
MATERIALS RESEARCH & Effective Date: & $04 / 30 / 08$ & Page: 2 of 156 \\
AND DEVELOPMENT PLAN &
\end{tabular}

materials a significant challenge; thus, different materials and new design approaches may be required. The mission of the NGNP Materials Program must support the objectives associated with the NGNP in the Energy Policy Act of 2005 and provide any materials-related support required during the development of the NGNP Program.

A number of NGNP materials R\&D objectives are specifically related to materials for high temperature applications such as the Intermediate Heat Exchanger (IHX), the core barrel and core internals such as the control rod sleeves. Research is needed to develop improved high temperature design methodologies for high temperature metallic alloys. Currently, the data and models are inadequate for many of the high temperature alloys required and the codes and standards need to be expanded. An improved understanding and models may be needed for the environmental effects and thermal aging of the high temperature alloys. In addition, welding and joining procedures must be developed, evaluated and certified for the various materials and components, including very thick plate and thin sheets. Inspection needs and the procedures for those inspections must be defined and developed. The R\&D Plan also includes support of selected university materials related R\&D activities and international materials related collaboration activities that would be of direct benefit to the NGNP Project.

\subsection{Assumptions}

The following assumptions have been incorporated into the mission statements and are fundamental to estimating the scope, cost, and schedule for completing the materials R\&D processes:

- The NGNP will be a full-sized reactor plant capable of electricity generation with a hydrogen demonstration unit of appropriate size.

- The reactor design will be helium-cooled, graphite-moderated core design fueled with TRISO-design fuel particles in carbon-based compacts or pebbles.

- The NGNP must demonstrate the capability to obtain a Nuclear Regulatory Commission (NRC) operating license. The design, materials, and construction will need to meet appropriate Quality Assurance (QA) methods and criteria and other nationally recognized codes and standards.

- The demonstration plant will be designed to operate for a nominal 60 years.

- The NGNP Program, including the materials program, will continue to be directed by Idaho National Laboratory (INL) based on the guidelines given in the Energy Policy Act of 2005. The scope of work will be adjusted to reflect the level of congressional appropriations.

- Application for an NRC operating license and fabrication of the NGNP will occur with direct interaction and involvement of one or more commercial organizations.

\subsection{Approach}

Beyond the general assumptions listed above, this research plan will primarily address a baseline design case for the first NGNP, incorporating the most likely design features and conditions:

- An outlet gas temperature of $850^{\circ} \mathrm{C}$.

- A prismatic core design.

- An indirect cycle.

- IHX material is either Alloy 617 or Alloy 230.

- A low pressure differential between the primary and secondary loops. 
NEXT GENERATION NUCLEAR PLANT

INTERMEDIATE HEAT EXCHANGER

MATERIALS RESEARCH AND DEVELOPMENT PLAN
Identifier: $\quad$ PLN-2804

Revision: $\quad 0$

Effective Date: $04 / 30 / 08$

- A gaseous secondary coolant: either $\mathrm{He}$ or a $\mathrm{He} / \mathrm{N}$ mixture.

- Consideration of both thin and thick sections.

Variations of this baseline design will be discussed in less detail. These include:

- The second and third reactors that will be built using the NGNP design.

- Outlet gas temperatures as high as 950 or $1000^{\circ} \mathrm{C}$.

- A pebble-bed core design.

- Molten salt as a secondary coolant. 


\begin{tabular}{|c|lll|}
\hline $\begin{array}{c}\text { NEXT GENERATION NUCLEAR PLANT } \\
\text { INTERMEDIATE HEAT EXCHANGER }\end{array}$ & Identifier: & PLN-2804 & \\
MATERIALS RESEARCH & Revision: & 0 & \\
AND DEVELOPMENT PLAN & Effective Date: & $04 / 30 / 08$ & Page: 4 of 156 \\
\hline
\end{tabular}

\section{BACKGROUND}

\subsection{Previous and Current Research Plans}

\subsubsection{IHX Acquisition Plan}

An acquisition plan has been developed for the IHX. It considers in some detail issues that have bearing on IHX development and planning.

\subsubsection{FY-07 Research and Technology Plan (Preliminary)}

Work in FY-07 was dramatically reduced from the original plan. Limited funds were available and the majority of those funds were committed to graphite research and planning. The FY-07 Research and Technology Plan covered plans for graphite research in some detail, but presented other materials research plans, including high temperature materials research plans in less detail.

Key material issues were identified from the notes produced during a facilitated meeting of NGNP supported principal investigators and managers, vendor representatives, and additional technical experts in Salt Lake City, UT in June, 2006. It was suggested that working groups of laboratory and industry/vendor personnel be formed to define the tentative operating parameters and testing needs, and also define specific DOE objectives to be demonstrated with the NGNP. The principal concerns pertain to the reactor pressure vessel (RPV) and IHX and decisions about which and how many alloys will be kept.

The FY-07 research activities listed in the plan were of the highest priority to support the NGNP schedule. These activities were described without much detail in anticipation of this more detailed R\&D plan to follow. The breakdown of high temperature alloy tasks is given below in outline form. Pressure vessel and graphite tasks were also included in the FY-07 plan. A detailed FY-08 plan for RPV R\&D is presented in a separate document.

1. Very High Temperature Alloys:

a. Technology development and acquisition strategy.

b. Alloy 617/230 down-select criteria studies.

c. Creep/fatigue characterization.

d. Aging and environmental effects in impure He.

e. Define inspection needs of IHX.

f. Characterization of thin product forms.

g. Product form definition of materials (thin sheet and thick section).

h. Component definition (insulation, core barrel, control rods).

2. High Temperature Design Methodology:

a. Support high temperature material ASME code case.

b. Develop high temperature materials design rules.

c. Develop high temperature material creep/fatigue model. 


\begin{tabular}{|c|lll|}
\hline NEXT GENERATION NUCLEAR PLANT & Identifier: & PLN-2804 \\
INTERMEDIATE HEAT EXCHANGER & Revision: & 0 & Page: 5 of 156 \\
MATERIALS RESEARCH & Effective Date: & $04 / 30 / 08$ & \\
AND DEVELOPMENT PLAN &
\end{tabular}
d. Support development of materials handbook.
e. Develop a unified high temperature constitutive model.

3. Welding (and other joining):
a. Evaluate behavior of fusion weldments.
b. Fusion welding of Ni-based alloys.
c. Characterization of weldments and bonded regions.
d. Fusion welding of steels.
e. Aging effects on weldments.
f. Alloy fabricability of Ni-based alloys.

4. NGNP Component Testing.

5. Evaluate R\&D needs for composite development.

\subsection{IHX Design Alternatives}

Three preconceptual studies from potential NGNP vendors were completed in FY-07. These studies are summarized in subsequent sections of this document. It should be noted that two vendors propose that the power turbine is on a secondary circuit while the third proposes a direct cycle turbine. An additional set of vendor reports were submitted at virtually the same time this report was published and changes or additions to the FY-07 reports are generally not included here.

The IHX may be arranged in parallel or in series with the NGNP power conversion system (PCS). In a serial arrangement, the total primary system flow (reactor outlet gas) passes through the IHX. The IHX receives gas of the highest possible temperature for delivery to the hydrogen production process (with slightly cooler gas going to the PCS), but must be large enough to handle the full primary flow. A parallel configuration splits the reactor outlet gas flow, with only about $10 \%$ entering the IHX for the hydrogen plant, and the remainder of primary flow going to a direct cycle power generation turbine. This results in the smallest possible IHX and the highest overall electrical power efficiency, but lower hydrogen production efficiency because of cooler gas reaching that process.

The IHX design for the hydrogen plant will be influenced by a number of interrelated considerations including the required separation distance between the NGNP reactor and the hydrogen production plant, the heat losses from the intermediate loop piping, the operating pressure, the working fluid, and the target efficiency of the hydrogen plant. The required separation distance will affect the intermediate loop piping size, the intermediate loop pumping requirements and the piping heat losses to the environment. The intermediate loop pressure is critical: a low pressure will produce a high pressure differential between the primary and secondary sides of the IHX - a critical design consideration for the IHX. A high intermediate loop pressure will produce a high pressure differential across the intermediate loop pipe walls and within the hydrogen production equipment unless the SI process pressure is also increased. Pumping power requirements, which also depend on the intermediate loop working fluid, and the fluid temperature and pressure, will have a small effect on the overall NGNP cycle efficiency. ${ }^{1}$

The IHX design has not been decided, but a plate with fin, countercurrent tube and shell, involute heat exchangers, micro-channel heat exchangers and printed circuit heat exchanger (PCHE), designs are 


\begin{tabular}{|c|lll|}
\hline $\begin{array}{c}\text { NEXT GENERATION NUCLEAR PLANT } \\
\text { INTERMEDIATE HEAT EXCHANGER }\end{array}$ & Identifier: & PLN-2804 & \\
MATERIALS RESEARCH & Revision: & 0 & \\
AND DEVELOPMENT PLAN & Effective Date: & $04 / 30 / 08$ & Page: 6 of 156 \\
\hline
\end{tabular}

all under consideration by at least one of the vendors. A tube and shell design has the advantage of technological maturity. Compact heat exchanger designs have the potential for reduced materials cost and greater efficiency; however, they are much less technologically mature and increase the risk of the project.

\subsubsection{Shell-and-Tube}

A shell-and-tube heat exchanger is the most common type of heat exchanger. It consists of a number of tubes (often finned) placed inside a volume (shell). One of the fluids runs through the tubes while the second fluid runs across and along the tubes to be heated or cooled. The heat exchanger that connects the heat transport loop to the hydrogen production plant is referred to as the process heat exchanger (PHX) and is assumed to be a tube-in-shell heat exchanger. The heat transport fluid will flow on the shell side, allowing the tubes to contain the catalysts necessary for hydrogen production. In the simple configurations, the tube axis is parallel to that of the shell. The NGNP IHX proposed design features the tubes arranged in a helical configuration. This type of arrangement increases efficiency due to increased surface area and reduces the size, providing the potential to decrease the materials cost. Tube and shell heat exchangers represent relatively mature technology that has been widely commercialized in both nuclear and fossil energy systems.

\subsubsection{Involute}

A relatively new tube-type concept referred tp as the Involute Heat Exchanger, shown in Figure 1, has been considered by Westinghouse. While little detail of the design is available, it appears to be a helical compact heat exchanger and as such would offer the potential to reduce the amount of material required for fabrication. It features high flexibility to mitigate potentially damaging thermal strains; however detecting, isolating and plugging leaks is complicated by the large number of tubes. Westinghouse is not currently recommending this design.

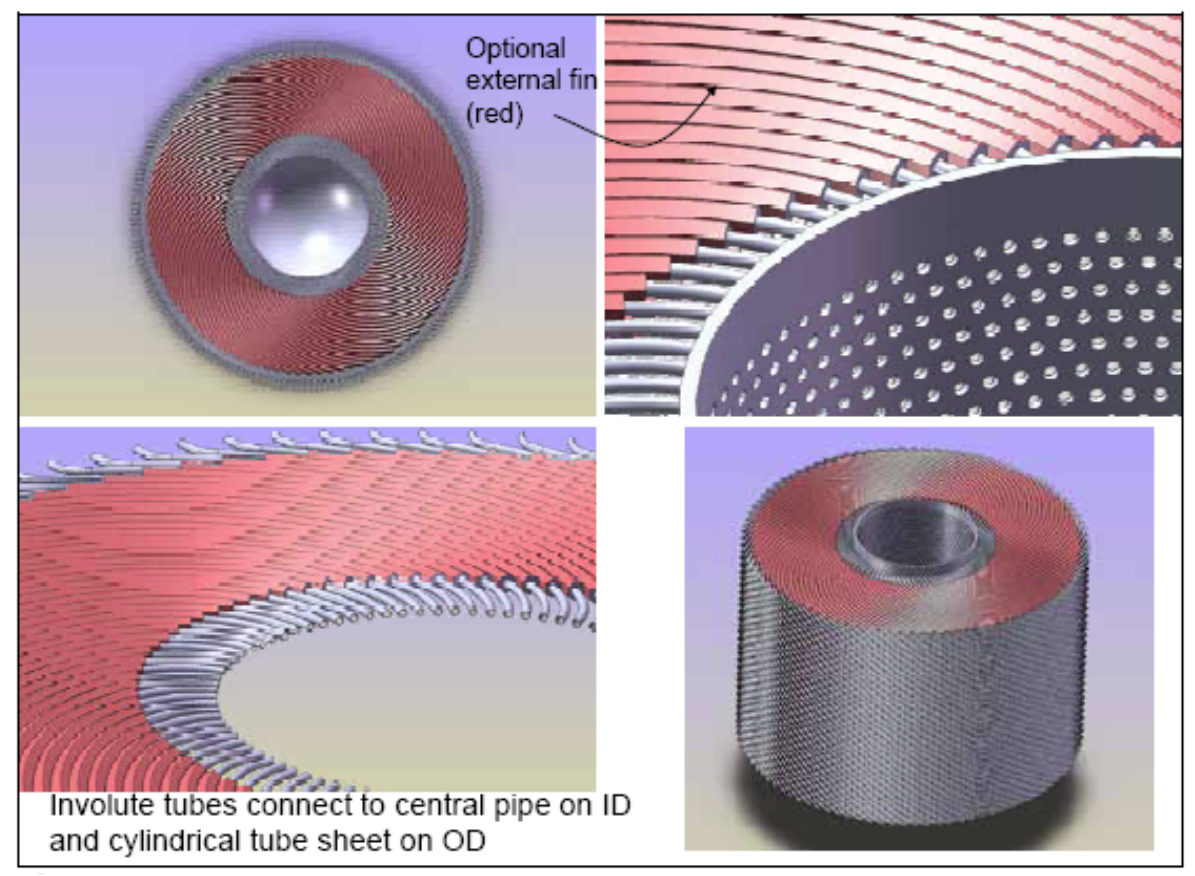

Figure 1. Involute Heat Exchanger viewed from several perspectives. 


\begin{tabular}{|c|lll|}
\hline NEXT GENERATION NUCLEAR PLANT & Identifier: & PLN-2804 & \\
INTERMEDIATE HEAT EXCHANGER & Revision: & 0 & \\
MATERIALS RESEARCH & Effective Date: & $04 / 30 / 08$ & Page: 7 of 156 \\
AND DEVELOPMENT PLAN & &
\end{tabular}

\subsubsection{Plate with Fin}

The plate with fin heat exchanger transfers heat between two fluids by directing flow through baffles so that the fluids are separated by metal plates with very large surface areas. The fluids spread out over the plate, which facilitates the fastest possible transfer of heat. This design has a major advantage over a conventional heat exchanger because the size of the heat exchanger is less, but the same amount of heat is exchanged. However, the candidate heat exchanger materials have relatively low thermal conductivities and will deduce the efficiency of a finned structure. The fins are considered secondary surfaces (the plate is a primary surface). Any finned structure will have reduced efficiency over a design that only has primary surfaces. ${ }^{2}$

Brazing is typically used to join the fins to the plate. Brazed plate heat exchangers are used in many applications, although usually at low or even cryogenic temperatures. The strength and creep properties of brazed joints in an IHX for a high temperature reactor are of great concern, although brazed products have been developed for high temperature aerospace applications. ${ }^{3}$

The Unit Cell heat exchanger is a typical modular plate-fin design that is being advanced by Brayton Energy. An example is shown in Figure 2. Many of these individual unit cells would be grouped into larger heat exchanger assemblies. Integration of the modules within the vessel and with the interfacing piping is key. Off-set fin plate heat exchangers have very large heat transfer area density and effective countercurrent flow.

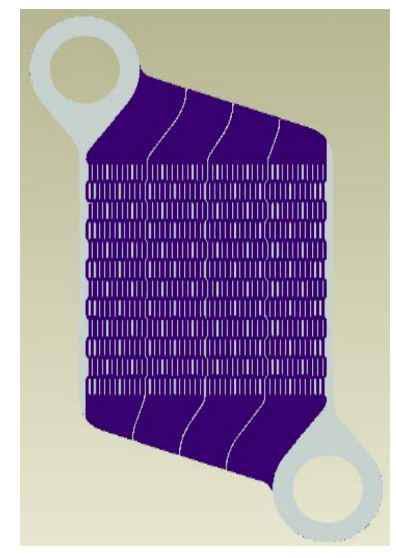

(a)

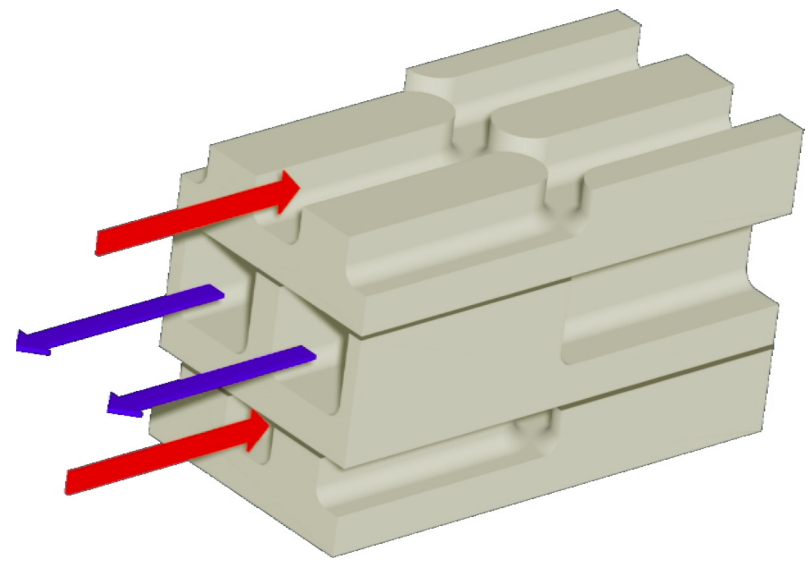

(b)

Figure 2. Unit Cell Heat Exchanger (a) primary side plate, (b) the unit cell showing counter-current flow.

\subsubsection{Etched Plate}

Etched plate heat exchangers are diffusion-bonded, highly compact heat exchangers that can achieve a thermal effectiveness of over $98 \%$ in a single unit. Compact heat exchangers are four to six times smaller and lighter than conventional shell and tube heat exchangers of the equivalent duty (Figure 3). The small size gives the compact diffusion-bonded heat exchangers significant benefits over conventional heat exchangers across a range of industries. They are well established in the upstream hydrocarbon processing, petrochemical, and refining industries. In addition they are suitable for a range of corrosive and high purity streams and are particularly advantageous when space is limited and weight is critical. Heatric claims pressure capability in excess of 600 bar (9000 psi) and the ability to withstand temperatures ranging up to $900^{\circ} \mathrm{C}$. 


\begin{tabular}{|c|lll|}
\hline NEXT GENERATION NUCLEAR PLANT & Identifier: & PLN-2804 & \\
INTERMEDIATE HEAT EXCHANGER & Revision: & 0 & \\
MATERIALS RESEARCH & Effective Date: & $04 / 30 / 08$ & Page: 8 of 156 \\
AND DEVELOPMENT PLAN &
\end{tabular}

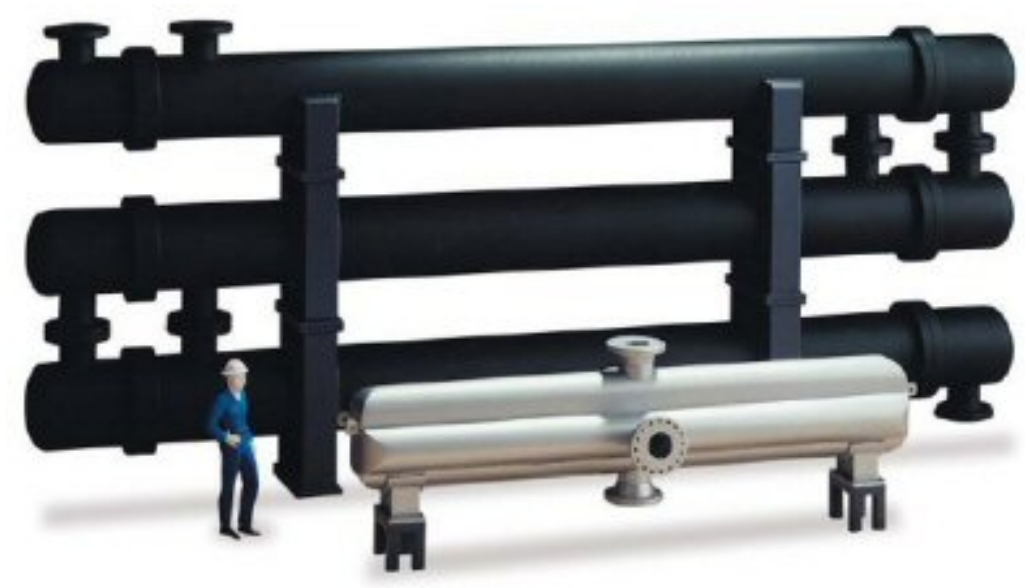

Figure 3. The diffusion-bonded heat exchanger in the foreground undertakes the same thermal duty, at the same pressure drop, as the stack of three shell and tube exchangers behind.

The most widely commercialized etched plate heat exchanger is a Printed Circuit Heat Exchanger (PCHE) developed by Heatric Division of Meggitt (UK) Ltd. PCHE consists of metal plates on the surface of which millimeter-scale semicircular fluid-flow channels are photo-chemically milled, using a process analogous to that used for the manufacture of electronic printed circuit boards, hence the name. ${ }^{3,4}$ The plates are then stacked and diffusion-bonded together to fabricate a heat exchanger core shown schematically in Figure 4. Note that the channels are straight in this schematic, but in reality they are have a zig-zig configuration. Flow distributors can be integrated into plates or welded outside the core, depending on the design. Several PCHE concepts have been developed by Heatric; a platelet configuration with flow distributors integrated into the plates is shown in Figure 5. The channel diameter, plate thickness, channel angles, and other attributes can be varied, so each PCHE is custom-built to fit a specified task. Channel dimensions are generally between 3 and $0.2 \mathrm{~mm}{ }^{5}$ The current fabrication limits are $1.5 \mathrm{~m} \mathrm{x} 0.6 \mathrm{~m}$ plates and $0.6 \mathrm{~m}$ stack height. The diffusion-bonded blocks are modular and multiple blocks can be welded together to form larger units.
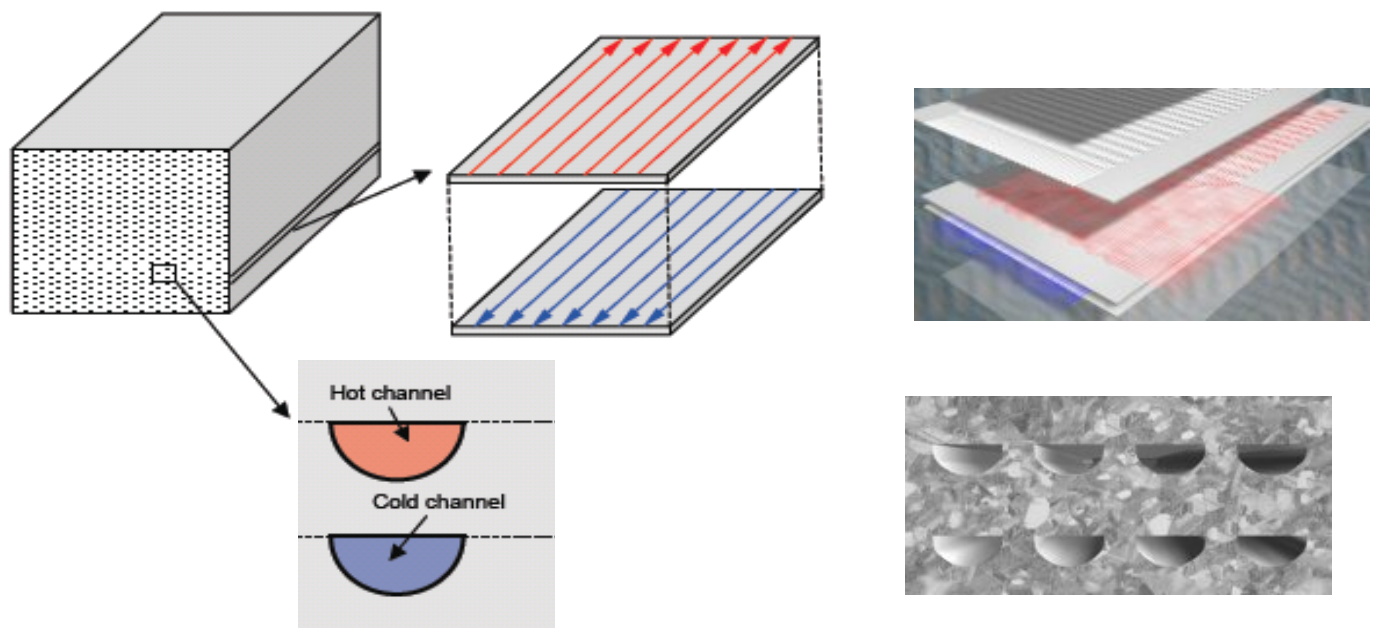

Figure 4. PCHE configuration for the model. 


\begin{tabular}{|c|lll|}
\hline $\begin{array}{c}\text { NEXT GENERATION NUCLEAR PLANT } \\
\text { INTERMEDIATE HEAT EXCHANGER }\end{array}$ & Identifier: & PLN-2804 & \\
MATERIALS RESEARCH & Revision: & 0 & \\
AND DEVELOPMENT PLAN & Effective Date: & $04 / 30 / 08$ & Page: 9 of 156 \\
\hline
\end{tabular}

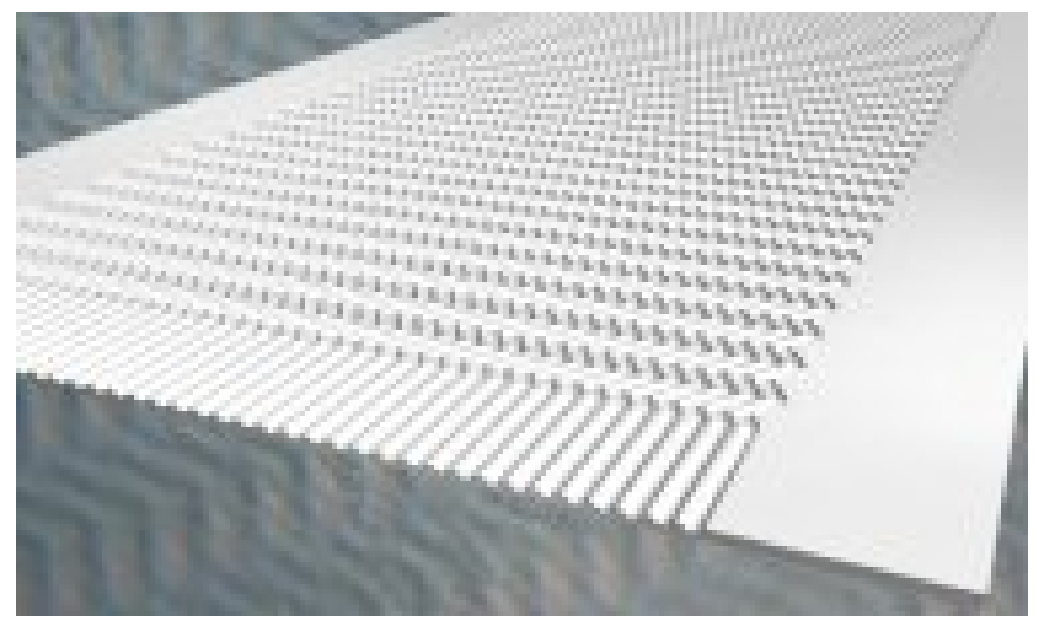

Figure 5. Heatric PCHE platelet design.

\subsubsection{Microchannel Heat Exchangers}

Microchannel heat exchangers, produced by Velocys, also feature a compact design similar to the etched plate design, however, the manufacturing process is somewhat different. They are constructed from diffusion-bonded corrugated sheets rather than etched plates. The layers of corrugated sheet form many small diameter channels that result in a high surface area/volume ratio and a high heat transfer coefficient, Figure 6. Velocys claims their microchannel heat exchangers have even better properties than those claimed for other compact heat exchangers, as shown in Table $1 .^{6}$

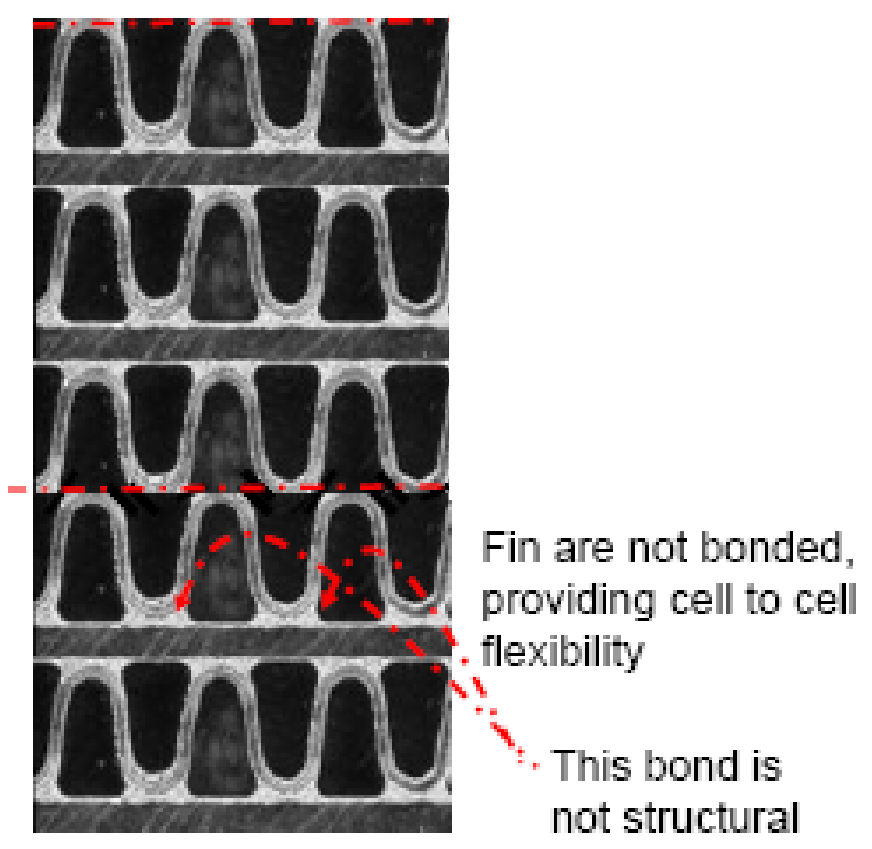

Figure 6. Section of Velocys heat exchanger showing layers of corrugated sheet. 


\begin{tabular}{c|lll|}
\hline $\begin{array}{l}\text { NEXT GENERATION NUCLEAR PLANT } \\
\text { INTERMEDIATE HEAT EXCHANGER }\end{array}$ & Identifier: & PLN-2804 & \\
MATERIALS RESEARCH & Revision: & 0 & \\
AND DEVELOPMENT PLAN & Effective Date: & $04 / 30 / 08$ & Page: 10 of 156 \\
\hline
\end{tabular}

Table 1. Properties of heat exchangers as presented by Velocys.

\begin{tabular}{llll}
\hline \multicolumn{1}{c}{ Parameter } & Shell and Tube & \multicolumn{1}{c}{ Compact } & Compact Micro-channel \\
\hline Surface Area/Volume $\left(\mathrm{m}^{2} / \mathrm{m}^{3}\right)$ & $50-100$ & $850-1500$ & $>1500$ \\
Heat Transfer Coefficient $\left(\mathrm{W} / \mathrm{m}^{2} / \mathrm{K}\right)(\mathrm{gas})$ & $20-100$ & $50-300$ & $400-2000$ \\
Approach Temperature $\left({ }^{\circ} \mathrm{C}\right)$ & $\sim 20$ & $\sim 10$ & $<10$ \\
Flow Regime & Turbulent & Turbulent & Laminar \\
\hline
\end{tabular}

\subsection{Pre-Conceptual HTGR Designs}

The viability of a graphite core planned for the NGNP has previously been demonstrated in HTGR plants (e.g., DRAGON, Peach Bottom, AVR, THTR, and Fort St. Vrain). Furthermore, the Japanese High-Temperature Engineering Test Reactor (HTTR) and Chinese High-Temperature Reactor (HTR) are demonstrating the feasibility of the reactor components and materials needed for NGNP (HTTR reached a maximum coolant outlet temperature of $950^{\circ} \mathrm{C}$ in April 2004). These reactor designs represent two categories: the Pebble Bed Reactor (PBR) and the Prismatic Modular Reactor (PMR).

In FY-07, preconceptual design work was initiated by the NGNP Project at INL. This section describes the current HTGR preconceptual designs in summary form which are described in detail in the NGNP Pre-Conceptual Design Report. ${ }^{7-10}$ This work was completed by three contractor teams with extensive experience in HTGR technology, nuclear power applications and hydrogen production. Each contractor developed a recommended design for NGNP and a commercial version of the HTGR. R\&D, data needs and future studies required to achieve operation of the NGNP were identified as part of the work. In addition, a number of special studies were requested from all three or two of the three teams. The special studies include Reactor Type Trade Study, ${ }^{11}$ Pre-conceptual Heat Transfer and Transport Studies, ${ }^{12}$ Primary and Secondary Cycle Trade Study, ${ }^{13}$ and Power Conversion System Trade Study. ${ }^{14}$ The three designs were developed are as follows:

1. The GT-MHR concept; team led by General Atomics team with Washington Group International; Rolls-Royce (United Kingdom); Toshiba Corporation and Fuji Electric Systems (Japan); Korean Atomic Energy Research Institute and DOOSAN Heavy Industries and Construction (Korea); and OKB Mechanical Design (Russia).

2. The ANTARES concept; team led by AREVA NP, Inc. with Burns \& Roe, Washington Group International, BWXT, Dominion Engineering, Air Products, Hamilton-Sundstrand-Rocketdyne, Mitsubishi Heavy Industries (MHI), NovaTech, and Entergy.

3. The PBMR concept; team led by Westinghouse Electric Company, LLC with Pebble Bed Modular Reactor (Pty) Ltd. and M-Tech Industrial (Pty) Ltd. (South Africa); The Shaw Group; Technology Insights; Air Products and Chemicals, Inc.; Nuclear Fuel Services; and Kadak Associates.

All three designs use TRISO fuel, graphite moderation and high temperature helium coolant in the primary system in the $800^{\circ} \mathrm{C}-950^{\circ} \mathrm{C}$ temperature range. All of the concepts feature various passive neutronic design features that result in a core with relatively low power density and a negative temperature coefficient of neutron reactivity. The shut-down cooling system, the secondary reactivity shut-down system, and the control rod design are all similar among the three designs. All of the reactor concepts could be used as a basis for the NGNP HTGR concept. The designs are not presented in detail in this document. Rather, this report primarily discusses the features that relate to IHX material selection and challenges. The key operating parameters and design features for all three designs are listed in Table 2 along with information for the Fort St. Vrain HTGR, the largest and most recent gas-cooled reactor to operate in the U.S. 
Idaho National Laboratory

\begin{tabular}{c|ll} 
NEXT GENERATION NUCLEAR PLANT & Identifier: & PLN-2804 \\
INTERMEDIATE HEAT EXCHANGER & Revision: & 0 \\
MATERIALS RESEARCH & Effective Date: & $04 / 30 / 08$ \\
AND DEVELOPMENT PLAN &
\end{tabular}

Page: 11 of 156

Table 2. Key operating parameters for the NGNP designs and the Fort St. Vrain HTGR.

\begin{tabular}{|c|c|c|c|c|}
\hline Condition or Feature & $\begin{array}{l}\text { Fort St. Vrain } \\
\text { HTGR }\end{array}$ & $\begin{array}{l}\text { General Atomics } \\
\text { GT-MHR }\end{array}$ & $\begin{array}{l}\text { AREVA } \\
\text { ANTERES }\end{array}$ & $\begin{array}{l}\text { Westinghouse } \\
\text { PBMR PHP }\end{array}$ \\
\hline Power Output (MWt) & 842 & $550-600$ & 565 & 500 \\
\hline Average power density $\left(\mathrm{w} / \mathrm{cm}^{3}\right)$ & 6.3 & 6.5 & & 6.0 \\
\hline Moderator & Graphite & Graphite & Graphite & Graphite \\
\hline Core Geometry & Cylindrical & Annular & Annular & Annular \\
\hline Reactor type & Prismatic & Prismatic & Prismatic & Pebble Bed \\
\hline Safety Design Philosophy & Active & Passive & Passive & Passive \\
\hline Plant Design Life (Years) & 30 & 60 & 60 & 60 \\
\hline Fuel - Coated Particle & $\begin{array}{l}\text { HEU-Th } /{ }^{235} \mathrm{U} \\
\text { (93\% enriched) }\end{array}$ & $\begin{array}{l}\text { TRISO UCO } \\
\text { (startup } \mathrm{UO}_{2} \text { ) }\end{array}$ & $\begin{array}{l}\text { TRISO UCO } \\
\text { (backup } \mathrm{UO}_{2} \text { ) }\end{array}$ & TRISO $\mathrm{UO}_{2}$ \\
\hline $\begin{array}{l}\text { Fuel Max Temp - Normal } \\
\text { Operation }\left({ }^{\circ} \mathrm{C}\right)\end{array}$ & 1260 & 1250 & 1300 & 1057 \\
\hline $\begin{array}{l}\text { Fuel Max Temp - Emergency } \\
\text { Conditions }\left({ }^{\circ} \mathrm{C}\right)\end{array}$ & $\begin{array}{l}\text { NA - Active } \\
\text { Safety System } \\
\text { cools fuel. }\end{array}$ & 1600 & 1600 & 1600 \\
\hline Power Conversion Configuration & Direct & Direct & Indirect & Indirect \\
\hline PCS Cycle Type & Reheat Steam & Brayton & Steam Rankine & Rankine \\
\hline $\begin{array}{r}\text { IHX Design Power } \\
\text { Process }\end{array}$ & NA & PCHE & $\begin{array}{l}\text { Shell \& Tube } \\
\text { PCHE or Fin- } \\
\text { Plate }\end{array}$ & PCHE \\
\hline Core outlet temperature $\left({ }^{\circ} \mathrm{C}\right)$ & 785 & Up to 950 & 900 & 950 \\
\hline Core inlet temperature $\left({ }^{\circ} \mathrm{C}\right)$ & 406 & 590 & 500 & 350 \\
\hline Coolant Pressure (MPa) & 4.8 & 7 & 5 & 9 \\
\hline Coolant Flow Rate $(\mathrm{kg} / \mathrm{s})$ & 428 & 320 & 272 & 161 \\
\hline Secondary outlet temperature $\left({ }^{\circ} \mathrm{C}\right)$ & 538 & 925 & $\begin{array}{l}850 / 875 \\
\mathrm{PCS} / \mathrm{H}_{2}\end{array}$ & 900 \\
\hline Secondary inlet temperature $\left({ }^{\circ} \mathrm{C}\right)$ & NA & 565 & $\begin{array}{l}450 / 475 \\
\mathrm{PCS} / \mathrm{H}_{2}\end{array}$ & NA \\
\hline Secondary Fluid & Steam & $\mathrm{He}$ & $\mathrm{He}$ & $\mathrm{He}-\mathrm{N}$ \\
\hline IHX Pressure Drop (kPa) & NA & 50 & 55 & 45 \\
\hline IHX Material & NA & In-617 & In-617 & In- 617 or $800 \mathrm{H}$ \\
\hline Core Barrel Material & Steel & Not specified & $800 \mathrm{H}$ & $316 \mathrm{H} \mathrm{SS}$ \\
\hline Control Rod Cladding & $800 \mathrm{H}$ & $\begin{array}{l}800 \mathrm{H} \text { (backup } \mathrm{C}_{\mathrm{f}} / \mathrm{C} \\
\text { composite) }\end{array}$ & $\begin{array}{c}\mathrm{C}_{\mathrm{f}} / \mathrm{C} \\
\text { composite }\end{array}$ & $800 \mathrm{H}$ \\
\hline
\end{tabular}




\begin{tabular}{|c|lll|}
\hline NEXT GENERATION NUCLEAR PLANT & Identifier: & PLN-2804 & \\
INTERMEDIATE HEAT EXCHANGER & Revision: & 0 & \\
MATERIALS RESEARCH & Effective Date: & $04 / 30 / 08$ & Page: 12 of 156 \\
AND DEVELOPMENT PLAN &
\end{tabular}

\subsubsection{General Atomics - GT-MHR Concept}

General Atomics recommended a direct power conversion cycle prismatic reactor design that is essentially the same as the GT-MHR with an additional primary coolant loop to transfer heat to the IHX. ${ }^{7,11}$ The core consists of graphite blocks with an annular-fueled region of 1,020 prismatic fuel blocks arranged in three columns. They argue that a prismatic reactor inherently allows higher reactor power density levels, resulting in better plant economics, involves fewer uncertainties (and therefore less risk) and allows more flexibility with respect to the use of alternate fuel cycles, such as those fabricated from surplus weapons grade plutonium or transuranics separated from spent light water reactor (LWR) fuel.

The temperature rise of the coolant in the various flow paths through the core varies over a wide range. Good mixing of the outlet coolant is needed to avoid excessive thermal stresses in the downstream components resulting from large temperature gradients and fluctuations, and to assure that the gas entering the turbine has a uniform mixed mean temperature. Figure 7 is an illustration of the GT-MHR reactor system cutaway that shows the metallic internals structures, core, control rod guide tubes and cross vessel.

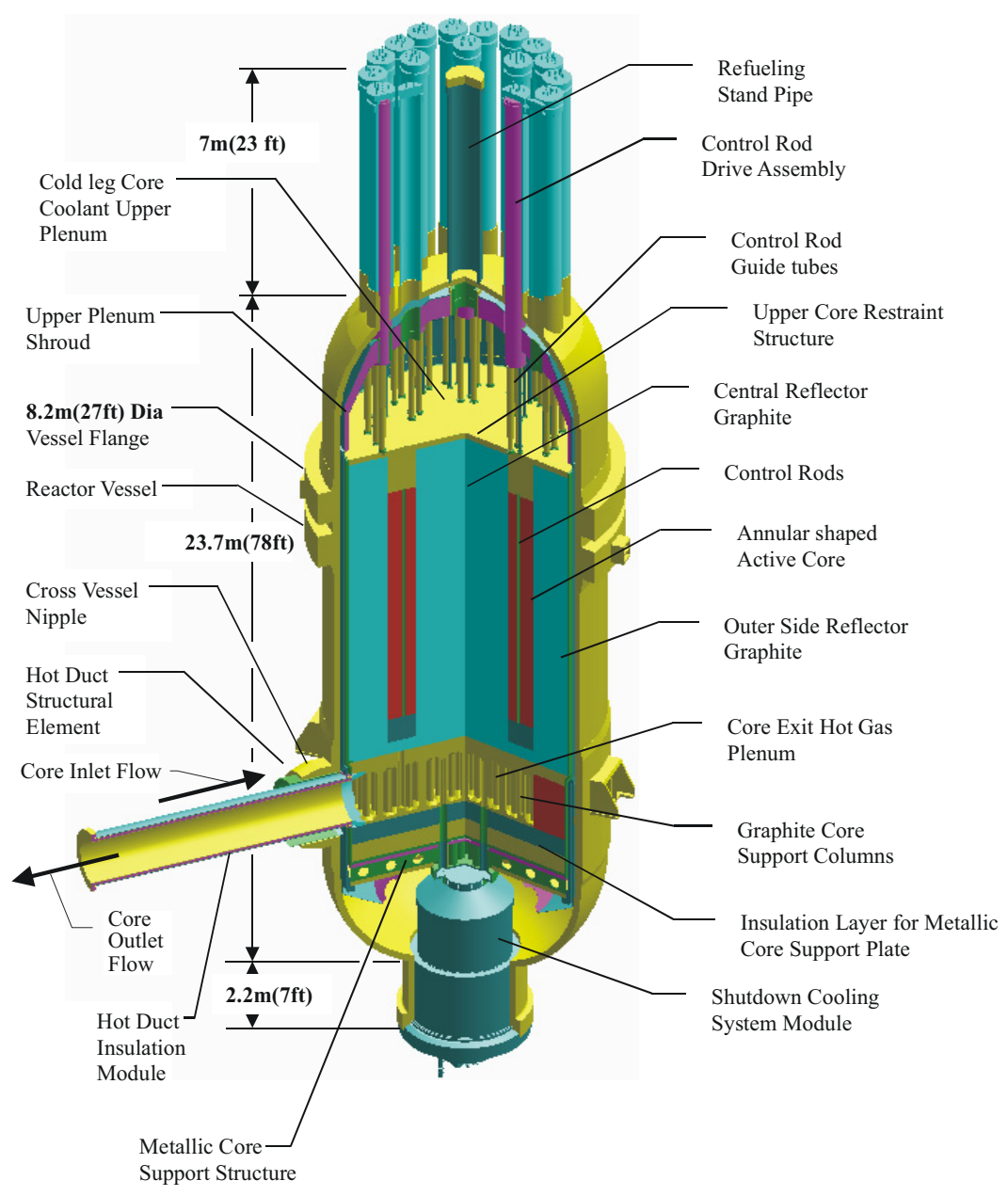

Figure 7. GT-MHR reactor system cutaway showing the metallic internals structures, core, control rod guide tubes and cross vessel (labeled as hot duct). 


\begin{tabular}{|c|lll|}
\hline NEXT GENERATION NUCLEAR PLANT & Identifier: & PLN-2804 & \\
INTERMEDIATE HEAT EXCHANGER & Revision: & 0 & \\
MATERIALS RESEARCH & Effective Date: & $04 / 30 / 08$ & Page: 13 of 156 \\
AND DEVELOPMENT PLAN &
\end{tabular}

\subsubsection{Reactivity Control Rods}

The control rods use $\mathrm{B}_{4} \mathrm{C}$ absorbers enclosed in Incoloy $800 \mathrm{H}$ canisters for structural support. Carbon/Carbon Composite $\left(\mathrm{C}_{\mathrm{f}} / \mathrm{C}\right)$ control rod sleeves may be used as an alternative. The control rod is lowered and raised with a flexible high nickel alloy (not specified) cable.

\subsubsection{Cross Vessel}

General Atomics specifies that the cross vessel and IHX vessel will both be made out of the same material as the RPV. The cross vessels connect the lower portion of the RPV to the lower portion of the power conversion system and IHX vessels. The cross vessels include a concentric duct (primary hot gas duct) that separates the hot (core exit) and the cold (core inlet) gas flow streams. The hot duct material will be a high temperature alloy (such as $800 \mathrm{H}$ or 617 ). The hot gas duct is insulated with a ceramic fiber insulation such as Kaowool. A similar insulation may also be included on the inside diameter of the cross vessel. The insulation is intended to reduce heat losses to the core inlet cold gas stream, and the insulation assemblies are designed to be remotely removed and replaced (if needed) during the 60-year plant life.

\subsubsection{Power Conversion and Intermediate Heat Exchanger}

General Atomics recommends the use of a direct Brayton Cycle vertical PCS for electricity generation and an indirect heat transport loop to transport thermal energy to the hydrogen production plant arranged in parallel (see Figure 8). The primary loop and the hydrogen heat transport loop would both use helium at $7 \mathrm{MPa}$ as a heat transport medium. The hydrogen heat transport loop would be sized to transmit up to $65 \mathrm{MWt}$. The assumed operating temperatures of the primary loop and hydrogen heat transport loop are $950^{\circ} \mathrm{C}$ and $925^{\circ} \mathrm{C}$, respectively. ${ }^{\text {a }}$

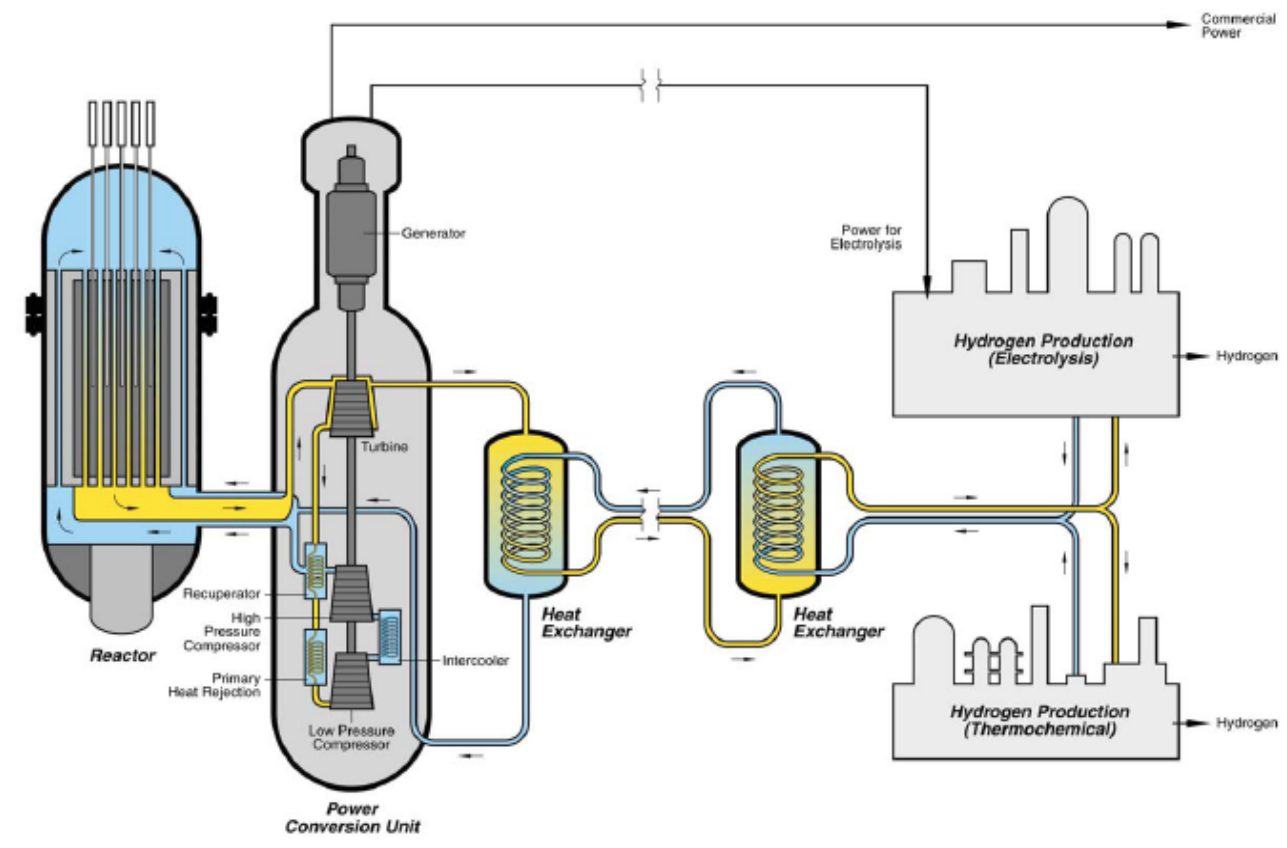

Figure 8. NGNP configuration as proposed by General Atomics.

a. These temperatures are from the heat transport study and are not consistent with the gas outlet temperature of $900^{\circ} \mathrm{C}$ assumed in the preconceptual design report. 

NEXT GENERATION NUCLEAR PLANT
INTERMEDIATE HEAT EXCHANGER
MATERIALS RESEARCH
AND DEVELOPMENT PLAN

$\begin{array}{ll}\text { Identifier: } & \text { PLN-2804 } \\ \text { Revision: } & 0 \\ \text { Effective Date: } & 04 / 30 / 08\end{array}$

Page: 14 of 156

The plan calls for a compact PCHE metallic heat exchanger module to serve as the intermediate heat exchanger for the hydrogen heat transport loop. General Atomics believes that compact heat exchangers will offer the best performance and will be most economical. The flow rates and pressures on the primary and secondary sides are essentially the same (Figure 9). Two alternate PCHE IHX designs were developed and an alternate shell and tube counter-flow design with a helically coiled tube (Figure 10). Although the shell and tube design results in a much larger IHX, it allows for in-service inspection and has a successful service record at $950^{\circ} \mathrm{C}$ in Japan's HTTR.

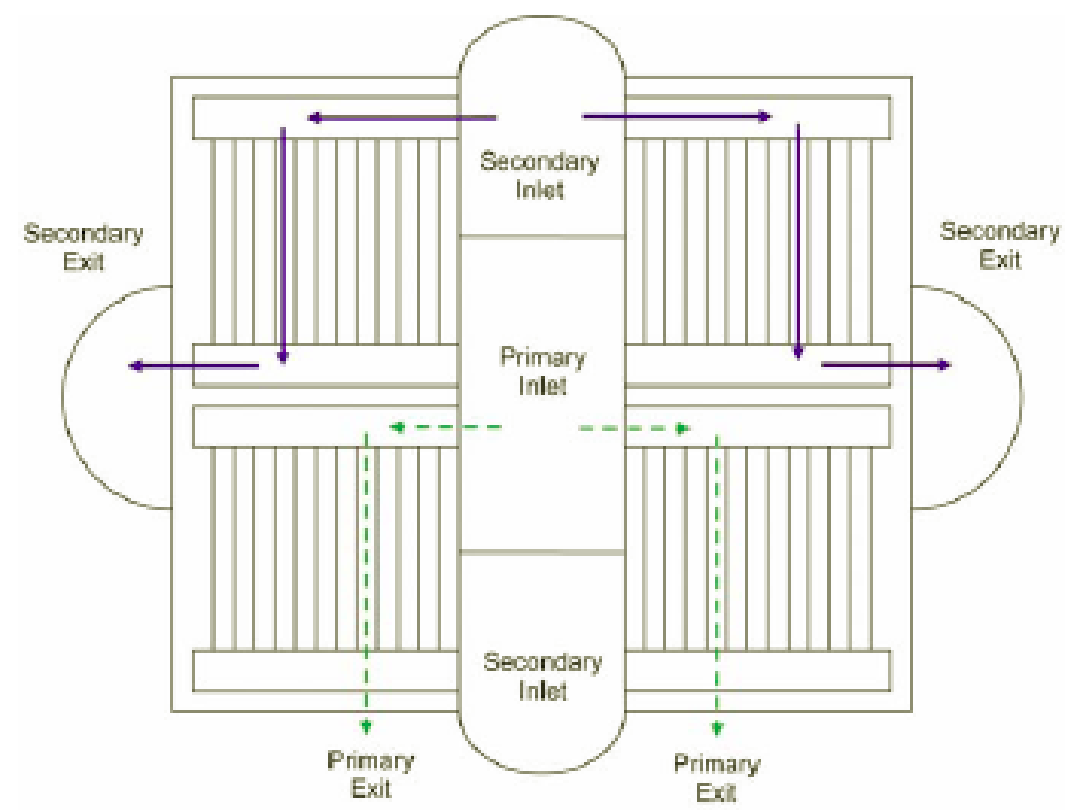

Figure 9. General arrangement of helical-coil IHX.

The hydrogen heat transport loops are parallel hot and cold transport pipes that use internal and external pipe insulation in order to lower the temperature of the metallic pipe, so that metals less expensive than Alloy 617 can be used for the long-distance (i.e., $90 \mathrm{~m}$ ) loop. The use of molten salt as a heat transport medium for the hydrogen heat transport loop was examined, and it was determined that molten salt is not yet ready to be deployed. There are issues of corrosion and materials compatibility, and concerns about the cost of the pipe materials, since it is believed that internal insulation could not be used to protect the heat transport pipes against the temperature.

\subsubsection{AREVA - ANTARES Concept}

AREVA recommended that the NGNP be a $565 \mathrm{MWt}$ prismatic reactor, citing advantages over a pebble-bed reactor design including greater economic potential, higher power level and passive safety, more useable power, greater design flexibility, greater ease in obtaining a license (because the concept was previously licensed for Fort St. Vrain), and a higher degree of predictability in core performance, forced outages, and scheduled outages. ${ }^{6,27}$ AREVA suggested a gas outlet temperature of $900^{\circ} \mathrm{C}$ as the best compromise between energy efficiency and the ability to produce hydrogen, and the durability of equipment. AREVA proposes using $\mathrm{He} / \mathrm{N}_{2}$ mixture in the power conversion unit (PCU) and $900^{\circ} \mathrm{C}$ is the maximum temperature they advise for nitrogen bearing gas because of nitriding concerns. ${ }^{12,14}$ 


\begin{tabular}{c|lll|}
$\begin{array}{c}\text { NEXT GENERATION NUCLEAR PLANT } \\
\text { INTERMEDIATE HEAT EXCHANGER }\end{array}$ & Identifier: & PLN-2804 & \\
MATERIALS RESEARCH & Revision: & 0 & \\
AND DEVELOPMENT PLAN & Effective Date: & $04 / 30 / 08$ & Page: 15 of 156 \\
\hline
\end{tabular}

The ANTARES design ${ }^{15,16}$ is also based in part on the GT-MHR concept, with 1020 fuel blocks arranged in three columns to form the annular core between inner and outer graphite reflectors. The primary loop pressure is limited to $5.5 \mathrm{MPa}$, which is substantially less than the 7 to $9 \mathrm{MPa}$ specified by the other contractors. AREVA believes the small operational losses resulting from the lower pressure would be offset by reduced capital costs associated with using thinner vessel walls for pressure containment. $^{12}$

\subsubsection{Reactivity Control Rods}

The control rods in this design employ $\mathrm{B}_{4} \mathrm{C}$ and will be enclosed in $\mathrm{C}_{\mathrm{f}} / \mathrm{C}$ canisters (cladding).
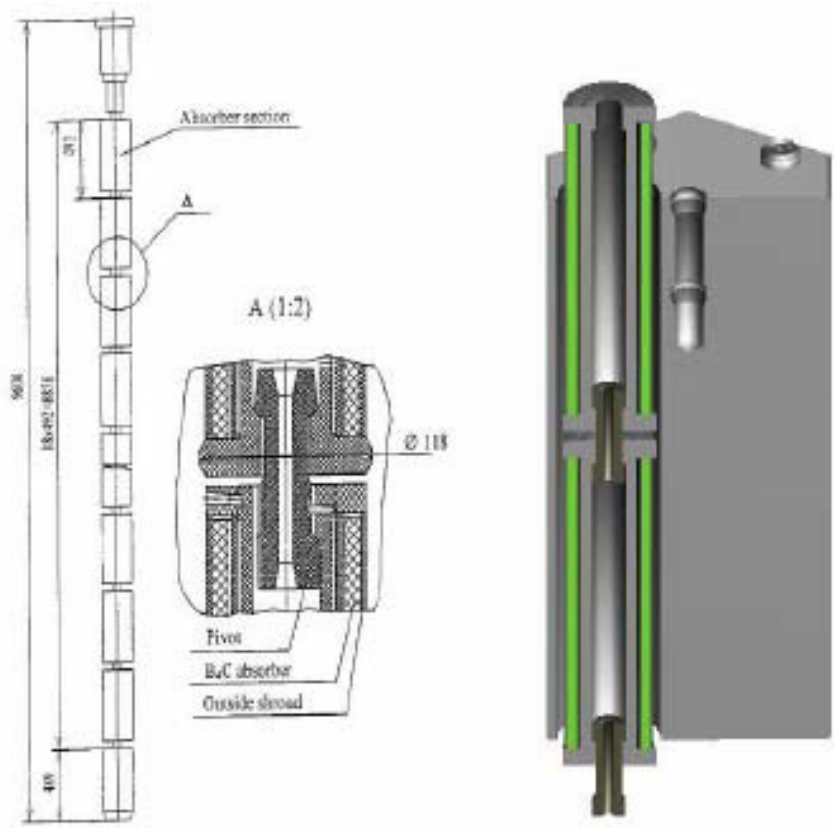

Figure 10. AREVA control rod design.

\subsubsection{Cross Vessel}

Like GA, AREVA has defined cross vessels (rather than pipes), with a concentrically arranged primary hot gas duct that separates the hot (core exit) and the cold (core inlet) gas flow streams. The hot gas duct is insulated to reduce regenerative heat losses to the outer flow stream (core inlet cold gas).

\subsubsection{Core Barrel}

The core barrel suggested is a double-wall structure made from $800 \mathrm{H}$.

\subsubsection{Power Conversion and Intermediate Heat Exchanger}

AREVA provided two plant configurations - a plant configuration with a Brayton Cycle to generate electrical power, and a plant configuration with steam to generate electricity by using a Rankine Cycle. The Brayton Cycle configuration is based upon the original ANTARES design. AREVA has recently concluded that the Rankine Cycle is more mature and may be more adaptable to NGNP requirements, and therefore preferable (Figure 11). 


\begin{tabular}{|c|lll|}
\hline $\begin{array}{c}\text { NEXT GENERATION NUCLEAR PLANT } \\
\text { INTERMEDIATE HEAT EXCHANGER }\end{array}$ & Identifier: & PLN-2804 & \\
MATERIALS RESEARCH & Revision: & 0 & \\
AND DEVELOPMENT PLAN & Effective Date: & $04 / 30 / 08$ & Page: 16 of 156 \\
\hline
\end{tabular}

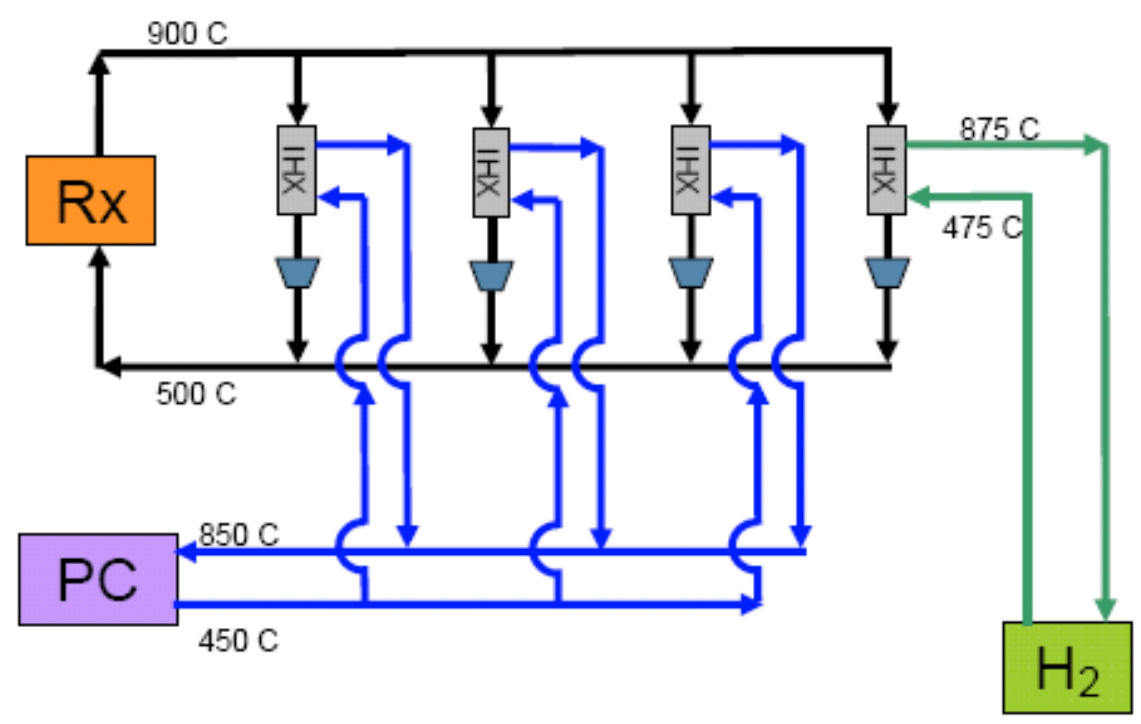

Figure 11. NGNP configuration as proposed by AREVA.

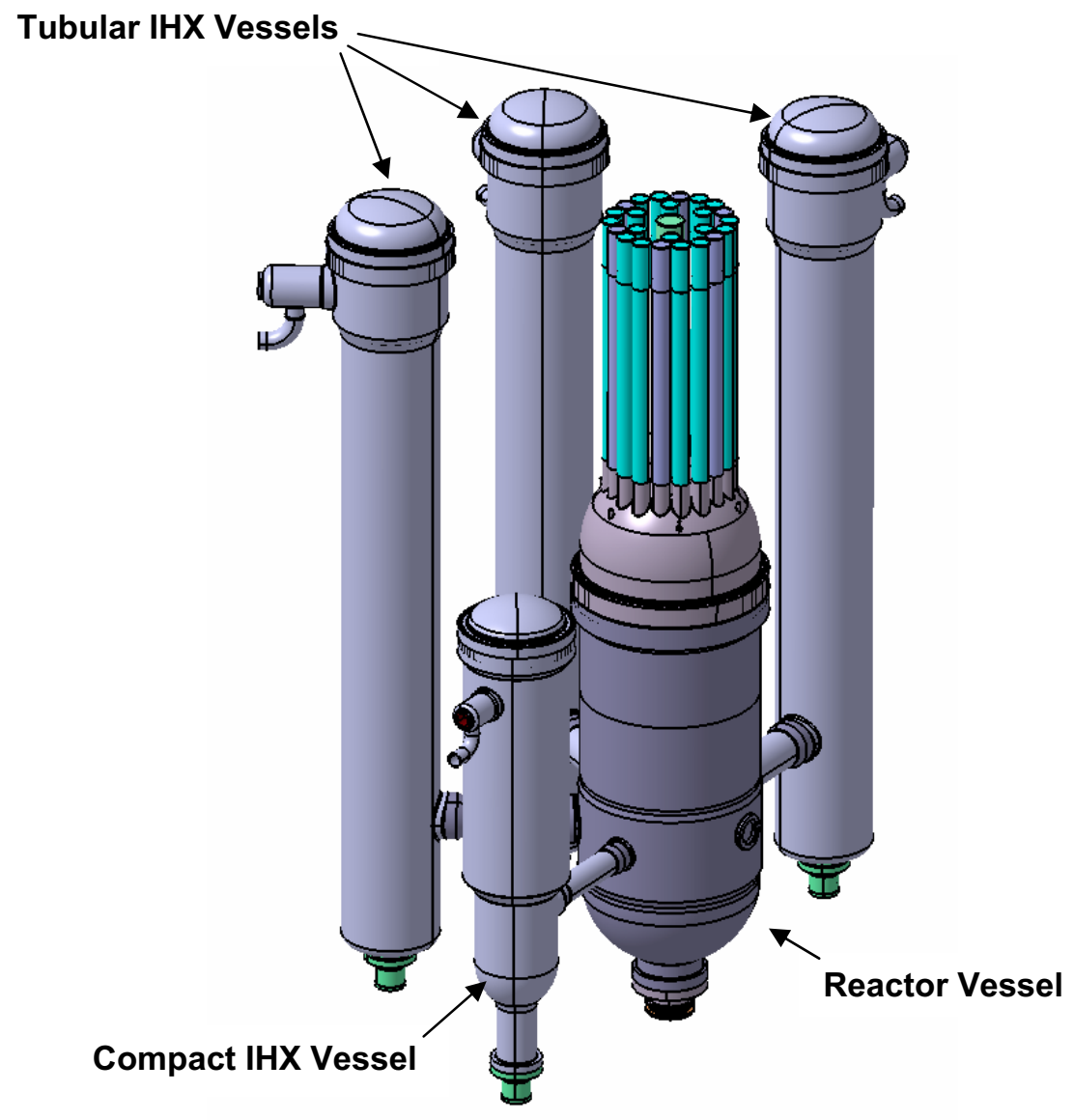

Figure 12. AREVA vessels arrangement. 


\begin{tabular}{c|lll|}
\hline $\begin{array}{c}\text { NEXT GENERATION NUCLEAR PLANT } \\
\text { INTERMEDIATE HEAT EXCHANGER }\end{array}$ & Identifier: & PLN-2804 & \\
MATERIALS RESEARCH & Revision: & 0 & \\
AND DEVELOPMENT PLAN & Effective Date: & $04 / 30 / 08$ & Page: 17 of 156 \\
\hline
\end{tabular}

The Combined Brayton Cycle configuration employs an indirect power conversion unit and an indirect hydrogen heat transport loop. The secondary loop used to provide energy to the Brayton Cycle turbines uses a $20 \% \mathrm{He} / 80 \% \mathrm{~N}$ gas mixture at $4.9 \mathrm{MPa}$. Heat recovery steam generators would be deployed following the Brayton Cycle turbines to supply a bottoming Rankine Cycle. The hydrogen heat transport loop would be designed to carry up to $60 \mathrm{MWt}$ to the hydrogen plant.

The indirect power conversion loop and indirect hydrogen heat transport loop are linked to the primary cooling loop in parallel. This design shows a potential for very high efficiency, $47 \%$ or more, while minimizing technological risk. In addition, the indirect combined-cycle is quite flexible to accommodate the simultaneous generation of electricity and industrial heat at any level between $800^{\circ} \mathrm{C}$ and ambient. In addition, the indirect coupling has lower potential for contamination than direct coupling.

AREVA recommends three primary-to-secondary heat transfer loops using metallic shell-and-tube heat exchangers to supply gas to the power conversion loop. They argue that, although large, shell and tube heat exchangers are more mature in design, reliability and operational experience. The parallel arrangement enables use of a smaller $(60 \mathrm{MWt})$ compact metallic heat exchanger with a reduced gas flow rate. They believe compact heat exchangers may offer economic breakthroughs and have a reasonable probability of being developed, tested, and ASME certified in the required time frame; but should be replaceable. ${ }^{12}$

The Rankine Cycle configuration differs from the Brayton Cycle configuration in that shell-and-tube steam generators are directly coupled to the primary cooling loop in order to drive the steam turbines. The steam generators are arranged in parallel with the hydrogen heat transport loop. The steam system would operate at a temperature of approximately $550^{\circ} \mathrm{C}$. No recommendation of steam system pressure was provided. The direct-cycle concept has little flexibility to adapt to cogeneration because when operating parameters change, efficiency drops and operation may become difficult. AREVA concluded that the Steam-Rankine cycle (possibly supercritical) is the best fit for near term applications because it provides high efficiency electricity production and can readily service near term process heat markets.

\subsubsection{PBMR Concept}

A reactor is being developed in South Africa by PBMR (Pty) Ltd. through a world-wide development effort. ${ }^{17-20}$ The program includes testing of mechanical systems and components, a comprehensive fuel development effort and a testing and verification program to support the licensing process. A full-sized (400 MWt) demonstration reactor, the PBMR Demonstration Power Plant (DPP), will be built at the Koeberg nuclear reactor site (owned by Eskom, the South African national utility) near Capetown, South Africa.

The PBMR utilizes 450,000 graphite-based spherical fuel elements, called pebbles, which are approximately 6 centimeters in diameter. In this design, based on the German HTR, the pebbles are located in an annular cavity in the reactor vessel. Pebbles proceed vertically downward until they are removed at the bottom. On removal they are checked, and if they are intact and not past the burn-up limit, they are circulated to the input queue again. Otherwise, they are replaced with fresh pebbles. This on-line refueling feature makes refueling shutdowns unnecessary, and it also allows the reactor to operate with almost no excess reactivity, which confers advantages in safety, economy, and resistance to nuclear weapons proliferation.

The building design for a single PBMR module consists of a reinforced concrete confinement structure, called the citadel, which houses the PCU. The PCU is located inside a more conventional concrete building that houses all of the auxiliary equipment. The citadel functions as a confinement structure to protect the nuclear components of the power conversion unit from external missiles and to retain the vast majority of fission products that might be released in the event of a reactor accident. The limited total core power allows the reactor to be designed for passive heat conduction from the core, thermal radiation and convection from the vessel and conduction to the confinement structure, keeping temperatures low enough to prevent core or fuel damage. 


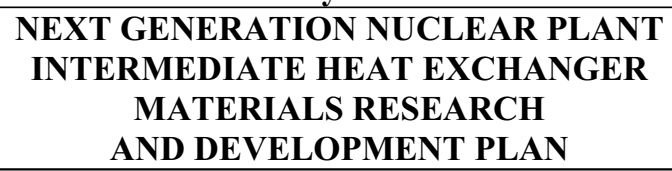

$\begin{array}{ll}\text { Identifier: } & \text { PLN-2804 } \\ \text { Revision: } & 0 \\ \text { Effective Date: } & 04 / 30 / 08\end{array}$

Page: 18 of 156

For the NGNP, Westinghouse recommended a pebble-bed reactor over a prismatic reactor design based on the fuel and fueling system demonstrated in Germany (AVR and THTR), minimal development costs and risks because of progress in South Africa, higher capacity leading to higher performance capability, lower fuel temperatures, and a strong vendor/supplier infrastructure. ${ }^{9}$ This $500 \mathrm{MWt}$ pebblebed design, termed the PBMR Process Heat Plant (PHP), emphasizes use of readily available materials that conform to standards and codes (American Society for Testing and Materials [ASTM]/ASME) and have been found acceptable by the NRC in prior applications. The material choices for the high temperature components of the PBMR-DPP are shown in Table 3 with the temperature and radiation exposures expected. These materials will not need any additional development or data base generation for use at the NGNP system design conditions.

Table 3. Material selections for elevated temperature components in the PBMR-DPP.

\begin{tabular}{lcccc}
\hline \multicolumn{1}{c}{ Components } & $\begin{array}{c}\text { Normal Operating } \\
\text { Temperature }\left({ }^{\circ} \mathrm{C}\right)\end{array}$ & $\begin{array}{c}\text { Design Basis Event } \\
\text { Maximum } \\
\text { Temperature }\left({ }^{\circ} \mathrm{C}\right)\end{array}$ & $\begin{array}{c}\text { Maximum Fast } \\
\text { Fluence }[\mathrm{E}>1 \mathrm{MeV}] \\
\left(\mathrm{n} / \mathrm{cm}^{2}\right)\end{array}$ & $\begin{array}{c}\text { Candidate } \\
\text { Materials }\end{array}$ \\
\hline Core Barrel & 400 & 556 & $3 \times 10^{18}$ & $316 \mathrm{SS}$ \\
Control Rods & 700 & 850 & $5 \times 10^{21}$ & $800 \mathrm{H}$ \\
Core Outlet Pipe & 900 & - & Not significant & $800 \mathrm{H}$ \\
Liner & 900 & - & Not significant & 617 \\
IHX & & &
\end{tabular}

\subsubsection{Reactivity Control Rods}

The PBMR preconceptual design study has the most detailed discussion of the control rod design. The control rods see the harshest conditions of all of the PBMR metallic materials with respect to high temperature and neutron irradiation. The control rods are part of the Reactivity Control System (RCS). The design aims to limit the stresses in the RCS cylinders to a minimum and the RCS is designed to be replaceable. The life of the RCS is limited by the creep strength of the material and the embrittlement due to temperature and thermal neutron exposure.

There are 24 control rods which are located in the side graphite reflector blocks. Half of the rods are used for control and the other half are used for shutdown. The shutdown rods are longer, running the length of the reflector blocks, while the control rods only run in the upper half of the reflector blocks. The control rod assembly is illustrated in Figure 13. The rods consist of a $\mathrm{B}_{4} \mathrm{C}$ rings between two coaxial cladding tubes. Although the clad material was not specified in the preconceptual design report, previous documents list Incoloy $800 \mathrm{H}$ as the most suitable material for the control rods for the following reasons:

1. Adequate high temperature strength at the normal operating temperature of $700^{\circ} \mathrm{C}$.

2. Creep resistance sufficiently qualified for long-term operation at $700^{\circ} \mathrm{C}$.

3. Limited operation at $850^{\circ} \mathrm{C}$ under abnormal events is allowed as per available data.

4. Irradiation response has been characterized to high levels of fast fluence.

5. Extensive qualification of Incoloy $800 \mathrm{H}$ control rods in previous German HTR programs.

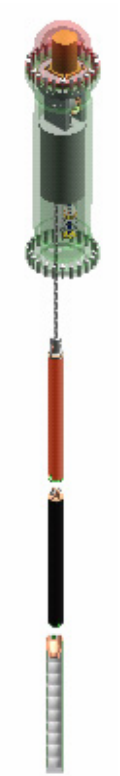

Figure 13. Schematic of the control rod assembly in the PBMR. ${ }^{21}$ 


\begin{tabular}{|c|lll|}
\hline NEXT GENERATION NUCLEAR PLANT & Identifier: & PLN-2804 & \\
INTERMEDIATE HEAT EXCHANGER & Revision: & 0 & \\
MATERIALS RESEARCH & Effective Date: & $04 / 30 / 08$ & Page: 19 of 156 \\
AND DEVELOPMENT PLAN &
\end{tabular}

\subsubsection{Core Outlet Pipe Liner}

The arrangement of the RPV core outlet pipe liner is shown in Figure 14. The liner forms an integral part of the insulation held between the liner and the outer pressure-boundary material. The insulation in the core outlet piping is a necessary component of the insulation system required for keeping the outer pressure-boundary (ferritic steel) temperatures within operational limits.

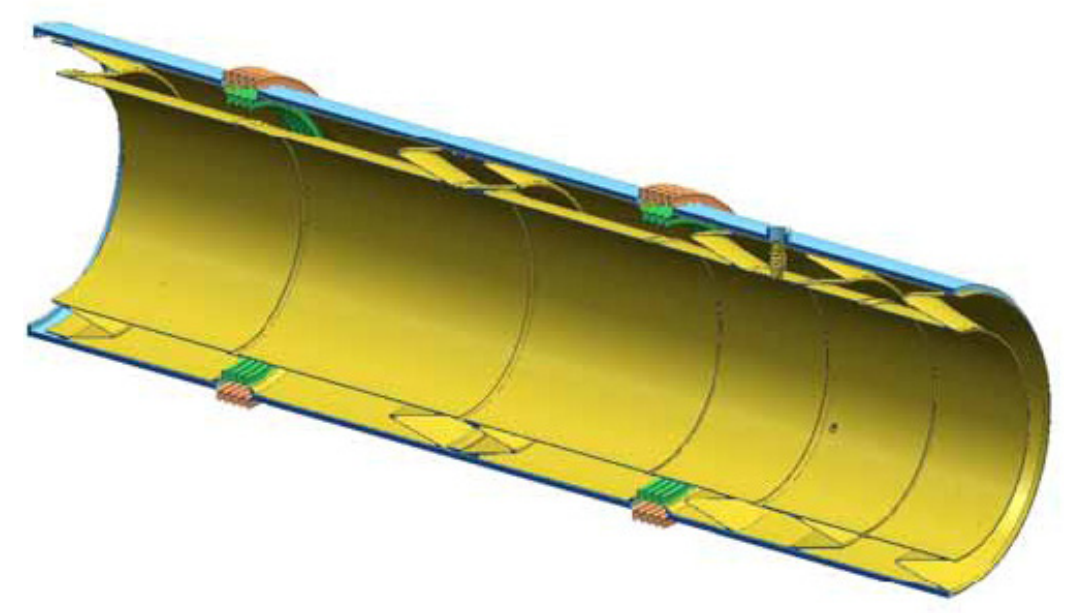

Figure 14. PBMR Core Outlet Pipe Liner.

The inner liner material of the core outlet pipe is specified as Incoloy $800 \mathrm{H}$. The liner has virtually no load-bearing function and the use of Incoloy $800 \mathrm{H}$ is dictated by its oxidation resistance to the impure helium, and adequate high temperature strength. As a liner material, Incoloy $800 \mathrm{H}$ has the following advantages:

1. Adequate high temperature strength and creep resistance.

2. Extensive fabrication experience in large diameter pipe sections.

3. Extensively tested as liner material for qualification of the insulated "hot pipe" design in the German HTR program up to $950^{\circ} \mathrm{C}$.

\subsubsection{Core Barrel}

The core barrel (Figure 15) will be made from $316 \mathrm{H}$ stainless steel, but will not require a core barrel conditioning system because of the low reactor inlet temperature. 


\begin{tabular}{|c|lll|}
\hline $\begin{array}{c}\text { NEXT GENERATION NUCLEAR PLANT } \\
\text { INTERMEDIATE HEAT EXCHANGER }\end{array}$ & Identifier: & PLN-2804 & \\
MATERIALS RESEARCH & Revision: & 0 & \\
AND DEVELOPMENT PLAN & Effective Date: & $04 / 30 / 08$ & Page: 20 of 156 \\
\hline
\end{tabular}
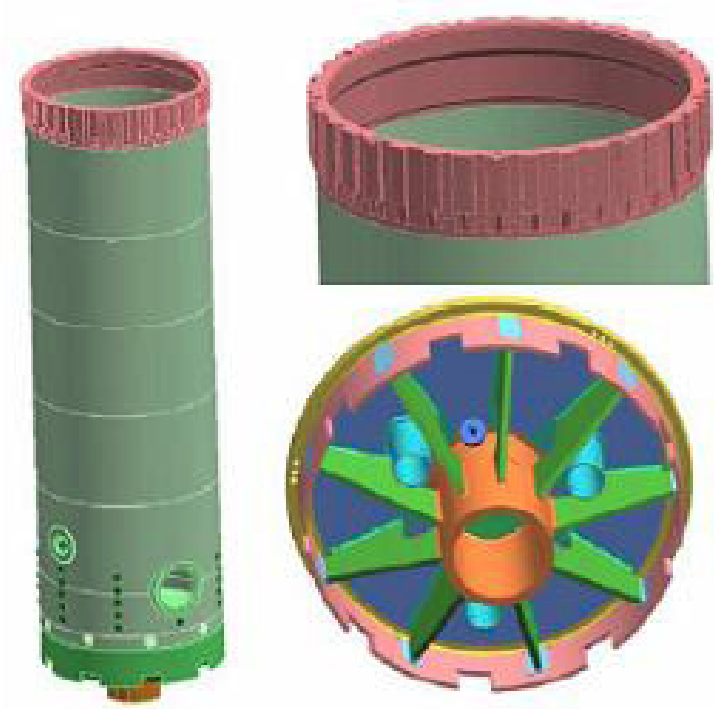

Figure 15. Westinghouse Core Barrel.

\subsubsection{Power Conversion and Intermediate Heat Exchanger}

Westinghouse recommends the use of an indirect power conversion cycle and an indirect hydrogen heat transport loop arranged in a serial fashion (Figure 16). The serial arrangement is simpler mechanically and less expensive and is used in Japan's HTTR. ${ }^{12}$ The intermediate heat exchanger for the hydrogen heat transport loop would be placed first in the series in order to obtain the highest temperature gas from the nuclear reactor. After the IHX extracts $50 \mathrm{MW}$, the cooled primary loop gas would then go to the PCU. The pressure of the primary loop is $9 \mathrm{MPa}$, and the secondary loop between 8.1 and $8.5 \mathrm{MPa}$. The power conversion cycle uses steam generators and a traditional Rankine Cycle to generate electricity, and would be designed to receive the full power of the reactor (Figure 17).

A two-part compact heat exchanger is suggested. Section 1 (IHX A), expected to be replaceable and made of metal or ceramic, operating at temperatures between 760 and $900^{\circ} \mathrm{C}$. If the NGNP schedule prevents the use of ceramic materials, metallic materials may have to be used during initial deployment until ceramic components can be tested and certified. ${ }^{12}$ Section 2 (IHX B), made of an ASME codified metal, would be expected to operate at temperatures below $760^{\circ} \mathrm{C}$ and would be designed for a 60 -year lifetime. Alloys 617 and $800 \mathrm{H}$ are currently recommended for the IHX A and IHX B, respectively. Both intermediate heat exchanger sections are envisioned as compact heat exchanger modules, as it is believed that tubular heat exchangers would be too large and costly to be economical. 
NEXT GENERATION NUCLEAR PLANT

INTERMEDIATE HEAT EXCHANGER

MATERIALS RESEARCH

AND DEVELOPMENT PLAN
Identifier:

Revision:

Effective Date: $04 / 30 / 08$

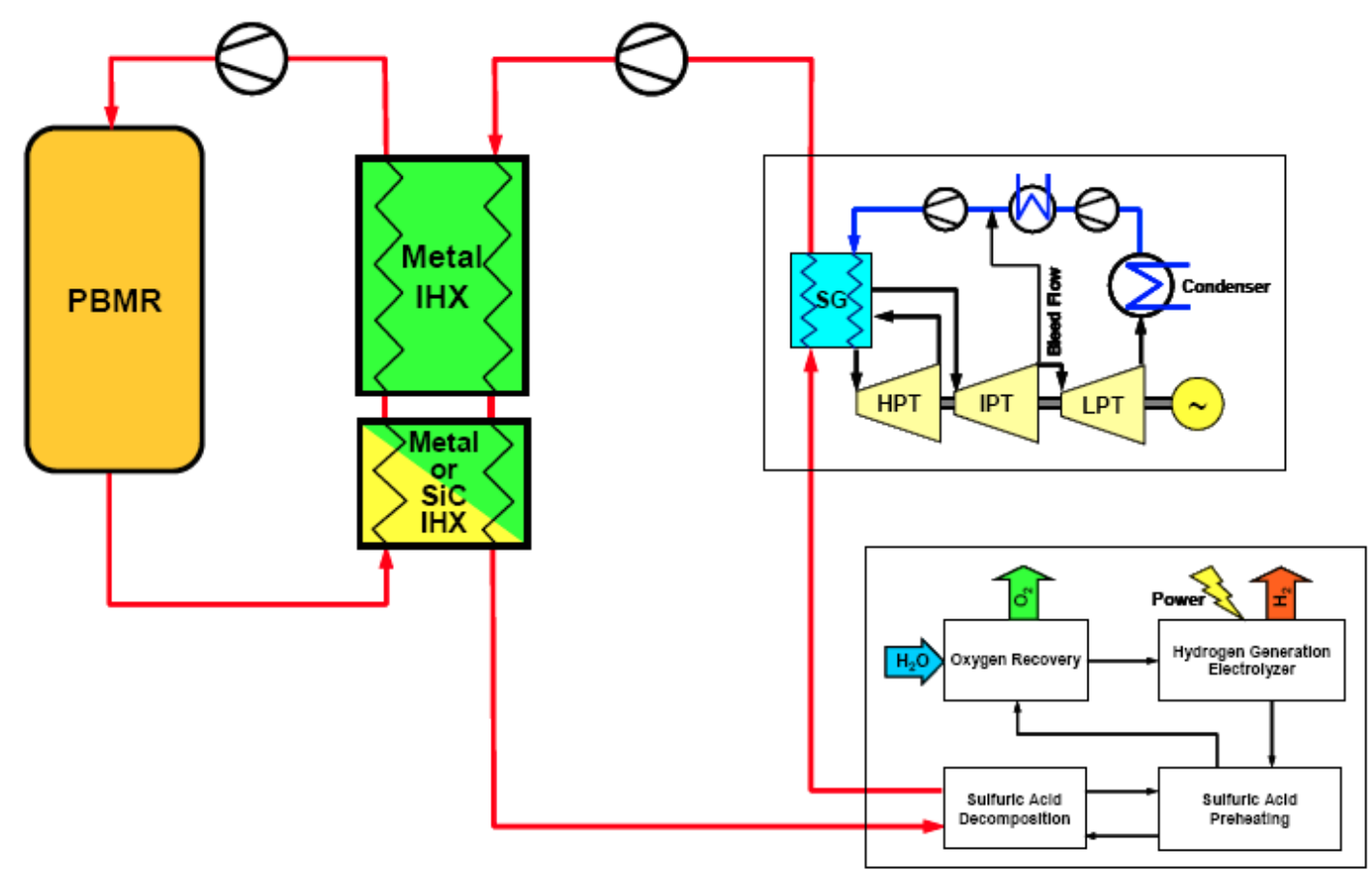

Figure 16. NGNP configuration as proposed by Westinghouse.

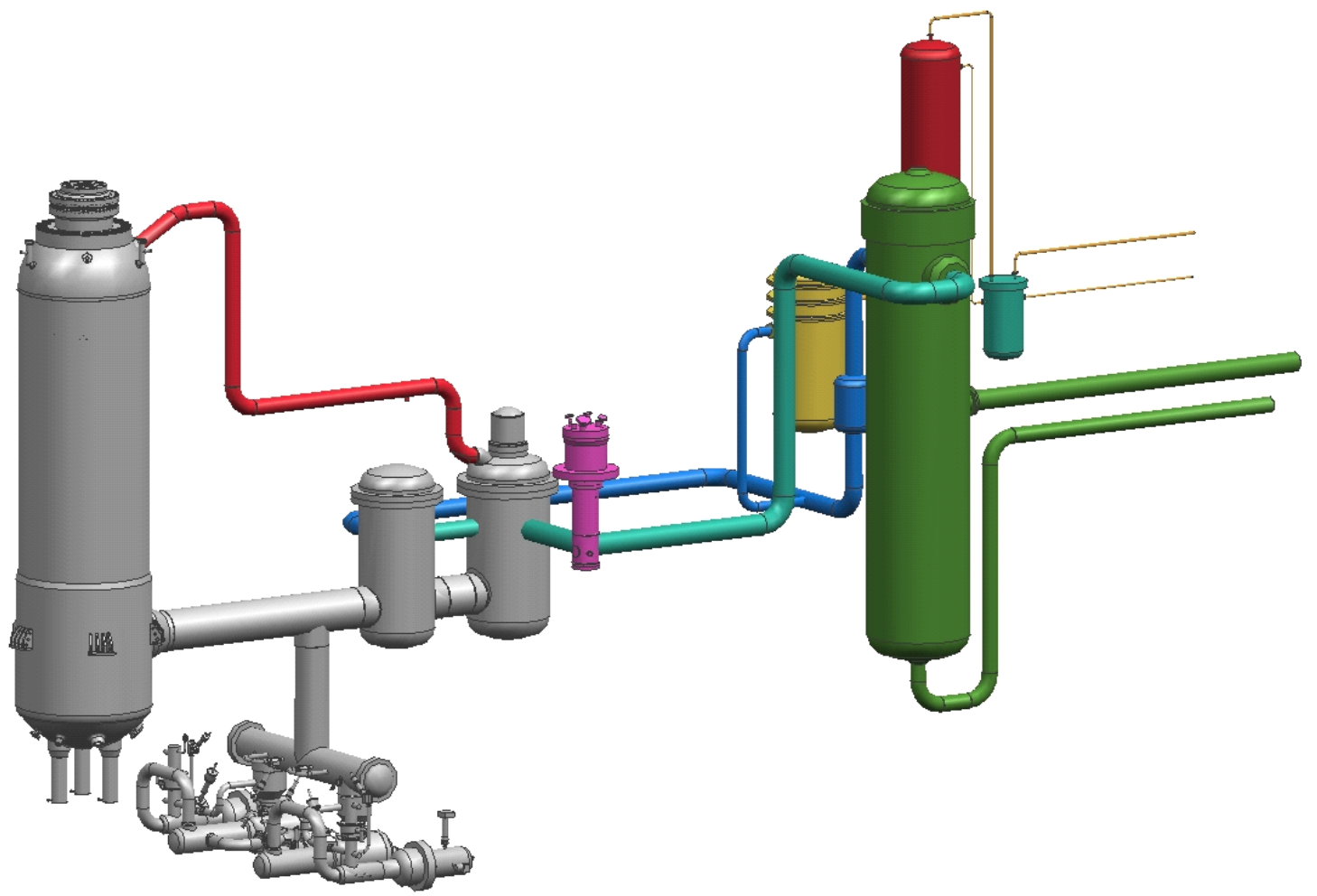

Figure 17. Proposed layout of the reactor unit system in relation to the PHTS, SHTS, SG and PCHX. 


\begin{tabular}{c|lll|}
\hline NEXT GENERATION NUCLEAR PLANT & Identifier: & PLN-2804 & \\
INTERMEDIATE HEAT EXCHANGER & Revision: & 0 & \\
MATERIALS RESEARCH & Effective Date: & $04 / 30 / 08$ & Page: 22 of 156 \\
AND DEVELOPMENT PLAN &
\end{tabular}

\subsection{Core Internals}

\subsubsection{Control Rods}

A prior report ${ }^{22}$ studied the potential materials that may be selected for the control rod sleeves and the issues associated with the selection of each material including how these issues relate to the reactor designs. The report examined past reactor designs and control rod performance, as well as the two reactor design concepts under consideration for NGNP in detail as they pertain to control rod design and performance. In addition to evaluating the material requirements, the report reviewed the irradiation behavior, testing, codification, cost, availability, and manufacturing issues of three materials $\mathrm{SiC}_{\mathrm{f}} / \mathrm{SiC}$ and $\mathrm{C}_{\mathrm{f}} / \mathrm{C}$ composites and Alloy $800 \mathrm{H}$.

\subsubsection{Core Barrel}

The core barrel is positioned between the pressure vessel and the graphite outer side reflector. It is not a pressure vessel and does not see significant stress although it supports the graphite core and helps maintain core geometry. The core barrel will be exposed to moderate radiation and temperatures, but must last the lifetime of the plant. Alloy $800 \mathrm{H}$ and 316 stainless steel have been suggested as materials. There may be procurement and fabrication issues because of its large size. It is expected that construction will require some on-site welding.

\subsection{Inter-organizational Structures}

\subsubsection{Generation IV International Forum}

The primary mechanism for international collaboration for materials $R \& D$ activities in support of a High Temperature Gas Reactor (HTGR) is through the Generation IV International Forum (GIF). The GIF is an international effort working to advance nuclear energy to meet future energy needs. It includes eight partners that have now signed the treaty-level GIF International Framework Agreement: Canada, France, Japan, the Republic of Korea, the Republic of South Africa, Switzerland, the United Kingdom, the United States and the European Union. These partners have agreed on a framework for international cooperation in research necessary to build a future generation of nuclear energy systems.

Generation I nuclear reactor systems are early prototype plants such as Magnox. Generation II plants are the current generation of electricity producing commercial nuclear plants. Generation III plants are advanced LWRs including Advanced Boiling Water Reactors. Generation IV plants are envisioned as highly economical, and proliferation resistant and feature enhanced safety and minimal waste; however they have yet to be commercially operated.

The objective is to have HTGR systems available for international deployment by about 2030 when many of the worlds currently operating nuclear plants will be at or near the end of their operating lifetimes. Collaboration plans for each materials R\&D area are being developed, and once in place, collaboration will begin immediately.

The specific international vehicle that will govern the exchange of GIF information on structural materials relevant to the NGNP, is the Project Arrangement on Materials for the International Research and Development of the Very-High-Temperature Reactor Nuclear Energy System. This Project Arrangement (PA) is being established by the VHTR Materials Project Management Board and covers both individual and cooperative contributions by the international partners. The initial PA will cover the exchange of materials information generated during the time frame from 2007 to 2012, as well historical 


\begin{tabular}{c|lll|}
\hline $\begin{array}{c}\text { NEXT GENERATION NUCLEAR PLANT } \\
\text { INTERMEDIATE HEAT EXCHANGER }\end{array}$ & Identifier: & PLN-2804 & \\
MATERIALS RESEARCH & Revision: & 0 & \\
AND DEVELOPMENT PLAN & Effective Date: & $04 / 30 / 08$ & Page: 23 of 156 \\
\hline
\end{tabular}

information that has heretofore not been publicly available. Information will be generated and exchanged on three major classes of materials: graphite for core components; metals for pressure boundaries, reactor internals, piping, heat exchangers, and balance of plant; and ceramics and ceramic composites for special needs, such as control rods, insulation, reactor internals, etc. All materials data identified within the PA that is produced by any partner shall be shared with all other partners for use in their national programs. Currently, about $\$ 120 \mathrm{M}$ in VHTR materials data has been committed as contributions by the GIF partners, including about $\$ 52 \mathrm{M}$ in generated metals data, plus significant amounts of proprietary historical data. Once the PA is signed and in effect, now anticipated to occur in the fall of 2008, detailed assessments will be made of the portion of the GIF VHTR materials data that will be available to meet the data needs of the NGNP and reduce the resources required by the project.

\subsubsection{INERI Programs}

International Nuclear Energy Research Initiatives (INERI) are designed to allow a free exchange of ideas and data between U.S. and international researchers working in similar research areas. This international agreement encourages strong collaborations between research institutions where a benefit to both countries is anticipated. An INERI between the U.S. and Korea is ongoing. An agreement between the NGNP high temperature materials program and the French program is under negotiation.

\subsubsection{University NERI Programs}

Nuclear Engineering Research Initiative (NERI) programs facilitate technical cooperation between the NGNP Materials Program and universities. Currently the University of Michigan working is to define strategies for the improvement of high temperature alloys for structural components, such as the NGNP IHX operating at $1000^{\circ} \mathrm{C}$ in helium. They will investigate the oxidation/carburization behavior and microstructure stability and how these processes affect creep in order to develop a fundamental understanding of how impurities in the He environment affect these degradation processes.

\subsubsection{The Independent Technical Review Group}

The Independent Technical Review Group (ITRG) was formed to provide a critical review of the proposed NGNP project and identify areas of R\&D that needed attention. The ITRG observations and recommendations focus on overall design features and important technology uncertainties of a very-high temperature nuclear system concept for the NGNP and were included in a 2003 report. ${ }^{23}$ They identified the IHX, hot duct, turbine inlet components and in-core metallic materials as the high-risk components. Consequently, lower gas outlet temperatures were recommended for start-up, with the option of eventually increasing to $1000^{\circ} \mathrm{C}$ by replacing the critical metal components with higher-temperature materials developed and qualified in parallel with construction and early operation of the NGNP. At the same time, they questioned the practicality of an outlet gas temperature of $1000^{\circ} \mathrm{C}$, and discouraged $\mathrm{R} \& \mathrm{D}$ to achieve this goal unless it could be justified by economic benefits. ${ }^{10}$

The ITRG recommended the indirect cycle based on the "large number and formidable nature of the risks associated with the direct cycle and their potential impact on the NGNP schedule" despite the significant developmental risks associated with the large IHX required for the indirect cycle. However, the ITRG also recognized the need to replace the IHX at least once during plant life because of the limitations of the metallic material, even with a gas outlet temperature of $900^{\circ} \mathrm{C}$. Furthermore, they are skeptical that a metallic material will become available to enable a gas outlet temperature of $1000^{\circ} \mathrm{C}$, or that an IHX could be constructed from a ceramic material. ${ }^{10}$ 


\begin{tabular}{c|lll|}
\hline $\begin{array}{l}\text { NEXT GENERATION NUCLEAR PLANT } \\
\text { INTERMEDIATE HEAT EXCHANGER }\end{array}$ & Identifier: & PLN-2804 & \\
MATERIALS RESEARCH & Revision: & 0 & \\
AND DEVELOPMENT PLAN & Effective Date: & $04 / 30 / 08$ & Page: 24 of 156 \\
\hline
\end{tabular}

\section{OPERATIONAL REQUIREMENTS}

\subsection{Baseline Case Definition}

Past interactions between material researchers and nuclear engineers have underscored a key difficulty with the NGNP project (and many others). A definition of the materials design and performance requirements is needed for material research issues to be defined and for correct material selections. The material researchers want the reactor design and operating parameters determined as soon as possible. However, design engineers want to know (or assume) material capabilities now and delay design decisions as other pressing technical, procedural and political issues dictate.

Determining the tentative operating parameters is most important to aid in identifying testing needs, including design of component test facilities. It is critical that decisions be made about which and how many alloys will be used and kept for development to decrease research requirements. A baseline case has been selected for initial operation of the NGNP that minimizes technical and schedule risks. This baseline case does nothing to preclude future development of novel, higher risk, technology.

\subsubsection{Reactor Design}

The NGNP program has not yet determined whether the reactor will be a pebble-bed or prismatic design. A pebble-bed core was utilized in two German reactors (AVR and THTR) and is scheduled to be implemented in the PBMR plant in South Africa well before the NGNP comes on line. A prismatic core was used in the Fort St. Vrain reactor and is currently operating in the HTTR in Japan.

The temperature of the IHX is determined by the reactor gas outlet temperature and does not depend on the reactor design; however, there is more concern about fouling in a pebble-bed design. Modeling and analysis of the two core configurations has indicated that there are small differences in the expected operating conditions (e.g., temperature)the prismatic core design runs hotter than the pebble-bed design within the RPV, ${ }^{24}$ which may impact the material choice for both the control rods and the core barrel. Preliminary calculations indicate $800 \mathrm{H}$ could be used for a prismatic core design, but the safety factor may not be large enough. ${ }^{22}$ Similarly, 316SS may not be a viable choice for the core barrel, especially for the prismatic design.

Currently the baseline reactor has an indirect cycle. An indirect cycle requires a large IHX since it must transfer the full $600 \mathrm{MWt}$ of reactor thermal power to the power conversion system and the hydrogen production process. The reactor is cooled with helium, which is on a separate primary loop, and the secondary loop also contains gas (He or a He-N mixture), about $10 \%$ of which will be diverted to a hydrogen plant. Power efficiencies of up to $50 \%$ can be achieved with this configuration.

\subsubsection{IHX}

The heat exchanger will perform several functions in the NGNP. It will separate the primary and secondary power generation circuits and will separate the hydrogen generation plant from the major reactor systems. This will minimize the potential for tritium migration, and ensure accident or upset conditions in the hydrogen production facility do not impact the operation of the reactor.

\subsubsection{IHX Design}

The IHX design has yet to be determined. Tube-shell, plate-fin, and PCHE heat exchangers are all under consideration. The size and number of heat exchangers is also unknown at this time. As a result, 


\begin{tabular}{c|lll|}
\hline $\begin{array}{c}\text { NEXT GENERATION NUCLEAR PLANT } \\
\text { INTERMEDIATE HEAT EXCHANGER }\end{array}$ & Identifier: & PLN-2804 & \\
MATERIALS RESEARCH & Revision: & 0 & \\
AND DEVELOPMENT PLAN & Effective Date: & $04 / 30 / 08$ & Page: 25 of 156 \\
\hline
\end{tabular}

both thin and thick product forms must be considered for research and development. These different product forms may have different microstructures and properties. The design strength should be at least double the design pressure. A design strength of $\sim 5 \mathrm{MPa}$ at operating temperature has been suggested. ${ }^{2}$ For maximum efficiency, a low pressure differential between inlet and outlet, $\sim 50 \mathrm{KPa}$, must be maintained which will likely limit the flow length. A small pressure drop must also be maintained between the inlet and outlet gases to ensure a low creep load on the structure. All three vendors report gas temperatures entering the IHX to be $25-50^{\circ}$ less that the core outlet gas temperature.

The Westinghouse design approach would use two IHX in series. A replaceable one subjected to temperatures in the range of $710-900^{\circ} \mathrm{C}$, and a second designed for temperatures less than $710^{\circ} \mathrm{C}$, intended to last the full lifetime of the plant.

Two primary options have been considered for hydrogen production using process heat from the reactor. High Temperature Electrolysis (HTE) relies primarily on electrical energy, with only a small amount of process heat required, while sulfur-iodine (SI) thermochemical production relies entirely on process heat from the reactor. The design conditions of the IHX considered in the baseline case are dictated by the SI process heat requirements. The IHX is designed assuming $50 \mathrm{MWt}$ are available for hydrogen production.

\subsubsection{IHX Materials}

Material considerations for the different heat exchanger designs are essentially similar, with the exception of some fabrication issues. The high strength and work hardening rate of the candidate alloys could make some plate or fin forming difficult. A gaseous secondary coolant, either $\mathrm{He}$ or a $\mathrm{He} / \mathrm{N}$ mixture is assumed. If a He/ $\mathrm{N}$ mixture is used, traditional gas-turbine technology can be used; otherwise, helium gas turbine technology will need to be developed.

Alloy 617 and Alloy 230 are the two leading candidate materials considered for the NGNP IHX application. The two alloys were developed as competitors for high temperature applications. Haynes introduced Alloy 188 as a development from Alloy L605 (also known as Haynes 25), and Special Metals responded by developing Alloy 617 with a lower Co content. Haynes competed with Alloy 230 with an even lower Co concentration. Since their introduction, significant research activities have been conducted to characterize both alloys and explore their potentials. Generally speaking, Alloy 617 has been more thoroughly studied with more data available compared to Alloy 230, due to its earlier introduction into the marketplace; while as a newer alloy, 230 may have valuable potential for Generation IV application. Both alloys have attractive properties for high temperature applications. Standard specifications have been developed and accepted by ASTM and ASME, so either alloy can be produced by other manufacturers.

Both Alloy 617 and 230 are candidates for operation at $850^{\circ} \mathrm{C}$, so construction of an IHX could proceed with reduced materials $\mathrm{R} \& \mathrm{D}$ (relative to other materials). This approach would also provide more time for expanding high temperature material databases and incorporating the chosen material into the appropriate codes for a high temperature nuclear application. Also, efforts have been made to modify the specifications to improve performance of both Alloy 617 and Alloy 230. The effort on Alloy 617 is aimed at improving high temperature strength; while that on Alloy 230 is aimed at improving corrosion resistance. More detailed information on the alloys will be presented in Section 4.1.1. 


\begin{tabular}{|c|lll|}
\hline NEXT GENERATION NUCLEAR PLANT & Identifier: & PLN-2804 & \\
INTERMEDIATE HEAT EXCHANGER & Revision: & 0 & \\
MATERIALS RESEARCH & Effective Date: & $04 / 30 / 08$ & Page: 26 of 156 \\
AND DEVELOPMENT PLAN &
\end{tabular}

\subsubsection{Core Internals}

\subsubsection{Control Rods}

The reactivity control rods for both the prismatic and pebble-bed design could arguably operate under the ASME code for $800 \mathrm{H}$, as it currently stands, with a maximum use temperature of $760^{\circ} \mathrm{C}$. Although (like all austenitic alloys) $800 \mathrm{H}$ experiences radiation embrittlement, the alloy is being used in HTGRs and the embrittlement can be accounted for in the component design. The primary problem with using $800 \mathrm{H}$ control rods is planning for high temperature off-normal events such as Depressurized Conduction Cool-down (DCC). Procedural solutions such as delayed scram or temperature testing will be required.

The design requirements are fairly similar for the preconceptual prismatic and PBR designs. Although the PBR has a slightly lower fluence value at the control rod location, it would not impact material selection. However the prismatic design has potentially higher control rod operating temperatures under certain conditions and also a higher maximum DCC temperature, which could be significant in discriminating between control rod sheathing materials. The temperatures seen by the control rods should be somewhat lower than those reported in Table 4 of Section 3.3.1 with an outlet gas $100^{\circ} \mathrm{C}$ cooler than the $950^{\circ} \mathrm{C}$ reported there. The PBMR DPP has reported its control rods will be exposed to a normal operating temperature of $700^{\circ} \mathrm{C}$, a design basis event maximum temperature of $850^{\circ} \mathrm{C}$, and a maximum end-of-life fast fluence of $5 \times 10^{21} \mathrm{n} / \mathrm{cm}^{2} .13$

\subsubsection{Core Barrel}

$316 \mathrm{H}$ stainless steel and $800 \mathrm{H}$ are under consideration as the core barrel material (GA did not specify a material in their preconceptual design report). $316 \mathrm{H}$ stainless steel is also Code qualified for up to $816^{\circ} \mathrm{C}$ and 300,000 hours in ASME Subsection NH. The core barrel may be either single or doublewalled. The 2003 development plan $^{25}$ has reported 0.05 dpa as a lifetime dose. The PBMR DPP has reported its core barrel to be $400^{\circ} \mathrm{C}$ with short-term abnormal temperature excursions of about $557^{\circ} \mathrm{C}$. The maximum End-of-Life Fast Fluence $(\mathrm{E}>0.1 \mathrm{MeV})$ is estimated at $3 \times 10^{18} \mathrm{n} / \mathrm{cm}^{2} .{ }^{13}$

\subsection{Alternative Cases}

\subsubsection{Reactor Design}

A direct cycle parallel IHX configuration is also under consideration. It would require the smallest IHX and result in the highest overall electrical power production efficiency. A second direct cycle configuration under consideration features a tertiary loop for added separation between the reactor and the hydrogen plant. It also requires a small IHX, but the added separation comes at the expense of lower hydrogen production efficiency. ${ }^{1}$

Another reactor design variable is supplementary cooling of the Reactor Pressure Vessel. This primarily impacts the RPV material selection, but if the "hot vessel option" (i.e., no cooling) is chosen, 316 SS may not be a viable material for the core barrel.

\subsubsection{Operating Conditions}

All three vendors report gas temperatures entering the IHX to be $25-50^{\circ}$ less that the core outlet gas temperature. Currently the plan is to start running the NGNP with a core outlet temperature of $850^{\circ} \mathrm{C}$, but plant flexibility to increase outlet gas temperatures up to $950^{\circ} \mathrm{C}$ at some future point is desirable. This could be achieved by replacing the IHX or by over designing it initially. 


\begin{tabular}{|c|lll|}
\hline NEXT GENERATION NUCLEAR PLANT & Identifier: & PLN-2804 & \\
INTERMEDIATE HEAT EXCHANGER & Revision: & 0 & \\
MATERIALS RESEARCH & Effective Date: & $04 / 30 / 08$ & Page: 27 of 156 \\
AND DEVELOPMENT PLAN &
\end{tabular}

\subsubsection{IHX Materials}

$800 \mathrm{H}$ is being considered by one of the vendors as an alternative to Alloy 617 or 230 . The high temperature properties are not as good, but it has the advantage of already being in the code, although only to $760^{\circ} \mathrm{C}$. Suitable higher-temperature materials, for example oxide dispersion-strengthened (ODS) alloys or ceramics, may be used for the IHX, either to replace an IHX in the NGNP at some future point, or to substitute for a metallic IHX in future HTGRs.

\subsubsection{IHX Design Configuration}

In addition to IHX size differences resulting from indirect vs. direct cycles (discussed in Section 2.2), a number of design variations are being considered by the potential vendors. Westinghouse has recommended two IHX's in series: a replaceable high temperature IHX made of Alloy 617, and a lower temperature IHX processing cooler gas that has already passed through made of $800 \mathrm{H}$ intended to last the life of the plant. In this configuration, the second IHX processes gas already cooled by the first, thus enduring much less harsh conditions. In time, higher temperature materials or different designs could be tested by installing them in the position of the replaceable IHX.

Another variation is whether the IHX must be placed in its own pressure vessel so that the IHX itself does not serve as a primary pressure-boundary.

Finally, there are numerous types of IHX designs under consideration: tube and shell, plate-fin, IPCE, involute, and micro-channel. Some of these designs are compact heat exchangers, which would be advantageous if the technology can progress and reliability can be demonstrated to the level required for this application. These designs are described in Section 2.2.

\subsubsection{Alternatives for Core Internals}

\subsubsection{Control Rod Features}

The most mature, and therefore lowest risk, concept for control rod sleeves is to use Incoloy $800 \mathrm{H}$. Composite control rod sleeves may be advantageous because of their potential ability to withstand higher radiation doses and temperatures. $\mathrm{C}_{\mathrm{f}} / \mathrm{C}$ composites are listed as the first choice by AREVA and as an option (after $800 \mathrm{H})$ by GA.

\subsubsection{Core Barrel Features}

The core barrel may be single or double-walled. The double-wall design uses gas flow to cool the core barrel as well as the RPV.

\subsection{Future Operation}

\subsubsection{Increased Outlet Gas Temperature}

Currently the plan is to start running the NGNP with a gas outlet temperature of $850^{\circ} \mathrm{C}$, but plant flexibility to increase outlet gas temperatures at some future point has been requested from designers. Ideally, the NGNP will operate with a higher outlet gas temperature at some point in the future so the hydrogen production process can operate more efficiently. Presumably future HTGRs based on the NGNP design will also operate at higher temperatures. 


\begin{tabular}{c|lll|}
\hline NEXT GENERATION NUCLEAR PLANT & Identifier: & PLN-2804 & \\
INTERMEDIATE HEAT EXCHANGER & Revision: & 0 & \\
MATERIALS RESEARCH & Effective Date: & $04 / 30 / 08$ & Page: 28 of 156 \\
AND DEVELOPMENT PLAN &
\end{tabular}

The IHX is likely the component most critically impacted by increased temperatures. Temperatures as high as $1000^{\circ} \mathrm{C}$ have been targeted. The outlet gas temperature does not affect material selection for the IHX in the range of $850-900^{\circ} \mathrm{C}$; however it may affect the design allowable stresses. Above $900^{\circ} \mathrm{C}$, other materials will need to be considered because alloys under consideration for the first IHX cannot endure such elevated temperatures for prolonged periods.

Other high temperature components may also be impacted by increased operating temperatures. Table 4 summarizes the estimated operating conditions of control rods in a reactor with a gas outlet temperature of $950^{\circ} \mathrm{C}$ calculated when that was still in the NGNP target range..$^{22,24}$ It is assumed that the shutdown rods in the prismatic design would be suspended above the core during normal operation and off-normal events.

Table 4. Current estimated operating conditions for NGNP control rods for outlet gas of $950^{\circ} \mathrm{C}$.

\begin{tabular}{lccc}
\hline & Normal temp & Max DCC temp & Lifetime dose \\
\hline Prismatic & $732^{\circ} \mathrm{C}$ & $1153^{\circ} \mathrm{C}$ & $8.4 \mathrm{dpa}$ \\
Pebble bed & $546^{\circ} \mathrm{C}$ & $1017^{\circ} \mathrm{C}$ & $7.9 \mathrm{dpa}$ \\
\hline
\end{tabular}

\subsubsection{New Component Designs}

Heatric is developing new and improved designs for PCHEs. Although details of the design are proprietary, the new design features fluids distributed to the active passages via internal ports, zigzag passage geometry reconfigured to enhance turbulence, reduced pressure drop characteristics, and heat transfer passages that result in pure counter-current flow. A small start-up company, Velocys, is developing compact heat exchangers as well. The Velocys design uses sheet material that is diffusionbonded into compact modules; however, the fabrication technology differs from the Heatric methods.

If ceramic composite control rods are implemented, the control rod design will be altered to accommodate the differences in fabricability, etc. No other dramatic changes in high temperature component design are anticipated at this point.

\subsubsection{Molten Salt as a Secondary Coolant}

The molten salt, FliNak, has been considered as an alternative secondary coolant. GA performed an evaluation focusing on economics and technical risk. Although the capital cost of a He heat transfer system was estimated to be about $\$ 16$ million more because of the need for a He circulator; the operating cost of a molten salt system was estimated to be substantially higher due to replacement costs of the IHX. More importantly, the technical risk of using molten salt is judged to be much greater. In fact, there is no known material that could handle the extremely corrosive environment created by high temperature molten salt while retaining necessary creep strength.

\subsection{Plant Transient Definitions}

The plant transient definitions below are borrowed from the PBMR white paper on Licensing Basis Event (LBE) selection for the purposes of discussing various scenarios. ${ }^{26}$ These definitions have not yet been endorsed by the NRC, and formal definitions for a HTGR have not been determined. The frequencies of LBEs are expressed in units of events per plant-year where a plant is defined as a collection of up to eight reactor modules having certain shared systems. 


\begin{tabular}{c|lll|}
\hline NEXT GENERATION NUCLEAR PLANT & Identifier: & PLN-2804 & \\
INTERMEDIATE HEAT EXCHANGER & Revision: & 0 & \\
MATERIALS RESEARCH & Effective Date: & $04 / 30 / 08$ & Page: 29 of 156 \\
AND DEVELOPMENT PLAN &
\end{tabular}

\subsubsection{Normal Operating Conditions}

The vendor preconceptual designs all recommended using a phased approach to operate the plant at lower temperature in the startup and early operation of the plant to provide more design margin for the available materials of construction. Baseline conditions assume an outlet gas temperature of $850^{\circ} \mathrm{C}$.

The gas in both the primary and secondary loops will be pressurized to avoid a significant pressure drop across the IHX. Pressure levels of about 5, 7, or $9 \mathrm{MPa}$, have been recommended in the preconceptual design reports of the three vendors.

\subsubsection{Anticipated Operational Occurrences}

An Anticipated Operational Occurrence (AOO) encompasses planned and anticipated events. The doses from AOOs are required to meet normal operation public dose requirements. AOOs are utilized to set operating limits for normal operation modes and states. AOOs are event sequences with a mean frequency greater than $10^{-2}$ per plant-year.

PBMR gives an example as the loss of the Power Conversion System (PCS) where one of the active core heat removal systems works as specified. Since the heat is successfully removed from the core, this occurrence would have little impact on the IHX or core internals. However, if the loss of the PCS results in a loss of secondary loop pressure, pressure as well as temperature transients in the IHX will result because in an indirect cycle the gases are flowing in independent loops. Precautions will be necessary to maintain the correct pressure differential. Start-up/shut-down is a relatively frequent AOO that poses the risk of thermal fatigue.

\subsubsection{Design Basis Events}

Design Basis Events (DBEs) encompass unplanned, off-normal events not expected in the plant's lifetime, but which might occur in the lifetimes of a fleet of plants. The doses from DBEs are required to meet accident public dose requirements. DBEs are the basis for the design, construction, and operation of the Safety Significant Components (SSCs) during accidents. Separate from the design certification, DBEs are also evaluated in developing emergency planning measures. DBEs have event sequences with mean frequencies less than $10^{-2}$ per plant-year and greater than $10^{-4}$ per plant-year. Any of a number of small break scenarios in the Helium Pressure Boundary are examples of DBEs given by PBMR.

It is likely that a loss of flow leading to a high pressure conduction cooldown (HPCC) and loss of coolant leading to a low pressure conduction cooldown (LPCC) will be defined as DBEs. The HPCC results in decay heat that is more uniformly distributed within the core and vessel than during an LPCC because the system remains at high pressure. The LPCC is typically initiated by a small leak of the primary coolant, resulting in depressurization and initiating a reactor trip. In both events, the shut-down cooling system fails to start and decay heat is removed passively by thermal radiation and natural convection from the reactor vessel. ${ }^{10}$ Peak temperatures for these events have been reported for the fuel, the control rods, and the RPV, but not yet for the IHX.

\subsubsection{Beyond Design Basis Events}

Beyond Design Basis Events (BDBEs) are rare, off-normal events of lower frequency than DBEs. BDBEs are evaluated to ensure that they do not pose an unacceptable risk to the public. Separate from the design certification, BDBEs are also evaluated in developing emergency planning measures. Loss of the PCS where the Reactor Control System (RCS) does not shut down the reactor is the example given by PBMR. BDBEs are defined as event sequences with mean frequencies less than $10^{-4}$ per plant-year and greater than $5 \times 10^{-7}$ per plant-year. BDBEs will not be considered in this report. 


\begin{tabular}{|c|lll|}
\hline NEXT GENERATION NUCLEAR PLANT & Identifier: & PLN-2804 \\
INTERMEDIATE HEAT EXCHANGER & Revision: & 0 & \\
MATERIALS RESEARCH & Effective Date: & $04 / 30 / 08$ & Page: 30 of 156 \\
AND DEVELOPMENT PLAN &
\end{tabular}

\subsection{Required Lifetime and Replacement Plans}

\subsubsection{IHX}

There is no requirement that the IHX(s) last the design lifetime of the plant (60 yrs.), although this would be ideal. Replacing the IHX is possible and in reality, probable. Traditional tube and shell heat exchangers used in the fossil fuel industry can be inspected, and in the event of a leak in the tube, they are patched. Compact heat exchangers have the advantage that they would be less cumbersome to change; however they cannot be easily repaired or inspected. Leaks would not be evident until tritium is detected on the secondary side. A two-stage heat exchanger system might present a compromise of these extremes.

\subsubsection{Core Internals}

The core barrel is not a replaceable part and therefore is expected to survive the full life of the plant. The lifetime of the control rod sleeves is of minimal significance, providing it is reasonable and the component can be changed during scheduled maintenance shutdowns. 


\begin{tabular}{c|lll|}
\hline $\begin{array}{c}\text { NEXT GENERATION NUCLEAR PLANT } \\
\text { INTERMEDIATE HEAT EXCHANGER }\end{array}$ & Identifier: & PLN-2804 & \\
MATERIALS RESEARCH & Revision: & 0 & \\
AND DEVELOPMENT PLAN & Effective Date: & $04 / 30 / 08$ & Page: 31 of 156 \\
\hline
\end{tabular}

\section{CURRENT STATE OF THE ART}

\subsection{Materials Research to Date}

\subsubsection{Candidate Materials}

Regardless of the IHX design, material selection for this component is critical. The material must be available in the appropriate product forms - both plate and sheet, weldable and suitable for use at $850^{\circ} \mathrm{C}$ or above. The majority of materials research and development programs in support of high temperature gas reactors (HTGRs) were conducted in the 1960s to early 1980s. The thrust of these programs was to develop a database on materials for application in steam-cycle and process-nuclear-heat based HTGRs. Less work has been done on materials with emphasis on direct and/or indirect gas-turbine-based HTGRs. The available material property data was reviewed in detail and an assessment of relevant factors was made including thermal expansion, thermal conductivity, tensile, creep, fatigue, creep-fatigue, and toughness properties for the candidate alloys. Thermal aging effects on the mechanical properties, ASME Code compliance information, and performance of the alloys in helium containing a wide range of impurity concentrations is also considered. ${ }^{27}$ The assessment includes four primary candidate alloys for the IHX: Alloy 617, Alloy 230, Alloy 800H, and Alloy X.

\subsubsection{Alloy 617 (52Ni-22Cr-13Co-9Mo)}

Alloy 617, also designated as Inconel 617, UNS N06617, or W. Nr. 2.4663a, was initially developed for high temperature applications above $800^{\circ} \mathrm{C}$. It is often considered for use in aircraft and land-based gas turbines, chemical manufacturing components, metallurgical processing facilities, and power generation structures. The alloy was also considered and investigated for the HTGR programs in the United States and Germany in the late 1970s and early 1980s.

\section{Microstructure and Chemistry of Alloy 617}

The chemical composition of Alloy 617 is given in Table 5. The high Ni and Cr contents provide the alloy with high resistance to a variety of reducing and oxidizing environments. The $\mathrm{Al}$, in conjunction with $\mathrm{Cr}$, offers oxidation resistance at high temperatures. In addition, the $\mathrm{Al}$ also forms intermetallic compound $\gamma^{\prime}$ over a range of temperatures, which results in precipitation strengthening on top of the solid solution strengthening imparted by the $\mathrm{Co}$ and Mo. Strengthening is also derived from $\mathrm{M}_{23} \mathrm{C}_{6}, \mathrm{M}_{6} \mathrm{C}, \mathrm{Ti}(\mathrm{C}$, $\mathrm{N})$ and other precipitates when in appropriate sizes, distributions, and volume fractions.

Table 5. Chemical Composition (wt. \%) of Alloy 617.

\begin{tabular}{|l|c|c|c|c|c|c|c|c|}
\hline & $\mathrm{Ni}$ & $\mathrm{Cr}$ & $\mathrm{Co}$ & $\mathrm{Mo}$ & $\mathrm{Fe}$ & $\mathrm{Mn}$ & $\mathrm{Al}$ & $\mathrm{C}$ \\
\hline Min & 44.5 & 20.0 & 10.0 & 8.0 & - & - & 0.8 & 0.05 \\
\hline Max & - & 24.0 & 15.0 & 10.0 & 3.0 & 1.0 & 1.5 & 0.15 \\
\hline & $\mathrm{Cu}$ & $\mathrm{Si}$ & $\mathrm{S}$ & $\mathrm{Ti}$ & $\mathrm{B}$ & $\mathrm{La}$ & $\mathrm{P}$ & $\mathrm{W}$ \\
\hline Min & - & - & - & - & - & & - & - \\
\hline Max & 0.5 & 1.0 & 0.015 & 0.6 & 0.006 & - & - & - \\
\hline
\end{tabular}

Observations and predictions of which precipitates form in Alloy 617 at given temperature ranges have not been consistent. A comprehensive reviews of the precipitates in Alloy 617 has been performed by Ren. ${ }^{28,29}$ Additional review can be found in Natesan et al. ${ }^{30}$ However, it was clear from the review that the kinetics of the precipitation and coarsening processes were important in determining the effects of aging on properties. The $\mathrm{Ni}_{3} \mathrm{Al}$ intermetallic is generally too fine to be observed in optical microscopy. 


\section{NEXT GENERATION NUCLEAR PLANT \\ INTERMEDIATE HEAT EXCHANGER \\ MATERIALS RESEARCH \\ AND DEVELOPMENT PLAN}

$\begin{array}{ll}\text { Identifier: } & \text { PLN-2804 } \\ \text { Revision: } & 0 \\ \text { Effective Date: } & \text { 04/30/08 }\end{array}$

Page: 32 of 156

Other phases that have been identified include $\mathrm{CrMo}(\mathrm{C}, \mathrm{N})$ and $\mathrm{TiN},{ }^{31} \mathrm{M}_{12} \mathrm{C}$ and a possible Laves phase, ${ }^{32}$ and a $\mathrm{Ni}_{2}(\mathrm{MoCr}){ }^{33}$ It is not known whether any of these phases influence the mechanical behavior considered in the assessment of aging effects. A summary of observations is given in Table 6 . The apparent trend is that in the temperature range of interest to the NGNP IHX, precipitates may form at initial exposure and the alloy may become stronger, but most of the precipitates will be dissolved after long-term exposure, and the alloy will depend on solid solution strengthening in the long run.

Table 6. Prediction and Observations of Second Phase Precipitates in Alloy 617.

\begin{tabular}{|c|c|c|c|c|c|}
\hline Investigator & $\mathrm{M}_{23} \mathrm{C}_{6}$ & $\mathrm{M}_{6} \mathrm{C}$ & $\gamma$ & $\mu$ & $\operatorname{Ti}(\mathrm{C}, \mathrm{N})$ \\
\hline $\begin{array}{l}\text { Thermocalc }{ }^{\circledR} \\
\text { Prediction } \\
{[\text { ORNL] }}\end{array}$ & $\begin{array}{l}\text { Stable } \\
\mathrm{T} \leq \\
800^{\circ} \mathrm{C}\end{array}$ & $\begin{array}{l}\text { Form } \\
\mathrm{T} \geq 780^{\circ} \mathrm{C}\end{array}$ & $\begin{array}{l}\text { wt }<5 \% \text { persist to } \\
\mathrm{T}=650^{\circ} \mathrm{C}\end{array}$ & $\begin{array}{l}\mathrm{wt}>10 \% \\
600 \sim 800^{\circ} \mathrm{C}\end{array}$ & Not reported \\
\hline \multicolumn{6}{|c|}{ Observation in material aged for 10,000 hours and less } \\
\hline $\begin{array}{l}\text { Mankins }^{31} \\
\text { Kimball }^{34}\end{array}$ & $\begin{array}{l}\mathrm{T} \leq \\
1093^{\circ} \mathrm{C}\end{array}$ & $\begin{array}{l}\text { Not } \\
\text { Observed }\end{array}$ & $\begin{array}{l}\text { Small wt } \% \text { persist to } \\
\mathrm{T}=760^{\circ} \mathrm{C}\end{array}$ & Not observed & $\begin{array}{l}\text { Not } \\
\text { observed }\end{array}$ \\
\hline Kihara $^{35}$ & $1000^{\circ} \mathrm{C}$ & $1000^{\circ} \mathrm{C}$ & Not reported & Not observed & Not reported \\
\hline Kirchhofer $^{32}$ & Observed & Observed & $550 \sim 1000^{\circ} \mathrm{C}$ & Not observed & $\begin{array}{l}400 \sim \\
1000^{\circ} \mathrm{C}\end{array}$ \\
\hline \multicolumn{6}{|c|}{ Observation in material aged for much longer than 10,000 hours at $482 \sim 871^{\circ} \mathrm{C}$} \\
\hline $\mathrm{Wu}^{33}$ & Observed & $\begin{array}{l}\text { Observed } \\
\text { Also } \\
\text { observed } \\
\text { eta-MC }\end{array}$ & $\begin{array}{l}\text { Observed at } 482,538, \& \\
593^{\circ} \mathrm{C} \text {, } \\
\text { not at } 704^{\circ} \mathrm{C} \text { for } 43,000 \mathrm{~h} \\
\text { and longer, nor } 870^{\circ} \mathrm{C} \text { after } \\
\text { long time. }\end{array}$ & Not observed & $\begin{array}{l}\text { TiN } \\
\text { observed }\end{array}$ \\
\hline
\end{tabular}

The grain size also plays an important roll in the strength of the alloy. For general applications, a grain size of ASTM No. $6(\sim 45 \mu \mathrm{m})$ or coarser is typically preferred, but it has been shown that creep strength increases with increasing grain size so microstructures of $100-200 \mu \mathrm{m}$ grain size are often produced. A tradeoff exists, however, when fatigue is an issue, since finer grain sizes are preferred for fatigue resistance. In addition, for compact IHX, the thin sheet form restricts large grain size. Whether the grains will significantly coarsen after the dissolution of certain grain boundary precipitates at long-term exposure is not clear.

\section{Properties of Alloy 617}

This nickel-based alloy is the primary candidate for construction of the NGNP IHX, and the existing mechanical property database is extensive (Table 7). It has adequate creep strength at temperatures above $870^{\circ} \mathrm{C}$, good cyclic oxidation and carburization resistance, and good weldability. It also has lower thermal expansion than most austenitic stainless steels and high thermal conductivity relative to the other candidates. It retains toughness after long-time exposure at elevated temperatures and does not form intermetallic phases that can cause embrittlement. Preliminary testing indicates Alloy 617 has the best carburization resistance of the four alloys.

In the past few years, significant efforts have been made by the Generation IV high temperature materials task to review and summarize the existing data. ${ }^{36}$ During early development, Alloy 617 was systematically studied by Huntington Alloys, Inc. for applications in gas turbines, nitric acid production catalyst-grids, heat-treating baskets, Mo refinement reduction boats, etc. When Alloy 617 was considered for the HTGR, it was extensively investigated by Huntington, Oak Ridge National Laboratory (ORNL), 


\begin{tabular}{c|lll|}
\hline $\begin{array}{c}\text { NEXT GENERATION NUCLEAR PLANT } \\
\text { INTERMEDIATE HEAT EXCHANGER }\end{array}$ & Identifier: & PLN-2804 & \\
MATERIALS RESEARCH & Revision: & 0 & \\
AND DEVELOPMENT PLAN & Effective Date: & $04 / 30 / 08$ & Page: 33 of 156 \\
\hline
\end{tabular}

and GE. The Huntington data were used to develop ASME Boiler and Pressure Vessel (B\&PV) Code, including the 1980s draft Code Case for the HTGR and applications covered by Section I and Section VIII Division 1. The Huntington dataset has been collected and digitized by the Gen IV Materials Handbook task. Preparation is underway to obtain detailed pedigree information and copyright permission before the data can be uploaded into the Handbook.

Both the ORNL-HTGR and GE-HTGR studies generated data from Alloy 617 that had been aged and/or tested in simulated HTGR helium. The helium impurities were the same to those considered for the NGNP system but the concentrations were different. The ORNL- and GE-HTGR datasets have been digitized and part of them has been uploaded into the Handbook. Unfortunately, only processed data still exist; all original test curves needed for certain modeling efforts are irretrievable.

Germany also extensively investigated Alloy 617 for its HTGR and other programs. The data generated were collected in the Online Data \& Information Network (ODIN). Original test curves, if not all, are stored in the ODIN. However, the strain measurements of creep test curves were not all conducted with fine resolution, and may not all be ideal for constitutive equation development. Access to the ODIN data on Alloy 617 is restricted; however, collaborations between the Gen IV Materials Handbook and the ODIN are under development. In addition, negotiation is underway by the Gen IV Materials Handbook task to obtain the data and relevant study results from investigations by Honeywell Aerospace.

The Gen IV Program also generated creep-fatigue data from 80 tests at 800 and $1000^{\circ} \mathrm{C}$ in test environments of air, pure helium, and vacuum. Details of the preliminary Gen IV investigation on Alloy 617 can be found in Ren et al. ${ }^{37}$ All original test records are preserved and will be loaded into the Gen IV Materials Handbook. The aging effects on Alloy 617 are summarized in Ren and Swindeman. ${ }^{28}$ The development in modeling creep behavior of Alloy 617 is summarized in Swindeman et al. ${ }^{38}$

Table 7. Summary of testing done on Alloy 617.

\begin{tabular}{|c|c|c|c|c|}
\hline $\begin{array}{c}\text { Research } \\
\text { organization }\end{array}$ & Number of heats & $\begin{array}{l}\text { Number of } \\
\text { samples }\end{array}$ & Test type & $\begin{array}{c}\text { Temperature } \\
\left({ }^{\circ} \mathrm{C}\right)\end{array}$ \\
\hline \multirow[t]{2}{*}{ Huntington Alloys } & $13+1$ wire & 179 & Tensile & $25-1093$ \\
\hline & & 249 & Creep & $593-1093$ \\
\hline \multirow[t]{4}{*}{ ORNL $^{\mathrm{a}}$} & 4 plate +1 wire & 73 & Tensile & $24-871$ \\
\hline & & 51 & Creep & $593-871$ \\
\hline & & 25 & Charpy & 24 \\
\hline & & 1 & Tensile after creep & RT after 871 \\
\hline \multirow{3}{*}{$\mathrm{GE}^{\mathrm{a}}$} & 1 plate +1 bar & 36 & Creep & $750-1100$ \\
\hline & & 7 & Creep-fatigue & 950 \\
\hline & & 40 & Fatigue & 850,950 \\
\hline \multirow[t]{4}{*}{ Germany } & Not specified & 302 & Tensile & RT-1000 \\
\hline & & 1947 & Creep & $500-1000$ \\
\hline & & 29 & Creep crack growth & $700-1000$ \\
\hline & & 261 & Low cycle fatigue & $<500-1000$ \\
\hline $\begin{array}{l}\text { Honeywell } \\
\text { Aerospace }\end{array}$ & Not specified & & Not specified & \\
\hline Gen IV program ${ }^{\mathrm{b}}$ & Not specified & 80 & Creep-fatigue & 800,1000 \\
\hline $\begin{array}{l}\text { a. some tests exposed to } \\
\text { b. air, pure helium and }\end{array}$ & $\begin{array}{l}\text { GR environment } \\
\text { am environments }\end{array}$ & & & \\
\hline
\end{tabular}




\begin{tabular}{c|lll|}
\hline $\begin{array}{c}\text { NEXT GENERATION NUCLEAR PLANT } \\
\text { INTERMEDIATE HEAT EXCHANGER }\end{array}$ & Identifier: & PLN-2804 & \\
MATERIALS RESEARCH & Revision: & 0 & \\
AND DEVELOPMENT PLAN & Effective Date: & $04 / 30 / 08$ & Page: 34 of 156 \\
\hline
\end{tabular}

Alloy 617 is not currently qualified for use in ASME Code Section III, although it is allowed in Section I and Section VIII, Division 1 (non-nuclear service). A draft code case for Alloy 617 has been developed but efforts to gain the approval from the ASME Code committees were stopped due to a loss in interest by DOE and its contractor. Efforts required in order to complete the 617 Code Case for NGNP applications are discussed further in Section 5.3.

\subsubsection{Alloy 230 (57Ni-22Cr-14W-2Mo-La)}

In addition to outstanding resistance to oxidizing environments, Alloy 230 has good weldability and fabricability. It also has a lower thermal expansion coefficient than Alloy 617; it appears thermal expansion has an inverse correlation with Ni content. Alloy 230 has higher tensile strength than Alloy 617 up to $800^{\circ} \mathrm{C}$, but above that the difference is insignificant. It appears Alloy 617 has slightly better creep properties than Alloy 230. Alloy 230 has better thermal fatigue crack initiation resistance but worse thermal cycling resistance.

\section{Microstructure and Chemistry of Alloy 230}

Alloy 230, also designated as Haynes 230, UNS N06230, or W. Nr. 2.4733, is a newer alloy than Alloy 617. Its chemical composition is given in Table 8. The Ni base and high $\mathrm{Cr}$ content impart great resistance to high temperature corrosion in various environments, and oxidation resistance is further enhanced by the micro-addition of rare earth element La. Compared to Alloy 617, Alloy 230 has a high W concentration. The $\mathrm{W}$ and $\mathrm{Mo}$ in conjunction with $\mathrm{C}$ are largely responsible for the strength of the alloy, and its relatively high B content in comparison to that in Alloy 617 can be controlled to achieve optimized creep resistance. Usually B acts as an electron donor; it can affect the grain boundary energy and help improve ductility. In Ni base alloys, B also segregates to grain boundaries and helps to slow grain boundary diffusion, thus reducing the creep process. On the other hand, because B interferes with neutrons, the level of B must be carefully controlled to achieve optimized performance.

Table 8. Chemical Composition (wt. \%) of Alloy 230.

\begin{tabular}{|c|c|c|c|c|c|c|c|c|}
\hline & $\mathrm{Ni}$ & $\mathrm{Cr}$ & $\mathrm{Co}$ & $\mathrm{Mo}$ & $\mathrm{Fe}$ & $\mathrm{Mn}$ & $\mathrm{Al}$ & $\mathrm{C}$ \\
\hline Min & - & 20.0 & - & 1.0 & - & 0.30 & 0.20 & 0.05 \\
\hline Max & $\mathrm{Bal}$ & 24.0 & 5.0 & 3.0 & 3.0 & 1.00 & 0.50 & 0.15 \\
\hline & $\mathrm{Cu}$ & $\mathrm{Si}$ & $\mathrm{S}$ & $\mathrm{Ti}$ & $\mathrm{B}$ & $\mathrm{La}$ & $\mathrm{P}$ & $\mathrm{W}$ \\
\hline Min & - & 0.25 & - & - & - & 0.005 & - & 13.0 \\
\hline Max & - & 0.75 & 0.015 & - & 0.015 & 0.05 & 0.030 & 15.0 \\
\hline
\end{tabular}

In the supplied solution annealed condition the grain size is typically ASTM No. 6. After aging, Alloy 230 typically precipitates $\mathrm{M}_{6} \mathrm{C}$ and $\mathrm{M}_{23} \mathrm{C}_{6}$. After aging for 1000 hours at $850^{\circ} \mathrm{C}$, quite large carbide precipitates rich in $\mathrm{W}$, presumably $\mathrm{M}_{6} \mathrm{C}$, and very small carbide precipitates rich $\mathrm{Cr}, \mathrm{M}_{23} \mathrm{C}_{6}$, were observed along the grain boundaries. No grain coarsening was observed. ${ }^{39}$ Creep strength is believed to be brought about by solid solution strengthening, low stacking fault energy, and precipitation of $\mathrm{M}_{23} \mathrm{C}_{6}$ carbides on glide dislocations. ${ }^{40,41}$ However, a negative impact of $\mathrm{M}_{23} \mathrm{C}_{6}$ on room temperature ductility was also reported. After aging at $871^{\circ} \mathrm{C}$ for 8000 hours, the room temperature tensile elongation of Alloy 230 decreased from approximately $50 \%$ to $35 \%$ with precipitation of $\mathrm{M}_{23} \mathrm{C}_{6}$ observed in microstructural examination, but an additional 8000 hours of aging did not further decrease ductility. ${ }^{40}$ Significant microstructural changes were also observed after thermal aging in air for 10,000 hours at temperatures ranging from $750-1050^{\circ} \mathrm{C}$. After the $750^{\circ} \mathrm{C}$ aging, coarser inter-granular precipitation of $\mathrm{M}_{23} \mathrm{C}_{6}$ and coarse and blocky intra- and inter-granular precipitates of $\mathrm{M}_{6} \mathrm{C}$ were observed. After the $850-1050^{\circ} \mathrm{C}$ aging, the $\mathrm{M}_{6} \mathrm{C}$ carbides were irregular in shape. After aging at $1050^{\circ} \mathrm{C}$, the secondary intra-granular $\mathrm{M}_{23} \mathrm{C}_{6}$ appeared to have dissolved. A decrease in toughness and ductility coincides with the appearance of the intra-granular $\mathrm{M}_{23} \mathrm{C}_{6}$, and reached a minimum after the aging at $850^{\circ} \mathrm{C}$. The toughness and ductility recovered after the aging at $1050^{\circ} \mathrm{C} .{ }^{42}$ 


\begin{tabular}{c|lll|}
\hline $\begin{array}{c}\text { NEXT GENERATION NUCLEAR PLANT } \\
\text { INTERMEDIATE HEAT EXCHANGER }\end{array}$ & Identifier: & PLN-2804 & \\
MATERIALS RESEARCH & Revision: & 0 & \\
AND DEVELOPMENT PLAN & Effective Date: & $04 / 30 / 08$ & Page: 35 of 156 \\
\hline
\end{tabular}

\section{Properties of Alloy 230}

There is less data on Alloy 230 than on Alloy 617 (Table 9). The major known large scale study was tensile and creep tests by Haynes International. Creep times ranged from 15.3 to 28,391 hours. Preliminary Generation IV Program tests on Alloy 230 include tensile and toughness data. All of these tests were conducted in air and the original test records are preserved and entered in the Generation IV Handbook.

Table 9. Summary of testing done on Alloy 230.

\begin{tabular}{lcll}
\hline Research organization & Number of samples & Test type & Temperature $\left({ }^{\circ} \mathrm{C}\right)$ \\
\hline Haynes International & 36 & Tensile & RT-1149 \\
Generation IV & 261 & Creep & $593-1149$ \\
& 24 & Tensile & $25-950$ \\
\hline
\end{tabular}

Like Alloy 617, Alloy 230 is not currently qualified for use in ASME Code Section III, although it is allowed in Section VIII, Division 1 (non-nuclear service). At present, the database for Alloy 230 is significantly smaller than that for Alloy 617 and a much larger effort is required to develop an Alloy 230 Code Case for elevated temperature application.

\subsubsection{3 $800 \mathrm{H}(42 \mathrm{Fe}-33 \mathrm{Ni}-21 \mathrm{Cr})$}

This alloy is the only iron-based alloy under consideration, although it has a solid-solution strengthened austenitic structure like the other three alloys. However, upon aging, precipitates can form and reduce the tensile and creep ductility. $800 \mathrm{H}$ has the lowest creep rupture strength and the worst resistance to oxidation of the four alloys.

Among the four candidate materials, Alloy $800 \mathrm{H}$ is the only one that is Code qualified for use in nuclear systems, but only for temperatures up to $760^{\circ} \mathrm{C}$ and a maximum service time of 300,000 hours. Westinghouse has explored the concept of using a high temperature IHX, which is replaceable, in series with a lower temperature IHX that operates for the full NGNP lifetime (Section 2.3.3.4). The target temperature of the lower temperature IHX is around $760^{\circ} \mathrm{C}$ and the candidate structural material is Alloy $800 \mathrm{H}$. As summarized in Section 4.2.3.1, there is currently effort in Task 1 of the DOE initiative to address ASME code issues for Generation IV reactors (DOE/ASME Generation IV project) to extend the allowable stresses of Alloy $800 \mathrm{H}$ to $900^{\circ} \mathrm{C}$ and 60 years. Alloy $800 \mathrm{H}$ was the primary high temperature alloy used in the German HTGR programs and an enormous amount of data was obtained. However, only very limited data from the German HTGR programs are currently available on the mechanical properties of this alloy beyond $800^{\circ} \mathrm{C}$, especially in impure helium environments.

\subsubsection{Hastelloy X (47Ni-22Cr-9Mo-18Fe)}

Hastelloy $\mathrm{X}$ has the best oxidation resistance of the four alloys, although its carburization resistance is the worst. Above $700^{\circ} \mathrm{C}$, Hastelloy X can form embrittling phases that result in property degradation. The creep rupture strength is not as good as Alloy 617 or 230 . The limitations of this alloy will be similar to the current draft code case for Alloy 617 in terms of grain size, product form and limitations on service time. 


\section{NEXT GENERATION NUCLEAR PLANT \\ INTERMEDIATE HEAT EXCHANGER \\ MATERIALS RESEARCH AND DEVELOPMENT PLAN}

$\begin{array}{ll}\text { Identifier: } & \text { PLN-2804 } \\ \text { Revision: } & 0 \\ \text { Effective Date: } & \text { 04/30/08 }\end{array}$

Page: 36 of 156

A limited database exists for Hastelloy X, but the high temperature scaling in Hastelloy X has not been acceptable. As a result, a modified version, Hastelloy XR, has been developed in Japan; however, the U.S. has little access to XR material, either for evaluation or for ASME Code qualification. The Japanese are currently using Hastelloy XR in a heat exchanger in the HTTR at temperatures of $850^{\circ} \mathrm{C}$ $950^{\circ} \mathrm{C}$. The material is codified in Japan for nuclear use, which would likely accelerate code acceptance in ASME. An extensive environmental database and HTGR experience exist. However, the database may be limited to large grain material, similar to Alloy 617 draft code case. Also, similar to the Alloy 617 draft code case, XR may have issues such as weldments that need to be addressed. The option of using Hastelloy XR may still be considered viable only if the U.S. can reach an agreement with Japan to acquire material and their existing database of Hastelloy XR to expedite an ASME code case for acceptance by $\mathrm{NH}$. It is uncertain if this alloy is available as a commercial product.

Figures 18, 19, 20, 21 compare the creep rupture strength, oxidation behavior, carburization behavior, and allowable stress for the four alloys, respectively.

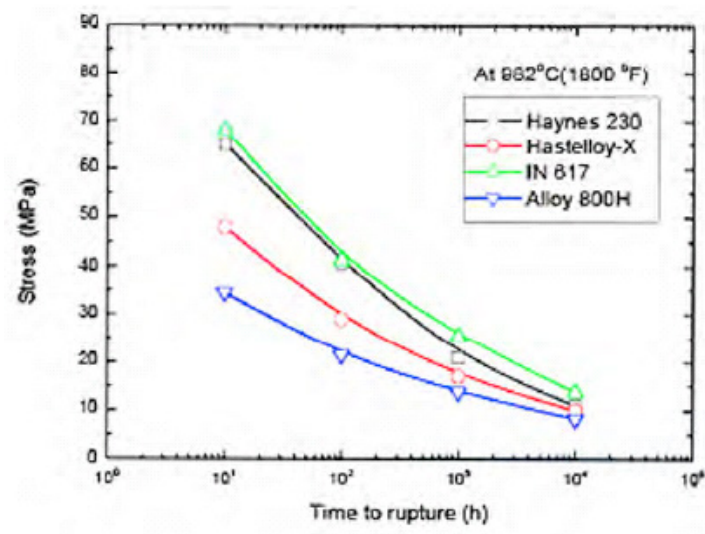

Figure 18. Creep rupture strength at $962^{\circ} \mathrm{C}$ in air.

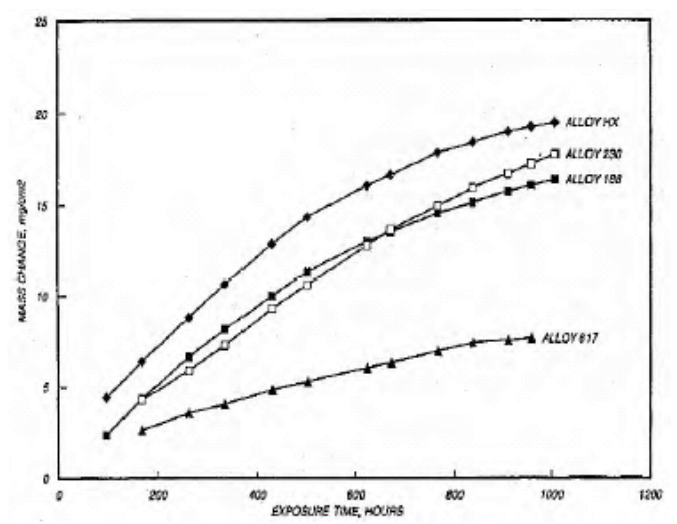

Figure 20. Mass change as a function of time in $\mathrm{H} 2-5.5 \% \mathrm{CH} 4-4.5 \% \mathrm{CO} 2$ carburizing environment at materials for plate, sheet and strip forms. $1000^{\circ} \mathrm{C}$.

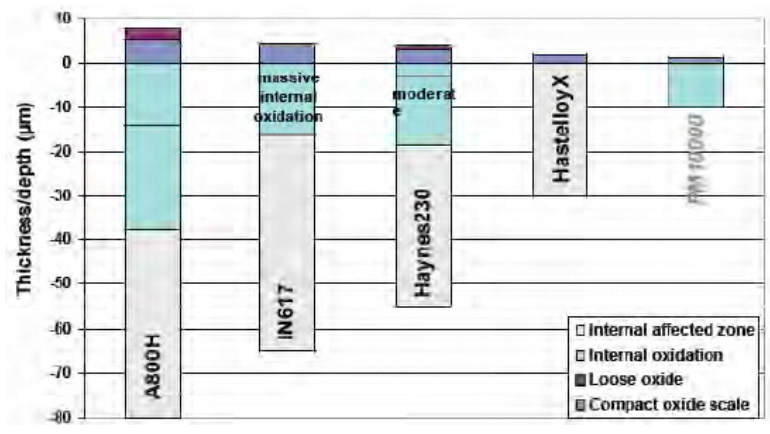

Figure 19. Isothermal oxidation behavior after $800 \mathrm{~h}$ exposure at $950^{\circ} \mathrm{C}$ in helium environment.

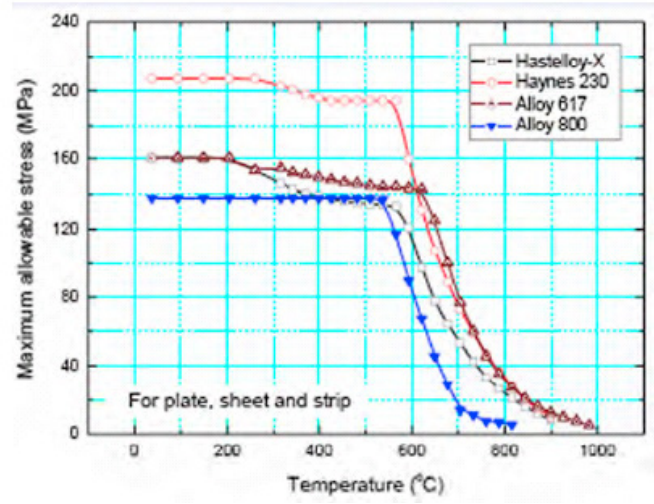

Figure 21. Allowable stress for heat exchanger 

NEXT GENERATION NUCLEAR PLANT
INTERMEDIATE HEAT EXCHANGER
MATERIALS RESEARCH
AND DEVELOPMENT PLAN

$\begin{array}{ll}\text { Identifier: } & \text { PLN-2804 } \\ \text { Revision: } & 0 \\ \text { Effective Date: } & 04 / 30 / 08\end{array}$

Page: 37 of 156

\subsubsection{Welding}

\subsubsection{Properties}

Alloy 617 has excellent weldability. Inconel Filler Metal 617 is used for gas-tungsten-arc (GTAW) and gas-metal-arc welding (GMAW). The composition of the filler metal matches that of the base metal, and deposited weld metal is comparable to the wrought alloy in strength and corrosion resistance. ${ }^{43}$ HAYNES ${ }^{\circledR} 230 \circledR$ alloy is also readily welded by GTAW and GMAW. Shielded Metal Arc Welding (SMAW) and resistance welding techniques can also be used. Submerged-arc welding is not recommended as this process is characterized by high heat input to the base metal and slow cooling of the weld. These factors can increase weld restraint and promote cracking. The as-welded properties of these alloys are given in Table $10 .^{44}$

Table 10. Room-temperature tensile properties of joints in as-welded condition.

\begin{tabular}{|c|c|c|c|c|c|}
\hline Alloy & Specimen & $\begin{array}{c}\text { Yield Strength } \\
(0.2 \% \text { Offset }) \\
\mathrm{MPa}\end{array}$ & $\begin{array}{c}\text { Tensile Strength } \\
\mathrm{MPa}\end{array}$ & $\begin{array}{c}\text { Elongation } \\
\%\end{array}$ & $\begin{array}{c}\text { Reduction } \\
\text { of Area } \\
\%\end{array}$ \\
\hline $617^{43}$ & $\begin{array}{l}\text { GMAW }^{\mathrm{a}} \\
\text { GTAW }^{\mathrm{b}}\end{array}$ & $\begin{array}{l}510 \\
542\end{array}$ & $\begin{array}{l}761 \\
823\end{array}$ & $\begin{array}{l}43.3 \\
37.3\end{array}$ & $\begin{array}{l}42.0 \\
38.3\end{array}$ \\
\hline $230^{44}$ & $\mathrm{GMAW}^{\mathrm{c}}$ & 490 & 785 & 48.2 & \\
\hline $\begin{array}{l}\text { Inconel F } \\
\text { Inconel F } \\
\text { Haynes } 2\end{array}$ & $\begin{array}{l}\text { letal } 617 \text {. Av } \\
\text { Metal } 617 \text {. Av } \\
\text { filler wire. }\end{array}$ & $\begin{array}{l}\mathrm{f} \text { ten tests. } \\
\mathrm{f} \text { seventeen tests. }\end{array}$ & & & \\
\hline
\end{tabular}

The welds exhibit room temperature strength that matches or is slightly better than the base metal but a considerable decrease in ductility at elevated temperatures, as shown in Table 11. Preliminary tests in other programs at ORNL also suggest a decrease in creep ductility in the weld metal.

Table 11. Tensile properties of 230 base and weld metals.

\begin{tabular}{|c|c|c|c|c|c|c|c|c|c|}
\hline & \multicolumn{3}{|c|}{$23^{\circ} \mathrm{C}$} & \multicolumn{3}{|c|}{$538^{\circ} \mathrm{C}$} & \multicolumn{3}{|c|}{$871^{\circ} \mathrm{C}$} \\
\hline & UTS & YS & EL & UTS & YS & EL & UTS & YS & EL \\
\hline $\begin{array}{l}\text { GMAW Deposit } \\
\text { Weld Metal }\end{array}$ & 785 & 490 & 48.2 & 610 & 435 & 34.8 & 310 & 275 & 45.4 \\
\hline $\begin{array}{l}\text { Cold-Rolled and } 1232^{\circ} \mathrm{C} \\
\text { Solution Annealed (Sheet) }\end{array}$ & 838 & 422 & 47.2 & 699 & 303 & 53.7 & 308 & 234 & 75.0 \\
\hline $\begin{array}{l}\text { Hot-Rolled and } 1232^{\circ} \mathrm{C} \\
\text { Solution Annealed (Plate) }\end{array}$ & 840 & 375 & 47.7 & 690 & 251 & 54.6 & 315 & 242 & 99.5 \\
\hline $\begin{array}{l}\text { Vacuum Investment } \\
\text { Castings (As Cast) }\end{array}$ & 615 & 325 & 37.8 & 450 & 230 & 38.2 & 285 & 185 & 19.0 \\
\hline
\end{tabular}




\begin{tabular}{|c|lll|}
\hline NEXT GENERATION NUCLEAR PLANT & Identifier: & PLN-2804 \\
INTERMEDIATE HEAT EXCHANGER & Revision: & 0 & Page: 38 of 156 \\
MATERIALS RESEARCH & Effective Date: & $04 / 30 / 08$ & \\
AND DEVELOPMENT PLAN &
\end{tabular}

\subsubsection{Process Development}

\section{Base Metal Preparation}

The welding surface and adjacent regions should be thoroughly cleaned with an appropriate solvent prior to any welding operation. All greases, oils, corrosion products, and other foreign matter should be completely removed. It is preferable, but not necessary, that the alloy be in the solution annealed condition when welded. ${ }^{44}$

\section{Filler Metal Selection}

Inconel filler metal 617 and HAYNES 230-WTM (AWS A5.14, ERNiCrWMo-1) filler wire are recommended for joining alloy 617 and 230, respectively, by GTAW or GMAW. The filler metals are not specifically design for nuclear application. For dissimilar metal joining of alloy 230 to nickel-, cobalt-, or ironbase materials, 230-W filler wire, HAYNES 556 ${ }^{\mathrm{TM}}$ alloy, HASTELLOY S alloy or HASTELLOY W alloy welding products may all be considered, depending upon the particular case. ${ }^{43,44}$

\section{Preheating, Interpass Temperatures, and Post-Weld Heat Treatment}

Preheat is not required, generally room temperature (typical shop conditions) are fine. Interpass temperature should be maintained below $93^{\circ} \mathrm{C}$. Auxiliary cooling methods may be used between weld passes, as needed, providing that such methods do not introduce contaminants. Post-weld heat treatment is not generally required either.

\section{Nominal Welding Parameters}

Table 12 shows the nominal welding parameters based on welding conditions used in the Haynes International laboratories and should serve as a guide for performing typical GTAW and GMAW operations on Alloy 230. All processes used 230-W filler wire. ${ }^{44}$

Table 12. Weld Parameters for Haynes Alloy 230. ${ }^{44}$

\begin{tabular}{|c|c|c|c|}
\hline Welding method & GMAW & GTAW - auto & GTAW - manual \\
\hline Configuration (mm) & $\begin{array}{l}\text { Thickness }>2.3 \\
1.1 \text { dia. wire }\end{array}$ & $\begin{array}{l}\text { Square butt joints } \\
1.0 / 1.6 / 3.2 \text { thick, } 1.6 \\
\text { electrode with } 45^{\circ} \\
\text { included shape. }\end{array}$ & $\begin{array}{l}\text { V or U groove, }>3.6 \text { thick, } 3.6 \\
\text { dia. wire, } 3.6 \text { electrode with } 30^{\circ} \\
\text { included shape. }\end{array}$ \\
\hline Technique & $\begin{array}{l}\text { Stringer bead or } \\
\text { slight weave }\end{array}$ & No filler metal added & Stringer Bead Interpass $\mathrm{T}<100^{\circ} \mathrm{C}$ \\
\hline Current, amperes & $100-130^{\mathrm{a}}$ & $50 / 80 / 120^{\mathrm{b}}$ & 120 root, $140-150$ fill $^{\mathrm{b}}$ \\
\hline Voltage, volts & $18-21$ & $8.0 / 8.5 / 9.5$ & $11-14$ \\
\hline Feed rate $(\mathrm{m} / \mathrm{min})$ & 4.3-4.8 & & \\
\hline Stick-out (mm) & $12.7-19.1$ & & \\
\hline Travel speed, $\mathrm{mm} / \mathrm{min}$ & $203-356$ & $10 / 12 / 12$ & $102-152$ \\
\hline Gas flow (liters/minute) & Torch, 50 & Shield, 14.2 Backing, 4.7 & Shield, 14.2-16.5 Backup, 4.7 \\
\hline Gas & $\mathrm{Ar}-25 \% \mathrm{He}$ & Argon & Argon \\
\hline $\begin{array}{l}\text { a. DCEP, torch flow CFPH } \\
\text { b. DCEN }\end{array}$ & & & \\
\hline
\end{tabular}




\begin{tabular}{|c|lll|}
\hline $\begin{array}{c}\text { NEXT GENERATION NUCLEAR PLANT } \\
\text { INTERMEDIATE HEAT EXCHANGER }\end{array}$ & Identifier: & PLN-2804 & \\
MATERIALS RESEARCH & Revision: & 0 & \\
AND DEVELOPMENT PLAN & Effective Date: & $04 / 30 / 08$ & Page: 39 of 156 \\
\hline
\end{tabular}

\subsubsection{Environmental Effects}

A number of very high temperature helium-cooled reactors have been built and operated for extended periods. The helium coolant in the primary circuit has been found to contain low levels of impurities after steady-state operation that can lead to an environmental degradation of the high temperature alloys used for internals and heat exchangers. All reactors that have operated to date have had similar impurity levels, and there have been no reported problems with failure of components on the primary side associated with environmental effects. The impurity levels in the coolant for HTGRs that have operated, perhaps fortuitously, were in the stable oxidizing condition (zone III in Figure 22 below) for chromia forming alloys. The massive amounts of graphite in the reactor play a major role in maintaining the gas chemistry.

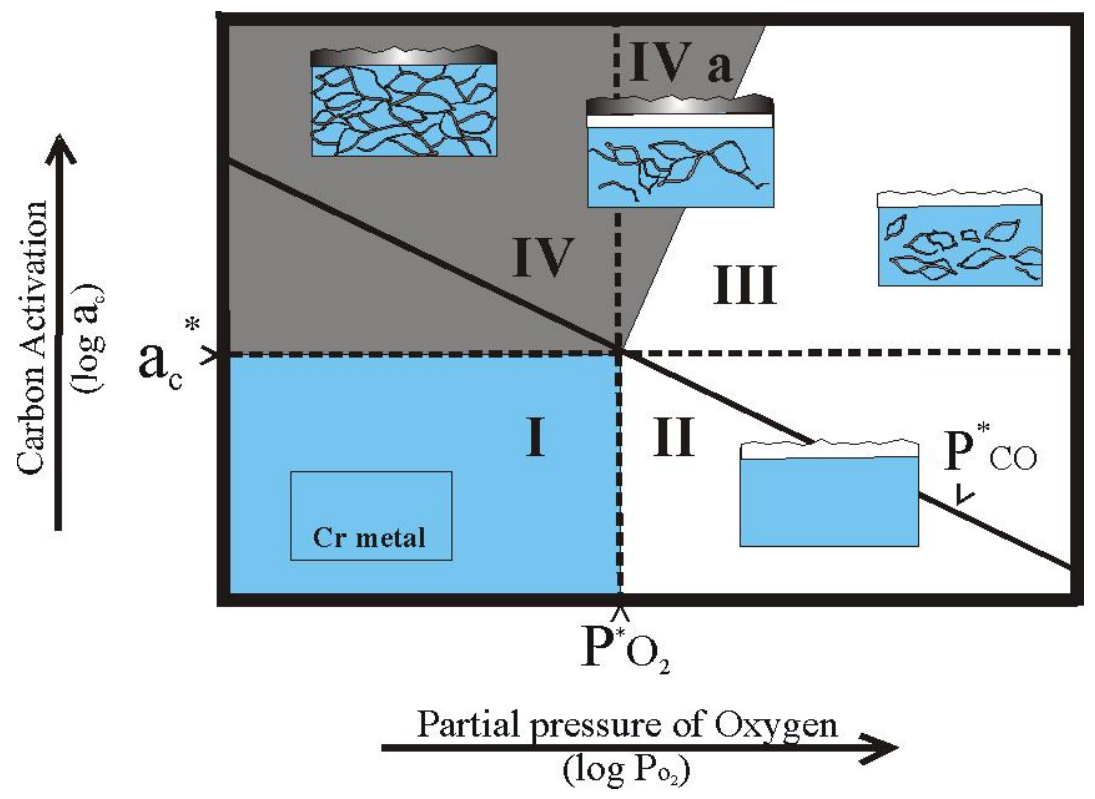

Figure 22. The modified Ellingham stability diagram for Alloy 617.

Depending on the impurity concentration and the temperature, high temperature alloys can undergo oxidation, carburization, or decarburization. Carburization is associated with low temperature embrittlement and decarburization is linked to reduced creep rupture strength. The optimum coolant chemistry for long-term stability of high temperature alloys is slightly oxidizing and results in formation of a tenacious and protective $\mathrm{Cr}_{2} \mathrm{O}_{3}$ scale. The concentrations of $\mathrm{H}_{2} \mathrm{O}$ and $\mathrm{CO}$ are of particular interest because they essentially control the oxygen partial pressure and carbon activity, respectively. Model chemistries used in many of the controlled studies tend to have higher levels of some impurities than those found in operating reactors.

The mechanisms of environmental interaction between Alloy 617 and prototype HTGR helium chemistries have been extensively studied. A modified type of Ellingham diagram that maps the ranges of carbon activity and oxygen partial pressure that result in each of the degradation mechanisms has been developed (Figure 22). Zone III in the Ellingham stability diagram is preferred for optimal chromia layer protection against corrosion. In addition, there is a maximum service temperature above about $950^{\circ} \mathrm{C}$ for each alloy determined by the microclimate reaction or volatilization of $\mathrm{Cr}_{2} \mathrm{O}_{3}$. 


\begin{tabular}{|c|lll|}
\hline NEXT GENERATION NUCLEAR PLANT & Identifier: & PLN-2804 & \\
INTERMEDIATE HEAT EXCHANGER & Revision: & 0 & \\
MATERIALS RESEARCH & Effective Date: & $04 / 30 / 08$ & Page: 40 of 156 \\
AND DEVELOPMENT PLAN & &
\end{tabular}

\subsubsection{NGNP research}

The NGNP materials program has extended previous studies on environmental effects of prototype impure helium on Alloy 617 by increasing temperatures and using test coupons that incorporate fusion welds in controlled chemistry test loops. In addition, parallel studies have been initiated with Alloy 230 . The ultimate goal is to be able to predict the corrosion mechanism in effect for a particular gas chemistry at a given temperature for the selected alloy.

A closed-circuit, low-flow velocity test loop has been designed and assembled at INL. A schematic of the loop is shown in Figure 23. It has the potential to continuously getter excess impurities and add necessary trace impurities based on mass spectroscopy measurements in a closed loop system. The system volume is about 20 liters, can be heated to $1000^{\circ} \mathrm{C}$, evacuated to a pressure of $10^{-6}$ torr and subjected to a flow rate of $40 \mathrm{l} / \mathrm{m}$. All impurities are added to the system as individual gases using a precisely controlled automated valve set-up. Impurities are controlled at parts per million levels in helium that flows in the closed loop at a flow rate of approximately $0.2 \mathrm{l} / \mathrm{s}$.

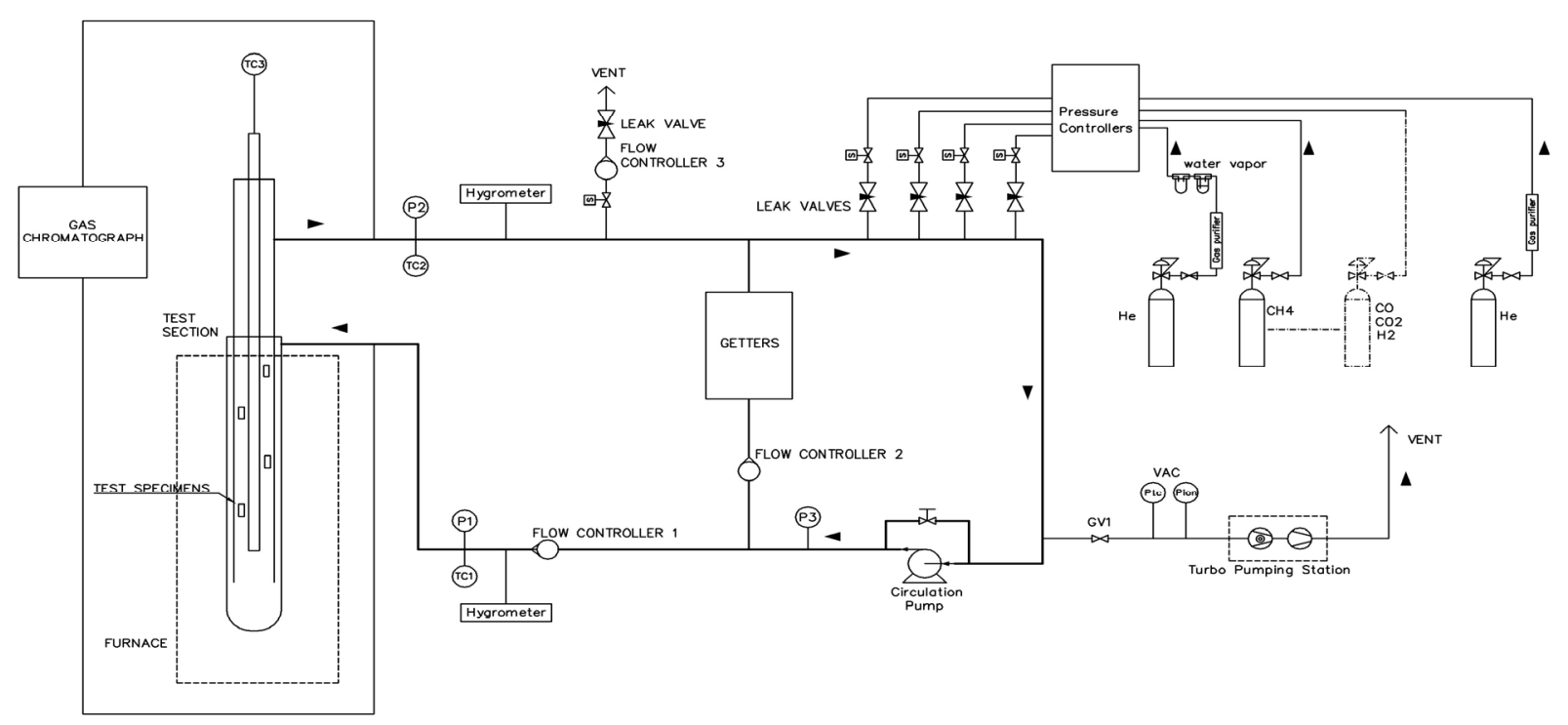

Figure 23. Schematic of the current configuration of the INL controlled chemistry high temperature testing loop.

Micrographs of cross-sections from the Alloy 617 and Alloy 230 plate material after exposure to oxidizing and carburizing atmospheres at $1000^{\circ} \mathrm{C}$ are shown in Figures 24 and 25, respectively. The microstructures shown in Figure 24 are largely as anticipated. Alloy 617 shows a relatively thick chromium oxide scale with significant formation of grain boundary aluminum oxides. Alloy 230 shows less surface oxidation and notably reduced tendency for formation of grain boundary oxides. A decarburization region is also apparent for both alloys; the decarburized region is particularly notable in the Alloy 230 shown in Figure 24. 


\begin{tabular}{|c|lll|}
\hline NEXT GENERATION NUCLEAR PLANT & Identifier: & PLN-2804 & \\
INTERMEDIATE HEAT EXCHANGER & Revision: & 0 & \\
MATERIALS RESEARCH & Effective Date: & $04 / 30 / 08$ & Page: 41 of 156 \\
AND DEVELOPMENT PLAN &
\end{tabular}

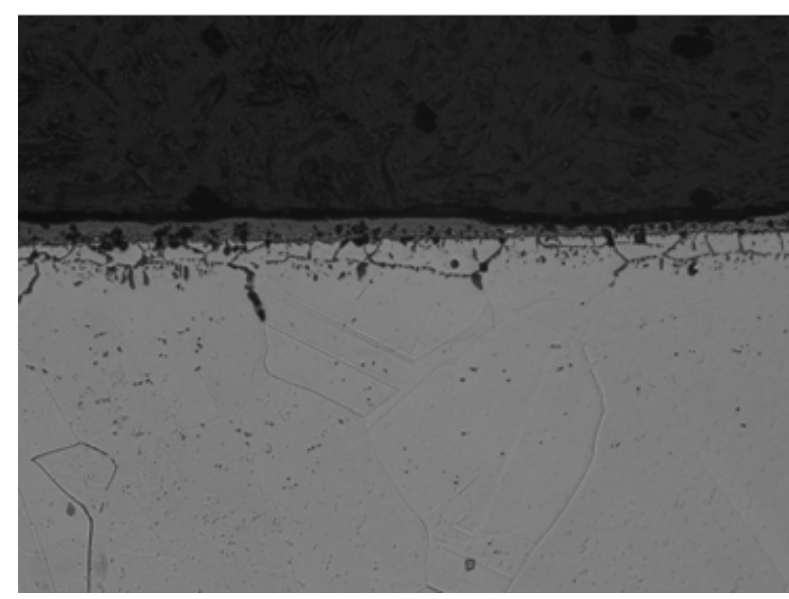

(a)

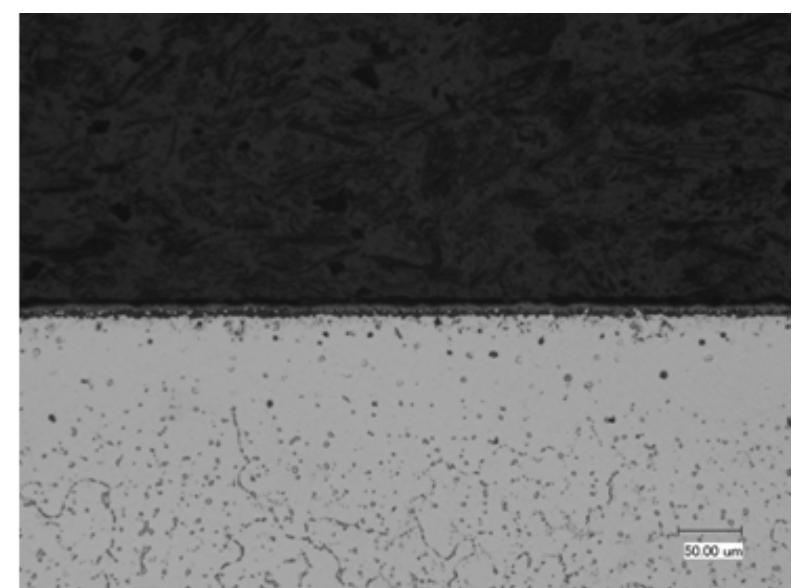

(b)

Figure 24. Optical micrographs of cross-sections through (a) Alloy 617 and (b) Alloy 230 for the $1000^{\circ} \mathrm{C}$ experiment under oxidizing conditions.

Carburization of Alloy 617 has been examined in previous work and the results shown in Figure 25 are largely consistent with behavior reported in the literature. ${ }^{45-48}$ For the conditions examined here, there is little formation of a surface oxide scale. Carbon uptake in the material is manifested by increased grain boundary carbide precipitate volume fraction. The behavior of Alloy 230 is markedly different from that of Alloy 617. As with the Alloy 617, there is little evidence of scale formation, however, there is a very large volume fraction of carbide formation in the alloy that heavily decorates both grain and twin boundaries. This large volume fraction of carbides was found through the entire thickness of the approximately $3 \mathrm{~mm}$ thick coupon after 500 hours at $1000^{\circ} \mathrm{C}$. A micrograph from the center of the carburized Alloy 230 coupon is shown in Figure 26. The behavior observed for the carburizing atmosphere at 800 and $900^{\circ}$ was qualitatively similar, however, the depth of carburization was reduced.

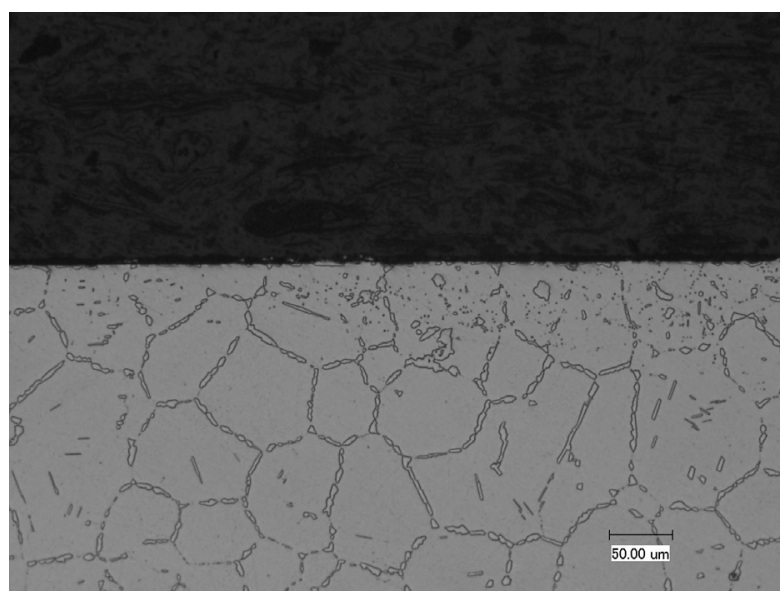

(a)

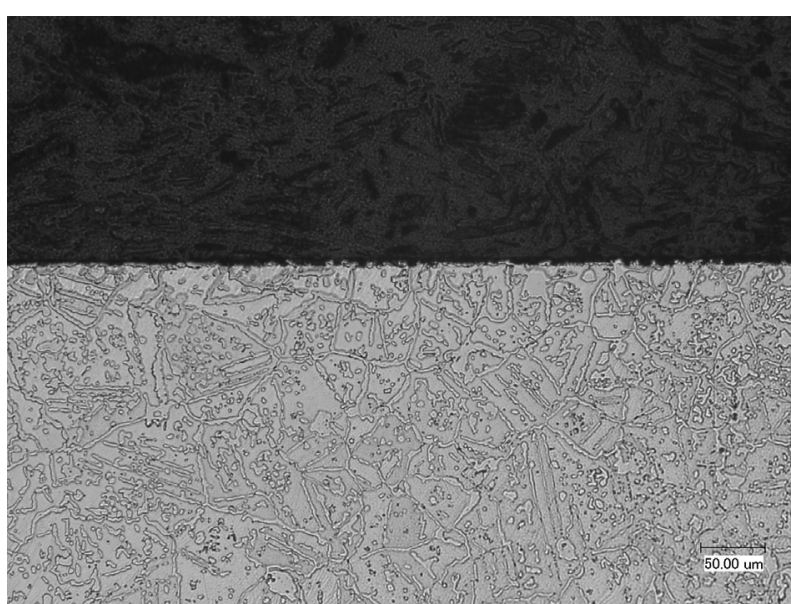

(b)

Figure 25. Optical micrographs of cross-sections through (a) Alloy 617 and (b) Alloy 230 for the $1000^{\circ} \mathrm{C}$ experiment under carburizing conditions. 


\begin{tabular}{|c|lll|}
\hline NEXT GENERATION NUCLEAR PLANT & Identifier: & PLN-2804 & \\
INTERMEDIATE HEAT EXCHANGER & Revision: & 0 & \\
MATERIALS RESEARCH & Effective Date: & $04 / 30 / 08$ & Page: 42 of 156 \\
\hline AND DEVELOPMENT PLAN & &
\end{tabular}

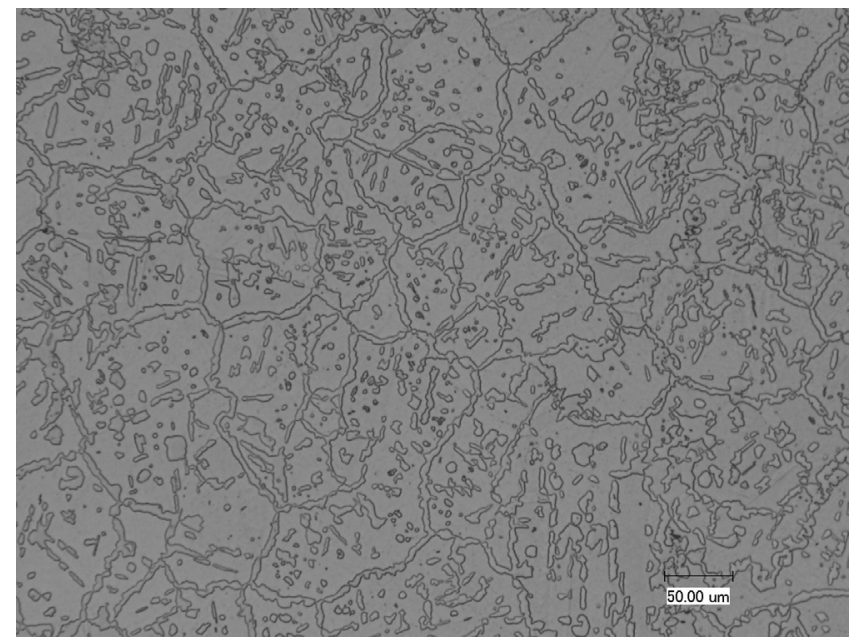

Figure 26. Optical micrograph of carbides in the center of the Alloy 230 coupon after carburizing exposure at $1000^{\circ} \mathrm{C}$.

$\mathrm{X}$-ray diffraction was used to determine the nature of the carbides formed in the Alloy 230. It appears that the carbide formed during testing in a carburizing atmosphere is of the $\mathrm{Cr}_{3} \mathrm{C}_{2}$ type. This phase is considerably more carbon rich compared to the $\mathrm{Cr}_{23} \mathrm{C}_{6}$ type carbide that is typically found in Alloy 230 plate material. X-ray diffraction indicated a similar type of carbide phase in the surface region of the corresponding Alloy 617 specimen, with considerably reduced volume fraction.

The extent of carburization of Alloy 230 compared to Alloy 617 is surprising. Previous experiments with Incoloy $800 \mathrm{H}$ and Hastelloy $\mathrm{X}$ in carburizing environments similar to those investigated here indicated that these alloys had behavior similar to Alloy 617. This similarity was attributed to the chromium content of the alloys all falling in the region of 20 to $22 \mathrm{wt} \%$. The Metals Handbook ${ }^{49}$ suggests $^{\circ}$ that increasing the cobalt content of nickel-based alloys improves the resistance to carburization. The Alloy 617 material used in these experiments had about $10 \mathrm{wt} \%$ cobalt and the Alloy 230 samples had essentially no cobalt. However, as noted above Incoloy $800 \mathrm{H}$ (containing no cobalt) and Hastelloy X (containing about 2 wt.\% cobalt) exhibited similar behavior to Alloy 617. Another possibility that has not been fully explored for the current experiments is that a protective oxide of one of the minor alloy constituents like aluminum or silicon that can be formed at lower oxygen partial pressure than chromium oxide inhibits carbon uptake of Alloy 617, but not Alloy 230.

\subsubsection{Generation IV research}

Through an INERI agreement with the French Gen IV materials program, the upper temperature limit determined by the so-called "microclimate reaction," or $\mathrm{Cr}_{2} \mathrm{O}_{3}$ volatility, will be determined. The focus and approach of the two systems is somewhat different so that they are complementary rather than duplicative. The system makes dynamic weight gain measurements on a single test coupon subjected to a premixed gas composition. The French system measures the level of moisture, but does not attempt to control it. The French program has been carrying out experimental work for several years and preliminary results have been published.

While the mechanisms of degradation are relatively well-known, the kinetics of the reactions for reactor conditions of high helium pressure and velocity are not well characterized. Most laboratory studies have been at very low-flow rates to approach thermodynamic equilibrium for fundamental studies of corrosion mechanisms. Similarly, typical test protocols have employed a pressure of $2 \mathrm{~atm}$, while the NGNP will operate at approximately $60 \mathrm{~atm}$. 


\begin{tabular}{|c|lll|}
\hline NEXT GENERATION NUCLEAR PLANT & Identifier: & PLN-2804 & \\
INTERMEDIATE HEAT EXCHANGER & Revision: & 0 & \\
MATERIALS RESEARCH & Effective Date: & $04 / 30 / 08$ & Page: 43 of 156 \\
AND DEVELOPMENT PLAN & & & \\
\hline
\end{tabular}

\subsubsection{IHX}

In the indirect cycle system, an IHX is used to transfer the heat from primary helium from the core to the secondary fluid, which can be helium, a nitrogen/helium mixture, or a molten salt. A recent report from $\mathrm{ANL}^{30}$ made a preliminary assessment of the issues pertaining to IHX for the NGNP. Two IHX designs: namely, shell-and-tube and compact printed circuit heat exchangers (PCHE) were considered.

\subsubsection{Thermal hydraulic analysis}

In addition to analyzing the materials under consideration, the ANL report ${ }^{21}$ performed a thermal hydraulic analysis for helium-to-helium, helium-to-helium/nitrogen, and helium-to-salt HXs. The model was used to determine the sensitivity of numerous HX parameters as well as the required size of the HX. Additional thermal conduction and stress analyses were used to perform ASME code compliance calculations and estimate maximum allowable design lives. Since the IHX is a high temperature component where creep is important, the draft code case for Alloy 617 patterned on ASME Code Section III, Subsection NH was used, assuming that the IHX will be classified as a Class 1 component. From these analyses, the following conclusions were reached.

Thin sections and diffusion bonding must also be considered. New design rules and analysis tools are needed for this type of structure.

Calculations were made to compare the performance of a PCHE with a shell-and-tube heat exchanger. The results (Table 13) showed large reductions in PCHE volume compared to a shell-and-tube HX, especially without ID and OD fins. Also, the PCHE had substantial increases in the pressure drop for the hot side and even larger pressure drop increases for the cold side compared to the shell-and-tube HX. The results also showed that for an IHX heat duty of $\approx 45 \mathrm{MWt}, \approx 20$ units of PCHE would be required based on the fabrication size limit used in the calculations.

Table 13. Comparison of PCHE and shell-and-tube IHX designs.

\begin{tabular}{lccc}
\hline \multicolumn{1}{c}{ Heat Exchanger Type } & PCHE & Shell-and-Tube \\
& & & \\
& $0.6 \mathrm{~m}(\mathrm{~L}) \mathrm{x}$ & $6 \mathrm{~m}(\mathrm{~L}) \mathrm{x}$ & $6 \mathrm{~m}(\mathrm{~L}) \mathrm{x}$ \\
Unit dimensions & $1.5 \mathrm{~m}(\mathrm{~W}) \mathrm{x}$ & $8.17 \mathrm{~m}(\mathrm{D})$ & $3.31 \mathrm{~m}(\mathrm{D})$ \\
& $0.6 \mathrm{~m} \mathrm{(H)}$ & & \\
Number of units & 19.408 & 1 & 1 \\
Total HX volume, $\mathrm{m}^{3}$ & 10.5 & 314.5 & 51.6 \\
Pressure drop, hot/cold sides, $\mathrm{kPa}$ & 25.6 & 0.05 & 3.2 \\
\hline
\end{tabular}

For a reactor outlet temperature and pressure of $900^{\circ} \mathrm{C}$ and $7 \mathrm{MPa}$, respectively, and a secondary side inlet temperature and pressure of $575^{\circ} \mathrm{C}$ and $1.95 \mathrm{MPa}$, respectively, the allowable design life (based on in-air tensile and creep rupture strengths of Alloy 617) of the PCHE is 80,000 h and that of the shell and tube IHX (for the tube size selected) is $20,000 \mathrm{~h}$. These design lifetimes are based on analyses of the IHX core and further reduction in life may result from interaction of the core region with the header region. The design lifetimes may also decrease, if thin section creep properties (which are generally less than 


\begin{tabular}{c|lll|}
\hline NEXT GENERATION NUCLEAR PLANT & Identifier: & PLN-2804 & \\
INTERMEDIATE HEAT EXCHANGER & Revision: & 0 & \\
MATERIALS RESEARCH & Effective Date: & $04 / 30 / 08$ & Page: 44 of 156 \\
AND DEVELOPMENT PLAN &
\end{tabular}

those of thicker material) are considered. In addition, the effect of impure helium on creep properties needs to be incorporated in the design data and in the lifetime calculations.

Replacing Alloy 617 with Alloy 230 will not lead to longer design lifetime for the IHX unless the performance of Alloy 230 in NGNP helium is significantly superior to that of Alloy 617.

\subsubsection{Core Internals}

Current preconceptual designs call for $800 \mathrm{H}$ control rod sleeves (composite is suggested in one case). The core barrel is specified as either $800 \mathrm{H}$ or $316 \mathrm{SS}$. Information on Alloy $800 \mathrm{H}$ is presented in Section 4.1.1.3

\subsubsection{Control Rods}

$\mathrm{C}_{\mathrm{f}} / \mathrm{C}$ composite material is being considered by two of the potential vendors for the control rod cladding material and Silicon-Carbide Fiber/Silicon-Carbide $\left(\mathrm{SiC}_{\mathrm{f}} / \mathrm{SiC}\right)$ composites have been considered as well. These composites are attractive because of their high temperature and irradiation resistance. However, the composite materials are non-homogeneous and anisotropic, and therefore require unique test methods to measure their properties. Test methods to evaluate these composite materials, particularly at elevated temperature, and including irradiation effects, will need to be developed and formalized. This can be a lengthy process, depending on the complexity of the test method proposed, and would be the first step in the NRC acceptance process.

Following development of standardized test methods, the material(s) of interest would have to go through the ASME codification process which also has the potential to be a lengthy process. There are no ASME specifications for composite materials to be used in nuclear applications. Entirely different design and performance philosophies must be adopted for composite use. Existing design and assessment rationale are guided by homogeneous material characteristics. Furthermore, not only must the individual constituents of the final material be qualified and approved, but also the method of assembly.

The development of new licensing-strategies that utilize modern approaches to reactor design, operational risk assessment; and the development of a probabilistic risk assessment-based regulatory structure for future reactors should provide a shorter path from material identification to final approval. However, the time when a more progressive approach is developed and implemented for actual use is uncertain. For the time being, the approval process for a new type of material will still be a long process.

\subsection{Current Codes and Procedures}

\subsubsection{ASME Boiler and Pressure Vessel Code}

Due to the anticipated cyclic operation at elevated temperatures, the service conditions for the NGNP IHX are very severe. One of the current issues for NGNP IHX is that, as new systems, the system safety criteria and regulatory guidelines are less well founded than for the more established reactor systems.

The general requirements for Divisions 1 and 2 rules for construction of nuclear facility components are given in Section III, Subsection NCA of the ASME B\&PV Code. Section III, Division 1 of the B\&PV code contains specific rules for the construction of different nuclear facility components. The coverage of these construction rules by various subsections in Section III, and the code cases developed for elevated temperature service are shown in Tables 14 and 15, respectively. 


\begin{tabular}{c|lll|}
\hline NEXT GENERATION NUCLEAR PLANT & Identifier: & PLN-2804 & \\
INTERMEDIATE HEAT EXCHANGER & Revision: & 0 & \\
MATERIALS RESEARCH & Effective Date: & $04 / 30 / 08$ & Page: 45 of 156 \\
AND DEVELOPMENT PLAN &
\end{tabular}

Table 14. Definition of B\&PV Codes for Subsections in Section III Division 1.

\begin{tabular}{cl}
\hline Subsection of Section III, Div 1, B\&PV Code & \multicolumn{1}{c}{ Coverage } \\
\hline NB & Class 1 Components \\
NC & Class 2 Components \\
ND & Class 3 Components \\
NE & Class MC-Metal Containment Vessels \\
NF & Supports \\
NG & Class CS-Core Support Structures \\
NH & Class 1 Components in Elevated Temperature Service \\
\hline
\end{tabular}

Table 15. Section III, Division 1 Code cases developed for elevated temperature service.

Code Case, Section III, Div 1

Coverage

N-201-5 Class CS (Core Support) Components in Elevated Temperature Service.

N-290-1 Expansion Joints in Class 1, Liquid Metal Piping.

N-253-14 Construction of Class 2 or Class 3 Components for Elevated Temperature Service.

N-254 Fabrication and Installation of Elevated Temperature Components, Class 2 and 3.

N-257 Protection Against Overpressure of Elevated Temperature Components, Classes 2 and 3.

N-467 Testing of Elevated Temperature Components, Classes 2 and 3.

N-499-2 Use of SA-533 Grade B, Class 1 Plate and SA-508 Class 3 Forgings and their Weldments for Limited Elevated Temperature Service.

Per ASME Section III Subsection NCA, construction rules are specified for components that are designated Code Classes 1, 2, 3, CS - core support structures, and MC - metal containment vessels for Division 1, and CC - concrete containments for Division 2. The various class distinctions designate "...the different levels of importance associated with the function of each item as related to the safe operation of the nuclear power plant" (with Class 1 requiring the highest level of safety). The intent of these Code Classes is to allow a choice of rules by the "Owner" (NGNP in this case) that provides assurance of structural integrity and quality commensurate with the relative importance assigned to the individual components of a nuclear power plant. Designation of Code Classes for nuclear components by the "Owner" is based on assessment of public safety as implemented through system safety criteria and regulatory guidelines. Component classification shall be included in the Design Specification.

A decision on the Code Class designation of NGNP IHX components has not been made. In the following sections, the rules of construction for potentially relevant codes and code cases for elevated temperature service will be reviewed. The rules include Subsection NH and Code cases N-253, N-254, N257, and N-467. A draft Code case on Alloy 617 for high temperature gas-cooled reactor applications was 


\begin{tabular}{c|lll|}
\hline NEXT GENERATION NUCLEAR PLANT & Identifier: & PLN-2804 & \\
INTERMEDIATE HEAT EXCHANGER & Revision: & 0 & \\
MATERIALS RESEARCH & Effective Date: & $04 / 30 / 08$ & Page: 46 of 156 \\
AND DEVELOPMENT PLAN &
\end{tabular}

developed in the 1980's but the effort was stopped due to the redirection of DOE priorities. This draft code case is very relevant to the NGNP IHX components and it will also be reviewed.

For elevated temperature metallic core support structures, Code Case N-201 provides the relevant rules of construction.

\subsubsection{Subsection $\mathrm{NH}$}

The current Subsection NH criteria and material coverage originate largely from the liquid-metal reactor (LMR) program of the late 1960s to early 1980s. In the late 1960s, the Atomic Energy Commission initiated a Materials and Structures Technology program and simultaneously asked the ASME Boiler and Pressure Vessel Code Committee to charge an expanded Subgroup on Elevated Temperature Design with developing the design rules that eventually provided the basis for Subsection NH.

\section{Load and Deformation Controlled Quantities}

The purpose of the early code cases for elevated temperature service was to provide rules for construction that account for the effects of deformation and damage due to creep with the same rigor that Subsection NB addressed the temperature regime below which creep effects are significant. As in Subsection NB, the rules of construction in Subsection NH are based on the Design-by-Analysis approach. Stresses are still categorized into primary, secondary and peak stresses. However, due to the significant difference in the structural behavior at elevated temperature as compared with that at low temperature, Subsection NH has adopted the approach of placing limits on two basic types of controlled quantities: (1) load-controlled, and (2) deformation-controlled.

The structural failure modes covered by Subsection NH for elevated temperature service include the time-independent structural failure modes of Subsection NB:

1. Ductile rupture from short-term loading.

2. Gross distortion due to incremental collapse and ratcheting.

3. Loss of function due to excessive deformation.

4. Buckling due to short-term loading and new time-dependent structural failure modes.

5. Creep rupture from long-term loading.

6. Creep-fatigue failure.

7. Creep-buckling due to long-term loading.

Load-controlled quantities are primary stresses. But at elevated temperatures, some stresses that would have been considered as secondary per the familiar classification of Subsection NB take on the characteristics of primary stresses due to elastic follow-up. To account for differing loads, times and temperatures, the stress allowable $\mathrm{S}_{\mathrm{m}}$ from Subsection NB is retained for time-independent loads, and a new time-dependent stress allowable $\mathrm{S}_{\mathrm{t}}$ is introduced for time-dependent loads and is based on the time to $1 \%$ total strain, time to start of tertiary creep and creep rupture strength. The stress $\mathrm{S}_{\mathrm{mt}}$ defined as the lower of $\mathrm{S}_{\mathrm{m}}$ and $\mathrm{S}_{\mathrm{t}}$ is also introduced.

These allowable stresses are used to set different primary stress limits for Level A (normal), B (upset), C (emergency), and D (faulted) service events, similarly to Subsection NB. But time-of-loading is an additional variable that needs to be considered due to the time dependency. A different criterion is used to set the primary stress limits for Design Conditions. It is adopted from Section I and VIII and 


\begin{tabular}{c|lll|}
\hline NEXT GENERATION NUCLEAR PLANT & Identifier: & PLN-2804 & \\
INTERMEDIATE HEAT EXCHANGER & Revision: & 0 & \\
MATERIALS RESEARCH & Effective Date: & $04 / 30 / 08$ & Page: 47 of 156 \\
AND DEVELOPMENT PLAN &
\end{tabular}

based on 100,000-hour creep rupture properties and a creep rate of $0.01 \%$ per 1000 hours. Only elastic analysis results are required to satisfy the primary stress limits. The primary stress limits cover structural failure modes (1) and (5) listed above.

The deformation-controlled quantities are stresses, strains, and deformations resulting from load, deflection and strain compatibility. Acceptable deformation-controlled limits are given in Appendix T of Subsection NH and they cover strain limits/ratcheting, creep-fatigue damage, and buckling and welds. Strain limits and creep-fatigue damage rules can be satisfied using either elastic or inelastic analysis methods. Elastic analysis rules, sometimes referred to as Simplified Methods, were originally envisioned as simpler, more conservative and less costly screening method. Inelastic rules which required inelastic analyses were envisioned as more costly and time consuming, but adequately conservative "gold standard." Failure modes (2), (3), and (6) listed above are covered by the strain limits and creep-fatigue damage rules of Appendix T.

In addition to deformation-controlled limits, Appendix $\mathrm{T}$ also includes rules for general loading conditions evaluated with inelastic analysis, including the time-dependent effects of creep. Rules to address structural failure modes (4) and (7) on short-term and long-term buckling are given in Appendix T.

\section{Weld and Component Requirements}

Subsection NH provides analysis requirements for the design and location of all pressure retaining and other primary structural welds under elevated temperature service. Special examination requirements are included for welded joints. Permissible weld materials are limited. Creep stress-rupture reduction factors for weldments are given as a function of temperature and time. Subsection NH further provides special limits on strain accumulations in the weld regions by limiting the weld strains to be one-half of the strain limits permitted for the parent material. The allowable number of design cycles for weldments is restricted to one-half that of the parent metal. The allowable time for creep rupture damage is also reduced by multiplying the stress by the weld strength reduction factor when determining the time-torupture. Subsection $\mathrm{NH}$ also imposes additional examination requirements on category A, B, C and D vessel weld joints.

Subsection NH also provides component design rules that cover vessels, pumps, valves and piping. These design rules permit the use of Subsection NB component rules, charts, and formulas for meeting the design and service limits for some applications. Generally, Subsection NH permits the use of Subsection NB procedures for the satisfaction of primary (load-controlled) stress limits and when creep effects are negligible. For vessels and piping the stress indices from Subsection NB may also be used in evaluation of Subsection NH's limits on deformation controlled loading with restrictions to ensure their relevance in the creep regime.

The guidance on fabrication and installation, welding and brazing qualifications, examination, and testing are all provided in Subsection NH as a supplement, referral or replacement to Subsection NB. Cold work effects such as loss of ductility, particularly for 304 and 316 stainless steels, and loss of creeprupture strength, particularly at low strain and long times, are emphasized. For welding, NH references Subsection NB, which invokes Section IX. Since a crack-like defect is more likely to propagate at elevated temperature, additional volumetric examinations that include ultrasonic, eddy current, and radiography from two angles are required in addition to the single radiography of NB. NH makes a pneumatic test an equal alternative to hydrostatic test and a Helium leak test is required only on certain closure welds. The use of an internal pressure test is permitted as the basis to test components and appurtenances that will be subjected to external pressure loads in service. NH incorporates changes to better reflect the characteristics of sodium systems and the use of a rupture disk test as a sole means of overpressure protection is permitted. 

NEXT GENERATION NUCLEAR PLANT
INTERMEDIATE HEAT EXCHANGER
MATERIALS RESEARCH
AND DEVELOPMENT PLAN

$\begin{array}{ll}\text { Identifier: } & \text { PLN-2804 } \\ \text { Revision: } & 0 \\ \text { Effective Date: } & 04 / 30 / 08\end{array}$

Page: 48 of 156

\section{NH Code Materials}

The number of Subsection NH code materials for elevated temperature service is much smaller than that of Subsection NB. The temperature limits for NH code materials, other than bolting, at 300,000 hours are listed in Table 16. The maximum temperatures at which fatigue curves are provided are also listed. Bolting materials are shown in Table 17.

Table 16. Materials specified in NH for elevated temperature service in nuclear applications.

Maximum temperature

NH code materials (other than bolting)
For stress allowables S0, Smt, St, Sr up to 300,000 hours $^{\mathrm{a}}$
For fatigue curves

304 stainless steels

(UNS S30400, S30409)

$816^{\circ} \mathrm{C}$

$704^{\circ} \mathrm{C}$

316 stainless steel

(UNS S31600, S31609)

$816^{\circ} \mathrm{C}$

$704^{\circ} \mathrm{C}$

Alloy 800H (UNS N08810)

$760^{\circ} \mathrm{C}$

$760^{\circ} \mathrm{C}$

$2^{1 / 4} \mathrm{Cr} 1 \mathrm{Mo}$ steel, annealed condition

(UNS K21590)

$593^{\circ} \mathrm{C}^{\mathrm{b}}$

$593^{\circ} \mathrm{C}$

Grade 91 steel

(UNS K90901) ${ }^{\mathrm{c}}$

$649^{\circ} \mathrm{C}$

$538^{\circ} \mathrm{C}$

a. The primary stress limits are very low at 300,000 hours and the maximum temperature limit

b. Temperatures up to $649^{\circ} \mathrm{C}\left(1200^{\circ} \mathrm{F}\right)$ are allowed up to 1,000 hours

c.The specifications for Grade 91 steel covered by Subsection NH are SA-182 (forgings), SA-213 (small tube), SA-335 (small pipe), and SA-387 (plate). The forging size for SA-182 is not to exceed $4540 \mathrm{~kg}$.

Table 17. The temperature and time limits for NH code materials for bolting.

\begin{tabular}{lcc}
\hline \multicolumn{1}{c}{ NH code materials for bolting } & $\begin{array}{c}\text { Maximum temperature for } \\
\text { stress allowables } \mathrm{S}_{0}, \mathrm{Sm}_{\mathrm{t}}\end{array}$ & $\begin{array}{c}\text { Maximum duration for } \\
\text { stress allowables } \mathrm{S}_{0}, \mathrm{Sm}_{\mathrm{t}}\end{array}$ \\
\hline $\begin{array}{l}\text { 304 stainless steels } \\
\text { (B8 Class 1, and B8A, Class 1A) }\end{array}$ & $704^{\circ} \mathrm{C}$ & 200,000 hours \\
$\begin{array}{l}\text { 316 stainless steel } \\
\text { (B8M Class 1, and B8MA, Class 1A) }\end{array}$ & $704^{\circ} \mathrm{C}$ & 200,000 hours \\
Alloy 718 (UNS N07718) & $566^{\circ} \mathrm{C}$ & 300,000 hours \\
\hline
\end{tabular}

The delta ferrite limits are defined by the ferrite number (FN), a magnetic means of measuring the amount of ferrite in a stainless steel. The designated minimum of 5-FN in Subsection NB is changed to a range of 3-FN to 10-FN in Subsection NH. Reduction in the yield and tensile strength due to aging is required in Subsection NH. In addition to meeting other materials acceptance requirements specified in Subsection NB, creep-fatigue acceptance test is required for 304 and 316 stainless steels. The creep- 


\begin{tabular}{c|lll|} 
NEXT GENERATION NUCLEAR PLANT & Identifier: & PLN-2804 & \\
INTERMEDIATE HEAT EXCHANGER & Revision: & 0 & \\
MATERIALS RESEARCH & Effective Date: & $04 / 30 / 08$ & Page: 49 of 156 \\
AND DEVELOPMENT PLAN &
\end{tabular}

fatigue acceptance test requirement was implemented in response to problems encountered in the field where a heat of 304 stainless steel passed the then required acceptance tests but exhibited very low creep ductility, $0.5 \%$ in a $10,000 \mathrm{hr}$ test. The creep-fatigue acceptance test involves fatigue test in air at $595^{\circ} \mathrm{C}$ at an axial strain range of $1.0 \%$ with a one-hour hold period at the maximum positive strain point in each cycle. Test should be performed to ASTM Standard E 606. The material lot is acceptable if the test exceeds 200 cycles without fracture or a $20 \%$ drop in the load range.

Data in support of the development of various stress allowables in Subsection NH are based on tests in air. Similar to Subsection NB, rules that govern the deterioration of material caused by service are not covered by Subsection NH. It is the responsibility of the Owner to account for such effects. Currently, design correlations to account for the environmental effects due to neutron irradiation or impure helium coolant are not available.

The criteria documents for Class 1 components covered by Subsection NH are given in the literature ${ }^{50-52}$ and a detailed summary of the Subsection $\mathrm{NH}$ rules is given in the Companion Guide to the B\&PV code. ${ }^{53}$ A recent overview of the Subsection NH rules is given in an NRC NUREG report. ${ }^{54}$

\section{Recent Code Activities on Subsection NH}

The task activities carried out in the first round of the DOE/ASME Generation IV project, as summarized in Section 4.2.3, have had the most significant and positive impact on the Subsection NH code rules. Similar impact is expected from the task activities from the second round.

Elevated temperature code rule developments for Section VIII applications are currently being carried out. The tasks include:

1. Time dependent allowable stress for Section VIII, Div 1.

2. Extend time-dependent range for low-chrome alloys.

3. Extend fatigue rules to $482^{\circ} \mathrm{C}$ for low-chrome alloys.

4. Creep-buckling analysis methods.

5. Bolted flange design at elevated temperature.

Insights learned from these projects could be helpful in improving Subsection NH code rules.

\subsubsection{Code Cases for Class 2 and 3 Components}

The extension of the rules of construction of Class 2 and 3 components in Subsection NC and ND to elevated temperature service is provided in a series of Section III code cases. The rules for materials and design are provided in Code Case N-253-14, fabrication and installation in Code Case N-254, overpressure protection in Code Case N-257, and testing in Code Case N-467.

The materials of construction covered by Code Case N-253-14 are required to meet the acceptance requirements in Subsection NC (Class 2) and Subsection ND (Class 3). For welds, the minimum acceptable delta ferrite is FN-5 for design temperatures of $427^{\circ} \mathrm{C}$ and below, and limited to the range FN3 to FN-10 for design temperature above $427^{\circ} \mathrm{C}$. For statically and centrifugally cast products, in addition to the requirements of Subsection NC and ND, the delta ferrite is limited to a maximum of FN-12 for design temperature exceeding $427^{\circ} \mathrm{C}$.

Code Case N-253-14 provides allowable stresses for both negligible creep regime (Table C-1.1) and creep regime (Table $\mathrm{C}$-1.2). Time-temperature limits for negligible creep regime are provided for carbon 


\begin{tabular}{c|lll|}
\hline $\begin{array}{c}\text { NEXT GENERATION NUCLEAR PLANT } \\
\text { INTERMEDIATE HEAT EXCHANGER }\end{array}$ & Identifier: & PLN-2804 & \\
MATERIALS RESEARCH & Revision: & 0 & \\
AND DEVELOPMENT PLAN & Effective Date: & $04 / 30 / 08$ & Page: 50 of 156 \\
\hline
\end{tabular}

steels; low alloy steels; 304 and 316 wrought and cast stainless steels; and Alloy $800 \mathrm{H}$ among others. The allowable stresses for the negligible creep regime protect the components against those failure modes that are due to short-term load applications such as those in Subsection NC and ND.

The allowable stresses for the creep regime are based on the same criteria as those for Section I and VIII, Division 1 which are based on 100,000 hour properties Weld strength reduction factors are provided for weldments in the creep regime.

The structural design criteria for vessel, pump and valve are based on the design-by-formula rules of Subsection NC and ND, but using the extended allowable stresses in Table C-1.1 or Table C-1.2, depending on whether the negligible creep criteria are satisfied. These rules do not explicitly address fatigue damage (creep-fatigue) from cyclic service. Time-dependent buckling procedure from Subsection $\mathrm{NH}$ is adopted when creep is not negligible.

For piping design, rules from Subsection NC and ND can be used with the extended allowable stresses in Table C-1.1 when the component is in the negligible creep regime. When the piping is in the creep regime, the "stress reduction factor for cyclic service" for evaluation of expansion stresses is further reduced to account for the effects of creep damage incurred as the restrained thermal expansion stresses relax. The allowable stresses are from Table $\mathrm{C}$-1.2. It is noted that these piping rules which account for the effects of creep-fatigue damage are different from those in Subsection NH.

Code Cases N-254, N-257, and N-467 supplement, the rules for fabrication and installation, overpressure protection, and testing of Subsection NC and ND for elevated temperature service, respectively.

\subsubsection{Draft Alloy 617 Code Case}

The draft Code Case for Alloy 617 provides design rules for HTGRs with reactor outlet temperatures of about 950C. The original request to the ASME B\&PV Code Committee for design rules for very high temperature nuclear components came from the U.S. DOE and one of its contractors. An ad hoc task force of the ASME Code was established in 1983 to address the design of reactors operating at very high temperatures. The task force was organized under the jurisdiction of the Subgroup on Elevated Temperature Design of the Subcommittee on Design. The Task Force completed the draft code case in 1989 and submitted it to the Subgroup, which later approved the code case. No further work was done on the draft code case because of the lack of further interest from US DOE and its contractor.

The draft code case focused on Alloy 617 because it was a leading candidate of designers, and there was a significant material properties database at the temperature of interest. The code case focused on all the failure modes that are addressed by Subsections NB and NH, including non-ductile failure. The last failure mode was considered because of the significant loss of fracture toughness in Alloy 617 after longterm exposure to high temperatures.

The draft code case was patterned after relevant portions of Code Case N-47 and was limited to $982^{\circ} \mathrm{C}$, and a maximum service life [total life at temperatures $>427^{\circ} \mathrm{C}$ ] of 100,000 hours or less. This design life (shorter than the 300,000 hours specified in Subsection NH) was selected because of the uncertainties of data extrapolation at very high temperatures, and the lack of experience in designing reliably at low allowable stresses for long times. The allowable stresses are less than $1 \mathrm{ksi}$ at the highest temperature.

Most of the design rules provided by the draft code case are similar to those provided by Subsection $\mathrm{NH}$, although some are different because the draft code case considers higher temperatures and a different 


\begin{tabular}{c|lll|}
\hline NEXT GENERATION NUCLEAR PLANT & Identifier: & PLN-2804 & \\
INTERMEDIATE HEAT EXCHANGER & Revision: & 0 & \\
MATERIALS RESEARCH & Effective Date: & $04 / 30 / 08$ & Page: 51 of 156 \\
AND DEVELOPMENT PLAN &
\end{tabular}

material. Alloy 617 exhibits unique behavior that includes (1) lack of clear distinction between timeindependent and time-dependent behavior, (2) high dependence of flow stress on strain rate, and (3) softening with time, temperature, and strain. Therefore, design rules of Subsection NH that are time- and rate-independent, or strain-hardening idealizations of material behavior, required careful consideration in the draft case. For example, the case specifies that inelastic design analyses for temperatures above $649^{\circ} \mathrm{C}$ must be based on unified constitutive equations, which do not distinguish between time-independent plasticity and time-dependent creep.

Extended exposure at elevated temperature may cause a significant reduction in fracture toughness of Alloy 617. The draft case requires a fracture mechanics analysis to justify the ability of the component to withstand the expected service conditions, especially when the component cools down to lower temperatures. Because of this concern for potential loss of fracture toughness, Alloy 617 bolting is excluded from the draft case. In addition, exposure of cold worked material to very high temperatures results in recrystallization. Therefore, cold worked Alloy 617 is also excluded from the draft case.

\subsubsection{Code Case N-201-5}

Section III Subsection NG establishes rules of construction for materials, design, fabrication, examination, and preparation of reports required in the manufacture and installation of core support structures, internal structures, threaded structural fasteners, and temporary attachments. The rules of construction in Subsection NG are for low temperature service $\left(371^{\circ} \mathrm{C}\right.$ for ferritic steels and $427^{\circ} \mathrm{C}$ for austenitic steels). Code Case N-201-5 extends the rules of construction of Subsection NG to elevated temperature service.

Code Case N-201-5 contains two parts. Part A involves the extension of the Subsection NG rules of construction to restricted service at elevated temperature without explicit consideration of creep and stress-rupture. Part B extends the Subsection NG rules of construction to service at elevated temperature to suitably account for creep and stress-rupture effects. The negligible creep criteria are similar to Appendix E in Code Case N-253-14 which is more restrictive as the limit on the temperature-dependent time-use fraction is 0.9 for Code Case N-253-14 and 1.0 for Code Case N-201-5.

Part A supplements the rules of construction in Subsection NG. The same allowable stress basis, Sm, and design rules as Subsection NG, with some modification, are used in Part A. The materials of construction include 304 and 316 stainless steels, and Alloy $800 \mathrm{H}$ for structural materials and 304 and 316 stainless steels and Alloy 800 for threaded fasteners. Time independent rules similar to those in Subsection NH are introduced for buckling and instability.

Part B replaces the rules of construction in Subsection NG by those in Subsection NH, but adapted to Core Support Structures. The structural failure modes covered by N-201-5 Part B are the same as those covered by Subsection NH:

1. Ductile rupture from short-term loading.

2. Gross distortion due to incremental collapse and ratcheting.

3. Loss of function due to excessive deformation.

4. Buckling due to short-term loading.

5. Creep rupture from long-term loading.

6. Creep-fatigue failure.

7. Creep-buckling due to long-term loading. 


\begin{tabular}{c|lll|}
\hline $\begin{array}{c}\text { NEXT GENERATION NUCLEAR PLANT } \\
\text { INTERMEDIATE HEAT EXCHANGER }\end{array}$ & Identifier: & PLN-2804 & \\
MATERIALS RESEARCH & Revision: & 0 & \\
AND DEVELOPMENT PLAN & Effective Date: & $04 / 30 / 08$ & Page: 52 of 156 \\
\hline
\end{tabular}

The Subsection NH materials and allowable stresses are provided in Part B. However, the Subsection $\mathrm{NH}$ methodology for deterioration due to time-at-temperature is not implemented. The $\mathrm{K}$ ' factor in the creep damage portion of the creep-fatigue evaluation is set at 0.9 in Part B. In the latest addenda of Subsection NH, $\mathrm{K}^{\prime}$ is equal to 0.9 when simplified analysis method (elastic) is used and 0.67 when inelastic analysis method is used.

Consistent with Subsection NG, the design condition is not used in both Part A and B, and pressure difference instead of pressure is considered.

Task 4 of the first round of the DOE/ASME Generation IV project, as summarized in Section 4.2.3.1, has produced a draft to update Code Case N-201-5.

\subsubsection{Code Rules for Shell and Tube IHX Designs}

Section VIII, Divisions 1 and 2 (for non-nuclear service) have design rules for shell and tube heat exchangers. Section VIII Division 2 also has analysis formulas for perforated plates. The Section VIII Division 1 rules may be used in the creep regime. The Section VIII Division 2 rules may only be used in the creep regime if exempted from fatigue analysis by the rules for similar equipment in similar service. Neither Section VIII Division 1 nor Division 2 rules address creep-fatigue.

Subsection NH does not have specific rules for shell and tube heat exchangers but the design-byanalysis procedures in NH-3200 as supplemented by Appendix T are conceptually applicable to any component. The CRBR steam generator and IHX were both designed using Code Case N-47, the Subsection NH precursor. The steam generator was a shell and tube heat exchanger as was the IHX.

In summary, Subsection NH covers the shell and tube IHX for both creep and creep-fatigue based on design-by-analysis. Section VIII, Division 1 has design-by-rule procedures for shell and tube heat exchangers that may be used in the creep regime.

\subsubsection{Foreign Codes}

\subsubsection{French Code RCC-MR}

RCC-MR was developed in France as a high temperature extension to RCC-M, for the French breeder reactor program. The basic rules in RCC-MR are similar to those in ASME Code Subsection NH and the choice of materials is also limited. RCC-MR provides more detailed instructions for fatigue and creepfatigue design analysis than given in the ASME Codes. It also uses a somewhat different approach for analysis of creep ratcheting without the use of isochronous stress-strain curves. But the basic safety factors used in the generation of design curves in the two codes are comparable.

\subsubsection{British Procedure R5}

Procedure R5 is a comprehensive assessment procedure for the high temperature response of structures. The procedure addresses several aspects of high temperature behavior, including creep and creep-fatigue crack growth, and both similar and dissimilar metal welds. The main objective of the procedure is to ensure that failure of both defect-free and defective components by creep rupture is avoided. The calculation of the expected lifetime is performed by conservative approximations based on Reference Stress Techniques. Procedure R5 permits use of ductility exhaustion for creep-fatigue evaluation, if the material data are available. If appropriate data are not available, linear damage summation, similar to that recommended by ASME Code Subsection NH, is used. 


\begin{tabular}{c|lll|}
\hline $\begin{array}{l}\text { NEXT GENERATION NUCLEAR PLANT } \\
\text { INTERMEDIATE HEAT EXCHANGER }\end{array}$ & Identifier: & PLN-2804 & \\
MATERIALS RESEARCH & Revision: & 0 & \\
AND DEVELOPMENT PLAN & Effective Date: & $04 / 30 / 08$ & Page: 53 of 156 \\
\hline
\end{tabular}

Procedure R5, which is a guideline and not a code, considers creep cracking explicitly. Neither the ASME Code nor the RCC-MR Code addresses the subject because creep cracking is more of an issue in residual life assessment than design. Therefore, the use of this procedure in the design of HTGR components is limited. However, the procedure presents the use of ductility exhaustion as an alternative to the linear damage rule for calculating the creep component of damage. The use of ductility exhaustion instead of linear damage rule may be more suitable for estimating creep damage in the HTGR materials and should be evaluated for incorporation in Subsection NH.

\subsubsection{DOE Initiative to Address ASME Code Issues for Gen IV Reactors}

Nuclear structural component construction in the U.S. complies with Section III of the ASME Boiler and Pressure Vessel Code, although licensing is granted by the NRC. A number of technical topics were identified by DOE, ORNL, INL, and ASME to have particular value with respect to the ASME Code. A three-year collaboration between DOE and ASME was established that addresses twelve topics in support of an industrial stakeholder's application for licensing of a Gen IV nuclear reactor.

The majority of these tasks are relevant to action items within ASME Section III Subsection NH, and the nature of the topics inherently include significant overlap, and in some cases parallel activities on the same issue.

\subsubsection{First Round Tasks}

The first five topics were funded in the first round of the DOE/ASME Gen IV project. All of these tasks are now complete and final reports have been submitted by the task investigators to ASME. The results of the investigations are summarized below.

\section{Task 1: Verification of Allowable Stresses}

The ASME Section III Subsection NH criteria for estimating the time-dependent allowable stress $S_{t}$ include the average strength for $1 \%$ total strain, $80 \%$ of the minimum strength for tertiary creep, and $67 \%$ of the minimum rupture strength values. The extension in temperature and/or time for the stress allowables established in Task 1 is of significance to the NGNP project.

\section{Part I. Alloy $800 \mathrm{H}$ base metal}

The objective of Part I of this task was to review Alloy $800 \mathrm{H}$ stress allowables in Subsection NH and to perform a data gap analysis to assess the possibilities of extending the time-dependent allowable stresses to $900^{\circ} \mathrm{C}$ and 600,000 hours. Alloy $800 \mathrm{H}$ is used as a control rod cladding material for the Westinghouse and GA designs, as a core barrel material for the AREVA design, and as the material of construction for the lower-temperature IHX.

$\underline{\text { Results }}$

Procedures for analyzing creep and creep-rupture data for Subsection NH were reviewed and compared to the procedures used to develop the current Subsection NH $S_{t}$ values for Alloy $800 \mathrm{H}$. Procedures used by Section II were also compared with those of Subsection NH.

Databases summarizing the creep and creep-rupture properties of Alloy $800 \mathrm{H}$ were collected. The data were carefully reviewed to show compliance with the requirements of the Alloy $800 \mathrm{H}$ specifications applicable to Subsection NH. A subset in the temperature range of $750^{\circ} \mathrm{C}$ to $900^{\circ} \mathrm{C}$ were selected and used to estimate the strength in conformance with the Subsection $\mathrm{NH}$ criteria that were the basis for estimating $S_{t}$. 


\begin{tabular}{c|lll|}
\hline NEXT GENERATION NUCLEAR PLANT & Identifier: & PLN-2804 & \\
INTERMEDIATE HEAT EXCHANGER & Revision: & 0 & \\
MATERIALS RESEARCH & Effective Date: & $04 / 30 / 08$ & Page: 54 of 156 \\
AND DEVELOPMENT PLAN &
\end{tabular}

It was concluded that there are sufficient creep-rupture data for Alloy $800 \mathrm{H}$ to permit the extension of the creep rupture strengths in time and temperature. Creep rupture strengths to $900^{\circ} \mathrm{C}$ and 600,000 hour were developed.

For the $1 \%$ strain criterion, it was found that the variability in the primary creep behavior complicated the development of a temperature-stress-time model needed for the evaluation of $1 \%$ strain criterion for long-times at temperatures of $800^{\circ} \mathrm{C}$ and above. A low value for the stress exponent caused the estimated stresses to fall rapidly at long times, and at $850^{\circ} \mathrm{C}$ and $900^{\circ} \mathrm{C}$ the model reached its stress-based extrapolation limit before reaching the 600,000 hours life target. Similar difficulties were encountered in estimating the tertiary creep criterion.

An alternate correlation between the time to tertiary creep and the rupture life produced a favorable model for estimating $80 \%$ of the minimum strength for tertiary creep. The estimated strengths from this tertiary creep model based on rupture life were very close to those estimated from $67 \%$ of the minimum rupture strength. Both the Larson-Miller parameter and the Orr-Sherby-Dorn parameter were used to estimate the stresses for $100 \%$ of the average time to $1 \%$ strain and $80 \%$ of the stress for the initiation of tertiary creep. Both global and lot centering analysis methods were investigated for the Larson-Miller parameter but it was observed that the polynomial stress function that accompanied the model was not suitable for extrapolation.

Tables were developed that compared the strengths produced by the three criteria and analysis methods. The Orr-Sherby-Dorn parameter in combination with a well-behaved stress function was selected for the estimation of the long-time strength for $1 \%$ strain. With this choice, it was found that the minimum rupture strength criterion controlled $S_{t}$ for most times at $750^{\circ} \mathrm{C}$, for the first 100,000 hours at $800^{\circ} \mathrm{C}$, and for shorter times at $850^{\circ} \mathrm{C}$ and $900^{\circ} \mathrm{C}$. The average stress to produce $1 \%$ creep controlled the long time stress limits at $850^{\circ} \mathrm{C}$ and $900^{\circ} \mathrm{C}$.

\section{$\underline{\text { Recommendations }}$}

- Collect additional data to better assess the stress for $1 \%$ creep at long times and above $800^{\circ} \mathrm{C}$, since a possibility for diffusional creep may exist.

- Determine time-independent allowable stresses $S_{m}$, up to $900^{\circ} \mathrm{C}$ in addition to the time-dependent allowable stresses $S_{t}$. MPC will provide these required tensile and yield strengths.

- Perform tensile tests to assess the strain-rate effect on the tensile and yield strengths.

\section{Part II. Alloy $800 H$ weldment}

The objective of Part II of Task 1 was to review the strength of weldments for Alloy $800 \mathrm{H}$ and to perform a data gap analysis to assess the possibilities of extending the time-dependent allowable stresses to $900^{\circ} \mathrm{C}$ and 600,000 hours.

\section{$\underline{\text { Results }}$}

Filler metals for joining Alloy $800 \mathrm{H}$ were reviewed and references bearing on the tensile and stressrupture behavior of deposited weld metal and weldments were summarized. Data were collected for several coated and bare-wire electrodes. They include stress-rupture data for Alloy A deposited weld metal and deposited cross-welds, Alloy 21-33Nb weld metal, Alloy 182 deposited weld metal and crossweld, and Alloy 82 deposited weld metal and cross-welds.

Yield data for several weld and weldment materials were compared to the Y-1 and $S_{y 1}$ versus temperature trends for Alloy $800 \mathrm{H}$. Similarly, ultimate tensile strength data were compared to the $\mathrm{U}$ and 


\begin{tabular}{c|lll|}
\hline NEXT GENERATION NUCLEAR PLANT & Identifier: & PLN-2804 & \\
INTERMEDIATE HEAT EXCHANGER & Revision: & 0 & \\
MATERIALS RESEARCH & Effective Date: & $04 / 30 / 08$ & Page: 55 of 156 \\
AND DEVELOPMENT PLAN &
\end{tabular}

$S_{U}$ versus temperature trend for Alloy $800 \mathrm{H}$. It was observed that weld metal and weldments always exceeded the strength of the Alloy $800 \mathrm{H}$ base metal.

The stress-rupture strengths of several weld and weldment materials were compared to the rupture strength of Alloy $800 \mathrm{H}$ for the temperature range $750^{\circ} \mathrm{C}$ to $1000^{\circ} \mathrm{C}$ on the basis of the Larson-Miller parametric curve using a common parametric constant characteristic of Alloy $800 \mathrm{H}$. It was found that weld metals and weldments were stronger than Alloy $800 \mathrm{H}$ at low temperatures and high stresses but appeared to be weaker at high temperatures. Alloy $21 / 33 \mathrm{Nb}$ was an exception and the deposited filler metal was stronger or equivalent to Alloy $800 \mathrm{H}$ over the range of temperatures and stresses where data were available.

An attempt was made to estimate the Strength Reduction Factors (SRFs) for weldments made with Alloy A (ENiCrFe-2) and Alloy 82 (ERNiCrFe-3). It was found that the lack of long-time, high temperature data made it difficult to produce reliable results. Analysis was undertaken using the LarsonMiller parametric procedure. Both global (batch) and lot-centered methods were applied. It was found that for Alloy 82, estimates of SRFs were reasonably close to those provided in ASME III-NH Table I-10 C-2 for $760^{\circ} \mathrm{C}$. Values for Alloy A were higher than expected and well above the SRFs provided in ASME IIINH Table I-10 C-1.

\section{$\underline{\text { Recommendation }}$}

A creep-rupture experimental program was recommended to address SRF for weldments in Alloy $800 \mathrm{H}$ for service above $750^{\circ} \mathrm{C}$. The recommended test temperatures are between $900^{\circ} \mathrm{C}$ and $1000^{\circ} \mathrm{C}$, in $25^{\circ} \mathrm{C}$ increments. A minimum of 10,000 hours test time was recommended. The test matrix includes Alloy 82, Alloy A, and Alloy 800H weldments, and Alloy 117, Alloy 617, and Alloy 21/33Nb weld metals.

\section{Part III. Grade 91 steel}

Grade 91 steel is not relevant to components considered in this report and will not be discussed here.

\section{Task 2: Regulatory Safety Issues in Structural Design Criteria}

The objective of Task 2 was to identify issues relevant to ASME Section III Subsection NH, and related Code Cases that must be resolved for licensing purposes for Very High Temperature Gas Reactor concepts; and to develop a description of how Subsection NH of the ASME Codes addresses these issues and the further needs to add criteria to cover unresolved safety concerns for HTGR.

The Energy Policy Act (EPACT) of 2005 stated that NGNP shall be licensed by the Nuclear Regulatory Commission (NRC) and by July, 2008 the NRC and DOE shall jointly submit a licensing strategy to Congress. This task directly supports the activities related to the licensing of NGNP.

\section{$\underline{\text { Results }}$}

The task report included the description of (1) NRC and Advisory Committee on Reactor Safety (ACRS) safety concerns raised during the licensing process of the Clinch River Breeder Reactor (CRBR), and other subsequent high temperature reactor concepts, (2) how some of these issues are addressed by the current Subsection NH of the ASME Code; and (3) the material models, design criteria, and analysis methods that need to be added to the ASME Code and Code Cases to cover unresolved regulatory issues for very high temperature service. 


\section{NEXT GENERATION NUCLEAR PLANT \\ INTERMEDIATE HEAT EXCHANGER \\ MATERIALS RESEARCH AND DEVELOPMENT PLAN}

$\begin{array}{ll}\text { Identifier: } & \text { PLN-2804 } \\ \text { Revision: } & 0 \\ \text { Effective Date: } & 04 / 30 / 08\end{array}$

Page: 56 of 156

The NRC and ACRS issues which were raised in conjunction with the licensing of CRBR and the Power Reactor Innovative Small Module (PRISM) Liquid-Metal Reactor, and more recent NRC/RES efforts on licensing issues for high temperature reactors were summarized.

The CRBR license application for a construction permit was approved by NRC, subject to project R\&D activities to address concerns identified by NRC and ACRS. However, due to the abrupt cancellation of the project that led to the cessation of all activities, NRC had not progressed to a point to either approve or disapprove the ASME Code Case N-47, a precursor to Subsection NH, which was the basis for the design of Class 1 pressure-retaining components for elevated temperature service for CRBR. This remains the status of Subsection NH to date.

Table 18, (shown here in the draft form) is being prepared by the NRC staff. It summarizes the current understanding of the licensing concerns by the task investigators, based on the elevated temperature structural integrity issues identified by the NRC licensing review of CRBR. The order is not ranked.

Table 18. Summary of licensing concerns based on elevated temperature structural integrity issues.

\begin{tabular}{|c|c|c|c|c|}
\hline \multirow{2}{*}{$\begin{array}{c}\text { Elevated temperature Structural } \\
\text { Integrity Issues }\end{array}$} & \multicolumn{4}{|c|}{$\begin{array}{l}\text { Priority Level: } \\
\text { (1) issue to be of higher concern or safety significance, } \\
\text { (2) issue addressed by ASME BPV Code or of a lower concern, } \\
\text { (3) issue beyond scope of Subsection NH, } \\
\text { (4) issue considered to be of no concern }\end{array}$} \\
\hline & CRBR & $\begin{array}{c}\text { Pebble-Bed } \\
\text { Reactor ( } \& \text { cold } \\
\text { vessel option for } \\
\text { VHTR) }\end{array}$ & $\begin{array}{l}\text { VHTR (hot } \\
\text { vessel option) }\end{array}$ & Gen IV \\
\hline Transition joints & $(1)$ & (4) & $(1)$ & (1) \\
\hline Weld residual stresses & (1) & (4) & (1) & (1) \\
\hline Design loading combinations & $(1)$ & $(3)$ & $(3)$ & $(3)$ \\
\hline Creep-rupture and fatigue damage & $(1)$ & $(2)$ & $(1)$ & $(1)$ \\
\hline Simplified bounds for creep ratcheting & $(1)$ & $(2)$ & $(1)$ & $(1)$ \\
\hline Thermal striping & $(1)$ & $(2)$ & $(2)$ & $(1)$ \\
\hline $\begin{array}{l}\text { Creep-fatigue analysis of Class } 2 \text { and } \\
3 \text { piping }\end{array}$ & (1) & (2) & (2) & (2) \\
\hline $\begin{array}{l}\text { Are limits of Case N-253 for elevated } \\
\text { temp. Class } 2 \text { and } 3 \text { components met? }\end{array}$ & (1) & $(2)$ & (2) & (2) \\
\hline $\begin{array}{l}\text { Creep buckling under axial } \\
\text { compression - design margins }\end{array}$ & (1) & $(2)$ & (2) & (2) \\
\hline $\begin{array}{l}\text { Identify areas where Appendix T rules } \\
\text { are not met }\end{array}$ & (1) & $(2)$ & (1) & (1) \\
\hline $\begin{array}{l}\text { Rules for component supports at } \\
\text { elevated temperature }\end{array}$ & (1) & $(2)$ & $(2)$ & $(2)$ \\
\hline $\begin{array}{l}\text { Strain and deformation limits at } \\
\text { elevated temperature }\end{array}$ & (1) & $(2)$ & (4) & (1) \\
\hline Evaluation of weldments & $(1)$ & $(1)$ & $(1)$ & (1) \\
\hline $\begin{array}{l}\text { Material acceptance criteria for } \\
\text { elevated temperature }\end{array}$ & (1) & $(2)$ & $(2)$ & (1) \\
\hline $\begin{array}{l}\text { Creep-rupture damage due to forming } \\
\text { and welding }\end{array}$ & (1) & (2) & (1) & (1) \\
\hline
\end{tabular}




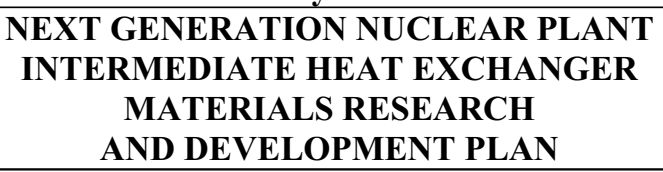

$\begin{array}{ll}\text { Identifier: } & \text { PLN-2804 } \\ \text { Revision: } & 0 \\ \text { Effective Date: } & 04 / 30 / 08\end{array}$

Table 18. (continued).

\begin{tabular}{|c|c|c|c|c|}
\hline \multirow{2}{*}{$\begin{array}{l}\text { Elevated temperature Structural } \\
\text { Integrity Issues }\end{array}$} & \multicolumn{4}{|c|}{$\begin{array}{l}\text { Priority Level: } \\
\text { (1) issue to be of higher concern or safety significance, } \\
\text { (2) issue addressed by ASME BPV Code or of a lower concern, } \\
\text { (3) issue beyond scope of Subsection NH, } \\
\text { (4) issue considered to be of no concern }\end{array}$} \\
\hline & CRBR & $\begin{array}{c}\text { Pebble-Bed } \\
\text { Reactor ( } \& \text { cold } \\
\text { vessel option for } \\
\text { VHTR) }\end{array}$ & $\begin{array}{l}\text { VHTR (hot } \\
\text { vessel option) }\end{array}$ & Gen IV \\
\hline Mass transfer effects & (1) & $(2)$ & $(2)$ & (2) \\
\hline Environmental effects & $(1)$ & $(1),(3)$ & $(1),(3)$ & $(1),(3)$ \\
\hline Fracture toughness criteria & $(1)$ & $(2)$ & $(1)$ & $(1)$ \\
\hline Thermal aging effects & (1) & (1) & $(1)$ & (1) \\
\hline Irradiation effects & $(1)$ & $(1),(3)$ & $(1),(3)$ & $(1),(3)$ \\
\hline $\begin{array}{l}\text { Use of simplified bounding rules at } \\
\text { discontinuities }\end{array}$ & (1) & (1) & (1) & (1) \\
\hline Elastic follow-up & $(1)$ & $(4)$ & (4) & $(4)$ \\
\hline $\begin{array}{l}\text { Design criteria for elevated temp. core } \\
\text { support structures and welds }\end{array}$ & (1) & $(2)$ & $(2)$ & $(1)$ \\
\hline $\begin{array}{l}\text { Elevated temperature data base for } \\
\text { mechanical properties }\end{array}$ & (1) & (1) & (1) & (1) \\
\hline $\begin{array}{l}\text { Basis for leak-before-break at } \\
\text { elevated temperatures }\end{array}$ & (1) & (4) & (1) & (1) \\
\hline
\end{tabular}

The task investigators provided an account on the manner in which NRC licensing issues for the structural design of HTGR and Gen IV systems are addressed in the current ASME Subsection NH and Code Cases. The creep behavior, creep-fatigue, and environmental effects are addressed in Subsection $\mathrm{NH}$ and Code Cases largely in terms of design criteria and allowable stress and strain values. The detailed material properties needed for cyclic finite element creep design analyses are generally not provided in the Code. The NRC perspective is that the Code and/or Code Cases currently do not adequately cover the material behavior under cyclic loads in the creep regime, and creep-fatigue and creep-rupture interaction effects.

It is noted that for CRBR, the guidance on inelastic finite element analyses, external to the Code, was provided in NE F9-5T, Nuclear Standard, Guidelines and Procedures for Design of Class 1 Elevated Temperature Nuclear System Components.

Subsection NH has rules for the design of welded joints separated into categories A through D. The permissible types of welded joints and their dimensional requirements are specified. Paragraph 3353 of Subsection NH provides analysis requirements for the design and location of all pressure retaining welds operating at temperatures where creep effects are significant. Reduction factors for creep stress rupture are given as a function of time and temperature. Permissible weld metals are limited and special examination requirements are imposed.

Probably the most restrictive Subsection NH requirements for welds is that the inelastic accumulated strains are limited to one-half the allowable strain limits for the base metal. This has forced designers to keep welds out of high stress areas. The allowable fatigue at weldments is limited to one-half the design cycles allowed for the base metal. The allowable creep rupture damage at weldments is limited in 


\begin{tabular}{c|lll|}
\hline NEXT GENERATION NUCLEAR PLANT & Identifier: & PLN-2804 & \\
INTERMEDIATE HEAT EXCHANGER & Revision: & 0 & \\
MATERIALS RESEARCH & Effective Date: & $04 / 30 / 08$ & Page: 58 of 156 \\
AND DEVELOPMENT PLAN &
\end{tabular}

Subsection NH by requiring that the rupture strength be reduced by the weld strength reduction factor when determining the time-to-rupture. The Code also imposes additional examination requirements on Category A through D welded joints. The adequacy of these and other Code weldment structural design requirements has been questioned by the NRC, even for the temperatures currently covered, which are lower than the HTGR and Gen IV High Temperature Systems.

Because of the importance of potential elevated temperature cracking of weldments, NRC wanted the designer to account for potential creep strain concentrations due to metallurgical notch effects. Subsection $\mathrm{NH}$ does not include methods for analyzing the effects of varying properties between the base metal, weld metal and Heat Affected Zone (HAZ), or even how to determine these properties after welding and post weld heat treatment. Moreover, NRC expressed concern with potential early crack initiation at the inside wall surface in the HAZ, how crack propagation can be quantified, and the stability of the remaining uncracked wall section.

Methods for evaluating the structural integrity of welds essentially parallel the Section XI flaw evaluation methods which are only applicable below the creep regime. The NRC has also requested confirmation of the creep rupture, creep-fatigue, and interaction evaluation procedures at weldments, accounting for load sequence effects.

Verification testing was carried out on representative structural features of CRBR as part of the licensing effort. HTGR temperatures are much higher than the CRBR temperatures. Existing simplified design analysis methods have proven to be very valuable in providing assurance of structural integrity in the moderate creep regime and have been used in France, Germany, Japan, and the U.S. for this purpose. Cyclic finite element creep analysis results are difficult to trust without having comparative results of simplified design analysis methods.

\section{$\underline{\text { Recommendations (data needs) }}$}

The task report provides a discussion on the material models, design criteria, and analysis methods that need to be added to the ASME Code and Code Cases to cover unresolved regulatory issues for very high temperature service.

Needs for material creep behavior, creep-fatigue and environmental effects:

- Extend temperature and/or time for current code materials to cover HTGR conditions.

- Add new materials to the code to cover HTGR applications.

- Appropriate databases for calculating fatigue, creep, creep-fatigue, and stress corrosion cracking (SCC) lifetimes, including environmental effects of impure helium and crevice concentration.

- Aging behavior of alloys.

- Degradation by carburization, decarburization, and oxidation.

- Sensitization of austenitic alloys and weldments.

Needs for design methods:

- Treatment of connecting pipe as a vessel for code application.

- In-service inspection plans and methods.

- Probabilistic risk assessment methodologies for vessels, pipes, and components. 


\begin{tabular}{c|lll|} 
NEXT GENERATION NUCLEAR PLANT & Identifier: & PLN-2804 & \\
INTERMEDIATE HEAT EXCHANGER & Revision: & 0 & \\
MATERIALS RESEARCH & Effective Date: & $04 / 30 / 08$ & Page: 59 of 156 \\
AND DEVELOPMENT PLAN &
\end{tabular}

Needs for developing methods of evaluating the structural integrity of welds and safety margins:

- Materials models.

- Cyclic creep analysis methods.

- Crack growth analyses.

- Remaining ligament enhanced creep stability analysis methods.

Development and verification of simplified design analysis methods.

Additional verification testing to validate the elevated temperature designs of HTGRs:

- Validation of the material models needed to perform cyclic creep analyses.

- Validation of the finite element software capabilities to handle cyclic creep at structural discontinuities.

- Elastic follow-up.

- Creep rupture at notches.

- Weldment behavior.

- Possibly flaw tolerance evaluation methods.

\section{Task 3: Improvement of Subsection NH Rules for Grade 91 Steel}

Grade 91 steel is not relevant to components considered in this report and will not be discussed here.

\section{Task 4: Update Code Case N-201 to Accommodate HTGRs}

The objective of this task was to expand the scope of code case N-201 to include the materials with higher allowable temperatures or extend the temperature limits of current materials, and to confirm that the design methodology used is acceptable for design of core support structure components at the appropriate elevated temperatures. Task 4 was embarked upon in recognition of the number of ongoing reactor designs utilizing high temperature technology in their designs of metallic core support structures. Update and improvement of Code Case N-201 will support the design effort for core support structures in all three vendor designs for NGNP.

\section{$\underline{\text { Results }}$}

A questionnaire concerning materials of interest and operating conditions for the core support structures of Gen IV high temperature gas-cooled reactors was developed and distributed to PBMR, GA, AREVA, and the Japan Atomic Energy Agency (JAEA). The responses received from PBMR, JAEA, and GA indicated that, the metal temperature for normal operation, are such that the creep effects will be minimal, but still must be considered in the analysis. It was concluded that it should be possible for these designs to make extensive use of the simplified analysis and bounding methods provided in Part B of the applicable Code Case N-201. The design procedures in Part B are essentially the same as Subsection NH. The normal operating metal temperature stated for the high temperature gas reactor metallic core support structures for AREVA is well below the creep range, therefore explicit consideration of creep and stress rupture is not necessary.

The identified off-normal conditions for the HTGR metallic core support structures were in the fringes, where creep effects may also need to be considered. At these short duration elevated temperature conditions, it was concluded that significant creep accelerated crack growth is unlikely. However, proving unlikely growth quantitatively, particularly creep crack growth at weldments and notches might be very difficult. 


\begin{tabular}{c|lll|}
\hline NEXT GENERATION NUCLEAR PLANT & Identifier: & PLN-2804 & \\
INTERMEDIATE HEAT EXCHANGER & Revision: & 0 & \\
MATERIALS RESEARCH & Effective Date: & $04 / 30 / 08$ & Page: 60 of 156 \\
AND DEVELOPMENT PLAN &
\end{tabular}

The identified off-normal conditions for the HTGR metallic core support structures were in the fringes, where creep effects may also need to be considered. At these short duration elevated temperature conditions, it was concluded that significant creep accelerated crack growth is unlikely. However, proving unlikely growth quantitatively, particularly creep crack growth at weldments and notches might be very difficult. Based on the results of the survey, it was concluded that additional work must be done to update Code Case N-201. The results of Task 4 activities provided the framework for the Code Case N-201 update, as well as future work to provide material input.

Since Code Case N-201 "Class CS Components in Elevated Temperature Service," ASME Section III Division 1, has not seen a major revision since December 1994, a comprehensive review of this Code Case was performed against the latest Edition and Addenda of ASME Code Subsection NG and Subsection NH. Many errors, omissions, and substantive questions were identified in Code Case N-201, especially when compared to Subsection NH. This partially stems from the fact that it was issued in essentially its present form 15 to 20 years ago, and has had little, if any, use since then. In conjunction with the preliminary responses and recommended actions to these identified issues, the Task 4 report provided a compilation of these findings for consideration by the ASME Subgroup on Elevated Temperature Design (SG-ETD). Draft recommended changes to the latest issued revision to CC N-201 (i.e., CC N-201-5) were presented as an Appendix to the Task 4 report and transmitted to SG-ETD for comments.

Upon the receipt of the proposed changes to CC N-201-5, SG-ETD had provided the Task 4 team members detailed technical and editorial comments. Actions on these comments are currently being taken by Task 4 as a follow-on task, using the original first round budget.

It is noted that the survey was performed before the vendors (Westinghouse/PBMR, AREVA and GA) had delivered the NGNP preconceptual design reports. The operating conditions stated in the survey were somewhat different than those given for the NGNP preconceptual designs. However, the conclusions from the Task 4 report remain generally valid.

\section{$\underline{\text { Recommendations }}$}

- Obtain experimental data for very long duration loading at the threshold of creep. It was recommended that this issue be addressed as a part of the complete Task 2 effort.

- Add Type 321 and Type 347 austenitic stainless steels and Grade 91 steel to Code Case N-201 for core support construction.

- Add Alloy 718 to Code Case N-201 for threaded structural fasteners.

- Address design life beyond 300,000 hours, especially in consideration of 60-year design life.

- Develop detailed recommended changes to CC N-201 for consideration to ASME SG-ETD.

\section{Task 5: Collect Creep-Fatigue Data and Study Evaluation Procedures for Grade 91 Steel and Hastelloy XR}

Grade 91 steel is not relevant for components considered in this report will not be discussed here. Hastelloy XR was a potential IHX material, although a lack of accessible data because most of the data were generated by JAEA, has eliminated it from consideration. However, the studies reported in this task on Hastelloy XR provide valuable information on the design and materials issues for an IHX with He as a coolant. This information could possibly be used for other Ni-base alloys such as Alloy 617 and Alloy 230 . 


\begin{tabular}{c|lll|}
\hline $\begin{array}{c}\text { NEXT GENERATION NUCLEAR PLANT } \\
\text { INTERMEDIATE HEAT EXCHANGER } \\
\text { MATERIALS RESEARCH }\end{array}$ & Identifier: & PLN-2804 & \\
AND DEVELOPMENT PLAN & Effective Date: & $04 / 30 / 08$ & Page: 61 of 156 \\
\hline
\end{tabular}

\section{Part II. Hastelloy XR}

Material characterizations for Hastelloy XR suggested that special considerations should be made to account for dynamic recrystallization at high temperatures. A new tensile test procedure with a change in strain rate to $100 \% / \mathrm{min}$ at temperatures over $800^{\circ} \mathrm{C}$ to obtain the time-independent elastic-plastic property for Hastelloy XR was proposed. Further material characterization and component-wise structural mechanics research works revealed that design rules for austenitic stainless steels can be applied to Hastelloy XR; therefore, the high temperature structural design guideline was established with reference to the Fast Breeder Reactor (FBR) Design Code.

\section{$\underline{\text { Results }}$}

The High Temperature Structural Design Guideline for HTGR, used for the design of the structural components of the HTTR, is described in the task report. A creep analysis method was established for Hastelloy XR through several Japanese research works, in which the creep equation was generated from Garofalo's version of the time function. It was demonstrated that the strain hardening rule and Von Mises' flow rule are applicable to Hastelloy XR.

Cumulative creep strain and cumulative creep and fatigue damage factors, based on the high temperature structural design guideline for the Hastelloy XR components of the HTTR IHX, were evaluated based on inelastic analysis.

The linear summation rule of cycle and time fractions is applicable to Hastelloy XR with large safety margins, even at very high temperatures. It was suggested that the same conclusion would be expected of other Ni-base superalloys such as Alloy 617 and Alloy 230. However, testing would be required to either confirm this expectation or to suggest the need for developing new methods.

In the design of the IHX for HTTR, inelastic analysis was necessary to evaluate creep strain and creep damage at very high temperatures. Similarly, in the design of high temperature components such as IHX made of Alloy 617 and Alloy 230 for NGNP, inelastic analysis would be inevitable. In the design of HTTR IHX, conventional Garofalo's expression was used as a creep constitutive equation because the high temperature structural design guideline was developed in the 1980s. Since then, significant advances have been made in the development of unified viscoplasticity constitutive equations such as those given by Chaboche, Krempl, Walker, etc. In the future design of high temperature components, use of unified inelastic constitutive equations should be investigated.

Impurities in the primary coolant of the HTTR must be controlled so that primary coolant shall be in the regime where mild carburization occurs. For this purpose, $R \& D$ are underway in the HTTR to develop methods to control the helium purification system. Similarly, research and developments will be needed for future HTGRs on Alloy 617 and Alloy 230 to determine the optimum level of impurities in the primary coolant as well as to control the helium purification system to maintain the optimum level.

\section{$\underline{\text { Recommendations }}$}

- Perform tests to confirm that the linear summation rule of cycle and time fractions is applicable to Alloy 617 and Alloy 230.

- Investigate use of unified inelastic constitutive equations.

- Develop methods to control the helium purification system.

- Determine the optimum level of impurities in the primary coolant. 


\begin{tabular}{c|lll|}
$\begin{array}{c}\text { NEXT GENERATION NUCLEAR PLANT } \\
\text { INTERMEDIATE HEAT EXCHANGER }\end{array}$ & Identifier: & PLN-2804 & \\
MATERIALS RESEARCH & Revision: & 0 & \\
AND DEVELOPMENT PLAN & Effective Date: & $04 / 30 / 08$ & Page: 62 of 156 \\
\hline
\end{tabular}

\subsubsection{Second Round Tasks}

The original twelve topics developed in the DOE Initiative to address ASME Code issues were drafted almost three years ago. With the completion of the NGNP preconceptual design reports from the vendors, a clearer picture of the future NGNP configuration has started to emerge. Thus, the remaining topics from the original list have been re-prioritized, some work scopes have been modified, and new work scopes have been added. Five new tasks in the second round of the DOE Initiative have been agreed upon between DOE and ASME. They are described in the following.

\section{TASK 6: Operating Condition Allowable Stress Values}

A spot check of minimum stress to rupture values provided in $\mathrm{NH}$ revealed that there was disagreement between the minimum stress to rupture values, $S_{r}$, at 100,000 hours and the values of Design Condition stress intensity, $S_{o}$. Based on the allowable stress criteria, the values of $S_{o}$ should be no greater than $80 \%$ of $S_{r}$ at 100,000 hours. However, for all the listed NH materials, at higher temperature there were values of $S_{o}$ which exceeded $80 \%$ of $S_{r}$. In most, if not all cases, the values of $S_{o}$ were significantly higher at some temperatures. Since the NH values of $S_{o}$ are in agreement with the allowable stress values listed in Section II, Part D, the expectation is that the values of $S_{r}$ are lower than would be expected if they were derived from the same data as the values for $S_{o}$. Further, the values of $S_{t}$, the allowable stresses for Operating Conditions, appear consistent with the values of $S_{r}$, thus throwing in doubt all the allowable Operating Condition stress values for both load-controlled stress limits and displacement controlled limits in $\mathrm{NH}$.

Part I will be a review of current values of $S_{r}$ and $S_{o}$ and identification of discrepancies. The same will be done with $S_{t}$ and $S_{r}$. The database(s) used to establish $S_{r}, S_{t}$ and $S_{o}$ must be reviewed and identified. In Part II these assembled databases will be reviewed for completeness and consistency, identifying areas of inconsistency and recommending a course of action to resolve them. This should include additional testing if required. The time and temperature regimes must be identified where the listed values of $S_{t}$ and $S_{r}$ are correct and no further action is required. Finally in part III members will prepare recommended corrections to the currently listed values of $S_{t}$ and $S_{r}$ based on currently available data (where the data is sufficient) for those time/temperature regimes that require corrections. A rough order of magnitude cost estimate for the testing required to complete these corrections will be prepared.

\section{TASK 7: Considerations for the Intermediate Heat Exchanger (IHX)}

The intent of this task is to recommend how and where within ASME codes and standards, the IHX, safety valve, etc. would be addressed and to provide guidance to equipment suppliers on potential critical code issues to be addressed. Part of this determination is the role of the IHX primary to secondary heat exchanger surface in plant licensing considerations. Although the main focus of this activity is on compact, micro channel heat exchangers due to their unique design features, consideration should also be given to plate-fin and shell-and-tube concepts in considering equivalent reliability and assessing critical "construction" issues at very high temperatures representative of HTGR operation. Note that in this context "construction" refers to the full scope of ASME Code rules, namely: materials, design, fabrication and installation, examination and overpressure protection. Inservice examination issues should also be considered.

In Part I the objective is to identify, to the extent feasible, the current status of compact/micro channel heat exchanger "construction" (including aging and coolant corrosion effects where available) of representative heat exchanger pressure-boundary and internal designs. Heat exchangers with working fluid temperatures at the upper end of the creep regime for their materials of construction will be emphasized. Candidate designs should include shell-and-tube, plate-fin, and compact design. Additional 


\begin{tabular}{c|lll|}
\hline $\begin{array}{c}\text { NEXT GENERATION NUCLEAR PLANT } \\
\text { INTERMEDIATE HEAT EXCHANGER }\end{array}$ & Identifier: & PLN-2804 & \\
MATERIALS RESEARCH & Revision: & 0 & \\
AND DEVELOPMENT PLAN & Effective Date: & $04 / 30 / 08$ & Page: 63 of 156 \\
\hline
\end{tabular}

concepts will be identified if possible. This is to be accomplished by soliciting input from component vendors, reactor heat transport system designers and process heat end users. Particular attention will be paid to (a) service experience and problem resolution, (b) design criteria including methods, if any, for evaluation of cyclic life, (c) construction codes of record and designated pressure boundaries, and (d) qualification of materials and fabrication techniques for the intended service.

Once the compact heat exchangers have been assessed, collaborators will recommend key features of a construction code needed to address the unique issues associated with the HTGR IHX and associated equipment. As examples of what might be considered: (a) because the sharp corners associated with many if not all micro channel designs is a key feature, what test(s) should be required to establish cyclic life or to calibrate design methods, and (b) what sort of inspection or process control is required to achieve adequate joint reliability in components with on the order of a million joints and limited accessibility? Candidate Codes to be considered include Subsection NB and NH, Subsection NC and ND and their respective elevated temperature Code Cases and Section VIII, Div 1 and 2. A rough order of magnitude estimate will be prepared for the cost and schedule of implementing the proposed Code approach.

Further, it would be desirable to review the adequacy of existing ASTM specifications for materials, testing, examination, etc. to determine if any new standards will need to be developed to support IHX design, fabrication, operation or inspection. We need to understand in the near term if the ASTM specification infrastructure will also have to be augmented in order to support the new test and inspection requirements for IHX.

\section{TASK 8: Creep and Creep-Fatigue Crack Growth at Structural Discontinuities and Welds}

The lack of a quantitative methodology for evaluating the potential for creep and creep-fatigue crack growth at structural discontinuities and weldments has been identified in NRC reviews as an NH shortcoming. $\mathrm{NH}$ does provide a number of design factors and procedures to ensure elevated temperature weldments and stress risers will perform satisfactorily but does not provide for a quantitative assessment of creep crack growth. Although desirable for design, such a methodology is even more needed for evaluation of potential cracks and crack growth detected during in-service inspection. During the early years of the evolution of the current $\mathrm{NH}$, such methodologies for evaluation of creep crack growth were in their infancy. However, there have been numerous advances in the technology in recent years, for both nuclear and non-nuclear applications. A key issue for nuclear applications is whether these methodologies are sufficiently well established. They must give the required assurances without undue conservatism which would preclude designs and/or operating parameters that are actually not susceptible to premature failure.

In Part I investigators will review currently used methods for creep and creep-fatigue crack growth at discontinuities and in weldments to assess their applicability for design and in-service inspection assessment of NH components. Methods used in other nuclear standards such as R5, RCC-MR and KTA shall be considered as well as those employed in assessments of non-nuclear equipment. Currently approved materials for $\mathrm{NH}$ construction shall be considered as well as potential additions such as Alloy 617 and 230, and a low carbon/high nitrogen version of 316 stainless steel. Identify promising technologies and the testing required to implement the specific methodology in NH. In Part II collaborators will prepare draft rules based on this assessment for implementation in NH. These rules should be based on existing data where feasible.

\section{TASKS 9 \& 10: Update and Improve Subsection NH}

Current design analysis rules in Subsection $\mathrm{NH}$ were developed during the decades ending in the late 1980's. Since then there have been notable advances in computing technology that permit evaluation 


\begin{tabular}{|c|lll|}
\hline NEXT GENERATION NUCLEAR PLANT & Identifier: & PLN-2804 \\
INTERMEDIATE HEAT EXCHANGER & Revision: & 0 & \\
MATERIALS RESEARCH & Effective Date: & $04 / 30 / 08$ & Page: 64 of 156 \\
AND DEVELOPMENT PLAN & ENA
\end{tabular}

methodologies not previously considered. There have also been advances in the understanding of elevated temperature material behavior and failure mechanisms. Also, as shown by the results from Tasks 3 and 5 of the first round DOE/ASME Gen IV Materials Project, the current methodologies for evaluating creepfatigue interaction have a number of deficiencies.

\section{TASK 9: Simplified Elastic and Inelastic Design Analysis Methods}

Review and compare current design methods and assessment techniques in ASME NH, RCC-MR, BC5500, DIN, and JNC, R5, API 579 and other relevant sources. Propose a range of design analysis methods consisting of: (1) elastic analysis, (2) reference stress method, and (3) limit load, shakedown, and ratcheting analysis. Recommend requisite requirements for codification, including data generation, data extrapolation strategies, round-robin structural analyses, and feature testing to validate methods.

\section{TASK 10: Alternative Simplified Creep-Fatigue Design Methods}

Review creep-fatigue methodologies, including damage-based, strain-based, and methods not involving separate accounting of creep and fatigue damage in various design codes, assessment procedures and relevant literatures. Assess the potential of deploying these methods in NH either to remove excessive conservatism or to resolve NH issues identified in the final report of Task 2 . Where applicable, provide rationale and propose implementation strategies for these methods. Propose methods to address the effects of aging, surface conditions, and geometric discontinuity. Recommend requisite requirements for codification, including data generation, data extrapolation strategies, and feature testing to validate methods. 


\begin{tabular}{c|lll|}
\hline $\begin{array}{l}\text { NEXT GENERATION NUCLEAR PLANT } \\
\text { INTERMEDIATE HEAT EXCHANGER }\end{array}$ & Identifier: & PLN-2804 & \\
MATERIALS RESEARCH & Revision: & 0 & \\
AND DEVELOPMENT PLAN & Effective Date: & $04 / 30 / 08$ & Page: 65 of 156 \\
\hline
\end{tabular}

\section{CODE COMPLIANCE/LICENSING ISSUES}

This section addresses issues with code qualification of a material or materials that are common to IHX and other core internals. It also addresses application of the ASME code to design of the IHX and core internals.

\subsection{NRC Structural Integrity Issues}

The ASME Boiler and Pressure Vessels Code Section III, Division 1, Subsections NB, NC, ND, NE, $\mathrm{NF}$, and NG, are incorporated by reference into Section 50.55a of Title 10 of the Code of Federal Regulations (10 CFR 50.55a) as the rules of construction for LWR nuclear power plant components. Section III Code Cases, which provide alternatives to the Section III, Division 1 Code requirements under special circumstances, are reviewed by the NRC staff and its findings are published in the regulatory guides. The acceptable and conditionally acceptable Section III Code Cases listed in the regulatory guides are then incorporated by reference into 10 CFR $50.55 \mathrm{a}$.

While the rules of construction of the ASME Code and Code Cases cover many aspects related to structural integrity, they do not explicitly address issues such as degradation of properties because of service conditions or environment. However, these structural integrity issues are highlighted in the Code and it is the responsibility of the "Owner" to demonstrate to NRC that these additional issues are adequately addressed.

Section III, Subsection NH and its Code Cases contain rules of construction for metallic components under elevated temperature service. Code Case N-47, a precursor to Subsection NH, had been reviewed by NRC during the application of a construction permit by the Clinch River Breeder Reactor (CRBR) Project in the late $70 \mathrm{~s}$ and early $80 \mathrm{~s}$. The licensing process was stopped because of the abrupt cancellation of the CRBR project. However, a list of safety related issues were identified by NRC. NRC had also performed a pre-application safety evaluation of the Power Reactor Innovative Small Module (PRISM) liquid-metal reactor design in the mid 90s and similar issues were raised. These NRC issues have been documented in Task 2 of the DOE/ASME Gen IV project and the task report was summarized in Section 4.2.3.1.

The Code/licensing issues for NGNP can be grouped into two major areas; existing Subsection NH code procedures, and issues that are the responsibility of the "Owner," which would be the NGNP Project. Strategies and plans to address these two areas are to be established in this technology development plan (TDP) to support project schedule. It is important to note that there are added burdens in licensing NGNP as Subsection NH and its Code Cases have not been approved by NRC.

The NGNP elevated temperature metallic components including core internals, control-rod cladding, hot-gas primary piping, and intermediate heat exchangers (IHX) are subject to cyclic service. The CRBR safety related issues identified by NRC are discussed with respect to these NGNP applications. Most of the issues on the NRC list are addressed in one form or another by the current rules in Subsection NH, with the exception of environmental effects, which are considered as the "Owner" responsibility and are beyond the scope of the Code.

An assessment of the NRC issues with respect to the NGNP elevated temperature metallic components and the corresponding recommended actions are given in Table 19. It is noted that the NRC issues list is not ranked relative to the severity of the concerns. 


Idaho National Laboratory
\begin{tabular}{|c|lll|}
\hline NEXT GENERATION NUCLEAR PLANT & Identifier: & PLN-2804 \\
INTERMEDIATE HEAT EXCHANGER & Revision: & 0 & Page: 66 of 156 \\
MATERIALS RESEARCH & Effective Date: & $04 / 30 / 08$ & \\
AND DEVELOPMENT PLAN &
\end{tabular}

Table 19. NRC Issues List from CRBR Review.

\begin{tabular}{|c|c|c|c|}
\hline Issue \# & $\begin{array}{l}\text { Structural Integrity } \\
\text { Issues Identified by } \\
\text { NRC for CRBR }\end{array}$ & $\begin{array}{l}\text { Assessment with Respect to IHX, Hot-gas Piping and } \\
\text { Core Iinternals }\end{array}$ & Required Actions \\
\hline 1 & $\begin{array}{l}\text { Transition joints (i.e., } \\
\text { dissimilar metals) }\end{array}$ & $\begin{array}{l}\text { Code specified approach is to model joint with base } \\
\text { metal properties to the weld centerline, then include } \\
\text { differences in connecting base metal properties in the } \\
\text { weldment stress analysis. }\end{array}$ & $\begin{array}{l}\text { This issue needs to be addressed if such transition } \\
\text { joints are present in the down-selected vendor design } \\
\text { concept. }\end{array}$ \\
\hline 2 & Weld residual stresses & $\begin{array}{l}\text { Not considered in Subsection NH methodology - } \\
\text { current approach implies selection of weld wires and } \\
\text { welding process produce ductile welds and subsequent } \\
\text { load cycling and creep reduce residual stresses. }\end{array}$ & $\begin{array}{l}\text { This is a lower-tier issue for elevated temperature } \\
\text { service. No immediate action is recommended. }\end{array}$ \\
\hline 3 & $\begin{array}{l}\text { Design loading } \\
\text { combinations }\end{array}$ & $\begin{array}{l}\text { Owner/regulator issue - beyond scope of Subsection } \\
\text { NH. }\end{array}$ & This is an action for the reactor vendor. \\
\hline 4 & $\begin{array}{l}\text { Creep-rupture and } \\
\text { fatigue damage }\end{array}$ & This is a valid concern. & $\begin{array}{l}\text { Proposed new work (Task 10) in DOE/ASME Gen } \\
\text { IV project will address this issue. } \\
\text { Recommended testing from Task } 10 \text { will be assessed } \\
\text { and relevant testing will be proposed. } \\
\text { Creep-fatigue tests for Alloy } 617 \text { base metal, weld } \\
\text { metals and weldments are proposed in this TDP. }\end{array}$ \\
\hline 5 & $\begin{array}{l}\text { Simplified bounds for } \\
\text { creep ratcheting }\end{array}$ & This is a valid concern. & $\begin{array}{l}\text { Proposed new work (Task 9) in DOE/ASME Gen IV } \\
\text { project addresses this issue. } \\
\text { Recommended testing from Task } 9 \text { will be assessed } \\
\text { and relevant testing will be proposed. }\end{array}$ \\
\hline 6 & Thermal striping & $\begin{array}{l}\text { Current Subsection NH rules provide framework for } \\
\text { assessment of structural response. Generally, issue is } \\
\text { determining thermal hydraulic response. Not an issue } \\
\text { for gas-cooled reactors. Assess recent R \& D in Japan } \\
\text { for relevance and incorporation. }\end{array}$ & No action is required. \\
\hline
\end{tabular}




Idaho National Laboratory
\begin{tabular}{|c|lll|}
\hline NEXT GENERATION NUCLEAR PLANT & Identifier: & PLN-2804 \\
INTERMEDIATE HEAT EXCHANGER & Revision: & 0 & Page: 67 of 156 \\
MATERIALS RESEARCH & Effective Date: & $04 / 30 / 08$ & \\
AND DEVELOPMENT PLAN & &
\end{tabular}

Table 19. (continued).

\begin{tabular}{|c|c|c|c|}
\hline Issue \# & $\begin{array}{l}\text { Structural Integrity } \\
\text { Issues Identified by } \\
\text { NRC for CRBR }\end{array}$ & $\begin{array}{l}\text { Assessment with Respect to IHX, Hot-gas Piping and } \\
\text { Core Iinternals }\end{array}$ & Required Actions \\
\hline 7 & $\begin{array}{l}\text { Creep-fatigue analysis } \\
\text { of Class } 2 \text { and } 3 \\
\text { piping }\end{array}$ & $\begin{array}{l}\text { As summarized in Section } 4.2 .1 .2 \text {, piping is only } \\
\text { component with Code Case N-253 specified creep- } \\
\text { fatigue analysis procedure. Candidate piping materials } \\
\text { (Alloy } 617 \& 230 \text { ) not covered by this Code Case. }\end{array}$ & $\begin{array}{l}\text { New work in Task } 7 \text { of the DOE/ASME Gen IV } \\
\text { project addresses generic issue of Code rules for } \\
\text { IHX. Approach to Code rule development and } \\
\text { material codification is proposed in this TDP. }\end{array}$ \\
\hline 8 & $\begin{array}{l}\text { Limits of Case N-253 } \\
\text { for elevated } \\
\text { temperature Class } 2 \& \\
3 \text { components met? }\end{array}$ & $\begin{array}{l}\text { Creep-fatigue analysis for piping in Code Case N-253 } \\
\text { only deals with pipe loads and does not default to the } \\
\text { creep-fatigue design-by-analysis procedure in } \\
\text { Subsection NH (see Section 4.2.1.2). }\end{array}$ & $\begin{array}{l}\text { The issue is related to Item } 7 \text { above and will be } \\
\text { addressed collectively. }\end{array}$ \\
\hline 9 & $\begin{array}{l}\text { Creep buckling under } \\
\text { axial compression - } \\
\text { design margins }\end{array}$ & $\begin{array}{l}\text { Code committee responsible for Subsection NH not } \\
\text { aware of any generic issues or inconsistencies within } \\
\text { the creep buckling rules - particularly for thick walled } \\
\text { components. Should consider French concerns; it may } \\
\text { be a local crimpling issue for very large diameter, thin- } \\
\text { walled vessels. }\end{array}$ & $\begin{array}{l}\text { This is a lower-tier issue. No immediate action is } \\
\text { recommended. }\end{array}$ \\
\hline 10 & $\begin{array}{l}\text { Identify areas where } \\
\text { Appendix T rules are } \\
\text { not met }\end{array}$ & $\begin{array}{l}\text { Appendix T provides procedures to determine strain } \\
\text { range using elastic analysis. If these rules can not be } \\
\text { satisfied, additional rules are provided, based on results } \\
\text { of inelastic analyses. However, inelastic analysis } \\
\text { requires detailed constitutive models of material } \\
\text { behavior under time varying loading conditions. For } \\
\text { the CRBR these behavioral models were based on } \\
\text { Nuclear Standard NE F9-5T. Standards no longer } \\
\text { maintained and numerous technical developments } \\
\text { made since. Development of material models for } \\
\text { materials not currently covered or for temperatures } \\
\text { beyond original range of verification will be } \\
\text { considerable effort. }\end{array}$ & $\begin{array}{l}\text { Development of experimentally verified unified } \\
\text { constitutive model for Alloy } 617 \text { is among highest } \\
\text { priority recommended actions. Will provide inelastic } \\
\text { analysis tools for components like IHX expected to } \\
\text { have low design margins in critical locations. Also } \\
\text { provides "gold standard" to benchmark simplified } \\
\text { methods to be developed under new tasks of } \\
\text { DOE/ASME Gen IV project. } \\
\text { Establishment of guidelines similar to Nuclear } \\
\text { Standard NE F9-5T, developed specifically for high } \\
\text { temperature design of liquid metal fast breeder } \\
\text { reactor components, is recommended in this TDP. }\end{array}$ \\
\hline
\end{tabular}




Idaho National Laboratory
\begin{tabular}{|c|lll|}
\hline NEXT GENERATION NUCLEAR PLANT & Identifier: & PLN-2804 \\
INTERMEDIATE HEAT EXCHANGER & Revision: & 0 & Page: 68 of 156 \\
MATERIALS RESEARCH & Effective Date: & $04 / 30 / 08$ & \\
AND DEVELOPMENT PLAN & &
\end{tabular}

Table 19. (continued).

\begin{tabular}{|c|c|c|c|}
\hline Issue \# & $\begin{array}{l}\text { Structural Integrity } \\
\text { Issues Identified by } \\
\text { NRC for CRBR }\end{array}$ & $\begin{array}{l}\text { Assessment with Respect to IHX, Hot-gas Piping and } \\
\text { Core Iinternals }\end{array}$ & Required Actions \\
\hline 11 & $\begin{array}{l}\text { Rules for component } \\
\text { supports at elevated } \\
\text { temperature }\end{array}$ & $\begin{array}{l}\text { Rules are provided in Code Case N- } 201 \text { for Core } \\
\text { Support Structures. Supports other than core support } \\
\text { structures are not covered in the creep regime nor has } \\
\text { there been any indication that they need be. }\end{array}$ & $\begin{array}{l}\text { As summarized in Section } 4.2 .3 .1 \text {, this has been } \\
\text { addressed in Task } 4 \text { of the DOE/ASME Gen IV } \\
\text { project. Code Case N-201-5 has been updated to } \\
\text { make it consistent with current Code edition of } \\
\text { Subsection NH and has been forwarded to relevant } \\
\text { Code committees for action. } \\
\text { No immediate action is required. }\end{array}$ \\
\hline 12 & $\begin{array}{l}\text { Strain and } \\
\text { deformation limits at } \\
\text { elevated temperature }\end{array}$ & $\begin{array}{l}\text { Extrapolation of creep-fatigue data is a challenge, } \\
\text { particularly at the extremes of the creep regime. At the } \\
\text { low temperature end the concern involves the } \\
\text { definition of negligible creep and at the very high } \\
\text { temperature end one of the issues is whether plasticity } \\
\text { and creep can be separated. The major issues identified } \\
\text { for Subsection NH is that NH is too conservative for } \\
\text { materials such as Grade } 91 \text { steel, particularly with } \\
\text { respect to other international codes. }\end{array}$ & $\begin{array}{l}\text { Creep and creep-fatigue testing for Alloy } 617 \text { to } \\
\text { support development of design rules with appropriate } \\
\text { conservatism is proposed in this TDP. }\end{array}$ \\
\hline 13 & $\begin{array}{l}\text { Evaluation of } \\
\text { weldments }\end{array}$ & $\begin{array}{l}\text { A number of provisions in Subsection NH and related } \\
\text { documents assure reliable weld joints. NH methods } \\
\text { exceed current requirements for nonnuclear } \\
\text { applications as well as nuclear applications below the } \\
\text { creep regime. }\end{array}$ & $\begin{array}{l}\text { The issue of creep and creep-fatigue crack growth in } \\
\text { geometric (notches) and material (welds) } \\
\text { discontinuities will be addressed in Task } 8 \text { of the } \\
\text { DOE/ASME Gen IV project. } \\
\text { Recommended testing from this task will be assessed } \\
\text { and relevant testing will be proposed. }\end{array}$ \\
\hline
\end{tabular}




Idaho National Laboratory
\begin{tabular}{|c|lll|}
\hline NEXT GENERATION NUCLEAR PLANT & Identifier: & PLN-2804 \\
INTERMEDIATE HEAT EXCHANGER & Revision: & 0 & Page: 69 of 156 \\
MATERIALS RESEARCH & Effective Date: & $04 / 30 / 08$ & \\
AND DEVELOPMENT PLAN & &
\end{tabular}

Table 19. (continued).

\begin{tabular}{|c|c|c|c|}
\hline Issue \# & $\begin{array}{l}\text { Structural Integrity } \\
\text { Issues Identified by } \\
\text { NRC for CRBR }\end{array}$ & $\begin{array}{l}\text { Assessment with Respect to IHX, Hot-gas Piping and } \\
\text { Core Iinternals }\end{array}$ & Required Actions \\
\hline 14 & $\begin{array}{l}\text { Material acceptance } \\
\text { criteria for elevated } \\
\text { temperature }\end{array}$ & $\begin{array}{l}\text { A } 60 \text {-year design life at } 850-950^{\circ} \mathrm{C} \text { for the candidate } \\
\text { IHX materials such as Alloy } 617 \text { and Alloy is very } \\
\text { challenging. The reliability of extrapolating shorter } \\
\text { term data to various design life times for Alloy } 617 \text {, } \\
\text { Alloy } 230 \text {, and Alloy } 800 \mathrm{H} \text { is a valid issue. } \\
\text { The ability to demonstrate confidence in using } \\
\text { accelerated test data to predict performance for NGNP } \\
\text { design life time is paramount for licensing success. }\end{array}$ & $\begin{array}{l}\text { Task } 1 \text { of the DOE/ASME Gen IV project addresses } \\
\text { the issue of extending the stress allowables for Alloy } \\
800 \mathrm{H} \text { and its associated weldments. The testing } \\
\text { recommended in the task report has been assessed } \\
\text { and is proposed in this TDP. } \\
\text { A two-pronged approach is needed: (1) develop a } \\
\text { strategy to generate longer-term data, (2) leverage } \\
\text { the advancement in understanding of deformation } \\
\text { and failure mechanisms to transition from current } \\
\text { empirical practice in the Code to a more science- } \\
\text { based approach. } \\
\text { A long-term aging facility is proposed in this TDP } \\
\text { for performing very long-term, aging, creep rupture, } \\
\text { crack growth tests to address this issue. }\end{array}$ \\
\hline 15 & $\begin{array}{l}\text { Creep-rupture damage } \\
\text { due to forming and } \\
\text { welding }\end{array}$ & $\begin{array}{l}\text { This issue is also covered under Issue } 2 \text {. Issues related } \\
\text { to forming/cold work are addressed in NH- } 4000 \text {. }\end{array}$ & $\begin{array}{l}\text { This needs to be addressed as part of the Code Case } \\
\text { for new Subsection NH Code material. } \\
\text { Cold worked material was excluded from the Draft } \\
\text { Alloy } 617 \text { Code Case because of possible } \\
\text { recrystallization during elevated temperature service. } \\
\text { It will also be excluded from new Alloy } 617 \text { Code } \\
\text { Case because of concerns of reduced tensile ductility. }\end{array}$ \\
\hline 16 & Mass transfer effects & $\begin{array}{l}\text { This is an issue for liquid metal and molten salt } \\
\text { reactors but not for gas-cooled (helium) reactor. }\end{array}$ & No action is required. \\
\hline 17 & Environmental effects & $\begin{array}{l}\text { This is an important area not covered by specific code } \\
\text { rules in Subsection NH. This is an Owner/regulator } \\
\text { issue. }\end{array}$ & $\begin{array}{l}\text { Testing of Alloy } 617 \text { in NGNP coolant (helium) } \\
\text { chemistry is proposed in this TDP. }\end{array}$ \\
\hline
\end{tabular}




Idaho National Laboratory
\begin{tabular}{|c|lll|}
\hline NEXT GENERATION NUCLEAR PLANT & Identifier: & PLN-2804 \\
INTERMEDIATE HEAT EXCHANGER & Revision: & 0 & Page: 70 of 156 \\
MATERIALS RESEARCH & Effective Date: & $04 / 30 / 08$ & \\
AND DEVELOPMENT PLAN & &
\end{tabular}

Table 19. (continued).

\begin{tabular}{|c|c|c|c|}
\hline Issue \# & $\begin{array}{l}\text { Structural Integrity } \\
\text { Issues Identified by } \\
\text { NRC for CRBR }\end{array}$ & $\begin{array}{l}\text { Assessment with Respect to IHX, Hot-gas Piping and } \\
\text { Core Iinternals }\end{array}$ & Required Actions \\
\hline 18 & $\begin{array}{l}\text { Fracture toughness } \\
\text { criteria }\end{array}$ & $\begin{array}{l}\text { The formation of embrittling phases, e.g., gamma } \\
\text { prime, during long-term thermal exposure of Alloy } 617 \\
\text { in a certain temperature range (below the intended } \\
\text { steady state operating temperature for IHX } \\
\text { components) has a negative impact on the toughness. }\end{array}$ & $\begin{array}{l}\text { A combination of toughness testing on thermally } \\
\text { exposed compact-tension specimens and } \\
\text { thermodynamics modeling of the formation of } \\
\text { embrittling phases over the service lifetime is } \\
\text { needed; testing is proposed in this TDP to } \\
\text { characterize the fracture toughness degradation due } \\
\text { to thermal aging. }\end{array}$ \\
\hline 19 & Thermal aging effects & $\begin{array}{l}\text { Thermal aging effects on stress allowables are } \\
\text { addressed in Subsection NH. Thermal aging and cyclic } \\
\text { softening are important issues for creep-fatigue } \\
\text { evaluation. }\end{array}$ & $\begin{array}{l}\text { Creep-fatigue evaluation methods for dealing with } \\
\text { these issues are addressed in the DOE/ASME Gen } \\
\text { IV project. } \\
\text { A test plan is proposed in this TDP to address } \\
\text { modeling of thermal aging in unified constitutive } \\
\text { equations for Alloy } 617 \text {. } \\
\text { Testing to address thermal aging effect on yield and } \\
\text { tensile strengths for } 617 \text { is proposed in this TDP. }\end{array}$ \\
\hline 20 & Irradiation effects & $\begin{array}{l}\text { This is an important area not covered by specific Code } \\
\text { rules in Subsection NH. This is an Owner/regulator } \\
\text { issue and is relevant for the metallic cladding of the } \\
\text { control rods. }\end{array}$ & $\begin{array}{l}\text { Action is proposed in the TDP to address irradiation } \\
\text { effects for core internals. }\end{array}$ \\
\hline 21 & $\begin{array}{l}\text { Use of simplified } \\
\text { bounding rules at } \\
\text { discontinuities }\end{array}$ & $\begin{array}{l}\text { This important issue is the subject of ongoing } R \& D \\
\text { efforts. }\end{array}$ & $\begin{array}{l}\text { Similar to Issue 5, this will be addressed by the } \\
\text { proposed work (Task 9) in the DOE/ASME Gen IV } \\
\text { project. } \\
\text { Recommended testing from this task will be assessed } \\
\text { and relevant testing will be proposed. }\end{array}$ \\
\hline
\end{tabular}




Idaho National Laboratory
\begin{tabular}{|c|lll|}
\hline NEXT GENERATION NUCLEAR PLANT & Identifier: & PLN-2804 \\
INTERMEDIATE HEAT EXCHANGER & Revision: & 0 & Page: 71 of 156 \\
MATERIALS RESEARCH & Effective Date: & $04 / 30 / 08$ & \\
AND DEVELOPMENT PLAN & &
\end{tabular}

Table 19. (continued).

\begin{tabular}{|c|c|c|c|}
\hline Issue \# & $\begin{array}{l}\text { Structural Integrity } \\
\text { Issues Identified by } \\
\text { NRC for CRBR }\end{array}$ & $\begin{array}{l}\text { Assessment with Respect to IHX, Hot-gas Piping and } \\
\text { Core Iinternals }\end{array}$ & Required Actions \\
\hline 22 & Elastic follow-up & $\begin{array}{l}\text { This is part of Issue } 21 \text { as accounting for the effects of } \\
\text { elastic follow-up is a significant part of simplified } \\
\text { bounding rules. }\end{array}$ & $\begin{array}{l}\text { Similar to Issues } 5 \text { and } 21 \text {, this will be addressed by } \\
\text { the proposed work (Task } 9 \text { ) in the DOE/ASME Gen } \\
\text { IV project. } \\
\text { Recommended testing from this task will be assessed } \\
\text { and relevant testing will be proposed. }\end{array}$ \\
\hline 23 & $\begin{array}{l}\text { Design criteria for } \\
\text { elevated temperature } \\
\text { core support structures } \\
\text { and welds }\end{array}$ & $\begin{array}{l}\text { The elevated temperature core support rules where } \\
\text { creep is significant are based on Subsection NH. } \\
\text { The duration and temperature for the stress allowables } \\
\text { of candidate core structural materials need to be } \\
\text { increased. }\end{array}$ & $\begin{array}{l}\text { There is an ongoing effort to directly reference } \\
\text { Subsection NH for much of the N-201 data and rules } \\
\text { through the Task } 4 \text { work of the DOE/ASME Gen IV } \\
\text { project. } \\
\text { Task } 1 \text { of the DOE/ASME Gen IV project has } \\
\text { addressed this issue for Alloy } 800 \mathrm{H} \text { and its } \\
\text { weldment. } \\
\text { Recommended test matrix from Task } 1 \text { will be } \\
\text { assessed and relevant testing will be proposed. }\end{array}$ \\
\hline 24 & $\begin{array}{l}\text { Elevated temperature } \\
\text { data base for } \\
\text { mechanical properties }\end{array}$ & This issue is similar to Issues $13,14,18,19$ and 23 . & $\begin{array}{l}\text { This and the related issues need to be addressed in an } \\
\text { integrated manner. }\end{array}$ \\
\hline 25 & $\begin{array}{l}\text { Basis for leak-before- } \\
\text { break at elevated } \\
\text { temperatures }\end{array}$ & This is closely related to Issues 13 and 18 . & $\begin{array}{l}\text { This needs to be addressed together with Issues } 13 \\
\text { and } 18 \text { in an integrated manner. }\end{array}$ \\
\hline
\end{tabular}




\begin{tabular}{c|lll|}
\hline $\begin{array}{c}\text { NEXT GENERATION NUCLEAR PLANT } \\
\text { INTERMEDIATE HEAT EXCHANGER }\end{array}$ & Identifier: & PLN-2804 & \\
MATERIALS RESEARCH & Revision: & 0 & \\
AND DEVELOPMENT PLAN & Effective Date: & $04 / 30 / 08$ & Page: 72 of 156 \\
\hline
\end{tabular}

\subsection{Strategy to Support Code and Licensing Needs}

The elevated temperature design analysis methodologies in Subsection NH are predicated on the concept of protection against applicable structural failure modes. Stress and deformation states for different component geometries and load and temperature histories are obtained by elastic and inelastic analyses. These analysis results are parsed into different categories and compared against different deformation and failure criteria to ascertain the structural integrity.

Unlike the design-by-rule methods, which are applicable only to specific component geometry and loading, the design-by-analysis methodology of Subsection NH provides a more general approach to the structural design of elevated temperature components. This is illustrated by the treatment of elevated temperature core support structures where the applicable structural failure modes are judged to be similar to those considered in Subsection NH. This provides the technical basis for which appropriately adaptated Subsection NH design-by-analysis procedures are used in Code Case N-201 for elevated temperature core support structures even though they are not necessarily pressure-boundary components or shell-like geometries.

For IHX components, there are added burdens in the design analyses because of the geometric complexity of some IHX designs. But the same basic approach of Subsection NH can be employed for the IHX designs in guarding against structural failure modes. Such a design-by-analysis approach for elevated temperature IHX components would have the advantage that the resulting design criteria are applicable to different IHX design concepts. Detailed design analyses would address the structural integrity issues of specific design features of a down-selected IHX concept. Thus, work to establish an Alloy 617 Code Case can be initiated immediately so the project schedule can be supported.

IHX design studies are currently being pursued by different reactor vendors where broad spectrums of design concepts ranging from relatively thick to very thin component cross-sections are being considered. The desirable grain size varies with product form required for the IHX design. A minimum number of grains are required through the cross-section to achieve average material properties that are representative of those in a test database from which design stress allowables are developed. However, the grain size has a strong influence on the tensile and creep strengths, and hence design stress allowables. This poses a dilemma in developing a testing campaign because a down-selection of the IHX design concepts has not been made. The pros and cons of various strategies had been delineated, ${ }^{55}$ but without a clear path to success.

A different paradigm is recommended herein as a path forward to address data needs of the design and the eventual license approval of elevated temperature hot-gas piping and IHX components while adhering to the project schedule. The key elements of the new strategy involve:

1. Leverage standard grain size Alloy 617 databases:

a. Currently assessable databases:

(1) Huntington Alloys database where the ASME Draft Alloy 617 Code Case was based.

(2) General Electric database from the DOE HTGR Program.

(3) The ORNL dataset.

b. Needed database acquisition:

(1) Petten (data from the German HTGR program of the 80s).

(2) European Creep Collaborative Committee (ECCC) databases. 


\begin{tabular}{|c|lll|}
\hline NEXT GENERATION NUCLEAR PLANT & Identifier: & PLN-2804 \\
INTERMEDIATE HEAT EXCHANGER & Revision: & 0 & Page: 73 of 156 \\
MATERIALS RESEARCH & Effective Date: & $04 / 30 / 08$ & PNE \\
AND DEVELOPMENT PLAN &
\end{tabular}

c. Potential additional Alloy 617 databases: from signatory members of the Gen IV International Forum (GIF) Metals and Design Methods Working Group.

2. Start test program in earnest to fill data gap in the above aggregate database for standard grain size.

3. Develop smaller database for Alloy 617 product forms with small grain sizes to establish grain size rupture factors for stress allowables for Code use.

The aggregate Alloy 617 database for standard grain size material from Item 1 above will be used to develop interim design allowable stresses to support conceptual and preliminary design activities. Confirmatory data developed from Item 2 will be used to support final design activities and final license approval. Therefore, the pursuant of Items 1 and 2 would allow the early project need dates to be met, and also would afford the project time to generate needed long-term data to fill any data gaps and to support final license approval. This new strategy should also provide relief in testing requirements as compared with the enormous task of codifying a new elevated temperature material.

The concept of developing grain size rupture factors for stress allowables follows the approach employed in Subsection NH for the treatment of strength of weldments. The strategy is to leverage the larger Alloy 617 standard grain size database to determine reduction factors using a smaller database from reduced grain size product forms. However, the creep rupture strength of Alloy 617 could be significantly reduced for small grain size material as discussed in Section 6.2. The creep rupture strength envelope for small grain-sized product form of Alloy 617 has not been mapped out. A scoping study is proposed in Section 8.1.6 for this purpose.

The success of this new strategy relies heavily on accomplishing item $1 \mathrm{~b}$. The detailed plan for waging such a campaign will be described in Section 8.1.

\subsection{Alloy 617 Code Case}

\subsubsection{Actions for 617 Code Case (Standard Grain Size)}

As reviewed in Section 4.2.1.3, it took six years for the ASME Ad Hoc Task Force to develop the Draft Alloy 617 Code Case, using Alloy 617 data that had already been generated by the materials vendor Huntington Alloys, and DOE contractor General Electric through the HTGR Program. The extended development time was in part caused by a significant difference in the elevated temperature deformation behavior of Alloy 617 from 304 and 316 stainless steels; as many procedures in Code Case N-47, the fore-runner of Subsection NH, were established based on the behavior of 304 and 316 stainless steels.

A Code Case for a new class of Subsection NH material such as Alloy 617 involves more than just establishing the stress allowables. The full scope of ASME Code rules of construction: materials, design, fabrication and installation, examination, and overpressure protection, need to be considered.

When the DOE programs supporting the need for the Code Case were canceled, the progression of the draft Code Case through the ASME Code Committees was halted. A number of issues to be resolved were identified at that time, ${ }^{56}$ and additional issues have emerged since. The issues identified by Blass and Corum $^{56}$ are shown in Table 20. Additional issues that need to be addressed to bring the construction rules in the Code Case up-to-date with the current edition of Subsection NH are given in Table 21. Some significant issues that are raised recently and required immediate actions are provided in Table 22 . Finally, Table 23 has issues that require action for Alloy $800 \mathrm{H}$. 


\begin{tabular}{|c|lll|}
\hline NEXT GENERATION NUCLEAR PLANT & Identifier: & PLN-2804 \\
INTERMEDIATE HEAT EXCHANGER & Revision: & 0 & Page: 74 of 156 \\
MATERIALS RESEARCH & Effective Date: & $04 / 30 / 08$ & \\
AND DEVELOPMENT PLAN &
\end{tabular}

\subsubsection{Implication of Code Class Designation for Alloy 617 Code Case}

As mentioned in Section 4.2.1, a decision on the Code Class designation of NGNP hot-gas piping and IHX components has not been made. Designation of Code Classes for nuclear components by the Owner is based on assessment of public safety as implemented through system safety criteria and regulatory guidelines. Class designation probably would not be required by NRC if there is truly no public or plant operator safety implication owing to structural failure of these components. However, even under such a scenario, the Owner could still decide to assign a Class designation for these components for plant reliability consideration.

Irrespective of whether a component is designated by the Owner as Class 1, 2, or 3, or having no designation at all, based on the assessment of public safety implication, the structural failure modes for the component would remain the same, granted that implementing safety systems for these Code Classes could be different. As the Alloy 617 Code Case will be built on the foundation of protection against structural failure modes using the design-by-analysis approach, the resulting construction rules would be mostly independent of Code Classes. Thus, work to establish an Alloy 617 Code Case could be initiated before the issue on Code Class designation of these elevated temperature components is resolved. In fact, to support the project schedule, it is recommended that test programs for this Code Case be initiated as soon as possible. 
Form 412.09 (Rev. 10)

Idaho National Laboratory
\begin{tabular}{|c|lll|}
\hline NEXT GENERATION NUCLEAR PLANT & Identifier: & PLN-2804 \\
INTERMEDIATE HEAT EXCHANGER & Revision: & 0 & Page: 75 of 156 \\
MATERIALS RESEARCH & Effective Date: & $04 / 30 / 08$ & \\
AND DEVELOPMENT PLAN &
\end{tabular}

Table 20. Issues originally identified for the Draft Alloy 617 Code Case.

\begin{tabular}{|c|c|c|c|}
\hline $\begin{array}{l}\text { Item ID } \\
\text { Priority }\end{array}$ & $\begin{array}{c}\text { Description (Relevant } \\
\text { Sections of Subsection NH) }\end{array}$ & Assessment & Required Actions \\
\hline \multicolumn{4}{|c|}{ A. Actions to complete the Draft Code Case } \\
\hline A1 & \multirow{2}{*}{$\begin{array}{l}\text { Include Alloy } 617 \text { allowable } \\
\text { stresses in Section II for } \\
\text { Subsection NB application } \\
(\mathrm{NH}-2121(\mathrm{a})) \text {. }\end{array}$} & \multirow{2}{*}{$\begin{array}{l}\text { This action is necessary as the Code construction rules for } \\
\text { metal temperatures below } 427^{\circ} \mathrm{C} \text { are in Subsection NB. }\end{array}$} & \multirow{2}{*}{$\begin{array}{l}\text { Execution strategy is proposed in } \\
\text { this TDP. }\end{array}$} \\
\hline High & & & \\
\hline $\mathrm{A} 2$ & \multirow{2}{*}{$\begin{array}{l}\text { Add weld strength reduction } \\
\text { factors }(\mathrm{NH}-3221(\mathrm{~b})(2))\end{array}$} & \multirow{2}{*}{$\begin{array}{l}\text { This is necessary as the weld strength reduction factors (also } \\
\text { referred to as stress rupture factors for welds) are relied upon } \\
\text { in Subsection NH for the treatment of weldments. }\end{array}$} & \multirow{2}{*}{$\begin{array}{l}\text { Initiate test program immediately. } \\
\text { Long-term creep rupture tests } \\
\text { involved. }\end{array}$} \\
\hline V.High & & & \\
\hline A3 & \multirow{2}{*}{$\begin{array}{l}\text { Add mean and instantaneous } \\
\text { thermal expansion } \\
\text { coefficients }(\mathrm{NH}-3214.3(\mathrm{e})) \text {. }\end{array}$} & \multirow[t]{2}{*}{ These are required design data. } & \multirow{2}{*}{$\begin{array}{l}\text { Obtain from vendor datasheet or } \\
\text { propose testing. }\end{array}$} \\
\hline High & & & \\
\hline A4 & \multirow{2}{*}{$\begin{array}{l}\text { Complete isochronous } \\
\text { stress-strain curves in } \\
\text { temperature range } 427^{\circ} \mathrm{C}- \\
1000^{\circ} \mathrm{C}(\mathrm{NH}-3214.3(\mathrm{a}), \mathrm{T}- \\
1332(\mathrm{~b}), \mathrm{T}-1432(\mathrm{c}), \mathrm{T}- \\
1433(\mathrm{a})(2) \text { and } \mathrm{T}-1800)\end{array}$} & \multirow[t]{2}{*}{$\begin{array}{l}\text { Required design information missing from the Draft Alloy } 617 \\
\text { Code Case because of lack of data }\end{array}$} & \multirow{2}{*}{$\begin{array}{l}\text { Required isochronous stress-strain } \\
\text { curves will be established using to- } \\
\text { be-developed unified constitutive } \\
\text { model (see C1). }\end{array}$} \\
\hline High & & & \\
\hline
\end{tabular}


Form 412.09 (Rev. 10)

Idaho National Laboratory
\begin{tabular}{|c|lll|}
\hline NEXT GENERATION NUCLEAR PLANT & Identifier: & PLN-2804 \\
INTERMEDIATE HEAT EXCHANGER & Revision: & 0 & Page: 76 of 156 \\
MATERIALS RESEARCH & Effective Date: & $04 / 30 / 08$ & \\
AND DEVELOPMENT PLAN &
\end{tabular}

Table 20. (continued).

\begin{tabular}{|c|c|c|c|}
\hline Item ID & Description (Relevant & \multirow[b]{2}{*}{ Assessment } & \multirow[b]{2}{*}{ Required Actions } \\
\hline Priority & Sections of Subsection NH) & & \\
\hline \multicolumn{4}{|c|}{ B. Materials data needs } \\
\hline B1 & \multirow{2}{*}{$\begin{array}{l}\text { Weldment creep-fatigue data } \\
(\mathrm{T}-1715) \text {. }\end{array}$} & \multirow[b]{2}{*}{$\begin{array}{l}\text { Data are needed primarily to verify that creep-fatigue } \\
\text { interaction diagram for base metal also applies to weldments. } \\
\text { Ascertain that weldment creep-fatigue performance is no } \\
\text { worse than parent base metal, "normalized" for lower creep } \\
\text { rupture strength of weldment. Validate design evaluation } \\
\text { methodology. } \\
\text { Address NRC's basic concerns about weldment creep crack } \\
\text { growth etc., to verify overall conservatism of the design } \\
\text { process. }\end{array}$} & \multirow{2}{*}{$\begin{array}{l}\text { A test program is proposed in this } \\
\text { TDP. }\end{array}$} \\
\hline V.High & & & \\
\hline $\mathrm{B} 2$ & \multirow[t]{2}{*}{$\begin{array}{l}\text { Environmental effects (NH- } \\
1110(\mathrm{e}) \text { and NH-2160(a)). }\end{array}$} & $\begin{array}{l}\text { Environmental effects assigned to Owner (NGNP Project). } \\
\text { Code also requires that these effects be included in design } \\
\text { specification. } \\
\text { This issue expected to be high on NRC priority list. } \\
\text { Awareness of environmental effects heightened owing to } \\
\text { problems in LWRs. }\end{array}$ & \multirow[t]{2}{*}{$\begin{array}{l}\text { Efforts on carburization, } \\
\text { decarburization, and oxidation } \\
\text { (including internal) in NGNP } \\
\text { helium are proposed in this TDP. }\end{array}$} \\
\hline V.High & & $\begin{array}{l}\text { Subsection NH rules based on air environment. NGNP } \\
\text { environment is likely to be slightly oxidizing, so data in air are } \\
\text { applicable. Slightly oxidizing envelope for NGNP helium } \\
\text { chemistry developed. Data and supporting information needed } \\
\text { to support licensing and for Code committees' consideration, } \\
\text { so Alloy } 617 \text { Code Case rules do not preclude NGNP } \\
\text { applications. }\end{array}$ & \\
\hline
\end{tabular}


Form 412.09 (Rev. 10)

Idaho National Laboratory
\begin{tabular}{|c|lll|}
\hline NEXT GENERATION NUCLEAR PLANT & Identifier: & PLN-2804 \\
INTERMEDIATE HEAT EXCHANGER & Revision: & 0 & Page: 77 of 156 \\
MATERIALS RESEARCH & Effective Date: & $04 / 30 / 08$ & \\
AND DEVELOPMENT PLAN &
\end{tabular}

Table 20. (continued).

\begin{tabular}{|c|c|c|c|}
\hline Item ID & \multirow{2}{*}{$\begin{array}{c}\text { Description (Relevant } \\
\text { Sections of Subsection NH) }\end{array}$} & \multirow[b]{2}{*}{ Assessment } & \multirow[b]{2}{*}{ Required Actions } \\
\hline Priority & & & \\
\hline B3 & \multirow{2}{*}{$\begin{array}{l}\text { Synergistic effect of aging, } \\
\text { environment, loading and } \\
\text { temperature (NH-1110(e) } \\
\text { and NH-2160(a)). }\end{array}$} & \multirow{2}{*}{$\begin{array}{l}\text { Provide better understanding of potential synergistic effect of } \\
\text { these variables and determine if additional conservatism is } \\
\text { required in Code rules. } \\
\text { Initiate small program to examine possible difference in } \\
\text { microstructures for Alloy } 617 \text { samples that are aged (1) in air } \\
\text { only, (2) in NGNP environment, (3) under load in air, i.e., } \\
\text { creep and stress relaxation tests, and (4) under load in NGNP } \\
\text { helium. }\end{array}$} & \multirow{2}{*}{$\begin{array}{l}\text { Microstructural examination of } \\
\text { relevant samples collected from } \\
\text { other testing programs proposed in } \\
\text { the TDP will be performed. }\end{array}$} \\
\hline High & & & \\
\hline B4 & \multirow[t]{2}{*}{$\begin{array}{l}\text { Effects of aging on } \\
\text { toughness (NH-3241(a)). }\end{array}$} & \multirow{2}{*}{$\begin{array}{l}\text { Currently toughness requirement for long-term elevated } \\
\text { temperature service is highlighted in the Draft Code Case, but } \\
\text { without specific guidance or design procedure. The NGNP } \\
\text { Project would need to demonstrate to NRC that this is } \\
\text { satisfied. }\end{array}$} & $\begin{array}{l}\text { Toughness testing on thermally } \\
\text { aged compact tension specimens } \\
\text { will be proposed in this TDP. }\end{array}$ \\
\hline High & & & $\begin{array}{l}\text { Must immediately start thermal } \\
\text { aging exposures for different heats } \\
\text { of Alloy } 617 \text { in autoclaves. }\end{array}$ \\
\hline \multicolumn{4}{|c|}{ C. Design methodology issues } \\
\hline $\mathrm{C} 1$ & \multirow[t]{2}{*}{$\begin{array}{l}\text { Unified constitutive material } \\
\text { model for design analysis } \\
(\mathrm{NH}-3214.2) \text {. }\end{array}$} & \multirow{2}{*}{$\begin{array}{l}\text { This is key technology requirement that would provide } \\
\text { necessary inelastic design analysis tool for the design-by- } \\
\text { analysis approach of Alloy } 617 \text { Code Case to support the } \\
\text { range of possible IHX concepts. Also would serve as "gold } \\
\text { standard" in assessing adequacy of simplified methods to be } \\
\text { developed. } \\
\text { Unified constitutive material model for Alloy } 617 \text { and its finite } \\
\text { element implementation and design analyses guidance would } \\
\text { support the establishment of new guideline similar to Nuclear } \\
\text { Standard NE F9-5T. }\end{array}$} & $\begin{array}{l}\text { Support development of unified } \\
\text { constitutive material model and } \\
\text { finite element implementation for } \\
\text { inelastic design analyses as } \\
\text { proposed in the TDP. }\end{array}$ \\
\hline V.High & & & $\begin{array}{l}\text { Qualification of unified constitutive } \\
\text { model by comparing model } \\
\text { prediction to multi-axial test data } \\
\text { from key feature tests is planned, } \\
\text { see C2. }\end{array}$ \\
\hline
\end{tabular}




Idaho National Laboratory
\begin{tabular}{|c|lll|}
\hline NEXT GENERATION NUCLEAR PLANT & Identifier: & PLN-2804 \\
INTERMEDIATE HEAT EXCHANGER & Revision: & 0 & Page: 78 of 156 \\
MATERIALS RESEARCH & Effective Date: & $04 / 30 / 08$ & \\
AND DEVELOPMENT PLAN & &
\end{tabular}

Table 20. (continued).

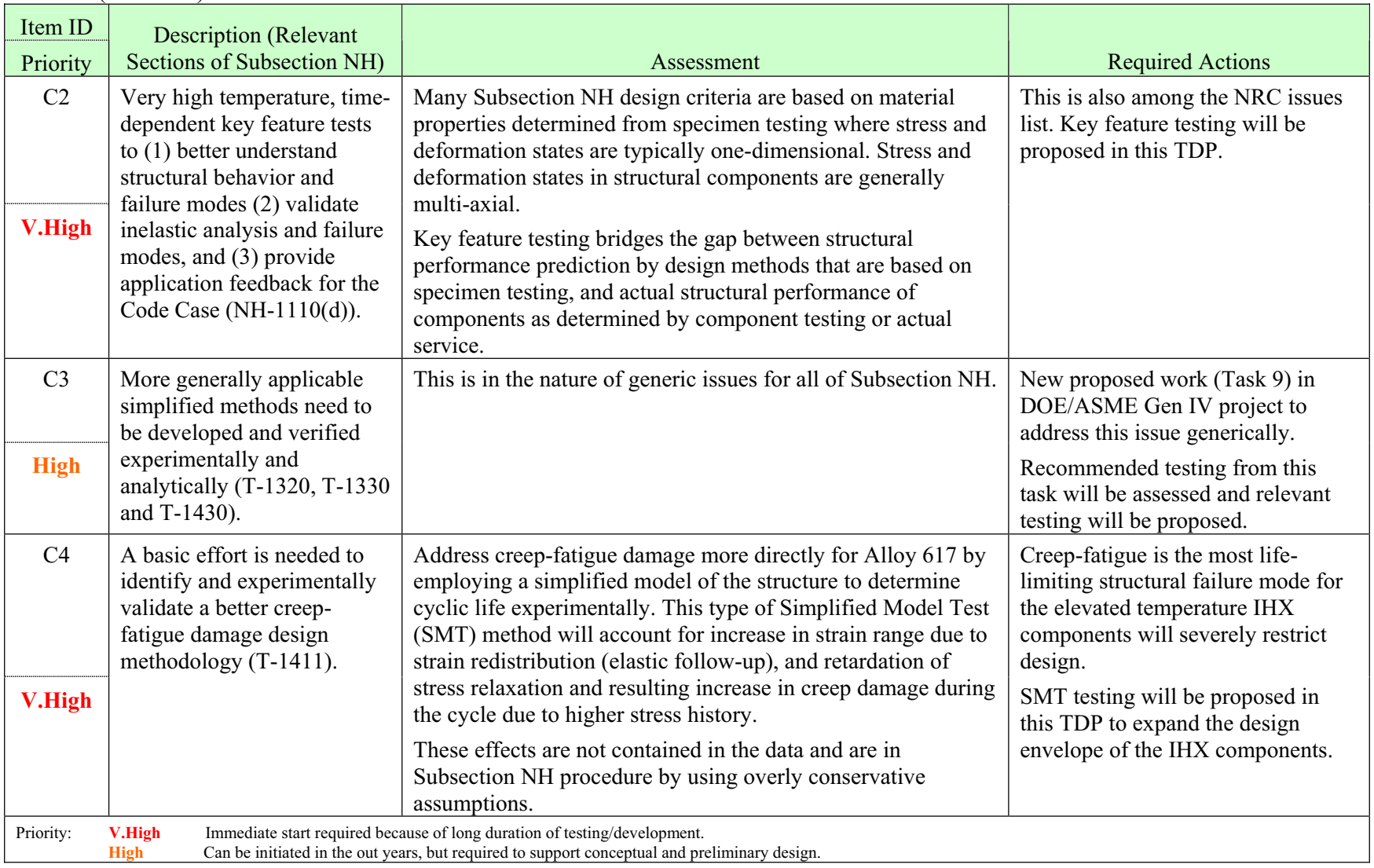




Idaho National Laboratory
\begin{tabular}{|c|lll|}
\hline NEXT GENERATION NUCLEAR PLANT & Identifier: & PLN-2804 \\
INTERMEDIATE HEAT EXCHANGER & Revision: & 0 & Page: 79 of 156 \\
MATERIALS RESEARCH & Effective Date: & $04 / 30 / 08$ & \\
AND DEVELOPMENT PLAN & &
\end{tabular}

Table 21. Additional issues to keep current with Subsection NH.

\begin{tabular}{|c|c|c|c|}
\hline $\begin{array}{c}\text { Item } \\
\text { Priority }\end{array}$ & $\begin{array}{c}\text { Description (Relevant sections of } \\
\text { Subsection NH) }\end{array}$ & Assessment & Required Actions \\
\hline \multicolumn{4}{|c|}{ D. Additional items that must be addressed for Code Case } \\
\hline D1 & \multirow{2}{*}{$\begin{array}{l}\text { Increase the stress allowables to } \\
\text { beyond } 100,000 \text { hours. }\end{array}$} & \multirow{2}{*}{$\begin{array}{l}\text { Extension necessary for required } \\
\text { lifetimes of the Alloy } 617 \text { hot-gas } \\
\text { piping and IHX components. }\end{array}$} & \multirow{2}{*}{$\begin{array}{l}\text { Very long-term, low-stress creep rupture test } \\
\text { program to fill data gap in the existing aggregate } \\
\text { database will be proposed in this TDP to support } \\
\text { license approval. }\end{array}$} \\
\hline V.High & & & \\
\hline D2 & \multirow{2}{*}{$\begin{array}{l}\text { Weldability and weld rod } \\
\text { composition - a prerequisite to } \\
\text { determining weld strength reduction } \\
\text { factors (Table I-14.10). }\end{array}$} & \multirow{2}{*}{$\begin{array}{l}\text { Requirement in Section II for new } \\
\text { code material. }\end{array}$} & \multirow{2}{*}{$\begin{array}{l}\text { NGNP Program scheduling constraints prohibit } \\
\text { optimization of compositions. Material vendor } \\
\text { recommended filler metals have good weldability and } \\
\text { will be used to generate weldment data. }\end{array}$} \\
\hline V.High & & & \\
\hline D3 & \multirow{2}{*}{$\begin{array}{l}\text { Yield and tensile strength reduction } \\
\text { factors owing to aging (NH- } \\
2160(d)(2)) \text {. }\end{array}$} & \multirow{2}{*}{$\begin{array}{l}\text { Required design information in } \\
\text { Subsection NH. }\end{array}$} & \multirow{2}{*}{$\begin{array}{l}\text { Tensile test program is proposed in this TDP. } \\
\text { Same as for B4, must start thermal aging exposures } \\
\text { for different heats of Alloy } 617 \text { in autoclaves. }\end{array}$} \\
\hline V.High & & & \\
\hline D4 & \multirow{2}{*}{$\begin{array}{l}\text { Fatigue curves as a function of } \\
\text { temperature (T-1411). }\end{array}$} & \multirow{2}{*}{$\begin{array}{l}\text { Continuous fatigue curves are } \\
\text { integral part of the creep-fatigue } \\
\text { procedure in Subsection NH. }\end{array}$} & \multirow[t]{2}{*}{ A test program is proposed in this TDP. } \\
\hline V.High & & & \\
\hline D5 & \multirow{2}{*}{$\begin{array}{l}\text { Potential need to optimize alloying } \\
\text { elements (Appendix A). }\end{array}$} & \multirow[t]{2}{*}{ Benefits the replacement IHX. } & \multirow[t]{2}{*}{ Effort to address to be proposed in the future. } \\
\hline Low & & & \\
\hline D6 & \multirow{2}{*}{$\begin{array}{l}\text { Consideration of cold work effect and } \\
\text { subsequent heat treatment } \\
\text { requirements (NH-4212). }\end{array}$} & \multirow{2}{*}{$\begin{array}{l}\text { Draft Alloy } 617 \text { Code Case excluded } \\
\text { cold worked material becausae of } \\
\text { possible recrystallization during } \\
\text { elevated temperature service. Cold } \\
\text { work also reduces tensile ductility. }\end{array}$} & \multirow[t]{2}{*}{ Cold worked material will be excluded. } \\
\hline High & & & \\
\hline D7 & \multirow{2}{*}{$\begin{array}{l}\text { Determination of creep-fatigue } \\
\text { interaction diagram (T-1420(c) and T- } \\
1431(\mathrm{~d})) \text {. }\end{array}$} & \multirow{2}{*}{$\begin{array}{l}\text { Required in the creep-fatigue } \\
\text { procedure. }\end{array}$} & \multirow{2}{*}{$\begin{array}{l}\text { Required creep-fatigue interaction diagram will be } \\
\text { established once fatigue tests with hold time are } \\
\text { complete, see E2. }\end{array}$} \\
\hline High & & & \\
\hline
\end{tabular}


Form 412.09 (Rev. 10)

Idaho National Laboratory
\begin{tabular}{|c|lll|}
\hline NEXT GENERATION NUCLEAR PLANT & Identifier: & PLN-2804 & \\
INTERMEDIATE HEAT EXCHANGER & Revision: & 0 & \\
MATERIALS RESEARCH & Effective Date: & $04 / 30 / 08$ & Page: 80 of 156 \\
AND DEVELOPMENT PLAN & &
\end{tabular}

Table 21. (continued).

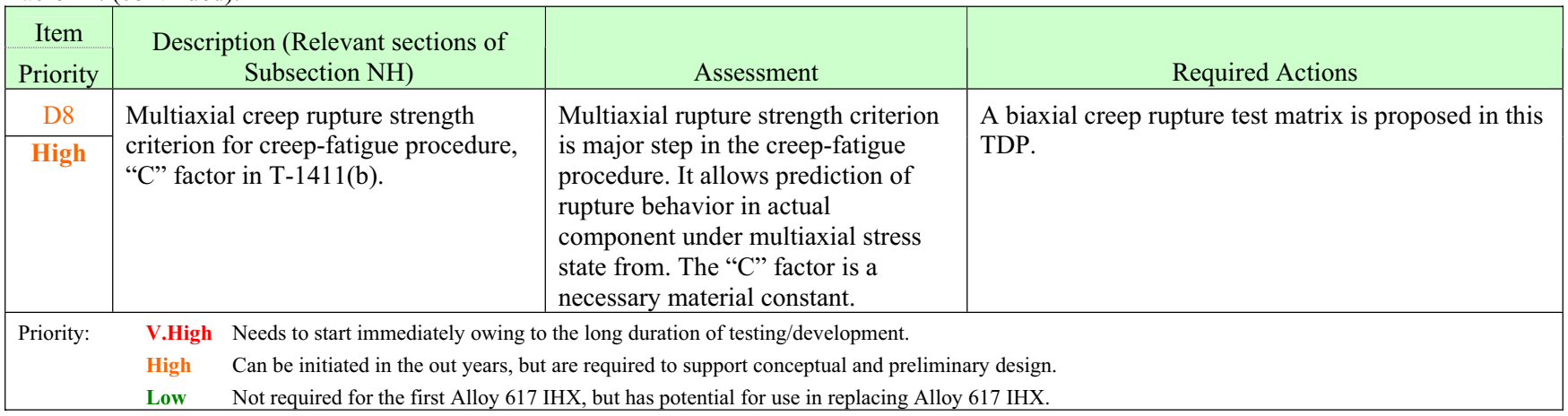


Form 412.09 (Rev. 10)

Idaho National Laboratory
\begin{tabular}{|c|lll|}
\hline NEXT GENERATION NUCLEAR PLANT & Identifier: & PLN-2804 & \\
INTERMEDIATE HEAT EXCHANGER & Revision: & 0 & \\
MATERIALS RESEARCH & Effective Date: & $04 / 30 / 08$ & Page: 81 of 156 \\
AND DEVELOPMENT PLAN &
\end{tabular}

Table 22. Significant issues that recently emerged.

\begin{tabular}{|c|c|c|c|}
\hline $\begin{array}{c}\text { Item } \\
\text { Priority } \\
\end{array}$ & $\begin{array}{l}\text { Description (Relevant } \\
\text { sections of Subsection } \\
\text { NH) }\end{array}$ & Assessment & Priority/Required Actions \\
\hline \multicolumn{4}{|c|}{ E. Recent issues that must be addressed for Alloy 617} \\
\hline E1 & \multirow[t]{3}{*}{$\begin{array}{l}\text { Justification for } \\
\text { dropping onset of } \\
\text { tertiary creep from the } \\
\text { allowable stress criteria } \\
(\mathrm{NH}-3221(\mathrm{~b})(1)(\mathrm{b}))\end{array}$} & $\begin{array}{l}\text { Current Subsection NH materials, base the time-dependent allowable } \\
\text { stress, } \mathrm{S}_{\mathrm{t}} \text {, on time-to- } 1 \% \text {-total-strain, time-to-onset-of-tertiary-creep and } \\
\text { time-to-creep-rupture. These materials exhibit classical creep curves with } \\
\text { identifiable primary, secondary and tertiary creep regimes. Nickel-base } \\
\text { alloys such as Alloy } 617 \text { and } 230 \text {, the secondary creep regime hardly exists } \\
\text { at elevated temperatures and the onset of tertiary creep occurs at very short } \\
\text { time, with creep strain accumulated very gradually with time. }\end{array}$ & \multirow[t]{3}{*}{$\begin{array}{l}\text { A test program to perform } \\
\text { interrupted creep tests to } \\
\text { determine microstructure and } \\
\text { damage will be proposed in } \\
\text { this TDP. }\end{array}$} \\
\hline V.High & & $\begin{array}{l}\text { Including time-to-onset-of-tertiary-creep would be very restrictive in } \\
\text { setting the time-dependent allowable stress and was not used in setting } \mathrm{S}_{\mathrm{t}} \text { in } \\
\text { the Draft Alloy } 617 \text { Code Case. }\end{array}$ & \\
\hline & & $\begin{array}{l}\text { Information is needed on whether gradually increasing creep curve } \\
\text { indicates a different deformation mechanism typified by dislocation } \\
\text { generation and motion, or corresponds to creep damage such as grain } \\
\text { boundary cavitation and cracking reminiscent of classical tertiary creep } \\
\text { regime. Code requires that time-to-onset-of-tertiary-creep be included in } \\
\text { the criteria for classical tertiary creep. }\end{array}$ & \\
\hline E2 & \multirow{2}{*}{$\begin{array}{l}\text { Does the effect of hold } \\
\text { time saturate or is there } \\
\text { continuous degradation } \\
\text { owing to environmental } \\
\text { effects, e.g., oxidation } \\
\text { ahead of a creep crack } \\
\text { tip (NH-1110(e) and } \\
\text { NH-2160(a))? }\end{array}$} & \multirow[t]{2}{*}{$\begin{array}{l}\text { Important consideration as the hold times for NGNP hot-gas piping and } \\
\text { IHX components are much longer than those employed in tests. }\end{array}$} & \multirow{2}{*}{$\begin{array}{l}\text { Determine cycles to failure } \\
\text { for fatigue tests in air with } \\
\text { different hold times as } \\
\text { proposed in this TDP. } \\
\text { Evaluate microstructure of } \\
\text { failed samples. }\end{array}$} \\
\hline V.High & & & \\
\hline
\end{tabular}


Form 412.09 (Rev. 10)

Idaho National Laboratory
\begin{tabular}{|c|lll|}
\hline NEXT GENERATION NUCLEAR PLANT & Identifier: & PLN-2804 & \\
INTERMEDIATE HEAT EXCHANGER & Revision: & 0 & \\
MATERIALS RESEARCH & Effective Date: & $04 / 30 / 08$ & Page: 82 of 156 \\
AND DEVELOPMENT PLAN & &
\end{tabular}

Table 22. (continued).

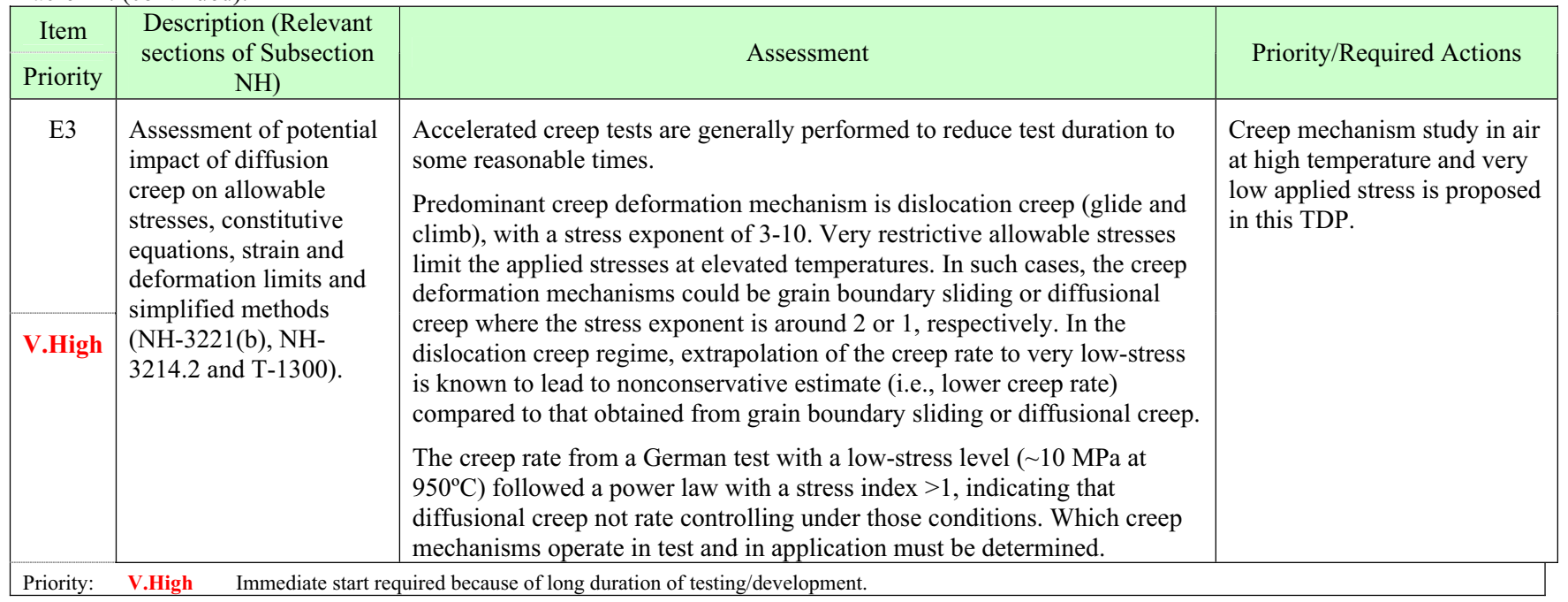


Form 412.09 (Rev. 10)

Idaho National Laboratory
\begin{tabular}{|c|lll|}
\hline NEXT GENERATION NUCLEAR PLANT & Identifier: & PLN-2804 \\
INTERMEDIATE HEAT EXCHANGER & Revision: & 0 & Page: 83 of 156 \\
MATERIALS RESEARCH & Effective Date: & $04 / 30 / 08$ & \\
AND DEVELOPMENT PLAN &
\end{tabular}

Table 23. Required Code Actions for Alloy $800 \mathrm{H}$.

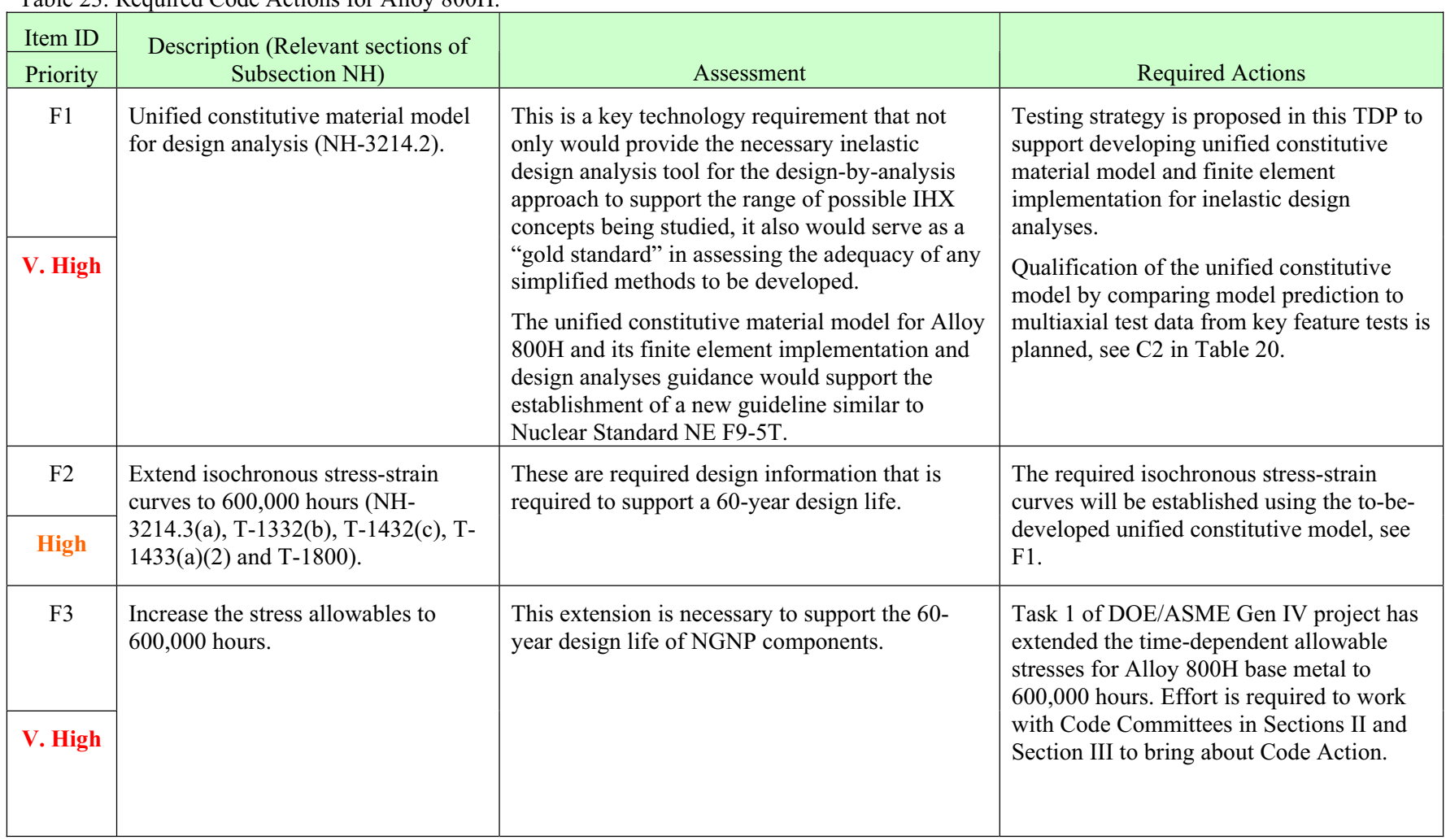




Idaho National Laboratory
\begin{tabular}{|c|lll|}
\hline NEXT GENERATION NUCLEAR PLANT & Identifier: & PLN-2804 \\
INTERMEDIATE HEAT EXCHANGER & Revision: & 0 & Page: 84 of 156 \\
MATERIALS RESEARCH & Effective Date: & $04 / 30 / 08$ & \\
AND DEVELOPMENT PLAN & &
\end{tabular}

Table 23. (continued).

\begin{tabular}{|c|c|c|c|}
\hline Item ID & \multirow{2}{*}{$\begin{array}{c}\text { Description (Relevant sections of } \\
\text { Subsection NH) } \\
\end{array}$} & \multirow[b]{2}{*}{ Assessment } & \multirow[b]{2}{*}{ Required Actions } \\
\hline Priority & & & \\
\hline $\mathrm{F} 4$ & \multirow{2}{*}{$\begin{array}{l}\text { Extend weld strength rupture factors } \\
\text { to } 600,000 \text { hours (NH-3221(b)(2)). }\end{array}$} & \multirow{2}{*}{$\begin{array}{l}\text { This extension is necessary to support the } 60 \text { - } \\
\text { year design life of NGNP components. }\end{array}$} & \multirow{2}{*}{$\begin{array}{l}\text { Task } 1 \text { of DOE/ASME Gen IV project has } \\
\text { identified the data needs. A creep rupture } \\
\text { test program is proposed in Section } 6 .\end{array}$} \\
\hline V. High & & & \\
\hline F5 & \multirow[t]{2}{*}{$\begin{array}{l}\text { Strain rate dependence of yield and } \\
\text { tensile strengths. }\end{array}$} & \multirow{2}{*}{$\begin{array}{l}\text { The range of applicability of tabulated yield and } \\
\text { tensile strengths for Alloy } 800 \mathrm{H} \text { needs to be } \\
\text { determined. }\end{array}$} & \multirow{2}{*}{$\begin{array}{l}\text { Task } 1 \text { of DOE/ASME Gen IV project has } \\
\text { identified the data needs. A tensile test } \\
\text { program is proposed in this TDP. }\end{array}$} \\
\hline High & & & \\
\hline F6 & \multirow{2}{*}{$\begin{array}{l}\text { Assessment of potential impact of } \\
\text { diffusion creep on allowable stresses, } \\
\text { constitutive equations, strain and } \\
\text { deformation limits and simplified } \\
\text { methods (NH-3221(b), NH-3214.2 } \\
\text { and T-1300). }\end{array}$} & \multirow[t]{2}{*}{$\begin{array}{l}\text { It is important to determine if diffusional creep } \\
\text { mechanisms are active in Alloy } 800 \mathrm{H} \text { at low- } \\
\text { stress and NGNP application temperatures. }\end{array}$} & \multirow[t]{2}{*}{$\begin{array}{l}\text { Task } 1 \text { of DOE/ASME Gen IV project has } \\
\text { identified the data needs. Effort to address } \\
\text { this issue is proposed in this TDP. }\end{array}$} \\
\hline V. High & & & \\
\hline F7 & \multirow{2}{*}{$\begin{array}{l}\text { Yield and tensile strength reduction } \\
\text { factors caused by aging (NH- } \\
2160(d)(2) \text {. }\end{array}$} & \multirow{2}{*}{$\begin{array}{l}\text { These are the required design information in } \\
\text { Subsection NH. Currently, yield and tensile } \\
\text { strength reduction factors of } 0.9 \text { are applied for } \\
\text { service temperatures }>730^{\circ} \mathrm{C} \text {. These factors are } \\
\text { valid up to } 300,000 \text { hours. Extension to } 600,000 \\
\text { hours is required. }\end{array}$} & \multirow{2}{*}{$\begin{array}{l}\text { Effort to address this item is proposed in } \\
\text { Section } 6 \text {. } \\
\text { Thermal aging exposures on Alloy } 800 \mathrm{H} \\
\text { need to be initiated as soon as possible, } \\
\text { because long aging time is required. }\end{array}$} \\
\hline V. High & & & \\
\hline F8 & \multirow[t]{2}{*}{$\begin{array}{l}\text { Consideration of cold work effect } \\
\text { and subsequent heat treatment } \\
\text { requirements (NH-4212). }\end{array}$} & \multirow{2}{*}{$\begin{array}{l}\text { Time and temperature limits for heat treatment of } \\
\text { cold worked material are currently provided in } \\
\text { Subsection NH for up to } 300,000 \text { hours. } \\
\text { Consideration of possible extension to } 600,000 \\
\text { hours is required. }\end{array}$} & \multirow[t]{2}{*}{$\begin{array}{l}\text { Effort is needed to consider if cold work } \\
\text { should be permitted for service beyond } \\
300,000 \text { hours. }\end{array}$} \\
\hline High & & & \\
\hline
\end{tabular}


Form 412.09 (Rev. 10)

Idaho National Laboratory
\begin{tabular}{|c|lll|}
\hline NEXT GENERATION NUCLEAR PLANT & Identifier: & PLN-2804 & \\
INTERMEDIATE HEAT EXCHANGER & Revision: & 0 & \\
MATERIALS RESEARCH & Effective Date: & $04 / 30 / 08$ & Page: 85 of 156 \\
AND DEVELOPMENT PLAN & &
\end{tabular}

Table 23. (continued).

\begin{tabular}{|c|c|c|c|}
\hline Item ID & \multirow{2}{*}{$\begin{array}{c}\text { Description (Relevant sections of } \\
\text { Subsection NH) }\end{array}$} & \multirow[b]{2}{*}{ Assessment } & \multirow[b]{2}{*}{ Required Actions } \\
\hline Priority & & & \\
\hline F9 & \multirow{2}{*}{$\begin{array}{l}\text { Multiaxial creep rupture strength } \\
\text { criterion for creep-fatigue procedure, } \\
\text { "C" factor in T-1411 (b). }\end{array}$} & \multirow[t]{2}{*}{ Need to validate the value of the "C" factor. } & \multirow{2}{*}{$\begin{array}{l}\text { A biaxial creep rupture test matrix is } \\
\text { proposed in this TDP to address this issue. }\end{array}$} \\
\hline High & & & \\
\hline rity: & $\begin{array}{l}\text { Immediate start required because } \mathrm{o} \\
\text { Can be initiated in the out years, bu }\end{array}$ & $\begin{array}{l}\text { long duration of testing/development. } \\
\text { required to support conceptual and preliminary design. }\end{array}$ & \\
\hline
\end{tabular}




\begin{tabular}{|c|lll|}
\hline $\begin{array}{c}\text { NEXT GENERATION NUCLEAR PLANT } \\
\text { INTERMEDIATE HEAT EXCHANGER }\end{array}$ & Identifier: & PLN-2804 & \\
MATERIALS RESEARCH & Revision: & 0 & \\
AND DEVELOPMENT PLAN & Effective Date: & $04 / 30 / 08$ & Page: 86 of 156 \\
\hline
\end{tabular}

\section{IHX SPECIFIC RESEARCH ISSUES}

This section will detail issues specific to the IHX in addition to design code discussed in Section 5.

\subsection{Procurement/Availability}

\subsubsection{Availability and Transportation}

Procurement and transportation will be addressed in detail in a separate acquisition report. It does not appear that these issues are important to the R\&D plan. Both the IHX materials and the components themselves are available from a number of vendors. It is possible field assembly issues may arise if a large heat exchanger design is selected.

\subsubsection{Fabrication}

Certain compact heat exchangers, where fabrication and design details are considered proprietary by the vendor, may potentially restrict our understanding and could impact the likeliness of that compact heat exchanger being selected.

Although both Alloy 617 and Alloy 230 offer good fabrication capabilities, some specific issues regarding the intended IHX applications should be assessed. Fabrication of thin sheets and foils requires very carefully controlled processing parameters different from those for other product forms such as plate and tubing. Also, specific microstructures, e.g., grain size, must be achieved to ensure proper creep resistance of such product forms. To achieve desired microstructures in the thin sheets or foils needed for compact heat exchanger, fabrication of such thin sheets and foils must be evaluated, and optimization of the resulting properties must be studied.

Even within the standard specification, there are still some vendor-raised concerns about cold and hot workability at the compositional high end of the Alloy 617 specification. ${ }^{37}$ These concerns were raised when developing the CSM 617 was discussed in FY05, but obviously these concerns are also valid in fabricating thin product forms, in which significant thickness reductions will be required. Preliminary investigations were started in FY06 to address these concerns but conclusive results were not yet reached. Continued efforts are needed if the concerns are to be addressed.

\subsection{Material Characteristics and Properties}

In Appendix E of the NGNP Pre-Conceptual Design Report, ${ }^{7}$ design data needs and R\&D needs as identified by the vendors are summarized. All three vendors placed a high priority on testing and codification for high temperature metals (Alloy 617 and/or 230). The Westinghouse team provided a more detailed list of needs for the two alloys:

- Reference specifications.

- Thermal/physical and mechanical properties.

- Welding and as-welded properties of materials.

- Aging effects:

- Environmental effects of impure helium.

- Influence of grain size on material properties. 


\begin{tabular}{c|lll|}
\hline NEXT GENERATION NUCLEAR PLANT & Identifier: & PLN-2804 & \\
INTERMEDIATE HEAT EXCHANGER & Revision: & 0 & \\
MATERIALS RESEARCH & Effective Date: & $04 / 30 / 08$ & Page: 87 of 156 \\
AND DEVELOPMENT PLAN &
\end{tabular}

Most of the material property testing is covered in detail in Section 5 and will be briefly summarized here, emphasizing IHX issues.

\subsubsection{Microstructural Stability}

Microstructural and mechanical property characterizations are needed for thin section materials, especially for use in PCHEs. Grain growth is of particular concern in thin sections because properties may degrade if there are not a sufficient number of grains in the through-thickness direction. Acceptable grain sizes should be specified.

Plate material has been shown to have microstructural stability after 10 years of aging in air at temperatures up to $1000^{\circ} \mathrm{C}$. However, sheet material is received in the cold rolled condition with the potential for recrystallization and abnormal grain growth either during diffusion bonding or during service.

\subsubsection{Cyclic Properties}

Nonlinear temperature profiles, particularly during transient cycles such as start-up and shutdown, can result in high local thermal stresses in areas of constraint that ultimately limit fatigue life. Thermal expansion of the materials and IHX design can both have an effect. Fatigue and creep-fatigue of the material testing will proceed as outlined in Sections 5 and 8.1 while the IHX design is being finalized. Thermal cycling of certain features or components may be required at a later date and will be coordinated with engineering efforts.

\subsubsection{Creep}

The properties of Alloy 617 have been characterized to more than 10 years in air and anticipated NGNP environments. The deleterious affects of the environment are well understood for those conditions. A phenomenon of carbide redistribution under creep load has been observed for 617. It is not known if Alloy 230 behaves similarly. The influence of carburizaton on creep properties is unknown. Also, the impact of the creep strain on grain boundary cavitation is little understood.

Neither 617 nor 230 exhibit a secondary creep regime. The NH design code for 617 does not allow use of materials in the tertiary creep range. New constitutive models will be developed as discussed in Section, 5 and 8.1. This information will be essential for accurate finite element modeling of NGNP IHX and other high temperature designs such as hot gas piping.

\subsubsection{Crack-Growth}

Crack growth is primarily an issue when the IHX is at temperatures below $850^{\circ}$ where creep crack growth and environmentally assisted crack growth are a concern. At elevated temperatures creep and creep-fatigue crack growth can occur, and are addressed through the DOE/ASME Task 8. Any proposed testing from Task 8 will be assessed and additional testing recommended if needed. Creep crack growth tests in NGNP helium are proposed in Section 8 to investigate the environmental effect.

\subsection{Material Degradation}

\subsubsection{Environmental Effects}

Because of the relatively pure He fluid (or possibly N/He fluid for the IHX), corrosion issues are generally of less concern than the high temperature strength issues. As discussed in the background 


\begin{tabular}{c|lll|}
\hline $\begin{array}{c}\text { NEXT GENERATION NUCLEAR PLANT } \\
\text { INTERMEDIATE HEAT EXCHANGER }\end{array}$ & Identifier: & PLN-2804 & \\
MATERIALS RESEARCH & Revision: & 0 & \\
AND DEVELOPMENT PLAN & Effective Date: & $04 / 30 / 08$ & Page: 88 of 156 \\
\hline
\end{tabular}

information in Chapter 2, the behavior expected in the NGNP environment has been studied at some length. The primary concern is carburization if there is reduced oxygen partial pressure. If a He/N is chosen as the coolant, traditional turbine technology can be utilized; however, nitriding will need to be studied. While the effect of nitrogen is unknown, typically $\mathrm{C}$ and $\mathrm{N}$ behave similarly so there is reason to believe there will be nitriding issues.

The objective of this work is to determine the effect of the $\mathrm{H}_{2} \mathrm{O}$ and $\mathrm{CO}$ concentrations on the corrosion mechanism, and the range of gas chemistries that gives rise to stable oxide formation for these alloys at temperatures potentially up to $1000^{\circ} \mathrm{C}$. This will experimentally verify the Ellingham diagram.

The current US and French programs will contribute little to the two significant issues that remain to be investigated with respect to possible environmental interactions in the NGNP: environmental interaction at reactor pressure and the influence of very high velocity gas on the environmental interaction. While it is anticipated that the reaction mechanism determined using low-pressure test loops will also be observed at high pressure, there is some concern that the kinetics of reaction will be altered. It is possible that the steady-state gas chemistry at the specimen surface could be considerably different with high velocity flow.

\subsubsection{Dust Clogging, Accumulation and Fouling}

All compact exchangers are to some extent susceptible to fouling and clogging because of their small and tortuous flow channels. For this application the fluid $(\mathrm{He}$ or $\mathrm{He} / \mathrm{N})$ is essentially clean compared with many hydrocarbon applications where PCHE and plate with fin heat exchangers are used. Fouling refers to the formation of unwanted deposits on the heat transfer surfaces which can inhibit fluid flow as well as impede heat transfer. The only fouling agent anticipated is carbon particulate from the reactor. Because all parts of the IHX will be at least $100^{\circ} \mathrm{C}$, there should be no moisture to act as a binding agent, so particle agglomeration is improbable. The anticipated particulate load is on the order of $0.1 \mathrm{~kg} / \mathrm{MW}$ at the end of reactor life. ${ }^{3}$

It is reasonable to assume that particles smaller than $1 / 3$ the channel diameter will pass through the exchanger. The graphite particulate should be less than $1 \mu \mathrm{m}$ across. The PCHE will have a semicircular channel of approximately $0.6 \mathrm{~mm}$, so particles of about $0.2 \mathrm{~mm}$ should pass through. This value is two orders of magnitude greater than the anticipated graphite particles. PCHE passages are continuous with no breaks or discontinuities. Combined with high wall shear, this ensures that there are no dead areas or areas of low velocity, and consequently particles should not settle or adhere to the walls. ${ }^{3}$

For plate with fin heat exchangers, designs with multiple fin pads and /or serrated fins have the greatest potential for fouling. The minimum passage dimension is not the fin height, but the distance between fins. A high-performance model would have a fin density of about 850 fins/meter and a foil thickness of about $0.2 \mathrm{~mm}$, so the clearance between fins is about $1 \mathrm{~mm}$. However, for serrated fins, this clear pathway is interrupted, with an actual clearance of about $0.4 \mathrm{~mm}$. Particles $1 / 3$ this size, about 130 $\mu \mathrm{m}$, will pass through the exchanger. Although the clearance is smaller than for the PCHE, it is still about two orders of magnitude greater than the graphite particles. ${ }^{3}$

It is anticipated that any dust-clogging accumulation or fouling problems would have engineering solutions; however related materials issues could arise.

\subsubsection{Erosion}

This is primarily a concern with pebble-bed designs. The concern is that wear on the pebbles during movement can generate dust that will act as a means for transporting fission products during loss of 


\begin{tabular}{c|lll|}
\hline NEXT GENERATION NUCLEAR PLANT & Identifier: & PLN-2804 & \\
INTERMEDIATE HEAT EXCHANGER & Revision: & 0 & \\
MATERIALS RESEARCH & Effective Date: & $04 / 30 / 08$ & Page: 89 of 156 \\
AND DEVELOPMENT PLAN &
\end{tabular}

coolant, and therefore could be related to the radiation exposure to the IHX. To determine the amount of dust to be generated, the tribological properties of the graphite must be determined.

\subsubsection{Radiation Effects}

With the pebble-bed design, there is concern that wear on the pebbles during movement through the core can generate dust that will act as a means for transporting fission products. It is likely that the IHX will be located within the containment vessel. Neither Westinghouse nor GA consider radioactive contamination nor dust a problem for a direct Brayton cycle PCS ${ }^{14}$ while AREVA sites operation and maintenance difficulties from radioactive contamination of the PCS argues as a factor against the direct Brayton cycle. ${ }^{8}$

\subsubsection{Tritium}

The primary nuclide contaminant of concern is tritium. Most of the tritium is produced from ternary fission, but that will be largely retained in the fuel particles. The major source of tritium in the primary loop will likely be the activation of the He-3 in the He coolant. A large portion of the circulating tritium is adsorbed within the core graphite. ${ }^{10}$ The most cost effective means of controlling tritium contamination would be addition of a He purification system to the secondary coolant loop. Tritium removed from the NGNP Helium coolant is predicted to be about $115 \mathrm{Ci} / \mathrm{yr}$.

Given its high mobility at high temperatures, some tritium will migrate through the IHX regardless of the primary and secondary cycle concept. ${ }^{13}$ There is extensive literature on tritium permeation through IHX materials that must be reviewed and evaluated. This should help in predicting tritium permeation from the primary to the secondary coolant loops and from the secondary loop to the hydrogen production facility. Coating the IHX between the primary and secondary loops to reduce tritium migration may be feasible. ${ }^{57}$

\subsubsection{Activated Materials}

The IHX should experience little to no radiation; therefore activated materials should not be an issue for this component.

\subsubsection{Fission Products}

Depending on the fuel performance, it is possible that some low-level fission products might be released into the primary coolant and come in contact with the IHX. Some of these products, like silver, may be corrosive to the nickel base alloys.

\subsection{Joining}

\subsubsection{Welding}

Most high temperature structural failures occur at weldments. Welded pipe, for example, has failed in high temperature fossil plants after many years of operation. Reliably guarding against weldment failures is particularly challenging at high temperatures, where variations in the inelastic response of the constituent parts of the weldment (i.e., weld metal, heat-affected zone, and base metal) can result in a strong metallurgical discontinuity. In the hearings for a construction permit for Clinch River Breeder Reactor Plant (CRBRP), early weldment cracking was identified by the NRC as the foremost structural integrity concern. The NRC and ACRS believed that designers should have a better understanding of the metallurgical interactions that take place in weldments and their effects on weldment life. The CRBRP 


\begin{tabular}{c|lll|}
\hline NEXT GENERATION NUCLEAR PLANT & Identifier: & PLN-2804 & \\
INTERMEDIATE HEAT EXCHANGER & Revision: & 0 & \\
MATERIALS RESEARCH & Effective Date: & $04 / 30 / 08$ & Page: 90 of 156 \\
AND DEVELOPMENT PLAN &
\end{tabular}

project committed to a five-year development program to address these issues before issuance of a plant operating license. The program was never carried out because of the subsequent demise of the project. This issue will certainly resurface with NGNP and other Gen IV reactors.

Cross-weld creep testing indicates that weldment strengths are usually in the range of $50-80 \%$ of those of base metals. Consequently, significant performance reductions are required for design of welded constructions of most Ni base alloys. Failures at the reduced loadings are usually in the weld deposits.

One potential problem often found in welding Ni base alloys with fully austenitic deposits is the occurrence of micro-fissuring in the HAZ, especially in multi-pass welds. Weld failure can happen in service if the inherent micro-fissuring propagates into cracks when subjected to thermal stresses. The micro-cracks in HAZ are intergranular associated with liquefied and resolidified products on grain boundaries. The cracks were often observed to be connected with the weld pool by a liquated grain boundary with a continuous string of precipitates on it. The tendency to micro-fissuring is attributed to liquation owing to high local concentrations of some minor elements as well as to $\delta$ phase-assisted liquation cracking. Chemical composition of the filler metal can significantly affect the tendency to micro-fissuring. Also, cracking of liquated regions can only occur in the presence of tensile stresses. Therefore, the degree of cracking will be influenced by welding and local tensile stresses during cooling of the welds.

\subsubsection{Process Development}

The welding process for Alloy 617 is well established. ${ }^{43}$ Alloy 230 is more difficult to weld, but process development also appears to be complete. ${ }^{44}$ Refer to Section 4.1.2.2.

\subsubsection{Proof Testing}

\section{Quasi-Static}

A fair amount of welded coupons have been tested in the laboratory. The uniaxial strength is well established; however, additional work may be needed to characterize the creep properties and to develop constitutive models for the welds.

\section{Cyclic}

Some work on fatigue and creep-fatigue has been done, but the draft code case submitted in the 1990s specifically noted insufficient understanding of creep-fatigue in weldments.

\subsubsection{Properties of Prototypical Welded Structures}

At this point, little has been done in this area. A review of the existing weld reduction factors for materials currently in $\mathrm{NH}$ will be required to begin to address the NRC concerns. ${ }^{56} \mathrm{~A}$ significant development program will be required to support ASME code activities for welding.

Owing to various geometric details of IHX structure, the welds will be subjected to stress conditions much more complicated than those in a regular lab mechanical testing specimen. The mechanical response of welds under such conditions should be evaluated to verify the integrity of the weldment. To characterize the welds for such conditions, customized specimens representing major characteristics of the prototypical welded structures in the IHX should be designed and tested. Design of the customized specimens must balance the characterization needs, the viability, and the cost. Whenever possible, the testing must be conducted in a simulated IHX working environment. 


\begin{tabular}{|c|c|c|c|}
\hline $\begin{array}{l}\text { NEXT GENERATION NUCLEAR PLANT } \\
\text { INTERMEDIATE HEAT EXCHANGER } \\
\text { MATERIALS RESEARCH } \\
\text { AND DEVELOPMENT PLAN }\end{array}$ & $\begin{array}{l}\text { Identifier: } \\
\text { Revision: } \\
\text { Effective Date: }\end{array}$ & $\begin{array}{l}\text { PLN-2804 } \\
0 \\
04 / 30 / 08\end{array}$ & Page: 91 of 156 \\
\hline
\end{tabular}

For the IHX application, the effects of weld deposit microstructures and chemical compositions on weldment creep properties should be determined to develop a foundation for improving them. Depending on the design, the NGNP IHX may be joined to piping or components of materials other than Alloy 617 or 230 , for example $800 \mathrm{H}$. Therefore, welding metallurgy and behavior of dissimilar weld joints must be studied. Emphasis should be put on the microstructure stability of the weld during long-time, elevatedtemperature exposure. Extended annealing of mixed-metal joints, both austenitic-austenitic and austeniticferritic, can lead to unique microstructures that result in unexpected results. Chemical gradients in representative mixed-metal weld joints should be characterized and their long-term aging behavior should be assessed. Approaches should be developed to adjust weld filler metal compositions to eliminate diffusion of critical alloying elements.

\subsubsection{Examination Methods}

No unique issues for examining welds in the IHX have been identified. The ASME rules for inspection are applicable to this welding application.

\subsubsection{Diffusion Bonding}

Diffusion-bonding is a solid-state joining process where metal surfaces are brought together under load at an elevated temperature (about $50 \%-90 \%$ of the absolute melting point of the parent material) for a period ranging from a few minutes to a few hours. The key for achieving a satisfactory bond in this process is to prepare extremely clean, fresh contact surfaces that form a high contact ratio. Under carefully controlled conditions neither metallurgical discontinuities nor porosity exist across the interface, and the diffusion-bonded joints can reach parent metal properties. Good dimensional tolerances for the products can be attained resulting in high-precision components with intricate shapes or cross sections without the need for subsequent machining.

During the first stage, the asperities on each of the faying surfaces deform plastically as the pressure is applied. These asperities arise from the grinding or polishing marks that have been produced in the surface finishing stage. As the deformation of asperities proceeds, more metal-to-metal contact is established because of local disruption of the relatively brittle oxide films that generally fracture readily. At the end of the first stage, the bonded area is less than $10 \%$ and a large volume of voids and oxide remains between localized bonded regions. In the second stage of bonding, thermally activated mechanisms (creep and diffusion) lead to void shrinkage and further increases the bonded areas. Ultimately, the joint is formed through atomic diffusion, thereby promoting grain growth between the surfaces.

For fabrication of the IHX, diffusion bonding may be used for joining the compact core (PCHE). However, because of the complex shapes of the channels on the stacking sheet surface and relatively large size of the stacking sheets, applying the load evenly to the contact interface to form bonds of uniformly high quality can be a great challenge.

\subsubsection{Process Development}

The aim in diffusion bonding is to bring the surfaces of the two pieces being joined sufficiently close that interdiffusion can result in bond formation. Great care is required in the surface preparation stage. Even highly polished surfaces come into contact only at their asperities and hence the ratio of contacting area to faying area is very low. Precise fitting-up of the mating parts is also critical. Excessive oxidation or contamination of the faying surfaces can decrease the joint strength drastically. Diffusion bonding of materials with stable oxide layers is very difficult. Production of large components is limited by the size of the bonding equipment used. 


\begin{tabular}{c|lll|}
\hline NEXT GENERATION NUCLEAR PLANT & Identifier: & PLN-2804 & \\
INTERMEDIATE HEAT EXCHANGER & Revision: & 0 & \\
MATERIALS RESEARCH & Effective Date: & $04 / 30 / 08$ & Page: 92 of 156 \\
AND DEVELOPMENT PLAN &
\end{tabular}

The reformation of the surface oxide is virtually instantaneous for many metallic alloys including most superalloys because they contain elements with a high affinity for oxygen, e.g., Ni, Cr, Al, Co, Ti, and W. A number of materials are being qualified by Heatric for IHX manufacture and include: Alloy 617, Alloy 230, Alloy X and XR, Alloy 800 variants and Alloy 602CA. Heatric reports that either Alloy 617 or 230 lend themselves to the diffusion-bonding process involved in the manufacture of their heat exchangers. ${ }^{2,4}$

While some diffusion bonding of Alloy 617 has been demonstrated, the optimum process parameters are not well defined. Adequate processing parameters must be developed including diffusion bonding temperature, applied loading level, and holding time. A significant portion of this effort has been carried out by the compact heat exchanger vendors, and at present they choose to hold this information proprietary. As noted above, microstructural stability during the high temperature exposure associated with diffusion bonding is a concern.

\subsubsection{Proof Testing}

The compact IHX core may be fabricated using the diffusion bonding process. Mechanical testing of the joints will be needed to identify promising joining parameters such as temperature, applied pressure, and hold time for optimization. The testing should include tensile, creep, creep-fatigue and fatigue properties of the joint. Heat exchanger vendors may have data on these properties, but they consider all such information proprietary, so significant testing may be required. To efficiently screen the specimens fabricated using various joining parameters and quickly narrow down to the promising processing parameter range for further detailed study, some quick and simple testing methods should be developed. Because the real components will require joining of thin walls, adequate specimen designs must be considered to facilitate testing for the detailed study.

\section{Quasi-Static}

Some data is available on room temperature tensile properties of diffusion-bonded 617; however, processing conditions to achieve those bonds are not specified. There is no known data for Alloy 230. An extensive program of tensile and creep testing will be required for either alloy.

\section{Cyclic}

No known data on cyclic properties exists for either alloy. Extensive test programs of fatigue and creep-fatigue, as a function of process conditions will be required. In addition, resistance to thermal fatigue in the impure helium environment should be investigated.

\subsubsection{Properties of Prototypical Diffusion Bonded Structures}

Properties of prototypical diffusion-bonded structures face the same issues as the welded structures. The welds will be subjected to stress conditions much more complicated than that in a regular lab mechanical testing specimen. Therefore, customized specimens representing major characteristics of the prototypical welded structures in the IHX should be designed and tested.

\subsubsection{Examination Methods}

There are no ASME code requirements for diffusion-bonded joints; therefore, inspection criteria must be developed. Compact heat exchangers use multiple layers of diffusion-bonded sheets or plates, and inspection methods are lacking for these structures. 


\begin{tabular}{|c|lll|}
\hline NEXT GENERATION NUCLEAR PLANT & Identifier: & PLN-2804 & \\
INTERMEDIATE HEAT EXCHANGER & Revision: & 0 & \\
MATERIALS RESEARCH & Effective Date: & $04 / 30 / 08$ & Page: 93 of 156 \\
AND DEVELOPMENT PLAN &
\end{tabular}

\subsubsection{Brazing}

Brazing is a joining process where a metallic filler material is heated to melting temperature (above $427^{\circ} \mathrm{C}$ ) and distributed between closely fitted surfaces to be joined by capillary action. The molten filler material interacts with the base metal and cools to form a bond from grain structure interaction. Because of the melting flux in the joining process, the surface preparation for brazing is much easier than that for diffusion bonding. However, significant work is needed to develop adequate filler material, especially for the very high temperature application desired for the IHX.

Plate fin heat exchangers are made by stacking corrugated sheets (fins) separated by planar sheets. The planar separation sheet usually has a clad alloy that will melt at a lower temperature than the parent alloy during brazing to bond the various sheets. The heat exchanger assembled from the stacked sheets and typically held together by tack welding a weld rod to the top and bottom layer. The stack is then placed within a fixture that exerts force on the individual pieces to keep them in contact. The part is then vacuum brazed in an environmentally-controlled room to ensure high quality and reliability. After brazing, the core is typically heat treated or aged to increase its strength. A quality braze joint can be stronger than the parent material being brazed.

Any braze alloy must have a melting point. Therefore, joint strength below that of the parent alloy is a concern.

\subsubsection{Process Development}

Little is known about brazing these alloys. Extensive process development will be required. Brazing uses low melting material, which raises concerns about the stability and mechanical properties of brazed joints. Significant work is needed to develop adequate filler material, especially for the very high temperature application desired for the IHX.

\subsubsection{Proof Testing}

For proof testing, the considerations for diffusion bonding previously discussed are valid for brazing. Mechanical testing of the joints will be needed to identify promising joining parameters such as temperature and hold time for optimization. In addition, testing is needed to facilitate selecting or developing filler materials. To efficiently screen the specimens fabricated using various joining parameters and quickly narrow down to the promising processing parameter range for further detailed study, some simple and fast testing methods should be developed. Because the real components will require joining of thin walls, adequate specimen designs must be considered to facilitate testing for the detailed study.

\section{Quasi-Static}

Virtually nothing is known about the performance of brazed joints for either alloy. Because filler material is used in the joining process and its melting point is lower than the base metal, high temperature properties are a concern. The joint must be specifically tested, and effects of long-term exposure to high temperature and impure helium on properties must also be evaluated.

\section{Cyclic}

Fatigue and creep-fatigue of brazed joints are potentially serious issues. In addition, resistance to thermal fatigue in the impure helium environment should be investigated. Brazed material is expected to have a low melting temperature and to behave quite differently from the base metal. 


\begin{tabular}{c|lll|}
\hline NEXT GENERATION NUCLEAR PLANT & Identifier: & PLN-2804 & \\
INTERMEDIATE HEAT EXCHANGER & Revision: & 0 & \\
MATERIALS RESEARCH & Effective Date: & $04 / 30 / 08$ & Page: 94 of 156 \\
AND DEVELOPMENT PLAN &
\end{tabular}

\subsubsection{Properties of Prototypical Brazed Structures}

At this point, little has been done in this area. A significant development program would be required to support ASME code activities for brazing.

Properties of prototypical brazing bonded structures face the same issues as the welded structures. The welds will be subjected to stress conditions much more complicated than those in a regular lab mechanical testing specimen. Therefore, customized specimens representing major characteristics of the prototypical welded structures in the IHX should be designed and tested.

\subsubsection{Examination Methods}

There are no ASME code requirements for brazed joints; therefore, inspection criteria must be developed.

\subsection{Expected Lifetime}

Ideally the IHX would last for the life of the plant; however the expected lifetime is unknown and a subject of some debate. Inspection methods will be key in determining repairs or replacements required for this component.

\subsubsection{Inspection}

\subsubsection{Pre-Service}

The testing and inspection program is anticipated to be performed over approximately one year before the NGNP start-up and two years following start-up.

Pre-operational tests are designed to demonstrate that individual system performance is acceptable and that the plant is ready for hot functional tests.

Baseline in-service inspections are performed to ensure that the in-service inspection methods are adequate and to provide base-line data for future in-service inspections.

Hot functional tests run the reactor primary system at full power, reactor inlet temperature, flow and He pressure. These provide data on flow performance throughout the primary system and functional testing on all monitoring instrumentation as well as a check on temperature management.

Start-up testing includes pre-critical, low power and power ascension testing. Operating parameters are verified to be within design limits, and response to load changes and reactor trips are demonstrated.

Performance tests subject the plant to events expected to occur during normal operation, although infrequently, such as loss of secondary system flow or pressure.

Response to accident tests demonstrate response to reactivity transients, pressurized cool down, water ingress and depressurized cool down. The performance of key systems that provide safety and investment protection are tested.

Following the above mentioned inspections, posttest inspections and maintenance demonstrations are performed. A shut-down is scheduled to perform inspections and demonstrate major maintenance operations. Replacing an IHX heat transfer element or a control rod would fall in this category. 


\begin{tabular}{|c|lll|}
\hline NEXT GENERATION NUCLEAR PLANT & Identifier: & PLN-2804 \\
INTERMEDIATE HEAT EXCHANGER & Revision: & 0 & Page: 95 of 156 \\
MATERIALS RESEARCH & Effective Date: & $04 / 30 / 08$ & \\
AND DEVELOPMENT PLAN &
\end{tabular}

\subsubsection{In-Service}

Inspection of any heat exchanger is restricted to leak tests. As noted above, ASME code rules for inservice inspection for weldments will determine acceptable service conditions. There are currently no defined failure criteria for diffusion-bonded or brazed material.

\subsubsection{Acceptance Criteria}

Acceptance criteria must be developed for any of the joints or IHX designs. 


\begin{tabular}{c|lll|}
\hline $\begin{array}{c}\text { NEXT GENERATION NUCLEAR PLANT } \\
\text { INTERMEDIATE HEAT EXCHANGER }\end{array}$ & Identifier: & PLN-2804 & \\
MATERIALS RESEARCH & Revision: & 0 & \\
AND DEVELOPMENT PLAN & Effective Date: & $04 / 30 / 08$ & Page: 96 of 156 \\
\hline
\end{tabular}

\section{CORE INTERNALS RESEARCH ISSUES}

This section will detail issues specific to the core internals in addition to design code discussed in Section 5.

\subsection{Procurement/Availability}

Procurement issues do not appear important to the R\&D plan. The materials, $316 \mathrm{SS}, 800 \mathrm{H}$, and $\mathrm{C}_{\mathrm{f}} / \mathrm{C}$, are all available from a number of vendors. Methods for fabricating these materials are well established so no problems are anticipated in locating satisfactory vendors for the core internals.

Manufacturing the basic shapes required to make the control rod sheathing poses no particular problem for any of the materials. The necessary equipment, capacity, and expertise are available for $800 \mathrm{H}$ and $\mathrm{C}_{\mathrm{f}} / \mathrm{C}$ composites. Machining is not particularly difficult, but each material poses its own design challenges. $800 \mathrm{H}$ will be operating in a temperature regime where creep could be significant, so care must be taken with stress concentrations. Composites must be designed so that threads are either avoided or properly supported by fibers, with consideration not only towards the integrity of the part, but the difficulty in qualifying the component design. Both processing time and material availability could be issues if composites are chosen. Carbon fibers are mass produced by both domestic and foreign suppliers, but the industry is currently capacity constrained and certain types of fiber are very difficult to obtain. This may not be the case when material is needed for production of control rods, but would affect development.

The core barrel will be nearly as large as the pressure vessel, and may encounter the same transportation issues as discussed in the RPV acquisition plan. ${ }^{58}$ However, rolling/forging large sections of $316 \mathrm{SS}$ or $800 \mathrm{H}$ should not pose any particular problems. Although on-site fabrication may be required, welding of these materials is well established.

\subsection{Material Characteristics and Degradation}

Most of the material property testing is covered in detail in Section 5 and will be briefly summarized here, emphasizing core internal issues.

\subsubsection{Microstructural Stability}

There are no known long-term stability issues with either 316 or $800 \mathrm{H}$. There is the potential for carburization in the materials, which could cause microstructural changes and embrittlement. An oxidizing atmosphere will have little impact on the microstructure. These alloys have considerable experience in other reactors and there have been no indications of microstructural instability.

\subsubsection{Environmental Effects}

Environmental interaction is not anticipated with either $316 \mathrm{SS}$ or $800 \mathrm{H}$. The effect of the environment on carbon composites is unknown. Some environmental testing will be required.

While carburization could lead to embrittlement, oxidation may reduce the mechanical properties through a reduction of the load-bearing section.

High temperature testing is needed to determine if the control rod with $800 \mathrm{H}$ cladding would deform to the point it could not be extracted from the outer reflector after an off-normal event resulting in elevated temperature exposure. Although $800 \mathrm{H}$ will require additional testing, to fill out the database and to extend the use temperature specified in the ASME code, as discussed in Section 8.1.7, these needs 


\section{NEXT GENERATION NUCLEAR PLANT \\ INTERMEDIATE HEAT EXCHANGER \\ MATERIALS RESEARCH \\ AND DEVELOPMENT PLAN}

$\begin{array}{ll}\text { Identifier: } & \text { PLN-2804 } \\ \text { Revision: } & 0 \\ \text { Effective Date: } & 04 / 30 / 08\end{array}$

Page: 97 of 156

appear to be less than what would be required to codify composite materials, which is the alternative material for control rod sleeve applications.

\subsubsection{Radiation Effects}

\subsubsection{Embrittlement}

Like all austenitic alloys, $800 \mathrm{H}$ experiences radiation embrittlement. Control rod sleeves will experience a fluence $<0.15 \mathrm{E} 21 \mathrm{n} / \mathrm{cm}^{2} / \mathrm{yr}$ fast, $<2.5 \mathrm{E} 21 \mathrm{n} / \mathrm{cm}^{2} / \mathrm{yr}$ thermal. However, the alloy is being used in high temperature gas reactors (HTGRs) and the embrittlement can be accounted for in the component design.

Preliminary assessment of the behavior of Alloy $800 \mathrm{H}$ under neutron irradiation was begun as part of the Gen IV cross-cutting R\&D program. Miniature tensile bars were irradiated in High-Flux Isotope Reactor (HFIR) to a total dose of $1.28 \mathrm{dpa}$ at irradiation temperatures of 580 and $660^{\circ} \mathrm{C}$. Specimens were tested in tension after irradiation at a range of temperatures up to $700^{\circ} \mathrm{C}$. Figure 27 (a) and (b) show the yield strength and total elongation to failure, along with baseline data for the same material in the unirradiated condition. It is clear from these preliminary tests that the yield strength is influenced by neutron irradiation in a manner that depends on the irradiation temperature. The elongation to failure is reduced to near zero for post-irradiation tensile tests near $700^{\circ} \mathrm{C}$ for either irradiation temperature.
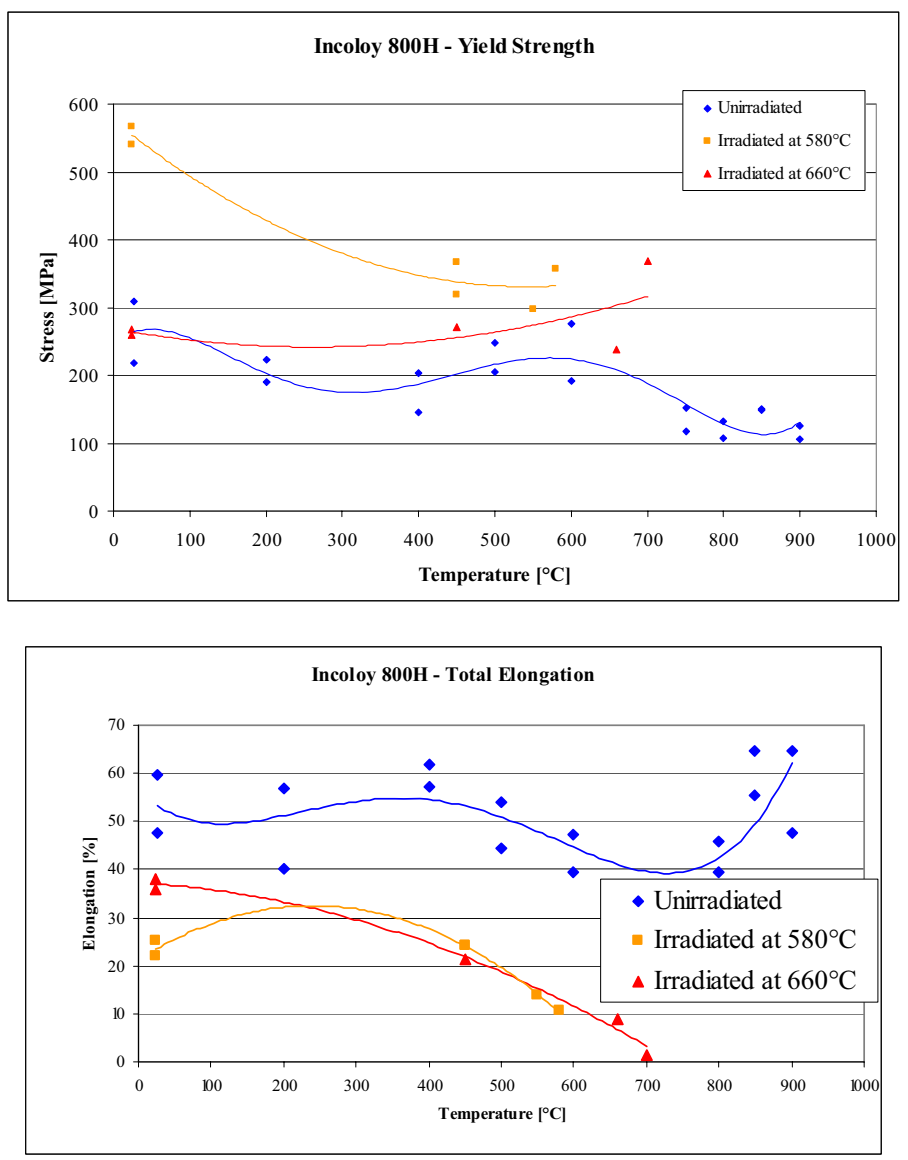

Figure 27. Tensile data for irradiated $800 \mathrm{H}$ (a) yield strength, (b) total elongation. 


\begin{tabular}{c|lll|}
\hline NEXT GENERATION NUCLEAR PLANT & Identifier: & PLN-2804 & \\
INTERMEDIATE HEAT EXCHANGER & Revision: & 0 & \\
MATERIALS RESEARCH & Effective Date: & $04 / 30 / 08$ & Page: 98 of 156 \\
AND DEVELOPMENT PLAN &
\end{tabular}

It is usually assumed that the mechanism of irradiation-induced embrittlement in nickel-based alloys irradiated above about $500^{\circ} \mathrm{C}$ is grain boundary failure resulting from nucleation and growth of helium bubbles formed through $(n, \alpha)$ reactions. The microstructure of specimens used in experiments with Alloy $800 \mathrm{H}$ carried out under the Gen IV program was never characterized to confirm this proposed mechanism for embrittlement.

Alloy $800 \mathrm{H}$ will require additional testing, including irradiation testing to fill out the database. Much of the original data is old, and was generated with samples made from 800 rather than $800 \mathrm{H}$. Creep rate and rupture time: $\mathrm{T} / \mathrm{t}$ limits for off-normal conditions. Low-cycle fatigue data must also be available to determine the allowable number of scram events. Post-irradiation tensile studies will determine the extent of embrittlement.

Alloy 316SS also has potential for radiation embrittlement, but the radiation exposure of the core barrel should be moderate. Because the core barrel is not structural, radiation damage should be less of an issue for this component.

Preliminary results indicate that $\mathrm{C}_{\mathrm{f}} / \mathrm{C}$ composites are reasonably resistant to radiation, but much work will be needed to fully demonstrate their suitability.

\subsection{Expected Lifetime}

Development of ceramic composite control rods should continue, even though they may not make the NGNP program deadlines because of challenges involved with achieving codification. In light of the revised design requirements of $\sim 8 \times 10^{21} \mathrm{n} / \mathrm{cm}^{2}$ for the 60 -year reactor lifetime, $\mathrm{C}_{\mathrm{f}} / \mathrm{C}$ composite material has sufficient radiation properties (up to $\sim 8 \mathrm{dpa}$ ) for the NGNP control rod. A composite control rod would be required to push the reactor temperature, and thus the efficiency, higher. At this point it would be premature to narrow the control rod material choices to one metal with significant issues to resolve; continuing composites research will help to mitigate technical risk. Continuing the composites development may also allow the NGNP program to leverage work being performed by the French, South Africans, and Japanese. The programs in these nations have expressed interest in the NGNP composites work and may collaborate in efforts to include the composites into the ASME code and to obtain Nuclear Regulatory Commission approval so that they can market reactors in the U.S.

\subsubsection{Inspection}

\subsubsection{Pre-Service}

Core barrel welds will need to be inspected, but methods should be standard.

\subsubsection{In-Service}

In-service inspection of the control rods may be required to ensure that no changes to the planned replacement interval are needed.

\subsubsection{Acceptance Criteria}

The acceptance criteria must be determined for the control rod. Acceptance criteria for the core barrel are already defined because welding of $800 \mathrm{H}$ and 316 is well understood. 
NEXT GENERATION NUCLEAR PLANT

INTERMEDIATE HEAT EXCHANGER

MATERIALS RESEARCH AND DEVELOPMENT PLAN
Identifier: $\quad$ PLN-2804

Revision: $\quad 0$

Effective Date: 04/30/08 Page: 99 of 156

\section{RESEARCH AND TECHNOLOGY PLAN}

\subsection{Required Actions for Code/Licensing Issues}

This section discusses the detailed plans to address the code and licensing issues highlighted in Section 5 for Alloy 617 and Alloy $800 \mathrm{H}$. Table 24. gives a summary of the testing proposed in this plan. Very detailed test plans, giving the conditions and testing of each individual specimen, are included in Appendix A. 
Idaho National Laboratory

NTERMEDIATE HEAT EXCH PLANT

MATERIALS RESEARCH MATERIALS RESEARCH
AND DEVELOPMENT PLAN

\begin{tabular}{|lll|}
\hline Identifier: & PLN-2804 & \\
Revision: & 0 & \\
Effective Date: & $04 / 30 / 08 \quad$ Page: 100 of 156 \\
\hline
\end{tabular}

Table 24. Summary of testing required to address code and licensing issues.

\begin{tabular}{|c|c|c|c|c|c|c|c|c|c|}
\hline $\begin{array}{l}\text { Test Matrix } \\
\text { Shown in detail in Appendix A }\end{array}$ & $\begin{array}{l}\text { Specimen } \\
\text { Type }\end{array}$ & $\begin{array}{c}\text { Number } \\
\text { Specimens }\end{array}$ & Environment & \begin{tabular}{|c|} 
Temperature \\
$\left({ }^{\circ} \mathrm{C}\right)$
\end{tabular} & $\begin{array}{l}\text { Product } \\
\text { Form }\end{array}$ & $\underset{(\mathrm{m} / \mathrm{m} / \mathrm{s})}{\text { Strain Rate }}$ & $\begin{array}{l}\text { Time (h) } \\
\text { (or as given) }\end{array}$ & $\begin{array}{l}\text { Exposure Temp }\left({ }^{\circ} \mathrm{C}\right) / \\
\text { Time }(\mathrm{h})\end{array}$ & Notes \\
\hline A1 Tensile Test Matrix for $S_{m}$ Confirmatory Testing & Tensile & 40 & Air & TBD & $2 \mathrm{pfs}$ & & & & \\
\hline \multirow{2}{*}{\begin{tabular}{|l|} 
A2 Test Matrix to Determine Weld Strength Rupture \\
Factor
\end{tabular}} & \multirow{2}{*}{$\begin{array}{l}\text { Weld } \\
\text { (GTA/ SMA) }\end{array}$} & \multirow[t]{2}{*}{130} & \multirow[t]{2}{*}{ Air } & \multirow[t]{2}{*}{$750-1000$} & \multirow{2}{*}{$\begin{array}{l}\mathrm{W} \\
\mathrm{lh}\end{array}$} & & \multirow{2}{*}{$\begin{array}{l}1341-62743 \\
\text { estimated rupture } \\
\text { time }\end{array}$} & & 8.5-135.0 MPa app. $\sigma$ \\
\hline & & & & & & & & & test deposited, longitudinal, and cross-welds \\
\hline \multirow[t]{2}{*}{ A3 Creep Fatigue Tests for Welds } & \multirow{2}{*}{\begin{tabular}{|l|} 
Weld \\
(GTA/ SMA)
\end{tabular}} & \multirow[t]{2}{*}{96} & \multirow{2}{*}{\begin{tabular}{|l|l} 
Air \& \\
NGNP He
\end{tabular}} & \multirow[t]{2}{*}{950} & \multirow{2}{*}{$\begin{array}{l}\text { WP } \\
1 \mathrm{~h}\end{array}$} & \multirow[t]{2}{*}{ TBD } & \multirow{2}{*}{$\begin{array}{l}0-600 \text { min } \\
\text { hold time in } \\
\text { tension }\end{array}$} & & $1.0 \%$ strain range \\
\hline & & & & & & & & & test deposited and cross-welds \\
\hline $\begin{array}{l}\text { A4(a) Aging Effects on Fracture Toughness of Wrought } \\
\text { Metal }\end{array}$ & $0.5 \mathrm{~T}-\mathrm{CT}$ & 384 & Air & $0-950$ & $\begin{array}{c}\mathrm{P} \\
2 \mathrm{~h}\end{array}$ & & & $\begin{array}{l}\text { none-1000/ } \\
\text { none-120000 }\end{array}$ & \\
\hline $\begin{array}{l}\text { A4(b) Aging Effects on Fracture Toughness of GTA } \\
\text { Weld from Filler } 617 \text { Metal }\end{array}$ & $\begin{array}{l}0.4 \mathrm{~T}-\mathrm{CT} \\
\text { (GTA) }\end{array}$ & 384 & Air & $0-950$ & $\begin{array}{c}\mathrm{P} \\
\mathrm{lh}\end{array}$ & & & $\begin{array}{l}\text { none-1000/ } \\
\text { none-120000 }\end{array}$ & test deposited and cross-welds \\
\hline $\begin{array}{l}\text { A4(c) Aging Effects on Fracture Toughness of SMA } \\
\text { Weld from Weld Electrode } 117\end{array}$ & $\begin{array}{l}0.4 \mathrm{~T}-\mathrm{CT} \\
\text { (SMA) }\end{array}$ & 384 & Air & $0-950$ & $\begin{array}{c}\mathrm{P} \\
\mathrm{lh}\end{array}$ & & & $\begin{array}{l}\text { none-1000/ } \\
\text { none-120000 }\end{array}$ & test deposited and cross-welds \\
\hline A5 Determine Strain Rate Sensitivity in Support of UCM & Tensile & 45 & Air & $20-1000$ & $\begin{array}{ll}\mathrm{P} \\
\mathrm{lh}\end{array}$ & & & & $2.5 \%$ strain range \\
\hline $\begin{array}{l}\text { A6 Torsion Test Matrix for Validating Von Mises } \\
\text { Criterion to Support UCM }\end{array}$ & Tubular & 15 & Air & $600-1000$ & $\begin{array}{ll}\mathrm{P} \\
\mathrm{lh}\end{array}$ & & & & \\
\hline A7 Stress Dip Matrix to Support UCM & Tensile & 27 & Air & $600-1000$ & $\begin{array}{c}\mathrm{P} \\
1 \mathrm{~h} \\
\end{array}$ & & & & \\
\hline \begin{tabular}{|l} 
A8 Short-Term (Days) Creep Tests to Support UCM \\
\end{tabular} & Tensile & 27 & Air & $600-1000$ & $\begin{array}{ll}\mathrm{P} \\
\mathrm{lh}\end{array}$ & & & & \\
\hline A9 Uniaxial Ratcheting Tests to Support UCM & Tensile & 27 & Air & $600-1000$ & $\begin{array}{ll}\mathrm{P} \\
\mathrm{lh}\end{array}$ & & & & \\
\hline A10 Torsional Cycling w/ Constant Axial Strain for UCM & Tubular & 36 & Air & 850,950 & $\begin{array}{c}\mathrm{P} \\
\mathrm{lh}\end{array}$ & $\begin{array}{c} \pm 1 \mathrm{E}-03 \\
\pm 1 \mathrm{E}-05 \text { shear }\end{array}$ & & & $0.0-0.3 \%$ axial strain range \\
\hline A11 Loading-Unloading-Creep Sequence for UCM & Tensile & 45 & Air & $600-1000$ & $\begin{array}{c}\mathrm{P} \\
\mathrm{lh}\end{array}$ & & & & $\begin{array}{l}\text { 1E+00, 1E-01, 1E-02 } \\
\text { MPa/s load-unload rate }\end{array}$ \\
\hline A12 Thermomechanical Cycling for UCM & Fatigue & 18 & Air & 600,1000 & $\begin{array}{c}P \\
\text { Ph }\end{array}$ & 1E-05 & & & \begin{tabular}{|l|}
$0.6-1.8 \%$ strain range \\
isothermal \& non-isothermal
\end{tabular} \\
\hline A13(a) Test Matrix for Creep Curves to Qualify UCM & Tensile & 24 & Air & $800-1000$ & $\begin{array}{c}\mathrm{P} \\
1 \mathrm{~h}\end{array}$ & & $\begin{array}{l}\begin{array}{l}4998-31615 \\
\text { est. rupture t }\end{array} \\
\end{array}$ & & 11-80 MPa applied $\sigma$ \\
\hline $\begin{array}{l}\text { A13(b) Stress Relaxation Test Matrix for Qualifying } \\
\text { UCM }\end{array}$ & Tensile & 24 & Air & $800-1000$ & $\begin{array}{c}\mathrm{P} \\
1 \mathrm{~h}\end{array}$ & & $\begin{array}{l}\text { 6000-20000 relax. } \\
\text { time }\end{array}$ & & 11-80 MPa (Initial) applied $\sigma$ \\
\hline $\begin{array}{l}\text { A14 Uniaxial Tests on Thermally aged Alloy } 617 \text { for } \\
\text { UCM }\end{array}$ & Tensile & 108 & Air & $750-1000$ & $\begin{array}{c}\mathrm{P} \\
\mathrm{lh} \\
\end{array}$ & & & \begin{tabular}{|l|l|}
$750-1000 /$ \\
$200-120000$
\end{tabular} & loading/unloading/creep strain rate change, stress dip testing \\
\hline \multirow{2}{*}{$\begin{array}{l}\text { A15 Tube Burst Tests for Alloy } 617 \text { and Alloy } 800 \mathrm{H} \\
\text { (w/ \& w/o welds \& notches) }\end{array}$} & \multirow{2}{*}{$\begin{array}{l}\text { Pressurized } \\
\text { tubes }\end{array}$} & 24 & \multirow[t]{2}{*}{ Air } & 950 & \multirow[t]{2}{*}{$\mathrm{T}$} & & & & precondition of structures: un-aged \& thermally aged for $15,000 \mathrm{~h}$ \\
\hline & & 12 & & 760 & & & & & \\
\hline A16 Creep-Fatigue Test Matrix for SMT Specimens & SMT & 40 & Air NGNP He & 950 & $\begin{array}{c}\mathrm{P} \\
\mathrm{lh}\end{array}$ & TBD & $\begin{array}{l}0-600 \text { min } \\
\text { hold time in } \\
\text { tension }\end{array}$ & & $\begin{array}{l}\text { internal pressure: } 0 \text {, TBD } \\
\Delta \varepsilon_{\mathrm{e}}=0.3,0.6 \% \text { (elastically calculated strain range) }\end{array}$ \\
\hline
\end{tabular}




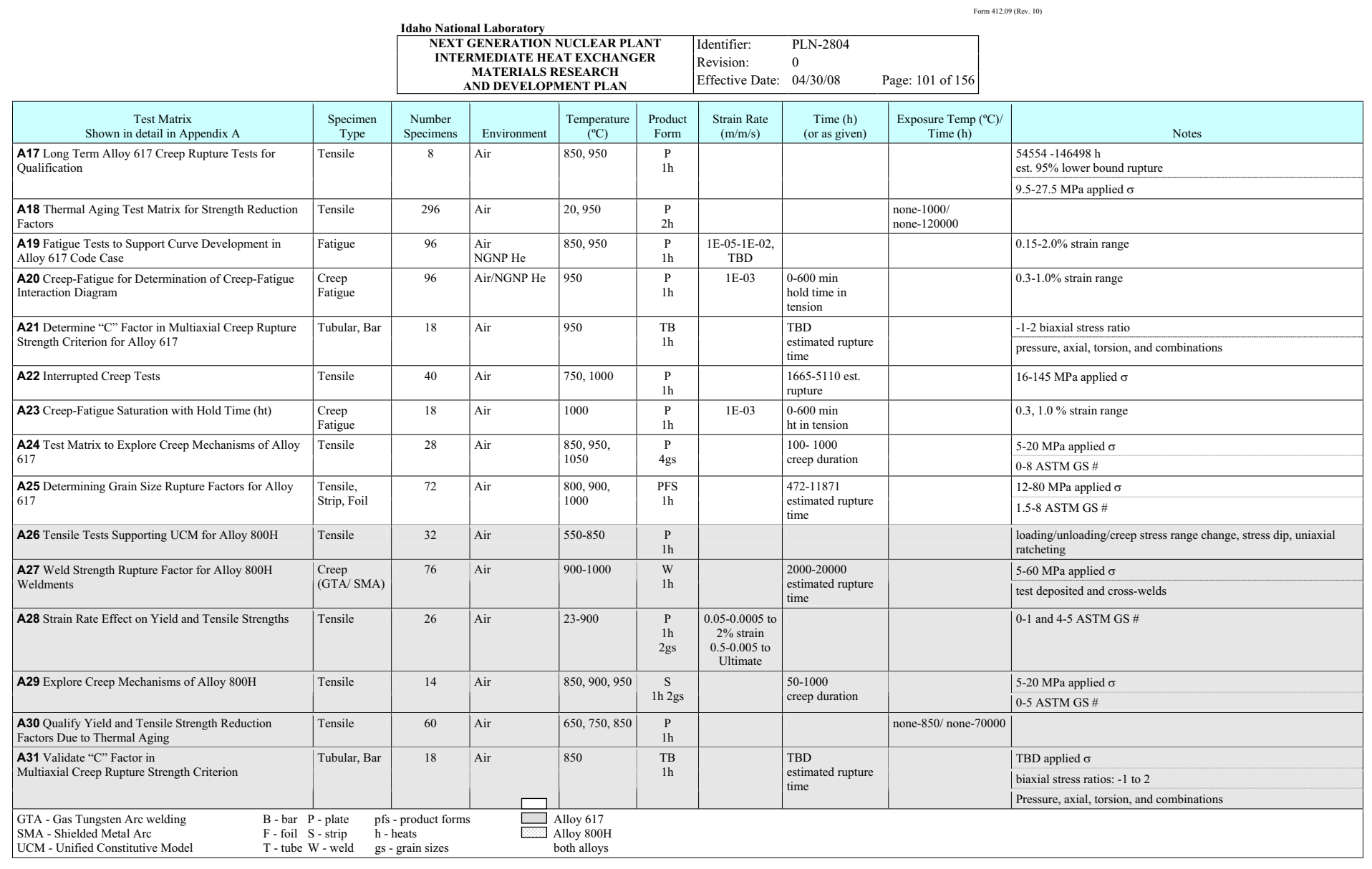




\begin{tabular}{c|lll|}
\hline NEXT GENERATION NUCLEAR PLANT & Identifier: & PLN-2804 & \\
INTERMEDIATE HEAT EXCHANGER & Revision: & 0 & \\
MATERIALS RESEARCH & Effective Date: & $04 / 30 / 08$ & Page: 102 of 156 \\
AND DEVELOPMENT PLAN &
\end{tabular}

\subsubsection{Issues Originally Identified for Draft Alloy 617 Code Case}

\subsubsection{Time-Independent Allowable Stresses, Yield and Tensile Strengths}

This effort addresses Item A1 in Table 20 of Section 5.

A new draft guideline on approving new materials in Section II, Part D, Appendix 5, recommends, for Code committee consideration, the submittal of tensile strength, yield strength, reduction of area, and elongation at $50^{\circ} \mathrm{C}$ intervals, from room temperature to $50^{\circ} \mathrm{C}$ above the maximum intended use temperature for three heats of appropriate product forms and sizes.

Allowable stresses, $S$, for all product forms of Alloy 617 are provided in Section II, Part D, Table 1B for Section I (up to $899^{\circ} \mathrm{C}$ ) and Section VIII, Division 1 (up to $982^{\circ} \mathrm{C}$ ) nonnuclear applications. However $S$ is based on 100,000-hour extrapolated allowable stresses and construction rules in Sections I and VIII do not consider creep-fatigue interaction.

While allowable stresses for Alloy 617 are currently not covered in Section II for Section III nuclear applications, it should hardly be considered as a "new material" because of a wealth of user experience base in nonnuclear applications. Thus, this would be leveraged in pursuing the establishment of allowable stresses for Alloy 617 with appropriate Code committees to lessen the burden on testing.

\section{Subsection NB Temperature Regime}

Incorporating Alloy 617 into Section III, Subsection NB was one of the original required actions for the Draft Alloy 617 Code Case. Time-independent design allowable stresses, $S_{m}$, for standard-grain-sized, annealed, Alloy 617 are not tabulated in Section II, Part D, Table 2B for use by the construction rules in Subsection NB. However, yield and tensile strengths for Alloy 617 are tabulated in Section II, Part D, Tables $\mathrm{Y} 1$ and $\mathrm{U}$, respectively, from room temperature to $525^{\circ} \mathrm{C}$. These Code values cover specifications SB-166 (bar and rod), SB-167 (seamless pipe and tube), SB-168 (plate, sheet, and strip), and SB-564 (forging).

Subsection NB covers nonferrous materials up to $427^{\circ} \mathrm{C}$. The existing database that supported the development of Tables $\mathrm{Y} 1$ and $\mathrm{U}$ for Alloy 617 is judged to be adequate for developing a Code Case by Section II for Subsection NB applications. The Task Force on Allowable Stresses of the Subgroup on Elevated Temperature Design (SG-ETD) must be approached to initiate this Code process for such a development.

\section{Subsection NH Temperature Regime}

For temperatures above $427^{\circ} \mathrm{C}$, the appropriate values for the time-independent allowable stress are under the jurisdiction of Subsection NH. An approach similar to that for establishing allowable stresses in Subsection NB should be recommended to the Task Force on Allowable Stresses of SG-ETD on the development of $S_{m}$ for Subsection NH, using existing Huntington Alloys tensile data and tensile data generated by the DOE/HTGR program. For planning purpose, a supplementary test matrix is given in Table A1 (in the Appendix) to accommodate any possible request for confirmatory tensile data from the Allowable Stresses Task Force. The Tensile Test Matrix for $S_{m}$ Confirmatory Testing will utilize 40 tensile specimens. The specimens will be tested in air at 10 different temperatures, TBD. Two different product forms will be used.

While the time-dependent primary stress limits, $S_{m t}$, of Subsection NH is generally controlled by the creep properties rather than $S_{m}$ under sustained loadings at elevated temperatures, $S_{m}$ at elevated 


\begin{tabular}{c|lll|}
\hline $\begin{array}{l}\text { NEXT GENERATION NUCLEAR PLANT } \\
\text { INTERMEDIATE HEAT EXCHANGER }\end{array}$ & Identifier: & PLN-2804 & \\
MATERIALS RESEARCH & Revision: & 0 & \\
AND DEVELOPMENT PLAN & Effective Date: & $04 / 30 / 08$ & Page: 103 of 156 \\
\hline
\end{tabular}

temperature is counted on to guard against the tensile failure mode owing to short duration loading at temperature, for example, during an earthquake.

\subsubsection{Strain Rate Effect}

Many test results have shown, the tensile curves of Alloy 617 are highly dependent on strain rates, with flow stress increasing with strain rate at temperatures above $650^{\circ} \mathrm{C}$. Thus, strain rate will affect the values of $S_{m}$ in the temperature range of interest to NGNP hot gas piping and IHX components.

This must be recognized as a design method issue. The full spectrum of strain rate effects on flow stress will be investigated in developing a unified constitutive model for Alloy 617. Inelastic analyses on prototypical component geometry and transient will be performed using this unified constitutive model to scope out the range of prototypical strain rates encountered in components. To protect against various failure modes which depend on tensile properties, these results will be used to develop a procedure to account for the strain rate effects in protecting against different failure modes that depend on yield and tensile strengths.

\subsubsection{Tests to Determine Weld Strength Rupture Factor for Alloy 617 Code Case}

This effort addresses Item A2 in Table 20 of Section 5.

The weld strength rupture factor (WSRF) is required in applying the creep-fatigue procedure in Subsection NH. WSRF is defined as the ratio of the creep rupture strength of the weldment to that of the base metal. It is time and temperature dependent in general. If the creep rupture strength of the weldment is higher than that of the base metal, WSRF is set to one.

For the weldment creep rupture test program, two welding processes will be used: GTA welding with filler metal 617 and SMA welding with Electrode 117. Tests for both deposited filler metal and crossweld are required. Table A2 presents the test matrix that supports the WSRF determination. The Test Matrix to Determine Weld Strength Rupture Factor will utilize 130 weld test specimens. The specimens will be tested in air from $750^{\circ}$ to $1000^{\circ}$ C. Gas Tungsten Arc (GTA) and Shielded Metal Arc (SMA) weld processes will be used with FM-617 filler and E-117 electrodes. Applied stress will range from 8.5 to 135.0 MPa. Estimated rupture time ranges from 1349-60968 hours. Product form will be plate from a single heat (W-heat 1). The first part of the test program would generate creep rupture data for determining the WSRF. Every attempt will be made to develop WSRFs in time to support the conceptual and preliminary design activities, using this data. The second part of the test program is comprised of very long-term creep tests. Data from these tests are needed to qualify the WSRFs for final design activities and to support final licensing approval.

\subsubsection{Physical Properties to Support Alloy 617 Code Case}

This effort addresses Item A3 in Table 20 of Section 5.

The physical properties that will be measured to support the Alloy 617 Code Case are as follows:

1. Values of the Young modulus from $850^{\circ} \mathrm{C}$ to $1000^{\circ} \mathrm{C}$ to supplement those from room temperature up to $850^{\circ} \mathrm{C}$, available in Section II.

2. Poisson's ratio at $20^{\circ} \mathrm{C}$ and from $50^{\circ} \mathrm{C}$ to $1000^{\circ} \mathrm{C}$ in $25^{\circ} \mathrm{C}$ intervals.

3. Instantaneous coefficient of thermal expansion at $20^{\circ} \mathrm{C}$ and from $50^{\circ} \mathrm{C}$ to $1000^{\circ} \mathrm{C}$ in $25^{\circ} \mathrm{C}$ intervals. 


\begin{tabular}{c|lll|}
\hline $\begin{array}{l}\text { NEXT GENERATION NUCLEAR PLANT } \\
\text { INTERMEDIATE HEAT EXCHANGER }\end{array}$ & Identifier: & PLN-2804 & \\
MATERIALS RESEARCH & Revision: & 0 & \\
AND DEVELOPMENT PLAN & Effective Date: & $04 / 30 / 08$ & Page: 104 of 156 \\
\hline
\end{tabular}

4. Mean coefficient of thermal expansion in going from $20^{\circ} \mathrm{C}$ to indicated temperature, $\mathrm{T}$, where $\mathrm{T}=$ $50^{\circ} \mathrm{C}$ to $1000^{\circ} \mathrm{C}$ in $25^{\circ} \mathrm{C}$ intervals.

5. Linear thermal expansion in going from $20^{\circ} \mathrm{C}$ to indicated temperature, $\mathrm{T}$, where $\mathrm{T}=50^{\circ} \mathrm{C}$ to $1000^{\circ} \mathrm{C}$ in $25^{\circ} \mathrm{C}$ intervals.

6. Thermal conductivity (TC) at $20^{\circ} \mathrm{C}$ and from $50^{\circ} \mathrm{C}$ to $1000^{\circ} \mathrm{C}$ in $25^{\circ} \mathrm{C}$ intervals.

7. Thermal diffusivity (TD) at $20^{\circ} \mathrm{C}$ and from $50^{\circ} \mathrm{C}$ to $1000^{\circ} \mathrm{C}$ in $25^{\circ} \mathrm{C}$ intervals.

8. Density at $20^{\circ} \mathrm{C}$ and from $50^{\circ} \mathrm{C}$ to $1000^{\circ} \mathrm{C}$ in $25^{\circ} \mathrm{C}$ intervals.

Note that TC, TD, density and specific heat are related by:

$$
\mathrm{TD}=\frac{\mathrm{TC}}{\text { density } \times \text { specific heat }}
$$

\subsubsection{Isochronous Stress-Strain Curves}

This effort addresses Item A4 in Table 20 of Section 5.

The isochronous stress-strain curves are required design information and will be constructed to support development of the Alloy 617 Code Case once the unified constitutive model is developed. They are obtained by using a qualified material model to simulate uniaxial creep response under constant stress. Based on these series of creep curves for different constant stresses, the strains are cross-plotted with stresses for a fixed time, resulting in the isochronous stress-strain curve construction.

\subsubsection{Data Needs Originally Identified for Draft Alloy 617 Code Case}

\subsubsection{Assess Creep-Fatigue Procedure for Alloy 617 Welds}

This effort addresses Item B1 in Table 20 and NRC concerns 4 and 12 in Table 19 of Section 5.

The creep-fatigue procedure in Subsection NH is established based on creep-fatigue data for base metal. It does not have a separate creep-fatigue procedure for welds. Instead, a number of conservative requirements are relied upon including (1) limiting the inelastic accumulated strains to one-half the allowable strain limits for the base metal, (2) limiting the allowable fatigue at weldments to one-half the design cycles allowed for the base metal, and (3) reducing the allowable creep rupture strength at weldments to a fraction of the base metal value through the weld strength rupture factor when determining the time-to-rupture.

Thus, creep-fatigue data for Alloy 617 weldments are needed to assess the adequacy of the treatment of welds per Subsection NH procedure under creep-fatigue conditions. They are also needed to ascertain that the weldment creep-fatigue performance is no worse than the parent base metal, "normalized" for lower creep rupture strength of the weldment, to validate the design evaluation methodology. From a licensing perspective, the availability of the creep-fatigue data for welds will help to address NRC's basic concerns about weldment creep crack growth etc., to verify overall conservatism of the design process.

One filler metal and one of the two welding processes to be selected in the screening task of Section 8.1.4.2 will be used to develop the weldment creep-fatigue data. Both deposited filler metal and crossweld will be tested. The strain rate will be the same as that selected from the continuous fatigue task. Table A3 shows the test matrix with various hold times. Testing in NGNP helium is included in the test matrix to qualify the "helium benefit" in the creep-fatigue procedure as discussed in Section 8.1.4.7. The 


\begin{tabular}{c|lll|}
\hline $\begin{array}{l}\text { NEXT GENERATION NUCLEAR PLANT } \\
\text { INTERMEDIATE HEAT EXCHANGER }\end{array}$ & Identifier: & PLN-2804 & \\
MATERIALS RESEARCH & Revision: & 0 & \\
AND DEVELOPMENT PLAN & Effective Date: & $04 / 30 / 08$ & Page: 105 of 156 \\
\hline
\end{tabular}

Creep-Fatigue Test matrix for Alloy 617 Welds will utilize 96 weld specimens. Half of the specimens will be tested in air while the other half will be tested in NGNP He. The specimens will be tested at $950^{\circ} \mathrm{C}$ at $1 \%$ strain. Hold times will range from 0 to 600 minutes. Gas Tungsten Arc and Shielded Metal Arc weld processes will be used with FM-617 filler and E-117 electrodes. Product form will be plate from a single heat (W-heat 1). Some of the tension holds in the test matrix might be revised to compression holds when the test program commences.

\subsubsection{Environment Effect}

This effort addresses Item B2 in Table 20 and NRC concern 17 in Table 19 of Section 5.

Characterizing environmental effects on the microstructure and properties of Alloy 617 will continue as a R\&D scoping activity. The substantial German programs from the 1980's have demonstrated that if the helium impurity chemistry is controlled to be slightly oxidizing, the material properties under HTGR helium are equivalent to those determined in air. Testing will continue under the NGNP program and with French collaborators under the INERI to complete characterizing the impact of decarburizing or carburizing conditions on the microstructure and properties of Alloy 617 for quasistatic conditions at one atmosphere pressure. Tensile and creep rupture properties will be measured postexposure to gas chemistries that are either decarburizing or carburizing to develop a qualitative understanding of the impact of these gas chemistries.

Gas velocities on the order of 50 to $75 \mathrm{~m} / \mathrm{s}$ are anticipated in some sections of the NGNP and it is possible that particulate will be entrained in the gas. When a component test loop becomes available, the impact of high velocity impure helium on the corrosion and erosion behavior of Alloy 617 will be characterized.

\subsubsection{Synergistic Effect of Aging, Environment, Loading and Temperature}

This addresses Item B3 in Table 20 of Section 5.

Microstructural examination of relevant samples collected from other testing programs proposed in the TDP will be performed. After preliminary analysis a small program may be initiated to examine possible differences in microstructures for Alloy 617 samples that are aged (1) in air only, (2) in NGNP environment, (3) under load in air, i.e., creep and stress relaxation tests, and (4) under load in NGNP helium.

\subsubsection{Characterize Aging Effects on Fracture Toughness}

This addresses Item B4 in Table 20 and NRC concern 18 in Table 19 of Section 5.

Solution annealed Alloy 617 in the as-received condition is very ductile. Because of its high fracture toughness, J-R Curve testing for Alloy 617 is very difficult to conduct; hence, not many fracture toughness data are reported in the literature. Figure 28 shows a J-R Curve at $700^{\circ} \mathrm{C}$, and Figures 29 (a) and (b) show the values of $\mathrm{J}_{0}$ (onset of stable ductile tearing) and the Tearing Modulus, respectively, as a function of test temperatures. These data are from the work of Krompholz, ${ }^{59}$ and multi-specimen technique was used in determining the J-R Curve. ${ }^{60,61}$ 


\section{NEXT GENERATION NUCLEAR PLANT \\ INTERMEDIATE HEAT EXCHANGER \\ MATERIALS RESEARCH \\ AND DEVELOPMENT PLAN}

Identifier: $\quad$ PLN-2804

Revision: $\quad 0$

Effective Date: $04 / 30 / 08$

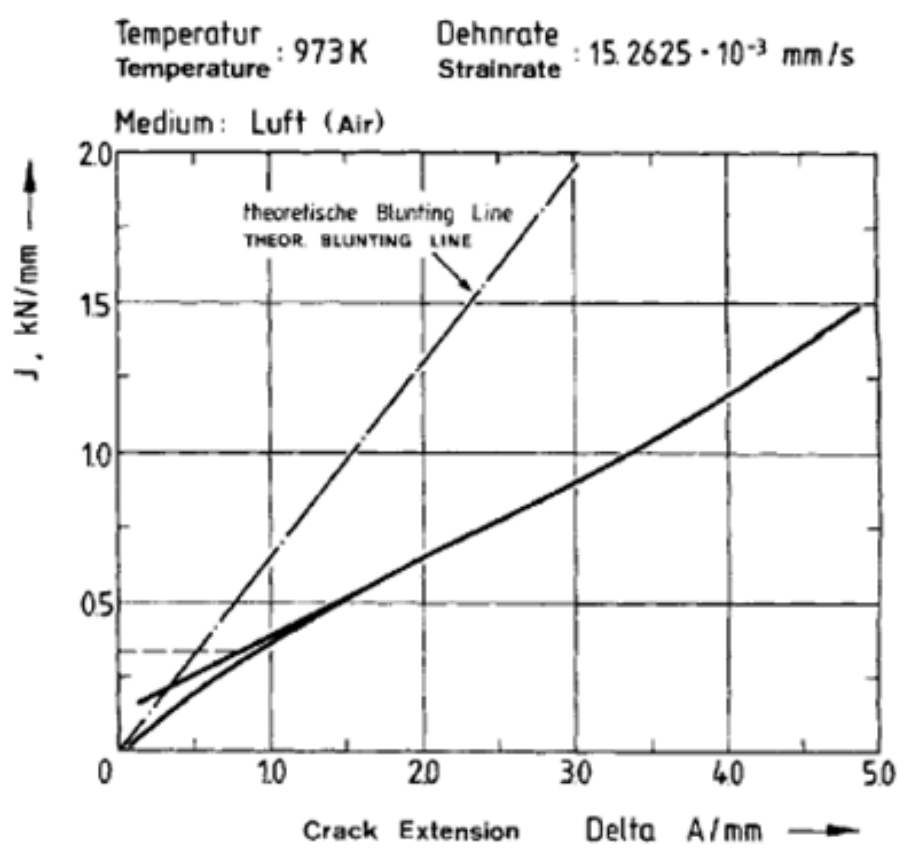

Figure 28. J-R Curve for Alloy 617 , as received, $700^{\circ} \mathrm{C} .{ }^{59}$
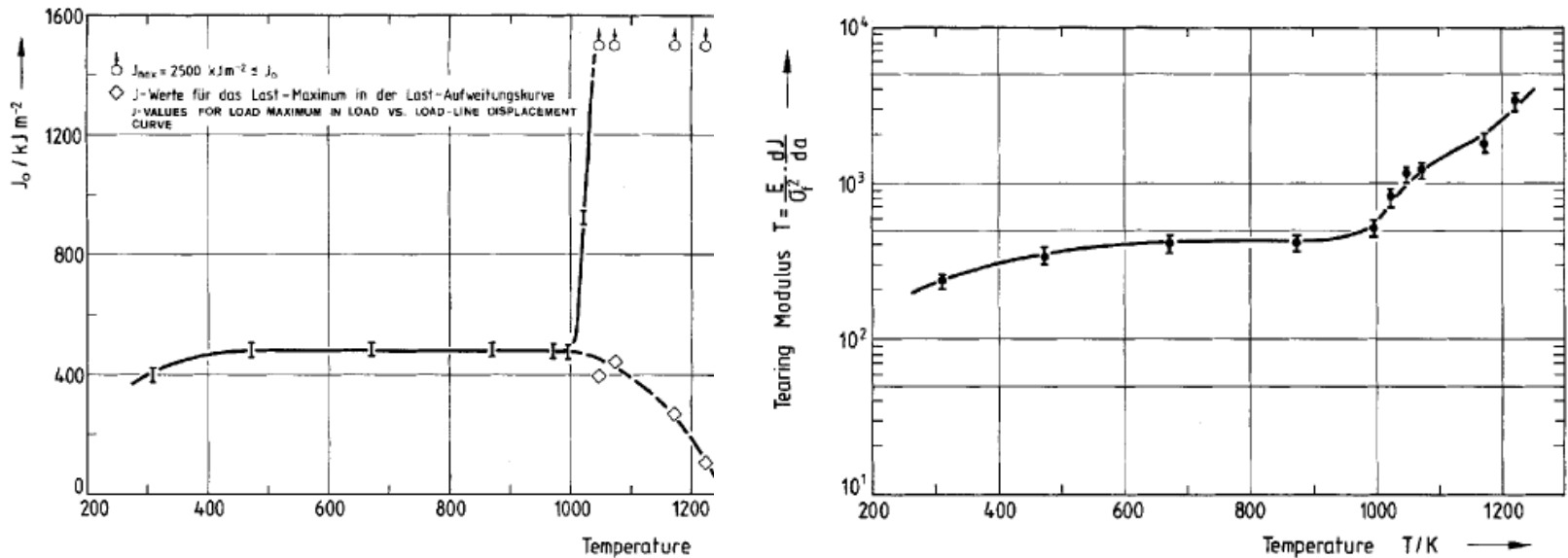

Figure 29.(a) Values of $\mathrm{J}_{0}$ and (b) tearing modulus for Alloy 617, as received (temperature in kelvin).

As observed from Figure 29(b), a small increase occurs in $\mathrm{J}_{0}$ between $35^{\circ} \mathrm{C}$ and $200^{\circ} \mathrm{C}$, and it remains constant from $200^{\circ} \mathrm{C}$ to $725^{\circ} \mathrm{C}$, then a strong increase occurs at $750^{\circ} \mathrm{C}$. Krompholz et al.$^{59}$ reported that no onset of stable tearing was detectable up to a J-integral value of $2500 \mathrm{~kJ} / \mathrm{m}^{2}$ at temperatures of $775^{\circ} \mathrm{C}$ and above.

No J-R Curve or toughness data were found from the literature on thermally aged Alloy 617. However, data on room-temperature Charpy V-Notch (CVN) energies from thermally aged Alloy 617 were reported by Bassford and Schill ${ }^{62}$ Figure 30, taken from Yakawa ${ }^{63}$ shows the Bassford-Schill data. It is seen that the room-temperature CVN energy dropped significantly, depending on the thermal exposure temperature and time, from an averaged unaged value of $170 \mathrm{ft} \mathrm{lb}$, to as low as $30 \mathrm{ft} \mathrm{lb}$ for aged Alloy 617. 
NEXT GENERATION NUCLEAR PLANT

INTERMEDIATE HEAT EXCHANGER

MATERIALS RESEARCH

AND DEVELOPMENT PLAN
Identifier: $\quad$ PLN-2804

Revision: $\quad 0$

Effective Date: $04 / 30 / 08 \quad$ Page: 107 of 156

CVN Energy (J)

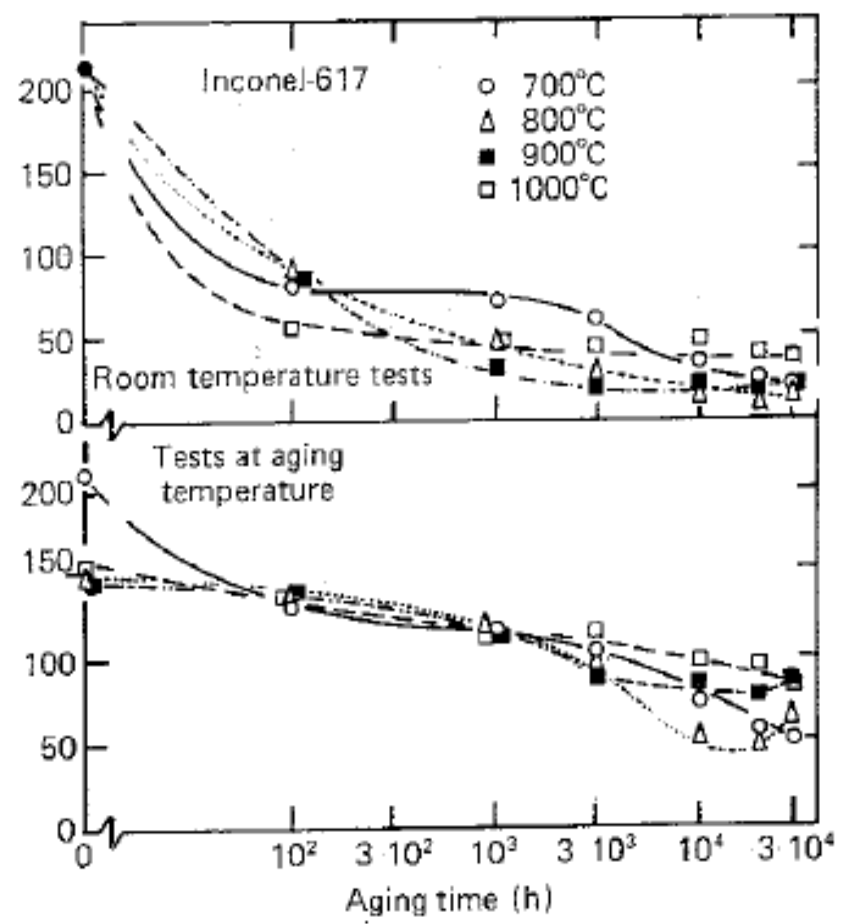

Figure 30. Room-temperature CVN energy of Alloy 617 after thermal exposure.

Figure 31 shows the CVN Energy at Room Temperature and Aging Temperature after thermal exposures for Alloy 617. The data are from Bruch et al. ${ }^{64}$ The room-temperature CVN energy dropped to below $10 \mathrm{~J}$ after exposure at $800^{\circ} \mathrm{C}$ and $900^{\circ} \mathrm{C}$ for 10,000 hours.

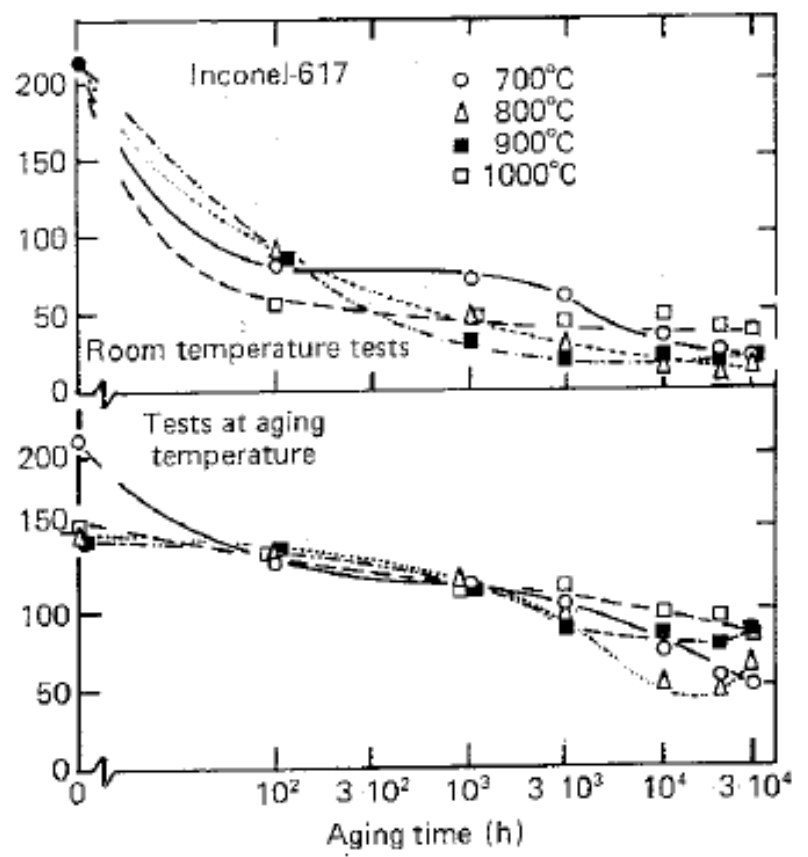

Figure 31. CVN energy at room temperature and aging temperature after thermal exposure. 


\begin{tabular}{c|lll|}
\hline $\begin{array}{c}\text { NEXT GENERATION NUCLEAR PLANT } \\
\text { INTERMEDIATE HEAT EXCHANGER }\end{array}$ & Identifier: & PLN-2804 & \\
MATERIALS RESEARCH & Revision: & 0 & \\
AND DEVELOPMENT PLAN & Effective Date: & $04 / 30 / 08$ & Page: 108 of 156 \\
\hline
\end{tabular}

All of these data show that nonductile failure is a significant failure mode for Alloy 617 for long-term elevated temperature service. The effects of thermal aging on the fracture toughness of Alloy 617 need to be characterized adequately to develop an operating envelope and an ancillary design procedure to protect against nonductile failure.

Limited CVN data for thermally aged Alloy 617 welds from Bassford, ${ }^{65}$ also showed drops in the room temperature $\mathrm{CVN}$ energy for aged material. Thus, toughness testing for thermally aged Alloy 617 weldments is necessary.

From the limited CVN data shown in Figure 31, toughness data from very long thermal exposures, at least 20,000 hours, are needed to establish the nonductile failure design procedure to support conceptual and preliminary design activities. Longer exposure times are necessary to qualify the procedure and to support the final design and licensing approval. Thus, there is a need to start the thermal exposure program as soon as possible.

Test matrices for fracture toughness testing of Alloy 617, Gas Tungsten Arc (GTA) welds, and Shielded Metal Arc (SMA) welds are shown in Tables A4(a), A4(b), and A4(c), respectively. Both deposited filler metal welds and cross-welds will be tested. The tests will be performed to the ASTM Standard E1820. Compact tension specimens of sizes $0.5 \mathrm{~T}$ and $0.4 \mathrm{~T}$ will be used for the base metal and weldments, respectively. E1820 permits the generation of test data that can be used either for J-R Curve or fracture toughness determination. The Aging Effects Test Matrix on Fracture Toughness of Alloy 617 Wrought Metal will utilize $3840.5-\mathrm{T}-\mathrm{CT}$ specimens. The specimens will be tested in air from $0^{\circ}$ to $950^{\circ} \mathrm{C}$.

Product form will be plate with two different heats (Aged -1, Aged -2). Exposure temperatures and times range from none to $1000^{\circ} \mathrm{C}$ and none to 120,000 hours. The Aging Effects Test Matrix on Fracture Toughness of GTA (Gas Tungsten Arc) Weld from Filler Metal 617 will utilize 384 0.4T-CT weld specimens. The specimens will be tested in air from $0^{\circ}$ to $950^{\circ} \mathrm{C}$. Product form will be plate with from a single heat (BM-1). Exposure temperatures and times range from none to $1000^{\circ} \mathrm{C}$ and none to 120,000 hours. The Aging Effects Test Matrix on Fracture Toughness of SMA (Shielded Metal Arc) Weld from Weld Electrode 117 will utilize $3840.4 \mathrm{~T}-\mathrm{CT}$ weld specimens. The specimens will be tested in air from $0^{\circ}$ to $950^{\circ} \mathrm{C}$. Product form will be plate with from a single heat (BM-1). Exposure temperatures and times range from none to $1000^{\circ} \mathrm{C}$ and none to 120,000 hours.

The planned thermal exposure times are 200 hours (h), $650 \mathrm{~h}, 2000 \mathrm{~h}, 5,300 \mathrm{~h}$, and 20,000 h for establishing the data to support conceptual and preliminary design activities. Longer thermal exposures of $32,000 \mathrm{~h}, 50,000 \mathrm{~h}, 76,000 \mathrm{~h}$, and $120,000 \mathrm{~h}$ are planned to develop toughness data for qualifying the nonductile failure design procedure.

A best effort was made to include adequate specimen counts in the test matrices to cover the change in the failure mode from ductile to brittle as thermal aging progresses. However, experience from aging test programs of this type suggests $t$ it is necessary to have ample aged materials to cover any emergent testing needs as the test program progresses over a long period.

\subsubsection{Design Methodology Issues for Alloy 617}

\subsubsection{Alloy 617 Unified Constitutive Model Development}

This effort addresses Items A4 and C1 in Table 20 of Section 5 and supports developing a new guideline for inelastic stress analysis similar to the Standard NE F9-5T. It also addresses NRC concern 10 in Table 19 of Section 5. 


\begin{tabular}{c|lll|}
\hline NEXT GENERATION NUCLEAR PLANT & Identifier: & PLN-2804 & \\
INTERMEDIATE HEAT EXCHANGER & Revision: & 0 & \\
MATERIALS RESEARCH & Effective Date: & $04 / 30 / 08$ & Page: 109 of 156 \\
AND DEVELOPMENT PLAN &
\end{tabular}

A literature survey has yielded two papers on unified constitutive equations for Alloy 617 for very high temperature applications. One was given by Schwertel et al. ${ }^{66}$ where models based on Roberson ${ }^{67}$ and Chaboche ${ }^{68}$ were developed, using the same dataset. The equations for both models are onedimensional and capable of modeling cyclic response. The predictions from both models compared quite well with short-term data. Schwertel et al. gave preference to Chaboche's formulation as it is more amenable to finite element implementation.

The second unified model appeared in a paper by Corum and Blass ${ }^{56}$ who attributed the development of the unified constitutive model to ORNL's S.-J. Chang, whose model was based on Roberson's formulation. ${ }^{69}$ The Chang model was used to simulate creep curves at different temperatures and loads. The results were cross-plotted in the format of isochronous stress-strain curves to support the Draft Alloy 617 Code Case. The equations from the Chang model are also one-dimensional but as presented the equations do not accommodate load reversal, and hence cannot be used to model cyclic loading.

The Schwertel model (based on the Chaboche formulation) and the Chang model were used to simulate the creep tests preformed by GE. ${ }^{70}$ The time-to- $1 \%$ strain as computed from the two models under various applied loads and the test result are shown in Table 25. The comparisons are poor, even with allowance for data scatter.

Table 25. Numerical simulation of creep tests.

\begin{tabular}{cccc}
\hline & \multicolumn{3}{c}{ Time to 1\% Total Strain (h) } \\
\cline { 2 - 4 } $\begin{array}{c}\text { Applied Load } \\
(\mathrm{MPa})\end{array}$ & Schwertel Model & Chang Model & GE Data \\
\hline 96.6 & 6.1 & 0.029 & 2.4 \\
79.3 & 8.5 & 0.059 & 16.5 \\
75.9 & 189 & 0.067 & 8.5 \\
72.4 & 469 & 0.086 & 20.5 \\
66.2 & 3091 & 0.12 & 26.0 \\
64.8 & 4819 & 0.14 & 13.8 \\
56.6 & 128300 & 0.29 & 55 to 1100 \\
\hline
\end{tabular}

A renewed effort in developing a new unified constitutive model for Alloy 617 is necessary. It is essential that the new unified constitutive model can make accurate predictions, particularly for longer time, and be qualified by test data from key feature tests.

\section{General Framework for Unified Constitutive Model}

An extensive survey of unified constitutive models shows that all have the same basic form. Generally, each will have a "flow rule," which gives an expression for the inelastic strain rate, $\dot{\varepsilon}^{\text {in }}$, in terms of three internal variables: the back stress, $X$, the yield stress, $Y$, and the drag stress, $D$. An additional internal variable $Y^{*}$ can be introduced to model aging. Evolution equations in the form of first order differential equations are then defined for the internal variables. Each of these internal variables may be composed of one or several terms, and each new term brings with it its own additional material constants. For example, in one-dimensional form, the inelastic strain rate and the evolution of the back stress can be represented as: 


\section{NEXT GENERATION NUCLEAR PLANT \\ INTERMEDIATE HEAT EXCHANGER \\ MATERIALS RESEARCH AND DEVELOPMENT PLAN}

$\begin{array}{ll}\text { Identifier: } & \text { PLN-2804 } \\ \text { Revision: } & 0 \\ \text { Effective Date: } & 04 / 30 / 08\end{array}$

$\dot{\varepsilon}^{i n}=F\left[\left\langle\frac{|\sigma-X|-Y-Y^{*}}{D}\right\rangle\right] \operatorname{sign}(\sigma-X)$

$$
\dot{X}=\underbrace{c \dot{\varepsilon}^{\text {in }}}_{\text {strain hardening }}-\frac{\overbrace{c \dot{\varepsilon}^{\text {in }} \mid X}^{\text {dynamic recovery }}}{L}-\underbrace{A|X|^{m-1} X}_{\text {static recovery }}
$$

where $\sigma$ is the stress, $F$ the flow function, $\langle>$ the Macaulay bracket, and $c, L, A$, and $m$ are material constants or functions.

\section{Alloy 617 Deformation Behaviors}

Table 26 summarizes the essential deformation/microstructural behaviors of Alloy 617 that are important to model.

Table 26. Deformation/microstructural behaviors to be modeled by unified constitutive equations.

\begin{tabular}{|c|c|}
\hline $\begin{array}{c}\text { Deformation/Microstructural } \\
\text { Behaviors }\end{array}$ & Remarks \\
\hline Strain rate sensitivity & Stress-strain curves change significantly when strain rates are changed. \\
\hline $\begin{array}{l}\text { Strain hardening and } \\
\text { softening }\end{array}$ & $\begin{array}{l}\text { Significant hardening at low temperature, and little hardening is } \\
\text { observed in monotonic and cyclic tests at elevated temperatures. }\end{array}$ \\
\hline Creep behavior & $\begin{array}{l}\text { Exhibits classical primary, secondary, and tertiary creep below } 800^{\circ} \mathrm{C} \text {. } \\
\text { Secondary creep (constant creep rate) is hardly noticeable at } 800^{\circ} \mathrm{C} \text { and } \\
\text { above. After the initial primary regime, the creep rate increases } \\
\text { gradually until rupture. }\end{array}$ \\
\hline Stress relaxation & Important in modeling creep-fatigue interaction. \\
\hline Ratcheting & Very challenging to model but essential for application. \\
\hline $\begin{array}{l}\text { Thermo-mechanical } \\
\text { behavior }\end{array}$ & $\begin{array}{l}\text { Model will be developed largely based on test data from constant } \\
\text { temperature tests, but applications involve thermal transients } \\
\text { (temperature change). }\end{array}$ \\
\hline $\begin{array}{l}\text { Hardening under different } \\
\text { strain ranges }\end{array}$ & Increasing hardening under increasing strain amplitude cycling. \\
\hline Microstructure effects & $\begin{array}{l}\text { Grain coarsening, grain boundary migration, etc. affect yield and tensile } \\
\text { strengths (aging). }\end{array}$ \\
\hline
\end{tabular}

\section{Finite Element Implementation of Unified Constitutive Equations}

Implementing the Alloy 617 unified constitutive equations in finite element solvers such as ABAQUS and ANSYS will be carried out so that the unified constitutive model can be used by designers to perform inelastic analyses. This will be an important task in supporting the development of analysis guidelines similar to the Nuclear Standard NE F9-5T. 


\begin{tabular}{c|lll|}
\hline $\begin{array}{c}\text { NEXT GENERATION NUCLEAR PLANT } \\
\text { INTERMEDIATE HEAT EXCHANGER }\end{array}$ & Identifier: & PLN-2804 & \\
MATERIALS RESEARCH & Revision: & 0 & \\
AND DEVELOPMENT PLAN & Effective Date: & $04 / 30 / 08$ & Page: 111 of 156 \\
\hline
\end{tabular}

It is also important to note that unified constitutive equations and finite element implementation methodology (i.e., time integration algorithm) need to be developed in an integrated manner. Frequently, unified constitutive equations developed without the consideration of time integration method are too stiff numerically to be solvable by the finite element method.

The hierarchical structure of the unified constitutive model will be exploited in the finite element implementation so that it is more straightforward to extend them to other candidate materials such as Alloy $800 \mathrm{H}$, hence reducing $\mathrm{R} \& \mathrm{D}$ costs.

\section{Testing to Develop Unified Constitutive Equations}

Testing to support the development of unified constitutive equations for Alloy 617 can be divided into two groups, A and B. Tests in Group A last for a relatively short duration, from minutes to weeks, and are designed to probe the rate (time-dependent) response of Alloy 617. They include tests at different strain and stress rates, rate change, loading/unloading, cyclic, short-term creep and stress relaxation etc., all at uniform temperatures. Thermo-mechanical tests are also included in Group A. Data from testing in Group A will be used to set the material constants and material functions of the unified constitutive equations.

However, as demonstrated by the results in Table 25, models based on short-term data need to be supplemented with longer-term data. The testing in Group B includes longer-term creep and stress relaxation tests and will provide such information for the Alloy 617 unified constitutive model.

Generating the test data from the same heat and product form, if possible, is advantageous to obtaining more consistent results by removing heat-to-heat and product-form variability. The required testing to support the development of the unified constitutive model for Alloy 617 is outlined below. Note that the test matrices are developed based on the best current information. Minor changes could take place as the testing program progresses.

\section{Strain Rate Change Tensile Tests}

These tensile tests are designed to obtain data to determine the strain rate sensitivity of Alloy 617 . A wide range of strain rates is sampled within a single test. The tests cover the full range of temperatures, from room temperature to $1000^{\circ} \mathrm{C}$. The following loading sequence is applied to each test:

1. Load at a constant strain rate of $1.0 \mathrm{E}-6 \mathrm{~m} / \mathrm{m} / \mathrm{s}$ until the total strain reaches $0.5 \%$.

2. Change to a constant strain rate of $1.0 \mathrm{E}-5 \mathrm{~m} / \mathrm{m} / \mathrm{s}$ and load to a total strain of $1 \%$.

3. Change to a constant strain rate of $1.0 \mathrm{E}-4 \mathrm{~m} / \mathrm{m} / \mathrm{s}$ and load to a total strain of $1.5 \%$.

4. Change to a constant strain rate of $1.0 \mathrm{E}-3 \mathrm{~m} / \mathrm{m} / \mathrm{s}$ and load to a total strain of $2 \%$.

5. Change to a constant strain rate of $1.0 \mathrm{E}-2 \mathrm{~m} / \mathrm{m} / \mathrm{s}$ and load to a total strain of $2.5 \%$.

6. Unload to zero load at a stress rate of $-0.1 \mathrm{MPa} / \mathrm{s}$.

The test matrix is presented in Table A5. The Tensile Test Matrix to Determine Strain Rate Sensitivity in Support of Unified Constitutive Model will utilize 45 tensile specimens. The specimens will be tested in air with a temperature range of $20^{\circ}$ to $1000^{\circ} \mathrm{C}$. Total strain will be $2.5 \%$. Product form will be plate from a single heat (xyz-CF).

\section{Strain Rate Change Torsion Tests}

These tests are designed to gather data on the strain rate sensitivity of Alloy 617. The data in shear will be used to verify whether the frequently used Von Mises assumption, used to generalize one- 


\begin{tabular}{c|lll|} 
NEXT GENERATION NUCLEAR PLANT & Identifier: & PLN-2804 & \\
INTERMEDIATE HEAT EXCHANGER & Revision: & 0 & \\
MATERIALS RESEARCH & Effective Date: & $04 / 30 / 08$ & Page: 112 of 156 \\
AND DEVELOPMENT PLAN &
\end{tabular}

dimensional constitutive equations to multi-dimensions, is adequate. Tubular specimens will be used as test articles to approximate uniform deformation in the cylinder wall. The loading sequence applied to each test is as follows:

1. Load at a constant shear rate of $1.0 \mathrm{E}-6 \mathrm{~m} / \mathrm{m} / \mathrm{s}$ until the total shear strain reaches $0.5 \%$.

2. Change to a constant shear rate of $1.0 \mathrm{E}-5 \mathrm{~m} / \mathrm{m} / \mathrm{s}$ and load to a total shear strain of $1 \%$.

3. Change to a constant shear rate of $1.0 \mathrm{E}-4 \mathrm{~m} / \mathrm{m} / \mathrm{s}$ and load to a total shear strain of $1.5 \%$.

4. Change to a constant shear rate of $1.0 \mathrm{E}-3 \mathrm{~m} / \mathrm{m} / \mathrm{s}$ and load to a total shear strain of $2 \%$.

5. Change to a constant shear rate of $1.0 \mathrm{E}-2 \mathrm{~m} / \mathrm{m} / \mathrm{s}$ and load to a total shear strain of $2.5 \%$.

6. Unload to zero load at a stress rate of $-0.1 \mathrm{MPa} / \mathrm{s}$.

The test matrix is given in Table A6. The Torsion Test Matrix for Validating Von Mises Criterion to Support Unified Constitutive Model will utilize 15 tubular specimens. The specimens will be tested in air with a temperature range of $600^{\circ}$ to $1000^{\circ} \mathrm{C}$. Product form will be plate from a single heat (xyz-CF).

\section{Stress Dip Tests}

These tensile tests are designed to obtain data for determining the materials constants related to the internal variables. During the stress dip period, the test samples a wide range of inelastic strain rates. The loading sequence applied to each test is as follows:

1. Load at a constant strain rate of $1.0 \mathrm{E}-6 \mathrm{~m} / \mathrm{m} / \mathrm{s}$ until the total strain reaches $0.5 \%$, then hold the total strain constant at $0.5 \%$ for a period of B hours, where B will be on the order of 6 to 12 hours, to be determined when the test program commences. The stress relaxes during this hold time, and hence the term "stress dip."

2. At the end of the relaxation period, reload at a constant strain rate of $1.0 \mathrm{E}-5 \mathrm{~m} / \mathrm{m} / \mathrm{s}$ until the total strain reaches $1 \%$, then perform stress relaxation for B hours.

3. At the end of the relaxation period, reload at a constant strain rate of $1.0 \mathrm{E}-4 \mathrm{~m} / \mathrm{m} / \mathrm{s}$ until the total strain reaches $1.5 \%$, then perform stress relaxation for B hours.

4. At the end of the relaxation period, reload at a constant strain rate of $1.0 \mathrm{E}-3 \mathrm{~m} / \mathrm{m} / \mathrm{s}$ until the total strain reaches $2 \%$, then perform stress relaxation for B hours.

5. At the end of the relaxation period, reload at a constant strain rate of $1.0 \mathrm{E}-2 \mathrm{~m} / \mathrm{m} / \mathrm{s}$ until the total strain reaches $2.5 \%$, then perform stress relaxation for B hours.

6. Unload the tensile specimen to zero load at a stress rate of $-0.1 \mathrm{MPa} / \mathrm{s}$.

The test matrix is presented in Table A7. The Stress Dip Test Matrix to Support Unified Constitutive Model will utilize 27 tensile specimens. The specimens will be tested in air with a temperature range of $600^{\circ}$ to $1000^{\circ} \mathrm{C}$. Product form will be plate from a single heat (xyz-CF).

\section{Short-term Creep Tests}

These tensile tests are designed to obtain data for determining the materials constants related to the internal variables. The loading sequence applied to each test is as follows:

1. Load at a constant stress rate of $0.01 \mathrm{MPa} / \mathrm{s}$ until the stress reaches $\mathrm{X} 1 \mathrm{MPa}$, then hold the load constant for a period of B hours. The specimen will creep. 


\begin{tabular}{c|lll|}
\hline NEXT GENERATION NUCLEAR PLANT & Identifier: & PLN-2804 & \\
INTERMEDIATE HEAT EXCHANGER & Revision: & 0 & \\
MATERIALS RESEARCH & Effective Date: & $04 / 30 / 08$ & Page: 113 of 156 \\
AND DEVELOPMENT PLAN &
\end{tabular}

2. At the end of the creep period, reload at a constant stress rate of $0.05 \mathrm{MPa} / \mathrm{s}$ until the stress reaches $\mathrm{X} 2$ $\mathrm{MPa}$, then hold the load constant for a period of B hours.

3. At the end of the creep period, reload at a constant stress rate of $0.1 \mathrm{MPa} / \mathrm{s}$ until the stress reaches $\mathrm{X} 3$ $\mathrm{MPa}$, then hold the load constant for a period of B hours.

4. Unload the tensile specimen to zero load at a stress rate of $-0.1 \mathrm{MPa} / \mathrm{s}$.

The duration of short-term creep period, B, will be on the order of 6 to 12 hours. The stress levels X1, $\mathrm{X} 2$, and $\mathrm{X} 3$ are different for different test temperatures and scoping will be required to determine their values when the test program commences. Care will be taken to ensure that they do not exceed the corresponding tensile strengths. The test matrix is presented in Table A8. The Test Matrix for Short-term (Days) Creep Tests to Support Unified Constitutive Model will utilize 27 Alloy 617 tensile specimens. The specimens will be tested in air with a temperature range of $600^{\circ}$ to $1000^{\circ} \mathrm{C}$. Product form will be plate from a single heat (xyz-CF).

\section{Uniaxial Ratcheting}

These ratcheting tests are designed to obtain data for determining the materials constants related to the internal variables. The loading sequence applied to each test is as follows:

1. Preload at a constant strain rate of $1 . \mathrm{E}-3 \mathrm{~m} / \mathrm{m} / \mathrm{s}$ to a strain of $1 \%$. Unload to zero stress at a strain rate of $-1 . \mathrm{E}-3 \mathrm{~m} / \mathrm{m} / \mathrm{s}$.

2. Start at zero stress, load at a constant stress rate of $0.01 \mathrm{MPa} / \mathrm{s}$ to the stress level of $\mathrm{X} 1 \mathrm{MPa}$, then unload to zero stress at a stress rate of $-0.01 \mathrm{MPa} / \mathrm{s}$. Repeat this loading/unloading sequence for $\mathrm{M}$ cycles.

3. Continue test and repeat Step 2 except with loading rate of $0.1 \mathrm{MPa} / \mathrm{s}$ and unloading at a stress rate of $-0.1 \mathrm{MPa} / \mathrm{s}$.

4. Continue test and repeat Step 2 except with loading rate of $1.0 \mathrm{MPa} / \mathrm{s}$ and unloading at a stress rate of $-1.0 \mathrm{MPa} / \mathrm{s}$.

The stress level X1 is equal to or slightly less than the maximum preload stress. It will be different for different test temperatures. The number of cycles, M, will be on the order of 20 . The test matrix is presented in Table A9. The Test Matrix for Uniaxial Ratcheting Tests to Support Unified Constitutive Model will utilize 27 tensile specimens. The specimens will be tested in air with a temperature range of $600^{\circ}$ to $1000^{\circ} \mathrm{C}$. Product form will be plate from a single heat (xyz-CF).

\section{Torsional Cycling with Constant Axial Strain}

These biaxial tests are designed to obtain data for determining the materials constants related to the internal variables. The loading sequence applied to each test is as follows:

1. Load specimen axially at a constant axial strain rate of $1 \mathrm{E}-3 \mathrm{~m} / \mathrm{m} / \mathrm{s}$ until $\mathrm{A} \%$ axial strain is reached. Hold axial strain at $\mathrm{A} \%$.

2. Torsionally cycle the specimen at the shear strain rates of $\pm \mathrm{T} \mathrm{m} / \mathrm{m} / \mathrm{s}$ and a shear strain range of $0.04 \%$ until hysteresis loops stabilize.

3. Increase the shear strain range to a value of $\mathrm{f}$ while torsionally cycle the specimen at the same shear strain rates of $\pm \mathrm{T} \mathrm{m} / \mathrm{m} / \mathrm{s}$ until hysteresis loops stabilize.

4. Execute Step 3 for $\mathrm{f}=0.1 \%, 0.2 \%, 0.3 \%, 0.4 \%, 0.5 \%, 0.6 \%, 0.7 \%, 0.8 \%, 0.9 \%$, and $1 \%$, consecutive. 


\begin{tabular}{c|lll|}
\hline NEXT GENERATION NUCLEAR PLANT & Identifier: & PLN-2804 & \\
INTERMEDIATE HEAT EXCHANGER & Revision: & 0 & \\
MATERIALS RESEARCH & Effective Date: & $04 / 30 / 08$ & Page: 114 of 156 \\
AND DEVELOPMENT PLAN &
\end{tabular}

Perform Steps $1-4$ at $\mathrm{T}=1 . \mathrm{E}-3$, and for each of $\mathrm{A}=0,0.15,0.3$, respectively.

Repeat Steps 1- 4 at $\mathrm{T}=1 . \mathrm{E}-5$, and for each of $\mathrm{A}=0,0.15,0.3$, respectively.

The test matrix is presented in Table A10. The Test Matrix for Torsional Cycling with Constant Axial Strain to Support Unified Constitutive Model will utilize 36 tubular specimens. The specimens will be tested in air at $850^{\circ}$ and $950^{\circ} \mathrm{C}$. Shear strain rates of $\pm 1 \mathrm{E}-03$ and $\pm 1 \mathrm{E}-05 \mathrm{~m} / \mathrm{m} / \mathrm{s}$ will be used at axial strains of $0.00,0.15$, and $0.30 \%$. Product form will be plate from a single heat (xyz-CF).

\section{Tensile Loading-Unloading-Creep Sequence}

These tensile tests are designed to obtain data for determining the materials constants related to the internal variables. The loading sequence applied to each test is as follows:

Loading and unloading rates for each test are kept at the same magnitude of $\mathrm{Y} \mathrm{MPa} / \mathrm{s}$.

1. Load tensile specimen at constant stress rate $\mathrm{Y} \mathrm{MPa} / \mathrm{s}$ until the stress reaches $\mathrm{X} \mathrm{MPa}$, then unload specimen at to a stress level equal to a fraction, $\mathrm{f}$, of $\mathrm{X}$ at the same stress rate magnitude. Let the specimen creep for B hours.

2. Perform Step 1 consecutively for $\mathrm{f}=0,0.1,0.2,0.3,0.4,0.5,0.6,0.65,0.7,0.75,0.8,0.85,0.9$, and 0.95 .

3. At the end of the last creep period, unload specimen to zero load.

Perform Steps 1-3 for Y = 1.E-2, 1.E-1, 1, respectively.

The stress level $\mathrm{X}$ and the creep period $\mathrm{B}$ will be determined when the test program commences. It could be different for different temperature. Care will be taken to ensure that the stress $\mathrm{X}$ does not exceed the corresponding tensile strength.

Dependent on the stress level that the specimen is unloaded to, the creep rate during the creep period could be positive, zero, or negative, because the back stress lies somewhere below the flow curve and the inelastic strain rate is proportional to the sign of $(\sigma-\mathrm{X})$. Hence, if creep takes place at a stress level that is lower than the back stress, negative creep rate results. Otherwise, the creep rate could be zero or positive depending on whether the creep stress is equal to or greater than the back stress. The test matrix is presented in Table A11. The Test Matrix for Loading-Unloading-Creep Sequence to Support Unified Constitutive Model will utilize 45 tensile specimens. The specimens will be tested in air with a temperature range of $600^{\circ}$ to $1000^{\circ} \mathrm{C}$. Loading-Unloading rates of $1 \mathrm{E}-02,1 \mathrm{E}-01$, and $1 \mathrm{E}+00 \mathrm{MPa} / \mathrm{s}$ will be used. Product form will be plate from a single heat (xyz-CF).

\section{Thermomechanical Cycling Tests}

Out-of-phase thermomechanical cycling tests are proposed to determine the nonisothermal response of Alloy 617. Each specimen is cycled at a constant strain rate of $\mathrm{E} \mathrm{m} / \mathrm{m} / \mathrm{s}$ and a strain range of $\mathrm{y} \%$ for 100 cycles. The temperature is cycled between temperatures A1 and A2 and is out of phase with the strain cycles. The specific test parameters will be determined when the test program commences. Examples parameters are: strain rate $=1 . \mathrm{E}-5 \mathrm{~m} / \mathrm{m} / \mathrm{s}$, strain range $=0.6 \%, 1.2 \%$ and $1.8 \%, \mathrm{~A} 1=600^{\circ} \mathrm{C}, \mathrm{A} 2=$ $1000^{\circ} \mathrm{C}$. Baseline isothermal cycling data will also be required. A test matrix is presented in Table A12. The Test Matrix for Thermomechanical Cycling to Support Unified Constitutive Model will utilize 18 fatigue specimens. The specimens will be tested in air using isothermal conditions at $600^{\circ}$ and $1000^{\circ} \mathrm{C}$ and non-isothermal at $600 / 1000^{\circ} \mathrm{C}$. A strain rate of $1 \mathrm{E}-05 \mathrm{~m} / \mathrm{m} / \mathrm{s}$ will be used over a strain range of 0.6 to $1.8 \%$. Product form will be plate from a single heat (xyz-CF). 


\begin{tabular}{c|lll|}
\hline $\begin{array}{c}\text { NEXT GENERATION NUCLEAR PLANT } \\
\text { INTERMEDIATE HEAT EXCHANGER }\end{array}$ & Identifier: & PLN-2804 & \\
MATERIALS RESEARCH & Revision: & 0 & \\
AND DEVELOPMENT PLAN & Effective Date: & $04 / 30 / 08$ & Page: 115 of 156 \\
\hline
\end{tabular}

\section{Creep and Relaxation Curves}

The short-term data discussed above will be used to determine the material constants. However, longer term creep and stress relaxation responses are needed to qualify the long-term predictability of the unified constitutive model. To support the early need dates of the conceptual/preliminary design activities, data from the data $\log$ at 4- month intervals will be used to calibrate/fine-tune the material constants of the unified constitutive equations for Alloy 617. This is done to gain confidence in the unified constitutive equations to support conceptual/preliminary design activities.

Table A13(a) shows the test matrix for the creep tests. The estimated rupture times and their $95 \%$ lower and upper bounds for the given applied stresses are tabulated in the table for reference. The Test Matrix for Creep Curves to Qualify Unified Constitutive Model will utilize 24 tensile specimens. The specimens will be tested in air at $800^{\circ}, 900^{\circ}$, and $1000^{\circ} \mathrm{C}$. Applied stresses will range from 11 to $80 \mathrm{MPa}$. Estimated ruptures times for the specimens range from 4998 to 31615 hours. Product form will be plate from a single heat (xyz-CF). The test matrix for the stress relaxation tests is shown in Table A13(b). The Stress Relaxation Test Matrix for Qualifying Unified Constitutive Model will utilize 24 tensile specimens. The specimens will be tested in air at $800^{\circ}, 900^{\circ}$, and $1000^{\circ} \mathrm{C}$. Initial stress values will range from 11 to $80 \mathrm{MPa}$. Relaxation times will range from 6,000 to 120,000 hours. Product form will be plate from a single heat (xyz-CF).

\section{Thermal Aging Effects}

The data will be used to determine the influence of thermal aging on the material constants of the unified constitutive model. This effort also addresses NRC concerns 19 in Table 19 of Section 5.

Alloy 617 undergoes thermal aging when exposed to elevated temperatures for long-time service. Tensile specimens prepared from thermally aged material will be used to perform (1) strain rate change tests, (2) stress dip tests, and (3) loading/unloading/creep tests at the aging temperatures.

Table A14 gives the test matrix. The aging temperatures are $750^{\circ} \mathrm{C}, 850^{\circ} \mathrm{C}, 950^{\circ} \mathrm{C}$, and $1000^{\circ} \mathrm{C}$, and the exposure times are $200 \mathrm{~h}, 650 \mathrm{~h}, 2000 \mathrm{~h}, 5,300 \mathrm{~h}, 20,000 \mathrm{~h}, 32,000 \mathrm{~h}, 50,000 \mathrm{~h}, 76,000 \mathrm{~h}$, and 120,000 h. The Uniaxial Test Matrix on Thermally-aged Alloy 617 to Support Unified Constitutive Model will utilize 108 tensile specimens. The specimens will be tested in air with a temperature range of $750^{\circ}$ to $1000^{\circ} \mathrm{C}$. Exposure temperature and times range from $750^{\circ}$ to $1000^{\circ} \mathrm{C}$ and 200 to 120000 hours. Product form will be plate from a single heat (xyz-CF).

\subsubsection{Key Feature Testing}

This effort addresses Item C2 in Table 20 of Section 5.

Many of the design criteria in Subsection NH are based on material properties determined from specimen testing where the stress and deformation states are typically one-dimensional. However, these criteria are used in structural design to establish the theoretical structural adequacy of a particular component design configuration subjected to a particular set of loading conditions. The stress and deformation states in the structural components are generally multi-axial. Key feature testing is a way to bridge the gap between structural performance prediction by design methods which are established based on specimen testing, and the actual structural performance of the component as determined from component testing or actual service.

The idea behind a key feature test is to identify a particular failure mode(s) of interest and then identify a test article configuration and testing condition that will demonstrate the appropriateness of the 


\begin{tabular}{c|lll|}
\hline $\begin{array}{l}\text { NEXT GENERATION NUCLEAR PLANT } \\
\text { INTERMEDIATE HEAT EXCHANGER } \\
\text { MATERIALS RESEARCH }\end{array}$ & Identifier: & PLN-2804 & \\
Revision: & 0 & \\
AND DEVELOPMENT PLAN & Effective Date: & $04 / 30 / 08$ & Page: 116 of 156 \\
\hline
\end{tabular}

criteria selected to guard against that failure mode. For example, in Subsection NH, in a cylindrical section remote from discontinuities, the material property parameter is the allowable stress based on the governing value of creep rupture strength, creep rate or onset of tertiary creep. The criterion for protection against failure owing to internal pressure loading is the elastically calculated membrane stress intensity. An appropriate key feature test would be an internally pressurized cylinder operating in the creep regime. By measuring the time to failure, it can be determined whether the allowable stress used with the elastically calculated membrane stress provides an appropriate margin of safety.

Another use of the key feature test is to determine an allowable loading parameter, such as internal pressure, for use with a particular configuration that is too complex for reliable determination of an allowable value. Examples include using burst tests to determine the pressure-temperature rating of valve bodies, flanged joints and piping components. In this case, the results are sometimes incorporated in ASME Code design rules by reference to the appropriate component standard.

\section{Verification of Unified Constitutive Equations for Alloy 617}

Subsection NH, Appendix $\mathrm{T}$ is structured to permit using the results of elastic analyses to bound the effects of creep on strain, deformation and cyclic damage at elevated temperature. These elastic results are used in conjunction with simplified mechanistic models that are approximations of real component and material behavior; thus, the resultant design criteria are conservative, in some cases quite conservative. When the criteria based on elastic analyses cannot be satisfied, the potentially more accurate results of inelastic analyses can be used in conjunction with criteria based on using such analytical models. Generally, these criteria are less conservative than those based on elastic analyses.

The Simplified Model Test (SMT) can be used as a key feature test for evaluating the validity of inelastic analysis using unified constitutive model for Alloy 617. The SMT incorporates elastic follow-up characteristics representative of the stress and strain redistribution occurring in more complex structures. However, unlike the complex structure, the SMT article is amenable to direct measurement of both stress and strain throughout the cyclic life, thus providing an excellent test bed for evaluating the unified constitutive equations for Alloy 617. As discussed in Section 8.1.3.4, SMT testing is part of the effort to remove unnecessary conservatism in the Subsection NH creep-fatigue procedure. Stress and strain measurements from those tests will be used to qualify the unified constitutive model for Alloy 617.

\section{Model Tube Burst Tests - Alloy 617 and Alloy $800 \mathrm{H}$}

This is envisioned as a series of model tube burst tests to demonstrate the adequacy of the criteria and adjusted allowable stress values to address NRC concerns for (a) long-term thermal aging and (b) crack initiation and subcritical crack growth, respectively. Table A15 gives a test matrix. Note that these test results will also address NRC concern regarding weld integrity. The Tube Burst Tests Matrix for Alloy 617 and Alloy $800 \mathrm{H}$ will utilize 24 Alloy 617 tube specimens and 12 Alloy $800 \mathrm{H}$ tube specimens. Internal tube pressures are TBD. The specimens will be tube, tube with stressed welds and tube with stressed welds and EDM slots. The specimens will be tested in air at $950^{\circ} \mathrm{C}$ (Alloy 617) and $760^{\circ} \mathrm{C}$ (Alloy $800 \mathrm{H}$ ). Pre-conditioning of the structures will be either un-aged or thermally aged at temperature for 15,000 hours.

\section{Vessel and Piping Ratcheting Tests - Alloy 617 and Alloy 800H}

These tests address NRC concerns on whether the current simplified bounding methods in Appendix $\mathrm{T}$ of Subsection NH are appropriate not only for the geometry and conditions for which they were derived, a pressurized cylinder with cyclic linear through-the-wall thermal gradients, but also for the more general geometries and loading conditions for which they are currently permitted. 


\begin{tabular}{c|lll|}
\hline NEXT GENERATION NUCLEAR PLANT & Identifier: & PLN-2804 & \\
INTERMEDIATE HEAT EXCHANGER & Revision: & 0 & \\
MATERIALS RESEARCH & Effective Date: & $04 / 30 / 08$ & Page: 117 of 156 \\
AND DEVELOPMENT PLAN &
\end{tabular}

Prior testing has been done here and abroad for materials and geometries used in the Liquid Metal Fast Breeder Reactor (LMFBR) program, so part of this task is to assess those tests for applicability to NGNP. An issue not addressed in previous testing is the effect of strain rate-dependent yield strength at high to very high temperatures on creep ratcheting models. Also, continuing improvements are being developed for bounding techniques for strain limits owing to cyclic loading. These tests results can also be used to verify these new technologies.

\section{Reference Stress Verification Tests - Alloy 617 and Alloy $800 \mathrm{H}$}

Subsection NH currently relies on the results of elastic analysis and stress classification to establish required wall thicknesses, not only for simple cylindrical geometries but also for more complex geometries such as vessel nozzles subjected to both internal pressure and external piping loads.

To avoid undue conservatism using the results of detailed elastic finite element analysis, it is necessary to categorize the results into stress components relevant to the failure mode under consideration. For complex structures and loading, this process is more of an art than a science and is fraught with opportunities for error.

Another problem with the current approach is that it does not take into consideration the extra load capacity of redundant structures. These objections can be addressed by reference stress methods that do not require stress classification and do consider redundancy. Currently used in British nuclear elevated temperature structural design criteria, there has been limited key feature testing to demonstrate the validity of reference stress methods, but apparently no tests consider significantly unbalanced systems or those with combined loading.

\subsubsection{More General Simplified Methods}

This is in the nature of generic issues for all of Subsection NH. New work in the Task 9 of the DOE/ASME Gen IV Materials Project will address this issue. Recommended testing from the task will be assessed and tests relevant to NGNP will be proposed.

\subsubsection{Improve Alloy 617 Creep-Fatigue Procedure}

This effort addresses Item C4 in Table 20 and NRC concern 22 in Table 19 of Section 5.

The current Subsection NH creep-fatigue procedure was established by the steps of (1) analytically obtaining a detailed stress-strain history, (2) comparing the stress and strain components to cyclic test results deconstructed into stress and strain quantities, and (3) recombining the results to obtain a damage function. Instead of these steps, elastic follow-up testing uses a simplified model of the structure to determine the cyclic life experimentally_thus the name, Simplified Model Test or SMT approach.

Subject to the constraints and procedures identified in Jetter, ${ }^{71}$ the approach reduces to a procedure similar to that used in the early elevated temperature ASME Code Cases where creep damage owing to pure stress relaxation was built into the cyclic design life curves. However, those curves did not account for the increase in strain range owing to strain redistribution (elastic follow-up) nor did they account for the retardation of stress relaxation and resulting increase in creep damage during the cycle owing to the higher stress history. These two effects were compensated by conservative assumptions that undoubtedly resulted in large and sometimes unworkable conservatism in the Subsection NH rules based on elastic analysis. In the SMT approach, the strain range enhancement and retardation of stress relaxation are built into the test results and do not require the previous conservative assumptions. The rational for the followup test specimen and test procedure is a major feature of the approach. ${ }^{71}$ 


\begin{tabular}{c|lll|}
\hline NEXT GENERATION NUCLEAR PLANT & Identifier: & PLN-2804 & \\
INTERMEDIATE HEAT EXCHANGER & Revision: & 0 & \\
MATERIALS RESEARCH & Effective Date: & $04 / 30 / 08$ & Page: 118 of 156 \\
AND DEVELOPMENT PLAN &
\end{tabular}

A key feature of the SMT approach is the test procedure in which the controlled input is displacement, not strain. Practically, this means it is necessary to accurately measure and control the relative displacement of the ends of the test section. Figure 32 shows a sketch of a SMT specimen, sized for Alloy 617 with an elastic follow-up factor in the range of 3.5 to 4.0. It is the longer, thicker sections on either end that supply the elastic follow-up to the center section. The relative displacement of the ends is analogous to the relative thermal displacement in an actual component. The cylindrical specimen shown has the added advantage that sustained loading caused by internal pressure can be superimposed on the displacement-controlled axial loading to more fully model actual component behavior. The results of elastically predicted stress and strain in the test specimen are analogous to the elastically predicted stress and strain in the component. Thus, test results are tabulated as cycles to failure versus the elastically calculated strain from the applied displacement, not a measured strain as is the procedure in a conventional test.

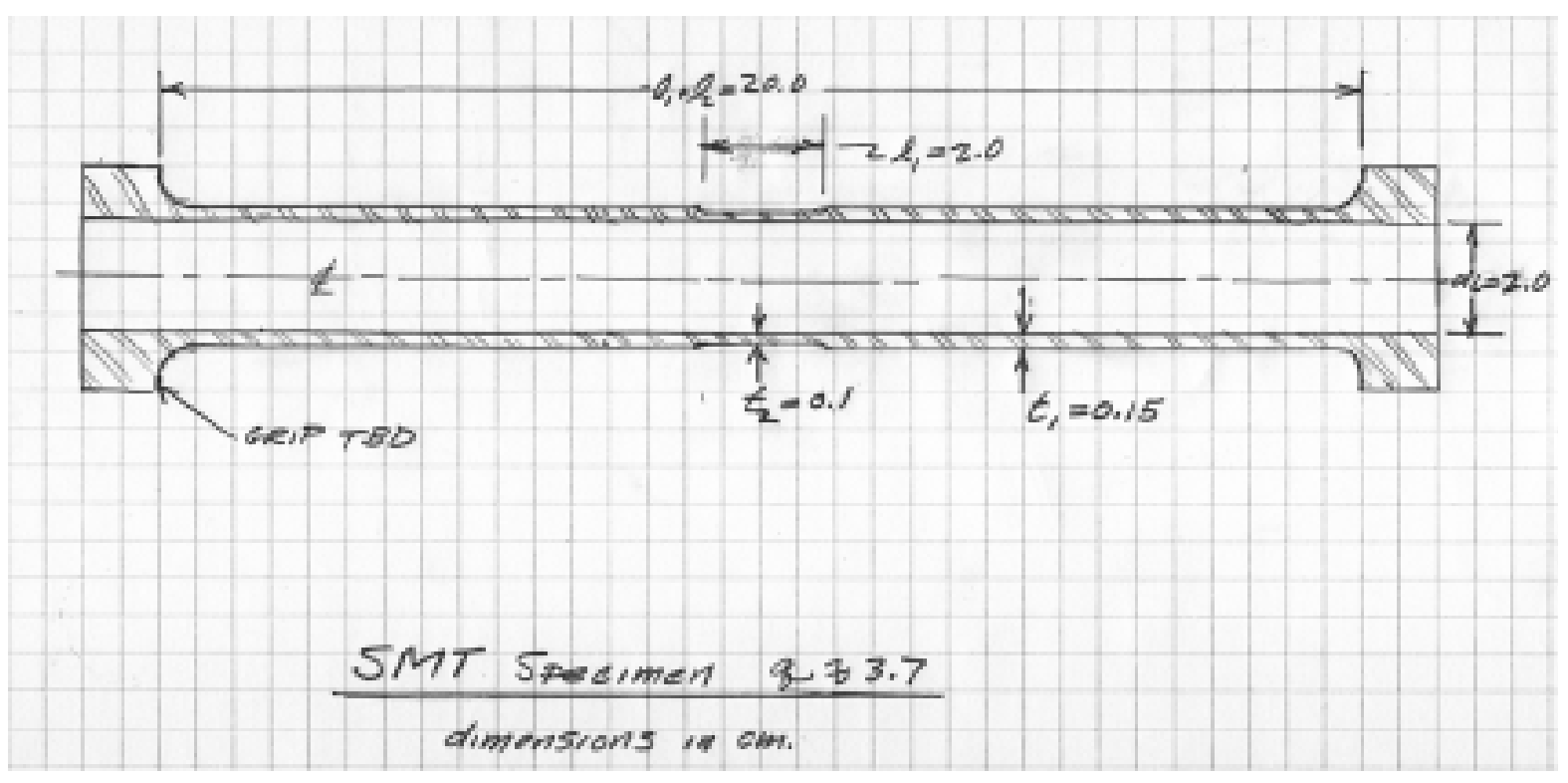

Figure 32. Sketch of SMT specimen.

In its simplest form, only the elastically computed strain and the cyclic life at a given temperature are required parameters from an SMT approach test. However, because the load and areas are readily known, if strains are measured, the test results also provide an accurate vehicle for calibrating or verifying the results of a full-scale inelastic analysis and failure prediction in a specimen with representative strain redistribution.

Table A16 shows a test matrix for generating creep-fatigue data using the SMT specimens. The strain rate $\mathrm{S} 1$ listed in the table will be selected from the strain-rate study of the continuous fatigue task. The Creep-Fatigue Test Matrix for SMT Specimens will utilize 48 SMT specimens. Half the specimens will be tested in air while the second half will be tested in NGNP He. Both sets will be tested at $950^{\circ} \mathrm{C}$. Strain rate and internal pressure is TBD. All specimens will be held in tension with hold times ranging from 0 to 600 minutes. $\Delta \varepsilon_{e}$ (elastically calculated strain range in percent) will be 0.3 and 0.6 . Product form will be plate from a single heat (xyz-CF).

Testing in NGNP helium environment is proposed to obtain data to support the inclusion of a less restrictive design curve in the Alloy 617 Code Case. The stresses and strains measured from the SMT specimens will be used as key feature test results to qualify the Alloy 617 unified constitutive equations. 


\begin{tabular}{|c|lll|}
\hline NEXT GENERATION NUCLEAR PLANT & Identifier: & PLN-2804 \\
INTERMEDIATE HEAT EXCHANGER & Revision: & 0 & \\
MATERIALS RESEARCH & Effective Date: & $04 / 30 / 08$ & Page: 119 of 156 \\
AND DEVELOPMENT PLAN &
\end{tabular}

\subsubsection{Additional Issues to Update Alloy 617 Data for Subsection NH}

\subsubsection{Time-Dependent Allowable Stresses}

This effort addresses Item D1 in Table 21 of Section 5.

The ASME Section III Subsection NH criteria for estimating the time-dependent allowable stress $S_{t}$ include (1) the average strength for $1 \%$ total strain, (2) $80 \%$ of the minimum strength for tertiary creep, and (3) $67 \%$ of the minimum rupture strength values. The Draft Alloy 617 Code Case had established the time-dependent allowable stress $S_{t}$ based only on criteria (1) and (3) and for 100,000 hours.

While the design life of NGNP is 60 years, it has been recognized by the NGNP Materials R\&D Team and validated by the reactor vendors through their recent engineering studies that Alloy 617 cannot be used for IHX components that operate at the highest metal temperature of $950^{\circ} \mathrm{C}$, owing to low timedependent strengths and elevated temperature cyclic service that induce severe creep-fatigue damage. Hence the reactor vendors have considered the concept of high/intermediate temperature IHXs in series where the IHX that sees a metal temperature of $950^{\circ} \mathrm{C}$ would have a reduced design life and be replaceable. The design goal for the replaceable IHX is a lifetime longer than 100,000 hours. The hot-gas piping, while not as severely stressed as the IHX components, will likely be designed as a nonreplaceable component for the full NGNP design life. Thus in either case, the time-dependent allowable stresses in the Draft Alloy 617 Code Case would have to be extended.

The time-dependent allowable stresses in the Draft Alloy 617 Code Case were established using a database developed by Huntington Alloys. Table 27 presents a summary of the Huntington database. The longest creep rupture time is about 40,000 hours. Because the required data to support the establishment of time-dependent allowable stresses take a very long time to develop, it would severely impact the schedule of conceptual and preliminary design activities if new creep tests longer than 40,000 hours are relied upon to support these activities.

Tables 28 and 29 give a summary of the datasets developed by General Electric under the DOE HTGR program and by ORNL, respectively. The Huntington, General Electric and ORNL data are currently accessible in the Gen IV Materials Handbook. Tables 30 and 31 summarize two large European databases from the European Creep Collaborative Committee (ECCC) and the ODIN database of the Joint Research Centre (JRC) of the European Commission at Petten, the Netherlands. While details of the creep rupture times from the Petten database are not currently available (although a request for information has already been made) the size of the database is substantially larger than the combined dataset from the Huntington, General Electric and ORNL databases. 
Idaho National Laboratory

NEXT GENERATION NUCLEAR PLANT

INTERMEDIATE HEAT EXCHANGER

MATERIALS RESEARCH

AND DEVELOPMENT PLAN
Identifier:

Revision:

Effective Date: $04 / 30 / 08$
Page: 120 of 156

Table 27. Huntington Alloys creep rupture data for Alloy 617 in air.

\begin{tabular}{|c|c|c|c|c|c|c|c|c|c|}
\hline \multicolumn{10}{|c|}{ Huntington Alloys Database ${ }^{65}$} \\
\hline \multirow[b]{2}{*}{$\begin{array}{l}\text { Temp } \\
\left({ }^{\circ} \mathrm{C}\right)\end{array}$} & \multicolumn{5}{|c|}{$\begin{array}{l}\text { Number of tests with specified durations } \\
\text { (unfailed tests in parenthesis) }\end{array}$} & \multirow{2}{*}{$\begin{array}{l}\text { Max. } \\
\text { rupture } \\
\text { duration } \\
\text { (h) }\end{array}$} & \multirow{2}{*}{$\begin{array}{l}\text { Max. } \\
\text { duration } \\
\text { of } \\
\text { unfailed } \\
\text { test (h) }\end{array}$} & \multirow{2}{*}{$\begin{array}{l}\text { Min. } \\
\text { applied } \\
\text { stress } \\
(\mathrm{MPa})\end{array}$} & \multirow{2}{*}{$\begin{array}{l}\text { Max. } \\
\text { applied } \\
\text { stress } \\
(\mathrm{MPa})\end{array}$} \\
\hline & $<10 \mathrm{kh}$ & $\begin{array}{c}10- \\
20 \mathrm{kh}\end{array}$ & $\begin{array}{c}20- \\
30 \mathrm{kh}\end{array}$ & $\begin{array}{c}30- \\
40 \mathrm{kh}\end{array}$ & $\begin{array}{c}40- \\
50 \mathrm{kh}\end{array}$ & & & & \\
\hline 593 & 5 & 0 & 2 & 0 & 0 & 28,735 & & 324.1 & 537.8 \\
\hline 649 & $16(3)$ & (2) & 1 & 0 & 0 & 24,482 & 16,562 & 241.3 & 517.1 \\
\hline 704 & 6 & (1) & 1 & 0 & 0 & 20,023 & 15,700 & 137.9 & 310.3 \\
\hline 760 & $14(4)$ & $2(2)$ & 0 & (1) & 1 & 40,127 & 35,647 & 62.1 & 255.1 \\
\hline 816 & $22(1)$ & 1 & 0 & 0 & 0 & 19,008 & 3,023 & 55.2 & 165.5 \\
\hline 871 & $41(20)$ & 3 & (1) & 0 & 0 & 3,552 & 26,680 & 21.4 & 117.2 \\
\hline 927 & $3(3)$ & 0 & 0 & 0 & 0 & 1,590 & 3,000 & 27.6 & 89.6 \\
\hline 982 & $14(11)$ & 0 & 0 & 0 & 0 & 4,788 & 3,088 & 12.4 & 48.3 \\
\hline 1000 & $12(6)$ & 0 & 0 & 0 & 0 & 3,552 & 5,466 & 10.3 & 34.5 \\
\hline 1038 & 5 & 0 & 0 & 0 & 0 & 2,621 & & 13.8 & 41.4 \\
\hline 1093 & $24(7)$ & 0 & 0 & 0 & 0 & 5,323 & 1,612 & 6.2 & 20.7 \\
\hline Total & $162(55)$ & $6(5)$ & $4(1)$ & (1) & 1 & \multicolumn{4}{|c|}{ Total data $=173(62)$} \\
\hline
\end{tabular}

Table 28. General Electric creep rupture data for Alloy 617 in air.

General Electric Dataset, ${ }^{70}$ Gen IV Materials Handbook

\begin{tabular}{|c|c|c|c|c|c|c|c|c|}
\hline \multirow[b]{2}{*}{$\begin{array}{l}\text { Temp } \\
\left({ }^{\circ} \mathrm{C}\right)\end{array}$} & \multicolumn{5}{|c|}{ Number of tests with specified durations } & \multirow{2}{*}{$\begin{array}{c}\text { Max. } \\
\text { rupture } \\
\text { duration }(h)\end{array}$} & \multirow{2}{*}{$\begin{array}{l}\text { Min. } \\
\text { applied } \\
\text { stress } \\
(\mathrm{MPa})\end{array}$} & \multirow{2}{*}{$\begin{array}{l}\text { Max. } \\
\text { applied } \\
\text { stress } \\
(\mathrm{MPa})\end{array}$} \\
\hline & $<1 \mathrm{kh}$ & $\begin{array}{c}1-3 \\
\mathrm{kh}\end{array}$ & $\begin{array}{c}3-10 \\
\mathrm{kh}\end{array}$ & $\begin{array}{c}10-20 \\
\mathrm{kh}\end{array}$ & $\begin{array}{c}20-30 \\
\text { kh }\end{array}$ & & & \\
\hline 750 & 1 & 0 & 0 & 0 & 0 & 625 & 200 & 200 \\
\hline 850 & 4 & 3 & 2 & 1 & 0 & 12,207 & 44.8 & 96.6 \\
\hline 950 & 5 & 3 & 1 & 0 & 1 & 22,188 & 20.7 & 55.2 \\
\hline 1050 & & 1 & 2 & 0 & 0 & 9,285 & 10.7 & 20.7 \\
\hline 1100 & 1 & 0 & 0 & 0 & 0 & 723 & 15.2 & 15.5 \\
\hline Total & 11 & 7 & 5 & 1 & 1 & & tal Data $=25$ & \\
\hline
\end{tabular}


Idaho National Laboratory

NEXT GENERATION NUCLEAR PLANT

INTERMEDIATE HEAT EXCHANGER

MATERIALS RESEARCH

AND DEVELOPMENT PLAN
Identifier: $\quad$ PLN-2804

Revision: $\quad 0$

Effective Date: $04 / 30 / 08 \quad$ Page: 121 of 156

Table 29. ORNL creep rupture data for Alloy 617 in air.

\begin{tabular}{|c|c|c|c|c|c|c|c|c|c|}
\hline \multicolumn{10}{|c|}{ ORNL Dataset, Ref. Gen IV Materials Handbook } \\
\hline \multirow[b]{2}{*}{$\begin{array}{c}\text { Temp } \\
\left({ }^{\circ} \mathrm{C}\right)\end{array}$} & \multicolumn{6}{|c|}{ Number of tests with specified durations } & \multirow{2}{*}{$\begin{array}{l}\text { Max. } \\
\text { rupture } \\
\text { duration } \\
\text { (h) }\end{array}$} & \multirow{2}{*}{$\begin{array}{l}\text { Min. } \\
\text { applied } \\
\text { stress } \\
(\mathrm{MPa})\end{array}$} & \multirow{2}{*}{$\begin{array}{l}\text { Max. } \\
\text { applied } \\
\text { stress } \\
(\mathrm{MPa})\end{array}$} \\
\hline & $<1 \mathrm{kh}$ & $\begin{array}{c}1-3 \\
\mathrm{kh}\end{array}$ & $\begin{array}{c}3-10 \\
\mathrm{kh}\end{array}$ & $\begin{array}{c}10-20 \\
\mathrm{kh}\end{array}$ & $\begin{array}{c}20-30 \\
\mathrm{kh}\end{array}$ & $\begin{array}{c}30-50 \\
\mathrm{kh}\end{array}$ & & & \\
\hline 593 & 0 & 1 & 1 & 0 & 0 & 0 & 3,570 & 345 & 414 \\
\hline 649 & 1 & 1 & 0 & 0 & 1 & 0 & 25,566 & 276 & 276 \\
\hline 704 & 0 & 1 & 0 & 0 & 0 & 0 & 2,621 & 207 & 207 \\
\hline 750 & 1 & 0 & 0 & 0 & 0 & 0 & 625 & 200 & 200 \\
\hline 760 & 0 & 1 & 0 & 0 & 1 & 0 & 20,702 & 103 & 138 \\
\hline 850 & 4 & 3 & 2 & 1 & 0 & 0 & 12,207 & 44.8 & 96.6 \\
\hline 871 & 1 & 0 & 0 & 0 & 0 & 1 & 34,231 & 35 & 69 \\
\hline 950 & 5 & 3 & 1 & 0 & 1 & 0 & 22,188 & 20.7 & 55.2 \\
\hline 1050 & 0 & 1 & 2 & 0 & 0 & 0 & 9,285 & 10.7 & 20.7 \\
\hline 1100 & 1 & 0 & 0 & 0 & 0 & 0 & 723 & 15.2 & 15.2 \\
\hline Total & 13 & 11 & 6 & 1 & 3 & 1 & \multicolumn{3}{|c|}{ Total Data $=35$} \\
\hline
\end{tabular}

Table 30. European Creep Collaborative Committee creep rupture data for Alloy 617 in air.

\begin{tabular}{|c|c|c|c|c|c|c|c|c|c|c|}
\hline \multicolumn{11}{|c|}{ European Creep Collaborative Committee (ECCC) Database ${ }^{72}$} \\
\hline \multirow[b]{2}{*}{$\begin{array}{l}\text { Temp } \\
\left({ }^{\circ} \mathrm{C}\right)\end{array}$} & \multicolumn{7}{|c|}{$\begin{array}{l}\text { Number of tests with specified durations } \\
\text { (unfailed tests in parenthesis) }\end{array}$} & \multirow{2}{*}{$\begin{array}{c}\text { Max. } \\
\text { rupture } \\
\text { duration } \\
\text { (h) }\end{array}$} & \multirow{2}{*}{$\begin{array}{l}\text { Min. } \\
\text { applied } \\
\text { stress } \\
(\mathrm{MPa})\end{array}$} & \multirow{2}{*}{$\begin{array}{c}\text { Max. } \\
\text { applied } \\
\text { stress } \\
(\mathrm{MPa})\end{array}$} \\
\hline & $<1 \mathrm{kh}$ & $\begin{array}{c}1-3 \\
\mathrm{kh}\end{array}$ & $\begin{array}{c}3-10 \\
\mathrm{kh}\end{array}$ & $\begin{array}{l}10- \\
20 \mathrm{kh}\end{array}$ & $\begin{array}{c}20- \\
30 \mathrm{kh}\end{array}$ & $\begin{array}{c}30- \\
50 \mathrm{kh}\end{array}$ & $\begin{array}{c}50- \\
70 \mathrm{kh}\end{array}$ & & & \\
\hline 595 & 3 & 1 & 1 & & 2 & & & 28,500 & 332 & 540 \\
\hline 600 & 2 & 2 & 2 & 1 & & & & 10,355 & 330 & 480 \\
\hline 650 & 11 & 5 & $5(2)$ & $(1)$ & $(1)$ & $(1)$ & & 9,660 & 201 & 201 \\
\hline 700 & 2 & & & 1 & & & & 19,926 & 100 & 298 \\
\hline 750 & 6 & 3 & 3 & & & & & 9,986 & 110 & 301 \\
\hline 800 & 3 & 1 & & & & & & 2,500 & 81 & 303 \\
\hline 850 & 27 & 13 & $15(3)$ & 2 & (3) & $2(3)$ & (2) & 40,321 & 36 & 198 \\
\hline 900 & 9 & 3 & 4 & 1 & & & & 12,302 & 30 & 81 \\
\hline 950 & 13 & 9 & 7 & 2 & & & & 15,036 & 15 & 40 \\
\hline 1000 & 11 & 6 & 8 & $2(1)$ & 1 & $1(4)$ & & 41,747 & 4.1 & 50 \\
\hline 1100 & 1 & 1 & & $(1)$ & & & & 1,022 & 10.3 & 15 \\
\hline Total & 88 & 44 & $45(5)$ & $9(3)$ & $3(4)$ & $3(8)$ & (2) & Total & ata $=19$ & $2(22)$ \\
\hline
\end{tabular}




\section{NEXT GENERATION NUCLEAR PLANT \\ INTERMEDIATE HEAT EXCHANGER \\ MATERIALS RESEARCH \\ AND DEVELOPMENT PLAN}

$\begin{array}{ll}\text { Identifier: } & \text { PLN-2804 } \\ \text { Revision: } & 0 \\ \text { Effective Date: } & 04 / 30 / 08\end{array}$

Page: 122 of 156

Table 31. Petten creep rupture data for Alloy 617 in air.

\begin{tabular}{|c|c|c|c|c|c|c|c|c|c|}
\hline \multicolumn{10}{|c|}{ Petten Database, From ODIN at JRC of European Commission, Petten, the Netherlands ${ }^{73}$} \\
\hline \multirow[b]{2}{*}{ Source } & \multirow[b]{2}{*}{$\begin{array}{l}\text { Material } \\
\text { Type }\end{array}$} & \multirow[b]{2}{*}{$\begin{array}{c}\text { Total } \\
\text { No. of } \\
\text { Tests } \\
\end{array}$} & \multicolumn{7}{|c|}{ Number of creep tests in temperature intervals } \\
\hline & & & $\begin{array}{c}< \\
500 \\
{ }^{\circ} \mathrm{C} \\
\end{array}$ & $\begin{array}{l}500^{\circ} \mathrm{C} \\
\text { to } \\
600^{\circ} \mathrm{C} \\
\end{array}$ & $\begin{array}{c}600^{\circ} \mathrm{C} \\
\text { to } \\
700^{\circ} \mathrm{C} \\
\end{array}$ & $\begin{array}{c}700^{\circ} \mathrm{C} \\
\text { to } \\
800^{\circ} \mathrm{C} \\
\end{array}$ & $\begin{array}{c}800^{\circ} \mathrm{C} \\
\text { to } \\
900^{\circ} \mathrm{C} \\
\end{array}$ & $\begin{array}{c}900^{\circ} \mathrm{C} \\
\text { to } \\
1000^{\circ} \mathrm{C}\end{array}$ & $\stackrel{>}{>}$ \\
\hline $\begin{array}{c}\text { FZJ - COST / } \\
\text { MATFO }\end{array}$ & Base Metal & 267 & 0 & 13 & 26 & 29 & 99 & 64 & 36 \\
\hline $\begin{array}{c}\text { FZJ - HTR - } \\
617\end{array}$ & Base Metal & 1134 & 0 & 58 & 71 & 173 & 506 & 326 & 0 \\
\hline $\begin{array}{l}\text { PE - TUD - } \\
\text { Alloy } 617\end{array}$ & Base Metal & 60 & 0 & 7 & 33 & 20 & 0 & 0 & 0 \\
\hline $\begin{array}{c}\text { FZJ - HTR - } \\
617\end{array}$ & $\begin{array}{l}\text { Base Metal } \\
\text { (Irradiated) }\end{array}$ & 175 & 0 & 23 & 17 & 46 & 51 & 38 & 0 \\
\hline $\begin{array}{c}\text { FZJ - } \\
\text { COST/MATFO }\end{array}$ & $\begin{array}{c}\text { Similar } \\
\text { Metal Joint }\end{array}$ & 159 & 0 & 2 & 23 & 7 & 62 & 65 & 0 \\
\hline $\begin{array}{c}\text { FZJ - HTR - } \\
617 \\
\end{array}$ & $\begin{array}{c}\text { Similar } \\
\text { Metal Joint }\end{array}$ & 152 & 0 & 4 & 9 & 25 & 73 & 41 & 0 \\
\hline \multicolumn{3}{|c|}{$\begin{array}{l}\text { Total Base Metal Data } \\
=1461\end{array}$} & \multicolumn{4}{|c|}{$\begin{array}{l}\text { Total Irradiated Base Metal } \\
\qquad \text { Data }=175\end{array}$} & \multicolumn{3}{|c|}{$\begin{array}{c}\text { Total Cross Weld Data } \\
=311\end{array}$} \\
\hline
\end{tabular}

\section{Acquisition of Alloy 617 Databases}

Section 5 highlights a strategy to overcome the schedule issue for the conceptual and preliminary design activities. This strategy relies on the successful acquisition of the Petten and ECCC databases, in particular the entire Petten Alloy 617 database, by the NGNP Project. This action item has the highest priority in the Technology Development Plan. The combined data will be used to develop time-dependent allowable stresses to support the conceptual and preliminary designs of the high temperature IHX and hot-gas piping.

Extrapolation of data would still be necessary even with the combined dataset from the Huntington, ${ }^{65}$ General Electric, ${ }^{70}$ ORNL, ECCC ${ }^{72}$ and Petten databases. ${ }^{73}$ A more rigorous statistical approach as employed by Eno et al., ${ }^{74}$ in analyzing the Huntington creep data for the NASA Space Reactor applications will be used to develop the allowable stresses. This approach involves using the method of maximum likelihood estimation (MLE) to yield more precise model parameter estimates.

MLE is an established statistical methodology, with well-understood statistical properties based on asymptotic theory, and in particular, the MLE method is asymptotically efficient, meaning that for large datasets, no other estimation procedure will yield more precise model parameter estimates. Furthermore, formal quantitative inferences can be made through MLE theory, such as confidence interval estimation of model parameters and hypothesis tests to determine the statistical significance of individual model terms. By comparing the optimized likelihood function for different formulations (based on the different engineering creep parameters), the goodness-of-fit of the formulations can be objectively and quantitatively compared.

MLE has the advantage of being readily able to accommodate censored data, which can occur in two distinct forms. Right-censored data, or runouts, are specimens that have not ruptured at the conclusion of 


\begin{tabular}{c|lll|}
\hline NEXT GENERATION NUCLEAR PLANT & Identifier: & PLN-2804 & \\
INTERMEDIATE HEAT EXCHANGER & Revision: & 0 & \\
MATERIALS RESEARCH & Effective Date: & $04 / 30 / 08$ & Page: 123 of 156 \\
AND DEVELOPMENT PLAN &
\end{tabular}

the experiment; the specimens' rupture time is longer than the test duration. Left-censored data arise from an experiment in which the lack of in-situ monitoring prevents direct observation of rupture time. If specimens are tested for a fixed time $t$, and are found to be ruptured at the conclusion, it can be stated their lifetimes were less than the fixed test duration $t$.

Lower-bound curves for time to creep rupture can be computed based on the fitted model and the observed variability ("data scatter") in measured times. A lower-bound curve should also account for uncertainty in the fitted model parameters. Accounting for uncertainties creates a lower bound that is backed off from the best estimate by a different amount at different stress-temperature combinations. The propagation of uncertainties depends on the degree to which the model is extrapolated relative to the database. The distance of the back-off is the smallest near the middle of the database and the greatest at the temperature and stress extremes of the database. Conceptually, this is because predictions surrounded by supporting data are more reliable than predictions near the ends of the database, which have less locally supporting data. This is particularly useful as it provides a quantitative means to extrapolate data to different conditions with different prediction bounds (wider or narrower) but the same level of confidence. Of course, care must be exercised in judging whether the engineering creep model is applicable at those extrapolated conditions.

Based on the MLE methodology, design curves for allowable stresses can be developed for different applications and for different stages of the design cycle by adopting, e.g., different confidence levels $(95 \%$ or $98 \%)$ in constructing the design curves.

To support Code acceptance, final design activities and final licensing approval, long-term creep rupture tests at low-stress levels are required. Such data will also serve to qualify the conservatism of the allowable stresses established for the conceptual and preliminary designs. Finally, a few very long-term creep rupture tests at prototypical operating stress levels should be initiated to provide creep rupture data that would lead the NGNP. Test matrix for this long-term testing is given in Table A17. The Long Term Alloy 617 Creep Rupture Test Matrix for Qualification will utilize 8 tensile specimens. The specimens will be tested in air at $850^{\circ}$ and $950^{\circ} \mathrm{C}$. Applied stress will range from 9,5 to $27.5 \mathrm{MPa}$. The estimated 95\% Lower Bound Rupture time will range from 6.2 to 16.2 years. Product form will be plate from a single heat (xyz-CF).

\subsubsection{Selection of Weld Consumables and Welding Processes}

This effort addresses Item D2 in Table 21 of Section 5.

Special Metals has published a data sheet with weld process parameters and filler metal recommendations. Filler metal 617 and welding electrode 117 have the closest match to the chemical composition of Alloy 617 base metal. Filler metal 617 can be used for Gas Tungsten Arc (GTA) and Gas Metal Arc (GMA) welding. Welding electrode 117 can be used for Shielded Metal Arc (SMA) welding. For the section sizes anticipated for conventional heat exchangers, arc welding is the most likely fabrication process. There has been no report in successfully using filler metal 617 for submerged arc welding; sub-arc involves higher heat input and generally is used for thick sections, however, and is not likely to be applicable to the NGNP IHX. The welding process parameters and weld filler metals in the Special Metals data sheets provide adequate weldability and result in weldments with adequate properties.

Given that the welding effort needs to be completed as soon as possible so that long-term creep rupture tests and thermal aging on welds can start, there is no time within the NGNP program constraints to further develop weld processes or filler-wire compositions. The recommendations from Special Metals will be used to fabricate weldments that include filler metal 617/GTA and Electrode 117/SMA for testing. The NGNP program is aware of welding development activities, including modification to weld filler 


\section{NEXT GENERATION NUCLEAR PLANT \\ INTERMEDIATE HEAT EXCHANGER \\ MATERIALS RESEARCH AND DEVELOPMENT PLAN}

$\begin{array}{ll}\text { Identifier: } & \text { PLN-2804 } \\ \text { Revision: } & 0 \\ \text { Effective Date: } & 04 / 30 / 08\end{array}$

Page: 124 of 156

metal composition that is underway in Europe. Details of this program are not currently available. Data from materials welded using the Special Metals recommendations will be valid for Code and licensing purposes and can be considered to be conservative values if improved welding procedures are developed at a later date.

\subsubsection{Yield and Tensile Strength Reduction Factors}

This effort addresses Item D3 in Table 21 and NRC concerns List 19 in Table 19 of Section 5.

For extended elevated temperature service, Subsection NH requires using yield and tensile strengthreduction factors that are functions of exposure time and exposure temperature to account for possible decrease in the yield and tensile strengths caused by thermal aging.

A review of the aging effects in Alloy 617 has been provided by Swindeman and Ren. ${ }^{75}$ Figures 33 and 34 show thermal aging data in air from the Special Metals Data Sheet for room temperature yield and tensile strengths, respectively, as a function of exposure time at various exposure temperatures.

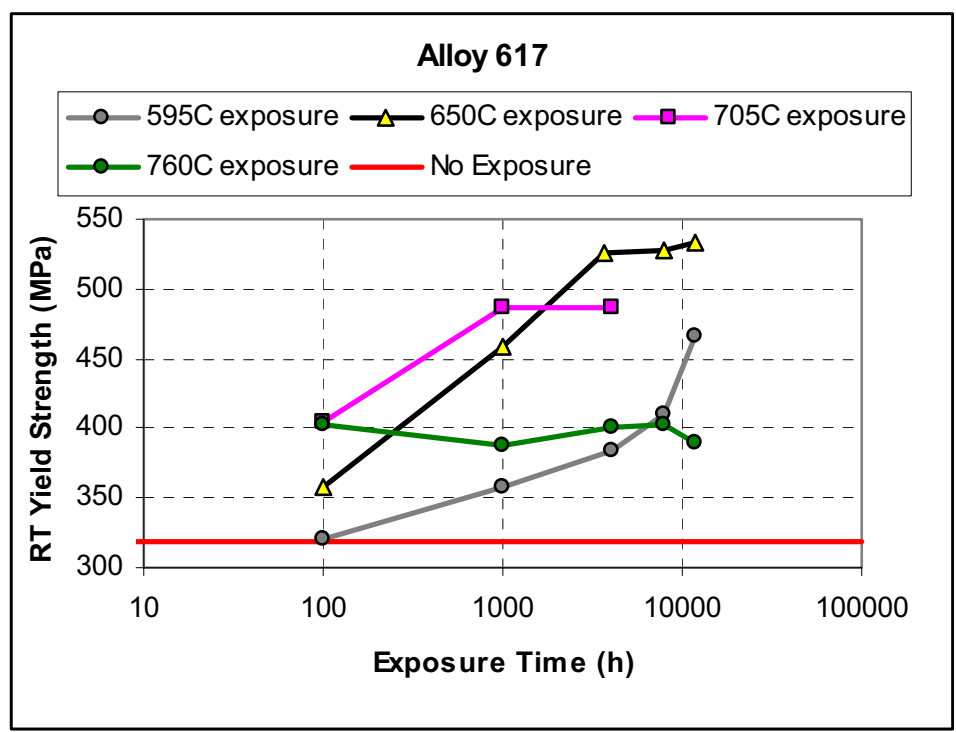

Figure 33. Thermal aging effect on room temperature yield strength. 
NEXT GENERATION NUCLEAR PLANT

INTERMEDIATE HEAT EXCHANGER

MATERIALS RESEARCH

AND DEVELOPMENT PLAN
Identifier: $\quad$ PLN-2804

Revision: $\quad 0$

Effective Date: $\quad 04 / 30 / 08 \quad$ Page: 125 of 156

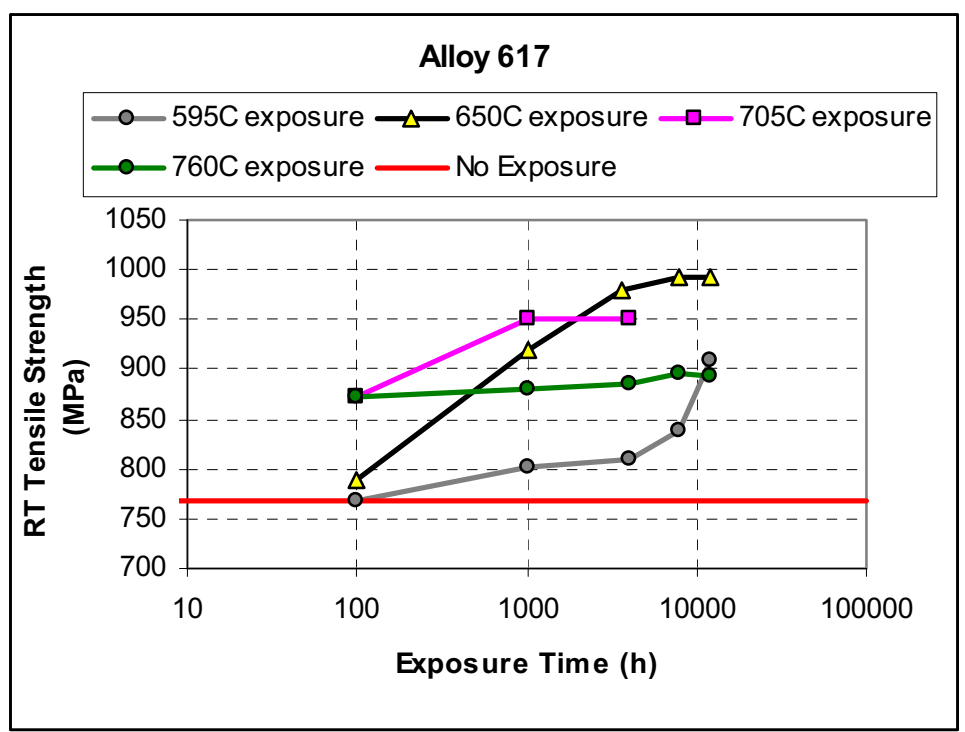

Figure 34. Thermal aging effect on room temperature tensile strength.

The strengthening shown in the data was attributed by Special Metals to carbide formation at $595^{\circ} \mathrm{C}$, and to precipitation of gamma prime phase at exposure temperatures of $650^{\circ} \mathrm{C}$ to $760^{\circ} \mathrm{C}$. The strengthening tapers off in this temperature range as exposure time increases. The strengthening effect decreases as the exposure temperature is increased toward the normal operating metal temperature of NGNP hot-gas piping and IHX components.

Quoting the data from McCoy and King, Swindeman and Ren ${ }^{75}$ showed a plot of the strength data after $871{ }^{\circ} \mathrm{C}$ thermal exposure at different exposure times. Figure 35 shows their plot and the reduction in yield strength.

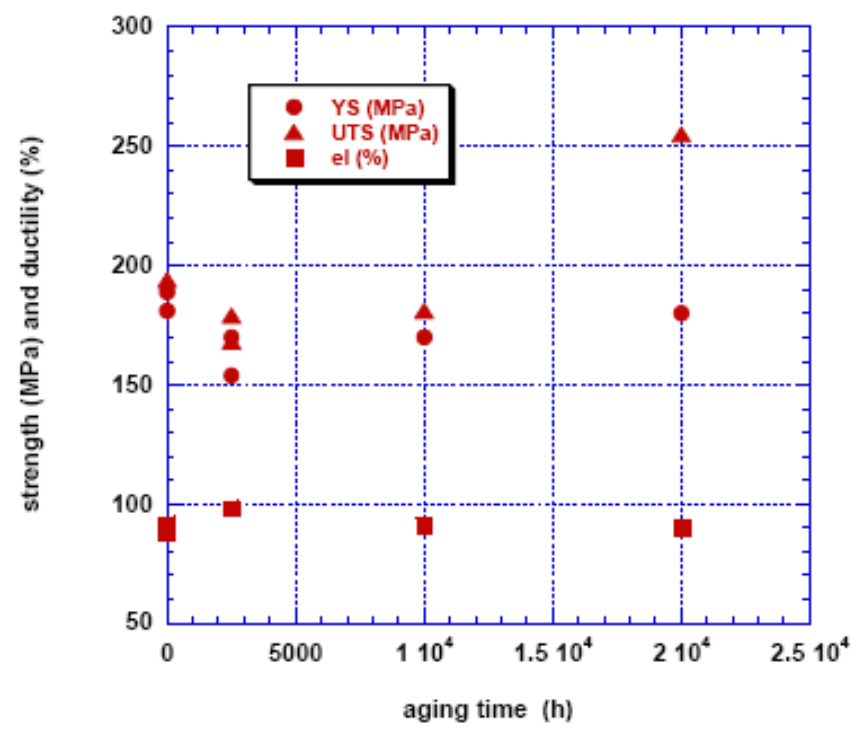

Figure 35. Effect of aging at $871^{\circ} \mathrm{C}$ on strengths and elongation of Alloy 617. 


\begin{tabular}{c|lll|}
\hline NEXT GENERATION NUCLEAR PLANT & Identifier: & PLN-2804 & \\
INTERMEDIATE HEAT EXCHANGER & Revision: & 0 & \\
MATERIALS RESEARCH & Effective Date: & $04 / 30 / 08$ & Page: 126 of 156 \\
AND DEVELOPMENT PLAN &
\end{tabular}

Thermodynamics calculations have also been performed to investigate the thermal aging issue, as discussed in Section 4, but no consensus has emerged.

Testing of long-term thermally exposed Alloy 617 in air is required to determine the yield and tensile strength- reduction factors. A test matrix is proposed in Table A18 for such determination. The Thermal Aging Test Matrix for Strength Reduction Factors will utilize 296 tensile specimens. The specimens will be tested in air with exposure temperatures of none to $1000^{\circ} \mathrm{C}$ and exposure times from none to 120,000 hours. Tensile testing of the specimens will be performed at $20^{\circ}$ and $950^{\circ} \mathrm{C}$. Product form will be plate from a two different heats (Aged-3 and Aged-4). Two heats are included in the test matrix to cover variability. Two specimens will be used for each of the exposure time, exposure temperature and test temperature combination for each heat. The planned thermal exposure temperatures are $750^{\circ} \mathrm{C}, 850^{\circ} \mathrm{C}$, $950^{\circ} \mathrm{C}$, and $1000^{\circ} \mathrm{C}$, and the exposure times are $200 \mathrm{~h}, 650 \mathrm{~h}, 2000 \mathrm{~h}, 5,300 \mathrm{~h}, 20,000 \mathrm{~h}, 32,000 \mathrm{~h}, 50,000$ $\mathrm{h}, 76,000 \mathrm{~h}$, and $120,000 \mathrm{~h}$. The tensile test temperatures are $20^{\circ} \mathrm{C}$ and $950^{\circ} \mathrm{C}$. All the tensile tests will be conducted in strain-control and at a strain rate of $1 . \mathrm{E}-3 \mathrm{~m} / \mathrm{m} / \mathrm{s}$.

Tensile specimens will be machined from thermally exposed materials. Samples will also be prepared from the thermally exposed materials to investigate the effects of thermal aging on the microstructure. Together with the strength data from the aged materials, structural-property relation can also be studied.

The testing is divided into two parts. Data from the YT-SRF Test Program with thermal exposure times up to 20,000 hours will be used to develop the yield and tensile strength reduction factors for conceptual and preliminary design activities. A tentative model for the change in strength for each of the yield and tensile strengths of the form:

$$
\Delta(\text { Strength })=A \times t^{m} \times \exp \left(-\frac{Q}{R}\left[\frac{1}{T}-\frac{1}{T_{0}}\right]\right)
$$

will be used to correlate with the data. Here $t$ is time, $T$ is the exposure temperature in absolute temperature scale, $R$ is the universal gas constant, $T_{0}$ is a scaling constant, and $A, Q$, and $m$ are fitting constants. Other correlation models will also be investigated when necessary. Data from the YT-QUAL Test Program with thermal exposure times up to 120,000 hours will be used to qualify the yield and tensile strength reduction factors developed from the YT-SRF Test Program.

\subsubsection{Fatigue Design Curves for Alloy 617 Code Case (Standard Grain Size)}

This effort addresses Item D4 in Table 21 of Section 5.

The continuous fatigue design curves are an integral part of the creep-fatigue procedure in Subsection $\mathrm{NH}$. At higher temperatures and lower strain rates, cyclic inelastic strains and crack growth change from transgranular to intergranular, and there is a significant effect of strain rate. Table A19 presents a test matrix. The Fatigue Tests to Support Design Curve Development in Alloy 617 Code Case will utilize 96 fatigue specimens. Half the samples will be tested in air and the other half in NGNP He. The specimens will be tested at $850^{\circ}$ and $950^{\circ} \mathrm{C}$ with strains ranging from 0.15 to $2.0 \%$. Strain rates of $1 \mathrm{E}-02$ to $1 \mathrm{E}-05$ $\mathrm{m} / \mathrm{m} / \mathrm{s}$ for a limited number of samples will be used. The rest are TBD. Product form will be plate from a single heat (xyz-CF).

The strain rate effect is first investigated by keeping the strain range constant and varying the strain rates. Electron scanning microscopy would then be used on the failed specimens to identify the failure mechanism transition from predominately transgranular by striation to intergranular cracking. A strain rate is then selected to generate continuous fatigue data to support developing the fatigue design curves in 


\begin{tabular}{c|lll|}
$\begin{array}{c}\text { NEXT GENERATION NUCLEAR PLANT } \\
\text { INTERMEDIATE HEAT EXCHANGER }\end{array}$ & Identifier: & PLN-2804 & \\
MATERIALS RESEARCH & Revision: & 0 & \\
AND DEVELOPMENT PLAN & Effective Date: & $04 / 30 / 08$ & Page: 127 of 156 \\
\hline
\end{tabular}

the Alloy 617 Code Case. The temperatures are selected to support an initial metal temperature of $850^{\circ} \mathrm{C}$ and future increase to $950^{\circ} \mathrm{C}$.

Testing in NGNP helium is also proposed in Table A19, using the same testing strategy as for the air tests. This is part of an overall strategy as has been discussed, to generate fatigue data in supporting the inclusion of a less restrictive creep-fatigue design procedure in the Alloy 617 Code Case.

\subsubsection{Potential Need to Optimize Alloying Elements}

This addresses Item D5 in Table 21 of Section 5.

Appendix X of Subsection NH provides guidelines for restricted material specifications to improve performance in certain service applications. For Alloy 617, an effort to define a Controlled Material Specification (CMS) within the standard specification to improve performance for NGNP applications has been made. ${ }^{29}$ Preliminary results on testing and characterization of CMS Alloy 617 were reported in Ren et al. ${ }^{37}$ There have also been efforts in France to refine the compositions of Alloy 617 to improve the creep properties and corrosion resistance.

From the perspective of the Code rules, if higher allowable stresses were to be leveraged based on the improved properties of materials with restricted compositions, a rather extensive database from long-term creep tests for materials with such restricted compositions would have to be generated. However, owing to the NGNP Program constraints, there is no time to develop the Alloy 617 Code Case based on such restricted material specification. This is the same NGNP Program constraint that motivates the strategy to acquire the Petten Alloy 617 database as discussed in Section 8.1.4.1.

It is recommended that the Alloy 617 data from standard specification will be used to develop the Alloy 617 Code Case. This is a prudent approach for design activities and licensing purposes. If improved properties owing to composition refinement are developed at a later date, they can be incorporated into the design of the replacement IHX.

\subsubsection{Cold Work Effect and Heat Treatment Requirement}

This addresses Item D6 in Table 21 of Section 5.

At high homologous temperatures $(\geq 0.6)$ power law creep may be accompanied by repeated waves of recrystallizaton ${ }^{76}$ that drastically changes the dislocation structure with each passage, allowing a period of primary creep that would lead to an acceleration of the overall creep rate. Because of concerns that cold worked Alloy 617 would undergo recrystallization during elevated temperature service, it was excluded from use in the Draft Alloy 617 Code Case.

Cook $^{77}$ had conducted creep tests of $\sim 3000$ hours at $850^{\circ} \mathrm{C}$ in helium on specimens with prior cold work of $5 \%$ to $20 \%$. Prior cold work reduced the initial creep rate, but it also reduced the room temperature tensile ductility of these crept specimens.

Owing to the concerns on recrystallization and loss of tensile ductility, the restriction on cold worked material in the Draft Alloy 617 Code Case will be retained in the new Alloy 617 Code Case. This restriction could be relaxed in the future for applications where these concerns could be mitigated.

\subsubsection{Creep-Fatigue Interaction Diagram for Alloy 617 (Standard Grain Size)}

This effort addresses Item D7 in Table 21 and NRC Lists s 4 and 12 in Table 19 of Section 5. 


\begin{tabular}{c|lll|}
\hline NEXT GENERATION NUCLEAR PLANT & Identifier: & PLN-2804 & \\
INTERMEDIATE HEAT EXCHANGER & Revision: & 0 & \\
MATERIALS RESEARCH & Effective Date: & $04 / 30 / 08$ & Page: 128 of 156 \\
AND DEVELOPMENT PLAN &
\end{tabular}

The creep-fatigue interaction diagram is an integral part of the creep-fatigue procedure of Subsection $\mathrm{NH}$. A test matrix for generating creep-fatigue data to support the determination of the creep-fatigue interaction diagram in the Alloy 617 Code Case is proposed and presented in Table A20. The Creepfatigue Test Matrix to Support Determination of Creep-Fatigue Interaction Diagram will utilize 96 creepfatigue specimens. Half the samples will be tested in air and the other half in NGNP He. The specimens will be tested in tension at $950^{\circ} \mathrm{C}$. Strain will range from 0.3 to $1 \%$ with hold time ranging from 0 to 600 minutes. Product form will be plate from a single heat (xyz-CF).

Jetter and McGreevy ${ }^{78}$ concluded that the fatigue performance of Alloy 617 in impure helium is approximately five times better than that in air. Testing in NGNP helium environment is proposed to quantify the benefit for NGNP applications and to obtain data to support the inclusion of this less restrictive creep-fatigue procedure in the Alloy 617 Code Case. Without generating adequate creepfatigue data in NGNP helium for inclusion in the Alloy 617 Code Case, the NGNP Project could only justify to NRC that the creep-fatigue performance of Alloy 617 in NGNP helium is no worse than that in air. The benefit of the NGNP helium environment on the creep-fatigue performance of Alloy 617 could not be factored explicitly into the design under such a scenario. Tests in both air and NGNP helium environment are included in Table A20. Some of the tension holds in the test matrix might be revised to compression holds when the test program commences.

\subsubsection{Multiaxial Creep Rupture Failure Criterion for Alloy 617 (Standard Grain Size)}

This effort addresses Item D8 in Table 21 of Section 5.

Creep rupture data that support the creep-fatigue design procedure of Subsection NH are based on uniaxial testing. Structural components generally undergo multiaxial loading. In Subsection NH, an effective stress defined with respect to a multiaxial rupture strength criterion ${ }^{79}$ is used to relate the multiaxial stress state in a component determined by inelastic analysis to the uniaxial creep rupture data. This effective stress, $\sigma$ is defined as:

$$
\sigma_{e}=\sqrt{\frac{\left(\sigma_{1}-\sigma_{2}\right)^{2}+\left(\sigma_{2}-\sigma_{3}\right)^{2}+\left(\sigma_{3}-\sigma_{1}\right)^{2}}{2}} \cdot \exp \left[C\left(\frac{\sigma_{1}+\sigma_{2}+\sigma_{3}}{\sqrt{\sigma_{1}^{2}+\sigma_{2}^{2}+\sigma_{3}^{2}}}-1\right)\right]
$$

where $\sigma_{1}, \sigma_{2}$, and $\sigma_{3}$ are the principal stresses and $C$ is a material constant. A value of $C=0.24$ for 304 and 316 stainless steels was selected for Alloy 617 in the Draft Alloy 617 Code Case. Biaxial creep rupture tests at $950^{\circ} \mathrm{C}$ are proposed in Table $\mathrm{A} 21$ of the Appendix to validate the value of $\mathrm{C}=0.24$ or to arrive at a new value for $\mathrm{C}$. Biaxial stress ratios of $2,1,05,0,-0,5$ and -1 are planned. They are achieved by different combinations of pressure, axial, and torsional loads.

\subsubsection{Significant Recently Emerged Issues for Alloy 617}

\subsubsection{Microstructural Determination of the Onset of Tertiary Creep}

This effort addresses Item E1 in Table 22 of Section 5.

The ASME Section III Subsection NH criteria for estimating the time-dependent allowable stress $S_{t}$ include (1) the average strength for $1 \%$ total strain, (2) $80 \%$ of the minimum strength for tertiary creep, and (3) $67 \%$ of the minimum rupture strength values. These criteria are based on materials that exhibit the classical creep response with identifiable primary, secondary, and tertiary creep regimes in the creep curves. 


\begin{tabular}{c|lll|}
\hline $\begin{array}{l}\text { NEXT GENERATION NUCLEAR PLANT } \\
\text { INTERMEDIATE HEAT EXCHANGER }\end{array}$ & Identifier: & PLN-2804 & \\
MATERIALS RESEARCH & Revision: & 0 & \\
AND DEVELOPMENT PLAN & Effective Date: & $04 / 30 / 08$ & Page: 129 of 156 \\
\hline
\end{tabular}

Alloy 617 exhibits classical primary, secondary, and tertiary regimes in the creep response at temperatures below $800^{\circ} \mathrm{C}$. But secondary creep (constant creep rate) is hardly noticeable in the creep curves at $800^{\circ} \mathrm{C}$ and above. After the initial primary creep regime, the creep rate increases gradually until rupture. Thus the onset of tertiary creep based on the classical definition occurs at very short time. The inclusion of time-to-onset-of-tertiary-creep in setting the time-dependent allowable stress $S_{t}$ would be very restrictive. This criterion was not used in setting $S_{t}$ in the Draft Alloy 617 Code Case.

Information is needed on whether the gradually increasing creep curve is a manifestation of different deformation mechanisms typified by dislocation generation and motion, or if it corresponds to creep damage such as grain boundary cavitation and cracking reminiscent of those occurring in the classical tertiary creep regime.

A test matrix is proposed in Table A22 for interrupted creep tests. The Test Matrix for Interrupted Creep Tests will utilize 40 tensile specimens. The specimens will be tested in air at $750^{\circ}$ and $1000^{\circ} \mathrm{C}$. Applied stress ranges from 16 to $145 \mathrm{MPa}$. Estimated rupture time ranges from 1665 to 5110 hours. Product form will be plate from a single heat (xyz-CF). The temperatures of $750^{\circ} \mathrm{C}$ and $1000^{\circ} \mathrm{C}$ are selected to capture the two different creep behaviors. Microstructural evaluations (TEM, SEM, etc.) will be performed on crept specimens at certain strain levels or periods along the creep curves. The test specimens should be cooled under load before their removal from the test frame to preserve the existing microstructure. The objective is to identify different microstructural processes such as dislocation interactions, subgrain formations, dislocation multiplication, dislocation-carbide interactions, diffusional creep mechanism, grain boundary cavitation, cracking, etc., at different locations along a creep curve. This will differentiate the contributions of deformation and damage in the part of the creep curve usually considered to be in the tertiary creep regime. The results from this effort will provide input to the Code committee on whether time to onset of tertiary creep needs to be included in the criteria for defining the time-dependent allowable stress, $S_{t}$.

\subsubsection{Fatigue with Hold Time for Alloy 617 (Standard Grain Size)}

This effort addresses Item E2 in Table 22 and NRC concerns 4 and 12 in Table 19 of Section 5.

The baseline operating temperature for an Alloy $617 \mathrm{IHX}$ is $850^{\circ} \mathrm{C}$, with possible future up-rating to $950^{\circ} \mathrm{C}$. Owing to the low design allowable stresses at these elevated temperatures, sustained stress levels in these components are low. A preliminary evaluation of the NGNP operating transients indicates the normal cyclic service will consist of several hundred very slow transients with hold times on the order of 1,000 hours. There is also the possibility of a limited number (less than 10) of off-normal cycles with more rapid ramp rates and shorter hold times.

The above brings up the critical issue of whether the creep-fatigue behavior of Alloy 617 saturates with increasing hold time. In this context, saturation means that the number of cycles to failure is no longer increasing, or nearly so, as the hold time increases.

Figure 36 shows a plot of the cycle-to-failure with hold time normalized by the cycle-to-failure from continuous cycling versus the tensile hold time from the German HTGR Alloy 617 creep-fatigue tests at $950^{\circ} \mathrm{C}$ in impure helium. The plot shows that the data were not indicating saturation. If the German data are extrapolated linearly on the log-log plot there is a dramatic reduction in cycles to failure for very long hold times. This is one of the reasons the design curves in Jetter and McGreevy ${ }^{78}$ appear so conservative.

On the other hand, the preliminary INL data, shown in Figures 37(a)-(c), do show signs of saturation. Accordingly, a creep-fatigue test matrix as shown in Table A23 is recommended to clarify this critical issue. The strain rate $\mathrm{S} 1$ listed in the table will be selected from the strain rate study of the continuous fatigue task. The Test Matrix to Address Creep-Fatigue Saturation with Hold Time will utilize 18 tensile specimens. The specimens will be held in tension in air at $1000^{\circ} \mathrm{C}$ at strains of 0.3 and $1.0 \%$. Hold times will be 0,150 , and 600 minutes. The strain rate will be $1 \mathrm{E}-03 \mathrm{~m} / \mathrm{m} / \mathrm{s}$. Product form will be plate from a single heat (xyz-CF). 
NEXT GENERATION NUCLEAR PLANT

INTERMEDIATE HEAT EXCHANGER

MATERIALS RESEARCH

AND DEVELOPMENT PLAN

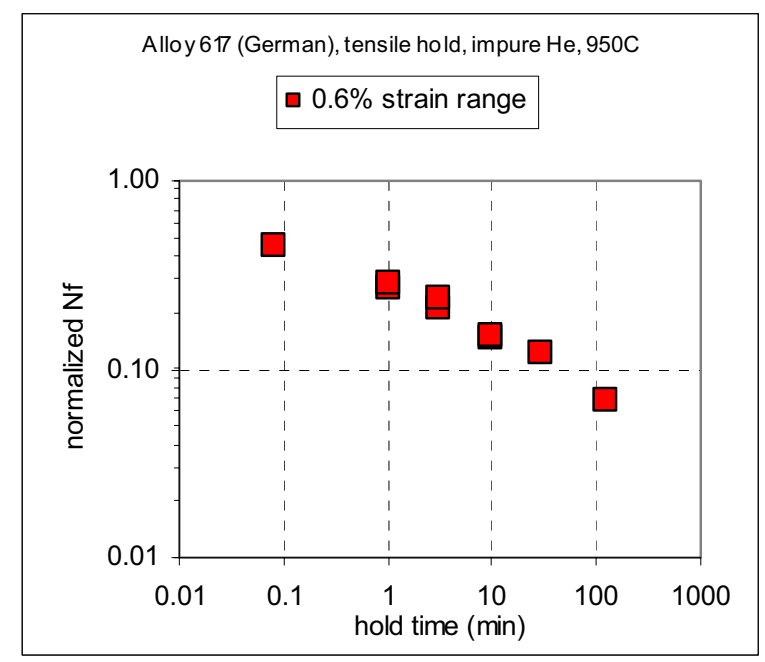

Figure 36. German creep-fatigue data for Alloy 617 in impure helium at $950^{\circ} \mathrm{C}$.

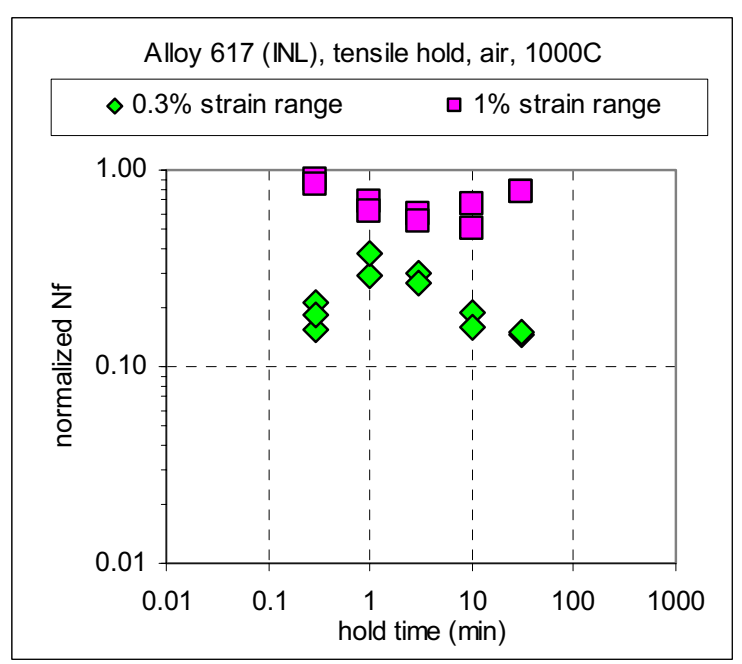

Figure 37(b). Preliminary INL creep-fatigue data for Alloy 617 in air at $1000^{\circ} \mathrm{C}$.
Identifier: PLN-2804

Revision: $\quad 0$

Effective Date: $04 / 30 / 08 \quad$ Page: 130 of 156

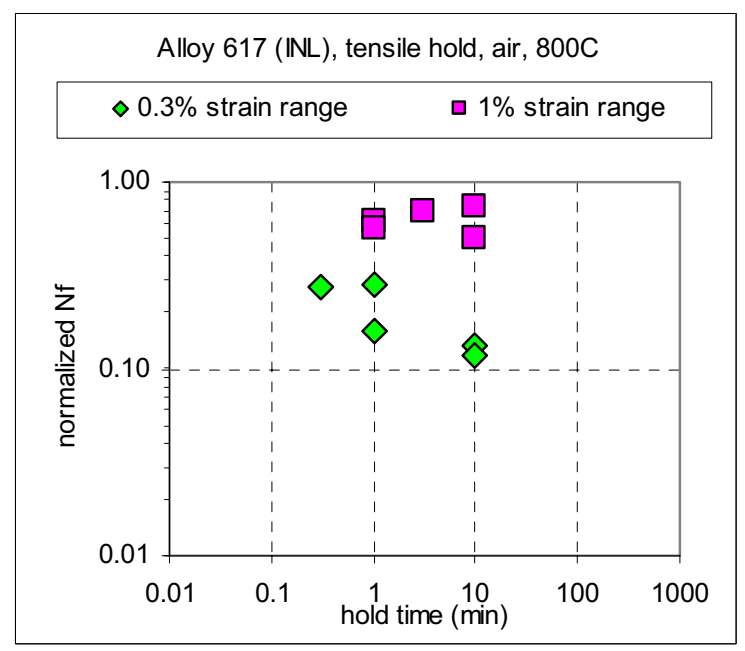

Figure 37.(a). Preliminary INL creep-fatigue data for Alloy 617 in air at $800^{\circ} \mathrm{C}$.

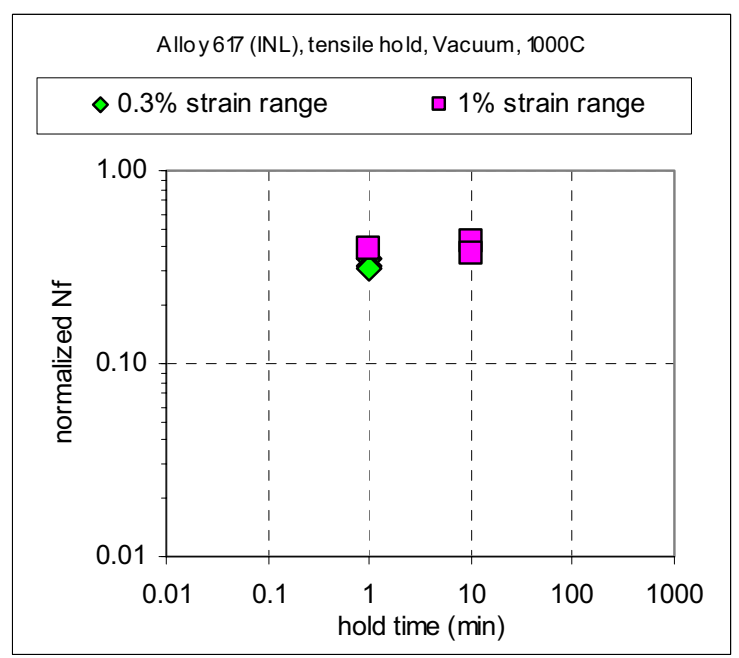

Figure 37(c). Preliminary INL creep-fatigue data for Alloy 617 in vacuum at $1000^{\circ} \mathrm{C}$. 
Idaho National Laboratory

\begin{tabular}{c|lll|}
\hline $\begin{array}{c}\text { NEXT GENERATION NUCLEAR PLANT } \\
\text { INTERMEDIATE HEAT EXCHANGER } \\
\text { MATERIALS RESEARCH }\end{array}$ & Identifier: & PLN-2804 & \\
AND DEVELOPMENT PLAN & Effective Date: & $04 / 30 / 08$ & Page: 131 of 156 \\
\hline
\end{tabular}

\subsubsection{Assessment of Diffusional Creep for Alloy 617}

This effort addresses Item E3 in Table 22 of Section 5.

Accelerated creep tests are generally performed to reduce the test durations to reasonable times. Stress-time-temperature correlation is then used to extrapolate accelerated creep rupture data to long time and low-stress service conditions. The data from the accelerated creep rupture tests in the Huntington Alloy 617 database are mainly in the dislocation creep (glide and climb) regime, with a stress exponent ranging from approximately 3 to 10 for the minimum creep rates. However, for elevated temperature applications, the applied stresses must be very low owing to the very restrictive allowable stresses. In such cases, the creep deformation mechanisms could be grain boundary sliding or diffusional creep where the stress exponent is around 2 or 1 , respectively.

Extrapolation of the creep rate in the dislocation creep regime to very low-stress could lead to a nonconservative estimate (i.e., lower creep rate) relative to that obtained from the diffusional creep regime for the same low-stress level. On the other hand, results from Schubert et al.$^{80}$ showed that the creep rate from a stress level as low as $\sim 10 \mathrm{MPa}$ at $950^{\circ} \mathrm{C}$ still followed a power law with a stress index greater than one. This indicates that diffusional creep was not rate controlling under those conditions. However, whether the creep mechanisms operating in test is the same as the in application is an important issue. Thus, both experimental and theoretical studies are proposed.

The issue of diffusional creep was also highlighted in the Task 1 report of the DOE/ASME Gen IV Materials Project for Alloy $800 \mathrm{H}$. A plan to investigate diffusional creep for Alloy $800 \mathrm{H}$ was developed and the same plan has been adapted for Alloy 617. The motivation for the proposed plan of study is as follows.

For dislocation creep, which includes power law creep by dislocation glide alone, power law creep by dislocation glide-plus-climb, and the Harper Dorn creep, the creep rate is independent of the grain size, $d$, and proportional to stress raised to a power $n$, with $n>1$ except for the Harper Dorn creep where $n=1$. Diffusional creep includes Coble creep and Nabarro-Herring creep. Coble creep operates at lower temperature with grain boundary diffusion being the rate-controlling mechanism. The Coble creep rate is inversely proportional to $d^{3}$ and linearly proportional to stress. Nabarro-Herring creep operates at high temperature where lattice diffusion is the rate-controlling mechanism. The Nabarro-Herring creep rate is inversely proportional to $d^{2}$ and linearly proportional to stress. With different dependence on grain size and stress for the creep mechanisms, creep tests on specimens with different grain size and different stress could lead to significant difference in the measured creep rates. Hence, the creep mechanisms for Alloy 617 at very high temperature and low-stress can be explored using the creep test plan shown in Table A24 of the Appendix. Note that the applied stresses and creep times shown in Table A24 might require adjustment when the study commences.

It is proposed that this research be performed at a university where diverse capabilities can be leveraged. A Statement of Work is being developed for a subcontract with University of Cincinnati to perform testing and theoretical development of the creep mechanisms for Alloy 617 at very high temperature and low applied stress. Heat treatment studies would be required to produce specimens with the desired range of grain sizes for creep testing. The data from testing per Table A24 will be analyzed to determine the stress exponents, activation energies and operative creep mechanisms, as well as to obtain values for the material constant for the minimum creep rate in the relevant creep regime. This analysis will serve as the theoretical basis for establishing deformation mechanism maps to predict the creep 
Idaho National Laboratory

\begin{tabular}{c|lll} 
NEXT GENERATION NUCLEAR PLANT & Identifier: & PLN-2804 & \\
INTERMEDIATE HEAT EXCHANGER & Revision: & 0 & \\
MATERIALS RESEARCH & Effective Date: & $04 / 30 / 08$ & Page: 132 of 156 \\
AND DEVELOPMENT PLAN &
\end{tabular}

behavior (strain rates, operative mechanisms, stress and temperature dependence) over a wider range of temperatures and stress levels.

It is anticipated that the nature of the grain boundaries (random vs special), as well as the presence of carbides along the boundaries will play important roles in diffusional creep, grain boundary sliding and void formation. Thus, electron back scattered diffraction (EBSD)/Orientation imaging (OIM) in the SEM will be utilized for accurate determination of grain size, grain size distribution, texture, the nature of grain boundaries and the occurrence of grain boundary migration, recrystallization and grain growth. In addition, the structure, chemistry, size and distribution of carbides will be characterized in detail to establish the effects of these precipitates on the creep and damage mechanisms. Furthermore, the development of damage in the form of voids at grain boundaries, their size and size distribution and relationship to the nature of grain boundaries will be carefully studied. The finer details of microstructural changes following creep will be studied by TEM:

- Characterization dislocations if present.

- Their Burgers vectors, line directions, slip planes and density.

- Presence of dislocation loops and occurrence of climb.

- Dislocation dissociations and formation of stacking faults and twins.

- Dislocation interactions with each other, second phase particles and grain boundaries.

- Characteristics of grain boundary migration, recrystallization, and grain growth.

\subsubsection{Second Round DOE/ASME Gen IV Materials Project}

The second round of the DOE/ASME Gen IV Materials Project involves five tasks as described in Section 4.2.3.2. They are:

- Task 6: Operating Condition Allowable Stress Values.

- Task 7: Considerations for the Intermediate Heat Exchanger (IHX).

- Task 8: Creep and Creep-Fatigue Crack Growth at Structural Discontinuities and Weld.

- Task 9: Simplified Elastic and Inelastic Design Analysis Methods.

- Task 10: Alternative Simplified Creep-Fatigue Design Method.

Activities from these tasks will be monitored, early findings will be evaluated, and the TDP updated, if necessary. Recommendation on data needs from these tasks will be assessed relative to the NGNP Project priority and relevant testing will be proposed.

\subsubsection{Small Grain-Sized Product Form for Alloy 617}

A wide spectrum of design concepts are being considered by reactor vendors for the IHX. They range from the traditional shell-and-tube concept to innovative designs such as the microchannel/printed circuit and the plate-fin concepts. A key issue for the Alloy 617 Code allowable stresses is the component crosssectional thickness for these new compact IHX concepts. As the cross-sectional thickness is reduced, the grain size would need to be reduced accordingly as a minimum number of grains are required through the cross-section to retain the properties of polycrystalline materials. An estimate of a grain size as fine as ASTM GS No. 8 (approximately $20 \mu \mathrm{m}$ ) is required for the thinnest cross section considered by reactor vendors. 
Idaho National Laboratory
NEXT GENERATION NUCLEAR PLANT
INTERMEDIATE HEAT EXCHANGER
MATERIALS RESEARCH
AND DEVELOPMENT PLAN

\author{
Identifier: \\ PLN-2804 \\ Revision: \\ 0 \\ Effective Date: $04 / 30 / 08$
}
Page: 133 of 156

The impact of grain size on creep properties is illustrated in Figures 38(a) and (b) ${ }^{81}$ where the creep response of two commercial high temperature alloys, HR-120 and Alloy 230, are shown for different cross-section thicknesses: foils of 3.2 mils $(0.08 \mathrm{~mm})$ and 4 mils $(0.1 \mathrm{~mm})$ and standard product forms.
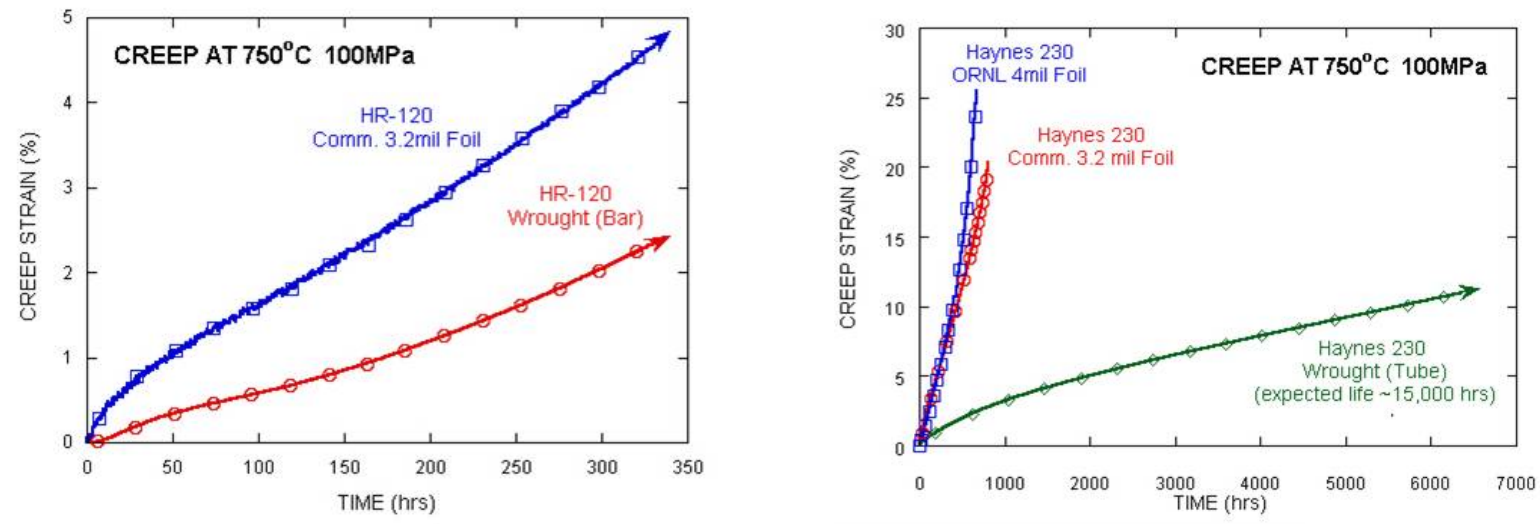

Figure 38. Creep curves for (a) HR-120, and (b) Alloy 230.

The creep rate is increased as the cross-sectional thickness is reduced, resulting in shortened creep rupture life. In addition to mechanical properties, it is expected that grain size will affect fabricability, weldability, and corrosion behavior.

Additional data for the creep rupture tests on standard grain-sized tube and small grain-sized foils for Alloy 230 are provided by Shingledecker. ${ }^{82}$ They are shown in Table 32. Based on the measured creep rupture time, a correlation for standard grain size Alloy 230 is used to compute the best estimate creep rupture stress. ${ }^{74}$ The grain size rupture factor is calculated as the ratio of the applied stress to the computed creep rupture stress. These results are also included in Table 4.

Table 32. Creep rupture data for Alloy 230 tube and foils.

\begin{tabular}{|c|c|c|c|c|c|c|c|}
\hline $\begin{array}{c}\text { Product } \\
\text { Form }\end{array}$ & $\begin{array}{c}\text { Thickness } \\
(\mathrm{mils} / \mathrm{mm})\end{array}$ & $\begin{array}{c}\text { Heat } \\
\text { Treatment }\end{array}$ & $\begin{array}{c}\text { Temp } \\
\left({ }^{\circ} \mathrm{C}\right)\end{array}$ & $\begin{array}{c}\text { Applied } \\
\text { Stress } \\
(\mathrm{MPa})\end{array}$ & $\begin{array}{c}\text { Rupture } \\
\text { Time } \\
(\mathrm{h})\end{array}$ & $\begin{array}{c}\text { Computed Best } \\
\text { Est. Rupture } \\
\text { Stress (MPa) }\end{array}$ & $\begin{array}{c}\text { Grain Size } \\
\text { Rupture } \\
\text { Factor }\end{array}$ \\
\hline Foil & $3.2 / 0.08$ & as-received & 750 & 100 & 800.9 & 158 & 0.63 \\
\hline Foil & $3.2 / 0.08$ & as-received & 704 & 152 & 514.0 & 227 & 0.67 \\
\hline Foil & $4 / 0.1$ & not known & 750 & 100 & 672.2 & 163 & 0.61 \\
\hline Tube & $\begin{array}{c}\text { Standard } \\
\text { Grain Size }\end{array}$ & as-received & 750 & 100 & 16725.6 & 98 & 1.02 \\
\hline
\end{tabular}

The grain size rupture factor is approximately one for the standard grain-sized tube specimen, hence providing a consistency check. The grain size rupture factors are ?of the order of 0.6 for the 4 mil $(0.1$ $\mathrm{mm})$ and $3.2 \mathrm{mil}(0.08 \mathrm{~mm})$ thick foils. Grain size information for the foils has not been determined but the specimens are available for such determination. The expected grain size rupture factor for Alloy 617 would be ?of the same order of magnitude as that for Alloy 230. While data at higher temperatures are not available, the grain size rupture factor could be lower at higher temperatures. 
Idaho National Laboratory

\begin{tabular}{c|lll|} 
NEXT GENERATION NUCLEAR PLANT & Identifier: & PLN-2804 & \\
INTERMEDIATE HEAT EXCHANGER & Revision: & 0 & \\
MATERIALS RESEARCH & Effective Date: & $04 / 30 / 08$ & Page: 134 of 156 \\
AND DEVELOPMENT PLAN &
\end{tabular}

While compact IHX has many advantages in terms of heat transfer efficiency, size, cost of material of construction, etc., the reduced creep rupture strength owing to grain size effects could present a significant challenge, and in particular, a potential technical risk that might not be alleviated through testing as a significant reduction is expected based on a few data points from Alloy 230, athough the rupture strength envelope for Alloy 617 foils has not been quantified.

The following scoping R\&D effort is needed to provide supporting data for the down-selection of the IHX designs from the perspective of structural integrity.

\subsubsection{Scoping Study for Creep Rupture Strength of Alloy 617 Foils}

Accelerated creep rupture tests on foils with different grain sizes need to be initiated as soon as possible. The resulting creep rupture times from small grain-sized specimens are to be compared with those from standard grain-sized specimens under the same temperature and stress conditions. At this time, it might not be possible to identify a vendor that will supply materials with the appropriate thickness and grain size. ORNL has the capability and facility to perform hot rolling to produce creep specimens with the required thickness and grain size. Creep rupture test procedure for foils has also been established successfully through prior programs.

This study will scope out the creep rupture strength penalty associated with small grain-sized product form, at least for the accelerated test conditions. This effort needs to be integrated with the task described in Section 8.1.5.3 on diffusional creep to establish if power-law, dislocation creep persists in the small grain-sized product form.

Based on these data, if sufficient performance envelope exists and the creep deformation mechanism is similar to the standard grain-sized product forms, the following steps could be taken to support code qualification.

\subsubsection{Material Specification and Supplier}

For a material to be considered for incorporation into the Code, three heats produced by a commercial process are required. Also it is required to call out a specification. Currently, strip products from material vendors such as Haynes International and Special Metals are produced by sub-tier vendors. One such subtier vendor would take a waiver on any specification for strip that required a grain size, and the vendor would also be hesitant about any request for Alloy 617 strip. Typically, the vendor produces stainless steel strips with grain size of No. 8 or finer. This is a result of a patent that Special Metals holds related to a heat treatment that results in $\mathrm{M}_{6} \mathrm{C}$ carbide formation rather than $\mathrm{M}_{23} \mathrm{C}_{6}$. There are issues in fabricating strip that has grain sizes coarser than No 8. Orange peeling and low ductility are two. High strength can be a problem in the "gathering" process used for making the convolutions for the fin-plate or prime surface concepts.

Thus, an effort is required to discuss issues related to alloys, specifications, and the like with various sub-tier vendors directly.

The current ASME specifications applicable to Alloy 617 are SB-166 for rod, bar and wire, SB-167 for seamless pipe and tube, and SB-168 for plate, sheet and strip. There is no grain size requirement in SB-166 and SB-167. Similarly, no grain size requirement is given in SB-168 for plate. However, grain sizes are specified for different thicknesses of sheets and strips in SB-168 as shown below (Table 33). 
Idaho National Laboratory

\begin{tabular}{c|lll|}
\hline $\begin{array}{l}\text { NEXT GENERATION NUCLEAR PLANT } \\
\text { INTERMEDIATE HEAT EXCHANGER } \\
\text { MATERIALS RESEARCH }\end{array}$ & Identifier: & PLN-2804 & \\
Revision: & 0 & \\
AND DEVELOPMENT PLAN & Effective Date: & $04 / 30 / 08$ & Page: 135 of 156 \\
\hline
\end{tabular}

Table 33. Grain sizes specified for various sheet and strip thicknesses in ASME SB-168.

\begin{tabular}{ccc}
\hline Thickness $(\mathrm{mm})$ & Average Grain Diameter $(\mu \mathrm{m})$ & ASTM MicroGrain Size No. \\
\hline Less than 1.3 & Sheet $(1.42 \mathrm{~m}$ Wide and Under $)$ & \\
1.3 to 6.4 & 75 & 3.5 \\
& 110 & 3.5 \\
\hline 0.13 to 0.25 & Strip $(305 \mathrm{~mm}$ Wider and Under $)$ & 8 \\
Greater than 0.25 to 3.2 & 22 & 4.5 \\
\hline
\end{tabular}

Subject-matter experts were contacted and they are willing to serve on a working group under ASME SC-D, SG-ETD that will look into Code issues related to strip products as well as assisting the NGNP Program to develop an ASTM specification or supplement to a specification, if needed, to deal with the grain size requirements for strip.

Once a path toward developing new material specification or supplement is established and a supplier is identified who is willing to produce the strip product, the creep rupture test effort described in the next section can proceed.

\subsubsection{Creep Rupture Tests to Develop Grain Size Rupture Factors}

The test matrix that supports the determination of the grain size rupture factors is proposed in Table A25 of the Appendix. One standard grain size (ASTM GS No. 1.5, $200 \mu \mathrm{m}$ ) and three smaller grain sizes (ASTM GS No. 3.5, 4.5, 8, $\sim 110 \mu \mathrm{m}, 75 \mu \mathrm{m}, 22 \mu \mathrm{m}$ ) are included. The test temperatures are $800^{\circ} \mathrm{C}$, $900^{\circ} \mathrm{C}$ and $1000^{\circ} \mathrm{C}$. The best estimate and $95 \%$ upper and lower prediction bounds from the standardgrain-sized Alloy 617 creep rupture time correlations are used to estimate the rupture times for various smaller grain sizes by assuming grain size rupture factors shown in Table A25. These assumed grain size rupture factors will be updated and the applied stresses revised once the scoping study described in Section 8.1.6.1 is concluded.

\subsubsection{Compact IHX Heat Transfer Surface Mockup Tests}

This effort will be conducted if the compact IHX concept is down-selected.

The goal of these tests will be to address NRC concerns on (a) crack initiation and propagation, (b) primary boundary design methodology limitations and (c) manufacturing phenomena respectively. Note that key feature tests are virtually the only way to assess the combined effect of these concerns.

Because it is likely that the IHX heat transfer surfaces will be located in a pressurized lower temperature vessel to minimize pressure induced stresses at very high temperatures, the most likely failure mode will be caused by cyclic thermally induced stresses in combination with differential pressure-induced stresses.

A characteristic of most, if not all, compact, micro-channel type devices is the presence of sharp, crack-like corners where segments of the heat transfer surfaces are joined by brazing or diffusion bonding. Not only is the creep-fatigue life of the joint suspect, but current elevated temperature design methods do not consider crack-like defects for fatigue analyses, and the mechanics of crack initiation and growth at the brazed or bonded joint interface is not well understood. For these reasons, it may be that key 
Idaho National Laboratory

\begin{tabular}{c|lll|} 
NEXT GENERATION NUCLEAR PLANT & Identifier: & PLN-2804 & \\
INTERMEDIATE HEAT EXCHANGER & Revision: & 0 & \\
MATERIALS RESEARCH & Effective Date: & $04 / 30 / 08$ & Page: 136 of 156 \\
AND DEVELOPMENT PLAN &
\end{tabular}

feature tests will become a part of the required elevated temperature design process, analogous to what is done in Code Case N-290 for elevated temperature bellows.

\subsubsection{Required Code Actions for Alloy $800 \mathrm{H}$}

\subsubsection{Unified Constitutive Model}

This effort addresses Item F1 in Table 23 of Section 5.

To develop the unified constitutive equations for Alloy $800 \mathrm{H}$, appropriate data are required to determine the material constants of the model. Task 1 of the DOE/ASME Gen IV Materials Project performed a detailed review of the Alloy $800 \mathrm{H}$ creep database. It found that some but not all of the original creep curves produced by INCO are available. ${ }^{83}$ The curves examined by Booker et al ${ }^{84}$ are missing but there are a few reproduced curves. The creep curves from GE could not be located. ${ }^{70}$ Creep curves from ORNL testing also could not be retrieved. ${ }^{85}$ The low strain sections of the NIMS curves can be reconstructed from the NIMS reports. ${ }^{86-89}$ The Electric Power Research Institute commissioned a very extensive survey of the high temperature mechanical behavior of Alloy $800 \mathrm{H} .{ }^{90}$ All properties were included in the survey and there were hundreds of references. Plots of creep curves were reproduced from various papers and reports but no tabulations of new data were included. Only yield and tensile strength data are provided, not the stress-strain curves, in the work reviewed.

A unified constitutive model based on the overstress concept was developed by Tachibana and Krempl, ${ }^{91-93}$ using Alloy $800 \mathrm{H}$ creep and tensile test data from JAEA between $750^{\circ} \mathrm{C}$ and $1050^{\circ} \mathrm{C}$. The longest creep time accumulated in the test data for use in the unified constitutive model development was approximately 1700 hours. The model predictions compare reasonably with test data. However, comparison with long time low-stress data was not possible as they were not available.

As the previous survey shows, many tests have been carried out for Alloy $800 \mathrm{H}$ since the 1970 s and creep information needed for unified constitutive model development could be synthesized from open literature sources. However, tensile data that would allow some of the material constants in the unified constitutive equations to be determined are not available. A small test program is proposed in Table A26 of the Appendix to supplement the open literature data. The tensile tests proposed include (1) strain-rate change, (2) stress dip, (3) loading/unloading/creep at a stress rate of $0.01 \mathrm{MPa} / \mathrm{s}$, and (4) uniaxial ratcheting. The test temperatures are selected to be $550^{\circ} \mathrm{C}, 650^{\circ} \mathrm{C}, 750^{\circ} \mathrm{C}$, and $850^{\circ} \mathrm{C}$.

The general unified constitutive model framework described in Section 8.1.3.1 will also be employed for Alloy $800 \mathrm{H}$. This will allow the module/subroutine for Alloy $800 \mathrm{H}$ to be embedded in the same hierarchical structure of the Alloy 617 finite element implementation, hence reducing R\&D costs. Alloy $800 \mathrm{H}$ will also be included in the new analysis guideline that is similar to the Nuclear Standard NE F9-5T.

\subsubsection{Extend Isochronous Stress-Strain Curves to 600,000 hours}

This effort addresses Item F2 in Table 23 of Section 5.

Isochronous stress-strain curves are required in applying the Subsection NH design procedures. These curves are provided in Subsection NH for Alloy $800 \mathrm{H}$ up to 300,000 hours. Thus in support of those Alloy $800 \mathrm{H}$ applications that require the full 60-year NGNP design life, the isochronous stress-strain 
Idaho National Laboratory

\begin{tabular}{c|lll|}
\hline NEXT GENERATION NUCLEAR PLANT & Identifier: & PLN-2804 & \\
INTERMEDIATE HEAT EXCHANGER & Revision: & 0 & \\
MATERIALS RESEARCH & Effective Date: & $04 / 30 / 08$ & Page: 137 of 156 \\
AND DEVELOPMENT PLAN &
\end{tabular}

curves up to 600,000 hours will be generated for incorporation into Subsection NH once the unified constitutive model described in Section 8.1.7.1 is developed.

\subsubsection{Time-Dependent Allowable Stresses}

This effort addresses Item F3 in Table 23 of Section 5.

Task 1 of the DOE/ASME Gen IV Materials Project has extended the time-dependent allowable stresses for Alloy $800 \mathrm{H}$ to 600,000 hours. Effort will be made to ensure that Code action will be taken to incorporate the extended allowable stresses into Subsection NH to support NGNP conceptual and preliminary design activities.

\subsubsection{Alloy 800H Weldments}

This effort addresses Item F4 in Table 23 of Section 5.

A creep-rupture experimental program was recommended in the Task 1 report to extend Subsection $\mathrm{NH}$ WSRFs for Alloy $800 \mathrm{H}$ weldments, filler metals 82 (ERNiCr-3) and A (ENiCrFe-2), to 60 years of service and above the current temperature limit of $760^{\circ} \mathrm{C}$. Subject area experts judge that developing WSRFs for 60 years and up to $850^{\circ} \mathrm{C}$ is an achievable goal. Based on the Task 1 recommendation, a test plan is proposed in Table A27 of the Appendix to generate creep rupture data for Alloy $800 \mathrm{H}$ weldments support of the time and temperature extension of Alloy $800 \mathrm{H}$ WSRF in Subsection NH. Limited testing is also proposed to study other Alloy $800 \mathrm{H}$ welds for elevated temperature service. In the test plan, filler metals 82 (ERNiCr-3), 617 (ERNiCrCoMo-1), and 21/33Nb will be used for GTA welding, and electrodes A (ENiCrFe-2), 117 (ENiCrCoMo-1), and 21/33Nb will be used for SMA welding.

The testing plan for filler metal 82 and electrode A deposited weld metal and cross weld specimens is designed to supplement existing data, which have been identified in the Task 1 report. No testing below $900^{\circ} \mathrm{C}$ is included in the test matrix as the existing database is adequate to establish WSRFs at lower temperatures and the test data recommended will be used to estimate WSRFs for long times by means of time-temperature parametric prediction methods.

The testing plan for filler metal 617 and electrode 117 specimens is directed toward understanding the effect of the mismatch in strength on the high temperature performance of weldments. Only cross welds with Alloy $800 \mathrm{H}$ base metal are included as testing for 617 and 117 deposited welds at $750^{\circ} \mathrm{C}$ and above is included in the task on establishing WSRFs for Alloy 617 weldments.

The matching weld metal, $21 / 33 \mathrm{Nb}$, is used extensively for high temperatures service. Test data are scarce, and available data have been documented in the Task 1 report. The test data from the testing plan will be used to evaluate $21 / 33 \mathrm{Nb}$ for service above $750^{\circ} \mathrm{C}$.

The Task 1 report recommended that the Alloy $800 \mathrm{H}$ base material for welding the cross welds be taken from archival material Jessup Steel Heat No. 37459 currently in storage at the Oak Ridge National Laboratory. ${ }^{85}$ This material was purchased for use on the Modular High-Temperature Gas-Cooled Reactor Program and meets the necessary specifications required by Subsection NH. When welded, the 12.7-mm (1/2-in) thick plates will be adequate for weld metal coupons, cross-weld coupons, and "full-thickness" weldments with transverse and longitudinal weld orientations. 
Idaho National Laboratory

\begin{tabular}{|c|lll|}
\hline NEXT GENERATION NUCLEAR PLANT & Identifier: & PLN-2804 \\
INTERMEDIATE HEAT EXCHANGER & Revision: & 0 & \\
MATERIALS RESEARCH & Effective Date: & $04 / 30 / 08$ & Page: 138 of 156 \\
AND DEVELOPMENT PLAN &
\end{tabular}

\subsubsection{Strain Rate Effect on Yield and Tensile Strengths}

This effort addresses Item F5 in Table 23 of Section 5.

ASME Section III Subsection NH provides values for the minimum yield strength, $S_{Y I}$, and minimum tensile strength, $S_{U}$, for the range of temperatures applicable for construction with specific alloys. Currently, Alloy $800 \mathrm{H}$ is approved for construction to $760^{\circ} \mathrm{C}$. Task 1 of the DOE/ASME Gen IV Materials Project was charged to consider extending the applicable temperature range for Alloy $800 \mathrm{H}$ to $900^{\circ} \mathrm{C}$. Average and minimum stresses were determined and recommended for Code action in the Task 1 Report, as summarized in Section 4.2.3.1. Although generally not very sensitive to strain rate at lower temperatures, the yield and tensile strengths depend on the strain rate at $760^{\circ} \mathrm{C}$ and above, with lower strengths expected for lower strain rates. Notes will be needed in the appropriate tables for yield and tensile strengths in Subsection NH to alert the user that the tabulated values for Alloy $800 \mathrm{H}$ only apply to specific ranges of strain rates. To better understand the range of applicability of the recommended values, further testing at various strain rates is needed. Table A28 in the Appendix provides some recommended tests to define this range.

Two metallurgical conditions are included to cover the range of acceptable grain sizes (ASTM GS Numbers $\leq 0$ to 5). Room temperature tests will be performed to characterize the materials and form a basis for hot-to-room temperature strength ratios. Temperatures need to cover only the range of interest because the data will not be used to set any allowable stresses but only to help in defining the limits in the notes. The strain rates cover three orders of magnitude for both yield and tensile strengths. The strengths may be produced by changing the applied rate after reaching $2 \%$ strain or performing constant rate tests to the ultimate at $0.5,0.05,0.005 / \mathrm{min}$ and testing to the yield at $0.0005 / \mathrm{min}$. The flow stress is expected to vary by $\pm 25 \%$ about the flow strength for the standard rate $(0.005 / \mathrm{min})$.

\subsubsection{Effects of Diffusional Creep Mechanism on Allowable Stresses}

This effort addresses Item F6 in Table 23 of Section 5.

According to the literature survey conducted by Task 1 of the DOE/ASME Generation IV Materials Project, diffusional creep mechanisms are active in Alloy $800 \mathrm{H}$ at $800^{\circ} \mathrm{C}$ and higher at stresses typical of long time service. ${ }^{94}$ Data produced by NIMS for several lots of Alloy $800 \mathrm{H}$ indicate rapid linear creep at low-stresses and high temperatures to strains in excess of $1 \% .{ }^{88,89}$ The creep rate appears to be proportional to stress.

Two diffusional creep processes, Nabarro-Herring and Coble creep, produce linear stress dependence as well as the Harper-Dorn mechanism. The Coble and Nabarro-Herring mechanisms differ in regard to the activation energy for creep and the grain size dependency of creep. The Harper-Dorn mechanism does not depend on grain size. Because one of the criteria in ASME III-NH for setting $S_{t}$ is the stress to produce $1 \%$ strain in a specific time, some testing of Alloy $800 \mathrm{H}$ is needed to clearly establish the temperature, stress, and grain size dependency of the early creep process at temperatures above $800^{\circ} \mathrm{C}$.

The Task 1 report observed that Alloy $800 \mathrm{H}$ grain sizes generally range from ASTM GS No. 0 to 5 which corresponds to a range from 360 to $64 \mu \mathrm{m}$. This size difference produces a factor of 200 in creep rate from coarse to fine, so this aspect of diffusional creep can be easily assessed from this perspective. A factor of two in stress corresponds to a factor of two in the diffusional creep rate and a factor of 16 for dislocation creep rate, so testing at stresses that are a factor of two apart would accurately assess this aspect of diffusional creep. Regarding temperature sensitivity, a difference of $\pm 50^{\circ} \mathrm{C}$, say between 850 


\begin{tabular}{c|lll|}
\hline $\begin{array}{c}\text { NEXT GENERATION NUCLEAR PLANT } \\
\text { INTERMEDIATE HEAT EXCHANGER } \\
\text { MATERIALS RESEARCH }\end{array}$ & Identifier: & PLN-2804 & \\
RND DEVELOPMENT PLAN & Effective Date: & $04 / 30 / 08$ & Page: 139 of 156 \\
\hline
\end{tabular}

and $950^{\circ} \mathrm{C}$, would produce an increase in the diffusional creep rate of a factor of four and an increase in the dislocation creep rate of a factor around 20.

Based on these observations, a test plan was developed by Task 1 to explore the creep mechanisms of Alloy $800 \mathrm{H}$. The test matrix is shown in Table A29 of the Appendix. It is recommended that the creep mechanisms study for Alloy $800 \mathrm{H}$ be combined with that for Alloy 617 discussed in Section 8.1.5.3 through the same university subcontract. A Statement of Work is being developed for a subcontract with University of Cincinnati to perform testing and theoretical development to explore the creep mechanisms for Alloy 617 and Alloy $800 \mathrm{H}$.

\subsubsection{Yield and Tensile Strength Reduction Factor}

This effort addresses Item F7 in Table 23 of Section 5.

Thermal aging is not a significant concern within the specified temperature limit of $760^{\circ} \mathrm{C}$ for Alloy $800 \mathrm{H}$. Yield and tensile strength reduction factors of 0.9 and 0.9 , respectively, are required for service temperatures greater than $730^{\circ} \mathrm{C}$ in Subsection NH. These factors are valid up to 300,000 hours. Extension of these factors to 600,000 hours is required to support the NGNP intermediate temperature IHX and core internal application.

The longest aging time in the original dataset that supported the current strength reduction factors was $\sim 20,000$ hours. Recently, Swindeman et al. ${ }^{95}$ have compared the yield and tensile strengths of serviceexposed Alloy $800 \mathrm{H}\left(73,500 \mathrm{~h}\right.$ at $752^{\circ} \mathrm{C}$ to $\left.774^{\circ} \mathrm{C}\right)$ with laboratory results from Alloy $800 \mathrm{H}$, thermally aged for 18,600 hours at $760^{\circ} \mathrm{C}$ (see Figure 39 ). Only very small drops in strengths, within the typical data scatter, are observed.

It is proposed to assemble a database from the literature that includes the original dataset that supported the current strength reduction factors. Strength reduction factors up to 600,000 hours will be developed by extrapolating the data using statistical methods to support conceptual and preliminary design activities. These reduction factors will be qualified for final design and licensing approval using data from a small-scale long-term aging qualification test program as proposed in Table A30 of the Appendix. 


\begin{tabular}{c|lll|}
\hline NEXT GENERATION NUCLEAR PLANT & Identifier: & PLN-2804 \\
INTERMEDIATE HEAT EXCHANGER & Revision: & 0 & \\
MATERIALS RESEARCH & Effective Date: & $04 / 30 / 08$ & Page: 140 of 156 \\
AND DEVELOPMENT PLAN &
\end{tabular}

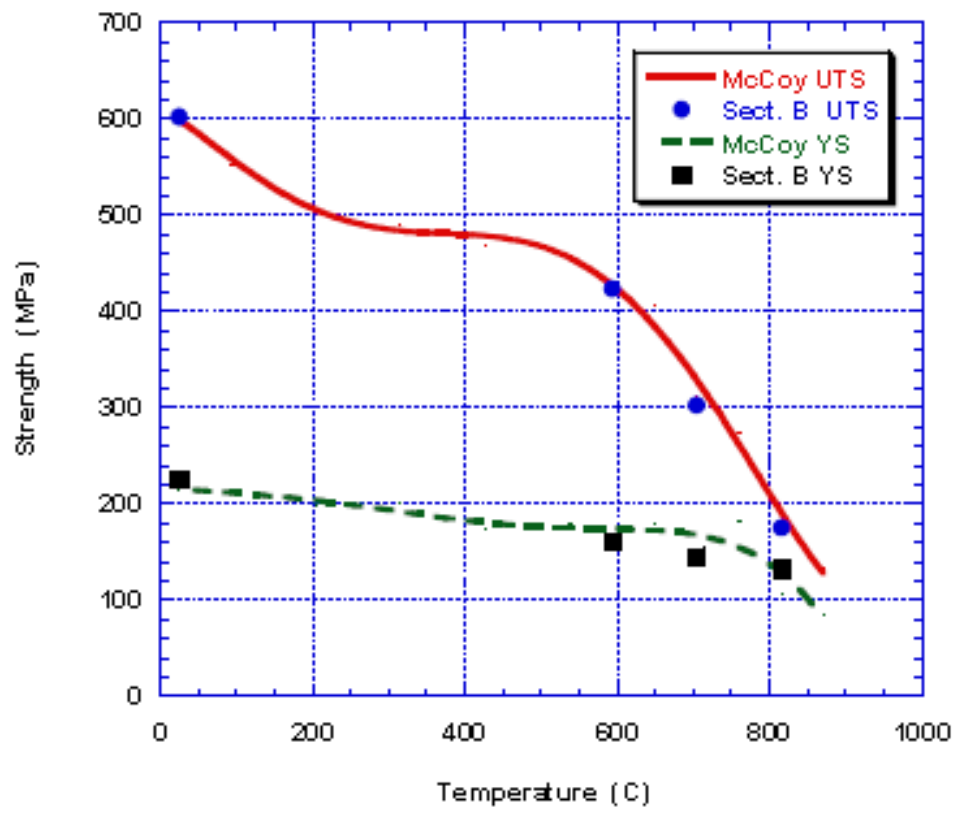

Figure 39. Strengths comparison of service-exposed (73,500 hours) and laboratory-exposed $(18,600$ hours) Alloy $800 \mathrm{H}$.

\subsubsection{Cold Work Effect and Subsequent Heat Treatment Requirements}

This effort addresses Item F8 in Table 23 of Section 5.

The Alloy $800 \mathrm{H}$ time-temperature curve that governs short-term temperature excursion beyond the maximum allowable temperature for the purpose of heat treatment needs to be extended to 600,000 hours. Research into how the original curve for up to 300,000 hours was created will be performed. Additional tests will be proposed in the future if it is determined that testing is necessary to support the extension of the time-temperature curve. Prohibiting cold work for service beyond 300,000 hours is an option under consideration.

\subsubsection{Effect of Multiaxial Stress State on Creep-Fatigue Procedure}

This effort addresses Item F9 in Table 23 of Section 5.

The " $\mathrm{C}$ " factor in the multiaxial creep rupture strength criterion has a value of $\mathrm{C}=0$ for Alloy $800 \mathrm{H}$ in Subsection NH. Biaxial creep rupture tests similar to those proposed for Alloy 617 in Section 8.1.4.8, but at $850^{\circ} \mathrm{C}$, are proposed in Table $\mathrm{A} 31$ of the Appendix to validate the value of $\mathrm{C}=0$ for Alloy $800 \mathrm{H}$.

\subsubsection{Long-Term Aging Facility}

This effort addresses NRC concerns List 14 in Table 19 of Section 5.

A long-term aging facility will be required to support the licensing effort for both IHX and RPV materials. The facility will allow both static aging (e.g., in air in a box furnace) and long-term testing to develop data under prototypical NGNP conditions (low-stress, etc). 
Idaho National Laboratory

\begin{tabular}{c|lll|}
\hline NEXT GENERATION NUCLEAR PLANT & Identifier: & PLN-2804 & \\
INTERMEDIATE HEAT EXCHANGER & Revision: & 0 & \\
MATERIALS RESEARCH & Effective Date: & $04 / 30 / 08$ & Page: 141 of 156 \\
AND DEVELOPMENT PLAN &
\end{tabular}

Tests such as creep, thermal aging, crack growth, environmental effects in air, and emissivity degradation are envisioned. It will be important to initiate this effort soon to maximize the benefits of long-term testing. Two general goals are: gathering as much long-term data as soon as possible to use in on-going design evaluations and using the long-term test results as a leading indicator for potential remedial action involving the operating reactor system. Verification of extrapolation techniques will be an important factor in maximizing confidence in current design parameters. For the second goal, it will be necessary to accumulate more time under prototypical operating conditions than the actual components in service to identify potential degradation issues in time to mitigate for the reactor system.

This facility will not require a large amount of manpower; much of the data collection will be automated. A substantial amount of material will be required for the aging studies so that samples can be removed periodically for testing while the remainder accumulate more time under simulated service conditions. It is likely that sheet material required for some of the compact heat exchangers may exhibit different aging behavior than plate material. Specific materials and product forms that will require longterm testing cannot be determined until the design of the IHX is finalized.

\subsection{Additional Research Programs}

\subsubsection{Joining}

\subsubsection{Welding}

\section{Define adequate weldments}

A test program must be developed to determine mechanical properties of the welds. In addition it must be verified that the environmental effects in the weld and heat affected zone are similar to the base metal, that the microstructure is stable with no chemical inhomogeneity, and that the grain size is acceptable.

\section{Determine welding process and procedures}

It appears from vendor literature on the alloys that the welding process and procedures for 617 and 230. Improved methods of joining Alloy 230 will be investigated.

Dissimilar metal welds required to join components must be identified. Weld process development, as well as microstructure and mechanical property testing, will need to be identified for these cases.

\section{Define testing schemes}

- Creep and creep/fatigue behavior of weldments in Alloy 617 and Alloy 230 joined using best current commercial practice will be evaluated.

- Microstructure and mechanical properties of thin section Alloy 617 and Alloy 230 weldments and diffusion bonds will be characterized.

- The long-term metallurgical stability of fusion welds in Ni-based alloys will be examined.

\subsubsection{Diffusion bonding}

The potential for detrimental effects associated with high temperature thermal cycles during brazing and diffusion bonding will be determined. 
Idaho National Laboratory

\begin{tabular}{c|lll} 
NEXT GENERATION NUCLEAR PLANT & Identifier: & PLN-2804 & \\
INTERMEDIATE HEAT EXCHANGER & Revision: & 0 & \\
MATERIALS RESEARCH & Effective Date: & $04 / 30 / 08$ & Page: 142 of 156 \\
AND DEVELOPMENT PLAN &
\end{tabular}

\section{Define adequate diffusion bonds}

A test program must be developed to determine mechanical properties of the diffusion bonds. In addition it must be verified that the environmental effects in the diffusion-bonded regions are similar to the base metal, that the microstructure is stable with no chemical inhomogeneity, and that the grain size is acceptable.

\section{Determine diffusion bonding process and procedures}

The optimum atmosphere, time, temperature and applied pressure must be defined for the diffusion bonding process, and the impact of any of these parameters on the microstructural stability must be determined.

\subsubsection{Brazing}

\section{Define adequate brazed joints}

A test program must be developed to determine mechanical properties of the brazed joints. Any microstructural instability associated with the braze material or chemical interaction between the braze material and the base metal must be investigated. In addition it must be verified that the environmental effects near the brazed joint are similar to the base metal, and that the grain size is acceptable.

\section{Determine bonding process and procedures}

The optimum atmosphere, time, temperature and applied pressure must be defined for the brazing process, and the impact of any of these parameters on the microstructural stability must be determined. The composition of the braze material must also be defined.

\subsubsection{Characterization of Degradation}

\subsubsection{Environmental Effects}

Experiments must be designed to test materials and components in gas representative of the NGNP gas. The chemical composition including anticipated impurities and moisture levels, the pressure ( $\sim 7 \mathrm{MPa}$ ) and velocities up to $75 \mathrm{~m} / \mathrm{s}$ must all be accounted for. Under these conditions there is an increased potential for erosion.

Assuming Alloy 617 is selected, the following tests will be required. A similar test plan would be used for Alloy 230.

1. Subject samples to long-term exposure in the controlled chemistry loop in the microclimate regime. Characterize post-exposure microstructure and mechanical property changes as a function of time and $\mathrm{CO}$ concentration.

2. Conduct controlled chemistry creep crack growth measurements on plate, weldments and carburized material. Tests will be done at temperatures in the range of about 650 to $800^{\circ} \mathrm{C}$ where the material will flow but maintains enough strength to prevent flow that blunts crack growth.

3. Measure environmentally assisted crack growth rates as a function of oxygen partial pressure in the vicinity of $600^{\circ} \mathrm{C}$. Tests will include plate, weldments and carburized material. 
Idaho National Laboratory

\begin{tabular}{c|lll|}
\hline NEXT GENERATION NUCLEAR PLANT & Identifier: & PLN-2804 & \\
INTERMEDIATE HEAT EXCHANGER & Revision: & 0 & \\
MATERIALS RESEARCH & Effective Date: & $04 / 30 / 08$ & Page: 143 of 156 \\
AND DEVELOPMENT PLAN &
\end{tabular}

4. Test plate and weldments will in expected NGNP environmental conditions including NGNP pressure (7MPa or so) from 800 to $1000^{\circ} \mathrm{C}$ in quasi-static gas and with gas velocity from 25 to 75 $\mathrm{m} / \mathrm{s}$. Particle erosion effects will be included in the high velocity tests using particles selected to represent relatively soft graphite dust as well as harder oxides spalled from alloy surfaces (pressure vessel and IHX).

5. Conduct carburization and microclimate testing on $800 \mathrm{H}$ in the controlled chemistry loop, assuming it is chosen for control rods.

In addition to the scoping studies to characterize bulk corrosion issues in the NGNP environment, the NRC PIRT study identified several potential concerns with embrittlement in service in lower temperature sections of the heat exchanger. Studies are currently underway in collaboration with MIT to investigate crack growth rates associated with stress assisted grain boundary oxidation in both Alloy 617 and Alloy 230. The results of this study at MIT will determine if further work in the area will be necessary as part of the NGNP project.

The other area of possible concern was creep crack growth in regions of the heat exchanger that experience temperatures intermediate between those that give rise to stress assisted grain boundary oxidation $\left(<700^{\circ} \mathrm{C}\right)$ and the creep-fatigue regime $\left(>850^{\circ} \mathrm{C}\right)$. In this temperature range, there is sufficient creep deformation to drive crack growth and sufficient material strength to prevent crack blunting by massive deformation. A university project between MIT, Boise State University and University of Nevada Las Vegas is investigating creep crack growth in Alloy 230, but scoping experiments to determine the potential for premature failure due to creep crack growth will be required for Alloy 617 as part of this project. Tests are identified elsewhere for material aged and tested in air; additional tests in the NGNP environment are outlined in Table 34 below. For each aging time and temperature three replicate tests are required.

Table 34. Creep crack growth in NGNP He.

\begin{tabular}{|c|c|c|c|}
\hline Aging Temperature & Test Temperature & Aging Time, hours & Number of specimens \\
\hline $700^{\circ} \mathrm{C}$ & $700-850^{\circ} \mathrm{C}$ & 100 and 1000 & 18 \\
\hline $750^{\circ} \mathrm{C}$ & $700-850^{\circ} \mathrm{C}$ & 100 and 1000 & 18 \\
\hline $800^{\circ} \mathrm{C}$ & $700-850^{\circ} \mathrm{C}$ & 100 and 1000 & 18 \\
\hline $850^{\circ} \mathrm{C}$ & $700-850^{\circ} \mathrm{C}$ & 100 and 1000 & 18 \\
\hline $900^{\circ} \mathrm{C}$ & $700-850^{\circ} \mathrm{C}$ & 100 and 1000 & 18 \\
\hline $950^{\circ} \mathrm{C}$ & $700-850^{\circ} \mathrm{C}$ & 100 and 1000 & 18 \\
\hline
\end{tabular}

Experimental validation of an environmental effects model in controlled chemistry He will be completed for Alloy 617 and Alloy 230. The stability of microstructures and mechanical properties will be characterized for temperatures ranging from $800-1000^{\circ} \mathrm{C}$, with impurity contents expected in the NGNP environment. 
Idaho National Laboratory

\begin{tabular}{|c|lll|}
\hline NEXT GENERATION NUCLEAR PLANT & Identifier: & PLN-2804 \\
INTERMEDIATE HEAT EXCHANGER & Revision: & 0 & \\
MATERIALS RESEARCH & Effective Date: & $04 / 30 / 08$ & Page: 144 of 156 \\
AND DEVELOPMENT PLAN & &
\end{tabular}

\subsubsection{Erosion}

Weight loss (or gain) optical and scanning electron microscopy will be used to study possible erosion in samples exposed to the representative environment. The range of particulate material should be characterized (material, particle size, etc.) to understand the sources of erosion. Ultimately, acceptance criteria for erosion must be defined.

\subsubsection{Dust Clogging and Accumulation}

The testing requirements for dust clogging and accumulation are similar to those listed above for erosion in Section 8.2.2.2; however, samples must have channels of typical size and configuration for the IHX design under consideration.

Westinghouse proposes to prepare a white paper on dust control to determine whether it is necessary to test the IHX for dust blockage and release during accidents. They would consider similarities and differences with the PBMR DPP and its approach to dust management. ${ }^{9}$

\subsubsection{Radiation Effects}

\section{Tritium}

Experimental investigation of tritium transport through the alloys as a function of surface condition is needed.

\section{Activated Materials}

Activated materials are not expected to be an issue for the parts discussed in this report.

\section{Fission Products}

Possible environmental interactions between fission products released from the fuel and the IHX alloys must be considered.

\section{Neutron Irradiation}

Radiation effects of the core barrel should be irrelevant. For the control rods, radiation embrittlement will define the replacement schedule.

A scoping program to further investigate irradiation-induced changes in properties of Alloy $800 \mathrm{H}$ will be required to identify potential issues with this material in control rod sleeve applications. This program will consist of:

- Characterization of the existing specimens from the Generation IV program irradiations using electron microscopy. Confirm that helium transport to the grain boundaries is the primary embrittling mechanism.

- Additional irradiations at temperatures of 700,750 and $800^{\circ} \mathrm{C}$ to approximately $1.25 \mathrm{dpa}$. These conditions reflect the upper limit in code, and will result in the most damage because exposures are at the highest plausible temperature. 
Idaho National Laboratory

\begin{tabular}{c|lll|}
\hline NEXT GENERATION NUCLEAR PLANT & Identifier: & PLN-2804 & \\
INTERMEDIATE HEAT EXCHANGER & Revision: & 0 & \\
MATERIALS RESEARCH & Effective Date: & $04 / 30 / 08$ & Page: 145 of 156 \\
AND DEVELOPMENT PLAN &
\end{tabular}

- Mechanical property characterization of the newly irradiated specimens from room temperature to $800^{\circ} \mathrm{C}$ :

- Tensile.

- Stress Rupture.

- Characterization of the mechanical property specimens post-test to, including the fracture surfaces, to determine the mechanism of embrittlement.

If the scoping tests indicate a significant issue - plan a larger irradiation campaign with range of irradiation temperatures. Include flaw sensitivity and fracture toughness testing.

\section{Rules for Fabrication}

Microstructure and properties of thin sections will be characterized and compared to plate material.

A study will be completed to determine the requirement for thin sheet characterization as part of the data package to support the code case.

\subsubsection{Test Methods}

\subsubsection{Lab-scale}

Section 8.1 details the laboratory scale testing planned.

\subsubsection{Pilot and component scale}

Conceptual design for a facility to test pumps, valves and heat exchangers will be completed. Prototype IHX's will be tested in a high velocity flow loop to confirm the performance is consistent with the design rules on scaled down components.

\subsubsection{Engineering scale}

There are no engineering scale issues from a materials point of view. There will be engineering tests to determine the flow, pressure drop, etc. of the IHX are satisfactory.

\subsubsection{Data Management}

Data management for this program should consist of at least three major parts: (1) plans for efficient data generation in resources, time, and cost; (2) maintenance of data to achieve maximum benefits to the present reactor development and future reactor operation; (3) quality assurance.

Data generation plans will be developed with full review of existing data and consultation with major data users. Plans will be reviewed and agreed upon by relevant personnel before implementation. In data maintenance and quality assurance, the technical information produced from the R\&D activities in this program will need to be kept retrievable for the entire period of the reactor development, plus the reactor service life of 60 years and beyond.

Therefore, all the information generated should be documented in compliance with relevant QA requirements. Further, all the raw data generated from successful tests must be stored in Excel spreadsheets, and be prepared for input to the Generation IV Materials Handbook. Technical reports will 
Idaho National Laboratory

\begin{tabular}{c|lll|}
\hline NEXT GENERATION NUCLEAR PLANT & Identifier: & PLN-2804 & \\
INTERMEDIATE HEAT EXCHANGER & Revision: & 0 & \\
MATERIALS RESEARCH & Effective Date: & $04 / 30 / 08$ & Page: 146 of 156 \\
AND DEVELOPMENT PLAN &
\end{tabular}

also be prepared in PDF for Handbook input so that they can be conveniently retrieved and will not be scattered in years to come.

The major steps in preparation of data include collecting, formatting/editing, error checking, and technical approval. Traceability must be ensured in each step of the entire process. For raw test data, the following metadata must be provided in data documentation and record preparation.

Data Project Name / ID

Testing Organization

Original Test Number

Original Test Filename

Test Operator

Test Standards

Data Processed by

Applicable QA Requirements

Record Edited by

Record Error Checked By

Record Technical Approval by

The Handbook task is responsible for providing detailed guidance for data preparation, including developing a customized Handbook data Importer Templates to meet particular testing machine output formats when needed. An introduction of the Handbook development can be found in Ren. ${ }^{96}$

\subsection{Cost}

\subsubsection{Material and Fabrication}

The following materials will need to be purchased:

1. Approximately $5000 \mathrm{lbs}$ of one heat of Alloy 617 plate, and $2500 \mathrm{lbs}$ of each of two additional heats at an estimated price of $\$ 40 / \mathrm{lb}$. In addition $3 \mathrm{~mm}$ sheet of the heats must be obtained for experiments in case a thin sheet IHX is used.

2. About $2500 \mathrm{lbs}$. of $800 \mathrm{H}$ plate and sheet for testing at an estimated price of $\$ 40 / \mathrm{lb}$.

3. Miscellaneous consumables such as atmospheric gases and welding wire.

From this material, hundreds of test specimens of various types must be prepared, some of which require careful polishing, or more complex geometries than the typical tensile specimen. Preliminary processing such as pre-cracking, welding, heat treating, irradiation, etc. is required for many of the specimens.

Extra material must be purchased to allow for future testing from the same heats. This will provide for additional testing deemed necessary during the NGNP design and development phase after preliminary data has been gathered. In addition, it must be sufficient for any future testing needs that may arise during the life of the plant. It could also support future modifications or additions to the code. 
Idaho National Laboratory

\begin{tabular}{c|lll|} 
NEXT GENERATION NUCLEAR PLANT & Identifier: & PLN-2804 & \\
INTERMEDIATE HEAT EXCHANGER & Revision: & 0 & \\
MATERIALS RESEARCH & Effective Date: & $04 / 30 / 08$ & Page: 147 of 156 \\
AND DEVELOPMENT PLAN &
\end{tabular}

\subsubsection{Cost of Testing}

Appropriate test facilities are rare if they exist at all, especially for controlled impure He and at elevated temperatures. Refurbishing or modification of existing equipment requires careful planning, time, and resources, and new equipment can be costly.

The following equipment must be purchased and/or built to conduct experiments:

1. High pressure quasi-static controlled chemistry test system (most likely an autoclave).

2. High velocity test loop or a test station on the component test loop that the Engineering department is designing. Laser doppler velocimetery, and particle injection and characterization capabilities will be required.

3. A fogging mirror humidity metering for a controlled chemistry test loop.

4. Four DC potential drop systems for creep crack growth.

5. A system for controlled chemistry environmentally assisted crack growth testing.

6. Relatively large dewars to be used for several applications.

Some of the proposed tests are fairly unique and sophisticated with variations in strain rate, load magnitude or direction, cycle frequency, hold times, etc. It appears that only limited irradiation testing is required; however, that testing is particularly costly as sample time in a reactor is extremely hard to obtain and very expensive. It is anticipated that some engineering design will be required for fixturing and test set-up.

With testing comes analysis. The microstructure and/or fracture surfaces will require metallurgical analysis for many, if not all of the samples. Data must be analyzed for individual specimens to ensure valid testing and extract necessary quantities, for groups of specimens to ensure statistical significance and make comparisons, produce figures and the like.

Constitutive modeling is a significant task and current plans are to subcontract much of that work. Efforts to support ASME code modifications will also be substantial. As always, analysis and reporting will be an ongoing tasks.

The cost break down is shown in Tables 35 and 36. 


\section{Idaho National Laboratory \\ NEXT GENERATION NUCLEAR PLANT \\ INTERMEDIATE HEAT EXCHANGER \\ MATERIALS RESEARCH \\ AND DEVELOPMENT PLAN}

\begin{tabular}{|lll|} 
Identifier: & PLN-2804 & \\
Revision: & 0 & \\
Effective Date: & $04 / 30 / 08$ & Page: 148 of 156 \\
\hline
\end{tabular}

Table 35. Cost Breakdown of Mechanical Property Testing.

\begin{tabular}{|c|c|c|c|c|c|c|c|c|c|c|}
\hline Test Type & \# Tests & $\begin{array}{c}\text { Product } \\
\text { Form }\end{array}$ & Sample Form & $\begin{array}{c}\text { Cost/ } \\
\text { Sample }^{1}\end{array}$ & $\begin{array}{c}\text { Sample } \\
\text { Cost }^{2}\end{array}$ & $\begin{array}{c}\text { Time/ } \\
\text { Test } \\
\text { (h) }\end{array}$ & $\begin{array}{c}\text { Total } \\
\text { Test } \\
\text { Time }\end{array}$ & $\begin{array}{c}\text { Post Test } \\
\text { Time }^{3} \\
\end{array}$ & Testing Cost ${ }^{4}$ & Grand Total \\
\hline tensile & 535 & plate & tensile & 50 & 40,125 & 3 & 1,605 & 1,605 & 481,500 & \\
\hline creep & 232 & plate & tensile & 50 & 17,400 & 7 & 1,624 & 1,624 & 487,200 & \\
\hline creep-fatigue & 210 & plate & crp-fatigue & 100 & 31,500 & 10 & 2,100 & 2,100 & 630,000 & \\
\hline fracture toughness & 1152 & plate & CT & 100 & 172,800 & 8 & 9,216 & 9,216 & $2,764,800$ & \\
\hline stress rupture & 206 & plate & tube & 75 & 23,175 & 10 & 2,060 & 2,060 & 618,000 & \\
\hline torsion & 51 & plate & tube & 75 & 5,738 & 8 & 408 & 408 & 122,400 & \\
\hline stress dip & 63 & plate & tensile & 50 & 4,725 & 10 & 630 & 630 & 189,000 & \\
\hline ratcheting & 27 & plate & tensile & 50 & 2,025 & 5 & 135 & 135 & 40,500 & \\
\hline fatigue & 111 & plate & fatigue & 75 & 12,488 & 7 & 777 & 777 & 233,100 & \\
\hline stress relaxation & 24 & plate & tensile & 50 & 1,800 & 7 & 168 & 168 & 50,400 & \\
\hline tube burst & 36 & tube & tube & 75 & 4,050 & 10 & 360 & 360 & 108,000 & \\
\hline $\mathrm{C}$ factor & 36 & tube, bar & $?$ & 75 & 4,050 & 10 & 360 & 360 & 108,000 & \\
\hline creep (grain size) & 54 & strip, foil & tensile & 50 & 4,050 & 7 & 378 & 378 & 113,400 & \\
\hline long-term creep & 40 & plate & SMT & 50 & 3,000 & 15 & 600 & 600 & 180,000 & \\
\hline SMT creep-fatigue & 8 & plate & tensile & 100 & 1,200 & 12 & 96 & 96 & 28,800 & \\
\hline Subtotals & 2785 & & & & 328,125 & & & & $6,155,100$ & $6,483,225$ \\
\hline
\end{tabular}


Idaho National Laboratory

NEXT GENERATION NUCLEAR PLANT

INTERMEDIATE HEAT EXCHANGER

MATERIALS RESEARCH AND DEVELOPMENT PLAN
Identifier: $\quad$ PLN-2804

Revision: $\quad 0$

Effective Date: $04 / 30 / 08 \quad$ Page: 149 of 156

Table 36. Cost breakdown for high temperature materials R\&D plan.

\begin{tabular}{|c|c|c|}
\hline FY09-FY14 (All values in FY08 burdened \$) & $\operatorname{Cost}(\$)$ & Subtotals \\
\hline Material Cost & & $1,028,125$ \\
\hline Raw Material & & 500,000 \\
\hline 617 & 400,000 & \\
\hline $800 \mathrm{H}$ & 100,000 & \\
\hline cost to machine samples & 328,125 & \\
\hline consumables & 200,000 & \\
\hline Adder for purchasing $(30 \%)$ & 308,438 & $1,336,563$ \\
\hline Labor for Testing & & $7,155,100$ \\
\hline mechanical property testing & $6,155,100$ & \\
\hline physical property testing & 500,000 & \\
\hline corrosion testing & 500,000 & \\
\hline irradiation testing & $1,000,000$ & \\
\hline Equipment Purchase & & $3,325,000$ \\
\hline Load Frames & $1,500,000$ & \\
\hline Fixtures & 75,000 & \\
\hline Furnaces & 250,000 & \\
\hline Repair, Upgrade and Refurbishing & $1,500,000$ & \\
\hline Adder for purchasing $(30 \%)$ & 997,500 & $4,322,500$ \\
\hline Other Labor & & $4,800,000$ \\
\hline Analysis and Reporting & 900,000 & \\
\hline Engineering Design Support & 600,000 & \\
\hline Project Engineer & 900,000 & \\
\hline $\begin{array}{l}\text { Constitutive } \\
\text { Modeling }\end{array}$ & 800,000 & \\
\hline ASME Code Interface & $1,600,000$ & \\
\hline Subcontracts & $1,100,000$ & \\
\hline Subtotal for Labor & & $11,955,100$ \\
\hline Subtotal for Materials \& Equipment & & $5,659,063$ \\
\hline Subtotal & & $19,714,163$ \\
\hline Quality Assurance (10\%) & $1,971,416$ & \\
\hline Program Management $(10 \%)$ & $1,971,416$ & \\
\hline Total & $23,656,995$ & \\
\hline
\end{tabular}


Identifier: $\quad$ PLN-2804

Revision: $\quad 0$

Effective Date: $04 / 30 / 08 \quad$ Page: 150 of 156

\subsection{Schedule}

A large matrix of required testing to support design and licensing of the NGNP has been developed as part of this Technology Development plan. Investment in additional testing capabilities and development of a long-term aging facility will be necessary to accomplish all of the required tests. If sufficient funding is available, completion of the necessary research and development can be accomplished to support the NGNP schedule.

A detailed resource loaded schedule will be developed in conjunction with evaluation of the completed vendor preconceptual design reports. 


\begin{tabular}{c|lll|}
\hline $\begin{array}{l}\text { NEXT GENERATION NUCLEAR PLANT } \\
\text { INTERMEDIATE HEAT EXCHANGER } \\
\text { MATERIALS RESEARCH }\end{array}$ & Identifier: & PLN-2804 & \\
RND DEVELOPMENT PLAN & Effective Date: & $04 / 30 / 08$ & Page: 151 of 156 \\
\hline
\end{tabular}

\section{REFERENCES}

1. Harvego, E. A., INL, Evaluation of Next Generation Nuclear Power Plant (NGNP) Intermediate Heat Exchanger (Ihx) Operation Conditions; INL/EXT - 06-11109; April 2006.

2. Dewson, S. J., Li, X., "Selection Criteria for the High Temperature Reactor Intermediate Heat Exchanger," Proceedings of ICAPP'05, Seoul, Korea, May 15-19, 2005pp. 1-7.

3. Dewson, S. J., Thonon, B., "The Development of High Efficiency Heat Exchangers for Helium Gas Cooled Reactors," Proceedings of the International Congress on Advances in Nuclear Power Plants, Cordoba, Spain, May 4-7 2003pp. 1-13.

4. Li, X., Le Pierres, R., Dewson, S. J., "Heat Exchangers for the Next Generation of Nuclear Reactors," Proceedings of ICAPP '06, Reno, NV, June 4-8. 2006.

5. $\quad$ Pua, L. M., Rumbold, S. O., "Industrial Microchannel Devices - Where Are We Today?," Rochester, NY, April 24-25, 2003.

6. Tonkovich, A. L., "Microchannel Heat Exchangers:Applications and Limitations," slides Plain City, $\mathrm{OH}$.

7. INL, Next Generation Nuclear Plant Pre-Conceptual Design Report; Revision 1; INL/EXT-07-12967; November 2007.

8. $\quad$ AREVA NP Inc., AREVA NP Inc., NGNP with Hydrogen Production Preconceptual Design Studies Report Executive Summary; 12-9052076-000; June 2007.

9. Caspersson, S. A., Westinghouse Electric Company LLC, Nuclear Power Plants, NGNP and Hydrogen Production Preconceptual Design Report Executive Summary Report; NGNP-ESR-RPT-001 Revision 1; June 2007.

10. General Atomics, GA, Preconceptual Engineering Services for the Next Generation Nuclear Plant (NGNP) with Hydrogen Production; PC-000544; 7/10/2007.

11. Weaver, K. D., Idaho National Laboratory, NGNP Engineering White Paper: Reactor Type Trade Study; INL/EXT-07-12729.

12. Sherman, S. R., Idaho National Laboratory, INL, NGNP Engineering White Paper: NGNP Project Pre-Conceptual Heat Transfer and Transport Studies; INL/EXT-07-12730; April 2007.

13. Vandel, D. S., Idaho National Laboratory, INL, NGNP Engineering White Paper: Primary and Secondary Cycle Trade Study; INL/EXT-07-12732; April 2007.

14. Schultz, R. R., Idaho National Laboratory, INL, NGNP Engineering White Paper: Power Conversion System Trade Study; INL/EXT-07-12727; April 2007.

15. Copsey, B., Lecomte, M., Brinkmann, G., et al., "The Framatome Anp Indirect-Cycle Very High-Temperature Reactor," ICAPP 2004, Pittsburg, PA, June 13-17, 2004.

16. Proceedings of ICAPP '05, Seoul, Korea, May 15-19, 2005.

17. Fazluddin, S., Smit, K., Slabber, J., "The Use of Advanced Materials in VHTR's," 2nd International Topical Meeting on High Temperature Reactor Technology, Beijing, China, September 22-24, 2004.

18. Ion, S., Nicholls, D., Matzie, R., et al. "Pebble Bed Modular Reactor the First Generation IV Reactor to Be Constructed," http://www.world-nuclear.org/sym/2003/matzie.htm.

19. Matzner, D., "PBMR Project Status and the Way Ahead," Proceedings of the 2nd International Topical Meeting on High Temperature Reactor Technology, Beijing China, September 22-24, 2004, International Atomic Energy Agency: pp. 1-13. 


\begin{tabular}{c|lll|}
\hline $\begin{array}{l}\text { NEXT GENERATION NUCLEAR PLANT } \\
\text { INTERMEDIATE HEAT EXCHANGER }\end{array}$ & Identifier: & PLN-2804 & \\
MATERIALS RESEARCH & Revision: & 0 & \\
AND DEVELOPMENT PLAN & Effective Date: & $04 / 30 / 08$ & Page: 152 of 156 \\
\hline
\end{tabular}

20. Koster, A., Matzie, R., Matzner, D., "PBMR: A Generation IV High Temperature Gas Cooled Reactor," Proc. Instn Mech. Engrs, J. Power and Energy, Vol. 218, Part A.

21. Broom, N., Smit, K., "PBMR Design Methodology," slides from Generation IV International Forum, Oak Ridge, TN, 12th April 2005.

22. Wright, J. K., Lloyd, W. L., Idaho National Laboratory, Analysis of Potential Materials for the Control Rod Sleeves of the Next Generation Nuclear Plant INL/EXT-06-11614; October, 2006.

23. INEEL, Idaho National Engineering and Environmental Laboratory, Design Features and Technology Uncertainties for the Next Generation Nuclear Plant; INEEL/EXT-04-01816; June 30, 2004.

24. Davis, C. B., Revised RELAP5-3D Thermal Analysis Results for Prismatic VHTR, 2006, unpublished work.

25. INEEL, Idaho National Engineering and Environmental Laboratory, Next Generation Nuclear Plant Materials Research and Development Program Plan; INEEL/EXT-03-001128; November 7, 2003.

26. PBMR, PBMR, Licensing Basis Event Selection for the Pebble Bed Modular Reactor; PBMR-040251.

27. Natesan, K., Purohit, A., Tam, S. W., Argonne National Laboratory, Materials Behavior in HTGR Environments; ANL-02/37; February 2003.

28. Ren, W., Swindeman, R. W., "A Review of Aging Effects in Alloy 617 for Gen IV Nuclear Reactor Applications," Proceedings of the 2006 ASME Pressure Vessels and Piping Division Conference, Vancouver, BC Canada, July 23 - 27, 2006.

29. Ren, W., Swindeman, M. J., ORNL, Development of a Controlled Material Specification for Alloy 617 for Nuclear Applications; ORNL/TM-2005/504; May 30, 2005.

30. Natesan, K., Moisseytsev, A., Majumdar, S., et al., Argonne National Laboratory, Preliminary Issues Associated with the Next Generation Nuclear Plant Intermediate Heat Exchanger Design; ANL/EXT-06-46; September 2006.

31. Mankins, W. L., Lamb, S., ASM Handbook Formerly Tenth Edition, Metals Handbook. Tenth ed.; ASM International, 1990.

32. Kirchhofer, H., Schubert, F., Nickel, H., "Precipitation Behavior of Ni-Cr-22fe-18mo (Hastelloy $\mathrm{X}$ ) and Ni-Cr-2co-12mo (Inconel 617) after Isothermal Aging," Nuclear Technology, Vol. 66, 1984, pp. 139-148.

33. Wu, Q., Vasudevan, V. K., Characterization of Boiler Materials for Ultracritical Coal Power Plants Annual Progress Report for Period August 1, 2002 to July 30, 2003; under UT-Battelle Sub Contract Number 4000017043; January 28, 2004.

34. Kimball, G. F., Lai, G. Y., Reynolds, G. H., "Effects of Thermal Aging on Microstructural and Mechanical Properties of a Commercial Ni-Cr-Co-Mo Alloy (Inconel 617)," Metallurgical Transactions, Vol. 7a, 1976, pp. 1951-1952.

35. Kihara, S., Newkirk, J. B., Ohtomo, A., et al., "Morphological Changes of Carbides During Creep and Their Effects on the Creep Properties of Inconel 617 at $1000^{\circ} \mathrm{C}, "$ Metallurgical Transactions, Vol. 11A, 1980, pp. 1019-1031.

36. Ren, W., Swindeman, R., "Preliminary Consideration of Alloys 617 and 230 for Generation IV Nuclear Reactor Applications," Proceedings of the 2007 ASME Pressure Vessels and Piping Division Conference, San Antonio, TX, July 22-26, 2007. 


\begin{tabular}{c|lll|}
\hline $\begin{array}{l}\text { NEXT GENERATION NUCLEAR PLANT } \\
\text { INTERMEDIATE HEAT EXCHANGER }\end{array}$ & Identifier: & PLN-2804 & \\
MATERIALS RESEARCH & Revision: & 0 & \\
AND DEVELOPMENT PLAN & Effective Date: & $04 / 30 / 08$ & Page: 153 of 156 \\
\hline
\end{tabular}

37. Ren, W., Totemeier, T., Santella, M., et al., U. S. Department of Energy Generation IV Nuclear Reactor Program, Status of Testing and Characterization of Cms Alloy 617 and Alloy 230; ORNL/TM-2006-547; August 31, 2006.

38. Swindeman, R. W., Swindeman, M. J., Ren, W., "A Brief Review of Models Representing Creep of Alloy 617," Proceedings of the 2005 ASME Pressure Vessels and Piping Conference, Denver, Colorado, July $17-21,2005$.

39. Séran, J. L., Billot, P., Burlet, H., et al., "Metallic and Graphite Materials for out-of-Core and inCore Components of the VHTR: First Results of the Cea R\&D Program," Beijing, China, September 22-24, 2004.

40. Klarstrom, D. L., "The Development of Haynes 230 Alloy". In Materials Design Approaches and Experiences, J. C. Zhao and Fahrmann, M., et al., Eds. TMS: 2001; pp. 297-307.

41. Tawancy, H. M., " High Temperature Creep Behavior of a Ni-Cr-W-B Alloy " Journal of Materials Science, Vol. 27, 1992, pp. 6481-6489.

42. Jordan, C. E., Rasefske, R. K., Castagna, A., "Thermal Stability of High Temperature Structural Alloys". In Long Term Stability of High Temperature Materials, G. E. Fuchs and Dannemann, K. A., et al., Eds. TMS: 1999; pp. 55-67.

43. High Temp Metals Inc. "Inconel 617 Technical Data," http:/www.hightempmetals.com/techdata/hitempInconel617data.php (2/5/08).

44. Haynes International High-Temperature Alloys "Haynes ${ }^{\circledR} 230 ®$ Alloy," www.haynesintl.com $(2 / 5 / 08)$.

45. Christ, H. J., Kunecke, U., Meyer, K., et al., "Mechanisms of High-Temperature Corrosion in Helium Containing Small Amounts of Impurities. II. Corrosion of Nickel- Base Alloy Inconel 617," Oxidation of Metals, Vol. 30, 1988, pp. 27-51.

46. Christ, H. J., Kunecke, U., Meyer, K., et al., "High Temperature Corrosion of the Nickel-Based Alloy Inconel 617 in Helium Containing Small Amounts of Impurities," Materials Science and Engineering, Vol. 87, 1987, pp. 161-168.

47. Graham, L. W., "Corrosion of Metallic Materials in HTR-Helium Environments," Journal of Nuclear Materials, Vol. 171, 1977, pp. 155-178.

48. Brenner, K. G. E., Graham, L. W., "The Development and Application of a Unified Corrosion Model for High-Temperature Gas-Cooled Reactor Systems," Nuclear Technology, Vol. 66, 1984, pp. 404-414.

49. Klarstrom, D. L., Metals Handbook Ninth Edition. Ninth ed.; Metals Park: ASM International, 1987.

50. Berman, I., Gupta, G. D., "Buckling Rules for Nuclear Components," "Journal of Pressure Vessel Technology, Vol. 98, 1976, pp. 229-231.

51. Jakub, M. T., "New Rules for Construction of Section III, Class 1 Components for Elevated Temperature Service," Journal of Pressure Vessel Technology, Vol. 98, 1976, pp. 214-222.

52. Jetter, R. I., "Elevated Temperature Design - Development and Implementation of Code Case 1592," Journal of Pressure Vessel Technology, Vol. 98, 1976, pp. 222-229.

53. Companion Guide to the ASME Boiler \& Pressure Vessel Code. New York, NY: ASME Press, 2002.

54. Shah, V. N., Majumdar, S., Natesan, K., Argonne National Laboratory, Review and Assessment of Codes and Procedures for HTGR Components; NUREG/CR-6816; June 2003.

55. Hayner, G. O., Bratton, R. L., Mizia, R. E., et al., INL, Next Generation Nuclear Plant Materials Research and Development Program Plan, Revision 4; INL/EXT-06-11701; 10/03/2007. 


\begin{tabular}{c|lll|}
\hline $\begin{array}{l}\text { NEXT GENERATION NUCLEAR PLANT } \\
\text { INTERMEDIATE HEAT EXCHANGER }\end{array}$ & Identifier: & PLN-2804 & \\
MATERIALS RESEARCH & Revision: & 0 & \\
AND DEVELOPMENT PLAN & Effective Date: & $04 / 30 / 08$ & Page: 154 of 156 \\
\hline
\end{tabular}

56. Corum, J. M., Blass, J. J., "Rules for Design of Alloy 617 Nuclear Components to Very High Temperatures," PVP (Pressure Vessel and Piping), Vol. 215, Fatigue, Fracture, and Risk ASME, 1991, pp. 147-153.

57. Vandel, D. S., Bader, S., Idaho National Laboratory (INL), NGNP Engineering White Paper: By-Products Trade Study; INL/EXT - 07-12728; April 2007.

58. Mizea, R. E., INL, Next Generation Nuclear Plant Reactor Pressure Vessel Acquisition Strategy; INL/EXT-08-13951; April 2008,.

59. Krompholz, K., Grosser, E. D., Ewert, K., "Determination of J-Integral R-Curves for Hastelloy X and Inconel 617 up to 1223k Using the Potential Drop Technique," Werkstofftech., Vol. 13, 1982, pp. 236-244.

60. Clarke, G. A., Andrews, W. R., Begley, J. A., et al., "A Procedure for Determination of Ductile Fracture Toughness Values Using J-Integral Techniques," Journal of Testing and Evaluation, Vol. 7, 1979, pp. 49-56.

61. Landes, J. D., Begley, J. A., ASTM, Test Results from J-Integral Studies; an Attempt to Establish a JIC Testing Procedure; STP 560.

62. Bassford, T. H., Schill, T. V., "A Review of Inconel Alloy 617 and Its Properties after Long-Time Exposure to Intermediate Temperatures". In Applications of Materials for Pressure Vessels and Piping, G. V. Smith, Ed. ASME: 1979; Vol. MPC-10, pp. 1-12.

63. Yukawa, S., "Wrc Bulletin 378," 1993.

64. Bruch, U., Schuhmacher, D., Ennis, P., et al., "Tensile and Impact Properties of Candidate Alloys for High-Temperature Gas-Cooled Reactor Applications," Nuclear Technology, Vol. 66, 1984, pp. 357-362.

65. Bassford, T. H., Data Package Provided by Huntington Alloys to ASME Code Committee for Use in the Development of the Draft Alloy 617 Code Case.

66. Schwertel, J., Merckling, G., Hornberger, K., et al., "Experimental Investigations on the Ni-Base Superalloy In617 and Their Theoretical Description". In High Temperature Constitutive Modeling - Theory and Application, A. Freed, Walker, K., Eds. ASME: New York, N.Y., 1991; Vol. MD-Vol. 26, pp. 285-295.

67. Roberson, D. N., Bartolotta, P. A., NASA, Viscoplastic Constitutive Relationships with Dependence on Thermomechanical History; NASA CR174836.

68. Chaboche, J. L., Nouailhas, D., "A Unified Constitutive Model for Cyclic Viscoplasticity and Its Applications to Various Stainless Steels," Journal of Engineering Materials and Technology, Vol. 111, 1989, pp. 424-430.

69. Roberson, D. N., "Constitutive Relationship for Anisotropic High Temperature Alloys," Nuclear Engineering and Design, Vol. 83, 1984, pp. 389-396.

70. Baldwin, D. H., Kimball, O. F., Williams, R. A., General Electric Company, Design Data for Reference Alloys: Inconel 617 and Alloy 800H; DOE/HTGR-86-041; April 1986.

71. Jetter, R. I., "An Alternate Approach to Evaluation of Creep-Fatigue Damage for High Temperature Structural Design Criteria". In PVP Fatigue, Fracture, and High Temperature Design Methods in Pressure Vessels and Piping, ASME: New York, N.Y., 1988; Vol. 5, .

72. Chandra, S., Cotgrove, R., Holdsworth, S. R., et al., "Creep Rupture Data Assessments of Alloy 617," Proceedings, Creep \& Fracture in High Temperature Components - Design \& Life Assessment Issues; I. A. Shibli, al., e., Eds.pp. 178-188.

73. Petten Database. ODIN at JRC of European Commission. 


\begin{tabular}{c|lll|}
\hline $\begin{array}{l}\text { NEXT GENERATION NUCLEAR PLANT } \\
\text { INTERMEDIATE HEAT EXCHANGER }\end{array}$ & Identifier: & PLN-2804 & \\
MATERIALS RESEARCH & Revision: & 0 & \\
AND DEVELOPMENT PLAN & Effective Date: & $04 / 30 / 08$ & Page: 155 of 156 \\
\hline
\end{tabular}

74. Eno, D. R., Young, G. A., Sham, T.-L., ASME, A Unified View of Engineering Creep Parameters; PVP2008-61129.

75. Swindeman, M. J., Ren, W., ORNL; ORNL/TM-2005/511.

76. Frost, H. J., Ashby, M. F., Deformation Mechanism Maps. Pergamon Press, 1982.

77. Cook, "Creep Properties of Inconel-617 in Air and Helium at 800 to 1000c," Nuclear Technology, Vol. 66, 1984, pp. 283-288.

78. Jetter, R. I., McGreevy, T. E., ORNL, Simplified Design Criteria for Very High Temperature Applications in Generation IV Reactors; ORNL/TM-2004/308.

79. Huddleston, R. L., "An Improved Multiaxial Creep-Rupture Strength Criterion," Journal of Pressure Vessel Technology, Vol. 107, 1985, pp. 421-429.

80. Schubert, F., Bruch, U., Cook, R., et al., "Creep Rupture Behavior of Candidate Materials for Nuclear Process Heat Applications," Nuclear Technology, Vol. 66, 1984, pp. 227-240.

81. Maziasz, P. J., Pint, B. A., Shingledecker, J. P., et al., ASME, Austenitic Stainless Steels and Alloys with Improved High-Temperature Performance for Advanced Microturbine Recuperators; GT2004-54239.

82. Shingledecker, J. P., Creep Data for Alloy 230, 2008, personal communication with T.-L. Sham.

83. Martin, J. M., Incoloy Alloy 800 Data for Use in Design of Gas Cooled and Liquid Metal Fast Reactors, Huntington Alloys, 1975, personal communication with J. M. o. W. E. C. Duke.

84. Booker, M. K., Baylor, V. B., Booker, B. P. L., ORNL, Survey of Available Creep and Tensile Data for Alloy $800 H$ ORNL/TM-6029; January 1978.

85. McCoy, H. E., ORNL, Tensile and Creep Tests on a Single Heat of Alloy 800H; ORNL/TM12436; September 1993.

86. NIMS, National Institute for Materials Science, Data Sheets on the Elevated-Temperature Stress Relaxation Properties of Iron Based 21cr-32ni-Ti-Al Alloy for Corrosion-Resisting and HeatResisting Superalloy Bar (Ncf 800H-B); NIMS Creep Data Sheet No. 47; March 1999.

87. NIMS, National Institute for Materials Science, Long-Term Creep Rupture Data Obtained after Publishing the Final Edition of the Creep Data Sheets; NMIS Creep Data Sheet No. 50; March 2004.

88. NRIM, National Research Institute for Metals, Data Sheets on the Elevated-Temperature Properties of Iron Based 21cr-32ni-Ti-Al Alloy for Heat Exchanger Seamless Tubes (Ncf 800H Tb); NRIM Creep Data Sheet No. 26B; September, 1998.

89. NRIM, National Research Institute for Metals, Data Sheets on the Elevated-Temperature Properties of Iron Based 21cr-32ni-Ti-Al Superalloy for Corrosion-Resisting and Heat-Resisting Superalloy Plates (Ncf 800H-P) NRIM Creep Data Sheet No. 27B; March 2000.

90. EPRI, Electric Power Research Institute, Survey and Guidelines for High Strength Superheater Materials-Alloy 800H; EPRI Program RP1403-14 Task 13; November 1987.

91. Tachibana, Y., Krempl, E., "Modeling of High Homologous Temperature Deformation Behavior Using the Viscoplasticity Theory Based on Overstress (Vbo): Part I - Creep and Tensile Behavior," Journal of Engineering Materials and Technology, Vol. 117, 1995, pp. 456-461.

92. Tachibana, Y., Krempl, E., "Modeling of High Homologous Temperature Deformation Behavior Using the Viscoplasticity Theory Based on Overstress (Vbo): Part II - Characteristics of the Vbo Model," Journal of Engineering Materials and Technology, Vol. 119, 1997, pp. 1-6. 
NEXT GENERATION NUCLEAR PLANT

INTERMEDIATE HEAT EXCHANGER

MATERIALS RESEARCH AND DEVELOPMENT PLAN
Identifier: $\quad$ PLN-2804

Revision: $\quad 0$

Effective Date: $04 / 30 / 08 \quad$ Page: 156 of 156

93. Tachibana, Y., Krempl, E., "Modeling of High Homologous Temperature Deformation Behavior Using the Viscoplasticity Theory Based on Overstress (Vbo): Part III -a Simplified Model," Journal of Engineering Materials and Technology, Vol. 120, 1998, pp. 193-196.

94. Gommans, R. J., Verheesen, K. F., Heerings, J. H., "Oxidation Cracking and Residual Creep Life of an Incoloy $800 \mathrm{H}$ Bottom Manifold in a Steam Reformer at $800^{\circ} \mathrm{C}$," Proceedings of the Fifth International Conference on Creep of Materials, Lake Buena Vista, FL, May 18-21, 1992, pp. 257-263.

95. Swindeman, M. J., Zamrik, S. Y., Maziasz, P. J., ASME, Effects of Long-Term Service on the Microstructure and Tensile Properties of Alloy 800h; CREEP2007-26167.

96. Ren, W., "Development of Digital Materials Database for Design and Construction of New Power Plants," Proceedings of 2008 International Congress on Advances in Nuclear Power Plants, Anaheim CA, June 8-12, 2008. 


\section{Appendix A}

\section{Test Matrices}


NEXT GENERATION NUCLEAR PLANT

INTERMEDIATE HEAT EXCHANGER

MATERIALS RESEARCH

AND DEVELOPMENT PLAN
Identifier: PLN-2804

Revision: $\quad 0$

Effective Date: $04 / 30 / 08 \quad$ Page: A-2 of A-114 
Idaho National Laboratory

NEXT GENERATION NUCLEAR PLANT

INTERMEDIATE HEAT EXCHANGER

MATERIALS RESEARCH AND DEVELOPMENT PLAN
Identifier: $\quad$ PLN-2804

Revision: $\quad 0$

Effective Date: $04 / 30 / 08$

Page: A-3 of A-114

\begin{tabular}{|c|c|c|c|c|c|}
\hline \multicolumn{6}{|c|}{ Table A1. Tensile Test Matrix for $S_{m}$ Confirmatory Testing } \\
\hline Specimen Type & Specimen \# & Material & Product Form & Environment & Temp. $\left({ }^{\circ} \mathrm{C}\right)$ \\
\hline Tensile & 1 & Alloy 617 & PF-1 & air & $\mathrm{T} 1$ \\
\hline Tensile & 2 & Alloy 617 & PF-1 & air & $\mathrm{T} 1$ \\
\hline Tensile & 3 & Alloy 617 & PF-1 & air & $\mathrm{T} 2$ \\
\hline Tensile & 4 & Alloy 617 & PF-1 & air & $\mathrm{T} 2$ \\
\hline Tensile & 5 & Alloy 617 & PF-1 & air & T3 \\
\hline Tensile & 6 & Alloy 617 & PF-1 & air & T3 \\
\hline Tensile & 7 & Alloy 617 & PF-1 & air & $\mathrm{T} 4$ \\
\hline Tensile & 8 & Alloy 617 & PF-1 & air & $\mathrm{T} 4$ \\
\hline Tensile & 9 & Alloy 617 & PF-1 & air & $\mathrm{T} 5$ \\
\hline Tensile & 10 & Alloy 617 & PF-1 & air & T5 \\
\hline Tensile & 11 & Alloy 617 & PF-1 & air & T6 \\
\hline Tensile & 12 & Alloy 617 & PF-1 & air & T6 \\
\hline Tensile & 13 & Alloy 617 & PF-1 & air & $\mathrm{T} 7$ \\
\hline Tensile & 14 & Alloy 617 & PF-1 & air & $\mathrm{T} 7$ \\
\hline Tensile & 15 & Alloy 617 & PF-1 & air & $\mathrm{T} 8$ \\
\hline Tensile & 16 & Alloy 617 & PF-1 & air & T8 \\
\hline Tensile & 17 & Alloy 617 & PF-1 & air & T9 \\
\hline Tensile & 18 & Alloy 617 & PF-1 & air & T9 \\
\hline Tensile & 19 & Alloy 617 & PF-1 & air & $\mathrm{T} 10$ \\
\hline Tensile & 20 & Alloy 617 & PF-1 & air & $\mathrm{T} 10$ \\
\hline Tensile & 21 & Alloy 617 & PF-2 & air & $\mathrm{T} 1$ \\
\hline Tensile & 22 & Alloy 617 & PF-2 & air & $\mathrm{T} 1$ \\
\hline Tensile & 23 & Alloy 617 & PF-2 & air & $\mathrm{T} 2$ \\
\hline Tensile & 24 & Alloy 617 & PF-2 & air & $\mathrm{T} 2$ \\
\hline Tensile & 25 & Alloy 617 & PF-2 & air & T3 \\
\hline Tensile & 26 & Alloy 617 & PF-2 & air & T3 \\
\hline Tensile & 27 & Alloy 617 & PF-2 & air & $\mathrm{T} 4$ \\
\hline Tensile & 28 & Alloy 617 & PF-2 & air & $\mathrm{T} 4$ \\
\hline Tensile & 29 & Alloy 617 & PF-2 & air & T5 \\
\hline Tensile & 30 & Alloy 617 & PF-2 & air & $\mathrm{T} 5$ \\
\hline Tensile & 31 & Alloy 617 & PF-2 & air & $\mathrm{T} 6$ \\
\hline Tensile & 32 & Alloy 617 & PF-2 & air & T6 \\
\hline Tensile & 33 & Alloy 617 & PF-2 & air & $\mathrm{T} 7$ \\
\hline Tensile & 34 & Alloy 617 & PF-2 & air & $\mathrm{T} 7$ \\
\hline Tensile & 35 & Alloy 617 & PF-2 & air & $\mathrm{T} 8$ \\
\hline Tensile & 36 & Alloy 617 & PF-2 & air & $\mathrm{T} 8$ \\
\hline Tensile & 37 & Alloy 617 & PF-2 & air & T9 \\
\hline Tensile & 38 & Alloy 617 & PF-2 & air & T9 \\
\hline Tensile & 39 & Alloy 617 & PF-2 & air & $\mathrm{T} 10$ \\
\hline Tensile & 40 & Alloy 617 & PF-2 & air & $\mathrm{T} 10$ \\
\hline
\end{tabular}




Idaho National Laboratory
\begin{tabular}{|c|lll|}
\hline NEXT GENERATION NUCLEAR PLANT & Identifier: & PLN-2804 & \\
INTERMEDIATE HEAT EXCHANGER & Revision: & 0 & \\
MATERIALS RESEARCH & Effective Date: & $04 / 30 / 08$ & Page: A-4 of A-114 \\
AND DEVELOPMENT PLAN & &
\end{tabular}

\begin{tabular}{|c|c|c|c|c|c|c|c|c|c|c|c|}
\hline \multicolumn{12}{|c|}{ Table A2. Test Matrix to Determine Weld Strength Rupture Factor } \\
\hline Test Prgm & Specimen \# & $\begin{array}{c}\text { Weld } \\
\text { Consumable }\end{array}$ & $\begin{array}{c}\text { Weld } \\
\text { Process }\end{array}$ & $\begin{array}{c}\text { Alloy } 617 \\
\text { Plate, } \\
\text { Heat \# }\end{array}$ & $\begin{array}{c}\text { Weld to be } \\
\text { Tested }\end{array}$ & Env. & $\begin{array}{c}\text { Temp. } \\
{ }^{\circ} \mathrm{C}\end{array}$ & $\begin{array}{l}\text { Applied } \\
\text { Stress } \\
(\mathrm{MPa})\end{array}$ & $\begin{array}{l}\text { Est. } \\
\text { Rupture } \\
\text { Time } \\
\text { (h) }\end{array}$ & $\begin{array}{c}\text { Est. } 95 \% \\
\text { Lower Bound } \\
\text { Rupture Time } \\
\text { (h) }\end{array}$ & $\begin{array}{c}\text { Est. 95\% } \\
\text { Upper Bound } \\
\text { Rupture Time } \\
\text { (h) }\end{array}$ \\
\hline WSRF & 1 & FM-617 & GTA & NA & Deposited & air & 1000 & 19.0 & 1341 & 197 & 2485 \\
\hline WSRF & 2 & FM-617 & GTA & NA & Deposited & air & 1000 & 19.0 & 1341 & 197 & 2485 \\
\hline WSRF & 3 & FM-617 & GTA & NA & Deposited & air & 1000 & 16.0 & 3031 & 446 & 5617 \\
\hline WSRF & 4 & FM-617 & GTA & NA & Deposited & air & 1000 & 16.0 & 3031 & 446 & 5617 \\
\hline WSRF & 5 & FM-617 & GTA & NA & Deposited & air & 1000 & 12.0 & 11871 & 1745 & 21997 \\
\hline WSRF & 6 & FM-617 & GTA & NA & Deposited & air & 1000 & 12.0 & 11871 & 1745 & 21997 \\
\hline WSRF & 7 & FM-617 & GTA & NA & Deposited & air & 950 & 28.5 & 1357 & 194 & 2520 \\
\hline WSRF & 8 & FM-617 & GTA & NA & Deposited & air & 950 & 28.5 & 1357 & 194 & 2520 \\
\hline WSRF & 9 & FM-617 & GTA & NA & Deposited & air & 950 & 24.0 & 3198 & 457 & 5939 \\
\hline WSRF & 10 & FM-617 & GTA & NA & Deposited & air & 950 & 24.0 & 3198 & 457 & 5939 \\
\hline WSRF & 11 & FM-617 & GTA & NA & Deposited & air & 950 & 18.5 & 11825 & 1689 & 21960 \\
\hline WSRF & 12 & FM-617 & GTA & NA & Deposited & air & 950 & 18.5 & 11825 & 1689 & 21960 \\
\hline WSRF & 13 & FM-617 & GTA & NA & Deposited & air & 850 & 63.0 & 1349 & 181 & 2518 \\
\hline WSRF & 14 & FM-617 & GTA & NA & Deposited & air & 850 & 63.0 & 1349 & 181 & 2518 \\
\hline WSRF & 15 & FM-617 & GTA & NA & Deposited & air & 850 & 54.0 & 3169 & 424 & 5914 \\
\hline WSRF & 16 & FM-617 & GTA & NA & Deposited & air & 850 & 54.0 & 3169 & 424 & 5914 \\
\hline WSRF & 17 & FM-617 & GTA & NA & Deposited & air & 850 & 43.0 & 11158 & 1494 & 20822 \\
\hline WSRF & 18 & FM-617 & GTA & NA & Deposited & air & 850 & 43.0 & 11158 & 1494 & 20822 \\
\hline WSRF & 19 & FM-617 & GTA & NA & Deposited & air & 750 & 135.0 & 1349 & 167 & 2531 \\
\hline WSRF & 20 & FM-617 & GTA & NA & Deposited & air & 750 & 135.0 & 1349 & 167 & 2531 \\
\hline WSRF & 21 & FM-617 & GTA & NA & Deposited & air & 750 & 118.0 & 3107 & 385 & 5830 \\
\hline WSRF & 22 & FM-617 & GTA & NA & Deposited & air & 750 & 118.0 & 3107 & 385 & 5830 \\
\hline WSRF & 23 & FM-617 & GTA & NA & Deposited & air & 750 & 95.0 & 11911 & 1475 & 22347 \\
\hline WSRF & 24 & FM-617 & GTA & NA & Deposited & air & 750 & 95.0 & 11911 & 1475 & 22347 \\
\hline WSRF & 25 & FM-617 & GTA & W-heat-1 & X-Weld & air & 1000 & 19.0 & 1341 & 197 & 2485 \\
\hline
\end{tabular}


Idaho National Laboratory

\begin{tabular}{|c|c|c|c|}
\hline $\begin{array}{l}\text { NEXT GENERATION NUCLEAR PLANT } \\
\text { INTERMEDIATE HEAT EXCHANGER } \\
\text { MATERIALS RESEARCH } \\
\text { AND DEVELOPMENT PLAN }\end{array}$ & $\begin{array}{l}\text { Identifier: } \\
\text { Revision: } \\
\text { Effective Date: }\end{array}$ & $\begin{array}{l}\text { PLN-2804 } \\
0 \\
04 / 30 / 08\end{array}$ & Page: \\
\hline
\end{tabular}

\begin{tabular}{|c|c|c|c|c|c|c|c|c|c|c|c|}
\hline \multicolumn{12}{|c|}{ Table A2. Test Matrix to Determine Weld Strength Rupture Factor } \\
\hline Test Prgm & Specimen \# & $\begin{array}{c}\text { Weld } \\
\text { Consumable }\end{array}$ & $\begin{array}{c}\text { Weld } \\
\text { Process }\end{array}$ & $\begin{array}{c}\text { Alloy } 617 \\
\text { Plate, } \\
\text { Heat \# }\end{array}$ & $\begin{array}{c}\text { Weld to be } \\
\text { Tested }\end{array}$ & Env. & $\begin{array}{c}\text { Temp. } \\
{ }^{\circ} \mathrm{C}\end{array}$ & $\begin{array}{c}\text { Applied } \\
\text { Stress } \\
(\mathrm{MPa}) \\
\end{array}$ & $\begin{array}{l}\text { Est. } \\
\text { Rupture } \\
\text { Time } \\
\text { (h) }\end{array}$ & $\begin{array}{c}\text { Est. } 95 \% \\
\text { Lower Bound } \\
\text { Rupture Time } \\
\text { (h) }\end{array}$ & $\begin{array}{c}\text { Est. 95\% } \\
\text { Upper Bound } \\
\text { Rupture Time } \\
\text { (h) }\end{array}$ \\
\hline WSRF & 26 & FM-617 & GTA & W-heat-1 & X-Weld & air & 1000 & 19.0 & 1341 & 197 & 2485 \\
\hline WSRF & 27 & FM-617 & GTA & W-heat-1 & X-Weld & air & 1000 & 16.0 & 3031 & 446 & 5617 \\
\hline WSRF & 28 & FM-617 & GTA & W-heat-1 & X-Weld & air & 1000 & 16.0 & 3031 & 446 & 5617 \\
\hline WSRF & 29 & FM-617 & GTA & W-heat-1 & X-Weld & air & 1000 & 12.0 & 11871 & 1745 & 21997 \\
\hline WSRF & 30 & FM-617 & GTA & W-heat-1 & X-Weld & air & 1000 & 12.0 & 11871 & 1745 & 21997 \\
\hline WSRF & 31 & FM-617 & GTA & W-heat-1 & X-Weld & air & 950 & 28.5 & 1357 & 194 & 2520 \\
\hline WSRF & 32 & FM-617 & GTA & W-heat-1 & X-Weld & air & 950 & 28.5 & 1357 & 194 & 2520 \\
\hline WSRF & 33 & FM-617 & GTA & W-heat-1 & X-Weld & air & 950 & 24.0 & 3198 & 457 & 5939 \\
\hline WSRF & 34 & FM-617 & GTA & W-heat-1 & X-Weld & air & 950 & 24.0 & 3198 & 457 & 5939 \\
\hline WSRF & 35 & FM-617 & GTA & W-heat-1 & X-Weld & air & 950 & 18.5 & 11825 & 1689 & 21960 \\
\hline WSRF & 36 & FM-617 & GTA & W-heat-1 & X-Weld & air & 950 & 18.5 & 11825 & 1689 & 21960 \\
\hline WSRF & 37 & FM-617 & GTA & W-heat-1 & X-Weld & air & 850 & 63.0 & 1349 & 181 & 2518 \\
\hline WSRF & 38 & FM-617 & GTA & W-heat-1 & X-Weld & air & 850 & 63.0 & 1349 & 181 & 2518 \\
\hline WSRF & 39 & FM-617 & GTA & W-heat-1 & X-Weld & air & 850 & 54.0 & 3169 & 424 & 5914 \\
\hline WSRF & 40 & FM-617 & GTA & W-heat-1 & X-Weld & air & 850 & 54.0 & 3169 & 424 & 5914 \\
\hline WSRF & 41 & FM-617 & GTA & W-heat-1 & X-Weld & air & 850 & 47.5 & 6449 & 863 & 12035 \\
\hline WSRF & 42 & FM-617 & GTA & W-heat-1 & X-Weld & air & 850 & 47.5 & 6449 & 863 & 12035 \\
\hline WSRF & 43 & FM-617 & GTA & W-heat-1 & X-Weld & air & 850 & 43.0 & 11158 & 1494 & 20822 \\
\hline WSRF & 44 & FM-617 & GTA & W-heat-1 & X-Weld & air & 850 & 43.0 & 11158 & 1494 & 20822 \\
\hline WSRF & 45 & FM-617 & GTA & W-heat-1 & Long. Weld & air & 950 & 28.5 & 1357 & 194 & 2520 \\
\hline WSRF & 46 & FM-617 & GTA & W-heat-1 & Long. Weld & air & 950 & 28.5 & 1357 & 194 & 2520 \\
\hline WSRF & 47 & FM-617 & GTA & W-heat-1 & Long. Weld & air & 950 & 24.0 & 3198 & 457 & 5939 \\
\hline WSRF & 48 & FM-617 & GTA & W-heat-1 & Long. Weld & air & 950 & 24.0 & 3198 & 457 & 5939 \\
\hline WSRF & 49 & FM-617 & GTA & W-heat-1 & Long. Weld & air & 950 & 18.5 & 11825 & 1689 & 21960 \\
\hline WSRF & 50 & FM-617 & GTA & W-heat-1 & Long. Weld & air & 950 & 18.5 & 11825 & 1689 & 21960 \\
\hline WSRF & 51 & E-117 & SMA & NA & Deposited & air & 1000 & 19.0 & 1341 & 197 & 2485 \\
\hline
\end{tabular}


Idaho National Laboratory

NEXT GENERATION NUCLEAR PLANT

INTERMEDIATE HEAT EXCHANGER

MATERIALS RESEARCH

AND DEVELOPMENT PLAN

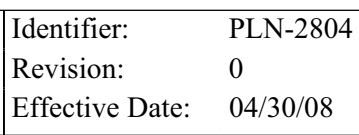

PLN-2804

Page: A-6 of A-114

\begin{tabular}{|c|c|c|c|c|c|c|c|c|c|c|c|}
\hline \multicolumn{12}{|c|}{ Table A2. Test Matrix to Determine Weld Strength Rupture Factor } \\
\hline Test Prgm & Specimen \# & $\begin{array}{c}\text { Weld } \\
\text { Consumable }\end{array}$ & $\begin{array}{c}\text { Weld } \\
\text { Process }\end{array}$ & $\begin{array}{c}\text { Alloy } 617 \\
\text { Plate, } \\
\text { Heat \# }\end{array}$ & $\begin{array}{c}\text { Weld to be } \\
\text { Tested }\end{array}$ & Env. & $\begin{array}{c}\text { Temp. } \\
{ }^{\circ} \mathrm{C}\end{array}$ & $\begin{array}{l}\text { Applied } \\
\text { Stress } \\
(\mathrm{MPa})\end{array}$ & $\begin{array}{l}\text { Est. } \\
\text { Rupture } \\
\text { Time } \\
\text { (h) }\end{array}$ & $\begin{array}{c}\text { Est. 95\% } \\
\text { Lower Bound } \\
\text { Rupture Time } \\
\text { (h) }\end{array}$ & $\begin{array}{c}\text { Est. } 95 \% \\
\text { Upper Bound } \\
\text { Rupture Time } \\
\text { (h) }\end{array}$ \\
\hline WSRF & 52 & E-117 & SMA & NA & Deposited & air & 1000 & 19.0 & 1341 & 197 & 2485 \\
\hline WSRF & 53 & E-117 & SMA & NA & Deposited & air & 1000 & 16.0 & 3031 & 446 & 5617 \\
\hline WSRF & 54 & E-117 & SMA & NA & Deposited & air & 1000 & 16.0 & 3031 & 446 & 5617 \\
\hline WSRF & 55 & E-117 & SMA & NA & Deposited & air & 1000 & 12.0 & 11871 & 1745 & 21997 \\
\hline WSRF & 56 & E-117 & SMA & NA & Deposited & air & 1000 & 12.0 & 11871 & 1745 & 21997 \\
\hline WSRF & 57 & E-117 & SMA & NA & Deposited & air & 950 & 28.5 & 1357 & 194 & 2520 \\
\hline WSRF & 58 & E-117 & SMA & NA & Deposited & air & 950 & 28.5 & 1357 & 194 & 2520 \\
\hline WSRF & 59 & E-117 & SMA & NA & Deposited & air & 950 & 24.0 & 3198 & 457 & 5939 \\
\hline WSRF & 60 & E-117 & SMA & NA & Deposited & air & 950 & 24.0 & 3198 & 457 & 5939 \\
\hline WSRF & 61 & E-117 & SMA & NA & Deposited & air & 950 & 18.5 & 11825 & 1689 & 21960 \\
\hline WSRF & 62 & E-117 & SMA & NA & Deposited & air & 950 & 18.5 & 11825 & 1689 & 21960 \\
\hline WSRF & 63 & E-117 & SMA & $\mathrm{NA}$ & Deposited & air & 850 & 63.0 & 1349 & 181 & 2518 \\
\hline WSRF & 64 & E-117 & SMA & NA & Deposited & air & 850 & 63.0 & 1349 & 181 & 2518 \\
\hline WSRF & 65 & E-117 & SMA & NA & Deposited & air & 850 & 54.0 & 3169 & 424 & 5914 \\
\hline WSRF & 66 & E-117 & SMA & NA & Deposited & air & 850 & 54.0 & 3169 & 424 & 5914 \\
\hline WSRF & 67 & E-117 & SMA & NA & Deposited & air & 850 & 43.0 & 11158 & 1494 & 20822 \\
\hline WSRF & 68 & E-117 & SMA & NA & Deposited & air & 850 & 43.0 & 11158 & 1494 & 20822 \\
\hline WSRF & 69 & E-117 & SMA & NA & Deposited & air & 750 & 135.0 & 1349 & 167 & 2531 \\
\hline WSRF & 70 & E-117 & SMA & NA & Deposited & air & 750 & 135.0 & 1349 & 167 & 2531 \\
\hline WSRF & 71 & E-117 & SMA & NA & Deposited & air & 750 & 118.0 & 3107 & 385 & 5830 \\
\hline WSRF & 72 & E-117 & SMA & NA & Deposited & air & 750 & 118.0 & 3107 & 385 & 5830 \\
\hline WSRF & 73 & E-117 & SMA & NA & Deposited & air & 750 & 95.0 & 11911 & 1475 & 22347 \\
\hline WSRF & 74 & E-117 & SMA & NA & Deposited & air & 750 & 95.0 & 11911 & 1475 & 22347 \\
\hline WSRF & 75 & E-117 & SMA & W-heat-1 & X-Weld & air & 1000 & 19.0 & 1341 & 197 & 2485 \\
\hline WSRF & 76 & E-117 & SMA & W-heat-1 & X-Weld & air & 1000 & 19.0 & 1341 & 197 & 2485 \\
\hline WSRF & 77 & E-117 & SMA & W-heat-1 & X-Weld & air & 1000 & 16.0 & 3031 & 446 & 5617 \\
\hline
\end{tabular}


Idaho National Laboratory

\begin{tabular}{|c|c|c|c|}
\hline $\begin{array}{l}\text { NEXT GENERATION NUCLEAR PLANT } \\
\text { INTERMEDIATE HEAT EXCHANGER } \\
\text { MATERIALS RESEARCH } \\
\text { AND DEVELOPMENT PLAN }\end{array}$ & $\begin{array}{l}\text { Identifier: } \\
\text { Revision: } \\
\text { Effective Date: }\end{array}$ & $\begin{array}{l}\text { PLN-2804 } \\
0 \\
04 / 30 / 08\end{array}$ & Page: \\
\hline
\end{tabular}

\begin{tabular}{|c|c|c|c|c|c|c|c|c|c|c|c|}
\hline \multicolumn{12}{|c|}{ Table A2. Test Matrix to Determine Weld Strength Rupture Factor } \\
\hline Test Prgm & Specimen \# & $\begin{array}{c}\text { Weld } \\
\text { Consumable }\end{array}$ & $\begin{array}{c}\text { Weld } \\
\text { Process }\end{array}$ & $\begin{array}{c}\text { Alloy } 617 \\
\text { Plate, } \\
\text { Heat \# }\end{array}$ & $\begin{array}{c}\text { Weld to be } \\
\text { Tested }\end{array}$ & Env. & $\begin{array}{c}\text { Temp. } \\
{ }^{\circ} \mathrm{C}\end{array}$ & $\begin{array}{c}\text { Applied } \\
\text { Stress } \\
(\mathrm{MPa}) \\
\end{array}$ & $\begin{array}{l}\text { Est. } \\
\text { Rupture } \\
\text { Time } \\
\text { (h) }\end{array}$ & $\begin{array}{c}\text { Est. } 95 \% \\
\text { Lower Bound } \\
\text { Rupture Time } \\
\text { (h) }\end{array}$ & $\begin{array}{c}\text { Est. 95\% } \\
\text { Upper Bound } \\
\text { Rupture Time } \\
\text { (h) }\end{array}$ \\
\hline WSRF & 78 & E-117 & SMA & W-heat-1 & X-Weld & air & 1000 & 16.0 & 3031 & 446 & 5617 \\
\hline WSRF & 79 & E-117 & SMA & W-heat-1 & X-Weld & air & 1000 & 12.0 & 11871 & 1745 & 21997 \\
\hline WSRF & 80 & E-117 & SMA & W-heat-1 & X-Weld & air & 1000 & 12.0 & 11871 & 1745 & 21997 \\
\hline WSRF & 81 & E-117 & SMA & W-heat-1 & X-Weld & air & 950 & 28.5 & 1357 & 194 & 2520 \\
\hline WSRF & 82 & E-117 & SMA & W-heat-1 & X-Weld & air & 950 & 28.5 & 1357 & 194 & 2520 \\
\hline WSRF & 83 & E-117 & SMA & W-heat-1 & X-Weld & air & 950 & 24.0 & 3198 & 457 & 5939 \\
\hline WSRF & 84 & E-117 & SMA & W-heat-1 & X-Weld & air & 950 & 24.0 & 3198 & 457 & 5939 \\
\hline WSRF & 85 & E-117 & SMA & W-heat-1 & X-Weld & air & 950 & 18.5 & 11825 & 1689 & 21960 \\
\hline WSRF & 86 & E-117 & SMA & W-heat-1 & X-Weld & air & 950 & 18.5 & 11825 & 1689 & 21960 \\
\hline WSRF & 87 & E-117 & SMA & W-heat-1 & X-Weld & air & 850 & 63.0 & 1349 & 181 & 2518 \\
\hline WSRF & 88 & E-117 & SMA & W-heat-1 & X-Weld & air & 850 & 63.0 & 1349 & 181 & 2518 \\
\hline WSRF & 89 & E-117 & SMA & W-heat-1 & X-Weld & air & 850 & 54.0 & 3169 & 424 & 5914 \\
\hline WSRF & 90 & E-117 & SMA & W-heat-1 & X-Weld & air & 850 & 54.0 & 3169 & 424 & 5914 \\
\hline WSRF & 91 & E-117 & SMA & W-heat-1 & X-Weld & air & 850 & 43.0 & 11158 & 1494 & 20822 \\
\hline WSRF & 92 & E-117 & SMA & W-heat-1 & X-Weld & air & 850 & 43.0 & 11158 & 1494 & 20822 \\
\hline WSRF & 93 & E-117 & SMA & W-heat-1 & Long. Weld & air & 950 & 28.5 & 1357 & 194 & 2520 \\
\hline WSRF & 94 & E-117 & SMA & W-heat-1 & Long. Weld & air & 950 & 28.5 & 1357 & 194 & 2520 \\
\hline WSRF & 95 & E-117 & SMA & W-heat-1 & Long. Weld & air & 950 & 24.0 & 3198 & 457 & 5939 \\
\hline WSRF & 96 & E-117 & SMA & W-heat-1 & Long. Weld & air & 950 & 24.0 & 3198 & 457 & 5939 \\
\hline WSRF & 97 & E-117 & SMA & W-heat-1 & Long. Weld & air & 950 & 18.5 & 11825 & 1689 & 21960 \\
\hline WSRF & 98 & E-117 & SMA & W-heat-1 & Long. Weld & air & 950 & 18.5 & 11825 & 1689 & 21960 \\
\hline W-QUAL & 99 & FM-617 & GTA & NA & Deposited & air & 1000 & 8.5 & 60968 & 8962 & 112974 \\
\hline W-QUAL & 100 & FM-617 & GTA & $\mathrm{NA}$ & Deposited & air & 1000 & 8.5 & 60968 & 8962 & 112974 \\
\hline W-QUAL & 101 & FM-617 & GTA & NA & Deposited & air & 950 & 13.5 & 56395 & 8055 & 104734 \\
\hline W-QUAL & 102 & FM-617 & GTA & NA & Deposited & air & 950 & 13.5 & 56395 & 8055 & 104734 \\
\hline W-QUAL & 103 & FM-617 & GTA & NA & Deposited & air & 850 & 31.5 & 62743 & 8399 & 117088 \\
\hline W-QUAL & 104 & FM-617 & GTA & NA & Deposited & air & 850 & 31.5 & 62743 & 8399 & 117088 \\
\hline
\end{tabular}


Idaho National Laboratory

\begin{tabular}{|c|c|c|c|}
\hline $\begin{array}{l}\text { NEXT GENERATION NUCLEAR PLANT } \\
\text { INTERMEDIATE HEAT EXCHANGER } \\
\text { MATERIALS RESEARCH } \\
\text { AND DEVELOPMENT PLAN }\end{array}$ & $\begin{array}{l}\text { Identifier: } \\
\text { Revision: } \\
\text { Effective Date: }\end{array}$ & $\begin{array}{l}\text { PLN-2804 } \\
0 \\
04 / 30 / 08\end{array}$ & Page: \\
\hline
\end{tabular}

\begin{tabular}{|c|c|c|c|c|c|c|c|c|c|c|c|}
\hline \multicolumn{12}{|c|}{ Table A2. Test Matrix to Determine Weld Strength Rupture Factor } \\
\hline Test Prgm & Specimen \# & $\begin{array}{c}\text { Weld } \\
\text { Consumable }\end{array}$ & $\begin{array}{c}\text { Weld } \\
\text { Process }\end{array}$ & $\begin{array}{c}\text { Alloy } 617 \\
\text { Plate, } \\
\text { Heat \# }\end{array}$ & $\begin{array}{c}\text { Weld to be } \\
\text { Tested }\end{array}$ & Env. & $\begin{array}{c}\text { Temp. } \\
{ }^{\circ} \mathrm{C}\end{array}$ & $\begin{array}{c}\text { Applied } \\
\text { Stress } \\
(\mathrm{MPa}) \\
\end{array}$ & $\begin{array}{l}\text { Est. } \\
\text { Rupture } \\
\text { Time } \\
\text { (h) }\end{array}$ & $\begin{array}{c}\text { Est. } 95 \% \\
\text { Lower Bound } \\
\text { Rupture Time } \\
\text { (h) }\end{array}$ & $\begin{array}{c}\text { Est. 95\% } \\
\text { Upper Bound } \\
\text { Rupture Time } \\
\text { (h) }\end{array}$ \\
\hline W-QUAL & 105 & FM-617 & GTA & NA & Deposited & air & 750 & 73 & 60954 & 7550 & 114358 \\
\hline W-QUAL & 106 & FM-617 & GTA & NA & Deposited & air & 750 & 73 & 60954 & 7550 & 114358 \\
\hline W-QUAL & 107 & FM-617 & GTA & W-heat-1 & X-Weld & air & 1000 & 8.5 & 60968 & 8962 & 112974 \\
\hline W-QUAL & 108 & FM-617 & GTA & W-heat-1 & X-Weld & air & 1000 & 8.5 & 60968 & 8962 & 112974 \\
\hline W-QUAL & 109 & FM-617 & GTA & W-heat-1 & X-Weld & air & 950 & 13.5 & 56395 & 8055 & 104734 \\
\hline W-QUAL & 110 & FM-617 & GTA & W-heat-1 & X-Weld & air & 950 & 13.5 & 56395 & 8055 & 104734 \\
\hline W-QUAL & 111 & FM-617 & GTA & W-heat-1 & X-Weld & air & 850 & 31.5 & 62743 & 8399 & 117088 \\
\hline W-QUAL & 112 & FM-617 & GTA & W-heat-1 & X-Weld & air & 850 & 31.5 & 62743 & 8399 & 117088 \\
\hline W-QUAL & 113 & FM-617 & GTA & W-heat-1 & Long. Weld & air & 950 & 13.5 & 56395 & 8055 & 104734 \\
\hline W-QUAL & 114 & FM-617 & GTA & W-heat-1 & Long. Weld & air & 950 & 13.5 & 56395 & 8055 & 104734 \\
\hline W-QUAL & 115 & E-117 & SMA & NA & Deposited & air & 1000 & 8.5 & 60968 & 8962 & 112974 \\
\hline W-QUAL & 116 & E-117 & SMA & NA & Deposited & air & 1000 & 8.5 & 60968 & 8962 & 112974 \\
\hline W-QUAL & 117 & E-117 & SMA & NA & Deposited & air & 950 & 13.5 & 56395 & 8055 & 104734 \\
\hline W-QUAL & 118 & E-117 & SMA & NA & Deposited & air & 950 & 13.5 & 56395 & 8055 & 104734 \\
\hline W-QUAL & 119 & E-117 & SMA & NA & Deposited & air & 850 & 31.5 & 62743 & 8399 & 117088 \\
\hline W-QUAL & 120 & E-117 & SMA & NA & Deposited & air & 850 & 31.5 & 62743 & 8399 & 117088 \\
\hline W-QUAL & 121 & E-117 & SMA & NA & Deposited & air & 750 & 73 & 60954 & 7550 & 114358 \\
\hline W-QUAL & 122 & E-117 & SMA & NA & Deposited & air & 750 & 73 & 60954 & 7550 & 114358 \\
\hline W-QUAL & 123 & E-117 & SMA & W-heat-1 & X-Weld & air & 1000 & 8.5 & 60968 & 8962 & 112974 \\
\hline W-QUAL & 124 & E-117 & SMA & W-heat-1 & X-Weld & air & 1000 & 8.5 & 60968 & 8962 & 112974 \\
\hline W-QUAL & 125 & E-117 & SMA & W-heat-1 & X-Weld & air & 950 & 13.5 & 56395 & 8055 & 104734 \\
\hline W-QUAL & 126 & E-117 & SMA & W-heat-1 & X-Weld & air & 950 & 13.5 & 56395 & 8055 & 104734 \\
\hline W-QUAL & 127 & E-117 & SMA & W-heat-1 & X-Weld & air & 850 & 31.5 & 62743 & 8399 & 117088 \\
\hline W-QUAL & 128 & E-117 & SMA & W-heat-1 & X-Weld & air & 850 & 31.5 & 62743 & 8399 & 117088 \\
\hline W-QUAL & 129 & E-117 & SMA & W-heat-1 & Long. Weld & air & 950 & 13.5 & 56395 & 8055 & 104734 \\
\hline W-QUAL & 130 & E-117 & SMA & W-heat-1 & Long. Weld & air & 950 & 13.5 & 56395 & 8055 & 104734 \\
\hline
\end{tabular}




Idaho National Laboratory
\begin{tabular}{|c|lll|}
\hline NEXT GENERATION NUCLEAR PLANT & Identifier: & PLN-2804 & \\
INTERMEDIATE HEAT EXCHANGER & Revision: & 0 & \\
MATERIALS RESEARCH & Effective Date: & $04 / 30 / 08$ & Page: A-9 of A-114 \\
AND DEVELOPMENT PLAN &
\end{tabular}

\begin{tabular}{|c|c|c|c|c|c|c|c|c|c|c|}
\hline \multicolumn{11}{|c|}{ Table A3. Creep-Fatigue Tests for Alloy 617 Welds } \\
\hline Specimen & $\begin{array}{c}\text { Weld } \\
\text { Consumable }\end{array}$ & $\begin{array}{c}\text { Weld } \\
\text { Process }\end{array}$ & $\begin{array}{c}\text { Alloy } 617 \\
\text { Plate, Heat \# }\end{array}$ & $\begin{array}{c}\text { Weld to be } \\
\text { Tested }\end{array}$ & $\begin{array}{c}\text { Strain Rate } \\
(\mathrm{m} / \mathrm{m} / \mathrm{s})\end{array}$ & Environment & $\begin{array}{l}\text { Hold time } \\
\text { in } \mathrm{T} / \mathrm{C}\end{array}$ & $\begin{array}{c}\text { Temp. } \\
{ }^{\circ} \mathrm{C}\end{array}$ & $\begin{array}{c}\text { Strain } \\
\text { Range (\%) }\end{array}$ & $\begin{array}{l}\text { Hold } \\
\text { Time } \\
(\mathrm{min})\end{array}$ \\
\hline 1 & FM-617 & GTA & NA & Deposited & S1 (TBD) & air & tension & 950 & 1.0 & 0 \\
\hline 2 & FM-617 & GTA & NA & Deposited & S1 (TBD) & air & tension & 950 & 1.0 & 0 \\
\hline 3 & FM-617 & GTA & NA & Deposited & S1 (TBD) & air & tension & 950 & 1.0 & 0 \\
\hline 4 & FM-617 & GTA & NA & Deposited & S1 (TBD) & air & tension & 950 & 1.0 & 3 \\
\hline 5 & FM-617 & GTA & NA & Deposited & S1 (TBD) & air & tension & 950 & 1.0 & 3 \\
\hline 6 & FM-617 & GTA & NA & Deposited & S1 (TBD) & air & tension & 950 & 1.0 & 3 \\
\hline 7 & FM-617 & GTA & NA & Deposited & S1 (TBD) & air & tension & 950 & 1.0 & 150 \\
\hline 8 & FM-617 & GTA & NA & Deposited & S1 (TBD) & air & tension & 950 & 1.0 & 150 \\
\hline 9 & FM-617 & GTA & NA & Deposited & S1 (TBD) & air & tension & 950 & 1.0 & 150 \\
\hline 10 & FM-617 & GTA & NA & Deposited & $\mathrm{S} 1$ (TBD) & air & tension & 950 & 1.0 & 600 \\
\hline 11 & FM-617 & GTA & NA & Deposited & S1 (TBD) & air & tension & 950 & 1.0 & 600 \\
\hline 12 & FM-617 & GTA & NA & Deposited & S1 (TBD) & air & tension & 950 & 1.0 & 600 \\
\hline 13 & FM-617 & GTA & W-heat-1 & X-Weld & S1 (TBD) & air & tension & 950 & 1.0 & 0 \\
\hline 14 & FM-617 & GTA & W-heat-1 & X-Weld & S1 (TBD) & air & tension & 950 & 1.0 & 0 \\
\hline 15 & FM-617 & GTA & W-heat-1 & X-Weld & S1 (TBD) & air & tension & 950 & 1.0 & 0 \\
\hline 16 & FM-617 & GTA & W-heat-1 & X-Weld & S1 (TBD) & air & tension & 950 & 1.0 & 3 \\
\hline 17 & FM-617 & GTA & W-heat-1 & X-Weld & S1 (TBD) & air & tension & 950 & 1.0 & 3 \\
\hline 18 & FM-617 & GTA & W-heat-1 & X-Weld & S1 (TBD) & air & tension & 950 & 1.0 & 3 \\
\hline 19 & FM-617 & GTA & W-heat-1 & X-Weld & S1 (TBD) & air & tension & 950 & 1.0 & 150 \\
\hline 20 & FM-617 & GTA & W-heat-1 & X-Weld & S1 (TBD) & air & tension & 950 & 1.0 & 150 \\
\hline 21 & FM-617 & GTA & W-heat-1 & X-Weld & S1 (TBD) & air & tension & 950 & 1.0 & 150 \\
\hline 22 & FM-617 & GTA & W-heat-1 & X-Weld & S1 (TBD) & air & tension & 950 & 1.0 & 600 \\
\hline 23 & FM-617 & GTA & W-heat-1 & X-Weld & S1 (TBD) & air & tension & 950 & 1.0 & 600 \\
\hline 24 & FM-617 & GTA & W-heat-1 & X-Weld & S1 (TBD) & air & tension & 950 & 1.0 & 600 \\
\hline 25 & E-117 & SMA & NA & Deposited & S1 (TBD) & air & tension & 950 & 1.0 & 0 \\
\hline 26 & E-117 & SMA & NA & Deposited & S1 (TBD) & air & tension & 950 & 1.0 & 0 \\
\hline
\end{tabular}


Idaho National Laboratory

\begin{tabular}{|c|c|c|c|}
\hline $\begin{array}{l}\text { NEXT GENERATION NUCLEAR PLANT } \\
\text { INTERMEDIATE HEAT EXCHANGER } \\
\text { MATERIALS RESEARCH } \\
\text { AND DEVELOPMENT PLAN }\end{array}$ & $\begin{array}{l}\text { Identifier: } \\
\text { Revision: } \\
\text { Effective Date: }\end{array}$ & $\begin{array}{l}\text { PLN-2804 } \\
0 \\
04 / 30 / 08\end{array}$ & Page: A-10 of A-114 \\
\hline
\end{tabular}

\begin{tabular}{|c|c|c|c|c|c|c|c|c|c|c|}
\hline \multicolumn{11}{|c|}{ Table A3. Creep-Fatigue Tests for Alloy 617 Welds } \\
\hline Specimen & $\begin{array}{c}\text { Weld } \\
\text { Consumable }\end{array}$ & $\begin{array}{c}\text { Weld } \\
\text { Process }\end{array}$ & $\begin{array}{c}\text { Alloy } 617 \\
\text { Plate, Heat \# }\end{array}$ & $\begin{array}{c}\text { Weld to be } \\
\text { Tested }\end{array}$ & $\begin{array}{c}\text { Strain Rate } \\
(\mathrm{m} / \mathrm{m} / \mathrm{s})\end{array}$ & Environment & $\begin{array}{l}\text { Hold time } \\
\text { in } \mathrm{T} / \mathrm{C}\end{array}$ & $\begin{array}{c}\text { Temp. } \\
{ }^{\circ} \mathrm{C}\end{array}$ & $\begin{array}{c}\text { Strain } \\
\text { Range (\%) }\end{array}$ & $\begin{array}{l}\text { Hold } \\
\text { Time } \\
(\mathrm{min})\end{array}$ \\
\hline 27 & E-117 & SMA & NA & Deposited & $\mathrm{S} 1$ (TBD) & air & tension & 950 & 1.0 & 0 \\
\hline 28 & E-117 & SMA & NA & Deposited & $\mathrm{S} 1(\mathrm{TBD})$ & air & tension & 950 & 1.0 & 3 \\
\hline 29 & E-117 & SMA & NA & Deposited & S1 (TBD) & air & tension & 950 & 1.0 & 3 \\
\hline 30 & E-117 & SMA & NA & Deposited & $\mathrm{S} 1$ (TBD) & air & tension & 950 & 1.0 & 3 \\
\hline 31 & E-117 & SMA & NA & Deposited & S1 (TBD) & air & tension & 950 & 1.0 & 150 \\
\hline 32 & E-117 & SMA & NA & Deposited & $\mathrm{S} 1$ (TBD) & air & tension & 950 & 1.0 & 150 \\
\hline 33 & E-117 & SMA & $\mathrm{NA}$ & Deposited & $\mathrm{S} 1$ (TBD) & air & tension & 950 & 1.0 & 150 \\
\hline 34 & E-117 & SMA & NA & Deposited & S1 (TBD) & air & tension & 950 & 1.0 & 600 \\
\hline 35 & E-117 & SMA & NA & Deposited & S1 (TBD) & air & tension & 950 & 1.0 & 600 \\
\hline 36 & E-117 & SMA & $\mathrm{NA}$ & Deposited & S1 (TBD) & air & tension & 950 & 1.0 & 600 \\
\hline 37 & E-117 & SMA & W-heat-1 & X-Weld & S1 (TBD) & air & tension & 950 & 1.0 & 0 \\
\hline 38 & E-117 & SMA & W-heat-1 & X-Weld & S1 (TBD) & air & tension & 950 & 1.0 & 0 \\
\hline 39 & E-117 & SMA & W-heat-1 & X-Weld & S1 (TBD) & air & tension & 950 & 1.0 & 0 \\
\hline 40 & E-117 & SMA & W-heat-1 & X-Weld & S1 (TBD) & air & tension & 950 & 1.0 & 3 \\
\hline 41 & E-117 & SMA & W-heat-1 & X-Weld & S1 (TBD) & air & tension & 950 & 1.0 & 3 \\
\hline 42 & E-117 & SMA & W-heat-1 & X-Weld & S1 (TBD) & air & tension & 950 & 1.0 & 3 \\
\hline 43 & E-117 & SMA & W-heat-1 & X-Weld & S1 (TBD) & air & tension & 950 & 1.0 & 150 \\
\hline 44 & E-117 & SMA & W-heat-1 & X-Weld & S1 (TBD) & air & tension & 950 & 1.0 & 150 \\
\hline 45 & E-117 & SMA & W-heat-1 & X-Weld & $\mathrm{S} 1$ (TBD) & air & tension & 950 & 1.0 & 150 \\
\hline 46 & E-117 & SMA & W-heat-1 & X-Weld & S1 (TBD) & air & tension & 950 & 1.0 & 600 \\
\hline 47 & E-117 & SMA & W-heat-1 & X-Weld & S1 (TBD) & air & tension & 950 & 1.0 & 600 \\
\hline 48 & E-117 & SMA & W-heat-1 & X-Weld & S1 (TBD) & air & tension & 950 & 1.0 & 600 \\
\hline 49 & FM-617 & GTA & NA & Deposited & S1 (TBD) & NGNP He & tension & 950 & 1.0 & 0 \\
\hline 50 & FM-617 & GTA & NA & Deposited & $\mathrm{S} 1$ (TBD) & NGNP He & tension & 950 & 1.0 & 0 \\
\hline 51 & FM-617 & GTA & NA & Deposited & S1 (TBD) & NGNP He & tension & 950 & 1.0 & 0 \\
\hline 52 & FM-617 & GTA & NA & Deposited & S1 (TBD) & NGNP He & tension & 950 & 1.0 & 3 \\
\hline 53 & FM-617 & GTA & NA & Deposited & S1 (TBD) & NGNP He & tension & 950 & 1.0 & 3 \\
\hline
\end{tabular}


Idaho National Laboratory

\begin{tabular}{|c|c|c|c|}
\hline $\begin{array}{l}\text { NEXT GENERATION NUCLEAR PLANT } \\
\text { INTERMEDIATE HEAT EXCHANGER } \\
\text { MATERIALS RESEARCH } \\
\text { AND DEVELOPMENT PLAN }\end{array}$ & $\begin{array}{l}\text { Identifier: } \\
\text { Revision: } \\
\text { Effective Date: }\end{array}$ & $\begin{array}{l}\text { PLN-2804 } \\
0 \\
04 / 30 / 08\end{array}$ & Page: A-11 of A-114 \\
\hline
\end{tabular}

\begin{tabular}{|c|c|c|c|c|c|c|c|c|c|c|}
\hline \multicolumn{11}{|c|}{ Table A3. Creep-Fatigue Tests for Alloy 617 Welds } \\
\hline Specimen & $\begin{array}{c}\text { Weld } \\
\text { Consumable }\end{array}$ & $\begin{array}{c}\text { Weld } \\
\text { Process }\end{array}$ & $\begin{array}{c}\text { Alloy } 617 \\
\text { Plate, Heat \# }\end{array}$ & $\begin{array}{c}\text { Weld to be } \\
\text { Tested }\end{array}$ & $\begin{array}{c}\text { Strain Rate } \\
(\mathrm{m} / \mathrm{m} / \mathrm{s})\end{array}$ & Environment & $\begin{array}{l}\text { Hold time } \\
\text { in } \mathrm{T} / \mathrm{C}\end{array}$ & $\begin{array}{c}\text { Temp. } \\
{ }^{\circ} \mathrm{C}\end{array}$ & $\begin{array}{c}\text { Strain } \\
\text { Range (\%) }\end{array}$ & $\begin{array}{l}\text { Hold } \\
\text { Time } \\
(\mathrm{min})\end{array}$ \\
\hline 54 & FM-617 & GTA & NA & Deposited & $\mathrm{S} 1$ (TBD) & NGNP He & tension & 950 & 1.0 & 3 \\
\hline 55 & FM-617 & GTA & NA & Deposited & $\mathrm{S} 1$ (TBD) & NGNP He & tension & 950 & 1.0 & 150 \\
\hline 56 & FM-617 & GTA & NA & Deposited & S1 (TBD) & NGNP He & tension & 950 & 1.0 & 150 \\
\hline 57 & FM-617 & GTA & NA & Deposited & $\mathrm{S} 1$ (TBD) & NGNP He & tension & 950 & 1.0 & 150 \\
\hline 58 & FM-617 & GTA & NA & Deposited & $\mathrm{S} 1$ (TBD) & NGNP He & tension & 950 & 1.0 & 600 \\
\hline 59 & FM-617 & GTA & NA & Deposited & $\mathrm{S} 1$ (TBD) & NGNP He & tension & 950 & 1.0 & 600 \\
\hline 60 & FM-617 & GTA & $\mathrm{NA}$ & Deposited & $\mathrm{S} 1$ (TBD) & NGNP He & tension & 950 & 1.0 & 600 \\
\hline 61 & FM-617 & GTA & W-heat-1 & X-Weld & S1 (TBD) & NGNP He & tension & 950 & 1.0 & 0 \\
\hline 62 & FM-617 & GTA & W-heat-1 & X-Weld & S1 (TBD) & NGNP He & tension & 950 & 1.0 & 0 \\
\hline 63 & FM-617 & GTA & W-heat-1 & X-Weld & S1 (TBD) & NGNP He & tension & 950 & 1.0 & 0 \\
\hline 64 & FM-617 & GTA & W-heat-1 & X-Weld & $\mathrm{S} 1$ (TBD) & NGNP He & tension & 950 & 1.0 & 3 \\
\hline 65 & FM-617 & GTA & W-heat-1 & X-Weld & $\mathrm{S} 1$ (TBD) & NGNP He & tension & 950 & 1.0 & 3 \\
\hline 66 & FM-617 & GTA & W-heat-1 & X-Weld & S1 (TBD) & NGNP He & tension & 950 & 1.0 & 3 \\
\hline 67 & FM-617 & GTA & W-heat-1 & X-Weld & S1 (TBD) & NGNP He & tension & 950 & 1.0 & 150 \\
\hline 68 & FM-617 & GTA & W-heat-1 & X-Weld & $\mathrm{S} 1$ (TBD) & NGNP He & tension & 950 & 1.0 & 150 \\
\hline 69 & FM-617 & GTA & W-heat-1 & X-Weld & $\mathrm{S} 1$ (TBD) & NGNP He & tension & 950 & 1.0 & 150 \\
\hline 70 & FM-617 & GTA & W-heat-1 & X-Weld & $\mathrm{S} 1$ (TBD) & NGNP He & tension & 950 & 1.0 & 600 \\
\hline 71 & FM-617 & GTA & W-heat-1 & X-Weld & $\mathrm{S} 1$ (TBD) & NGNP He & tension & 950 & 1.0 & 600 \\
\hline 72 & FM-617 & GTA & W-heat-1 & X-Weld & $\mathrm{S} 1$ (TBD) & NGNP He & tension & 950 & 1.0 & 600 \\
\hline 73 & E-117 & SMA & $\mathrm{NA}$ & Deposited & $\mathrm{S} 1$ (TBD) & NGNP He & tension & 950 & 1.0 & 0 \\
\hline 74 & E-117 & SMA & NA & Deposited & S1 (TBD) & NGNP He & tension & 950 & 1.0 & 0 \\
\hline 75 & E-117 & SMA & NA & Deposited & $\mathrm{S} 1$ (TBD) & NGNP He & tension & 950 & 1.0 & 0 \\
\hline 76 & E-117 & SMA & NA & Deposited & $\mathrm{S} 1$ (TBD) & NGNP He & tension & 950 & 1.0 & 3 \\
\hline 77 & E-117 & SMA & NA & Deposited & $\mathrm{S} 1$ (TBD) & NGNP He & tension & 950 & 1.0 & 3 \\
\hline 78 & E-117 & SMA & NA & Deposited & $\mathrm{S} 1$ (TBD) & NGNP He & tension & 950 & 1.0 & 3 \\
\hline 79 & E-117 & SMA & NA & Deposited & S1 (TBD) & NGNP He & tension & 950 & 1.0 & 150 \\
\hline 80 & E-117 & SMA & NA & Deposited & S1 (TBD) & NGNP He & tension & 950 & 1.0 & 150 \\
\hline
\end{tabular}


Form 412.09 (Rev. 10)

Idaho National Laboratory

NEXT GENERATION NUCLEAR PLANT

INTERMEDIATE HEAT EXCHANGER

MATERIALS RESEARCH

AND DEVELOPMENT PLAN

\begin{tabular}{|lll|} 
Identifier: & PLN-2804 & \\
Revision: & 0 & \\
Effective Date: & $04 / 30 / 08$ & Page: A-12 of A-114 \\
\hline
\end{tabular}

\begin{tabular}{|c|c|c|c|c|c|c|c|c|c|c|}
\hline \multicolumn{11}{|c|}{ Table A3. Creep-Fatigue Tests for Alloy 617 Welds } \\
\hline Specimen & $\begin{array}{c}\text { Weld } \\
\text { Consumable }\end{array}$ & $\begin{array}{c}\text { Weld } \\
\text { Process }\end{array}$ & $\begin{array}{c}\text { Alloy } 617 \\
\text { Plate, Heat \# }\end{array}$ & $\begin{array}{c}\text { Weld to be } \\
\text { Tested }\end{array}$ & $\begin{array}{c}\text { Strain Rate } \\
(\mathrm{m} / \mathrm{m} / \mathrm{s})\end{array}$ & Environment & $\begin{array}{l}\text { Hold time } \\
\text { in } \mathrm{T} / \mathrm{C}\end{array}$ & $\begin{array}{c}\text { Temp. } \\
{ }^{\circ} \mathrm{C} \\
\end{array}$ & $\begin{array}{c}\text { Strain } \\
\text { Range }(\%) \\
\end{array}$ & $\begin{array}{l}\text { Hold } \\
\text { Time } \\
\text { (min) }\end{array}$ \\
\hline 81 & E-117 & SMA & NA & Deposited & $\mathrm{S} 1$ (TBD) & NGNP He & tension & 950 & 1.0 & 150 \\
\hline 82 & E-117 & SMA & NA & Deposited & $\mathrm{S} 1$ (TBD) & NGNP He & tension & 950 & 1.0 & 600 \\
\hline 83 & E-117 & SMA & NA & Deposited & $\mathrm{S} 1(\mathrm{TBD})$ & NGNP He & tension & 950 & 1.0 & 600 \\
\hline 84 & E-117 & SMA & $\mathrm{NA}$ & Deposited & $\mathrm{S} 1$ (TBD) & NGNP He & tension & 950 & 1.0 & 600 \\
\hline 85 & E-117 & SMA & W-heat-1 & X-Weld & $\mathrm{S} 1$ (TBD) & NGNP He & tension & 950 & 1.0 & 0 \\
\hline 86 & E-117 & SMA & W-heat-1 & X-Weld & $\mathrm{S} 1$ (TBD) & NGNP He & tension & 950 & 1.0 & 0 \\
\hline 87 & E-117 & SMA & W-heat-1 & X-Weld & $\mathrm{S} 1$ (TBD) & NGNP He & tension & 950 & 1.0 & 0 \\
\hline 88 & E-117 & SMA & W-heat-1 & X-Weld & $\mathrm{S} 1$ (TBD) & NGNP He & tension & 950 & 1.0 & 3 \\
\hline 89 & E-117 & SMA & W-heat-1 & X-Weld & $\mathrm{S} 1$ (TBD) & NGNP He & tension & 950 & 1.0 & 3 \\
\hline 90 & E-117 & SMA & W-heat-1 & X-Weld & $\mathrm{S} 1$ (TBD) & NGNP He & tension & 950 & 1.0 & 3 \\
\hline 91 & E-117 & SMA & W-heat-1 & X-Weld & S1 (TBD) & NGNP He & tension & 950 & 1.0 & 150 \\
\hline 92 & E-117 & SMA & W-heat-1 & X-Weld & $\mathrm{S} 1$ (TBD) & NGNP He & tension & 950 & 1.0 & 150 \\
\hline 93 & E-117 & SMA & W-heat-1 & X-Weld & $\mathrm{S} 1$ (TBD) & NGNP He & tension & 950 & 1.0 & 150 \\
\hline 94 & E-117 & SMA & W-heat-1 & X-Weld & $\mathrm{S} 1$ (TBD) & NGNP He & tension & 950 & 1.0 & 600 \\
\hline 95 & E-117 & SMA & W-heat-1 & X-Weld & $\mathrm{S} 1$ (TBD) & NGNP He & tension & 950 & 1.0 & 600 \\
\hline 96 & E-117 & SMA & W-heat-1 & X-Weld & S1 (TBD) & NGNP He & tension & 950 & 1.0 & 600 \\
\hline
\end{tabular}




Idaho National Laboratory
\begin{tabular}{|c|lll|}
\hline NEXT GENERATION NUCLEAR PLANT & Identifier: & PLN-2804 & \\
INTERMEDIATE HEAT EXCHANGER & Revision: & 0 & \\
MATERIALS RESEARCH & Effective Date: & $04 / 30 / 08$ & Page: A-13 of A-114 \\
AND DEVELOPMENT PLAN &
\end{tabular}

\begin{tabular}{|c|c|c|c|c|c|c|c|c|c|c|}
\hline Test Prgm & $\begin{array}{l}\text { Spec. } \\
\text { Type }\end{array}$ & $\begin{array}{c}\text { Test } \\
\text { Method }\end{array}$ & Spec. \# & Material & $\begin{array}{l}\text { Product } \\
\text { Form }\end{array}$ & Heat \# & Env. & $\begin{array}{l}\text { Exposure } \\
\text { Temp. }\left({ }^{\circ} \mathrm{C}\right)\end{array}$ & $\begin{array}{l}\text { Exposure } \\
\text { Time (h) }\end{array}$ & $\begin{array}{c}\text { Test Temp. } \\
\left({ }^{\circ} \mathrm{C}\right)\end{array}$ \\
\hline K-BM & $0.5 \mathrm{~T}-\mathrm{CT}$ & E-1820 & 1 & Alloy 617 & Plate & Aged-1 & Air & None & None & 0 \\
\hline K-BM & $0.5 \mathrm{~T}-\mathrm{CT}$ & E-1820 & 2 & Alloy 617 & Plate & Aged-1 & Air & None & None & 0 \\
\hline K-BM & $0.5 \mathrm{~T}-\mathrm{CT}$ & E-1820 & 3 & Alloy 617 & Plate & Aged-1 & Air & None & None & 0 \\
\hline K-BM & $0.5 \mathrm{~T}-\mathrm{CT}$ & E-1820 & 4 & Alloy 617 & Plate & Aged-1 & Air & None & None & 0 \\
\hline K-BM & $0.5 \mathrm{~T}-\mathrm{CT}$ & E-1820 & 5 & Alloy 617 & Plate & Aged-1 & Air & None & None & 0 \\
\hline K-BM & $0.5 \mathrm{~T}-\mathrm{CT}$ & E-1820 & 6 & Alloy 617 & Plate & Aged-1 & Air & None & None & 0 \\
\hline K-BM & $0.5 \mathrm{~T}-\mathrm{CT}$ & E-1820 & 7 & Alloy 617 & Plate & Aged-1 & Air & None & None & 100 \\
\hline K-BM & $0.5 \mathrm{~T}-\mathrm{CT}$ & E-1820 & 8 & Alloy 617 & Plate & Aged-1 & Air & None & None & 100 \\
\hline K-BM & $0.5 \mathrm{~T}-\mathrm{CT}$ & E-1820 & 9 & Alloy 617 & Plate & Aged-1 & Air & None & None & 100 \\
\hline K-BM & $0.5 \mathrm{~T}-\mathrm{CT}$ & E-1820 & 10 & Alloy 617 & Plate & Aged-1 & Air & None & None & 100 \\
\hline K-BM & $0.5 \mathrm{~T}-\mathrm{CT}$ & E-1820 & 11 & Alloy 617 & Plate & Aged-1 & Air & None & None & 100 \\
\hline K-BM & $0.5 \mathrm{~T}-\mathrm{CT}$ & E-1820 & 12 & Alloy 617 & Plate & Aged-1 & Air & None & None & 100 \\
\hline K-BM & $0.5 \mathrm{~T}-\mathrm{CT}$ & E-1820 & 13 & Alloy 617 & Plate & Aged-1 & Air & None & None & 250 \\
\hline K-BM & $0.5 \mathrm{~T}-\mathrm{CT}$ & E-1820 & 14 & Alloy 617 & Plate & Aged-1 & Air & None & None & 250 \\
\hline K-BM & $0.5 \mathrm{~T}-\mathrm{CT}$ & E-1820 & 15 & Alloy 617 & Plate & Aged-1 & Air & None & None & 250 \\
\hline K-BM & $0.5 \mathrm{~T}-\mathrm{CT}$ & E-1820 & 16 & Alloy 617 & Plate & Aged-1 & Air & None & None & 250 \\
\hline K-BM & $0.5 \mathrm{~T}-\mathrm{CT}$ & E-1820 & 17 & Alloy 617 & Plate & Aged-1 & Air & None & None & 250 \\
\hline K-BM & $0.5 \mathrm{~T}-\mathrm{CT}$ & E-1820 & 18 & Alloy 617 & Plate & Aged-1 & Air & None & None & 250 \\
\hline K-BM & $0.5 \mathrm{~T}-\mathrm{CT}$ & E-1820 & 19 & Alloy 617 & Plate & Aged-1 & Air & None & None & 750 \\
\hline K-BM & $0.5 \mathrm{~T}-\mathrm{CT}$ & E-1820 & 20 & Alloy 617 & Plate & Aged-1 & Air & None & None & 750 \\
\hline K-BM & $0.5 \mathrm{~T}-\mathrm{CT}$ & E-1820 & 21 & Alloy 617 & Plate & Aged-1 & Air & None & None & 750 \\
\hline K-BM & $0.5 \mathrm{~T}-\mathrm{CT}$ & E-1820 & 22 & Alloy 617 & Plate & Aged-1 & Air & None & None & 750 \\
\hline K-BM & $0.5 \mathrm{~T}-\mathrm{CT}$ & E-1820 & 23 & Alloy 617 & Plate & Aged-1 & Air & None & None & 750 \\
\hline K-BM & $0.5 \mathrm{~T}-\mathrm{CT}$ & E-1820 & 24 & Alloy 617 & Plate & Aged-1 & Air & None & None & 750 \\
\hline K-BM & $0.5 \mathrm{~T}-\mathrm{CT}$ & E-1820 & 25 & Alloy 617 & Plate & Aged-1 & Air & None & None & 950 \\
\hline K-BM & $0.5 \mathrm{~T}-\mathrm{CT}$ & E-1820 & 26 & Alloy 617 & Plate & Aged-1 & Air & None & None & 950 \\
\hline K-BM & $0.5 \mathrm{~T}-\mathrm{CT}$ & E-1820 & 27 & Alloy 617 & Plate & Aged-1 & Air & None & None & 950 \\
\hline
\end{tabular}


Idaho National Laboratory

\section{NEXT GENERATION NUCLEAR PLANT INTERMEDIATE HEAT EXCHANGER MATERIALS RESEARCH} AND DEVELOPMENT PLAN

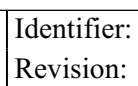

Table A4(a). Aging Effects on Fracture Toughness of Alloy 617 Wrought Metal

\begin{tabular}{|c|c|c|c|c|c|c|c|c|c|c|}
\hline Test Prgm & $\begin{array}{l}\text { Spec. } \\
\text { Type }\end{array}$ & $\begin{array}{c}\text { Test } \\
\text { Method }\end{array}$ & Spec. \# & Material & $\begin{array}{c}\text { Product } \\
\text { Form }\end{array}$ & Heat \# & Env. & $\begin{array}{c}\text { Exposure } \\
\text { Temp. }\left({ }^{\circ} \mathrm{C}\right)\end{array}$ & $\begin{array}{c}\text { Exposure } \\
\text { Time (h) }\end{array}$ & $\begin{array}{c}\text { Test Temp. } \\
\left({ }^{\circ} \mathrm{C}\right)\end{array}$ \\
\hline K-BM & $0.5 \mathrm{~T}-\mathrm{CT}$ & E-1820 & 28 & Alloy 617 & Plate & Aged-1 & Air & None & None & 950 \\
\hline K-BM & $0.5 \mathrm{~T}-\mathrm{CT}$ & E-1820 & 29 & Alloy 617 & Plate & Aged-1 & Air & None & None & 950 \\
\hline K-BM & $0.5 \mathrm{~T}-\mathrm{CT}$ & E-1820 & 30 & Alloy 617 & Plate & Aged-1 & Air & None & None & 950 \\
\hline K-BM & $0.5 \mathrm{~T}-\mathrm{CT}$ & E-1820 & 31 & Alloy 617 & Plate & Aged-2 & Air & None & None & 0 \\
\hline K-BM & $0.5 \mathrm{~T}-\mathrm{CT}$ & E-1820 & 32 & Alloy 617 & Plate & Aged-2 & Air & None & None & 0 \\
\hline K-BM & $0.5 \mathrm{~T}-\mathrm{CT}$ & E-1820 & 33 & Alloy 617 & Plate & Aged-2 & Air & None & None & 0 \\
\hline K-BM & $0.5 \mathrm{~T}-\mathrm{CT}$ & E-1820 & 34 & Alloy 617 & Plate & Aged-2 & Air & None & None & 0 \\
\hline K-BM & $0.5 \mathrm{~T}-\mathrm{CT}$ & E-1820 & 35 & Alloy 617 & Plate & Aged-2 & Air & None & None & 0 \\
\hline K-BM & $0.5 \mathrm{~T}-\mathrm{CT}$ & E-1820 & 36 & Alloy 617 & Plate & Aged-2 & Air & None & None & 0 \\
\hline K-BM & $0.5 \mathrm{~T}-\mathrm{CT}$ & E-1820 & 37 & Alloy 617 & Plate & Aged-2 & Air & None & None & 100 \\
\hline K-BM & $0.5 \mathrm{~T}-\mathrm{CT}$ & E-1820 & 38 & Alloy 617 & Plate & Aged-2 & Air & None & None & 100 \\
\hline K-BM & $0.5 \mathrm{~T}-\mathrm{CT}$ & E-1820 & 39 & Alloy 617 & Plate & Aged-2 & Air & None & None & 100 \\
\hline K-BM & $0.5 \mathrm{~T}-\mathrm{CT}$ & E-1820 & 40 & Alloy 617 & Plate & Aged-2 & Air & None & None & 100 \\
\hline K-BM & $0.5 \mathrm{~T}-\mathrm{CT}$ & E-1820 & 41 & Alloy 617 & Plate & Aged-2 & Air & None & None & 100 \\
\hline K-BM & $0.5 \mathrm{~T}-\mathrm{CT}$ & E-1820 & 42 & Alloy 617 & Plate & Aged-2 & Air & None & None & 100 \\
\hline K-BM & $0.5 \mathrm{~T}-\mathrm{CT}$ & E-1820 & 43 & Alloy 617 & Plate & Aged-2 & Air & None & None & 250 \\
\hline K-BM & $0.5 \mathrm{~T}-\mathrm{CT}$ & E-1820 & 44 & Alloy 617 & Plate & Aged-2 & Air & None & None & 250 \\
\hline K-BM & $0.5 \mathrm{~T}-\mathrm{CT}$ & E-1820 & 45 & Alloy 617 & Plate & Aged-2 & Air & None & None & 250 \\
\hline K-BM & $0.5 \mathrm{~T}-\mathrm{CT}$ & E-1820 & 46 & Alloy 617 & Plate & Aged-2 & Air & None & None & 250 \\
\hline K-BM & $0.5 \mathrm{~T}-\mathrm{CT}$ & E-1820 & 47 & Alloy 617 & Plate & Aged-2 & Air & None & None & 250 \\
\hline K-BM & $0.5 \mathrm{~T}-\mathrm{CT}$ & E-1820 & 48 & Alloy 617 & Plate & Aged-2 & Air & None & None & 250 \\
\hline K-BM & $0.5 \mathrm{~T}-\mathrm{CT}$ & E-1820 & 49 & Alloy 617 & Plate & Aged-2 & Air & None & None & 750 \\
\hline K-BM & $0.5 \mathrm{~T}-\mathrm{CT}$ & E-1820 & 50 & Alloy 617 & Plate & Aged-2 & Air & None & None & 750 \\
\hline K-BM & $0.5 \mathrm{~T}-\mathrm{CT}$ & E-1820 & 51 & Alloy 617 & Plate & Aged-2 & Air & None & None & 750 \\
\hline K-BM & $0.5 \mathrm{~T}-\mathrm{CT}$ & E-1820 & 52 & Alloy 617 & Plate & Aged-2 & Air & None & None & 750 \\
\hline K-BM & $0.5 \mathrm{~T}-\mathrm{CT}$ & E-1820 & 53 & Alloy 617 & Plate & Aged-2 & Air & None & None & 750 \\
\hline K-BM & $0.5 \mathrm{~T}-\mathrm{CT}$ & E-1820 & 54 & Alloy 617 & Plate & Aged-2 & Air & None & None & 750 \\
\hline K-BM & $0.5 \mathrm{~T}-\mathrm{CT}$ & E-1820 & 55 & Alloy 617 & Plate & Aged-2 & Air & None & None & 950 \\
\hline
\end{tabular}


Idaho National Laboratory

\section{NEXT GENERATION NUCLEAR PLANT INTERMEDIATE HEAT EXCHANGER MATERIALS RESEARCH} AND DEVELOPMENT PLAN

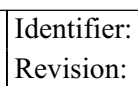

Table A4(a). Aging Effects on Fracture Toughness of Alloy 617 Wrought Metal

\begin{tabular}{|c|c|c|c|c|c|c|c|c|c|c|}
\hline Test Prgm & $\begin{array}{l}\text { Spec. } \\
\text { Type }\end{array}$ & $\begin{array}{c}\text { Test } \\
\text { Method }\end{array}$ & Spec. \# & Material & $\begin{array}{c}\text { Product } \\
\text { Form }\end{array}$ & Heat \# & Env. & $\begin{array}{c}\text { Exposure } \\
\text { Temp. }\left({ }^{\circ} \mathrm{C}\right)\end{array}$ & $\begin{array}{c}\text { Exposure } \\
\text { Time (h) }\end{array}$ & $\begin{array}{c}\text { Test Temp. } \\
\left({ }^{\circ} \mathrm{C}\right)\end{array}$ \\
\hline K-BM & $0.5 \mathrm{~T}-\mathrm{CT}$ & E-1820 & 56 & Alloy 617 & Plate & Aged-2 & Air & None & None & 950 \\
\hline K-BM & $0.5 \mathrm{~T}-\mathrm{CT}$ & E-1820 & 57 & Alloy 617 & Plate & Aged-2 & Air & None & None & 950 \\
\hline K-BM & $0.5 \mathrm{~T}-\mathrm{CT}$ & E-1820 & 58 & Alloy 617 & Plate & Aged-2 & Air & None & None & 950 \\
\hline K-BM & $0.5 \mathrm{~T}-\mathrm{CT}$ & E-1820 & 59 & Alloy 617 & Plate & Aged-2 & Air & None & None & 950 \\
\hline K-BM & $0.5 \mathrm{~T}-\mathrm{CT}$ & E-1820 & 60 & Alloy 617 & Plate & Aged-2 & Air & None & None & 950 \\
\hline K-BM & $0.5 \mathrm{~T}-\mathrm{CT}$ & E-1820 & 61 & Alloy 617 & Plate & Aged-1 & Air & 750 & 200 & 0 \\
\hline K-BM & $0.5 \mathrm{~T}-\mathrm{CT}$ & E-1820 & 62 & Alloy 617 & Plate & Aged-1 & Air & 750 & 200 & 0 \\
\hline K-BM & $0.5 \mathrm{~T}-\mathrm{CT}$ & E-1820 & 63 & Alloy 617 & Plate & Aged-1 & Air & 750 & 200 & 0 \\
\hline K-BM & $0.5 \mathrm{~T}-\mathrm{CT}$ & E-1820 & 64 & Alloy 617 & Plate & Aged-1 & Air & 750 & 200 & 100 \\
\hline K-BM & $0.5 \mathrm{~T}-\mathrm{CT}$ & E-1820 & 65 & Alloy 617 & Plate & Aged-1 & Air & 750 & 200 & 100 \\
\hline K-BM & $0.5 \mathrm{~T}-\mathrm{CT}$ & E-1820 & 66 & Alloy 617 & Plate & Aged-1 & Air & 750 & 200 & 100 \\
\hline K-BM & $0.5 \mathrm{~T}-\mathrm{CT}$ & E- 1820 & 67 & Alloy 617 & Plate & Aged-1 & Air & 750 & 200 & 950 \\
\hline K-BM & $0.5 \mathrm{~T}-\mathrm{CT}$ & E-1820 & 68 & Alloy 617 & Plate & Aged-1 & Air & 750 & 200 & 950 \\
\hline K-BM & $0.5 \mathrm{~T}-\mathrm{CT}$ & E-1820 & 69 & Alloy 617 & Plate & Aged-1 & Air & 750 & 200 & 950 \\
\hline K-BM & $0.5 \mathrm{~T}-\mathrm{CT}$ & E-1820 & 70 & Alloy 617 & Plate & Aged-2 & Air & 750 & 200 & 0 \\
\hline K-BM & $0.5 \mathrm{~T}-\mathrm{CT}$ & E-1820 & 71 & Alloy 617 & Plate & Aged-2 & Air & 750 & 200 & 0 \\
\hline K-BM & $0.5 \mathrm{~T}-\mathrm{CT}$ & E-1820 & 72 & Alloy 617 & Plate & Aged-2 & Air & 750 & 200 & 0 \\
\hline K-BM & $0.5 \mathrm{~T}-\mathrm{CT}$ & E-1820 & 73 & Alloy 617 & Plate & Aged-2 & Air & 750 & 200 & 100 \\
\hline K-BM & $0.5 \mathrm{~T}-\mathrm{CT}$ & E-1820 & 74 & Alloy 617 & Plate & Aged-2 & Air & 750 & 200 & 100 \\
\hline K-BM & $0.5 \mathrm{~T}-\mathrm{CT}$ & E-1820 & 75 & Alloy 617 & Plate & Aged-2 & Air & 750 & 200 & 100 \\
\hline K-BM & $0.5 \mathrm{~T}-\mathrm{CT}$ & E-1820 & 76 & Alloy 617 & Plate & Aged-2 & Air & 750 & 200 & 950 \\
\hline K-BM & $0.5 \mathrm{~T}-\mathrm{CT}$ & E-1820 & 77 & Alloy 617 & Plate & Aged-2 & Air & 750 & 200 & 950 \\
\hline K-BM & $0.5 \mathrm{~T}-\mathrm{CT}$ & E-1820 & 78 & Alloy 617 & Plate & Aged-2 & Air & 750 & 200 & 950 \\
\hline K-BM & $0.5 \mathrm{~T}-\mathrm{CT}$ & E-1820 & 79 & Alloy 617 & Plate & Aged-1 & Air & 1000 & 200 & 0 \\
\hline K-BM & $0.5 \mathrm{~T}-\mathrm{CT}$ & E-1820 & 80 & Alloy 617 & Plate & Aged-1 & Air & 1000 & 200 & 0 \\
\hline K-BM & $0.5 \mathrm{~T}-\mathrm{CT}$ & E-1820 & 81 & Alloy 617 & Plate & Aged-1 & Air & 1000 & 200 & 0 \\
\hline K-BM & $0.5 \mathrm{~T}-\mathrm{CT}$ & E-1820 & 82 & Alloy 617 & Plate & Aged-1 & Air & 1000 & 200 & 100 \\
\hline K-BM & $0.5 \mathrm{~T}-\mathrm{CT}$ & E-1820 & 83 & Alloy 617 & Plate & Aged-1 & Air & 1000 & 200 & 100 \\
\hline
\end{tabular}


Idaho National Laboratory

\section{NEXT GENERATION NUCLEAR PLANT INTERMEDIATE HEAT EXCHANGER MATERIALS RESEARCH} AND DEVELOPMENT PLAN

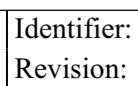

Table A4(a). Aging Effects on Fracture Toughness of Alloy 617 Wrought Metal

\begin{tabular}{|c|c|c|c|c|c|c|c|c|c|c|}
\hline Test Prgm & $\begin{array}{l}\text { Spec. } \\
\text { Type }\end{array}$ & $\begin{array}{c}\text { Test } \\
\text { Method }\end{array}$ & Spec. \# & Material & $\begin{array}{c}\text { Product } \\
\text { Form }\end{array}$ & Heat \# & Env. & $\begin{array}{c}\text { Exposure } \\
\text { Temp. }\left({ }^{\circ} \mathrm{C}\right)\end{array}$ & $\begin{array}{c}\text { Exposure } \\
\text { Time (h) }\end{array}$ & $\begin{array}{c}\text { Test Temp. } \\
\left({ }^{\circ} \mathrm{C}\right)\end{array}$ \\
\hline K-BM & $0.5 \mathrm{~T}-\mathrm{CT}$ & E-1820 & 84 & Alloy 617 & Plate & Aged-1 & Air & 1000 & 200 & 100 \\
\hline K-BM & $0.5 \mathrm{~T}-\mathrm{CT}$ & E- 1820 & 85 & Alloy 617 & Plate & Aged-1 & Air & 1000 & 200 & 950 \\
\hline K-BM & $0.5 \mathrm{~T}-\mathrm{CT}$ & E-1820 & 86 & Alloy 617 & Plate & Aged-1 & Air & 1000 & 200 & 950 \\
\hline K-BM & $0.5 \mathrm{~T}-\mathrm{CT}$ & E-1820 & 87 & Alloy 617 & Plate & Aged-1 & Air & 1000 & 200 & 950 \\
\hline K-BM & $0.5 \mathrm{~T}-\mathrm{CT}$ & E-1820 & 88 & Alloy 617 & Plate & Aged-2 & Air & 1000 & 200 & 0 \\
\hline K-BM & $0.5 \mathrm{~T}-\mathrm{CT}$ & E-1820 & 89 & Alloy 617 & Plate & Aged-2 & Air & 1000 & 200 & 0 \\
\hline K-BM & $0.5 \mathrm{~T}-\mathrm{CT}$ & E-1820 & 90 & Alloy 617 & Plate & Aged-2 & Air & 1000 & 200 & 0 \\
\hline K-BM & $0.5 \mathrm{~T}-\mathrm{CT}$ & E-1820 & 91 & Alloy 617 & Plate & Aged-2 & Air & 1000 & 200 & 100 \\
\hline K-BM & $0.5 \mathrm{~T}-\mathrm{CT}$ & E-1820 & 92 & Alloy 617 & Plate & Aged-2 & Air & 1000 & 200 & 100 \\
\hline K-BM & $0.5 \mathrm{~T}-\mathrm{CT}$ & E-1820 & 93 & Alloy 617 & Plate & Aged-2 & Air & 1000 & 200 & 100 \\
\hline K-BM & $0.5 \mathrm{~T}-\mathrm{CT}$ & E-1820 & 94 & Alloy 617 & Plate & Aged-2 & Air & 1000 & 200 & 950 \\
\hline K-BM & $0.5 \mathrm{~T}-\mathrm{CT}$ & E- 1820 & 95 & Alloy 617 & Plate & Aged-2 & Air & 1000 & 200 & 950 \\
\hline K-BM & $0.5 \mathrm{~T}-\mathrm{CT}$ & E-1820 & 96 & Alloy 617 & Plate & Aged-2 & Air & 1000 & 200 & 950 \\
\hline K-BM & $0.5 \mathrm{~T}-\mathrm{CT}$ & E-1820 & 97 & Alloy 617 & Plate & Aged-1 & Air & 750 & 650 & 0 \\
\hline K-BM & $0.5 \mathrm{~T}-\mathrm{CT}$ & E-1820 & 98 & Alloy 617 & Plate & Aged-1 & Air & 750 & 650 & 0 \\
\hline K-BM & $0.5 \mathrm{~T}-\mathrm{CT}$ & E-1820 & 99 & Alloy 617 & Plate & Aged-1 & Air & 750 & 650 & 0 \\
\hline K-BM & $0.5 \mathrm{~T}-\mathrm{CT}$ & E-1820 & 100 & Alloy 617 & Plate & Aged-1 & Air & 750 & 650 & 100 \\
\hline K-BM & $0.5 \mathrm{~T}-\mathrm{CT}$ & E-1820 & 101 & Alloy 617 & Plate & Aged-1 & Air & 750 & 650 & 100 \\
\hline K-BM & $0.5 \mathrm{~T}-\mathrm{CT}$ & E-1820 & 102 & Alloy 617 & Plate & Aged-1 & Air & 750 & 650 & 100 \\
\hline K-BM & $0.5 \mathrm{~T}-\mathrm{CT}$ & E-1820 & 103 & Alloy 617 & Plate & Aged-1 & Air & 750 & 650 & 950 \\
\hline K-BM & $0.5 \mathrm{~T}-\mathrm{CT}$ & E-1820 & 104 & Alloy 617 & Plate & Aged-1 & Air & 750 & 650 & 950 \\
\hline K-BM & $0.5 \mathrm{~T}-\mathrm{CT}$ & E-1820 & 105 & Alloy 617 & Plate & Aged-1 & Air & 750 & 650 & 950 \\
\hline K-BM & $0.5 \mathrm{~T}-\mathrm{CT}$ & E-1820 & 106 & Alloy 617 & Plate & Aged-2 & Air & 750 & 650 & 0 \\
\hline K-BM & $0.5 \mathrm{~T}-\mathrm{CT}$ & E-1820 & 107 & Alloy 617 & Plate & Aged-2 & Air & 750 & 650 & 0 \\
\hline K-BM & $0.5 \mathrm{~T}-\mathrm{CT}$ & E-1820 & 108 & Alloy 617 & Plate & Aged-2 & Air & 750 & 650 & 0 \\
\hline K-BM & $0.5 \mathrm{~T}-\mathrm{CT}$ & E-1820 & 109 & Alloy 617 & Plate & Aged-2 & Air & 750 & 650 & 100 \\
\hline K-BM & $0.5 \mathrm{~T}-\mathrm{CT}$ & E-1820 & 110 & Alloy 617 & Plate & Aged-2 & Air & 750 & 650 & 100 \\
\hline K-BM & $0.5 \mathrm{~T}-\mathrm{CT}$ & E-1820 & 111 & Alloy 617 & Plate & Aged-2 & Air & 750 & 650 & 100 \\
\hline
\end{tabular}


Idaho National Laboratory

\section{NEXT GENERATION NUCLEAR PLANT INTERMEDIATE HEAT EXCHANGER MATERIALS RESEARCH} AND DEVELOPMENT PLAN

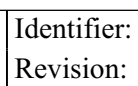

Table A4(a). Aging Effects on Fracture Toughness of Alloy 617 Wrought Metal

\begin{tabular}{|c|c|c|c|c|c|c|c|c|c|c|}
\hline Test Prgm & $\begin{array}{l}\text { Spec. } \\
\text { Type }\end{array}$ & $\begin{array}{c}\text { Test } \\
\text { Method }\end{array}$ & Spec. \# & Material & $\begin{array}{c}\text { Product } \\
\text { Form }\end{array}$ & Heat \# & Env. & $\begin{array}{c}\text { Exposure } \\
\text { Temp. }\left({ }^{\circ} \mathrm{C}\right)\end{array}$ & $\begin{array}{c}\text { Exposure } \\
\text { Time (h) }\end{array}$ & $\begin{array}{c}\text { Test Temp. } \\
\left({ }^{\circ} \mathrm{C}\right)\end{array}$ \\
\hline K-BM & $0.5 \mathrm{~T}-\mathrm{CT}$ & E-1820 & 112 & Alloy 617 & Plate & Aged-2 & Air & 750 & 650 & 950 \\
\hline K-BM & $0.5 \mathrm{~T}-\mathrm{CT}$ & E- 1820 & 113 & Alloy 617 & Plate & Aged-2 & Air & 750 & 650 & 950 \\
\hline K-BM & $0.5 \mathrm{~T}-\mathrm{CT}$ & E-1820 & 114 & Alloy 617 & Plate & Aged-2 & Air & 750 & 650 & 950 \\
\hline K-BM & $0.5 \mathrm{~T}-\mathrm{CT}$ & E-1820 & 115 & Alloy 617 & Plate & Aged-1 & Air & 1000 & 650 & 0 \\
\hline K-BM & $0.5 \mathrm{~T}-\mathrm{CT}$ & E-1820 & 116 & Alloy 617 & Plate & Aged-1 & Air & 1000 & 650 & 0 \\
\hline K-BM & $0.5 \mathrm{~T}-\mathrm{CT}$ & E-1820 & 117 & Alloy 617 & Plate & Aged-1 & Air & 1000 & 650 & 0 \\
\hline K-BM & $0.5 \mathrm{~T}-\mathrm{CT}$ & E-1820 & 118 & Alloy 617 & Plate & Aged-1 & Air & 1000 & 650 & 100 \\
\hline K-BM & $0.5 \mathrm{~T}-\mathrm{CT}$ & E-1820 & 119 & Alloy 617 & Plate & Aged-1 & Air & 1000 & 650 & 100 \\
\hline K-BM & $0.5 \mathrm{~T}-\mathrm{CT}$ & E-1820 & 120 & Alloy 617 & Plate & Aged-1 & Air & 1000 & 650 & 100 \\
\hline K-BM & $0.5 \mathrm{~T}-\mathrm{CT}$ & E-1820 & 121 & Alloy 617 & Plate & Aged-1 & Air & 1000 & 650 & 950 \\
\hline K-BM & $0.5 \mathrm{~T}-\mathrm{CT}$ & E-1820 & 122 & Alloy 617 & Plate & Aged-1 & Air & 1000 & 650 & 950 \\
\hline K-BM & $0.5 \mathrm{~T}-\mathrm{CT}$ & E-1820 & 123 & Alloy 617 & Plate & Aged-1 & Air & 1000 & 650 & 950 \\
\hline K-BM & $0.5 \mathrm{~T}-\mathrm{CT}$ & E-1820 & 124 & Alloy 617 & Plate & Aged-2 & Air & 1000 & 650 & 0 \\
\hline K-BM & $0.5 \mathrm{~T}-\mathrm{CT}$ & E-1820 & 125 & Alloy 617 & Plate & Aged-2 & Air & 1000 & 650 & 0 \\
\hline K-BM & $0.5 \mathrm{~T}-\mathrm{CT}$ & E-1820 & 126 & Alloy 617 & Plate & Aged-2 & Air & 1000 & 650 & 0 \\
\hline K-BM & $0.5 \mathrm{~T}-\mathrm{CT}$ & E-1820 & 127 & Alloy 617 & Plate & Aged-2 & Air & 1000 & 650 & 100 \\
\hline K-BM & $0.5 \mathrm{~T}-\mathrm{CT}$ & E-1820 & 128 & Alloy 617 & Plate & Aged-2 & Air & 1000 & 650 & 100 \\
\hline K-BM & $0.5 \mathrm{~T}-\mathrm{CT}$ & E-1820 & 129 & Alloy 617 & Plate & Aged-2 & Air & 1000 & 650 & 100 \\
\hline K-BM & $0.5 \mathrm{~T}-\mathrm{CT}$ & E-1820 & 130 & Alloy 617 & Plate & Aged-2 & Air & 1000 & 650 & 950 \\
\hline K-BM & $0.5 \mathrm{~T}-\mathrm{CT}$ & E-1820 & 131 & Alloy 617 & Plate & Aged-2 & Air & 1000 & 650 & 950 \\
\hline K-BM & $0.5 \mathrm{~T}-\mathrm{CT}$ & E-1820 & 132 & Alloy 617 & Plate & Aged-2 & Air & 1000 & 650 & 950 \\
\hline K-BM & $0.5 \mathrm{~T}-\mathrm{CT}$ & E-1820 & 133 & Alloy 617 & Plate & Aged-1 & Air & 750 & 2000 & 0 \\
\hline K-BM & $0.5 \mathrm{~T}-\mathrm{CT}$ & E-1820 & 134 & Alloy 617 & Plate & Aged-1 & Air & 750 & 2000 & 0 \\
\hline K-BM & $0.5 \mathrm{~T}-\mathrm{CT}$ & E-1820 & 135 & Alloy 617 & Plate & Aged-1 & Air & 750 & 2000 & 0 \\
\hline K-BM & $0.5 \mathrm{~T}-\mathrm{CT}$ & E-1820 & 136 & Alloy 617 & Plate & Aged-1 & Air & 750 & 2000 & 100 \\
\hline K-BM & $0.5 \mathrm{~T}-\mathrm{CT}$ & E-1820 & 137 & Alloy 617 & Plate & Aged-1 & Air & 750 & 2000 & 100 \\
\hline K-BM & $0.5 \mathrm{~T}-\mathrm{CT}$ & E-1820 & 138 & Alloy 617 & Plate & Aged-1 & Air & 750 & 2000 & 100 \\
\hline K-BM & $0.5 \mathrm{~T}-\mathrm{CT}$ & E-1820 & 139 & Alloy 617 & Plate & Aged-1 & Air & 750 & 2000 & 950 \\
\hline
\end{tabular}


Idaho National Laboratory

\section{NEXT GENERATION NUCLEAR PLANT INTERMEDIATE HEAT EXCHANGER MATERIALS RESEARCH} AND DEVELOPMENT PLAN

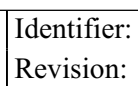

Table A4(a). Aging Effects on Fracture Toughness of Alloy 617 Wrought Metal

\begin{tabular}{|c|c|c|c|c|c|c|c|c|c|c|}
\hline Test Prgm & $\begin{array}{l}\text { Spec. } \\
\text { Type }\end{array}$ & $\begin{array}{c}\text { Test } \\
\text { Method }\end{array}$ & Spec. \# & Material & $\begin{array}{l}\text { Product } \\
\text { Form }\end{array}$ & Heat \# & Env. & $\begin{array}{c}\text { Exposure } \\
\text { Temp. }\left({ }^{\circ} \mathrm{C}\right)\end{array}$ & $\begin{array}{l}\text { Exposure } \\
\text { Time (h) }\end{array}$ & $\begin{array}{c}\text { Test Temp. } \\
\left({ }^{\circ} \mathrm{C}\right)\end{array}$ \\
\hline K-BM & $0.5 \mathrm{~T}-\mathrm{CT}$ & E-1820 & 140 & Alloy 617 & Plate & Aged-1 & Air & 750 & 2000 & 950 \\
\hline K-BM & $0.5 \mathrm{~T}-\mathrm{CT}$ & E-1820 & 141 & Alloy 617 & Plate & Aged-1 & Air & 750 & 2000 & 950 \\
\hline $\mathrm{K}-\mathrm{BM}$ & $0.5 \mathrm{~T}-\mathrm{CT}$ & E-1820 & 142 & Alloy 617 & Plate & Aged-2 & Air & 750 & 2000 & 0 \\
\hline K-BM & $0.5 \mathrm{~T}-\mathrm{CT}$ & E-1820 & 143 & Alloy 617 & Plate & Aged-2 & Air & 750 & 2000 & 0 \\
\hline K-BM & $0.5 \mathrm{~T}-\mathrm{CT}$ & E-1820 & 144 & Alloy 617 & Plate & Aged-2 & Air & 750 & 2000 & 0 \\
\hline K-BM & $0.5 \mathrm{~T}-\mathrm{CT}$ & E-1820 & 145 & Alloy 617 & Plate & Aged-2 & Air & 750 & 2000 & 100 \\
\hline K-BM & $0.5 \mathrm{~T}-\mathrm{CT}$ & E-1820 & 146 & Alloy 617 & Plate & Aged-2 & Air & 750 & 2000 & 100 \\
\hline K-BM & $0.5 \mathrm{~T}-\mathrm{CT}$ & E-1820 & 147 & Alloy 617 & Plate & Aged-2 & Air & 750 & 2000 & 100 \\
\hline K-BM & $0.5 \mathrm{~T}-\mathrm{CT}$ & E-1820 & 148 & Alloy 617 & Plate & Aged-2 & Air & 750 & 2000 & 950 \\
\hline K-BM & $0.5 \mathrm{~T}-\mathrm{CT}$ & E-1820 & 149 & Alloy 617 & Plate & Aged-2 & Air & 750 & 2000 & 950 \\
\hline K-BM & $0.5 \mathrm{~T}-\mathrm{CT}$ & E-1820 & 150 & Alloy 617 & Plate & Aged-2 & Air & 750 & 2000 & 950 \\
\hline K-BM & $0.5 \mathrm{~T}-\mathrm{CT}$ & E-1820 & 151 & Alloy 617 & Plate & Aged-1 & Air & 1000 & 2000 & 0 \\
\hline K-BM & $0.5 \mathrm{~T}-\mathrm{CT}$ & E-1820 & 152 & Alloy 617 & Plate & Aged-1 & Air & 1000 & 2000 & 0 \\
\hline K-BM & $0.5 \mathrm{~T}-\mathrm{CT}$ & E-1820 & 153 & Alloy 617 & Plate & Aged-1 & Air & 1000 & 2000 & 0 \\
\hline K-BM & $0.5 \mathrm{~T}-\mathrm{CT}$ & E-1820 & 154 & Alloy 617 & Plate & Aged-1 & Air & 1000 & 2000 & 100 \\
\hline K-BM & $0.5 \mathrm{~T}-\mathrm{CT}$ & E-1820 & 155 & Alloy 617 & Plate & Aged-1 & Air & 1000 & 2000 & 100 \\
\hline K-BM & $0.5 \mathrm{~T}-\mathrm{CT}$ & E-1820 & 156 & Alloy 617 & Plate & Aged-1 & Air & 1000 & 2000 & 100 \\
\hline K-BM & $0.5 \mathrm{~T}-\mathrm{CT}$ & E-1820 & 157 & Alloy 617 & Plate & Aged-1 & Air & 1000 & 2000 & 950 \\
\hline K-BM & $0.5 \mathrm{~T}-\mathrm{CT}$ & E-1820 & 158 & Alloy 617 & Plate & Aged-1 & Air & 1000 & 2000 & 950 \\
\hline K-BM & $0.5 \mathrm{~T}-\mathrm{CT}$ & E-1820 & 159 & Alloy 617 & Plate & Aged-1 & Air & 1000 & 2000 & 950 \\
\hline K-BM & $0.5 \mathrm{~T}-\mathrm{CT}$ & E-1820 & 160 & Alloy 617 & Plate & Aged-2 & Air & 1000 & 2000 & 0 \\
\hline K-BM & $0.5 \mathrm{~T}-\mathrm{CT}$ & E-1820 & 161 & Alloy 617 & Plate & Aged-2 & Air & 1000 & 2000 & 0 \\
\hline K-BM & $0.5 \mathrm{~T}-\mathrm{CT}$ & E-1820 & 162 & Alloy 617 & Plate & Aged-2 & Air & 1000 & 2000 & 0 \\
\hline K-BM & $0.5 \mathrm{~T}-\mathrm{CT}$ & E-1820 & 163 & Alloy 617 & Plate & Aged-2 & Air & 1000 & 2000 & 100 \\
\hline K-BM & $0.5 \mathrm{~T}-\mathrm{CT}$ & E-1820 & 164 & Alloy 617 & Plate & Aged-2 & Air & 1000 & 2000 & 100 \\
\hline K-BM & $0.5 \mathrm{~T}-\mathrm{CT}$ & E-1820 & 165 & Alloy 617 & Plate & Aged-2 & Air & 1000 & 2000 & 100 \\
\hline K-BM & $0.5 \mathrm{~T}-\mathrm{CT}$ & E-1820 & 166 & Alloy 617 & Plate & Aged-2 & Air & 1000 & 2000 & 950 \\
\hline K-BM & $0.5 \mathrm{~T}-\mathrm{CT}$ & E-1820 & 167 & Alloy 617 & Plate & Aged-2 & Air & 1000 & 2000 & 950 \\
\hline
\end{tabular}


Idaho National Laboratory

\section{NEXT GENERATION NUCLEAR PLANT INTERMEDIATE HEAT EXCHANGER MATERIALS RESEARCH} AND DEVELOPMENT PLAN

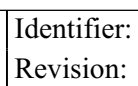

Table A4(a). Aging Effects on Fracture Toughness of Alloy 617 Wrought Metal

\begin{tabular}{|c|c|c|c|c|c|c|c|c|c|c|}
\hline Test Prgm & $\begin{array}{l}\text { Spec. } \\
\text { Type }\end{array}$ & $\begin{array}{c}\text { Test } \\
\text { Method }\end{array}$ & Spec. \# & Material & $\begin{array}{c}\text { Product } \\
\text { Form }\end{array}$ & Heat \# & Env. & $\begin{array}{c}\text { Exposure } \\
\text { Temp. }\left({ }^{\circ} \mathrm{C}\right)\end{array}$ & $\begin{array}{c}\text { Exposure } \\
\text { Time (h) }\end{array}$ & $\begin{array}{c}\text { Test Temp. } \\
\left({ }^{\circ} \mathrm{C}\right)\end{array}$ \\
\hline K-BM & $0.5 \mathrm{~T}-\mathrm{CT}$ & E-1820 & 168 & Alloy 617 & Plate & Aged-2 & Air & 1000 & 2000 & 950 \\
\hline K-BM & $0.5 \mathrm{~T}-\mathrm{CT}$ & E-1820 & 169 & Alloy 617 & Plate & Aged-1 & Air & 750 & 5300 & 0 \\
\hline K-BM & $0.5 \mathrm{~T}-\mathrm{CT}$ & E-1820 & 170 & Alloy 617 & Plate & Aged-1 & Air & 750 & 5300 & 0 \\
\hline K-BM & $0.5 \mathrm{~T}-\mathrm{CT}$ & E-1820 & 171 & Alloy 617 & Plate & Aged-1 & Air & 750 & 5300 & 0 \\
\hline K-BM & $0.5 \mathrm{~T}-\mathrm{CT}$ & E-1820 & 172 & Alloy 617 & Plate & Aged-1 & Air & 750 & 5300 & 100 \\
\hline K-BM & $0.5 \mathrm{~T}-\mathrm{CT}$ & E-1820 & 173 & Alloy 617 & Plate & Aged-1 & Air & 750 & 5300 & 100 \\
\hline K-BM & $0.5 \mathrm{~T}-\mathrm{CT}$ & E-1820 & 174 & Alloy 617 & Plate & Aged-1 & Air & 750 & 5300 & 100 \\
\hline K-BM & $0.5 \mathrm{~T}-\mathrm{CT}$ & E-1820 & 175 & Alloy 617 & Plate & Aged-1 & Air & 750 & 5300 & 950 \\
\hline K-BM & $0.5 \mathrm{~T}-\mathrm{CT}$ & E-1820 & 176 & Alloy 617 & Plate & Aged-1 & Air & 750 & 5300 & 950 \\
\hline K-BM & $0.5 \mathrm{~T}-\mathrm{CT}$ & E-1820 & 177 & Alloy 617 & Plate & Aged-1 & Air & 750 & 5300 & 950 \\
\hline K-BM & $0.5 \mathrm{~T}-\mathrm{CT}$ & E-1820 & 178 & Alloy 617 & Plate & Aged-2 & Air & 750 & 5300 & 0 \\
\hline K-BM & $0.5 \mathrm{~T}-\mathrm{CT}$ & E-1820 & 179 & Alloy 617 & Plate & Aged-2 & Air & 750 & 5300 & 0 \\
\hline K-BM & $0.5 \mathrm{~T}-\mathrm{CT}$ & E-1820 & 180 & Alloy 617 & Plate & Aged-2 & Air & 750 & 5300 & 0 \\
\hline K-BM & $0.5 \mathrm{~T}-\mathrm{CT}$ & E-1820 & 181 & Alloy 617 & Plate & Aged-2 & Air & 750 & 5300 & 100 \\
\hline K-BM & $0.5 \mathrm{~T}-\mathrm{CT}$ & E-1820 & 182 & Alloy 617 & Plate & Aged-2 & Air & 750 & 5300 & 100 \\
\hline K-BM & $0.5 \mathrm{~T}-\mathrm{CT}$ & E-1820 & 183 & Alloy 617 & Plate & Aged-2 & Air & 750 & 5300 & 100 \\
\hline K-BM & $0.5 \mathrm{~T}-\mathrm{CT}$ & E-1820 & 184 & Alloy 617 & Plate & Aged-2 & Air & 750 & 5300 & 950 \\
\hline K-BM & $0.5 \mathrm{~T}-\mathrm{CT}$ & E-1820 & 185 & Alloy 617 & Plate & Aged-2 & Air & 750 & 5300 & 950 \\
\hline K-BM & $0.5 \mathrm{~T}-\mathrm{CT}$ & E-1820 & 186 & Alloy 617 & Plate & Aged-2 & Air & 750 & 5300 & 950 \\
\hline K-BM & $0.5 \mathrm{~T}-\mathrm{CT}$ & E-1820 & 187 & Alloy 617 & Plate & Aged-1 & Air & 1000 & 5300 & 0 \\
\hline K-BM & $0.5 \mathrm{~T}-\mathrm{CT}$ & E-1820 & 188 & Alloy 617 & Plate & Aged-1 & Air & 1000 & 5300 & 0 \\
\hline K-BM & $0.5 \mathrm{~T}-\mathrm{CT}$ & E-1820 & 189 & Alloy 617 & Plate & Aged-1 & Air & 1000 & 5300 & 0 \\
\hline K-BM & $0.5 \mathrm{~T}-\mathrm{CT}$ & E-1820 & 190 & Alloy 617 & Plate & Aged-1 & Air & 1000 & 5300 & 100 \\
\hline K-BM & $0.5 \mathrm{~T}-\mathrm{CT}$ & E-1820 & 191 & Alloy 617 & Plate & Aged-1 & Air & 1000 & 5300 & 100 \\
\hline K-BM & $0.5 \mathrm{~T}-\mathrm{CT}$ & E-1820 & 192 & Alloy 617 & Plate & Aged-1 & Air & 1000 & 5300 & 100 \\
\hline K-BM & $0.5 \mathrm{~T}-\mathrm{CT}$ & E-1820 & 193 & Alloy 617 & Plate & Aged-1 & Air & 1000 & 5300 & 950 \\
\hline K-BM & $0.5 \mathrm{~T}-\mathrm{CT}$ & E-1820 & 194 & Alloy 617 & Plate & Aged-1 & Air & 1000 & 5300 & 950 \\
\hline K-BM & $0.5 \mathrm{~T}-\mathrm{CT}$ & E-1820 & 195 & Alloy 617 & Plate & Aged-1 & Air & 1000 & 5300 & 950 \\
\hline
\end{tabular}


Idaho National Laboratory

\section{NEXT GENERATION NUCLEAR PLANT INTERMEDIATE HEAT EXCHANGER MATERIALS RESEARCH} AND DEVELOPMENT PLAN

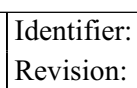

Table A4(a). Aging Effects on Fracture Toughness of Alloy 617 Wrought Metal

\begin{tabular}{|c|c|c|c|c|c|c|c|c|c|c|}
\hline Test Prgm & $\begin{array}{l}\text { Spec. } \\
\text { Type }\end{array}$ & $\begin{array}{c}\text { Test } \\
\text { Method }\end{array}$ & Spec. \# & Material & $\begin{array}{c}\text { Product } \\
\text { Form }\end{array}$ & Heat \# & Env. & $\begin{array}{c}\text { Exposure } \\
\text { Temp. }\left({ }^{\circ} \mathrm{C}\right)\end{array}$ & $\begin{array}{c}\text { Exposure } \\
\text { Time (h) }\end{array}$ & $\begin{array}{c}\text { Test Temp. } \\
\left({ }^{\circ} \mathrm{C}\right)\end{array}$ \\
\hline K-BM & $0.5 \mathrm{~T}-\mathrm{CT}$ & E-1820 & 196 & Alloy 617 & Plate & Aged-2 & Air & 1000 & 5300 & 0 \\
\hline K-BM & $0.5 \mathrm{~T}-\mathrm{CT}$ & E-1820 & 197 & Alloy 617 & Plate & Aged-2 & Air & 1000 & 5300 & 0 \\
\hline K-BM & $0.5 \mathrm{~T}-\mathrm{CT}$ & E-1820 & 198 & Alloy 617 & Plate & Aged-2 & Air & 1000 & 5300 & 0 \\
\hline K-BM & $0.5 \mathrm{~T}-\mathrm{CT}$ & E-1820 & 199 & Alloy 617 & Plate & Aged-2 & Air & 1000 & 5300 & 100 \\
\hline K-BM & $0.5 \mathrm{~T}-\mathrm{CT}$ & E-1820 & 200 & Alloy 617 & Plate & Aged-2 & Air & 1000 & 5300 & 100 \\
\hline K-BM & $0.5 \mathrm{~T}-\mathrm{CT}$ & E-1820 & 201 & Alloy 617 & Plate & Aged-2 & Air & 1000 & 5300 & 100 \\
\hline K-BM & $0.5 \mathrm{~T}-\mathrm{CT}$ & E-1820 & 202 & Alloy 617 & Plate & Aged-2 & Air & 1000 & 5300 & 950 \\
\hline K-BM & $0.5 \mathrm{~T}-\mathrm{CT}$ & E-1820 & 203 & Alloy 617 & Plate & Aged-2 & Air & 1000 & 5300 & 950 \\
\hline K-BM & $0.5 \mathrm{~T}-\mathrm{CT}$ & E-1820 & 204 & Alloy 617 & Plate & Aged-2 & Air & 1000 & 5300 & 950 \\
\hline K-BM & $0.5 \mathrm{~T}-\mathrm{CT}$ & E-1820 & 205 & Alloy 617 & Plate & Aged-1 & Air & 750 & 20000 & 0 \\
\hline K-BM & $0.5 \mathrm{~T}-\mathrm{CT}$ & E-1820 & 206 & Alloy 617 & Plate & Aged-1 & Air & 750 & 20000 & 0 \\
\hline K-BM & $0.5 \mathrm{~T}-\mathrm{CT}$ & E-1820 & 207 & Alloy 617 & Plate & Aged-1 & Air & 750 & 20000 & 0 \\
\hline K-BM & $0.5 \mathrm{~T}-\mathrm{CT}$ & E-1820 & 208 & Alloy 617 & Plate & Aged-1 & Air & 750 & 20000 & 100 \\
\hline K-BM & $0.5 \mathrm{~T}-\mathrm{CT}$ & E-1820 & 209 & Alloy 617 & Plate & Aged-1 & Air & 750 & 20000 & 100 \\
\hline K-BM & $0.5 \mathrm{~T}-\mathrm{CT}$ & E-1820 & 210 & Alloy 617 & Plate & Aged-1 & Air & 750 & 20000 & 100 \\
\hline K-BM & $0.5 \mathrm{~T}-\mathrm{CT}$ & E-1820 & 211 & Alloy 617 & Plate & Aged-1 & Air & 750 & 20000 & 950 \\
\hline K-BM & $0.5 \mathrm{~T}-\mathrm{CT}$ & E-1820 & 212 & Alloy 617 & Plate & Aged-1 & Air & 750 & 20000 & 950 \\
\hline K-BM & $0.5 \mathrm{~T}-\mathrm{CT}$ & E-1820 & 213 & Alloy 617 & Plate & Aged-1 & Air & 750 & 20000 & 950 \\
\hline K-BM & $0.5 \mathrm{~T}-\mathrm{CT}$ & E-1820 & 214 & Alloy 617 & Plate & Aged-2 & Air & 750 & 20000 & 0 \\
\hline K-BM & $0.5 \mathrm{~T}-\mathrm{CT}$ & E-1820 & 215 & Alloy 617 & Plate & Aged-2 & Air & 750 & 20000 & 0 \\
\hline K-BM & $0.5 \mathrm{~T}-\mathrm{CT}$ & E-1820 & 216 & Alloy 617 & Plate & Aged-2 & Air & 750 & 20000 & 0 \\
\hline K-BM & $0.5 \mathrm{~T}-\mathrm{CT}$ & E-1820 & 217 & Alloy 617 & Plate & Aged-2 & Air & 750 & 20000 & 100 \\
\hline K-BM & $0.5 \mathrm{~T}-\mathrm{CT}$ & E-1820 & 218 & Alloy 617 & Plate & Aged-2 & Air & 750 & 20000 & 100 \\
\hline K-BM & $0.5 \mathrm{~T}-\mathrm{CT}$ & E-1820 & 219 & Alloy 617 & Plate & Aged-2 & Air & 750 & 20000 & 100 \\
\hline K-BM & $0.5 \mathrm{~T}-\mathrm{CT}$ & E-1820 & 220 & Alloy 617 & Plate & Aged-2 & Air & 750 & 20000 & 950 \\
\hline K-BM & $0.5 \mathrm{~T}-\mathrm{CT}$ & E-1820 & 221 & Alloy 617 & Plate & Aged-2 & Air & 750 & 20000 & 950 \\
\hline K-BM & $0.5 \mathrm{~T}-\mathrm{CT}$ & E-1820 & 222 & Alloy 617 & Plate & Aged-2 & Air & 750 & 20000 & 950 \\
\hline K-BM & $0.5 \mathrm{~T}-\mathrm{CT}$ & E-1820 & 223 & Alloy 617 & Plate & Aged-1 & Air & 1000 & 20000 & 0 \\
\hline
\end{tabular}


Idaho National Laboratory

\section{NEXT GENERATION NUCLEAR PLANT INTERMEDIATE HEAT EXCHANGER MATERIALS RESEARCH} AND DEVELOPMENT PLAN

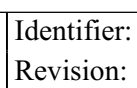

Table A4(a). Aging Effects on Fracture Toughness of Alloy 617 Wrought Metal

\begin{tabular}{|c|c|c|c|c|c|c|c|c|c|c|}
\hline Test Prgm & $\begin{array}{l}\text { Spec. } \\
\text { Type }\end{array}$ & $\begin{array}{c}\text { Test } \\
\text { Method }\end{array}$ & Spec. \# & Material & $\begin{array}{c}\text { Product } \\
\text { Form }\end{array}$ & Heat \# & Env. & $\begin{array}{c}\text { Exposure } \\
\text { Temp. }\left({ }^{\circ} \mathrm{C}\right)\end{array}$ & $\begin{array}{c}\text { Exposure } \\
\text { Time (h) }\end{array}$ & $\begin{array}{c}\text { Test Temp. } \\
\left({ }^{\circ} \mathrm{C}\right)\end{array}$ \\
\hline K-BM & $0.5 \mathrm{~T}-\mathrm{CT}$ & E-1820 & 224 & Alloy 617 & Plate & Aged-1 & Air & 1000 & 20000 & 0 \\
\hline K-BM & $0.5 \mathrm{~T}-\mathrm{CT}$ & E-1820 & 225 & Alloy 617 & Plate & Aged-1 & Air & 1000 & 20000 & 0 \\
\hline K-BM & $0.5 \mathrm{~T}-\mathrm{CT}$ & E-1820 & 226 & Alloy 617 & Plate & Aged-1 & Air & 1000 & 20000 & 100 \\
\hline K-BM & $0.5 \mathrm{~T}-\mathrm{CT}$ & E-1820 & 227 & Alloy 617 & Plate & Aged-1 & Air & 1000 & 20000 & 100 \\
\hline K-BM & $0.5 \mathrm{~T}-\mathrm{CT}$ & E-1820 & 228 & Alloy 617 & Plate & Aged-1 & Air & 1000 & 20000 & 100 \\
\hline K-BM & $0.5 \mathrm{~T}-\mathrm{CT}$ & E-1820 & 229 & Alloy 617 & Plate & Aged-1 & Air & 1000 & 20000 & 950 \\
\hline K-BM & $0.5 \mathrm{~T}-\mathrm{CT}$ & E-1820 & 230 & Alloy 617 & Plate & Aged-1 & Air & 1000 & 20000 & 950 \\
\hline K-BM & $0.5 \mathrm{~T}-\mathrm{CT}$ & E-1820 & 231 & Alloy 617 & Plate & Aged-1 & Air & 1000 & 20000 & 950 \\
\hline K-BM & $0.5 \mathrm{~T}-\mathrm{CT}$ & E-1820 & 232 & Alloy 617 & Plate & Aged-2 & Air & 1000 & 20000 & 0 \\
\hline K-BM & $0.5 \mathrm{~T}-\mathrm{CT}$ & E-1820 & 233 & Alloy 617 & Plate & Aged-2 & Air & 1000 & 20000 & 0 \\
\hline K-BM & $0.5 \mathrm{~T}-\mathrm{CT}$ & E-1820 & 234 & Alloy 617 & Plate & Aged-2 & Air & 1000 & 20000 & 0 \\
\hline K-BM & $0.5 \mathrm{~T}-\mathrm{CT}$ & E- 1820 & 235 & Alloy 617 & Plate & Aged-2 & Air & 1000 & 20000 & 100 \\
\hline K-BM & $0.5 \mathrm{~T}-\mathrm{CT}$ & E-1820 & 236 & Alloy 617 & Plate & Aged-2 & Air & 1000 & 20000 & 100 \\
\hline K-BM & $0.5 \mathrm{~T}-\mathrm{CT}$ & E-1820 & 237 & Alloy 617 & Plate & Aged-2 & Air & 1000 & 20000 & 100 \\
\hline K-BM & $0.5 \mathrm{~T}-\mathrm{CT}$ & E-1820 & 238 & Alloy 617 & Plate & Aged-2 & Air & 1000 & 20000 & 950 \\
\hline K-BM & $0.5 \mathrm{~T}-\mathrm{CT}$ & E-1820 & 239 & Alloy 617 & Plate & Aged-2 & Air & 1000 & 20000 & 950 \\
\hline K-BM & $0.5 \mathrm{~T}-\mathrm{CT}$ & E-1820 & 240 & Alloy 617 & Plate & Aged-2 & Air & 1000 & 20000 & 950 \\
\hline K-BM-QUAL & $0.5 \mathrm{~T}-\mathrm{CT}$ & E-1820 & 241 & Alloy 617 & Plate & Aged-1 & Air & 750 & 32000 & 0 \\
\hline K-BM-QUAL & $0.5 \mathrm{~T}-\mathrm{CT}$ & E-1820 & 242 & Alloy 617 & Plate & Aged-1 & Air & 750 & 32000 & 0 \\
\hline K-BM-QUAL & $0.5 \mathrm{~T}-\mathrm{CT}$ & E-1820 & 243 & Alloy 617 & Plate & Aged-1 & Air & 750 & 32000 & 0 \\
\hline K-BM-QUAL & $0.5 \mathrm{~T}-\mathrm{CT}$ & E-1820 & 244 & Alloy 617 & Plate & Aged-1 & Air & 750 & 32000 & 100 \\
\hline K-BM-QUAL & $0.5 \mathrm{~T}-\mathrm{CT}$ & E-1820 & 245 & Alloy 617 & Plate & Aged-1 & Air & 750 & 32000 & 100 \\
\hline K-BM-QUAL & $0.5 \mathrm{~T}-\mathrm{CT}$ & E-1820 & 246 & Alloy 617 & Plate & Aged-1 & Air & 750 & 32000 & 100 \\
\hline K-BM-QUAL & $0.5 \mathrm{~T}-\mathrm{CT}$ & E-1820 & 247 & Alloy 617 & Plate & Aged-1 & Air & 750 & 32000 & 950 \\
\hline K-BM-QUAL & $0.5 \mathrm{~T}-\mathrm{CT}$ & E-1820 & 248 & Alloy 617 & Plate & Aged-1 & Air & 750 & 32000 & 950 \\
\hline K-BM-QUAL & $0.5 \mathrm{~T}-\mathrm{CT}$ & E-1820 & 249 & Alloy 617 & Plate & Aged-1 & Air & 750 & 32000 & 950 \\
\hline K-BM-QUAL & $0.5 \mathrm{~T}-\mathrm{CT}$ & E-1820 & 250 & Alloy 617 & Plate & Aged-2 & Air & 750 & 32000 & 0 \\
\hline K-BM-QUAL & $0.5 \mathrm{~T}-\mathrm{CT}$ & E-1820 & 251 & Alloy 617 & Plate & Aged-2 & Air & 750 & 32000 & 0 \\
\hline
\end{tabular}


Idaho National Laboratory

\section{NEXT GENERATION NUCLEAR PLANT INTERMEDIATE HEAT EXCHANGER MATERIALS RESEARCH} AND DEVELOPMENT PLAN

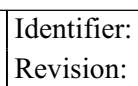

Table A4(a). Aging Effects on Fracture Toughness of Alloy 617 Wrought Metal

\begin{tabular}{|c|c|c|c|c|c|c|c|c|c|c|}
\hline Test Prgm & $\begin{array}{l}\text { Spec. } \\
\text { Type }\end{array}$ & $\begin{array}{c}\text { Test } \\
\text { Method }\end{array}$ & Spec. \# & Material & $\begin{array}{l}\text { Product } \\
\text { Form }\end{array}$ & Heat \# & Env. & $\begin{array}{c}\text { Exposure } \\
\text { Temp. }\left({ }^{\circ} \mathrm{C}\right)\end{array}$ & $\begin{array}{c}\text { Exposure } \\
\text { Time (h) }\end{array}$ & $\begin{array}{c}\text { Test Temp. } \\
\left({ }^{\circ} \mathrm{C}\right)\end{array}$ \\
\hline K-BM-QUAL & $0.5 \mathrm{~T}-\mathrm{CT}$ & E-1820 & 252 & Alloy 617 & Plate & Aged-2 & Air & 750 & 32000 & 0 \\
\hline K-BM-QUAL & $0.5 \mathrm{~T}-\mathrm{CT}$ & E-1820 & 253 & Alloy 617 & Plate & Aged-2 & Air & 750 & 32000 & 100 \\
\hline K-BM-QUAL & $0.5 \mathrm{~T}-\mathrm{CT}$ & E-1820 & 254 & Alloy 617 & Plate & Aged-2 & Air & 750 & 32000 & 100 \\
\hline K-BM-QUAL & $0.5 \mathrm{~T}-\mathrm{CT}$ & E-1820 & 255 & Alloy 617 & Plate & Aged-2 & Air & 750 & 32000 & 100 \\
\hline K-BM-QUAL & $0.5 \mathrm{~T}-\mathrm{CT}$ & E-1820 & 256 & Alloy 617 & Plate & Aged-2 & Air & 750 & 32000 & 950 \\
\hline K-BM-QUAL & $0.5 \mathrm{~T}-\mathrm{CT}$ & E-1820 & 257 & Alloy 617 & Plate & Aged-2 & Air & 750 & 32000 & 950 \\
\hline K-BM-QUAL & $0.5 \mathrm{~T}-\mathrm{CT}$ & E-1820 & 258 & Alloy 617 & Plate & Aged-2 & Air & 750 & 32000 & 950 \\
\hline K-BM-QUAL & $0.5 \mathrm{~T}-\mathrm{CT}$ & E-1820 & 259 & Alloy 617 & Plate & Aged-1 & Air & 1000 & 32000 & 0 \\
\hline K-BM-QUAL & $0.5 \mathrm{~T}-\mathrm{CT}$ & E-1820 & 260 & Alloy 617 & Plate & Aged-1 & Air & 1000 & 32000 & 0 \\
\hline K-BM-QUAL & $0.5 \mathrm{~T}-\mathrm{CT}$ & E-1820 & 261 & Alloy 617 & Plate & Aged-1 & Air & 1000 & 32000 & 0 \\
\hline K-BM-QUAL & $0.5 \mathrm{~T}-\mathrm{CT}$ & E-1820 & 262 & Alloy 617 & Plate & Aged-1 & Air & 1000 & 32000 & 100 \\
\hline K-BM-QUAL & $0.5 \mathrm{~T}-\mathrm{CT}$ & E-1820 & 263 & Alloy 617 & Plate & Aged-1 & Air & 1000 & 32000 & 100 \\
\hline K-BM-QUAL & $0.5 \mathrm{~T}-\mathrm{CT}$ & E-1820 & 264 & Alloy 617 & Plate & Aged-1 & Air & 1000 & 32000 & 100 \\
\hline K-BM-QUAL & $0.5 \mathrm{~T}-\mathrm{CT}$ & E-1820 & 265 & Alloy 617 & Plate & Aged-1 & Air & 1000 & 32000 & 950 \\
\hline K-BM-QUAL & $0.5 \mathrm{~T}-\mathrm{CT}$ & E-1820 & 266 & Alloy 617 & Plate & Aged-1 & Air & 1000 & 32000 & 950 \\
\hline K-BM-QUAL & $0.5 \mathrm{~T}-\mathrm{CT}$ & E-1820 & 267 & Alloy 617 & Plate & Aged-1 & Air & 1000 & 32000 & 950 \\
\hline K-BM-QUAL & $0.5 \mathrm{~T}-\mathrm{CT}$ & E-1820 & 268 & Alloy 617 & Plate & Aged-2 & Air & 1000 & 32000 & 0 \\
\hline K-BM-QUAL & $0.5 \mathrm{~T}-\mathrm{CT}$ & E-1820 & 269 & Alloy 617 & Plate & Aged-2 & Air & 1000 & 32000 & 0 \\
\hline K-BM-QUAL & $0.5 \mathrm{~T}-\mathrm{CT}$ & E-1820 & 270 & Alloy 617 & Plate & Aged-2 & Air & 1000 & 32000 & 0 \\
\hline K-BM-QUAL & $0.5 \mathrm{~T}-\mathrm{CT}$ & E-1820 & 271 & Alloy 617 & Plate & Aged-2 & Air & 1000 & 32000 & 100 \\
\hline K-BM-QUAL & $0.5 \mathrm{~T}-\mathrm{CT}$ & E-1820 & 272 & Alloy 617 & Plate & Aged-2 & Air & 1000 & 32000 & 100 \\
\hline K-BM-QUAL & $0.5 \mathrm{~T}-\mathrm{CT}$ & E-1820 & 273 & Alloy 617 & Plate & Aged-2 & Air & 1000 & 32000 & 100 \\
\hline K-BM-QUAL & $0.5 \mathrm{~T}-\mathrm{CT}$ & E-1820 & 274 & Alloy 617 & Plate & Aged-2 & Air & 1000 & 32000 & 950 \\
\hline K-BM-QUAL & $0.5 \mathrm{~T}-\mathrm{CT}$ & E-1820 & 275 & Alloy 617 & Plate & Aged-2 & Air & 1000 & 32000 & 950 \\
\hline K-BM-QUAL & $0.5 \mathrm{~T}-\mathrm{CT}$ & E-1820 & 276 & Alloy 617 & Plate & Aged-2 & Air & 1000 & 32000 & 950 \\
\hline K-BM-QUAL & $0.5 \mathrm{~T}-\mathrm{CT}$ & E-1820 & 277 & Alloy 617 & Plate & Aged-1 & Air & 750 & 50000 & 0 \\
\hline K-BM-QUAL & $0.5 \mathrm{~T}-\mathrm{CT}$ & E-1820 & 278 & Alloy 617 & Plate & Aged-1 & Air & 750 & 50000 & 0 \\
\hline K-BM-QUAL & $0.5 \mathrm{~T}-\mathrm{CT}$ & E-1820 & 279 & Alloy 617 & Plate & Aged-1 & Air & 750 & 50000 & 0 \\
\hline
\end{tabular}


Idaho National Laboratory

\section{NEXT GENERATION NUCLEAR PLANT INTERMEDIATE HEAT EXCHANGER MATERIALS RESEARCH} AND DEVELOPMENT PLAN

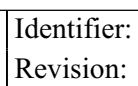

Table A4(a). Aging Effects on Fracture Toughness of Alloy 617 Wrought Metal

\begin{tabular}{|c|c|c|c|c|c|c|c|c|c|c|}
\hline Test Prgm & $\begin{array}{l}\text { Spec. } \\
\text { Type }\end{array}$ & $\begin{array}{c}\text { Test } \\
\text { Method }\end{array}$ & Spec. \# & Material & $\begin{array}{l}\text { Product } \\
\text { Form }\end{array}$ & Heat \# & Env. & $\begin{array}{c}\text { Exposure } \\
\text { Temp. }\left({ }^{\circ} \mathrm{C}\right)\end{array}$ & $\begin{array}{c}\text { Exposure } \\
\text { Time (h) }\end{array}$ & $\begin{array}{c}\text { Test Temp. } \\
\left({ }^{\circ} \mathrm{C}\right)\end{array}$ \\
\hline K-BM-QUAL & $0.5 \mathrm{~T}-\mathrm{CT}$ & E-1820 & 280 & Alloy 617 & Plate & Aged-1 & Air & 750 & 50000 & 100 \\
\hline K-BM-QUAL & $0.5 \mathrm{~T}-\mathrm{CT}$ & E-1820 & 281 & Alloy 617 & Plate & Aged-1 & Air & 750 & 50000 & 100 \\
\hline K-BM-QUAL & $0.5 \mathrm{~T}-\mathrm{CT}$ & E-1820 & 282 & Alloy 617 & Plate & Aged-1 & Air & 750 & 50000 & 100 \\
\hline K-BM-QUAL & $0.5 \mathrm{~T}-\mathrm{CT}$ & E-1820 & 283 & Alloy 617 & Plate & Aged-1 & Air & 750 & 50000 & 950 \\
\hline K-BM-QUAL & $0.5 \mathrm{~T}-\mathrm{CT}$ & E-1820 & 284 & Alloy 617 & Plate & Aged-1 & Air & 750 & 50000 & 950 \\
\hline K-BM-QUAL & $0.5 \mathrm{~T}-\mathrm{CT}$ & E-1820 & 285 & Alloy 617 & Plate & Aged-1 & Air & 750 & 50000 & 950 \\
\hline K-BM-QUAL & $0.5 \mathrm{~T}-\mathrm{CT}$ & E-1820 & 286 & Alloy 617 & Plate & Aged-2 & Air & 750 & 50000 & 0 \\
\hline K-BM-QUAL & $0.5 \mathrm{~T}-\mathrm{CT}$ & E-1820 & 287 & Alloy 617 & Plate & Aged-2 & Air & 750 & 50000 & 0 \\
\hline K-BM-QUAL & $0.5 \mathrm{~T}-\mathrm{CT}$ & E-1820 & 288 & Alloy 617 & Plate & Aged-2 & Air & 750 & 50000 & 0 \\
\hline K-BM-QUAL & $0.5 \mathrm{~T}-\mathrm{CT}$ & E-1820 & 289 & Alloy 617 & Plate & Aged-2 & Air & 750 & 50000 & 100 \\
\hline K-BM-QUAL & $0.5 \mathrm{~T}-\mathrm{CT}$ & E-1820 & 290 & Alloy 617 & Plate & Aged-2 & Air & 750 & 50000 & 100 \\
\hline K-BM-QUAL & $0.5 \mathrm{~T}-\mathrm{CT}$ & E-1820 & 291 & Alloy 617 & Plate & Aged-2 & Air & 750 & 50000 & 100 \\
\hline K-BM-QUAL & $0.5 \mathrm{~T}-\mathrm{CT}$ & E-1820 & 292 & Alloy 617 & Plate & Aged-2 & Air & 750 & 50000 & 950 \\
\hline K-BM-QUAL & $0.5 \mathrm{~T}-\mathrm{CT}$ & E-1820 & 293 & Alloy 617 & Plate & Aged-2 & Air & 750 & 50000 & 950 \\
\hline K-BM-QUAL & $0.5 \mathrm{~T}-\mathrm{CT}$ & E-1820 & 294 & Alloy 617 & Plate & Aged-2 & Air & 750 & 50000 & 950 \\
\hline K-BM-QUAL & $0.5 \mathrm{~T}-\mathrm{CT}$ & E-1820 & 295 & Alloy 617 & Plate & Aged-1 & Air & 1000 & 50000 & 0 \\
\hline K-BM-QUAL & $0.5 \mathrm{~T}-\mathrm{CT}$ & E-1820 & 296 & Alloy 617 & Plate & Aged-1 & Air & 1000 & 50000 & 0 \\
\hline K-BM-QUAL & $0.5 \mathrm{~T}-\mathrm{CT}$ & E-1820 & 297 & Alloy 617 & Plate & Aged-1 & Air & 1000 & 50000 & 0 \\
\hline K-BM-QUAL & $0.5 \mathrm{~T}-\mathrm{CT}$ & E-1820 & 298 & Alloy 617 & Plate & Aged-1 & Air & 1000 & 50000 & 100 \\
\hline K-BM-QUAL & $0.5 \mathrm{~T}-\mathrm{CT}$ & E-1820 & 299 & Alloy 617 & Plate & Aged-1 & Air & 1000 & 50000 & 100 \\
\hline K-BM-QUAL & $0.5 \mathrm{~T}-\mathrm{CT}$ & E-1820 & 300 & Alloy 617 & Plate & Aged-1 & Air & 1000 & 50000 & 100 \\
\hline K-BM-QUAL & $0.5 \mathrm{~T}-\mathrm{CT}$ & E-1820 & 301 & Alloy 617 & Plate & Aged-1 & Air & 1000 & 50000 & 950 \\
\hline K-BM-QUAL & $0.5 \mathrm{~T}-\mathrm{CT}$ & E-1820 & 302 & Alloy 617 & Plate & Aged-1 & Air & 1000 & 50000 & 950 \\
\hline K-BM-QUAL & $0.5 \mathrm{~T}-\mathrm{CT}$ & E-1820 & 303 & Alloy 617 & Plate & Aged-1 & Air & 1000 & 50000 & 950 \\
\hline K-BM-QUAL & $0.5 \mathrm{~T}-\mathrm{CT}$ & E-1820 & 304 & Alloy 617 & Plate & Aged-2 & Air & 1000 & 50000 & 0 \\
\hline K-BM-QUAL & $0.5 \mathrm{~T}-\mathrm{CT}$ & E-1820 & 305 & Alloy 617 & Plate & Aged-2 & Air & 1000 & 50000 & 0 \\
\hline K-BM-QUAL & $0.5 \mathrm{~T}-\mathrm{CT}$ & E-1820 & 306 & Alloy 617 & Plate & Aged-2 & Air & 1000 & 50000 & 0 \\
\hline K-BM-QUAL & $0.5 \mathrm{~T}-\mathrm{CT}$ & E-1820 & 307 & Alloy 617 & Plate & Aged-2 & Air & 1000 & 50000 & 100 \\
\hline
\end{tabular}


Idaho National Laboratory

\section{NEXT GENERATION NUCLEAR PLANT INTERMEDIATE HEAT EXCHANGER MATERIALS RESEARCH} AND DEVELOPMENT PLAN

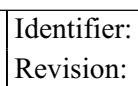

Table A4(a). Aging Effects on Fracture Toughness of Alloy 617 Wrought Metal

\begin{tabular}{|c|c|c|c|c|c|c|c|c|c|c|}
\hline Test Prgm & $\begin{array}{l}\text { Spec. } \\
\text { Type }\end{array}$ & $\begin{array}{c}\text { Test } \\
\text { Method }\end{array}$ & Spec. \# & Material & $\begin{array}{l}\text { Product } \\
\text { Form }\end{array}$ & Heat \# & Env. & $\begin{array}{c}\text { Exposure } \\
\text { Temp. }\left({ }^{\circ} \mathrm{C}\right)\end{array}$ & $\begin{array}{c}\text { Exposure } \\
\text { Time (h) }\end{array}$ & $\begin{array}{c}\text { Test Temp. } \\
\left({ }^{\circ} \mathrm{C}\right)\end{array}$ \\
\hline K-BM-QUAL & $0.5 \mathrm{~T}-\mathrm{CT}$ & E-1820 & 308 & Alloy 617 & Plate & Aged-2 & Air & 1000 & 50000 & 100 \\
\hline K-BM-QUAL & $0.5 \mathrm{~T}-\mathrm{CT}$ & E-1820 & 309 & Alloy 617 & Plate & Aged-2 & Air & 1000 & 50000 & 100 \\
\hline K-BM-QUAL & $0.5 \mathrm{~T}-\mathrm{CT}$ & E-1820 & 310 & Alloy 617 & Plate & Aged-2 & Air & 1000 & 50000 & 950 \\
\hline K-BM-QUAL & $0.5 \mathrm{~T}-\mathrm{CT}$ & E-1820 & 311 & Alloy 617 & Plate & Aged-2 & Air & 1000 & 50000 & 950 \\
\hline K-BM-QUAL & $0.5 \mathrm{~T}-\mathrm{CT}$ & E-1820 & 312 & Alloy 617 & Plate & Aged-2 & Air & 1000 & 50000 & 950 \\
\hline K-BM-QUAL & $0.5 \mathrm{~T}-\mathrm{CT}$ & E-1820 & 313 & Alloy 617 & Plate & Aged-1 & Air & 750 & 76000 & 0 \\
\hline K-BM-QUAL & $0.5 \mathrm{~T}-\mathrm{CT}$ & E-1820 & 314 & Alloy 617 & Plate & Aged-1 & Air & 750 & 76000 & 0 \\
\hline K-BM-QUAL & $0.5 \mathrm{~T}-\mathrm{CT}$ & E-1820 & 315 & Alloy 617 & Plate & Aged-1 & Air & 750 & 76000 & 0 \\
\hline K-BM-QUAL & $0.5 \mathrm{~T}-\mathrm{CT}$ & E-1820 & 316 & Alloy 617 & Plate & Aged-1 & Air & 750 & 76000 & 100 \\
\hline K-BM-QUAL & $0.5 \mathrm{~T}-\mathrm{CT}$ & E-1820 & 317 & Alloy 617 & Plate & Aged-1 & Air & 750 & 76000 & 100 \\
\hline K-BM-QUAL & $0.5 \mathrm{~T}-\mathrm{CT}$ & E-1820 & 318 & Alloy 617 & Plate & Aged-1 & Air & 750 & 76000 & 100 \\
\hline K-BM-QUAL & $0.5 \mathrm{~T}-\mathrm{CT}$ & E-1820 & 319 & Alloy 617 & Plate & Aged-1 & Air & 750 & 76000 & 950 \\
\hline K-BM-QUAL & $0.5 \mathrm{~T}-\mathrm{CT}$ & E-1820 & 320 & Alloy 617 & Plate & Aged-1 & Air & 750 & 76000 & 950 \\
\hline K-BM-QUAL & $0.5 \mathrm{~T}-\mathrm{CT}$ & E-1820 & 321 & Alloy 617 & Plate & Aged-1 & Air & 750 & 76000 & 950 \\
\hline K-BM-QUAL & $0.5 \mathrm{~T}-\mathrm{CT}$ & E-1820 & 322 & Alloy 617 & Plate & Aged-2 & Air & 750 & 76000 & 0 \\
\hline K-BM-QUAL & $0.5 \mathrm{~T}-\mathrm{CT}$ & E-1820 & 323 & Alloy 617 & Plate & Aged-2 & Air & 750 & 76000 & 0 \\
\hline K-BM-QUAL & $0.5 \mathrm{~T}-\mathrm{CT}$ & E-1820 & 324 & Alloy 617 & Plate & Aged-2 & Air & 750 & 76000 & 0 \\
\hline K-BM-QUAL & $0.5 \mathrm{~T}-\mathrm{CT}$ & E-1820 & 325 & Alloy 617 & Plate & Aged-2 & Air & 750 & 76000 & 100 \\
\hline K-BM-QUAL & $0.5 \mathrm{~T}-\mathrm{CT}$ & E-1820 & 326 & Alloy 617 & Plate & Aged-2 & Air & 750 & 76000 & 100 \\
\hline K-BM-QUAL & $0.5 \mathrm{~T}-\mathrm{CT}$ & E-1820 & 327 & Alloy 617 & Plate & Aged-2 & Air & 750 & 76000 & 100 \\
\hline K-BM-QUAL & $0.5 \mathrm{~T}-\mathrm{CT}$ & E-1820 & 328 & Alloy 617 & Plate & Aged-2 & Air & 750 & 76000 & 950 \\
\hline K-BM-QUAL & $0.5 \mathrm{~T}-\mathrm{CT}$ & E-1820 & 329 & Alloy 617 & Plate & Aged-2 & Air & 750 & 76000 & 950 \\
\hline K-BM-QUAL & $0.5 \mathrm{~T}-\mathrm{CT}$ & E-1820 & 330 & Alloy 617 & Plate & Aged-2 & Air & 750 & 76000 & 950 \\
\hline K-BM-QUAL & $0.5 \mathrm{~T}-\mathrm{CT}$ & E-1820 & 331 & Alloy 617 & Plate & Aged-1 & Air & 1000 & 76000 & 0 \\
\hline K-BM-QUAL & $0.5 \mathrm{~T}-\mathrm{CT}$ & E-1820 & 332 & Alloy 617 & Plate & Aged-1 & Air & 1000 & 76000 & 0 \\
\hline K-BM-QUAL & $0.5 \mathrm{~T}-\mathrm{CT}$ & E-1820 & 333 & Alloy 617 & Plate & Aged-1 & Air & 1000 & 76000 & 0 \\
\hline K-BM-QUAL & $0.5 \mathrm{~T}-\mathrm{CT}$ & E-1820 & 334 & Alloy 617 & Plate & Aged-1 & Air & 1000 & 76000 & 100 \\
\hline K-BM-QUAL & $0.5 \mathrm{~T}-\mathrm{CT}$ & E-1820 & 335 & Alloy 617 & Plate & Aged-1 & Air & 1000 & 76000 & 100 \\
\hline
\end{tabular}


Idaho National Laboratory

\section{NEXT GENERATION NUCLEAR PLANT INTERMEDIATE HEAT EXCHANGER MATERIALS RESEARCH} AND DEVELOPMENT PLAN

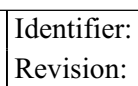

Table A4(a). Aging Effects on Fracture Toughness of Alloy 617 Wrought Metal

\begin{tabular}{|c|c|c|c|c|c|c|c|c|c|c|}
\hline Test Prgm & $\begin{array}{l}\text { Spec. } \\
\text { Type }\end{array}$ & $\begin{array}{c}\text { Test } \\
\text { Method }\end{array}$ & Spec. \# & Material & $\begin{array}{l}\text { Product } \\
\text { Form }\end{array}$ & Heat \# & Env. & $\begin{array}{c}\text { Exposure } \\
\text { Temp. }\left({ }^{\circ} \mathrm{C}\right)\end{array}$ & $\begin{array}{c}\text { Exposure } \\
\text { Time (h) }\end{array}$ & $\begin{array}{c}\text { Test Temp. } \\
\left({ }^{\circ} \mathrm{C}\right)\end{array}$ \\
\hline K-BM-QUAL & $0.5 \mathrm{~T}-\mathrm{CT}$ & E-1820 & 336 & Alloy 617 & Plate & Aged-1 & Air & 1000 & 76000 & 100 \\
\hline K-BM-QUAL & $0.5 \mathrm{~T}-\mathrm{CT}$ & E-1820 & 337 & Alloy 617 & Plate & Aged-1 & Air & 1000 & 76000 & 950 \\
\hline K-BM-QUAL & $0.5 \mathrm{~T}-\mathrm{CT}$ & E-1820 & 338 & Alloy 617 & Plate & Aged-1 & Air & 1000 & 76000 & 950 \\
\hline K-BM-QUAL & $0.5 \mathrm{~T}-\mathrm{CT}$ & E-1820 & 339 & Alloy 617 & Plate & Aged-1 & Air & 1000 & 76000 & 950 \\
\hline K-BM-QUAL & $0.5 \mathrm{~T}-\mathrm{CT}$ & E-1820 & 340 & Alloy 617 & Plate & Aged-2 & Air & 1000 & 76000 & 0 \\
\hline K-BM-QUAL & $0.5 \mathrm{~T}-\mathrm{CT}$ & E-1820 & 341 & Alloy 617 & Plate & Aged-2 & Air & 1000 & 76000 & 0 \\
\hline K-BM-QUAL & $0.5 \mathrm{~T}-\mathrm{CT}$ & E-1820 & 342 & Alloy 617 & Plate & Aged-2 & Air & 1000 & 76000 & 0 \\
\hline K-BM-QUAL & $0.5 \mathrm{~T}-\mathrm{CT}$ & E-1820 & 343 & Alloy 617 & Plate & Aged-2 & Air & 1000 & 76000 & 100 \\
\hline K-BM-QUAL & $0.5 \mathrm{~T}-\mathrm{CT}$ & E-1820 & 344 & Alloy 617 & Plate & Aged-2 & Air & 1000 & 76000 & 100 \\
\hline K-BM-QUAL & $0.5 \mathrm{~T}-\mathrm{CT}$ & E-1820 & 345 & Alloy 617 & Plate & Aged-2 & Air & 1000 & 76000 & 100 \\
\hline K-BM-QUAL & $0.5 \mathrm{~T}-\mathrm{CT}$ & E-1820 & 346 & Alloy 617 & Plate & Aged-2 & Air & 1000 & 76000 & 950 \\
\hline K-BM-QUAL & $0.5 \mathrm{~T}-\mathrm{CT}$ & E-1820 & 347 & Alloy 617 & Plate & Aged-2 & Air & 1000 & 76000 & 950 \\
\hline K-BM-QUAL & $0.5 \mathrm{~T}-\mathrm{CT}$ & E-1820 & 348 & Alloy 617 & Plate & Aged-2 & Air & 1000 & 76000 & 950 \\
\hline K-BM-QUAL & $0.5 \mathrm{~T}-\mathrm{CT}$ & E-1820 & 349 & Alloy 617 & Plate & Aged-1 & Air & 750 & 120000 & 0 \\
\hline K-BM-QUAL & $0.5 \mathrm{~T}-\mathrm{CT}$ & E-1820 & 350 & Alloy 617 & Plate & Aged-1 & Air & 750 & 120000 & 0 \\
\hline K-BM-QUAL & $0.5 \mathrm{~T}-\mathrm{CT}$ & E-1820 & 351 & Alloy 617 & Plate & Aged-1 & Air & 750 & 120000 & 0 \\
\hline K-BM-QUAL & $0.5 \mathrm{~T}-\mathrm{CT}$ & E-1820 & 352 & Alloy 617 & Plate & Aged-1 & Air & 750 & 120000 & 100 \\
\hline K-BM-QUAL & $0.5 \mathrm{~T}-\mathrm{CT}$ & E-1820 & 353 & Alloy 617 & Plate & Aged-1 & Air & 750 & 120000 & 100 \\
\hline K-BM-QUAL & $0.5 \mathrm{~T}-\mathrm{CT}$ & E-1820 & 354 & Alloy 617 & Plate & Aged-1 & Air & 750 & 120000 & 100 \\
\hline K-BM-QUAL & $0.5 \mathrm{~T}-\mathrm{CT}$ & E-1820 & 355 & Alloy 617 & Plate & Aged-1 & Air & 750 & 120000 & 950 \\
\hline K-BM-QUAL & $0.5 \mathrm{~T}-\mathrm{CT}$ & E-1820 & 356 & Alloy 617 & Plate & Aged-1 & Air & 750 & 120000 & 950 \\
\hline K-BM-QUAL & $0.5 \mathrm{~T}-\mathrm{CT}$ & E-1820 & 357 & Alloy 617 & Plate & Aged-1 & Air & 750 & 120000 & 950 \\
\hline K-BM-QUAL & $0.5 \mathrm{~T}-\mathrm{CT}$ & E-1820 & 358 & Alloy 617 & Plate & Aged-2 & Air & 750 & 120000 & 0 \\
\hline K-BM-QUAL & $0.5 \mathrm{~T}-\mathrm{CT}$ & E-1820 & 359 & Alloy 617 & Plate & Aged-2 & Air & 750 & 120000 & 0 \\
\hline K-BM-QUAL & $0.5 \mathrm{~T}-\mathrm{CT}$ & E-1820 & 360 & Alloy 617 & Plate & Aged-2 & Air & 750 & 120000 & 0 \\
\hline K-BM-QUAL & $0.5 \mathrm{~T}-\mathrm{CT}$ & E-1820 & 361 & Alloy 617 & Plate & Aged-2 & Air & 750 & 120000 & 100 \\
\hline K-BM-QUAL & $0.5 \mathrm{~T}-\mathrm{CT}$ & E-1820 & 362 & Alloy 617 & Plate & Aged-2 & Air & 750 & 120000 & 100 \\
\hline K-BM-QUAL & $0.5 \mathrm{~T}-\mathrm{CT}$ & E-1820 & 363 & Alloy 617 & Plate & Aged-2 & Air & 750 & 120000 & 100 \\
\hline
\end{tabular}


Idaho National Laboratory

NEXT GENERATION NUCLEAR PLANT INTERMEDIATE HEAT EXCHANGER

MATERIALS RESEARCH

AND DEVELOPMENT PLAN
Identifier:

Revision:

Effective Date: $\quad 04 / 30 / 08 \quad$ Page: A-26 of A-114

Table A4(a). Aging Effects on Fracture Toughness of Alloy 617 Wrought Metal

\begin{tabular}{|c|c|c|c|c|c|c|c|c|c|c|}
\hline Test Prgm & $\begin{array}{l}\text { Spec. } \\
\text { Type }\end{array}$ & $\begin{array}{c}\text { Test } \\
\text { Method }\end{array}$ & Spec. \# & Material & $\begin{array}{c}\text { Product } \\
\text { Form }\end{array}$ & Heat \# & Env. & $\begin{array}{c}\text { Exposure } \\
\text { Temp. }\left({ }^{\circ} \mathrm{C}\right)\end{array}$ & $\begin{array}{c}\text { Exposure } \\
\text { Time (h) }\end{array}$ & $\begin{array}{c}\text { Test Temp. } \\
\left({ }^{\circ} \mathrm{C}\right)\end{array}$ \\
\hline K-BM-QUAL & $0.5 \mathrm{~T}-\mathrm{CT}$ & E-1820 & 364 & Alloy 617 & Plate & Aged-2 & Air & 750 & 120000 & 950 \\
\hline K-BM-QUAL & $0.5 \mathrm{~T}-\mathrm{CT}$ & E-1820 & 365 & Alloy 617 & Plate & Aged-2 & Air & 750 & 120000 & 950 \\
\hline K-BM-QUAL & $0.5 \mathrm{~T}-\mathrm{CT}$ & E-1820 & 366 & Alloy 617 & Plate & Aged-2 & Air & 750 & 120000 & 950 \\
\hline K-BM-QUAL & $0.5 \mathrm{~T}-\mathrm{CT}$ & E-1820 & 367 & Alloy 617 & Plate & Aged-1 & Air & 1000 & 120000 & 0 \\
\hline K-BM-QUAL & $0.5 \mathrm{~T}-\mathrm{CT}$ & E-1820 & 368 & Alloy 617 & Plate & Aged-1 & Air & 1000 & 120000 & 0 \\
\hline K-BM-QUAL & $0.5 \mathrm{~T}-\mathrm{CT}$ & E-1820 & 369 & Alloy 617 & Plate & Aged-1 & Air & 1000 & 120000 & 0 \\
\hline K-BM-QUAL & $0.5 \mathrm{~T}-\mathrm{CT}$ & E-1820 & 370 & Alloy 617 & Plate & Aged-1 & Air & 1000 & 120000 & 100 \\
\hline K-BM-QUAL & $0.5 \mathrm{~T}-\mathrm{CT}$ & E-1820 & 371 & Alloy 617 & Plate & Aged-1 & Air & 1000 & 120000 & 100 \\
\hline K-BM-QUAL & $0.5 \mathrm{~T}-\mathrm{CT}$ & E-1820 & 372 & Alloy 617 & Plate & Aged-1 & Air & 1000 & 120000 & 100 \\
\hline K-BM-QUAL & $0.5 \mathrm{~T}-\mathrm{CT}$ & E-1820 & 373 & Alloy 617 & Plate & Aged-1 & Air & 1000 & 120000 & 950 \\
\hline K-BM-QUAL & $0.5 \mathrm{~T}-\mathrm{CT}$ & E-1820 & 374 & Alloy 617 & Plate & Aged-1 & Air & 1000 & 120000 & 950 \\
\hline K-BM-QUAL & $0.5 \mathrm{~T}-\mathrm{CT}$ & E-1820 & 375 & Alloy 617 & Plate & Aged-1 & Air & 1000 & 120000 & 950 \\
\hline K-BM-QUAL & $0.5 \mathrm{~T}-\mathrm{CT}$ & E-1820 & 376 & Alloy 617 & Plate & Aged-2 & Air & 1000 & 120000 & 0 \\
\hline K-BM-QUAL & $0.5 \mathrm{~T}-\mathrm{CT}$ & E-1820 & 377 & Alloy 617 & Plate & Aged-2 & Air & 1000 & 120000 & 0 \\
\hline K-BM-QUAL & $0.5 \mathrm{~T}-\mathrm{CT}$ & E-1820 & 378 & Alloy 617 & Plate & Aged-2 & Air & 1000 & 120000 & 0 \\
\hline K-BM-QUAL & $0.5 \mathrm{~T}-\mathrm{CT}$ & E-1820 & 379 & Alloy 617 & Plate & Aged-2 & Air & 1000 & 120000 & 100 \\
\hline K-BM-QUAL & $0.5 \mathrm{~T}-\mathrm{CT}$ & E-1820 & 380 & Alloy 617 & Plate & Aged-2 & Air & 1000 & 120000 & 100 \\
\hline K-BM-QUAL & $0.5 \mathrm{~T}-\mathrm{CT}$ & E-1820 & 381 & Alloy 617 & Plate & Aged-2 & Air & 1000 & 120000 & 100 \\
\hline K-BM-QUAL & $0.5 \mathrm{~T}-\mathrm{CT}$ & E-1820 & 382 & Alloy 617 & Plate & Aged-2 & Air & 1000 & 120000 & 950 \\
\hline K-BM-QUAL & $0.5 \mathrm{~T}-\mathrm{CT}$ & E-1820 & 383 & Alloy 617 & Plate & Aged-2 & Air & 1000 & 120000 & 950 \\
\hline K-BM-QUAL & $0.5 \mathrm{~T}-\mathrm{CT}$ & E-1820 & 384 & Alloy 617 & Plate & Aged-2 & Air & 1000 & 120000 & 950 \\
\hline
\end{tabular}




Idaho National Laboratory
\begin{tabular}{|c|lll|}
\hline NEXT GENERATION NUCLEAR PLANT & Identifier: & PLN-2804 & \\
INTERMEDIATE HEAT EXCHANGER & Revision: & 0 & \\
MATERIALS RESEARCH & Effective Date: & $04 / 30 / 08$ & Page: A-27 of A-114 \\
AND DEVELOPMENT PLAN &
\end{tabular}

\begin{tabular}{|c|c|c|c|c|c|c|c|c|c|c|c|}
\hline Test Prgm & $\begin{array}{l}\text { Spec. } \\
\text { Type }\end{array}$ & $\begin{array}{c}\text { Test } \\
\text { Method }\end{array}$ & $\begin{array}{c}\text { Spec. } \\
\#\end{array}$ & $\begin{array}{l}\text { Filler } \\
\text { Metal } \\
\end{array}$ & $\begin{array}{c}\text { Weld } \\
\text { Process }\end{array}$ & $\begin{array}{c}\text { A617 Plate } \\
\text { Heat \# }\end{array}$ & $\begin{array}{c}\text { Weld to be } \\
\text { Tested }\end{array}$ & Env. & $\begin{array}{c}\text { Exposure } \\
\text { Temp. }\left({ }^{\circ} \mathrm{C}\right)\end{array}$ & $\begin{array}{l}\text { Exposure } \\
\text { Time }(\mathrm{h})\end{array}$ & $\begin{array}{c}\text { Test Temp. } \\
\left({ }^{\circ} \mathrm{C}\right)\end{array}$ \\
\hline K-GTA & $0.4 \mathrm{~T}-\mathrm{CT}$ & E1820 & 1 & FM-617 & GTA & NA & Deposited & Air & None & None & 0 \\
\hline K-GTA & $0.4 \mathrm{~T}-\mathrm{CT}$ & E1820 & 2 & FM-617 & GTA & NA & Deposited & Air & None & None & 0 \\
\hline K-GTA & $0.4 \mathrm{~T}-\mathrm{CT}$ & E1820 & 3 & FM-617 & GTA & NA & Deposited & Air & None & None & 0 \\
\hline K-GTA & $0.4 \mathrm{~T}-\mathrm{CT}$ & E1820 & 4 & FM-617 & GTA & NA & Deposited & Air & None & None & 0 \\
\hline K-GTA & $0.4 \mathrm{~T}-\mathrm{CT}$ & E1820 & 5 & FM-617 & GTA & NA & Deposited & Air & None & None & 0 \\
\hline K-GTA & $0.4 \mathrm{~T}-\mathrm{CT}$ & E1820 & 6 & FM-617 & GTA & NA & Deposited & Air & None & None & 0 \\
\hline K-GTA & $0.4 \mathrm{~T}-\mathrm{CT}$ & E1820 & 7 & FM-617 & GTA & NA & Deposited & Air & None & None & 100 \\
\hline K-GTA & $0.4 \mathrm{~T}-\mathrm{CT}$ & E1820 & 8 & FM-617 & GTA & NA & Deposited & Air & None & None & 100 \\
\hline K-GTA & $0.4 \mathrm{~T}-\mathrm{CT}$ & E1820 & 9 & FM-617 & GTA & NA & Deposited & Air & None & None & 100 \\
\hline K-GTA & $0.4 \mathrm{~T}-\mathrm{CT}$ & E1820 & 10 & FM-617 & GTA & NA & Deposited & Air & None & None & 100 \\
\hline K-GTA & 0.4T-CT & E1820 & 11 & FM-617 & GTA & NA & Deposited & Air & None & None & 100 \\
\hline K-GTA & $0.4 \mathrm{~T}-\mathrm{CT}$ & E1820 & 12 & FM-617 & GTA & NA & Deposited & Air & None & None & 100 \\
\hline K-GTA & $0.4 \mathrm{~T}-\mathrm{CT}$ & E1820 & 13 & FM-617 & GTA & NA & Deposited & Air & None & None & 250 \\
\hline K-GTA & $0.4 \mathrm{~T}-\mathrm{CT}$ & E1820 & 14 & FM-617 & GTA & NA & Deposited & Air & None & None & 250 \\
\hline K-GTA & $0.4 \mathrm{~T}-\mathrm{CT}$ & E1820 & 15 & FM-617 & GTA & NA & Deposited & Air & None & None & 250 \\
\hline K-GTA & $0.4 \mathrm{~T}-\mathrm{CT}$ & E1820 & 16 & FM-617 & GTA & NA & Deposited & Air & None & None & 250 \\
\hline K-GTA & $0.4 \mathrm{~T}-\mathrm{CT}$ & E1820 & 17 & FM-617 & GTA & NA & Deposited & Air & None & None & 250 \\
\hline K-GTA & $0.4 \mathrm{~T}-\mathrm{CT}$ & E1820 & 18 & FM-617 & GTA & NA & Deposited & Air & None & None & 250 \\
\hline K-GTA & $0.4 \mathrm{~T}-\mathrm{CT}$ & E1820 & 19 & FM-617 & GTA & NA & Deposited & Air & None & None & 750 \\
\hline K-GTA & $0.4 \mathrm{~T}-\mathrm{CT}$ & E1820 & 20 & FM-617 & GTA & NA & Deposited & Air & None & None & 750 \\
\hline K-GTA & $0.4 \mathrm{~T}-\mathrm{CT}$ & E1820 & 21 & FM-617 & GTA & NA & Deposited & Air & None & None & 750 \\
\hline K-GTA & $0.4 \mathrm{~T}-\mathrm{CT}$ & E1820 & 22 & FM-617 & GTA & NA & Deposited & Air & None & None & 750 \\
\hline K-GTA & $0.4 \mathrm{~T}-\mathrm{CT}$ & E1820 & 23 & FM-617 & GTA & NA & Deposited & Air & None & None & 750 \\
\hline K-GTA & $0.4 \mathrm{~T}-\mathrm{CT}$ & E1820 & 24 & FM-617 & GTA & NA & Deposited & Air & None & None & 750 \\
\hline K-GTA & $0.4 \mathrm{~T}-\mathrm{CT}$ & E1820 & 25 & FM-617 & GTA & NA & Deposited & Air & None & None & 950 \\
\hline K-GTA & $0.4 \mathrm{~T}-\mathrm{CT}$ & E1820 & 26 & FM-617 & GTA & NA & Deposited & Air & None & None & 950 \\
\hline K-GTA & $0.4 \mathrm{~T}-\mathrm{CT}$ & E1820 & 27 & FM-617 & GTA & NA & Deposited & Air & None & None & 950 \\
\hline
\end{tabular}


Idaho National Laboratory

\begin{tabular}{|c|c|c|c|}
\hline $\begin{array}{l}\text { NEXT GENERATION NUCLEAR PLANT } \\
\text { INTERMEDIATE HEAT EXCHANGER } \\
\text { MATERIALS RESEARCH } \\
\text { AND DEVELOPMENT PLAN }\end{array}$ & $\begin{array}{l}\text { Identifier: } \\
\text { Revision: } \\
\text { Effective Date: }\end{array}$ & $\begin{array}{l}\text { PLN-2804 } \\
0 \\
04 / 30 / 08\end{array}$ & A-114 \\
\hline
\end{tabular}

\begin{tabular}{|c|c|c|c|c|c|c|c|c|c|c|c|}
\hline Test Prgm & $\begin{array}{l}\text { Spec. } \\
\text { Type }\end{array}$ & $\begin{array}{c}\text { Test } \\
\text { Method }\end{array}$ & $\begin{array}{c}\text { Spec. } \\
\#\end{array}$ & $\begin{array}{l}\text { Filler } \\
\text { Metal }\end{array}$ & $\begin{array}{c}\text { Weld } \\
\text { Process }\end{array}$ & $\begin{array}{c}\text { A617 Plate } \\
\text { Heat \# }\end{array}$ & $\begin{array}{c}\text { Weld to be } \\
\text { Tested }\end{array}$ & Env. & $\begin{array}{c}\text { Exposure } \\
\text { Temp. }\left({ }^{\circ} \mathrm{C}\right)\end{array}$ & $\begin{array}{c}\text { Exposure } \\
\text { Time (h) } \\
\end{array}$ & $\begin{array}{c}\text { Test Temp. } \\
\left({ }^{\circ} \mathrm{C}\right)\end{array}$ \\
\hline K-GTA & $0.4 \mathrm{~T}-\mathrm{CT}$ & E1820 & 28 & FM-617 & GTA & NA & Deposited & Air & None & None & 950 \\
\hline K-GTA & $0.4 \mathrm{~T}-\mathrm{CT}$ & E1820 & 29 & FM-617 & GTA & NA & Deposited & Air & None & None & 950 \\
\hline K-GTA & $0.4 \mathrm{~T}-\mathrm{CT}$ & E1820 & 30 & FM-617 & GTA & NA & Deposited & Air & None & None & 950 \\
\hline K-GTA & $0.4 \mathrm{~T}-\mathrm{CT}$ & E1820 & 31 & FM-617 & GTA & BM-1 & X-Weld & Air & None & None & 0 \\
\hline K-GTA & $0.4 \mathrm{~T}-\mathrm{CT}$ & E1820 & 32 & FM-617 & GTA & BM-1 & X-Weld & Air & None & None & 0 \\
\hline K-GTA & $0.4 \mathrm{~T}-\mathrm{CT}$ & E1820 & 33 & FM-617 & GTA & BM-1 & X-Weld & Air & None & None & 0 \\
\hline K-GTA & $0.4 \mathrm{~T}-\mathrm{CT}$ & E1820 & 34 & FM-617 & GTA & BM-1 & X-Weld & Air & None & None & 0 \\
\hline K-GTA & $0.4 \mathrm{~T}-\mathrm{CT}$ & E1820 & 35 & FM-617 & GTA & BM-1 & X-Weld & Air & None & None & 0 \\
\hline K-GTA & $0.4 \mathrm{~T}-\mathrm{CT}$ & E1820 & 36 & FM-617 & GTA & BM-1 & X-Weld & Air & None & None & 0 \\
\hline K-GTA & $0.4 \mathrm{~T}-\mathrm{CT}$ & E1820 & 37 & FM-617 & GTA & BM-1 & X-Weld & Air & None & None & 100 \\
\hline K-GTA & $0.4 \mathrm{~T}-\mathrm{CT}$ & E1820 & 38 & FM-617 & GTA & BM-1 & X-Weld & Air & None & None & 100 \\
\hline K-GTA & $0.4 \mathrm{~T}-\mathrm{CT}$ & E1820 & 39 & FM-617 & GTA & BM-1 & X-Weld & Air & None & None & 100 \\
\hline K-GTA & $0.4 \mathrm{~T}-\mathrm{CT}$ & E1820 & 40 & FM-617 & GTA & BM-1 & X-Weld & Air & None & None & 100 \\
\hline K-GTA & $0.4 \mathrm{~T}-\mathrm{CT}$ & E1820 & 41 & FM-617 & GTA & BM-1 & X-Weld & Air & None & None & 100 \\
\hline K-GTA & $0.4 \mathrm{~T}-\mathrm{CT}$ & E1820 & 42 & FM-617 & GTA & BM-1 & X-Weld & Air & None & None & 100 \\
\hline K-GTA & $0.4 \mathrm{~T}-\mathrm{CT}$ & E1820 & 43 & FM-617 & GTA & BM-1 & X-Weld & Air & None & None & 250 \\
\hline K-GTA & $0.4 \mathrm{~T}-\mathrm{CT}$ & E1820 & 44 & FM-617 & GTA & BM-1 & X-Weld & Air & None & None & 250 \\
\hline K-GTA & $0.4 \mathrm{~T}-\mathrm{CT}$ & E1820 & 45 & FM-617 & GTA & BM-1 & X-Weld & Air & None & None & 250 \\
\hline K-GTA & $0.4 \mathrm{~T}-\mathrm{CT}$ & E1820 & 46 & FM-617 & GTA & BM-1 & X-Weld & Air & None & None & 250 \\
\hline K-GTA & $0.4 \mathrm{~T}-\mathrm{CT}$ & E1820 & 47 & FM-617 & GTA & BM-1 & X-Weld & Air & None & None & 250 \\
\hline K-GTA & $0.4 \mathrm{~T}-\mathrm{CT}$ & E1820 & 48 & FM-617 & GTA & BM-1 & X-Weld & Air & None & None & 250 \\
\hline K-GTA & $0.4 \mathrm{~T}-\mathrm{CT}$ & E1820 & 49 & FM-617 & GTA & BM-1 & X-Weld & Air & None & None & 750 \\
\hline K-GTA & $0.4 \mathrm{~T}-\mathrm{CT}$ & E1820 & 50 & FM-617 & GTA & BM-1 & X-Weld & Air & None & None & 750 \\
\hline K-GTA & $0.4 \mathrm{~T}-\mathrm{CT}$ & E1820 & 51 & FM-617 & GTA & BM-1 & X-Weld & Air & None & None & 750 \\
\hline K-GTA & $0.4 \mathrm{~T}-\mathrm{CT}$ & E1820 & 52 & FM-617 & GTA & BM-1 & X-Weld & Air & None & None & 750 \\
\hline K-GTA & $0.4 \mathrm{~T}-\mathrm{CT}$ & E1820 & 53 & FM-617 & GTA & BM-1 & X-Weld & Air & None & None & 750 \\
\hline K-GTA & $0.4 \mathrm{~T}-\mathrm{CT}$ & E1820 & 54 & FM-617 & GTA & BM-1 & X-Weld & Air & None & None & 750 \\
\hline K-GTA & $0.4 \mathrm{~T}-\mathrm{CT}$ & E1820 & 55 & FM-617 & GTA & BM-1 & X-Weld & Air & None & None & 950 \\
\hline
\end{tabular}


Idaho National Laboratory

\begin{tabular}{|c|c|c|c|}
\hline $\begin{array}{l}\text { NEXT GENERATION NUCLEAR PLANT } \\
\text { INTERMEDIATE HEAT EXCHANGER } \\
\text { MATERIALS RESEARCH } \\
\text { AND DEVELOPMENT PLAN }\end{array}$ & $\begin{array}{l}\text { Identifier: } \\
\text { Revision: } \\
\text { Effective Date: }\end{array}$ & $\begin{array}{l}\text { PLN-2804 } \\
0 \\
04 / 30 / 08\end{array}$ & Page: A-29 of A-114 \\
\hline
\end{tabular}

\begin{tabular}{|c|c|c|c|c|c|c|c|c|c|c|c|}
\hline Test Prgm & $\begin{array}{l}\text { Spec. } \\
\text { Type }\end{array}$ & $\begin{array}{c}\text { Test } \\
\text { Method }\end{array}$ & $\begin{array}{c}\text { Spec. } \\
\#\end{array}$ & $\begin{array}{l}\text { Filler } \\
\text { Metal }\end{array}$ & $\begin{array}{c}\text { Weld } \\
\text { Process }\end{array}$ & $\begin{array}{c}\text { A617 Plate } \\
\text { Heat \# }\end{array}$ & $\begin{array}{c}\text { Weld to be } \\
\text { Tested }\end{array}$ & Env. & $\begin{array}{c}\text { Exposure } \\
\text { Temp. }\left({ }^{\circ} \mathrm{C}\right)\end{array}$ & $\begin{array}{l}\text { Exposure } \\
\text { Time (h) }\end{array}$ & $\begin{array}{c}\text { Test Temp. } \\
\left({ }^{\circ} \mathrm{C}\right)\end{array}$ \\
\hline K-GTA & $0.4 \mathrm{~T}-\mathrm{CT}$ & E1820 & 56 & FM-617 & GTA & BM-1 & X-Weld & Air & None & None & 950 \\
\hline K-GTA & $0.4 \mathrm{~T}-\mathrm{CT}$ & E1820 & 57 & FM-617 & GTA & BM-1 & X-Weld & Air & None & None & 950 \\
\hline K-GTA & $0.4 \mathrm{~T}-\mathrm{CT}$ & E1820 & 58 & FM-617 & GTA & BM-1 & X-Weld & Air & None & None & 950 \\
\hline K-GTA & $0.4 \mathrm{~T}-\mathrm{CT}$ & E1820 & 59 & FM-617 & GTA & BM-1 & X-Weld & Air & None & None & 950 \\
\hline K-GTA & $0.4 \mathrm{~T}-\mathrm{CT}$ & E1820 & 60 & FM-617 & GTA & BM-1 & X-Weld & Air & None & None & 950 \\
\hline K-GTA & $0.4 \mathrm{~T}-\mathrm{CT}$ & E1820 & 61 & FM-617 & GTA & NA & Deposited & Air & 750 & 200 & 0 \\
\hline K-GTA & $0.4 \mathrm{~T}-\mathrm{CT}$ & E1820 & 62 & FM-617 & GTA & NA & Deposited & Air & 750 & 200 & 0 \\
\hline K-GTA & $0.4 \mathrm{~T}-\mathrm{CT}$ & E1820 & 63 & FM-617 & GTA & NA & Deposited & Air & 750 & 200 & 0 \\
\hline K-GTA & $0.4 \mathrm{~T}-\mathrm{CT}$ & E1820 & 64 & FM-617 & GTA & NA & Deposited & Air & 750 & 200 & 100 \\
\hline K-GTA & $0.4 \mathrm{~T}-\mathrm{CT}$ & E1820 & 65 & FM-617 & GTA & NA & Deposited & Air & 750 & 200 & 100 \\
\hline K-GTA & $0.4 \mathrm{~T}-\mathrm{CT}$ & E1820 & 66 & FM-617 & GTA & NA & Deposited & Air & 750 & 200 & 100 \\
\hline K-GTA & $0.4 \mathrm{~T}-\mathrm{CT}$ & E1820 & 67 & FM-617 & GTA & NA & Deposited & Air & 750 & 200 & 950 \\
\hline K-GTA & $0.4 \mathrm{~T}-\mathrm{CT}$ & E1820 & 68 & FM-617 & GTA & NA & Deposited & Air & 750 & 200 & 950 \\
\hline K-GTA & $0.4 \mathrm{~T}-\mathrm{CT}$ & E1820 & 69 & FM-617 & GTA & NA & Deposited & Air & 750 & 200 & 950 \\
\hline K-GTA & $0.4 \mathrm{~T}-\mathrm{CT}$ & E1820 & 70 & FM-617 & GTA & BM-1 & X-Weld & Air & 750 & 200 & 0 \\
\hline K-GTA & $0.4 \mathrm{~T}-\mathrm{CT}$ & E1820 & 71 & FM-617 & GTA & BM-1 & X-Weld & Air & 750 & 200 & 0 \\
\hline K-GTA & $0.4 \mathrm{~T}-\mathrm{CT}$ & E1820 & 72 & FM-617 & GTA & BM-1 & X-Weld & Air & 750 & 200 & 0 \\
\hline K-GTA & 0.4T-CT & E1820 & 73 & FM-617 & GTA & BM-1 & X-Weld & Air & 750 & 200 & 100 \\
\hline K-GTA & $0.4 \mathrm{~T}-\mathrm{CT}$ & E1820 & 74 & FM-617 & GTA & BM-1 & X-Weld & Air & 750 & 200 & 100 \\
\hline K-GTA & $0.4 \mathrm{~T}-\mathrm{CT}$ & E1820 & 75 & FM-617 & GTA & BM-1 & X-Weld & Air & 750 & 200 & 100 \\
\hline K-GTA & $0.4 \mathrm{~T}-\mathrm{CT}$ & E1820 & 76 & FM-617 & GTA & BM-1 & X-Weld & Air & 750 & 200 & 950 \\
\hline K-GTA & $0.4 \mathrm{~T}-\mathrm{CT}$ & E1820 & 77 & FM-617 & GTA & BM-1 & X-Weld & Air & 750 & 200 & 950 \\
\hline K-GTA & $0.4 \mathrm{~T}-\mathrm{CT}$ & E1820 & 78 & FM-617 & GTA & BM-1 & X-Weld & Air & 750 & 200 & 950 \\
\hline K-GTA & $0.4 \mathrm{~T}-\mathrm{CT}$ & E1820 & 79 & FM-617 & GTA & NA & Deposited & Air & 1000 & 200 & 0 \\
\hline K-GTA & $0.4 \mathrm{~T}-\mathrm{CT}$ & E1820 & 80 & FM-617 & GTA & NA & Deposited & Air & 1000 & 200 & 0 \\
\hline K-GTA & $0.4 \mathrm{~T}-\mathrm{CT}$ & E1820 & 81 & FM-617 & GTA & NA & Deposited & Air & 1000 & 200 & 0 \\
\hline K-GTA & $0.4 \mathrm{~T}-\mathrm{CT}$ & E1820 & 82 & FM-617 & GTA & NA & Deposited & Air & 1000 & 200 & 100 \\
\hline K-GTA & $0.4 \mathrm{~T}-\mathrm{CT}$ & E1820 & 83 & FM-617 & GTA & NA & Deposited & Air & 1000 & 200 & 100 \\
\hline
\end{tabular}


Idaho National Laboratory

\begin{tabular}{|c|c|c|c|}
\hline $\begin{array}{l}\text { NEXT GENERATION NUCLEAR PLANT } \\
\text { INTERMEDIATE HEAT EXCHANGER } \\
\text { MATERIALS RESEARCH } \\
\text { AND DEVELOPMENT PLAN }\end{array}$ & $\begin{array}{l}\text { Identifier: } \\
\text { Revision: } \\
\text { Effective Date: }\end{array}$ & $\begin{array}{l}\text { PLN-2804 } \\
0 \\
04 / 30 / 08\end{array}$ & Page: A-30 of A-114 \\
\hline
\end{tabular}

\begin{tabular}{|c|c|c|c|c|c|c|c|c|c|c|c|}
\hline Test Prgm & $\begin{array}{l}\text { Spec. } \\
\text { Type }\end{array}$ & $\begin{array}{c}\text { Test } \\
\text { Method }\end{array}$ & $\begin{array}{c}\text { Spec. } \\
\#\end{array}$ & $\begin{array}{l}\text { Filler } \\
\text { Metal }\end{array}$ & $\begin{array}{l}\text { Weld } \\
\text { Process }\end{array}$ & $\begin{array}{c}\text { A617 Plate } \\
\text { Heat \# }\end{array}$ & $\begin{array}{c}\text { Weld to be } \\
\text { Tested }\end{array}$ & Env. & $\begin{array}{c}\text { Exposure } \\
\text { Temp. }\left({ }^{\circ} \mathrm{C}\right)\end{array}$ & $\begin{array}{l}\text { Exposure } \\
\text { Time (h) }\end{array}$ & $\begin{array}{c}\text { Test Temp } \\
\left({ }^{\circ} \mathrm{C}\right)\end{array}$ \\
\hline K-GTA & $0.4 \mathrm{~T}-\mathrm{CT}$ & E1820 & 84 & FM-617 & GTA & NA & Deposited & Air & 1000 & 200 & 100 \\
\hline K-GTA & $0.4 \mathrm{~T}-\mathrm{CT}$ & E1820 & 85 & FM-617 & GTA & NA & Deposited & Air & 1000 & 200 & 950 \\
\hline K-GTA & $0.4 \mathrm{~T}-\mathrm{CT}$ & E1820 & 86 & FM-617 & GTA & NA & Deposited & Air & 1000 & 200 & 950 \\
\hline K-GTA & $0.4 \mathrm{~T}-\mathrm{CT}$ & E1820 & 87 & FM-617 & GTA & NA & Deposited & Air & 1000 & 200 & 950 \\
\hline K-GTA & $0.4 \mathrm{~T}-\mathrm{CT}$ & E1820 & 88 & FM-617 & GTA & BM-1 & X-Weld & Air & 1000 & 200 & 0 \\
\hline K-GTA & $0.4 \mathrm{~T}-\mathrm{CT}$ & E1820 & 89 & FM-617 & GTA & BM-1 & X-Weld & Air & 1000 & 200 & 0 \\
\hline K-GTA & $0.4 \mathrm{~T}-\mathrm{CT}$ & E1820 & 90 & FM-617 & GTA & BM-1 & X-Weld & Air & 1000 & 200 & 0 \\
\hline K-GTA & $0.4 \mathrm{~T}-\mathrm{CT}$ & E1820 & 91 & FM-617 & GTA & BM-1 & X-Weld & Air & 1000 & 200 & 100 \\
\hline K-GTA & $0.4 \mathrm{~T}-\mathrm{CT}$ & E1820 & 92 & FM-617 & GTA & BM-1 & X-Weld & Air & 1000 & 200 & 100 \\
\hline K-GTA & $0.4 \mathrm{~T}-\mathrm{CT}$ & E1820 & 93 & FM-617 & GTA & BM-1 & X-Weld & Air & 1000 & 200 & 100 \\
\hline K-GTA & $0.4 \mathrm{~T}-\mathrm{CT}$ & E1820 & 94 & FM-617 & GTA & BM-1 & X-Weld & Air & 1000 & 200 & 950 \\
\hline K-GTA & $0.4 \mathrm{~T}-\mathrm{CT}$ & E1820 & 95 & FM-617 & GTA & BM-1 & X-Weld & Air & 1000 & 200 & 950 \\
\hline K-GTA & $0.4 \mathrm{~T}-\mathrm{CT}$ & E1820 & 96 & FM-617 & GTA & BM-1 & X-Weld & Air & 1000 & 200 & 950 \\
\hline K-GTA & $0.4 \mathrm{~T}-\mathrm{CT}$ & E1820 & 97 & FM-617 & GTA & NA & Deposited & Air & 750 & 650 & 0 \\
\hline K-GTA & $0.4 \mathrm{~T}-\mathrm{CT}$ & E1820 & 98 & FM-617 & GTA & NA & Deposited & Air & 750 & 650 & 0 \\
\hline K-GTA & $0.4 \mathrm{~T}-\mathrm{CT}$ & E1820 & 99 & FM-617 & GTA & NA & Deposited & Air & 750 & 650 & 0 \\
\hline K-GTA & $0.4 \mathrm{~T}-\mathrm{CT}$ & E1820 & 100 & FM-617 & GTA & NA & Deposited & Air & 750 & 650 & 100 \\
\hline K-GTA & $0.4 \mathrm{~T}-\mathrm{CT}$ & E1820 & 101 & FM-617 & GTA & NA & Deposited & Air & 750 & 650 & 100 \\
\hline K-GTA & $0.4 \mathrm{~T}-\mathrm{CT}$ & E1820 & 102 & FM-617 & GTA & NA & Deposited & Air & 750 & 650 & 100 \\
\hline K-GTA & $0.4 \mathrm{~T}-\mathrm{CT}$ & E1820 & 103 & FM-617 & GTA & NA & Deposited & Air & 750 & 650 & 950 \\
\hline K-GTA & $0.4 \mathrm{~T}-\mathrm{CT}$ & E1820 & 104 & FM-617 & GTA & NA & Deposited & Air & 750 & 650 & 950 \\
\hline K-GTA & $0.4 \mathrm{~T}-\mathrm{CT}$ & E1820 & 105 & FM-617 & GTA & NA & Deposited & Air & 750 & 650 & 950 \\
\hline K-GTA & $0.4 \mathrm{~T}-\mathrm{CT}$ & E1820 & 106 & FM-617 & GTA & BM-1 & X-Weld & Air & 750 & 650 & 0 \\
\hline K-GTA & $0.4 \mathrm{~T}-\mathrm{CT}$ & E1820 & 107 & FM-617 & GTA & BM-1 & X-Weld & Air & 750 & 650 & 0 \\
\hline K-GTA & $0.4 \mathrm{~T}-\mathrm{CT}$ & E1820 & 108 & FM-617 & GTA & BM-1 & X-Weld & Air & 750 & 650 & 0 \\
\hline K-GTA & $0.4 \mathrm{~T}-\mathrm{CT}$ & E1820 & 109 & FM-617 & GTA & BM-1 & X-Weld & Air & 750 & 650 & 100 \\
\hline K-GTA & $0.4 \mathrm{~T}-\mathrm{CT}$ & E1820 & 110 & FM-617 & GTA & BM-1 & X-Weld & Air & 750 & 650 & 100 \\
\hline K-GTA & $0.4 \mathrm{~T}-\mathrm{CT}$ & E1820 & 111 & FM-617 & GTA & BM-1 & X-Weld & Air & 750 & 650 & 100 \\
\hline
\end{tabular}


Idaho National Laboratory

\begin{tabular}{|c|c|c|c|}
\hline $\begin{array}{l}\text { NEXT GENERATION NUCLEAR PLANT } \\
\text { INTERMEDIATE HEAT EXCHANGER } \\
\text { MATERIALS RESEARCH } \\
\text { AND DEVELOPMENT PLAN }\end{array}$ & $\begin{array}{l}\text { Identifier: } \\
\text { Revision: } \\
\text { Effective Date: }\end{array}$ & $\begin{array}{l}\text { PLN-2804 } \\
0 \\
04 / 30 / 08\end{array}$ & Page: A-31 of A-114 \\
\hline
\end{tabular}

\begin{tabular}{|c|c|c|c|c|c|c|c|c|c|c|c|}
\hline Test Prgm & $\begin{array}{l}\text { Spec. } \\
\text { Type }\end{array}$ & $\begin{array}{c}\text { Test } \\
\text { Method }\end{array}$ & $\begin{array}{c}\text { Spec. } \\
\#\end{array}$ & $\begin{array}{l}\text { Filler } \\
\text { Metal }\end{array}$ & $\begin{array}{c}\text { Weld } \\
\text { Process }\end{array}$ & $\begin{array}{c}\text { A617 Plate } \\
\text { Heat \# }\end{array}$ & $\begin{array}{c}\text { Weld to be } \\
\text { Tested }\end{array}$ & Env. & $\begin{array}{c}\text { Exposure } \\
\text { Temp. }\left({ }^{\circ} \mathrm{C}\right)\end{array}$ & $\begin{array}{l}\text { Exposure } \\
\text { Time (h) }\end{array}$ & $\begin{array}{c}\text { Test Temp. } \\
\left({ }^{\circ} \mathrm{C}\right)\end{array}$ \\
\hline K-GTA & $0.4 \mathrm{~T}-\mathrm{CT}$ & E1820 & 112 & FM-617 & GTA & BM-1 & X-Weld & Air & 750 & 650 & 950 \\
\hline K-GTA & $0.4 \mathrm{~T}-\mathrm{CT}$ & E1820 & 113 & FM-617 & GTA & BM-1 & X-Weld & Air & 750 & 650 & 950 \\
\hline K-GTA & $0.4 \mathrm{~T}-\mathrm{CT}$ & E1820 & 114 & FM-617 & GTA & BM-1 & X-Weld & Air & 750 & 650 & 950 \\
\hline K-GTA & $0.4 \mathrm{~T}-\mathrm{CT}$ & E1820 & 115 & FM-617 & GTA & NA & Deposited & Air & 1000 & 650 & 0 \\
\hline K-GTA & $0.4 \mathrm{~T}-\mathrm{CT}$ & E1820 & 116 & FM-617 & GTA & NA & Deposited & Air & 1000 & 650 & 0 \\
\hline K-GTA & $0.4 \mathrm{~T}-\mathrm{CT}$ & E1820 & 117 & FM-617 & GTA & NA & Deposited & Air & 1000 & 650 & 0 \\
\hline K-GTA & $0.4 \mathrm{~T}-\mathrm{CT}$ & E1820 & 118 & FM-617 & GTA & NA & Deposited & Air & 1000 & 650 & 100 \\
\hline K-GTA & $0.4 \mathrm{~T}-\mathrm{CT}$ & E1820 & 119 & FM-617 & GTA & NA & Deposited & Air & 1000 & 650 & 100 \\
\hline K-GTA & $0.4 \mathrm{~T}-\mathrm{CT}$ & E1820 & 120 & FM-617 & GTA & NA & Deposited & Air & 1000 & 650 & 100 \\
\hline K-GTA & $0.4 \mathrm{~T}-\mathrm{CT}$ & E1820 & 121 & FM-617 & GTA & NA & Deposited & Air & 1000 & 650 & 950 \\
\hline K-GTA & $0.4 \mathrm{~T}-\mathrm{CT}$ & E1820 & 122 & FM-617 & GTA & NA & Deposited & Air & 1000 & 650 & 950 \\
\hline K-GTA & $0.4 \mathrm{~T}-\mathrm{CT}$ & E1820 & 123 & FM-617 & GTA & NA & Deposited & Air & 1000 & 650 & 950 \\
\hline K-GTA & $0.4 \mathrm{~T}-\mathrm{CT}$ & E1820 & 124 & FM-617 & GTA & BM-1 & X-Weld & Air & 1000 & 650 & 0 \\
\hline K-GTA & $0.4 \mathrm{~T}-\mathrm{CT}$ & E1820 & 125 & FM-617 & GTA & BM-1 & X-Weld & Air & 1000 & 650 & 0 \\
\hline K-GTA & $0.4 \mathrm{~T}-\mathrm{CT}$ & E1820 & 126 & FM-617 & GTA & BM-1 & X-Weld & Air & 1000 & 650 & 0 \\
\hline K-GTA & $0.4 \mathrm{~T}-\mathrm{CT}$ & E1820 & 127 & FM-617 & GTA & BM-1 & X-Weld & Air & 1000 & 650 & 100 \\
\hline K-GTA & $0.4 \mathrm{~T}-\mathrm{CT}$ & E1820 & 128 & FM-617 & GTA & BM-1 & X-Weld & Air & 1000 & 650 & 100 \\
\hline K-GTA & $0.4 \mathrm{~T}-\mathrm{CT}$ & E1820 & 129 & FM-617 & GTA & BM-1 & X-Weld & Air & 1000 & 650 & 100 \\
\hline K-GTA & $0.4 \mathrm{~T}-\mathrm{CT}$ & E1820 & 130 & FM-617 & GTA & BM-1 & X-Weld & Air & 1000 & 650 & 950 \\
\hline K-GTA & $0.4 \mathrm{~T}-\mathrm{CT}$ & E1820 & 131 & FM-617 & GTA & BM-1 & X-Weld & Air & 1000 & 650 & 950 \\
\hline K-GTA & $0.4 \mathrm{~T}-\mathrm{CT}$ & E1820 & 132 & FM-617 & GTA & BM-1 & X-Weld & Air & 1000 & 650 & 950 \\
\hline K-GTA & $0.4 \mathrm{~T}-\mathrm{CT}$ & E1820 & 133 & FM-617 & GTA & NA & Deposited & Air & 750 & 2000 & 0 \\
\hline K-GTA & $0.4 \mathrm{~T}-\mathrm{CT}$ & E1820 & 134 & FM-617 & GTA & NA & Deposited & Air & 750 & 2000 & 0 \\
\hline K-GTA & $0.4 \mathrm{~T}-\mathrm{CT}$ & E1820 & 135 & FM-617 & GTA & NA & Deposited & Air & 750 & 2000 & 0 \\
\hline K-GTA & $0.4 \mathrm{~T}-\mathrm{CT}$ & E1820 & 136 & FM-617 & GTA & NA & Deposited & Air & 750 & 2000 & 100 \\
\hline K-GTA & $0.4 \mathrm{~T}-\mathrm{CT}$ & E1820 & 137 & FM-617 & GTA & NA & Deposited & Air & 750 & 2000 & 100 \\
\hline K-GTA & $0.4 \mathrm{~T}-\mathrm{CT}$ & E1820 & 138 & FM-617 & GTA & NA & Deposited & Air & 750 & 2000 & 100 \\
\hline K-GTA & $0.4 \mathrm{~T}-\mathrm{CT}$ & E1820 & 139 & FM-617 & GTA & NA & Deposited & Air & 750 & 2000 & 950 \\
\hline
\end{tabular}


Idaho National Laboratory

\begin{tabular}{|c|c|c|c|}
\hline $\begin{array}{l}\text { NEXT GENERATION NUCLEAR PLANT } \\
\text { INTERMEDIATE HEAT EXCHANGER } \\
\text { MATERIALS RESEARCH } \\
\text { AND DEVELOPMENT PLAN }\end{array}$ & $\begin{array}{l}\text { Identifier: } \\
\text { Revision: } \\
\text { Effective Date: }\end{array}$ & $\begin{array}{l}\text { PLN-2804 } \\
0 \\
04 / 30 / 08\end{array}$ & Page: A-32 of A-114 \\
\hline
\end{tabular}

\begin{tabular}{|c|c|c|c|c|c|c|c|c|c|c|c|}
\hline Test Prgm & $\begin{array}{l}\text { Spec. } \\
\text { Type }\end{array}$ & $\begin{array}{c}\text { Test } \\
\text { Method }\end{array}$ & $\begin{array}{c}\text { Spec. } \\
\#\end{array}$ & $\begin{array}{l}\text { Filler } \\
\text { Metal }\end{array}$ & $\begin{array}{c}\text { Weld } \\
\text { Process }\end{array}$ & $\begin{array}{c}\text { A617 Plate } \\
\text { Heat \# }\end{array}$ & $\begin{array}{c}\text { Weld to be } \\
\text { Tested }\end{array}$ & Env. & $\begin{array}{c}\text { Exposure } \\
\text { Temp. }\left({ }^{\circ} \mathrm{C}\right)\end{array}$ & $\begin{array}{l}\text { Exposure } \\
\text { Time (h) }\end{array}$ & $\begin{array}{c}\text { Test Temp. } \\
\left({ }^{\circ} \mathrm{C}\right)\end{array}$ \\
\hline K-GTA & $0.4 \mathrm{~T}-\mathrm{CT}$ & E1820 & 140 & FM-617 & GTA & NA & Deposited & Air & 750 & 2000 & 950 \\
\hline K-GTA & $0.4 \mathrm{~T}-\mathrm{CT}$ & E1820 & 141 & FM-617 & GTA & NA & Deposited & Air & 750 & 2000 & 950 \\
\hline K-GTA & $0.4 \mathrm{~T}-\mathrm{CT}$ & E1820 & 142 & FM-617 & GTA & BM-1 & X-Weld & Air & 750 & 2000 & 0 \\
\hline K-GTA & $0.4 \mathrm{~T}-\mathrm{CT}$ & E1820 & 143 & FM-617 & GTA & BM-1 & X-Weld & Air & 750 & 2000 & 0 \\
\hline K-GTA & $0.4 \mathrm{~T}-\mathrm{CT}$ & E1820 & 144 & FM-617 & GTA & BM-1 & X-Weld & Air & 750 & 2000 & 0 \\
\hline K-GTA & $0.4 \mathrm{~T}-\mathrm{CT}$ & E1820 & 145 & FM-617 & GTA & BM-1 & X-Weld & Air & 750 & 2000 & 100 \\
\hline K-GTA & $0.4 \mathrm{~T}-\mathrm{CT}$ & E1820 & 146 & FM-617 & GTA & BM-1 & X-Weld & Air & 750 & 2000 & 100 \\
\hline K-GTA & $0.4 \mathrm{~T}-\mathrm{CT}$ & E1820 & 147 & FM-617 & GTA & BM-1 & X-Weld & Air & 750 & 2000 & 100 \\
\hline K-GTA & $0.4 \mathrm{~T}-\mathrm{CT}$ & E1820 & 148 & FM-617 & GTA & BM-1 & X-Weld & Air & 750 & 2000 & 950 \\
\hline K-GTA & $0.4 \mathrm{~T}-\mathrm{CT}$ & E1820 & 149 & FM-617 & GTA & BM-1 & X-Weld & Air & 750 & 2000 & 950 \\
\hline K-GTA & $0.4 \mathrm{~T}-\mathrm{CT}$ & E1820 & 150 & FM-617 & GTA & BM-1 & X-Weld & Air & 750 & 2000 & 950 \\
\hline K-GTA & $0.4 \mathrm{~T}-\mathrm{CT}$ & E1820 & 151 & FM-617 & GTA & NA & Deposited & Air & 1000 & 2000 & 0 \\
\hline K-GTA & $0.4 \mathrm{~T}-\mathrm{CT}$ & E1820 & 152 & FM-617 & GTA & NA & Deposited & Air & 1000 & 2000 & 0 \\
\hline K-GTA & $0.4 \mathrm{~T}-\mathrm{CT}$ & E1820 & 153 & FM-617 & GTA & NA & Deposited & Air & 1000 & 2000 & 0 \\
\hline K-GTA & $0.4 \mathrm{~T}-\mathrm{CT}$ & E1820 & 154 & FM-617 & GTA & NA & Deposited & Air & 1000 & 2000 & 100 \\
\hline K-GTA & $0.4 \mathrm{~T}-\mathrm{CT}$ & E1820 & 155 & FM-617 & GTA & NA & Deposited & Air & 1000 & 2000 & 100 \\
\hline K-GTA & $0.4 \mathrm{~T}-\mathrm{CT}$ & E1820 & 156 & FM-617 & GTA & NA & Deposited & Air & 1000 & 2000 & 100 \\
\hline K-GTA & $0.4 \mathrm{~T}-\mathrm{CT}$ & E1820 & 157 & FM-617 & GTA & NA & Deposited & Air & 1000 & 2000 & 950 \\
\hline K-GTA & $0.4 \mathrm{~T}-\mathrm{CT}$ & E1820 & 158 & FM-617 & GTA & NA & Deposited & Air & 1000 & 2000 & 950 \\
\hline K-GTA & $0.4 \mathrm{~T}-\mathrm{CT}$ & E1820 & 159 & FM-617 & GTA & NA & Deposited & Air & 1000 & 2000 & 950 \\
\hline K-GTA & $0.4 \mathrm{~T}-\mathrm{CT}$ & E1820 & 160 & FM-617 & GTA & BM-1 & X-Weld & Air & 1000 & 2000 & 0 \\
\hline K-GTA & $0.4 \mathrm{~T}-\mathrm{CT}$ & E1820 & 161 & FM-617 & GTA & BM-1 & X-Weld & Air & 1000 & 2000 & 0 \\
\hline K-GTA & $0.4 \mathrm{~T}-\mathrm{CT}$ & E1820 & 162 & FM-617 & GTA & BM-1 & X-Weld & Air & 1000 & 2000 & 0 \\
\hline K-GTA & $0.4 \mathrm{~T}-\mathrm{CT}$ & E1820 & 163 & FM-617 & GTA & BM-1 & X-Weld & Air & 1000 & 2000 & 100 \\
\hline K-GTA & $0.4 \mathrm{~T}-\mathrm{CT}$ & E1820 & 164 & FM-617 & GTA & BM-1 & X-Weld & Air & 1000 & 2000 & 100 \\
\hline K-GTA & $0.4 \mathrm{~T}-\mathrm{CT}$ & E1820 & 165 & FM-617 & GTA & BM-1 & X-Weld & Air & 1000 & 2000 & 100 \\
\hline K-GTA & $0.4 \mathrm{~T}-\mathrm{CT}$ & E1820 & 166 & FM-617 & GTA & BM-1 & X-Weld & Air & 1000 & 2000 & 950 \\
\hline K-GTA & $0.4 \mathrm{~T}-\mathrm{CT}$ & E1820 & 167 & FM-617 & GTA & BM-1 & X-Weld & Air & 1000 & 2000 & 950 \\
\hline
\end{tabular}


Idaho National Laboratory

\begin{tabular}{|c|c|c|c|}
\hline $\begin{array}{l}\text { NEXT GENERATION NUCLEAR PLANT } \\
\text { INTERMEDIATE HEAT EXCHANGER } \\
\text { MATERIALS RESEARCH } \\
\text { AND DEVELOPMENT PLAN }\end{array}$ & $\begin{array}{l}\text { Identifier: } \\
\text { Revision: } \\
\text { Effective Date: }\end{array}$ & $\begin{array}{l}\text { PLN-2804 } \\
0 \\
04 / 30 / 08\end{array}$ & Page: A-33 of A-114 \\
\hline
\end{tabular}

\begin{tabular}{|c|c|c|c|c|c|c|c|c|c|c|c|}
\hline Test Prgm & $\begin{array}{l}\text { Spec. } \\
\text { Type }\end{array}$ & $\begin{array}{c}\text { Test } \\
\text { Method }\end{array}$ & $\begin{array}{c}\text { Spec. } \\
\#\end{array}$ & $\begin{array}{l}\text { Filler } \\
\text { Metal }\end{array}$ & $\begin{array}{c}\text { Weld } \\
\text { Process }\end{array}$ & $\begin{array}{c}\text { A617 Plate } \\
\text { Heat \# }\end{array}$ & $\begin{array}{c}\text { Weld to be } \\
\text { Tested }\end{array}$ & Env. & $\begin{array}{c}\text { Exposure } \\
\text { Temp. }\left({ }^{\circ} \mathrm{C}\right)\end{array}$ & $\begin{array}{l}\text { Exposure } \\
\text { Time (h) }\end{array}$ & $\begin{array}{c}\text { Test Temp. } \\
\left({ }^{\circ} \mathrm{C}\right)\end{array}$ \\
\hline K-GTA & $0.4 \mathrm{~T}-\mathrm{CT}$ & E1820 & 168 & FM-617 & GTA & BM-1 & X-Weld & Air & 1000 & 2000 & 950 \\
\hline K-GTA & $0.4 \mathrm{~T}-\mathrm{CT}$ & E1820 & 169 & FM-617 & GTA & NA & Deposited & Air & 750 & 5300 & 0 \\
\hline K-GTA & $0.4 \mathrm{~T}-\mathrm{CT}$ & E1820 & 170 & FM-617 & GTA & NA & Deposited & Air & 750 & 5300 & 0 \\
\hline K-GTA & $0.4 \mathrm{~T}-\mathrm{CT}$ & E1820 & 171 & FM-617 & GTA & NA & Deposited & Air & 750 & 5300 & 0 \\
\hline K-GTA & $0.4 \mathrm{~T}-\mathrm{CT}$ & E1820 & 172 & FM-617 & GTA & NA & Deposited & Air & 750 & 5300 & 100 \\
\hline K-GTA & $0.4 \mathrm{~T}-\mathrm{CT}$ & E1820 & 173 & FM-617 & GTA & NA & Deposited & Air & 750 & 5300 & 100 \\
\hline K-GTA & $0.4 \mathrm{~T}-\mathrm{CT}$ & E1820 & 174 & FM-617 & GTA & NA & Deposited & Air & 750 & 5300 & 100 \\
\hline K-GTA & $0.4 \mathrm{~T}-\mathrm{CT}$ & E1820 & 175 & FM-617 & GTA & NA & Deposited & Air & 750 & 5300 & 950 \\
\hline K-GTA & $0.4 \mathrm{~T}-\mathrm{CT}$ & E1820 & 176 & FM-617 & GTA & NA & Deposited & Air & 750 & 5300 & 950 \\
\hline K-GTA & $0.4 \mathrm{~T}-\mathrm{CT}$ & E1820 & 177 & FM-617 & GTA & NA & Deposited & Air & 750 & 5300 & 950 \\
\hline K-GTA & $0.4 \mathrm{~T}-\mathrm{CT}$ & E1820 & 178 & FM-617 & GTA & BM-1 & X-Weld & Air & 750 & 5300 & 0 \\
\hline K-GTA & $0.4 \mathrm{~T}-\mathrm{CT}$ & E1820 & 179 & FM-617 & GTA & BM-1 & X-Weld & Air & 750 & 5300 & 0 \\
\hline K-GTA & $0.4 \mathrm{~T}-\mathrm{CT}$ & E1820 & 180 & FM-617 & GTA & BM-1 & X-Weld & Air & 750 & 5300 & 0 \\
\hline K-GTA & $0.4 \mathrm{~T}-\mathrm{CT}$ & E1820 & 181 & FM-617 & GTA & BM-1 & X-Weld & Air & 750 & 5300 & 100 \\
\hline K-GTA & $0.4 \mathrm{~T}-\mathrm{CT}$ & E1820 & 182 & FM-617 & GTA & BM-1 & X-Weld & Air & 750 & 5300 & 100 \\
\hline K-GTA & $0.4 \mathrm{~T}-\mathrm{CT}$ & E1820 & 183 & FM-617 & GTA & BM-1 & X-Weld & Air & 750 & 5300 & 100 \\
\hline K-GTA & $0.4 \mathrm{~T}-\mathrm{CT}$ & E1820 & 184 & FM-617 & GTA & BM-1 & X-Weld & Air & 750 & 5300 & 950 \\
\hline K-GTA & $0.4 \mathrm{~T}-\mathrm{CT}$ & E1820 & 185 & FM-617 & GTA & BM-1 & X-Weld & Air & 750 & 5300 & 950 \\
\hline K-GTA & $0.4 \mathrm{~T}-\mathrm{CT}$ & E1820 & 186 & FM-617 & GTA & BM-1 & X-Weld & Air & 750 & 5300 & 950 \\
\hline K-GTA & $0.4 \mathrm{~T}-\mathrm{CT}$ & E1820 & 187 & FM-617 & GTA & NA & Deposited & Air & 1000 & 5300 & 0 \\
\hline K-GTA & $0.4 \mathrm{~T}-\mathrm{CT}$ & E1820 & 188 & FM-617 & GTA & NA & Deposited & Air & 1000 & 5300 & 0 \\
\hline K-GTA & $0.4 \mathrm{~T}-\mathrm{CT}$ & E1820 & 189 & FM-617 & GTA & NA & Deposited & Air & 1000 & 5300 & 0 \\
\hline K-GTA & $0.4 \mathrm{~T}-\mathrm{CT}$ & E1820 & 190 & FM-617 & GTA & NA & Deposited & Air & 1000 & 5300 & 100 \\
\hline K-GTA & $0.4 \mathrm{~T}-\mathrm{CT}$ & E1820 & 191 & FM-617 & GTA & NA & Deposited & Air & 1000 & 5300 & 100 \\
\hline K-GTA & $0.4 \mathrm{~T}-\mathrm{CT}$ & E1820 & 192 & FM-617 & GTA & NA & Deposited & Air & 1000 & 5300 & 100 \\
\hline K-GTA & $0.4 \mathrm{~T}-\mathrm{CT}$ & E1820 & 193 & FM-617 & GTA & NA & Deposited & Air & 1000 & 5300 & 950 \\
\hline K-GTA & $0.4 \mathrm{~T}-\mathrm{CT}$ & E1820 & 194 & FM-617 & GTA & NA & Deposited & Air & 1000 & 5300 & 950 \\
\hline K-GTA & $0.4 \mathrm{~T}-\mathrm{CT}$ & E1820 & 195 & FM-617 & GTA & NA & Deposited & Air & 1000 & 5300 & 950 \\
\hline
\end{tabular}


Idaho National Laboratory

\begin{tabular}{|c|c|c|c|}
\hline $\begin{array}{l}\text { NEXT GENERATION NUCLEAR PLANT } \\
\text { INTERMEDIATE HEAT EXCHANGER } \\
\text { MATERIALS RESEARCH } \\
\text { AND DEVELOPMENT PLAN }\end{array}$ & $\begin{array}{l}\text { Identifier: } \\
\text { Revision: } \\
\text { Effective Date: }\end{array}$ & $\begin{array}{l}\text { PLN-2804 } \\
0 \\
04 / 30 / 08\end{array}$ & Page: A-34 of A-114 \\
\hline
\end{tabular}

\begin{tabular}{|c|c|c|c|c|c|c|c|c|c|c|c|}
\hline Test Prgm & $\begin{array}{l}\text { Spec. } \\
\text { Type }\end{array}$ & $\begin{array}{c}\text { Test } \\
\text { Method }\end{array}$ & $\begin{array}{c}\text { Spec. } \\
\#\end{array}$ & $\begin{array}{l}\text { Filler } \\
\text { Metal }\end{array}$ & $\begin{array}{c}\text { Weld } \\
\text { Process }\end{array}$ & $\begin{array}{c}\text { A617 Plate } \\
\text { Heat \# }\end{array}$ & $\begin{array}{l}\text { Weld to be } \\
\text { Tested }\end{array}$ & Env. & $\begin{array}{c}\text { Exposure } \\
\text { Temp. }\left({ }^{\circ} \mathrm{C}\right)\end{array}$ & $\begin{array}{l}\text { Exposure } \\
\text { Time (h) }\end{array}$ & $\begin{array}{c}\text { Test Temp. } \\
\left({ }^{\circ} \mathrm{C}\right)\end{array}$ \\
\hline K-GTA & $0.4 \mathrm{~T}-\mathrm{CT}$ & E1820 & 196 & FM-617 & GTA & BM-1 & X-Weld & Air & 1000 & 5300 & 0 \\
\hline K-GTA & $0.4 \mathrm{~T}-\mathrm{CT}$ & E1820 & 197 & FM-617 & GTA & BM-1 & X-Weld & Air & 1000 & 5300 & 0 \\
\hline K-GTA & $0.4 \mathrm{~T}-\mathrm{CT}$ & E1820 & 198 & FM-617 & GTA & BM-1 & X-Weld & Air & 1000 & 5300 & 0 \\
\hline K-GTA & $0.4 \mathrm{~T}-\mathrm{CT}$ & E1820 & 199 & FM-617 & GTA & BM-1 & X-Weld & Air & 1000 & 5300 & 100 \\
\hline K-GTA & $0.4 \mathrm{~T}-\mathrm{CT}$ & E1820 & 200 & FM-617 & GTA & BM-1 & X-Weld & Air & 1000 & 5300 & 100 \\
\hline K-GTA & $0.4 \mathrm{~T}-\mathrm{CT}$ & E1820 & 201 & FM-617 & GTA & BM-1 & X-Weld & Air & 1000 & 5300 & 100 \\
\hline K-GTA & $0.4 \mathrm{~T}-\mathrm{CT}$ & E1820 & 202 & FM-617 & GTA & BM-1 & X-Weld & Air & 1000 & 5300 & 950 \\
\hline K-GTA & $0.4 \mathrm{~T}-\mathrm{CT}$ & E1820 & 203 & FM-617 & GTA & BM-1 & X-Weld & Air & 1000 & 5300 & 950 \\
\hline K-GTA & $0.4 \mathrm{~T}-\mathrm{CT}$ & E1820 & 204 & FM-617 & GTA & BM-1 & X-Weld & Air & 1000 & 5300 & 950 \\
\hline K-GTA & $0.4 \mathrm{~T}-\mathrm{CT}$ & E1820 & 205 & FM-617 & GTA & NA & Deposited & Air & 750 & 20000 & 0 \\
\hline K-GTA & $0.4 \mathrm{~T}-\mathrm{CT}$ & E1820 & 206 & FM-617 & GTA & NA & Deposited & Air & 750 & 20000 & 0 \\
\hline K-GTA & $0.4 \mathrm{~T}-\mathrm{CT}$ & E1820 & 207 & FM-617 & GTA & NA & Deposited & Air & 750 & 20000 & 0 \\
\hline K-GTA & $0.4 \mathrm{~T}-\mathrm{CT}$ & E1820 & 208 & FM-617 & GTA & NA & Deposited & Air & 750 & 20000 & 100 \\
\hline K-GTA & $0.4 \mathrm{~T}-\mathrm{CT}$ & E1820 & 209 & FM-617 & GTA & NA & Deposited & Air & 750 & 20000 & 100 \\
\hline K-GTA & $0.4 \mathrm{~T}-\mathrm{CT}$ & E1820 & 210 & FM-617 & GTA & NA & Deposited & Air & 750 & 20000 & 100 \\
\hline K-GTA & $0.4 \mathrm{~T}-\mathrm{CT}$ & E1820 & 211 & FM-617 & GTA & NA & Deposited & Air & 750 & 20000 & 950 \\
\hline K-GTA & $0.4 \mathrm{~T}-\mathrm{CT}$ & E1820 & 212 & FM-617 & GTA & NA & Deposited & Air & 750 & 20000 & 950 \\
\hline K-GTA & $0.4 \mathrm{~T}-\mathrm{CT}$ & E1820 & 213 & FM-617 & GTA & NA & Deposited & Air & 750 & 20000 & 950 \\
\hline K-GTA & $0.4 \mathrm{~T}-\mathrm{CT}$ & E1820 & 214 & FM-617 & GTA & BM-1 & X-Weld & Air & 750 & 20000 & 0 \\
\hline K-GTA & $0.4 \mathrm{~T}-\mathrm{CT}$ & E1820 & 215 & FM-617 & GTA & BM-1 & X-Weld & Air & 750 & 20000 & 0 \\
\hline K-GTA & $0.4 \mathrm{~T}-\mathrm{CT}$ & E1820 & 216 & FM-617 & GTA & BM-1 & X-Weld & Air & 750 & 20000 & 0 \\
\hline K-GTA & $0.4 \mathrm{~T}-\mathrm{CT}$ & E1820 & 217 & FM-617 & GTA & BM-1 & X-Weld & Air & 750 & 20000 & 100 \\
\hline K-GTA & $0.4 \mathrm{~T}-\mathrm{CT}$ & E1820 & 218 & FM-617 & GTA & BM-1 & X-Weld & Air & 750 & 20000 & 100 \\
\hline K-GTA & $0.4 \mathrm{~T}-\mathrm{CT}$ & E1820 & 219 & FM-617 & GTA & BM-1 & X-Weld & Air & 750 & 20000 & 100 \\
\hline K-GTA & $0.4 \mathrm{~T}-\mathrm{CT}$ & E1820 & 220 & FM-617 & GTA & BM-1 & X-Weld & Air & 750 & 20000 & 950 \\
\hline K-GTA & $0.4 \mathrm{~T}-\mathrm{CT}$ & E1820 & 221 & FM-617 & GTA & BM-1 & X-Weld & Air & 750 & 20000 & 950 \\
\hline K-GTA & $0.4 \mathrm{~T}-\mathrm{CT}$ & E1820 & 222 & FM-617 & GTA & BM-1 & X-Weld & Air & 750 & 20000 & 950 \\
\hline K-GTA & $0.4 \mathrm{~T}-\mathrm{CT}$ & E1820 & 223 & FM-617 & GTA & NA & Deposited & Air & 1000 & 20000 & 0 \\
\hline
\end{tabular}


Idaho National Laboratory

\begin{tabular}{|c|c|c|c|}
\hline $\begin{array}{l}\text { NEXT GENERATION NUCLEAR PLANT } \\
\text { INTERMEDIATE HEAT EXCHANGER } \\
\text { MATERIALS RESEARCH } \\
\text { AND DEVELOPMENT PLAN }\end{array}$ & $\begin{array}{l}\text { Identifier: } \\
\text { Revision: } \\
\text { Effective Date: }\end{array}$ & $\begin{array}{l}\text { PLN-2804 } \\
0 \\
04 / 30 / 08\end{array}$ & Page: A-35 of A-114 \\
\hline
\end{tabular}

\begin{tabular}{|c|c|c|c|c|c|c|c|c|c|c|c|}
\hline Test Prgm & $\begin{array}{l}\text { Spec. } \\
\text { Type }\end{array}$ & $\begin{array}{c}\text { Test } \\
\text { Method }\end{array}$ & $\begin{array}{c}\text { Spec. } \\
\#\end{array}$ & $\begin{array}{l}\text { Filler } \\
\text { Metal }\end{array}$ & $\begin{array}{c}\text { Weld } \\
\text { Process }\end{array}$ & $\begin{array}{c}\text { A617 Plate } \\
\text { Heat \# }\end{array}$ & $\begin{array}{c}\text { Weld to be } \\
\text { Tested }\end{array}$ & Env. & $\begin{array}{c}\text { Exposure } \\
\text { Temp. }\left({ }^{\circ} \mathrm{C}\right)\end{array}$ & $\begin{array}{l}\text { Exposure } \\
\text { Time (h) }\end{array}$ & $\begin{array}{c}\text { Test Temp. } \\
\left({ }^{\circ} \mathrm{C}\right)\end{array}$ \\
\hline K-GTA & $0.4 \mathrm{~T}-\mathrm{CT}$ & E1820 & 224 & FM-617 & GTA & NA & Deposited & Air & 1000 & 20000 & 0 \\
\hline K-GTA & $0.4 \mathrm{~T}-\mathrm{CT}$ & E1820 & 225 & FM-617 & GTA & NA & Deposited & Air & 1000 & 20000 & 0 \\
\hline K-GTA & $0.4 \mathrm{~T}-\mathrm{CT}$ & E1820 & 226 & FM-617 & GTA & NA & Deposited & Air & 1000 & 20000 & 100 \\
\hline K-GTA & $0.4 \mathrm{~T}-\mathrm{CT}$ & E1820 & 227 & FM-617 & GTA & NA & Deposited & Air & 1000 & 20000 & 100 \\
\hline K-GTA & $0.4 \mathrm{~T}-\mathrm{CT}$ & E1820 & 228 & FM-617 & GTA & NA & Deposited & Air & 1000 & 20000 & 100 \\
\hline K-GTA & $0.4 \mathrm{~T}-\mathrm{CT}$ & E1820 & 229 & FM-617 & GTA & NA & Deposited & Air & 1000 & 20000 & 950 \\
\hline K-GTA & $0.4 \mathrm{~T}-\mathrm{CT}$ & E1820 & 230 & FM-617 & GTA & NA & Deposited & Air & 1000 & 20000 & 950 \\
\hline K-GTA & $0.4 \mathrm{~T}-\mathrm{CT}$ & E1820 & 231 & FM-617 & GTA & NA & Deposited & Air & 1000 & 20000 & 950 \\
\hline K-GTA & $0.4 \mathrm{~T}-\mathrm{CT}$ & E1820 & 232 & FM-617 & GTA & BM-1 & X-Weld & Air & 1000 & 20000 & 0 \\
\hline K-GTA & $0.4 \mathrm{~T}-\mathrm{CT}$ & E1820 & 233 & FM-617 & GTA & BM-1 & X-Weld & Air & 1000 & 20000 & 0 \\
\hline K-GTA & $0.4 \mathrm{~T}-\mathrm{CT}$ & E1820 & 234 & FM-617 & GTA & BM-1 & X-Weld & Air & 1000 & 20000 & 0 \\
\hline K-GTA & $0.4 \mathrm{~T}-\mathrm{CT}$ & E1820 & 235 & FM-617 & GTA & BM-1 & X-Weld & Air & 1000 & 20000 & 100 \\
\hline K-GTA & $0.4 \mathrm{~T}-\mathrm{CT}$ & E1820 & 236 & FM-617 & GTA & BM-1 & X-Weld & Air & 1000 & 20000 & 100 \\
\hline K-GTA & $0.4 \mathrm{~T}-\mathrm{CT}$ & E1820 & 237 & FM-617 & GTA & BM-1 & X-Weld & Air & 1000 & 20000 & 100 \\
\hline K-GTA & $0.4 \mathrm{~T}-\mathrm{CT}$ & E1820 & 238 & FM-617 & GTA & BM-1 & X-Weld & Air & 1000 & 20000 & 950 \\
\hline K-GTA & $0.4 \mathrm{~T}-\mathrm{CT}$ & E1820 & 239 & FM-617 & GTA & BM-1 & X-Weld & Air & 1000 & 20000 & 950 \\
\hline K-GTA & $0.4 \mathrm{~T}-\mathrm{CT}$ & E1820 & 240 & FM-617 & GTA & BM-1 & X-Weld & Air & 1000 & 20000 & 950 \\
\hline K-GTA-QUAL & $0.4 \mathrm{~T}-\mathrm{CT}$ & E1820 & 241 & FM-617 & GTA & NA & Deposited & Air & 750 & 32000 & 0 \\
\hline K-GTA-QUAL & $0.4 \mathrm{~T}-\mathrm{CT}$ & E1820 & 242 & FM-617 & GTA & NA & Deposited & Air & 750 & 32000 & 0 \\
\hline K-GTA-QUAL & $0.4 \mathrm{~T}-\mathrm{CT}$ & E1820 & 243 & FM-617 & GTA & NA & Deposited & Air & 750 & 32000 & 0 \\
\hline K-GTA-QUAL & $0.4 \mathrm{~T}-\mathrm{CT}$ & E1820 & 244 & FM-617 & GTA & NA & Deposited & Air & 750 & 32000 & 100 \\
\hline K-GTA-QUAL & $0.4 \mathrm{~T}-\mathrm{CT}$ & E1820 & 245 & FM-617 & GTA & NA & Deposited & Air & 750 & 32000 & 100 \\
\hline K-GTA-QUAL & $0.4 \mathrm{~T}-\mathrm{CT}$ & E1820 & 246 & FM-617 & GTA & NA & Deposited & Air & 750 & 32000 & 100 \\
\hline K-GTA-QUAL & $0.4 \mathrm{~T}-\mathrm{CT}$ & E1820 & 247 & FM-617 & GTA & NA & Deposited & Air & 750 & 32000 & 950 \\
\hline K-GTA-QUAL & $0.4 \mathrm{~T}-\mathrm{CT}$ & E1820 & 248 & FM-617 & GTA & NA & Deposited & Air & 750 & 32000 & 950 \\
\hline K-GTA-QUAL & $0.4 \mathrm{~T}-\mathrm{CT}$ & E1820 & 249 & FM-617 & GTA & NA & Deposited & Air & 750 & 32000 & 950 \\
\hline K-GTA-QUAL & $0.4 \mathrm{~T}-\mathrm{CT}$ & E1820 & 250 & FM-617 & GTA & BM-1 & X-Weld & Air & 750 & 32000 & 0 \\
\hline K-GTA-QUAL & $0.4 \mathrm{~T}-\mathrm{CT}$ & E1820 & 251 & FM-617 & GTA & BM-1 & X-Weld & Air & 750 & 32000 & 0 \\
\hline
\end{tabular}




Idaho National Laboratory
\begin{tabular}{|c|lll|}
\hline NEXT GENERATION NUCLEAR PLANT & Identifier: & PLN-2804 & \\
INTERMEDIATE HEAT EXCHANGER & Revision: & 0 & \\
MATERIALS RESEARCH & Effective Date: & $04 / 30 / 08$ & Page: A-36 of A-114 \\
AND DEVELOPMENT PLAN &
\end{tabular}

\begin{tabular}{|c|c|c|c|c|c|c|c|c|c|c|c|}
\hline Test Prgm & $\begin{array}{l}\text { Spec. } \\
\text { Type }\end{array}$ & $\begin{array}{c}\text { Test } \\
\text { Method } \\
\end{array}$ & $\begin{array}{c}\text { Spec. } \\
\#\end{array}$ & $\begin{array}{l}\text { Filler } \\
\text { Metal } \\
\end{array}$ & $\begin{array}{c}\text { Weld } \\
\text { Process }\end{array}$ & $\begin{array}{c}\text { A617 Plate } \\
\text { Heat \# }\end{array}$ & $\begin{array}{c}\text { Weld to be } \\
\text { Tested }\end{array}$ & Env. & $\begin{array}{c}\text { Exposure } \\
\text { Temp. }\left({ }^{\circ} \mathrm{C}\right)\end{array}$ & $\begin{array}{l}\text { Exposure } \\
\text { Time (h) }\end{array}$ & $\begin{array}{c}\text { Test Temp. } \\
\left({ }^{\circ} \mathrm{C}\right)\end{array}$ \\
\hline K-GTA-QUAL & $0.4 \mathrm{~T}-\mathrm{CT}$ & E1820 & 252 & FM-617 & GTA & BM-1 & X-Weld & Air & 750 & 32000 & 0 \\
\hline K-GTA-QUAL & $0.4 \mathrm{~T}-\mathrm{CT}$ & E1820 & 253 & FM-617 & GTA & BM-1 & X-Weld & Air & 750 & 32000 & 100 \\
\hline K-GTA-QUAL & $0.4 \mathrm{~T}-\mathrm{CT}$ & E1820 & 254 & FM-617 & GTA & BM-1 & X-Weld & Air & 750 & 32000 & 100 \\
\hline K-GTA-QUAL & $0.4 \mathrm{~T}-\mathrm{CT}$ & E1820 & 255 & FM-617 & GTA & BM-1 & X-Weld & Air & 750 & 32000 & 100 \\
\hline K-GTA-QUAL & $0.4 \mathrm{~T}-\mathrm{CT}$ & E1820 & 256 & FM-617 & GTA & BM-1 & X-Weld & Air & 750 & 32000 & 950 \\
\hline K-GTA-QUAL & $0.4 \mathrm{~T}-\mathrm{CT}$ & E1820 & 257 & FM-617 & GTA & BM-1 & X-Weld & Air & 750 & 32000 & 950 \\
\hline K-GTA-QUAL & $0.4 \mathrm{~T}-\mathrm{CT}$ & E1820 & 258 & FM-617 & GTA & BM-1 & X-Weld & Air & 750 & 32000 & 950 \\
\hline K-GTA-QUAL & $0.4 \mathrm{~T}-\mathrm{CT}$ & E1820 & 259 & FM-617 & GTA & NA & Deposited & Air & 1000 & 32000 & 0 \\
\hline K-GTA-QUAL & $0.4 \mathrm{~T}-\mathrm{CT}$ & E1820 & 260 & FM-617 & GTA & NA & Deposited & Air & 1000 & 32000 & 0 \\
\hline K-GTA-QUAL & $0.4 \mathrm{~T}-\mathrm{CT}$ & E1820 & 261 & FM-617 & GTA & NA & Deposited & Air & 1000 & 32000 & 0 \\
\hline K-GTA-QUAL & $0.4 \mathrm{~T}-\mathrm{CT}$ & E1820 & 262 & FM-617 & GTA & NA & Deposited & Air & 1000 & 32000 & 100 \\
\hline K-GTA-QUAL & $0.4 \mathrm{~T}-\mathrm{CT}$ & E1820 & 263 & FM-617 & GTA & NA & Deposited & Air & 1000 & 32000 & 100 \\
\hline K-GTA-QUAL & $0.4 \mathrm{~T}-\mathrm{CT}$ & E1820 & 264 & FM-617 & GTA & NA & Deposited & Air & 1000 & 32000 & 100 \\
\hline K-GTA-QUAL & $0.4 \mathrm{~T}-\mathrm{CT}$ & E1820 & 265 & FM-617 & GTA & NA & Deposited & Air & 1000 & 32000 & 950 \\
\hline K-GTA-QUAL & $0.4 \mathrm{~T}-\mathrm{CT}$ & E1820 & 266 & FM-617 & GTA & NA & Deposited & Air & 1000 & 32000 & 950 \\
\hline K-GTA-QUAL & $0.4 \mathrm{~T}-\mathrm{CT}$ & E1820 & 267 & FM-617 & GTA & NA & Deposited & Air & 1000 & 32000 & 950 \\
\hline K-GTA-QUAL & $0.4 \mathrm{~T}-\mathrm{CT}$ & E1820 & 268 & FM-617 & GTA & BM-1 & X-Weld & Air & 1000 & 32000 & 0 \\
\hline K-GTA-QUAL & $0.4 \mathrm{~T}-\mathrm{CT}$ & E1820 & 269 & FM-617 & GTA & BM-1 & X-Weld & Air & 1000 & 32000 & 0 \\
\hline K-GTA-QUAL & $0.4 \mathrm{~T}-\mathrm{CT}$ & E1820 & 270 & FM-617 & GTA & BM-1 & X-Weld & Air & 1000 & 32000 & 0 \\
\hline K-GTA-QUAL & $0.4 \mathrm{~T}-\mathrm{CT}$ & E1820 & 271 & FM-617 & GTA & BM-1 & X-Weld & Air & 1000 & 32000 & 100 \\
\hline K-GTA-QUAL & $0.4 \mathrm{~T}-\mathrm{CT}$ & E1820 & 272 & FM-617 & GTA & BM-1 & X-Weld & Air & 1000 & 32000 & 100 \\
\hline K-GTA-QUAL & $0.4 \mathrm{~T}-\mathrm{CT}$ & E1820 & 273 & FM-617 & GTA & BM-1 & X-Weld & Air & 1000 & 32000 & 100 \\
\hline K-GTA-QUAL & $0.4 \mathrm{~T}-\mathrm{CT}$ & E1820 & 274 & FM-617 & GTA & BM-1 & X-Weld & Air & 1000 & 32000 & 950 \\
\hline K-GTA-QUAL & $0.4 \mathrm{~T}-\mathrm{CT}$ & E1820 & 275 & FM-617 & GTA & BM-1 & X-Weld & Air & 1000 & 32000 & 950 \\
\hline K-GTA-QUAL & $0.4 \mathrm{~T}-\mathrm{CT}$ & E1820 & 276 & FM-617 & GTA & BM-1 & X-Weld & Air & 1000 & 32000 & 950 \\
\hline K-GTA-QUAL & $0.4 \mathrm{~T}-\mathrm{CT}$ & E1820 & 277 & FM-617 & GTA & NA & Deposited & Air & 750 & 50000 & 0 \\
\hline K-GTA-QUAL & $0.4 \mathrm{~T}-\mathrm{CT}$ & E1820 & 278 & FM-617 & GTA & NA & Deposited & Air & 750 & 50000 & 0 \\
\hline K-GTA-QUAL & $0.4 \mathrm{~T}-\mathrm{CT}$ & E1820 & 279 & FM-617 & GTA & NA & Deposited & Air & 750 & 50000 & 0 \\
\hline
\end{tabular}




Idaho National Laboratory
\begin{tabular}{|c|lll|}
\hline NEXT GENERATION NUCLEAR PLANT & Identifier: & PLN-2804 & \\
INTERMEDIATE HEAT EXCHANGER & Revision: & 0 & \\
MATERIALS RESEARCH & Effective Date: & $04 / 30 / 08$ & Page: A-37 of A-114 \\
AND DEVELOPMENT PLAN &
\end{tabular}

\begin{tabular}{|c|c|c|c|c|c|c|c|c|c|c|c|}
\hline Test Prgm & $\begin{array}{l}\text { Spec. } \\
\text { Type }\end{array}$ & $\begin{array}{c}\text { Test } \\
\text { Method } \\
\end{array}$ & $\begin{array}{c}\text { Spec. } \\
\#\end{array}$ & $\begin{array}{l}\text { Filler } \\
\text { Metal } \\
\end{array}$ & $\begin{array}{c}\text { Weld } \\
\text { Process }\end{array}$ & $\begin{array}{c}\text { A617 Plate } \\
\text { Heat \# }\end{array}$ & $\begin{array}{c}\text { Weld to be } \\
\text { Tested }\end{array}$ & Env. & $\begin{array}{c}\text { Exposure } \\
\text { Temp. }\left({ }^{\circ} \mathrm{C}\right)\end{array}$ & $\begin{array}{l}\text { Exposure } \\
\text { Time }(\mathrm{h})\end{array}$ & $\begin{array}{c}\text { Test Temp. } \\
\left({ }^{\circ} \mathrm{C}\right)\end{array}$ \\
\hline K-GTA-QUAL & $0.4 \mathrm{~T}-\mathrm{CT}$ & E1820 & 280 & FM-617 & GTA & NA & Deposited & Air & 750 & 50000 & 100 \\
\hline K-GTA-QUAL & $0.4 \mathrm{~T}-\mathrm{CT}$ & E1820 & 281 & FM-617 & GTA & NA & Deposited & Air & 750 & 50000 & 100 \\
\hline K-GTA-QUAL & $0.4 \mathrm{~T}-\mathrm{CT}$ & E1820 & 282 & FM-617 & GTA & NA & Deposited & Air & 750 & 50000 & 100 \\
\hline K-GTA-QUAL & $0.4 \mathrm{~T}-\mathrm{CT}$ & E1820 & 283 & FM-617 & GTA & NA & Deposited & Air & 750 & 50000 & 950 \\
\hline K-GTA-QUAL & $0.4 \mathrm{~T}-\mathrm{CT}$ & E1820 & 284 & FM-617 & GTA & NA & Deposited & Air & 750 & 50000 & 950 \\
\hline K-GTA-QUAL & $0.4 \mathrm{~T}-\mathrm{CT}$ & E1820 & 285 & FM-617 & GTA & NA & Deposited & Air & 750 & 50000 & 950 \\
\hline K-GTA-QUAL & $0.4 \mathrm{~T}-\mathrm{CT}$ & E1820 & 286 & FM-617 & GTA & BM-1 & X-Weld & Air & 750 & 50000 & 0 \\
\hline K-GTA-QUAL & $0.4 \mathrm{~T}-\mathrm{CT}$ & E1820 & 287 & FM-617 & GTA & BM-1 & X-Weld & Air & 750 & 50000 & 0 \\
\hline K-GTA-QUAL & $0.4 \mathrm{~T}-\mathrm{CT}$ & E1820 & 288 & FM-617 & GTA & BM-1 & X-Weld & Air & 750 & 50000 & 0 \\
\hline K-GTA-QUAL & $0.4 \mathrm{~T}-\mathrm{CT}$ & E1820 & 289 & FM-617 & GTA & BM-1 & X-Weld & Air & 750 & 50000 & 100 \\
\hline K-GTA-QUAL & $0.4 \mathrm{~T}-\mathrm{CT}$ & E1820 & 290 & FM-617 & GTA & BM-1 & X-Weld & Air & 750 & 50000 & 100 \\
\hline K-GTA-QUAL & $0.4 \mathrm{~T}-\mathrm{CT}$ & E1820 & 291 & FM-617 & GTA & BM-1 & X-Weld & Air & 750 & 50000 & 100 \\
\hline K-GTA-QUAL & $0.4 \mathrm{~T}-\mathrm{CT}$ & E1820 & 292 & FM-617 & GTA & BM-1 & X-Weld & Air & 750 & 50000 & 950 \\
\hline K-GTA-QUAL & $0.4 \mathrm{~T}-\mathrm{CT}$ & E1820 & 293 & FM-617 & GTA & BM-1 & X-Weld & Air & 750 & 50000 & 950 \\
\hline K-GTA-QUAL & $0.4 \mathrm{~T}-\mathrm{CT}$ & E1820 & 294 & FM-617 & GTA & BM-1 & X-Weld & Air & 750 & 50000 & 950 \\
\hline K-GTA-QUAL & $0.4 \mathrm{~T}-\mathrm{CT}$ & E1820 & 295 & FM-617 & GTA & NA & Deposited & Air & 1000 & 50000 & 0 \\
\hline K-GTA-QUAL & $0.4 \mathrm{~T}-\mathrm{CT}$ & E1820 & 296 & FM-617 & GTA & NA & Deposited & Air & 1000 & 50000 & 0 \\
\hline K-GTA-QUAL & $0.4 \mathrm{~T}-\mathrm{CT}$ & E1820 & 297 & FM-617 & GTA & NA & Deposited & Air & 1000 & 50000 & 0 \\
\hline K-GTA-QUAL & $0.4 \mathrm{~T}-\mathrm{CT}$ & E1820 & 298 & FM-617 & GTA & NA & Deposited & Air & 1000 & 50000 & 100 \\
\hline K-GTA-QUAL & $0.4 \mathrm{~T}-\mathrm{CT}$ & E1820 & 299 & FM-617 & GTA & NA & Deposited & Air & 1000 & 50000 & 100 \\
\hline K-GTA-QUAL & $0.4 \mathrm{~T}-\mathrm{CT}$ & E1820 & 300 & FM-617 & GTA & NA & Deposited & Air & 1000 & 50000 & 100 \\
\hline K-GTA-QUAL & $0.4 \mathrm{~T}-\mathrm{CT}$ & E1820 & 301 & FM-617 & GTA & NA & Deposited & Air & 1000 & 50000 & 950 \\
\hline K-GTA-QUAL & $0.4 \mathrm{~T}-\mathrm{CT}$ & E1820 & 302 & FM-617 & GTA & NA & Deposited & Air & 1000 & 50000 & 950 \\
\hline K-GTA-QUAL & $0.4 \mathrm{~T}-\mathrm{CT}$ & E1820 & 303 & FM-617 & GTA & NA & Deposited & Air & 1000 & 50000 & 950 \\
\hline K-GTA-QUAL & $0.4 \mathrm{~T}-\mathrm{CT}$ & E1820 & 304 & FM-617 & GTA & BM-1 & X-Weld & Air & 1000 & 50000 & 0 \\
\hline K-GTA-QUAL & $0.4 \mathrm{~T}-\mathrm{CT}$ & E1820 & 305 & FM-617 & GTA & BM-1 & X-Weld & Air & 1000 & 50000 & 0 \\
\hline K-GTA-QUAL & $0.4 \mathrm{~T}-\mathrm{CT}$ & E1820 & 306 & FM-617 & GTA & BM-1 & X-Weld & Air & 1000 & 50000 & 0 \\
\hline K-GTA-QUAL & $0.4 \mathrm{~T}-\mathrm{CT}$ & E1820 & 307 & FM-617 & GTA & BM-1 & X-Weld & Air & 1000 & 50000 & 100 \\
\hline
\end{tabular}




Idaho National Laboratory
\begin{tabular}{|c|lll|}
\hline NEXT GENERATION NUCLEAR PLANT & Identifier: & PLN-2804 & \\
INTERMEDIATE HEAT EXCHANGER & Revision: & 0 & \\
MATERIALS RESEARCH & Effective Date: & $04 / 30 / 08$ & Page: A-38 of A-114 \\
AND DEVELOPMENT PLAN &
\end{tabular}

\begin{tabular}{|c|c|c|c|c|c|c|c|c|c|c|c|}
\hline Test Prgm & $\begin{array}{l}\text { Spec. } \\
\text { Type }\end{array}$ & $\begin{array}{c}\text { Test } \\
\text { Method }\end{array}$ & $\begin{array}{c}\text { Spec. } \\
\#\end{array}$ & $\begin{array}{l}\text { Filler } \\
\text { Metal }\end{array}$ & $\begin{array}{c}\text { Weld } \\
\text { Process }\end{array}$ & $\begin{array}{c}\text { A617 Plate } \\
\text { Heat \# }\end{array}$ & $\begin{array}{c}\text { Weld to be } \\
\text { Tested }\end{array}$ & Env. & $\begin{array}{c}\text { Exposure } \\
\text { Temp. }\left({ }^{\circ} \mathrm{C}\right)\end{array}$ & $\begin{array}{l}\text { Exposure } \\
\text { Time (h) }\end{array}$ & $\begin{array}{c}\text { Test Temp. } \\
\left({ }^{\circ} \mathrm{C}\right)\end{array}$ \\
\hline K-GTA-QUAL & $0.4 \mathrm{~T}-\mathrm{CT}$ & E1820 & 308 & FM-617 & GTA & BM-1 & X-Weld & Air & 1000 & 50000 & 100 \\
\hline K-GTA-QUAL & $0.4 \mathrm{~T}-\mathrm{CT}$ & E1820 & 309 & FM-617 & GTA & BM-1 & X-Weld & Air & 1000 & 50000 & 100 \\
\hline K-GTA-QUAL & $0.4 \mathrm{~T}-\mathrm{CT}$ & E1820 & 310 & FM-617 & GTA & BM-1 & X-Weld & Air & 1000 & 50000 & 950 \\
\hline K-GTA-QUAL & $0.4 \mathrm{~T}-\mathrm{CT}$ & E1820 & 311 & FM-617 & GTA & BM-1 & X-Weld & Air & 1000 & 50000 & 950 \\
\hline K-GTA-QUAL & $0.4 \mathrm{~T}-\mathrm{CT}$ & E1820 & 312 & FM-617 & GTA & BM-1 & X-Weld & Air & 1000 & 50000 & 950 \\
\hline K-GTA-QUAL & $0.4 \mathrm{~T}-\mathrm{CT}$ & E1820 & 313 & FM-617 & GTA & NA & Deposited & Air & 750 & 76000 & 0 \\
\hline K-GTA-QUAL & $0.4 \mathrm{~T}-\mathrm{CT}$ & E1820 & 314 & FM-617 & GTA & NA & Deposited & Air & 750 & 76000 & 0 \\
\hline K-GTA-QUAL & $0.4 \mathrm{~T}-\mathrm{CT}$ & E1820 & 315 & FM-617 & GTA & NA & Deposited & Air & 750 & 76000 & 0 \\
\hline K-GTA-QUAL & $0.4 \mathrm{~T}-\mathrm{CT}$ & E1820 & 316 & FM-617 & GTA & NA & Deposited & Air & 750 & 76000 & 100 \\
\hline K-GTA-QUAL & $0.4 \mathrm{~T}-\mathrm{CT}$ & E1820 & 317 & FM-617 & GTA & NA & Deposited & Air & 750 & 76000 & 100 \\
\hline K-GTA-QUAL & $0.4 \mathrm{~T}-\mathrm{CT}$ & E1820 & 318 & FM-617 & GTA & NA & Deposited & Air & 750 & 76000 & 100 \\
\hline K-GTA-QUAL & $0.4 \mathrm{~T}-\mathrm{CT}$ & E1820 & 319 & FM-617 & GTA & NA & Deposited & Air & 750 & 76000 & 950 \\
\hline K-GTA-QUAL & $0.4 \mathrm{~T}-\mathrm{CT}$ & E1820 & 320 & FM-617 & GTA & NA & Deposited & Air & 750 & 76000 & 950 \\
\hline K-GTA-QUAL & $0.4 \mathrm{~T}-\mathrm{CT}$ & E1820 & 321 & FM-617 & GTA & NA & Deposited & Air & 750 & 76000 & 950 \\
\hline K-GTA-QUAL & $0.4 \mathrm{~T}-\mathrm{CT}$ & E1820 & 322 & FM-617 & GTA & BM-1 & X-Weld & Air & 750 & 76000 & 0 \\
\hline K-GTA-QUAL & $0.4 \mathrm{~T}-\mathrm{CT}$ & E1820 & 323 & FM-617 & GTA & BM-1 & X-Weld & Air & 750 & 76000 & 0 \\
\hline K-GTA-QUAL & $0.4 \mathrm{~T}-\mathrm{CT}$ & E1820 & 324 & FM-617 & GTA & BM-1 & X-Weld & Air & 750 & 76000 & 0 \\
\hline K-GTA-QUAL & $0.4 \mathrm{~T}-\mathrm{CT}$ & E1820 & 325 & FM-617 & GTA & BM-1 & X-Weld & Air & 750 & 76000 & 100 \\
\hline K-GTA-QUAL & $0.4 \mathrm{~T}-\mathrm{CT}$ & E1820 & 326 & FM-617 & GTA & BM-1 & X-Weld & Air & 750 & 76000 & 100 \\
\hline K-GTA-QUAL & $0.4 \mathrm{~T}-\mathrm{CT}$ & E1820 & 327 & FM-617 & GTA & BM-1 & X-Weld & Air & 750 & 76000 & 100 \\
\hline K-GTA-QUAL & $0.4 \mathrm{~T}-\mathrm{CT}$ & E1820 & 328 & FM-617 & GTA & BM-1 & X-Weld & Air & 750 & 76000 & 950 \\
\hline K-GTA-QUAL & $0.4 \mathrm{~T}-\mathrm{CT}$ & E1820 & 329 & FM-617 & GTA & BM-1 & X-Weld & Air & 750 & 76000 & 950 \\
\hline K-GTA-QUAL & $0.4 \mathrm{~T}-\mathrm{CT}$ & E1820 & 330 & FM-617 & GTA & BM-1 & X-Weld & Air & 750 & 76000 & 950 \\
\hline K-GTA-QUAL & $0.4 \mathrm{~T}-\mathrm{CT}$ & E1820 & 331 & FM-617 & GTA & NA & Deposited & Air & 1000 & 76000 & 0 \\
\hline K-GTA-QUAL & $0.4 \mathrm{~T}-\mathrm{CT}$ & E1820 & 332 & FM-617 & GTA & NA & Deposited & Air & 1000 & 76000 & 0 \\
\hline K-GTA-QUAL & $0.4 \mathrm{~T}-\mathrm{CT}$ & E1820 & 333 & FM-617 & GTA & NA & Deposited & Air & 1000 & 76000 & 0 \\
\hline K-GTA-QUAL & $0.4 \mathrm{~T}-\mathrm{CT}$ & E1820 & 334 & FM-617 & GTA & NA & Deposited & Air & 1000 & 76000 & 100 \\
\hline K-GTA-QUAL & $0.4 \mathrm{~T}-\mathrm{CT}$ & E1820 & 335 & FM-617 & GTA & NA & Deposited & Air & 1000 & 76000 & 100 \\
\hline
\end{tabular}




Idaho National Laboratory
\begin{tabular}{|c|lll|}
\hline NEXT GENERATION NUCLEAR PLANT & Identifier: & PLN-2804 & \\
INTERMEDIATE HEAT EXCHANGER & Revision: & 0 & \\
MATERIALS RESEARCH & Effective Date: & $04 / 30 / 08$ & Page: A-39 of A-114 \\
AND DEVELOPMENT PLAN &
\end{tabular}

\begin{tabular}{|c|c|c|c|c|c|c|c|c|c|c|c|}
\hline Test Prgm & $\begin{array}{l}\text { Spec. } \\
\text { Type }\end{array}$ & $\begin{array}{c}\text { Test } \\
\text { Method } \\
\end{array}$ & $\begin{array}{c}\text { Spec. } \\
\#\end{array}$ & $\begin{array}{l}\text { Filler } \\
\text { Metal } \\
\end{array}$ & $\begin{array}{c}\text { Weld } \\
\text { Process }\end{array}$ & $\begin{array}{c}\text { A617 Plate } \\
\text { Heat \# }\end{array}$ & $\begin{array}{c}\text { Weld to be } \\
\text { Tested }\end{array}$ & Env. & $\begin{array}{c}\text { Exposure } \\
\text { Temp. }\left({ }^{\circ} \mathrm{C}\right)\end{array}$ & $\begin{array}{l}\text { Exposure } \\
\text { Time }(\mathrm{h})\end{array}$ & $\begin{array}{c}\text { Test Temp. } \\
\left({ }^{\circ} \mathrm{C}\right)\end{array}$ \\
\hline K-GTA-QUAL & $0.4 \mathrm{~T}-\mathrm{CT}$ & E1820 & 336 & FM-617 & GTA & NA & Deposited & Air & 1000 & 76000 & 100 \\
\hline K-GTA-QUAL & $0.4 \mathrm{~T}-\mathrm{CT}$ & E1820 & 337 & FM-617 & GTA & NA & Deposited & Air & 1000 & 76000 & 950 \\
\hline K-GTA-QUAL & $0.4 \mathrm{~T}-\mathrm{CT}$ & E1820 & 338 & FM-617 & GTA & NA & Deposited & Air & 1000 & 76000 & 950 \\
\hline K-GTA-QUAL & $0.4 \mathrm{~T}-\mathrm{CT}$ & E1820 & 339 & FM-617 & GTA & NA & Deposited & Air & 1000 & 76000 & 950 \\
\hline K-GTA-QUAL & $0.4 \mathrm{~T}-\mathrm{CT}$ & E1820 & 340 & FM-617 & GTA & BM-1 & X-Weld & Air & 1000 & 76000 & 0 \\
\hline K-GTA-QUAL & $0.4 \mathrm{~T}-\mathrm{CT}$ & E1820 & 341 & FM-617 & GTA & BM-1 & X-Weld & Air & 1000 & 76000 & 0 \\
\hline K-GTA-QUAL & $0.4 \mathrm{~T}-\mathrm{CT}$ & E1820 & 342 & FM-617 & GTA & BM-1 & X-Weld & Air & 1000 & 76000 & 0 \\
\hline K-GTA-QUAL & $0.4 \mathrm{~T}-\mathrm{CT}$ & E1820 & 343 & FM-617 & GTA & BM-1 & X-Weld & Air & 1000 & 76000 & 100 \\
\hline K-GTA-QUAL & $0.4 \mathrm{~T}-\mathrm{CT}$ & E1820 & 344 & FM-617 & GTA & BM-1 & X-Weld & Air & 1000 & 76000 & 100 \\
\hline K-GTA-QUAL & $0.4 \mathrm{~T}-\mathrm{CT}$ & E1820 & 345 & FM-617 & GTA & BM-1 & X-Weld & Air & 1000 & 76000 & 100 \\
\hline K-GTA-QUAL & $0.4 \mathrm{~T}-\mathrm{CT}$ & E1820 & 346 & FM-617 & GTA & BM-1 & X-Weld & Air & 1000 & 76000 & 950 \\
\hline K-GTA-QUAL & $0.4 \mathrm{~T}-\mathrm{CT}$ & E1820 & 347 & FM-617 & GTA & BM-1 & X-Weld & Air & 1000 & 76000 & 950 \\
\hline K-GTA-QUAL & $0.4 \mathrm{~T}-\mathrm{CT}$ & E1820 & 348 & FM-617 & GTA & BM-1 & X-Weld & Air & 1000 & 76000 & 950 \\
\hline K-GTA-QUAL & $0.4 \mathrm{~T}-\mathrm{CT}$ & E1820 & 349 & FM-617 & GTA & NA & Deposited & Air & 750 & 120000 & 0 \\
\hline K-GTA-QUAL & $0.4 \mathrm{~T}-\mathrm{CT}$ & E1820 & 350 & FM-617 & GTA & NA & Deposited & Air & 750 & 120000 & 0 \\
\hline K-GTA-QUAL & $0.4 \mathrm{~T}-\mathrm{CT}$ & E1820 & 351 & FM-617 & GTA & NA & Deposited & Air & 750 & 120000 & 0 \\
\hline K-GTA-QUAL & $0.4 \mathrm{~T}-\mathrm{CT}$ & E1820 & 352 & FM-617 & GTA & NA & Deposited & Air & 750 & 120000 & 100 \\
\hline K-GTA-QUAL & $0.4 \mathrm{~T}-\mathrm{CT}$ & E1820 & 353 & FM-617 & GTA & NA & Deposited & Air & 750 & 120000 & 100 \\
\hline K-GTA-QUAL & $0.4 \mathrm{~T}-\mathrm{CT}$ & E1820 & 354 & FM-617 & GTA & NA & Deposited & Air & 750 & 120000 & 100 \\
\hline K-GTA-QUAL & $0.4 \mathrm{~T}-\mathrm{CT}$ & E1820 & 355 & FM-617 & GTA & NA & Deposited & Air & 750 & 120000 & 950 \\
\hline K-GTA-QUAL & $0.4 \mathrm{~T}-\mathrm{CT}$ & E1820 & 356 & FM-617 & GTA & NA & Deposited & Air & 750 & 120000 & 950 \\
\hline K-GTA-QUAL & $0.4 \mathrm{~T}-\mathrm{CT}$ & E1820 & 357 & FM-617 & GTA & NA & Deposited & Air & 750 & 120000 & 950 \\
\hline K-GTA-QUAL & $0.4 \mathrm{~T}-\mathrm{CT}$ & E1820 & 358 & FM-617 & GTA & BM-1 & X-Weld & Air & 750 & 120000 & 0 \\
\hline K-GTA-QUAL & $0.4 \mathrm{~T}-\mathrm{CT}$ & E1820 & 359 & FM-617 & GTA & BM-1 & X-Weld & Air & 750 & 120000 & 0 \\
\hline K-GTA-QUAL & $0.4 \mathrm{~T}-\mathrm{CT}$ & E1820 & 360 & FM-617 & GTA & BM-1 & X-Weld & Air & 750 & 120000 & 0 \\
\hline K-GTA-QUAL & $0.4 \mathrm{~T}-\mathrm{CT}$ & E1820 & 361 & FM-617 & GTA & BM-1 & X-Weld & Air & 750 & 120000 & 100 \\
\hline K-GTA-QUAL & $0.4 \mathrm{~T}-\mathrm{CT}$ & E1820 & 362 & FM-617 & GTA & BM-1 & X-Weld & Air & 750 & 120000 & 100 \\
\hline K-GTA-QUAL & $0.4 \mathrm{~T}-\mathrm{CT}$ & E1820 & 363 & FM-617 & GTA & BM-1 & X-Weld & Air & 750 & 120000 & 100 \\
\hline
\end{tabular}


Form 412.09 (Rev. 10)

Idaho National Laboratory
\begin{tabular}{|c|lll|}
\hline NEXT GENERATION NUCLEAR PLANT & Identifier: & PLN-2804 & \\
INTERMEDIATE HEAT EXCHANGER & Revision: & 0 & \\
MATERIALS RESEARCH & Effective Date: & $04 / 30 / 08$ & Page: A-40 of A-114 \\
AND DEVELOPMENT PLAN &
\end{tabular}

\begin{tabular}{|c|c|c|c|c|c|c|c|c|c|c|c|}
\hline Test Prgm & $\begin{array}{l}\text { Spec. } \\
\text { Type }\end{array}$ & $\begin{array}{c}\text { Test } \\
\text { Method }\end{array}$ & $\begin{array}{c}\text { Spec. } \\
\#\end{array}$ & $\begin{array}{l}\text { Filler } \\
\text { Metal } \\
\end{array}$ & $\begin{array}{c}\text { Weld } \\
\text { Process }\end{array}$ & $\begin{array}{c}\text { A617 Plate } \\
\text { Heat \# }\end{array}$ & $\begin{array}{c}\text { Weld to be } \\
\text { Tested }\end{array}$ & Env. & $\begin{array}{c}\text { Exposure } \\
\text { Temp. }\left({ }^{\circ} \mathrm{C}\right)\end{array}$ & $\begin{array}{c}\text { Exposure } \\
\text { Time (h) } \\
\end{array}$ & $\begin{array}{c}\text { Test Temp. } \\
\left({ }^{\circ} \mathrm{C}\right)\end{array}$ \\
\hline K-GTA-QUAL & $0.4 \mathrm{~T}-\mathrm{CT}$ & E1820 & 364 & FM-617 & GTA & BM-1 & X-Weld & Air & 750 & 120000 & 950 \\
\hline K-GTA-QUAL & $0.4 \mathrm{~T}-\mathrm{CT}$ & E1820 & 365 & FM-617 & GTA & BM-1 & X-Weld & Air & 750 & 120000 & 950 \\
\hline K-GTA-QUAL & $0.4 \mathrm{~T}-\mathrm{CT}$ & E1820 & 366 & FM-617 & GTA & BM-1 & X-Weld & Air & 750 & 120000 & 950 \\
\hline K-GTA-QUAL & $0.4 \mathrm{~T}-\mathrm{CT}$ & E1820 & 367 & FM-617 & GTA & NA & Deposited & Air & 1000 & 120000 & 0 \\
\hline K-GTA-QUAL & $0.4 \mathrm{~T}-\mathrm{CT}$ & E1820 & 368 & FM-617 & GTA & NA & Deposited & Air & 1000 & 120000 & 0 \\
\hline K-GTA-QUAL & $0.4 \mathrm{~T}-\mathrm{CT}$ & E1820 & 369 & FM-617 & GTA & NA & Deposited & Air & 1000 & 120000 & 0 \\
\hline K-GTA-QUAL & $0.4 \mathrm{~T}-\mathrm{CT}$ & E1820 & 370 & FM-617 & GTA & NA & Deposited & Air & 1000 & 120000 & 100 \\
\hline K-GTA-QUAL & $0.4 \mathrm{~T}-\mathrm{CT}$ & E1820 & 371 & FM-617 & GTA & NA & Deposited & Air & 1000 & 120000 & 100 \\
\hline K-GTA-QUAL & $0.4 \mathrm{~T}-\mathrm{CT}$ & E1820 & 372 & FM-617 & GTA & NA & Deposited & Air & 1000 & 120000 & 100 \\
\hline K-GTA-QUAL & $0.4 \mathrm{~T}-\mathrm{CT}$ & E1820 & 373 & FM-617 & GTA & NA & Deposited & Air & 1000 & 120000 & 950 \\
\hline K-GTA-QUAL & $0.4 \mathrm{~T}-\mathrm{CT}$ & E1820 & 374 & FM-617 & GTA & NA & Deposited & Air & 1000 & 120000 & 950 \\
\hline K-GTA-QUAL & $0.4 \mathrm{~T}-\mathrm{CT}$ & E1820 & 375 & FM-617 & GTA & $\mathrm{NA}$ & Deposited & Air & 1000 & 120000 & 950 \\
\hline K-GTA-QUAL & $0.4 \mathrm{~T}-\mathrm{CT}$ & E1820 & 376 & FM-617 & GTA & BM-1 & X-Weld & Air & 1000 & 120000 & 0 \\
\hline K-GTA-QUAL & $0.4 \mathrm{~T}-\mathrm{CT}$ & E1820 & 377 & FM-617 & GTA & BM-1 & X-Weld & Air & 1000 & 120000 & 0 \\
\hline K-GTA-QUAL & $0.4 \mathrm{~T}-\mathrm{CT}$ & E1820 & 378 & FM-617 & GTA & BM-1 & X-Weld & Air & 1000 & 120000 & 0 \\
\hline K-GTA-QUAL & $0.4 \mathrm{~T}-\mathrm{CT}$ & $\mathrm{E} 1820$ & 379 & FM-617 & GTA & BM-1 & X-Weld & Air & 1000 & 120000 & 100 \\
\hline K-GTA-QUAL & $0.4 \mathrm{~T}-\mathrm{CT}$ & E1820 & 380 & FM-617 & GTA & BM-1 & X-Weld & Air & 1000 & 120000 & 100 \\
\hline K-GTA-QUAL & $0.4 \mathrm{~T}-\mathrm{CT}$ & E1820 & 381 & FM-617 & GTA & BM-1 & X-Weld & Air & 1000 & 120000 & 100 \\
\hline K-GTA-QUAL & $0.4 \mathrm{~T}-\mathrm{CT}$ & E1820 & 382 & FM-617 & GTA & BM-1 & X-Weld & Air & 1000 & 120000 & 950 \\
\hline K-GTA-QUAL & $0.4 \mathrm{~T}-\mathrm{CT}$ & E1820 & 383 & FM-617 & GTA & BM-1 & X-Weld & Air & 1000 & 120000 & 950 \\
\hline K-GTA-QUAL & $0.4 \mathrm{~T}-\mathrm{CT}$ & E1820 & 384 & FM-617 & GTA & BM-1 & X-Weld & Air & 1000 & 120000 & 950 \\
\hline
\end{tabular}




Idaho National Laboratory
\begin{tabular}{|c|lll|}
\hline NEXT GENERATION NUCLEAR PLANT & Identifier: & PLN-2804 & \\
INTERMEDIATE HEAT EXCHANGER & Revision: & 0 & \\
MATERIALS RESEARCH & Effective Date: & $04 / 30 / 08$ & Page: A-41 of A-114 \\
AND DEVELOPMENT PLAN &
\end{tabular}

\begin{tabular}{|c|c|c|c|c|c|c|c|c|c|c|c|}
\hline Test Prgm & $\begin{array}{l}\text { Spec. } \\
\text { Type }\end{array}$ & $\begin{array}{c}\text { Test } \\
\text { Method }\end{array}$ & $\begin{array}{c}\text { Spec. } \\
\#\end{array}$ & $\begin{array}{c}\text { Weld } \\
\text { Electrode }\end{array}$ & $\begin{array}{c}\text { Weld } \\
\text { Process }\end{array}$ & $\begin{array}{c}\text { A617 Plate } \\
\text { Heat \# }\end{array}$ & $\begin{array}{l}\text { Weld to be } \\
\text { Tested }\end{array}$ & Env. & $\begin{array}{l}\text { Exposure } \\
\text { Temp. }\left({ }^{\circ} \mathrm{C}\right)\end{array}$ & $\begin{array}{l}\text { Exposure } \\
\text { Time (h) }\end{array}$ & $\begin{array}{c}\text { Test Temp. } \\
\left({ }^{\circ} \mathrm{C}\right)\end{array}$ \\
\hline K-SMA & $0.4 \mathrm{~T}-\mathrm{CT}$ & E1820 & 1 & E-117 & SMA & NA & Deposited & Air & None & None & 0 \\
\hline K-SMA & $0.4 \mathrm{~T}-\mathrm{CT}$ & E1820 & 2 & E-117 & SMA & NA & Deposited & Air & None & None & 0 \\
\hline K-SMA & $0.4 \mathrm{~T}-\mathrm{CT}$ & E1820 & 3 & E-117 & SMA & NA & Deposited & Air & None & None & 0 \\
\hline K-SMA & $0.4 \mathrm{~T}-\mathrm{CT}$ & E1820 & 4 & E-117 & SMA & NA & Deposited & Air & None & None & 0 \\
\hline K-SMA & $0.4 \mathrm{~T}-\mathrm{CT}$ & E1820 & 5 & E-117 & SMA & NA & Deposited & Air & None & None & 0 \\
\hline K-SMA & $0.4 \mathrm{~T}-\mathrm{CT}$ & E1820 & 6 & E-117 & SMA & NA & Deposited & Air & None & None & 0 \\
\hline K-SMA & $0.4 \mathrm{~T}-\mathrm{CT}$ & E1820 & 7 & E-117 & SMA & NA & Deposited & Air & None & None & 100 \\
\hline K-SMA & $0.4 \mathrm{~T}-\mathrm{CT}$ & E1820 & 8 & E-117 & SMA & NA & Deposited & Air & None & None & 100 \\
\hline K-SMA & $0.4 \mathrm{~T}-\mathrm{CT}$ & E1820 & 9 & E-117 & SMA & NA & Deposited & Air & None & None & 100 \\
\hline K-SMA & $0.4 \mathrm{~T}-\mathrm{CT}$ & E1820 & 10 & E-117 & SMA & NA & Deposited & Air & None & None & 100 \\
\hline K-SMA & $0.4 \mathrm{~T}-\mathrm{CT}$ & E1820 & 11 & E-117 & SMA & NA & Deposited & Air & None & None & 100 \\
\hline K-SMA & $0.4 \mathrm{~T}-\mathrm{CT}$ & E1820 & 12 & E-117 & SMA & NA & Deposited & Air & None & None & 100 \\
\hline K-SMA & $0.4 \mathrm{~T}-\mathrm{CT}$ & E1820 & 13 & E-117 & SMA & NA & Deposited & Air & None & None & 250 \\
\hline K-SMA & $0.4 \mathrm{~T}-\mathrm{CT}$ & E1820 & 14 & E-117 & SMA & NA & Deposited & Air & None & None & 250 \\
\hline K-SMA & $0.4 \mathrm{~T}-\mathrm{CT}$ & E1820 & 15 & E-117 & SMA & NA & Deposited & Air & None & None & 250 \\
\hline K-SMA & $0.4 \mathrm{~T}-\mathrm{CT}$ & E1820 & 16 & E-117 & SMA & NA & Deposited & Air & None & None & 250 \\
\hline K-SMA & $0.4 \mathrm{~T}-\mathrm{CT}$ & E1820 & 17 & E-117 & SMA & NA & Deposited & Air & None & None & 250 \\
\hline K-SMA & $0.4 \mathrm{~T}-\mathrm{CT}$ & E1820 & 18 & E-117 & SMA & NA & Deposited & Air & None & None & 250 \\
\hline K-SMA & $0.4 \mathrm{~T}-\mathrm{CT}$ & E1820 & 19 & E-117 & SMA & NA & Deposited & Air & None & None & 750 \\
\hline K-SMA & $0.4 \mathrm{~T}-\mathrm{CT}$ & E1820 & 20 & E-117 & SMA & NA & Deposited & Air & None & None & 750 \\
\hline K-SMA & $0.4 \mathrm{~T}-\mathrm{CT}$ & E1820 & 21 & E-117 & SMA & NA & Deposited & Air & None & None & 750 \\
\hline K-SMA & $0.4 \mathrm{~T}-\mathrm{CT}$ & E1820 & 22 & E-117 & SMA & NA & Deposited & Air & None & None & 750 \\
\hline K-SMA & $0.4 \mathrm{~T}-\mathrm{CT}$ & E1820 & 23 & E-117 & SMA & NA & Deposited & Air & None & None & 750 \\
\hline K-SMA & $0.4 \mathrm{~T}-\mathrm{CT}$ & E1820 & 24 & E-117 & SMA & NA & Deposited & Air & None & None & 750 \\
\hline K-SMA & $0.4 \mathrm{~T}-\mathrm{CT}$ & E1820 & 25 & E-117 & SMA & NA & Deposited & Air & None & None & 950 \\
\hline K-SMA & $0.4 \mathrm{~T}-\mathrm{CT}$ & E1820 & 26 & E-117 & SMA & NA & Deposited & Air & None & None & 950 \\
\hline K-SMA & $0.4 \mathrm{~T}-\mathrm{CT}$ & E1820 & 27 & E-117 & SMA & NA & Deposited & Air & None & None & 950 \\
\hline
\end{tabular}


Idaho National Laboratory

\begin{tabular}{|c|c|c|c|}
\hline $\begin{array}{l}\text { NEXT GENERATION NUCLEAR PLANT } \\
\text { INTERMEDIATE HEAT EXCHANGER } \\
\text { MATERIALS RESEARCH } \\
\text { AND DEVELOPMENT PLAN }\end{array}$ & $\begin{array}{l}\text { Identifier: } \\
\text { Revision: } \\
\text { Effective Date: }\end{array}$ & $\begin{array}{l}\text { PLN-2804 } \\
0 \\
04 / 30 / 08\end{array}$ & Pag \\
\hline
\end{tabular}

Table A4(c). Aging Effects on Fracture Toughness of SMA Weld from Weld Electrode 117

\begin{tabular}{|c|c|c|c|c|c|c|c|c|c|c|c|}
\hline Test Prgm & $\begin{array}{l}\text { Spec. } \\
\text { Type }\end{array}$ & $\begin{array}{c}\text { Test } \\
\text { Method }\end{array}$ & $\begin{array}{c}\text { Spec. } \\
\#\end{array}$ & $\begin{array}{c}\text { Weld } \\
\text { Electrode }\end{array}$ & $\begin{array}{c}\text { Weld } \\
\text { Process }\end{array}$ & $\begin{array}{c}\text { A617 Plate } \\
\text { Heat \# }\end{array}$ & $\begin{array}{c}\text { Weld to be } \\
\text { Tested }\end{array}$ & Env. & $\begin{array}{c}\text { Exposure } \\
\text { Temp. }\left({ }^{\circ} \mathrm{C}\right)\end{array}$ & $\begin{array}{l}\text { Exposure } \\
\text { Time (h) }\end{array}$ & $\begin{array}{c}\text { Test Temp. } \\
\left({ }^{\circ} \mathrm{C}\right)\end{array}$ \\
\hline K-SMA & $0.4 \mathrm{~T}-\mathrm{CT}$ & E1820 & 28 & E-117 & SMA & NA & Deposited & Air & None & None & 950 \\
\hline K-SMA & $0.4 \mathrm{~T}-\mathrm{CT}$ & E1820 & 29 & E-117 & SMA & NA & Deposited & Air & None & None & 950 \\
\hline K-SMA & $0.4 \mathrm{~T}-\mathrm{CT}$ & $\mathrm{E} 1820$ & 30 & E-117 & SMA & NA & Deposited & Air & None & None & 950 \\
\hline K-SMA & $0.4 \mathrm{~T}-\mathrm{CT}$ & E1820 & 31 & E-117 & SMA & BM-1 & X-Weld & Air & None & None & 0 \\
\hline K-SMA & $0.4 \mathrm{~T}-\mathrm{CT}$ & E1820 & 32 & E-117 & SMA & BM-1 & X-Weld & Air & None & None & 0 \\
\hline K-SMA & $0.4 \mathrm{~T}-\mathrm{CT}$ & E1820 & 33 & E-117 & SMA & BM-1 & X-Weld & Air & None & None & 0 \\
\hline K-SMA & $0.4 \mathrm{~T}-\mathrm{CT}$ & E1820 & 34 & E-117 & SMA & BM-1 & X-Weld & Air & None & None & 0 \\
\hline K-SMA & $0.4 \mathrm{~T}-\mathrm{CT}$ & E1820 & 35 & E-117 & SMA & BM-1 & X-Weld & Air & None & None & 0 \\
\hline K-SMA & $0.4 \mathrm{~T}-\mathrm{CT}$ & E1820 & 36 & E-117 & SMA & BM-1 & X-Weld & Air & None & None & 0 \\
\hline K-SMA & $0.4 \mathrm{~T}-\mathrm{CT}$ & E1820 & 37 & E-117 & SMA & BM-1 & X-Weld & Air & None & None & 100 \\
\hline K-SMA & $0.4 \mathrm{~T}-\mathrm{CT}$ & E1820 & 38 & E-117 & SMA & BM-1 & X-Weld & Air & None & None & 100 \\
\hline K-SMA & $0.4 \mathrm{~T}-\mathrm{CT}$ & E1820 & 39 & E-117 & SMA & BM-1 & X-Weld & Air & None & None & 100 \\
\hline K-SMA & $0.4 \mathrm{~T}-\mathrm{CT}$ & E1820 & 40 & E-117 & SMA & BM-1 & X-Weld & Air & None & None & 100 \\
\hline K-SMA & $0.4 \mathrm{~T}-\mathrm{CT}$ & E1820 & 41 & E-117 & SMA & BM-1 & X-Weld & Air & None & None & 100 \\
\hline K-SMA & $0.4 \mathrm{~T}-\mathrm{CT}$ & E1820 & 42 & E-117 & SMA & BM-1 & X-Weld & Air & None & None & 100 \\
\hline K-SMA & $0.4 \mathrm{~T}-\mathrm{CT}$ & E1820 & 43 & E-117 & SMA & BM-1 & X-Weld & Air & None & None & 250 \\
\hline K-SMA & $0.4 \mathrm{~T}-\mathrm{CT}$ & E1820 & 44 & E-117 & SMA & BM-1 & X-Weld & Air & None & None & 250 \\
\hline K-SMA & $0.4 \mathrm{~T}-\mathrm{CT}$ & E1820 & 45 & E-117 & SMA & BM-1 & X-Weld & Air & None & None & 250 \\
\hline K-SMA & $0.4 \mathrm{~T}-\mathrm{CT}$ & E1820 & 46 & E-117 & SMA & BM-1 & X-Weld & Air & None & None & 250 \\
\hline K-SMA & $0.4 \mathrm{~T}-\mathrm{CT}$ & E1820 & 47 & E-117 & SMA & BM-1 & X-Weld & Air & None & None & 250 \\
\hline K-SMA & $0.4 \mathrm{~T}-\mathrm{CT}$ & E1820 & 48 & E-117 & SMA & BM-1 & X-Weld & Air & None & None & 250 \\
\hline K-SMA & $0.4 \mathrm{~T}-\mathrm{CT}$ & E1820 & 49 & E-117 & SMA & BM-1 & X-Weld & Air & None & None & 750 \\
\hline K-SMA & $0.4 \mathrm{~T}-\mathrm{CT}$ & E1820 & 50 & E-117 & SMA & BM-1 & X-Weld & Air & None & None & 750 \\
\hline K-SMA & $0.4 \mathrm{~T}-\mathrm{CT}$ & E1820 & 51 & E-117 & SMA & BM-1 & X-Weld & Air & None & None & 750 \\
\hline K-SMA & $0.4 \mathrm{~T}-\mathrm{CT}$ & E1820 & 52 & E-117 & SMA & BM-1 & X-Weld & Air & None & None & 750 \\
\hline K-SMA & $0.4 \mathrm{~T}-\mathrm{CT}$ & E1820 & 53 & E-117 & SMA & BM-1 & X-Weld & Air & None & None & 750 \\
\hline K-SMA & $0.4 \mathrm{~T}-\mathrm{CT}$ & E1820 & 54 & E-117 & SMA & BM-1 & X-Weld & Air & None & None & 750 \\
\hline K-SMA & $0.4 \mathrm{~T}-\mathrm{CT}$ & E1820 & 55 & E-117 & SMA & BM-1 & X-Weld & Air & None & None & 950 \\
\hline
\end{tabular}


Idaho National Laboratory

\begin{tabular}{|c|c|c|c|}
\hline $\begin{array}{l}\text { NEXT GENERATION NUCLEAR PLANT } \\
\text { INTERMEDIATE HEAT EXCHANGER } \\
\text { MATERIALS RESEARCH } \\
\text { AND DEVELOPMENT PLAN }\end{array}$ & $\begin{array}{l}\text { Identifier: } \\
\text { Revision: } \\
\text { Effective Date: }\end{array}$ & $\begin{array}{l}\text { PLN-2804 } \\
0 \\
04 / 30 / 08\end{array}$ & A-114 \\
\hline
\end{tabular}

Table A4(c). Aging Effects on Fracture Toughness of SMA Weld from Weld Electrode 117

\begin{tabular}{|c|c|c|c|c|c|c|c|c|c|c|c|}
\hline Test Prgm & $\begin{array}{l}\text { Spec. } \\
\text { Type }\end{array}$ & $\begin{array}{c}\text { Test } \\
\text { Method }\end{array}$ & $\begin{array}{c}\text { Spec. } \\
\#\end{array}$ & $\begin{array}{c}\text { Weld } \\
\text { Electrode }\end{array}$ & $\begin{array}{c}\text { Weld } \\
\text { Process }\end{array}$ & $\begin{array}{c}\text { A617 Plate } \\
\text { Heat \# }\end{array}$ & $\begin{array}{c}\text { Weld to be } \\
\text { Tested }\end{array}$ & Env. & $\begin{array}{c}\text { Exposure } \\
\text { Temp. }\left({ }^{\circ} \mathrm{C}\right)\end{array}$ & $\begin{array}{c}\text { Exposure } \\
\text { Time (h) }\end{array}$ & $\begin{array}{c}\text { Test Temp. } \\
\left({ }^{\circ} \mathrm{C}\right)\end{array}$ \\
\hline K-SMA & $0.4 \mathrm{~T}-\mathrm{CT}$ & E1820 & 56 & E-117 & SMA & BM-1 & X-Weld & Air & None & None & 950 \\
\hline K-SMA & $0.4 \mathrm{~T}-\mathrm{CT}$ & E1820 & 57 & E-117 & SMA & BM-1 & X-Weld & Air & None & None & 950 \\
\hline K-SMA & $0.4 \mathrm{~T}-\mathrm{CT}$ & E1820 & 58 & E-117 & SMA & BM-1 & X-Weld & Air & None & None & 950 \\
\hline K-SMA & $0.4 \mathrm{~T}-\mathrm{CT}$ & E1820 & 59 & E-117 & SMA & BM-1 & X-Weld & Air & None & None & 950 \\
\hline K-SMA & $0.4 \mathrm{~T}-\mathrm{CT}$ & E1820 & 60 & E-117 & SMA & BM-1 & X-Weld & Air & None & None & 950 \\
\hline K-SMA & $0.4 \mathrm{~T}-\mathrm{CT}$ & E1820 & 61 & E-117 & SMA & NA & Deposited & Air & 750 & 200 & 0 \\
\hline K-SMA & $0.4 \mathrm{~T}-\mathrm{CT}$ & E1820 & 62 & E-117 & SMA & NA & Deposited & Air & 750 & 200 & 0 \\
\hline K-SMA & $0.4 \mathrm{~T}-\mathrm{CT}$ & E1820 & 63 & E-117 & SMA & NA & Deposited & Air & 750 & 200 & 0 \\
\hline K-SMA & $0.4 \mathrm{~T}-\mathrm{CT}$ & E1820 & 64 & E-117 & SMA & NA & Deposited & Air & 750 & 200 & 100 \\
\hline K-SMA & $0.4 \mathrm{~T}-\mathrm{CT}$ & $\mathrm{E} 1820$ & 65 & E-117 & SMA & NA & Deposited & Air & 750 & 200 & 100 \\
\hline K-SMA & $0.4 \mathrm{~T}-\mathrm{CT}$ & E1820 & 66 & E-117 & SMA & NA & Deposited & Air & 750 & 200 & 100 \\
\hline K-SMA & $0.4 \mathrm{~T}-\mathrm{CT}$ & E1820 & 67 & E-117 & SMA & NA & Deposited & Air & 750 & 200 & 950 \\
\hline K-SMA & $0.4 \mathrm{~T}-\mathrm{CT}$ & E1820 & 68 & E-117 & SMA & NA & Deposited & Air & 750 & 200 & 950 \\
\hline K-SMA & $0.4 \mathrm{~T}-\mathrm{CT}$ & $\mathrm{E} 1820$ & 69 & E-117 & SMA & NA & Deposited & Air & 750 & 200 & 950 \\
\hline K-SMA & $0.4 \mathrm{~T}-\mathrm{CT}$ & E1820 & 70 & E-117 & SMA & BM-1 & X-Weld & Air & 750 & 200 & 0 \\
\hline K-SMA & $0.4 \mathrm{~T}-\mathrm{CT}$ & E1820 & 71 & E-117 & SMA & BM-1 & X-Weld & Air & 750 & 200 & 0 \\
\hline K-SMA & $0.4 \mathrm{~T}-\mathrm{CT}$ & $\mathrm{E} 1820$ & 72 & E-117 & SMA & BM-1 & X-Weld & Air & 750 & 200 & 0 \\
\hline K-SMA & $0.4 \mathrm{~T}-\mathrm{CT}$ & E1820 & 73 & E-117 & SMA & BM-1 & X-Weld & Air & 750 & 200 & 100 \\
\hline K-SMA & $0.4 \mathrm{~T}-\mathrm{CT}$ & E1820 & 74 & E-117 & SMA & BM-1 & X-Weld & Air & 750 & 200 & 100 \\
\hline K-SMA & $0.4 \mathrm{~T}-\mathrm{CT}$ & E1820 & 75 & E-117 & SMA & BM-1 & X-Weld & Air & 750 & 200 & 100 \\
\hline K-SMA & $0.4 \mathrm{~T}-\mathrm{CT}$ & E1820 & 76 & E-117 & SMA & BM-1 & X-Weld & Air & 750 & 200 & 950 \\
\hline K-SMA & $0.4 \mathrm{~T}-\mathrm{CT}$ & E1820 & 77 & E-117 & SMA & BM-1 & X-Weld & Air & 750 & 200 & 950 \\
\hline K-SMA & $0.4 \mathrm{~T}-\mathrm{CT}$ & E1820 & 78 & E-117 & SMA & BM-1 & X-Weld & Air & 750 & 200 & 950 \\
\hline K-SMA & $0.4 \mathrm{~T}-\mathrm{CT}$ & $\mathrm{E} 1820$ & 79 & E-117 & SMA & NA & Deposited & Air & 1000 & 200 & 0 \\
\hline K-SMA & $0.4 \mathrm{~T}-\mathrm{CT}$ & E1820 & 80 & E-117 & SMA & NA & Deposited & Air & 1000 & 200 & 0 \\
\hline K-SMA & $0.4 \mathrm{~T}-\mathrm{CT}$ & E1820 & 81 & E-117 & SMA & NA & Deposited & Air & 1000 & 200 & 0 \\
\hline K-SMA & $0.4 \mathrm{~T}-\mathrm{CT}$ & E1820 & 82 & E-117 & SMA & NA & Deposited & Air & 1000 & 200 & 100 \\
\hline K-SMA & $0.4 \mathrm{~T}-\mathrm{CT}$ & E1820 & 83 & E-117 & SMA & NA & Deposited & Air & 1000 & 200 & 100 \\
\hline
\end{tabular}


Idaho National Laboratory

\begin{tabular}{|c|c|c|c|}
\hline $\begin{array}{l}\text { NEXT GENERATION NUCLEAR PLANT } \\
\text { INTERMEDIATE HEAT EXCHANGER } \\
\text { MATERIALS RESEARCH } \\
\text { AND DEVELOPMENT PLAN }\end{array}$ & $\begin{array}{l}\text { Identifier: } \\
\text { Revision: } \\
\text { Effective Date: }\end{array}$ & $\begin{array}{l}\text { PLN-2804 } \\
0 \\
04 / 30 / 08\end{array}$ & Pag \\
\hline
\end{tabular}

Table A4(c). Aging Effects on Fracture Toughness of SMA Weld from Weld Electrode 117

\begin{tabular}{|c|c|c|c|c|c|c|c|c|c|c|c|}
\hline Test Prgm & $\begin{array}{l}\text { Spec. } \\
\text { Type }\end{array}$ & $\begin{array}{c}\text { Test } \\
\text { Method }\end{array}$ & $\begin{array}{c}\text { Spec. } \\
\#\end{array}$ & $\begin{array}{c}\text { Weld } \\
\text { Electrode }\end{array}$ & $\begin{array}{c}\text { Weld } \\
\text { Process }\end{array}$ & $\begin{array}{c}\text { A617 Plate } \\
\text { Heat \# }\end{array}$ & $\begin{array}{c}\text { Weld to be } \\
\text { Tested }\end{array}$ & Env. & $\begin{array}{c}\text { Exposure } \\
\text { Temp. }\left({ }^{\circ} \mathrm{C}\right)\end{array}$ & $\begin{array}{c}\text { Exposure } \\
\text { Time (h) }\end{array}$ & $\begin{array}{c}\text { Test Temp. } \\
\left({ }^{\circ} \mathrm{C}\right)\end{array}$ \\
\hline K-SMA & $0.4 \mathrm{~T}-\mathrm{CT}$ & E1820 & 84 & E-117 & SMA & NA & Deposited & Air & 1000 & 200 & 100 \\
\hline K-SMA & $0.4 \mathrm{~T}-\mathrm{CT}$ & E1820 & 85 & E-117 & SMA & NA & Deposited & Air & 1000 & 200 & 950 \\
\hline K-SMA & $0.4 \mathrm{~T}-\mathrm{CT}$ & E1820 & 86 & E-117 & SMA & NA & Deposited & Air & 1000 & 200 & 950 \\
\hline K-SMA & $0.4 \mathrm{~T}-\mathrm{CT}$ & $\mathrm{E} 1820$ & 87 & E-117 & SMA & NA & Deposited & Air & 1000 & 200 & 950 \\
\hline K-SMA & $0.4 \mathrm{~T}-\mathrm{CT}$ & E1820 & 88 & E-117 & SMA & BM-1 & X-Weld & Air & 1000 & 200 & 0 \\
\hline K-SMA & $0.4 \mathrm{~T}-\mathrm{CT}$ & E1820 & 89 & E-117 & SMA & BM-1 & X-Weld & Air & 1000 & 200 & 0 \\
\hline K-SMA & $0.4 \mathrm{~T}-\mathrm{CT}$ & E1820 & 90 & E-117 & SMA & BM-1 & X-Weld & Air & 1000 & 200 & 0 \\
\hline K-SMA & $0.4 \mathrm{~T}-\mathrm{CT}$ & E1820 & 91 & E-117 & SMA & BM-1 & X-Weld & Air & 1000 & 200 & 100 \\
\hline K-SMA & $0.4 \mathrm{~T}-\mathrm{CT}$ & E1820 & 92 & E-117 & SMA & BM-1 & X-Weld & Air & 1000 & 200 & 100 \\
\hline K-SMA & $0.4 \mathrm{~T}-\mathrm{CT}$ & $\mathrm{E} 1820$ & 93 & E-117 & SMA & BM-1 & X-Weld & Air & 1000 & 200 & 100 \\
\hline K-SMA & $0.4 \mathrm{~T}-\mathrm{CT}$ & E1820 & 94 & E-117 & SMA & BM-1 & X-Weld & Air & 1000 & 200 & 950 \\
\hline K-SMA & $0.4 \mathrm{~T}-\mathrm{CT}$ & E1820 & 95 & E-117 & SMA & BM-1 & X-Weld & Air & 1000 & 200 & 950 \\
\hline K-SMA & $0.4 \mathrm{~T}-\mathrm{CT}$ & E1820 & 96 & E-117 & SMA & BM-1 & X-Weld & Air & 1000 & 200 & 950 \\
\hline K-SMA & $0.4 \mathrm{~T}-\mathrm{CT}$ & E1820 & 97 & E-117 & SMA & NA & Deposited & Air & 750 & 650 & 0 \\
\hline K-SMA & $0.4 \mathrm{~T}-\mathrm{CT}$ & E1820 & 98 & E-117 & SMA & NA & Deposited & Air & 750 & 650 & 0 \\
\hline K-SMA & $0.4 \mathrm{~T}-\mathrm{CT}$ & E1820 & 99 & E-117 & SMA & NA & Deposited & Air & 750 & 650 & 0 \\
\hline K-SMA & $0.4 \mathrm{~T}-\mathrm{CT}$ & $\mathrm{E} 1820$ & 100 & E-117 & SMA & NA & Deposited & Air & 750 & 650 & 100 \\
\hline K-SMA & $0.4 \mathrm{~T}-\mathrm{CT}$ & E1820 & 101 & E-117 & SMA & NA & Deposited & Air & 750 & 650 & 100 \\
\hline K-SMA & $0.4 \mathrm{~T}-\mathrm{CT}$ & E1820 & 102 & E-117 & SMA & NA & Deposited & Air & 750 & 650 & 100 \\
\hline K-SMA & $0.4 \mathrm{~T}-\mathrm{CT}$ & E1820 & 103 & E-117 & SMA & NA & Deposited & Air & 750 & 650 & 950 \\
\hline K-SMA & $0.4 \mathrm{~T}-\mathrm{CT}$ & E1820 & 104 & E-117 & SMA & NA & Deposited & Air & 750 & 650 & 950 \\
\hline K-SMA & $0.4 \mathrm{~T}-\mathrm{CT}$ & E1820 & 105 & E-117 & SMA & NA & Deposited & Air & 750 & 650 & 950 \\
\hline K-SMA & $0.4 \mathrm{~T}-\mathrm{CT}$ & E1820 & 106 & E-117 & SMA & BM-1 & X-Weld & Air & 750 & 650 & 0 \\
\hline K-SMA & $0.4 \mathrm{~T}-\mathrm{CT}$ & $\mathrm{E} 1820$ & 107 & E-117 & SMA & BM-1 & X-Weld & Air & 750 & 650 & 0 \\
\hline K-SMA & $0.4 \mathrm{~T}-\mathrm{CT}$ & E1820 & 108 & E-117 & SMA & BM-1 & X-Weld & Air & 750 & 650 & 0 \\
\hline K-SMA & $0.4 \mathrm{~T}-\mathrm{CT}$ & E1820 & 109 & E-117 & SMA & BM-1 & X-Weld & Air & 750 & 650 & 100 \\
\hline K-SMA & $0.4 \mathrm{~T}-\mathrm{CT}$ & E1820 & 110 & E-117 & SMA & BM-1 & X-Weld & Air & 750 & 650 & 100 \\
\hline K-SMA & $0.4 \mathrm{~T}-\mathrm{CT}$ & E1820 & 111 & E-117 & SMA & BM-1 & X-Weld & Air & 750 & 650 & 100 \\
\hline
\end{tabular}


Idaho National Laboratory

\begin{tabular}{|c|c|c|c|}
\hline $\begin{array}{l}\text { NEXT GENERATION NUCLEAR PLANT } \\
\text { INTERMEDIATE HEAT EXCHANGER } \\
\text { MATERIALS RESEARCH } \\
\text { AND DEVELOPMENT PLAN }\end{array}$ & $\begin{array}{l}\text { Identifier: } \\
\text { Revision: } \\
\text { Effective Date: }\end{array}$ & $\begin{array}{l}\text { PLN-2804 } \\
0 \\
04 / 30 / 08\end{array}$ & A-114 \\
\hline
\end{tabular}

Table A4(c). Aging Effects on Fracture Toughness of SMA Weld from Weld Electrode 117

\begin{tabular}{|c|c|c|c|c|c|c|c|c|c|c|c|}
\hline Test Prgm & $\begin{array}{l}\text { Spec. } \\
\text { Type }\end{array}$ & $\begin{array}{c}\text { Test } \\
\text { Method }\end{array}$ & $\begin{array}{c}\text { Spec. } \\
\#\end{array}$ & $\begin{array}{c}\text { Weld } \\
\text { Electrode }\end{array}$ & $\begin{array}{c}\text { Weld } \\
\text { Process }\end{array}$ & $\begin{array}{c}\text { A617 Plate } \\
\text { Heat \# }\end{array}$ & $\begin{array}{c}\text { Weld to be } \\
\text { Tested }\end{array}$ & Env. & $\begin{array}{c}\text { Exposure } \\
\text { Temp. }\left({ }^{\circ} \mathrm{C}\right)\end{array}$ & $\begin{array}{c}\text { Exposure } \\
\text { Time (h) }\end{array}$ & $\begin{array}{c}\text { Test Temp. } \\
\left({ }^{\circ} \mathrm{C}\right)\end{array}$ \\
\hline K-SMA & $0.4 \mathrm{~T}-\mathrm{CT}$ & E1820 & 112 & E-117 & SMA & BM-1 & X-Weld & Air & 750 & 650 & 950 \\
\hline K-SMA & $0.4 \mathrm{~T}-\mathrm{CT}$ & E1820 & 113 & E-117 & SMA & BM-1 & X-Weld & Air & 750 & 650 & 950 \\
\hline K-SMA & $0.4 \mathrm{~T}-\mathrm{CT}$ & E1820 & 114 & E-117 & SMA & BM-1 & X-Weld & Air & 750 & 650 & 950 \\
\hline K-SMA & $0.4 \mathrm{~T}-\mathrm{CT}$ & $\mathrm{E} 1820$ & 115 & E-117 & SMA & NA & Deposited & Air & 1000 & 650 & 0 \\
\hline K-SMA & $0.4 \mathrm{~T}-\mathrm{CT}$ & E1820 & 116 & E-117 & SMA & NA & Deposited & Air & 1000 & 650 & 0 \\
\hline K-SMA & $0.4 \mathrm{~T}-\mathrm{CT}$ & E1820 & 117 & E-117 & SMA & NA & Deposited & Air & 1000 & 650 & 0 \\
\hline K-SMA & $0.4 \mathrm{~T}-\mathrm{CT}$ & E1820 & 118 & E-117 & SMA & NA & Deposited & Air & 1000 & 650 & 100 \\
\hline K-SMA & $0.4 \mathrm{~T}-\mathrm{CT}$ & E1820 & 119 & E-117 & SMA & NA & Deposited & Air & 1000 & 650 & 100 \\
\hline K-SMA & $0.4 \mathrm{~T}-\mathrm{CT}$ & E1820 & 120 & E-117 & SMA & NA & Deposited & Air & 1000 & 650 & 100 \\
\hline K-SMA & $0.4 \mathrm{~T}-\mathrm{CT}$ & $\mathrm{E} 1820$ & 121 & E-117 & SMA & NA & Deposited & Air & 1000 & 650 & 950 \\
\hline K-SMA & $0.4 \mathrm{~T}-\mathrm{CT}$ & E1820 & 122 & E-117 & SMA & NA & Deposited & Air & 1000 & 650 & 950 \\
\hline K-SMA & $0.4 \mathrm{~T}-\mathrm{CT}$ & $\mathrm{E} 1820$ & 123 & E-117 & SMA & NA & Deposited & Air & 1000 & 650 & 950 \\
\hline K-SMA & $0.4 \mathrm{~T}-\mathrm{CT}$ & E1820 & 124 & E-117 & SMA & BM-1 & X-Weld & Air & 1000 & 650 & 0 \\
\hline K-SMA & $0.4 \mathrm{~T}-\mathrm{CT}$ & $\mathrm{E} 1820$ & 125 & E-117 & SMA & BM-1 & X-Weld & Air & 1000 & 650 & 0 \\
\hline K-SMA & $0.4 \mathrm{~T}-\mathrm{CT}$ & E1820 & 126 & E-117 & SMA & BM-1 & X-Weld & Air & 1000 & 650 & 0 \\
\hline K-SMA & $0.4 \mathrm{~T}-\mathrm{CT}$ & E1820 & 127 & E-117 & SMA & BM-1 & X-Weld & Air & 1000 & 650 & 100 \\
\hline K-SMA & $0.4 \mathrm{~T}-\mathrm{CT}$ & $\mathrm{E} 1820$ & 128 & E-117 & SMA & BM-1 & X-Weld & Air & 1000 & 650 & 100 \\
\hline K-SMA & $0.4 \mathrm{~T}-\mathrm{CT}$ & E1820 & 129 & E-117 & SMA & BM-1 & X-Weld & Air & 1000 & 650 & 100 \\
\hline K-SMA & $0.4 \mathrm{~T}-\mathrm{CT}$ & E1820 & 130 & E-117 & SMA & BM-1 & X-Weld & Air & 1000 & 650 & 950 \\
\hline K-SMA & $0.4 \mathrm{~T}-\mathrm{CT}$ & E1820 & 131 & E-117 & SMA & BM-1 & X-Weld & Air & 1000 & 650 & 950 \\
\hline K-SMA & $0.4 \mathrm{~T}-\mathrm{CT}$ & E1820 & 132 & E-117 & SMA & BM-1 & X-Weld & Air & 1000 & 650 & 950 \\
\hline K-SMA & $0.4 \mathrm{~T}-\mathrm{CT}$ & E1820 & 133 & E-117 & SMA & NA & Deposited & Air & 750 & 2000 & 0 \\
\hline K-SMA & $0.4 \mathrm{~T}-\mathrm{CT}$ & E1820 & 134 & E-117 & SMA & NA & Deposited & Air & 750 & 2000 & 0 \\
\hline K-SMA & $0.4 \mathrm{~T}-\mathrm{CT}$ & $\mathrm{E} 1820$ & 135 & E-117 & SMA & NA & Deposited & Air & 750 & 2000 & 0 \\
\hline K-SMA & $0.4 \mathrm{~T}-\mathrm{CT}$ & E1820 & 136 & E-117 & SMA & NA & Deposited & Air & 750 & 2000 & 100 \\
\hline K-SMA & $0.4 \mathrm{~T}-\mathrm{CT}$ & E1820 & 137 & E-117 & SMA & NA & Deposited & Air & 750 & 2000 & 100 \\
\hline K-SMA & $0.4 \mathrm{~T}-\mathrm{CT}$ & E1820 & 138 & E-117 & SMA & NA & Deposited & Air & 750 & 2000 & 100 \\
\hline K-SMA & $0.4 \mathrm{~T}-\mathrm{CT}$ & E1820 & 139 & E-117 & SMA & NA & Deposited & Air & 750 & 2000 & 950 \\
\hline
\end{tabular}


Idaho National Laboratory

\begin{tabular}{|c|c|c|c|}
\hline $\begin{array}{l}\text { NEXT GENERATION NUCLEAR PLANT } \\
\text { INTERMEDIATE HEAT EXCHANGER } \\
\text { MATERIALS RESEARCH } \\
\text { AND DEVELOPMENT PLAN }\end{array}$ & $\begin{array}{l}\text { Identifier: } \\
\text { Revision: } \\
\text { Effective Date: }\end{array}$ & $\begin{array}{l}\text { PLN-2804 } \\
0 \\
04 / 30 / 08\end{array}$ & Pag \\
\hline
\end{tabular}

Table A4(c). Aging Effects on Fracture Toughness of SMA Weld from Weld Electrode 117

\begin{tabular}{|c|c|c|c|c|c|c|c|c|c|c|c|}
\hline Test Prgm & $\begin{array}{l}\text { Spec. } \\
\text { Type }\end{array}$ & $\begin{array}{c}\text { Test } \\
\text { Method }\end{array}$ & $\begin{array}{c}\text { Spec. } \\
\#\end{array}$ & $\begin{array}{c}\text { Weld } \\
\text { Electrode }\end{array}$ & $\begin{array}{c}\text { Weld } \\
\text { Process }\end{array}$ & $\begin{array}{c}\text { A617 Plate } \\
\text { Heat \# }\end{array}$ & $\begin{array}{c}\text { Weld to be } \\
\text { Tested }\end{array}$ & Env. & $\begin{array}{c}\text { Exposure } \\
\text { Temp. }\left({ }^{\circ} \mathrm{C}\right)\end{array}$ & $\begin{array}{c}\text { Exposure } \\
\text { Time (h) }\end{array}$ & $\begin{array}{c}\text { Test Temp. } \\
\left({ }^{\circ} \mathrm{C}\right)\end{array}$ \\
\hline K-SMA & $0.4 \mathrm{~T}-\mathrm{CT}$ & E1820 & 140 & E-117 & SMA & NA & Deposited & Air & 750 & 2000 & 950 \\
\hline K-SMA & $0.4 \mathrm{~T}-\mathrm{CT}$ & E1820 & 141 & E-117 & SMA & NA & Deposited & Air & 750 & 2000 & 950 \\
\hline K-SMA & $0.4 \mathrm{~T}-\mathrm{CT}$ & E1820 & 142 & E-117 & SMA & BM-1 & X-Weld & Air & 750 & 2000 & 0 \\
\hline K-SMA & $0.4 \mathrm{~T}-\mathrm{CT}$ & E1820 & 143 & E-117 & SMA & BM-1 & X-Weld & Air & 750 & 2000 & 0 \\
\hline K-SMA & $0.4 \mathrm{~T}-\mathrm{CT}$ & E1820 & 144 & E-117 & SMA & BM-1 & X-Weld & Air & 750 & 2000 & 0 \\
\hline K-SMA & $0.4 \mathrm{~T}-\mathrm{CT}$ & E1820 & 145 & E-117 & SMA & BM-1 & X-Weld & Air & 750 & 2000 & 100 \\
\hline K-SMA & $0.4 \mathrm{~T}-\mathrm{CT}$ & E1820 & 146 & E-117 & SMA & BM-1 & X-Weld & Air & 750 & 2000 & 100 \\
\hline K-SMA & $0.4 \mathrm{~T}-\mathrm{CT}$ & E1820 & 147 & E-117 & SMA & BM-1 & X-Weld & Air & 750 & 2000 & 100 \\
\hline K-SMA & $0.4 \mathrm{~T}-\mathrm{CT}$ & E1820 & 148 & E-117 & SMA & BM-1 & X-Weld & Air & 750 & 2000 & 950 \\
\hline K-SMA & $0.4 \mathrm{~T}-\mathrm{CT}$ & E1820 & 149 & E-117 & SMA & BM-1 & X-Weld & Air & 750 & 2000 & 950 \\
\hline K-SMA & $0.4 \mathrm{~T}-\mathrm{CT}$ & E1820 & 150 & E-117 & SMA & BM-1 & X-Weld & Air & 750 & 2000 & 950 \\
\hline K-SMA & $0.4 \mathrm{~T}-\mathrm{CT}$ & E1820 & 151 & E-117 & SMA & NA & Deposited & Air & 1000 & 2000 & 0 \\
\hline K-SMA & $0.4 \mathrm{~T}-\mathrm{CT}$ & E1820 & 152 & E-117 & SMA & NA & Deposited & Air & 1000 & 2000 & 0 \\
\hline K-SMA & $0.4 \mathrm{~T}-\mathrm{CT}$ & E1820 & 153 & E-117 & SMA & NA & Deposited & Air & 1000 & 2000 & 0 \\
\hline K-SMA & $0.4 \mathrm{~T}-\mathrm{CT}$ & E1820 & 154 & E-117 & SMA & NA & Deposited & Air & 1000 & 2000 & 100 \\
\hline K-SMA & $0.4 \mathrm{~T}-\mathrm{CT}$ & E1820 & 155 & E-117 & SMA & NA & Deposited & Air & 1000 & 2000 & 100 \\
\hline K-SMA & $0.4 \mathrm{~T}-\mathrm{CT}$ & E1820 & 156 & E-117 & SMA & NA & Deposited & Air & 1000 & 2000 & 100 \\
\hline K-SMA & $0.4 \mathrm{~T}-\mathrm{CT}$ & E1820 & 157 & E-117 & SMA & NA & Deposited & Air & 1000 & 2000 & 950 \\
\hline K-SMA & $0.4 \mathrm{~T}-\mathrm{CT}$ & E1820 & 158 & E-117 & SMA & NA & Deposited & Air & 1000 & 2000 & 950 \\
\hline K-SMA & $0.4 \mathrm{~T}-\mathrm{CT}$ & E1820 & 159 & E-117 & SMA & NA & Deposited & Air & 1000 & 2000 & 950 \\
\hline K-SMA & $0.4 \mathrm{~T}-\mathrm{CT}$ & E1820 & 160 & E-117 & SMA & BM-1 & X-Weld & Air & 1000 & 2000 & 0 \\
\hline K-SMA & $0.4 \mathrm{~T}-\mathrm{CT}$ & E1820 & 161 & E-117 & SMA & BM-1 & X-Weld & Air & 1000 & 2000 & 0 \\
\hline K-SMA & $0.4 \mathrm{~T}-\mathrm{CT}$ & E1820 & 162 & E-117 & SMA & BM-1 & X-Weld & Air & 1000 & 2000 & 0 \\
\hline K-SMA & $0.4 \mathrm{~T}-\mathrm{CT}$ & E1820 & 163 & E-117 & SMA & BM-1 & X-Weld & Air & 1000 & 2000 & 100 \\
\hline K-SMA & $0.4 \mathrm{~T}-\mathrm{CT}$ & E1820 & 164 & E-117 & SMA & BM-1 & X-Weld & Air & 1000 & 2000 & 100 \\
\hline K-SMA & $0.4 \mathrm{~T}-\mathrm{CT}$ & E1820 & 165 & E-117 & SMA & BM-1 & X-Weld & Air & 1000 & 2000 & 100 \\
\hline K-SMA & $0.4 \mathrm{~T}-\mathrm{CT}$ & E1820 & 166 & E-117 & SMA & BM-1 & X-Weld & Air & 1000 & 2000 & 950 \\
\hline K-SMA & $0.4 \mathrm{~T}-\mathrm{CT}$ & E1820 & 167 & E-117 & SMA & BM-1 & X-Weld & Air & 1000 & 2000 & 950 \\
\hline
\end{tabular}


Idaho National Laboratory

\begin{tabular}{|c|c|c|c|}
\hline $\begin{array}{l}\text { NEXT GENERATION NUCLEAR PLANT } \\
\text { INTERMEDIATE HEAT EXCHANGER } \\
\text { MATERIALS RESEARCH } \\
\text { AND DEVELOPMENT PLAN }\end{array}$ & $\begin{array}{l}\text { Identifier: } \\
\text { Revision: } \\
\text { Effective Date: }\end{array}$ & $\begin{array}{l}\text { PLN-2804 } \\
0 \\
04 / 30 / 08\end{array}$ & Pag \\
\hline
\end{tabular}

Table A4(c). Aging Effects on Fracture Toughness of SMA Weld from Weld Electrode 117

\begin{tabular}{|c|c|c|c|c|c|c|c|c|c|c|c|}
\hline Test Prgm & $\begin{array}{l}\text { Spec. } \\
\text { Type }\end{array}$ & $\begin{array}{c}\text { Test } \\
\text { Method }\end{array}$ & $\begin{array}{c}\text { Spec. } \\
\#\end{array}$ & $\begin{array}{c}\text { Weld } \\
\text { Electrode }\end{array}$ & $\begin{array}{c}\text { Weld } \\
\text { Process }\end{array}$ & $\begin{array}{c}\text { A617 Plate } \\
\text { Heat \# }\end{array}$ & $\begin{array}{c}\text { Weld to be } \\
\text { Tested }\end{array}$ & Env. & $\begin{array}{c}\text { Exposure } \\
\text { Temp. }\left({ }^{\circ} \mathrm{C}\right)\end{array}$ & $\begin{array}{l}\text { Exposure } \\
\text { Time (h) }\end{array}$ & $\begin{array}{c}\text { Test Temp. } \\
\left({ }^{\circ} \mathrm{C}\right)\end{array}$ \\
\hline K-SMA & $0.4 \mathrm{~T}-\mathrm{CT}$ & E1820 & 168 & E-117 & SMA & BM-1 & X-Weld & Air & 1000 & 2000 & 950 \\
\hline K-SMA & $0.4 \mathrm{~T}-\mathrm{CT}$ & E1820 & 169 & E-117 & SMA & NA & Deposited & Air & 750 & 5300 & 0 \\
\hline K-SMA & $0.4 \mathrm{~T}-\mathrm{CT}$ & E1820 & 170 & E-117 & SMA & NA & Deposited & Air & 750 & 5300 & 0 \\
\hline K-SMA & $0.4 \mathrm{~T}-\mathrm{CT}$ & E1820 & 171 & E-117 & SMA & NA & Deposited & Air & 750 & 5300 & 0 \\
\hline K-SMA & $0.4 \mathrm{~T}-\mathrm{CT}$ & E1820 & 172 & E-117 & SMA & NA & Deposited & Air & 750 & 5300 & 100 \\
\hline K-SMA & $0.4 \mathrm{~T}-\mathrm{CT}$ & E1820 & 173 & E-117 & SMA & NA & Deposited & Air & 750 & 5300 & 100 \\
\hline K-SMA & $0.4 \mathrm{~T}-\mathrm{CT}$ & E1820 & 174 & E-117 & SMA & NA & Deposited & Air & 750 & 5300 & 100 \\
\hline K-SMA & $0.4 \mathrm{~T}-\mathrm{CT}$ & E1820 & 175 & E-117 & SMA & NA & Deposited & Air & 750 & 5300 & 950 \\
\hline K-SMA & $0.4 \mathrm{~T}-\mathrm{CT}$ & E1820 & 176 & E-117 & SMA & NA & Deposited & Air & 750 & 5300 & 950 \\
\hline K-SMA & $0.4 \mathrm{~T}-\mathrm{CT}$ & E1820 & 177 & E-117 & SMA & NA & Deposited & Air & 750 & 5300 & 950 \\
\hline K-SMA & $0.4 \mathrm{~T}-\mathrm{CT}$ & E1820 & 178 & E-117 & SMA & BM-1 & X-Weld & Air & 750 & 5300 & 0 \\
\hline K-SMA & $0.4 \mathrm{~T}-\mathrm{CT}$ & E1820 & 179 & E-117 & SMA & BM-1 & X-Weld & Air & 750 & 5300 & 0 \\
\hline K-SMA & $0.4 \mathrm{~T}-\mathrm{CT}$ & E1820 & 180 & E-117 & SMA & BM-1 & X-Weld & Air & 750 & 5300 & 0 \\
\hline K-SMA & $0.4 \mathrm{~T}-\mathrm{CT}$ & E1820 & 181 & E-117 & SMA & BM-1 & X-Weld & Air & 750 & 5300 & 100 \\
\hline K-SMA & $0.4 \mathrm{~T}-\mathrm{CT}$ & E1820 & 182 & E-117 & SMA & BM-1 & X-Weld & Air & 750 & 5300 & 100 \\
\hline K-SMA & $0.4 \mathrm{~T}-\mathrm{CT}$ & E1820 & 183 & E-117 & SMA & BM-1 & X-Weld & Air & 750 & 5300 & 100 \\
\hline K-SMA & $0.4 \mathrm{~T}-\mathrm{CT}$ & E1820 & 184 & E-117 & SMA & BM-1 & X-Weld & Air & 750 & 5300 & 950 \\
\hline K-SMA & $0.4 \mathrm{~T}-\mathrm{CT}$ & E1820 & 185 & E-117 & SMA & BM-1 & X-Weld & Air & 750 & 5300 & 950 \\
\hline K-SMA & $0.4 \mathrm{~T}-\mathrm{CT}$ & E1820 & 186 & E-117 & SMA & BM-1 & X-Weld & Air & 750 & 5300 & 950 \\
\hline K-SMA & $0.4 \mathrm{~T}-\mathrm{CT}$ & E1820 & 187 & E-117 & SMA & NA & Deposited & Air & 1000 & 5300 & 0 \\
\hline K-SMA & $0.4 \mathrm{~T}-\mathrm{CT}$ & E1820 & 188 & E-117 & SMA & NA & Deposited & Air & 1000 & 5300 & 0 \\
\hline K-SMA & $0.4 \mathrm{~T}-\mathrm{CT}$ & E1820 & 189 & E-117 & SMA & NA & Deposited & Air & 1000 & 5300 & 0 \\
\hline K-SMA & $0.4 \mathrm{~T}-\mathrm{CT}$ & E1820 & 190 & E-117 & SMA & NA & Deposited & Air & 1000 & 5300 & 100 \\
\hline K-SMA & $0.4 \mathrm{~T}-\mathrm{CT}$ & E1820 & 191 & E-117 & SMA & NA & Deposited & Air & 1000 & 5300 & 100 \\
\hline K-SMA & $0.4 \mathrm{~T}-\mathrm{CT}$ & E1820 & 192 & E-117 & SMA & NA & Deposited & Air & 1000 & 5300 & 100 \\
\hline K-SMA & $0.4 \mathrm{~T}-\mathrm{CT}$ & $\mathrm{E} 1820$ & 193 & E-117 & SMA & NA & Deposited & Air & 1000 & 5300 & 950 \\
\hline K-SMA & $0.4 \mathrm{~T}-\mathrm{CT}$ & E1820 & 194 & E-117 & SMA & NA & Deposited & Air & 1000 & 5300 & 950 \\
\hline K-SMA & $0.4 \mathrm{~T}-\mathrm{CT}$ & E1820 & 195 & E-117 & SMA & NA & Deposited & Air & 1000 & 5300 & 950 \\
\hline
\end{tabular}


Idaho National Laboratory

\begin{tabular}{|c|c|c|c|}
\hline $\begin{array}{l}\text { NEXT GENERATION NUCLEAR PLANT } \\
\text { INTERMEDIATE HEAT EXCHANGER } \\
\text { MATERIALS RESEARCH } \\
\text { AND DEVELOPMENT PLAN }\end{array}$ & $\begin{array}{l}\text { Identifier: } \\
\text { Revision: } \\
\text { Effective Date: }\end{array}$ & $\begin{array}{l}\text { PLN-2804 } \\
0 \\
04 / 30 / 08\end{array}$ & Pag \\
\hline
\end{tabular}

Table A4(c). Aging Effects on Fracture Toughness of SMA Weld from Weld Electrode 117

\begin{tabular}{|c|c|c|c|c|c|c|c|c|c|c|c|}
\hline Test Prgm & $\begin{array}{l}\text { Spec. } \\
\text { Type }\end{array}$ & $\begin{array}{c}\text { Test } \\
\text { Method }\end{array}$ & $\begin{array}{c}\text { Spec. } \\
\#\end{array}$ & $\begin{array}{c}\text { Weld } \\
\text { Electrode }\end{array}$ & $\begin{array}{c}\text { Weld } \\
\text { Process }\end{array}$ & $\begin{array}{c}\text { A617 Plate } \\
\text { Heat \# }\end{array}$ & $\begin{array}{c}\text { Weld to be } \\
\text { Tested }\end{array}$ & Env. & $\begin{array}{c}\text { Exposure } \\
\text { Temp. }\left({ }^{\circ} \mathrm{C}\right)\end{array}$ & $\begin{array}{l}\text { Exposure } \\
\text { Time (h) }\end{array}$ & $\begin{array}{c}\text { Test Temp. } \\
\left({ }^{\circ} \mathrm{C}\right)\end{array}$ \\
\hline K-SMA & $0.4 \mathrm{~T}-\mathrm{CT}$ & E1820 & 196 & E-117 & SMA & BM-1 & X-Weld & Air & 1000 & 5300 & 0 \\
\hline K-SMA & $0.4 \mathrm{~T}-\mathrm{CT}$ & E1820 & 197 & E-117 & SMA & BM-1 & X-Weld & Air & 1000 & 5300 & 0 \\
\hline K-SMA & $0.4 \mathrm{~T}-\mathrm{CT}$ & E1820 & 198 & E-117 & SMA & BM-1 & X-Weld & Air & 1000 & 5300 & 0 \\
\hline K-SMA & $0.4 \mathrm{~T}-\mathrm{CT}$ & E1820 & 199 & E-117 & SMA & BM-1 & X-Weld & Air & 1000 & 5300 & 100 \\
\hline K-SMA & $0.4 \mathrm{~T}-\mathrm{CT}$ & E1820 & 200 & E-117 & SMA & BM-1 & X-Weld & Air & 1000 & 5300 & 100 \\
\hline K-SMA & $0.4 \mathrm{~T}-\mathrm{CT}$ & E1820 & 201 & E-117 & SMA & BM-1 & X-Weld & Air & 1000 & 5300 & 100 \\
\hline K-SMA & $0.4 \mathrm{~T}-\mathrm{CT}$ & E1820 & 202 & E-117 & SMA & BM-1 & X-Weld & Air & 1000 & 5300 & 950 \\
\hline K-SMA & $0.4 \mathrm{~T}-\mathrm{CT}$ & E1820 & 203 & E-117 & SMA & BM-1 & X-Weld & Air & 1000 & 5300 & 950 \\
\hline K-SMA & $0.4 \mathrm{~T}-\mathrm{CT}$ & E1820 & 204 & E-117 & SMA & BM-1 & X-Weld & Air & 1000 & 5300 & 950 \\
\hline K-SMA & $0.4 \mathrm{~T}-\mathrm{CT}$ & E1820 & 205 & E-117 & SMA & NA & Deposited & Air & 750 & 20000 & 0 \\
\hline K-SMA & $0.4 \mathrm{~T}-\mathrm{CT}$ & E1820 & 206 & E-117 & SMA & NA & Deposited & Air & 750 & 20000 & 0 \\
\hline K-SMA & $0.4 \mathrm{~T}-\mathrm{CT}$ & E1820 & 207 & E-117 & SMA & NA & Deposited & Air & 750 & 20000 & 0 \\
\hline K-SMA & $0.4 \mathrm{~T}-\mathrm{CT}$ & E1820 & 208 & E-117 & SMA & NA & Deposited & Air & 750 & 20000 & 100 \\
\hline K-SMA & $0.4 \mathrm{~T}-\mathrm{CT}$ & E1820 & 209 & E-117 & SMA & NA & Deposited & Air & 750 & 20000 & 100 \\
\hline K-SMA & $0.4 \mathrm{~T}-\mathrm{CT}$ & E1820 & 210 & E-117 & SMA & NA & Deposited & Air & 750 & 20000 & 100 \\
\hline K-SMA & $0.4 \mathrm{~T}-\mathrm{CT}$ & E1820 & 211 & E-117 & SMA & NA & Deposited & Air & 750 & 20000 & 950 \\
\hline K-SMA & $0.4 \mathrm{~T}-\mathrm{CT}$ & E1820 & 212 & E-117 & SMA & NA & Deposited & Air & 750 & 20000 & 950 \\
\hline K-SMA & $0.4 \mathrm{~T}-\mathrm{CT}$ & E1820 & 213 & E-117 & SMA & NA & Deposited & Air & 750 & 20000 & 950 \\
\hline K-SMA & $0.4 \mathrm{~T}-\mathrm{CT}$ & E1820 & 214 & E-117 & SMA & BM-1 & X-Weld & Air & 750 & 20000 & 0 \\
\hline K-SMA & $0.4 \mathrm{~T}-\mathrm{CT}$ & E1820 & 215 & E-117 & SMA & BM-1 & X-Weld & Air & 750 & 20000 & 0 \\
\hline K-SMA & $0.4 \mathrm{~T}-\mathrm{CT}$ & E1820 & 216 & E-117 & SMA & BM-1 & X-Weld & Air & 750 & 20000 & 0 \\
\hline K-SMA & $0.4 \mathrm{~T}-\mathrm{CT}$ & E1820 & 217 & E-117 & SMA & BM-1 & X-Weld & Air & 750 & 20000 & 100 \\
\hline K-SMA & $0.4 \mathrm{~T}-\mathrm{CT}$ & E1820 & 218 & E-117 & SMA & BM-1 & X-Weld & Air & 750 & 20000 & 100 \\
\hline K-SMA & $0.4 \mathrm{~T}-\mathrm{CT}$ & E1820 & 219 & E-117 & SMA & BM-1 & X-Weld & Air & 750 & 20000 & 100 \\
\hline K-SMA & $0.4 \mathrm{~T}-\mathrm{CT}$ & E1820 & 220 & E-117 & SMA & BM-1 & X-Weld & Air & 750 & 20000 & 950 \\
\hline K-SMA & $0.4 \mathrm{~T}-\mathrm{CT}$ & $\mathrm{E} 1820$ & 221 & E-117 & SMA & BM-1 & X-Weld & Air & 750 & 20000 & 950 \\
\hline K-SMA & $0.4 \mathrm{~T}-\mathrm{CT}$ & E1820 & 222 & E-117 & SMA & BM-1 & X-Weld & Air & 750 & 20000 & 950 \\
\hline K-SMA & $0.4 \mathrm{~T}-\mathrm{CT}$ & E1820 & 223 & E-117 & SMA & NA & Deposited & Air & 1000 & 20000 & 0 \\
\hline
\end{tabular}


Idaho National Laboratory

\begin{tabular}{|c|c|c|c|}
\hline $\begin{array}{l}\text { NEXT GENERATION NUCLEAR PLANT } \\
\text { INTERMEDIATE HEAT EXCHANGER } \\
\text { MATERIALS RESEARCH } \\
\text { AND DEVELOPMENT PLAN }\end{array}$ & $\begin{array}{l}\text { Identifier: } \\
\text { Revision: } \\
\text { Effective Date: }\end{array}$ & $\begin{array}{l}\text { PLN-2804 } \\
0 \\
04 / 30 / 08\end{array}$ & Pag \\
\hline
\end{tabular}

Table A4(c). Aging Effects on Fracture Toughness of SMA Weld from Weld Electrode 117

\begin{tabular}{|c|c|c|c|c|c|c|c|c|c|c|c|}
\hline Test Prgm & $\begin{array}{l}\text { Spec. } \\
\text { Type }\end{array}$ & $\begin{array}{c}\text { Test } \\
\text { Method }\end{array}$ & $\begin{array}{c}\text { Spec. } \\
\#\end{array}$ & $\begin{array}{c}\text { Weld } \\
\text { Electrode }\end{array}$ & $\begin{array}{c}\text { Weld } \\
\text { Process }\end{array}$ & $\begin{array}{c}\text { A617 Plate } \\
\text { Heat \# }\end{array}$ & $\begin{array}{c}\text { Weld to be } \\
\text { Tested }\end{array}$ & Env. & $\begin{array}{c}\text { Exposure } \\
\text { Temp. }\left({ }^{\circ} \mathrm{C}\right)\end{array}$ & $\begin{array}{c}\text { Exposure } \\
\text { Time (h) }\end{array}$ & $\begin{array}{c}\text { Test Temp. } \\
\left({ }^{\circ} \mathrm{C}\right)\end{array}$ \\
\hline K-SMA & $0.4 \mathrm{~T}-\mathrm{CT}$ & E1820 & 224 & E-117 & SMA & NA & Deposited & Air & 1000 & 20000 & 0 \\
\hline K-SMA & $0.4 \mathrm{~T}-\mathrm{CT}$ & E1820 & 225 & E-117 & SMA & NA & Deposited & Air & 1000 & 20000 & 0 \\
\hline K-SMA & $0.4 \mathrm{~T}-\mathrm{CT}$ & E1820 & 226 & E-117 & SMA & NA & Deposited & Air & 1000 & 20000 & 100 \\
\hline K-SMA & $0.4 \mathrm{~T}-\mathrm{CT}$ & $\mathrm{E} 1820$ & 227 & E-117 & SMA & NA & Deposited & Air & 1000 & 20000 & 100 \\
\hline K-SMA & $0.4 \mathrm{~T}-\mathrm{CT}$ & E1820 & 228 & E-117 & SMA & NA & Deposited & Air & 1000 & 20000 & 100 \\
\hline K-SMA & $0.4 \mathrm{~T}-\mathrm{CT}$ & E1820 & 229 & E-117 & SMA & NA & Deposited & Air & 1000 & 20000 & 950 \\
\hline K-SMA & $0.4 \mathrm{~T}-\mathrm{CT}$ & E1820 & 230 & E-117 & SMA & NA & Deposited & Air & 1000 & 20000 & 950 \\
\hline K-SMA & $0.4 \mathrm{~T}-\mathrm{CT}$ & E1820 & 231 & E-117 & SMA & NA & Deposited & Air & 1000 & 20000 & 950 \\
\hline K-SMA & $0.4 \mathrm{~T}-\mathrm{CT}$ & E1820 & 232 & E-117 & SMA & BM-1 & X-Weld & Air & 1000 & 20000 & 0 \\
\hline K-SMA & $0.4 \mathrm{~T}-\mathrm{CT}$ & $\mathrm{E} 1820$ & 233 & E-117 & SMA & BM-1 & X-Weld & Air & 1000 & 20000 & 0 \\
\hline K-SMA & $0.4 \mathrm{~T}-\mathrm{CT}$ & E1820 & 234 & E-117 & SMA & BM-1 & X-Weld & Air & 1000 & 20000 & 0 \\
\hline K-SMA & $0.4 \mathrm{~T}-\mathrm{CT}$ & $\mathrm{E} 1820$ & 235 & E-117 & SMA & BM-1 & X-Weld & Air & 1000 & 20000 & 100 \\
\hline K-SMA & $0.4 \mathrm{~T}-\mathrm{CT}$ & E1820 & 236 & E-117 & SMA & BM-1 & X-Weld & Air & 1000 & 20000 & 100 \\
\hline K-SMA & $0.4 \mathrm{~T}-\mathrm{CT}$ & $\mathrm{E} 1820$ & 237 & E-117 & SMA & BM-1 & X-Weld & Air & 1000 & 20000 & 100 \\
\hline K-SMA & $0.4 \mathrm{~T}-\mathrm{CT}$ & $\mathrm{E} 1820$ & 238 & E-117 & SMA & BM-1 & X-Weld & Air & 1000 & 20000 & 950 \\
\hline K-SMA & $0.4 \mathrm{~T}-\mathrm{CT}$ & $\mathrm{E} 1820$ & 239 & E-117 & SMA & BM-1 & X-Weld & Air & 1000 & 20000 & 950 \\
\hline K-SMA & $0.4 \mathrm{~T}-\mathrm{CT}$ & $\mathrm{E} 1820$ & 240 & E-117 & SMA & BM-1 & X-Weld & Air & 1000 & 20000 & 950 \\
\hline K-SMA-QUAL & $0.4 \mathrm{~T}-\mathrm{CT}$ & E1820 & 241 & E-117 & SMA & NA & Deposited & Air & 750 & 32000 & 0 \\
\hline K-SMA-QUAL & $0.4 \mathrm{~T}-\mathrm{CT}$ & E1820 & 242 & E-117 & SMA & NA & Deposited & Air & 750 & 32000 & 0 \\
\hline K-SMA-QUAL & $0.4 \mathrm{~T}-\mathrm{CT}$ & E1820 & 243 & E-117 & SMA & NA & Deposited & Air & 750 & 32000 & 0 \\
\hline K-SMA-QUAL & $0.4 \mathrm{~T}-\mathrm{CT}$ & $\mathrm{E} 1820$ & 244 & E-117 & SMA & NA & Deposited & Air & 750 & 32000 & 100 \\
\hline K-SMA-QUAL & $0.4 \mathrm{~T}-\mathrm{CT}$ & $\mathrm{E} 1820$ & 245 & E-117 & SMA & NA & Deposited & Air & 750 & 32000 & 100 \\
\hline K-SMA-QUAL & $0.4 \mathrm{~T}-\mathrm{CT}$ & E1820 & 246 & E-117 & SMA & NA & Deposited & Air & 750 & 32000 & 100 \\
\hline K-SMA-QUAL & $0.4 \mathrm{~T}-\mathrm{CT}$ & $\mathrm{E} 1820$ & 247 & E-117 & SMA & NA & Deposited & Air & 750 & 32000 & 950 \\
\hline K-SMA-QUAL & $0.4 \mathrm{~T}-\mathrm{CT}$ & $\mathrm{E} 1820$ & 248 & E-117 & SMA & NA & Deposited & Air & 750 & 32000 & 950 \\
\hline K-SMA-QUAL & $0.4 \mathrm{~T}-\mathrm{CT}$ & E1820 & 249 & E-117 & SMA & NA & Deposited & Air & 750 & 32000 & 950 \\
\hline K-SMA-QUAL & $0.4 \mathrm{~T}-\mathrm{CT}$ & E1820 & 250 & E-117 & SMA & BM-1 & X-Weld & Air & 750 & 32000 & 0 \\
\hline K-SMA-QUAL & $0.4 \mathrm{~T}-\mathrm{CT}$ & E1820 & 251 & E-117 & SMA & BM-1 & X-Weld & Air & 750 & 32000 & 0 \\
\hline
\end{tabular}




Idaho National Laboratory
\begin{tabular}{|c|lll|}
\hline NEXT GENERATION NUCLEAR PLANT & Identifier: & PLN-2804 & \\
INTERMEDIATE HEAT EXCHANGER & Revision: & 0 & \\
MATERIALS RESEARCH & Effective Date: & $04 / 30 / 08$ & Page: A-50 of A-114 \\
AND DEVELOPMENT PLAN &
\end{tabular}

Table A4(c). Aging Effects on Fracture Toughness of SMA Weld from Weld Electrode 117

\begin{tabular}{|c|c|c|c|c|c|c|c|c|c|c|c|}
\hline Test Prgm & $\begin{array}{l}\text { Spec. } \\
\text { Type }\end{array}$ & $\begin{array}{c}\text { Test } \\
\text { Method }\end{array}$ & $\begin{array}{c}\text { Spec. } \\
\#\end{array}$ & $\begin{array}{c}\text { Weld } \\
\text { Electrode }\end{array}$ & $\begin{array}{c}\text { Weld } \\
\text { Process }\end{array}$ & $\begin{array}{c}\text { A617 Plate } \\
\text { Heat \# }\end{array}$ & $\begin{array}{l}\text { Weld to be } \\
\text { Tested }\end{array}$ & Env. & $\begin{array}{c}\text { Exposure } \\
\text { Temp. }\left({ }^{\circ} \mathrm{C}\right)\end{array}$ & $\begin{array}{l}\text { Exposure } \\
\text { Time (h) }\end{array}$ & $\begin{array}{c}\text { Test Temp. } \\
\left({ }^{\circ} \mathrm{C}\right)\end{array}$ \\
\hline K-SMA-QUAL & $0.4 \mathrm{~T}-\mathrm{CT}$ & E1820 & 252 & E-117 & SMA & BM-1 & X-Weld & Air & 750 & 32000 & 0 \\
\hline K-SMA-QUAL & $0.4 \mathrm{~T}-\mathrm{CT}$ & E1820 & 253 & E-117 & SMA & BM-1 & X-Weld & Air & 750 & 32000 & 100 \\
\hline K-SMA-QUAL & $0.4 \mathrm{~T}-\mathrm{CT}$ & E1820 & 254 & E-117 & SMA & BM-1 & X-Weld & Air & 750 & 32000 & 100 \\
\hline K-SMA-QUAL & $0.4 \mathrm{~T}-\mathrm{CT}$ & E1820 & 255 & E-117 & SMA & BM-1 & X-Weld & Air & 750 & 32000 & 100 \\
\hline K-SMA-QUAL & $0.4 \mathrm{~T}-\mathrm{CT}$ & E1820 & 256 & E-117 & SMA & BM-1 & X-Weld & Air & 750 & 32000 & 950 \\
\hline K-SMA-QUAL & $0.4 \mathrm{~T}-\mathrm{CT}$ & E1820 & 257 & E-117 & SMA & BM-1 & X-Weld & Air & 750 & 32000 & 950 \\
\hline K-SMA-QUAL & $0.4 \mathrm{~T}-\mathrm{CT}$ & E1820 & 258 & E-117 & SMA & BM-1 & X-Weld & Air & 750 & 32000 & 950 \\
\hline K-SMA-QUAL & $0.4 \mathrm{~T}-\mathrm{CT}$ & E1820 & 259 & E-117 & SMA & NA & Deposited & Air & 1000 & 32000 & 0 \\
\hline K-SMA-QUAL & $0.4 \mathrm{~T}-\mathrm{CT}$ & E1820 & 260 & E-117 & SMA & NA & Deposited & Air & 1000 & 32000 & 0 \\
\hline K-SMA-QUAL & $0.4 \mathrm{~T}-\mathrm{CT}$ & E1820 & 261 & E-117 & SMA & NA & Deposited & Air & 1000 & 32000 & 0 \\
\hline K-SMA-QUAL & $0.4 \mathrm{~T}-\mathrm{CT}$ & E1820 & 262 & E-117 & SMA & NA & Deposited & Air & 1000 & 32000 & 100 \\
\hline K-SMA-QUAL & $0.4 \mathrm{~T}-\mathrm{CT}$ & E1820 & 263 & E-117 & SMA & NA & Deposited & Air & 1000 & 32000 & 100 \\
\hline K-SMA-QUAL & $0.4 \mathrm{~T}-\mathrm{CT}$ & E1820 & 264 & E-117 & SMA & NA & Deposited & Air & 1000 & 32000 & 100 \\
\hline K-SMA-QUAL & $0.4 \mathrm{~T}-\mathrm{CT}$ & E1820 & 265 & E-117 & SMA & NA & Deposited & Air & 1000 & 32000 & 950 \\
\hline K-SMA-QUAL & $0.4 \mathrm{~T}-\mathrm{CT}$ & E1820 & 266 & E-117 & SMA & NA & Deposited & Air & 1000 & 32000 & 950 \\
\hline K-SMA-QUAL & $0.4 \mathrm{~T}-\mathrm{CT}$ & E1820 & 267 & E-117 & SMA & NA & Deposited & Air & 1000 & 32000 & 950 \\
\hline K-SMA-QUAL & $0.4 \mathrm{~T}-\mathrm{CT}$ & E1820 & 268 & E-117 & SMA & BM-1 & X-Weld & Air & 1000 & 32000 & 0 \\
\hline K-SMA-QUAL & $0.4 \mathrm{~T}-\mathrm{CT}$ & E1820 & 269 & E-117 & SMA & BM-1 & X-Weld & Air & 1000 & 32000 & 0 \\
\hline K-SMA-QUAL & $0.4 \mathrm{~T}-\mathrm{CT}$ & E1820 & 270 & E-117 & SMA & BM-1 & X-Weld & Air & 1000 & 32000 & 0 \\
\hline K-SMA-QUAL & $0.4 \mathrm{~T}-\mathrm{CT}$ & E1820 & 271 & E-117 & SMA & BM-1 & X-Weld & Air & 1000 & 32000 & 100 \\
\hline K-SMA-QUAL & $0.4 \mathrm{~T}-\mathrm{CT}$ & E1820 & 272 & E-117 & SMA & BM-1 & X-Weld & Air & 1000 & 32000 & 100 \\
\hline K-SMA-QUAL & $0.4 \mathrm{~T}-\mathrm{CT}$ & E1820 & 273 & E-117 & SMA & BM-1 & X-Weld & Air & 1000 & 32000 & 100 \\
\hline K-SMA-QUAL & $0.4 \mathrm{~T}-\mathrm{CT}$ & E1820 & 274 & E-117 & SMA & BM-1 & X-Weld & Air & 1000 & 32000 & 950 \\
\hline K-SMA-QUAL & $0.4 \mathrm{~T}-\mathrm{CT}$ & E1820 & 275 & E-117 & SMA & BM-1 & X-Weld & Air & 1000 & 32000 & 950 \\
\hline K-SMA-QUAL & $0.4 \mathrm{~T}-\mathrm{CT}$ & E1820 & 276 & E-117 & SMA & BM-1 & X-Weld & Air & 1000 & 32000 & 950 \\
\hline K-SMA-QUAL & $0.4 \mathrm{~T}-\mathrm{CT}$ & E1820 & 277 & E-117 & SMA & NA & Deposited & Air & 750 & 50000 & 0 \\
\hline K-SMA-QUAL & $0.4 \mathrm{~T}-\mathrm{CT}$ & E1820 & 278 & E-117 & SMA & NA & Deposited & Air & 750 & 50000 & 0 \\
\hline K-SMA-QUAL & $0.4 \mathrm{~T}-\mathrm{CT}$ & E1820 & 279 & E-117 & SMA & NA & Deposited & Air & 750 & 50000 & 0 \\
\hline
\end{tabular}




Idaho National Laboratory
\begin{tabular}{|c|lll|}
\hline NEXT GENERATION NUCLEAR PLANT & Identifier: & PLN-2804 & \\
INTERMEDIATE HEAT EXCHANGER & Revision: & 0 & \\
MATERIALS RESEARCH & Effective Date: & $04 / 30 / 08$ & Page: A-51 of A-114 \\
AND DEVELOPMENT PLAN &
\end{tabular}

Table A4(c). Aging Effects on Fracture Toughness of SMA Weld from Weld Electrode 117

\begin{tabular}{|c|c|c|c|c|c|c|c|c|c|c|c|}
\hline Test Prgm & $\begin{array}{l}\text { Spec. } \\
\text { Type }\end{array}$ & $\begin{array}{c}\text { Test } \\
\text { Method }\end{array}$ & $\begin{array}{c}\text { Spec. } \\
\#\end{array}$ & $\begin{array}{c}\text { Weld } \\
\text { Electrode }\end{array}$ & $\begin{array}{c}\text { Weld } \\
\text { Process }\end{array}$ & $\begin{array}{c}\text { A617 Plate } \\
\text { Heat \# }\end{array}$ & $\begin{array}{c}\text { Weld to be } \\
\text { Tested }\end{array}$ & Env. & $\begin{array}{c}\text { Exposure } \\
\text { Temp. }\left({ }^{\circ} \mathrm{C}\right)\end{array}$ & $\begin{array}{l}\text { Exposure } \\
\text { Time }(\mathrm{h})\end{array}$ & $\begin{array}{c}\text { Test Temp. } \\
\left({ }^{\circ} \mathrm{C}\right)\end{array}$ \\
\hline K-SMA-QUAL & $0.4 \mathrm{~T}-\mathrm{CT}$ & E1820 & 280 & E-117 & SMA & NA & Deposited & Air & 750 & 50000 & 100 \\
\hline K-SMA-QUAL & $0.4 \mathrm{~T}-\mathrm{CT}$ & E1820 & 281 & E-117 & SMA & NA & Deposited & Air & 750 & 50000 & 100 \\
\hline K-SMA-QUAL & $0.4 \mathrm{~T}-\mathrm{CT}$ & E1820 & 282 & E-117 & SMA & NA & Deposited & Air & 750 & 50000 & 100 \\
\hline K-SMA-QUAL & $0.4 \mathrm{~T}-\mathrm{CT}$ & E1820 & 283 & E-117 & SMA & NA & Deposited & Air & 750 & 50000 & 950 \\
\hline K-SMA-QUAL & $0.4 \mathrm{~T}-\mathrm{CT}$ & E1820 & 284 & E-117 & SMA & NA & Deposited & Air & 750 & 50000 & 950 \\
\hline K-SMA-QUAL & $0.4 \mathrm{~T}-\mathrm{CT}$ & E1820 & 285 & E-117 & SMA & NA & Deposited & Air & 750 & 50000 & 950 \\
\hline K-SMA-QUAL & $0.4 \mathrm{~T}-\mathrm{CT}$ & E1820 & 286 & E-117 & SMA & BM-1 & X-Weld & Air & 750 & 50000 & 0 \\
\hline K-SMA-QUAL & $0.4 \mathrm{~T}-\mathrm{CT}$ & E1820 & 287 & E-117 & SMA & BM-1 & X-Weld & Air & 750 & 50000 & 0 \\
\hline K-SMA-QUAL & $0.4 \mathrm{~T}-\mathrm{CT}$ & E1820 & 288 & E-117 & SMA & BM-1 & X-Weld & Air & 750 & 50000 & 0 \\
\hline K-SMA-QUAL & $0.4 \mathrm{~T}-\mathrm{CT}$ & E1820 & 289 & E-117 & SMA & BM-1 & X-Weld & Air & 750 & 50000 & 100 \\
\hline K-SMA-QUAL & $0.4 \mathrm{~T}-\mathrm{CT}$ & E1820 & 290 & E-117 & SMA & BM-1 & X-Weld & Air & 750 & 50000 & 100 \\
\hline K-SMA-QUAL & $0.4 \mathrm{~T}-\mathrm{CT}$ & E1820 & 291 & E-117 & SMA & BM-1 & X-Weld & Air & 750 & 50000 & 100 \\
\hline K-SMA-QUAL & $0.4 \mathrm{~T}-\mathrm{CT}$ & E1820 & 292 & E-117 & SMA & BM-1 & X-Weld & Air & 750 & 50000 & 950 \\
\hline K-SMA-QUAL & $0.4 \mathrm{~T}-\mathrm{CT}$ & E1820 & 293 & E-117 & SMA & BM-1 & X-Weld & Air & 750 & 50000 & 950 \\
\hline K-SMA-QUAL & $0.4 \mathrm{~T}-\mathrm{CT}$ & E1820 & 294 & E-117 & SMA & BM-1 & X-Weld & Air & 750 & 50000 & 950 \\
\hline K-SMA-QUAL & $0.4 \mathrm{~T}-\mathrm{CT}$ & E1820 & 295 & E-117 & SMA & NA & Deposited & Air & 1000 & 50000 & 0 \\
\hline K-SMA-QUAL & $0.4 \mathrm{~T}-\mathrm{CT}$ & E1820 & 296 & E-117 & SMA & NA & Deposited & Air & 1000 & 50000 & 0 \\
\hline K-SMA-QUAL & $0.4 \mathrm{~T}-\mathrm{CT}$ & E1820 & 297 & E-117 & SMA & NA & Deposited & Air & 1000 & 50000 & 0 \\
\hline K-SMA-QUAL & $0.4 \mathrm{~T}-\mathrm{CT}$ & E1820 & 298 & E-117 & SMA & NA & Deposited & Air & 1000 & 50000 & 100 \\
\hline K-SMA-QUAL & $0.4 \mathrm{~T}-\mathrm{CT}$ & E1820 & 299 & E-117 & SMA & NA & Deposited & Air & 1000 & 50000 & 100 \\
\hline K-SMA-QUAL & $0.4 \mathrm{~T}-\mathrm{CT}$ & E1820 & 300 & E-117 & SMA & NA & Deposited & Air & 1000 & 50000 & 100 \\
\hline K-SMA-QUAL & $0.4 \mathrm{~T}-\mathrm{CT}$ & E1820 & 301 & E-117 & SMA & NA & Deposited & Air & 1000 & 50000 & 950 \\
\hline K-SMA-QUAL & $0.4 \mathrm{~T}-\mathrm{CT}$ & E1820 & 302 & E-117 & SMA & NA & Deposited & Air & 1000 & 50000 & 950 \\
\hline K-SMA-QUAL & $0.4 \mathrm{~T}-\mathrm{CT}$ & E1820 & 303 & E-117 & SMA & NA & Deposited & Air & 1000 & 50000 & 950 \\
\hline K-SMA-QUAL & $0.4 \mathrm{~T}-\mathrm{CT}$ & E1820 & 304 & E-117 & SMA & BM-1 & X-Weld & Air & 1000 & 50000 & 0 \\
\hline K-SMA-QUAL & $0.4 \mathrm{~T}-\mathrm{CT}$ & E1820 & 305 & E-117 & SMA & BM-1 & X-Weld & Air & 1000 & 50000 & 0 \\
\hline K-SMA-QUAL & $0.4 \mathrm{~T}-\mathrm{CT}$ & E1820 & 306 & E-117 & SMA & BM-1 & X-Weld & Air & 1000 & 50000 & 0 \\
\hline K-SMA-QUAL & $0.4 \mathrm{~T}-\mathrm{CT}$ & E1820 & 307 & E-117 & SMA & BM-1 & X-Weld & Air & 1000 & 50000 & 100 \\
\hline
\end{tabular}




Idaho National Laboratory
\begin{tabular}{|c|lll|}
\hline NEXT GENERATION NUCLEAR PLANT & Identifier: & PLN-2804 & \\
INTERMEDIATE HEAT EXCHANGER & Revision: & 0 & \\
MATERIALS RESEARCH & Effective Date: & $04 / 30 / 08$ & Page: A-52 of A-114 \\
AND DEVELOPMENT PLAN &
\end{tabular}

Table A4(c). Aging Effects on Fracture Toughness of SMA Weld from Weld Electrode 117

\begin{tabular}{|c|c|c|c|c|c|c|c|c|c|c|c|}
\hline Test Prgm & $\begin{array}{l}\text { Spec. } \\
\text { Type }\end{array}$ & $\begin{array}{c}\text { Test } \\
\text { Method }\end{array}$ & $\begin{array}{c}\text { Spec. } \\
\#\end{array}$ & $\begin{array}{c}\text { Weld } \\
\text { Electrode }\end{array}$ & $\begin{array}{l}\text { Weld } \\
\text { Process }\end{array}$ & $\begin{array}{c}\text { A617 Plate } \\
\text { Heat \# }\end{array}$ & $\begin{array}{l}\text { Weld to be } \\
\text { Tested }\end{array}$ & Env. & $\begin{array}{c}\text { Exposure } \\
\text { Temp. }\left({ }^{\circ} \mathrm{C}\right)\end{array}$ & $\begin{array}{l}\text { Exposure } \\
\text { Time (h) }\end{array}$ & $\begin{array}{c}\text { Test Temp. } \\
\left({ }^{\circ} \mathrm{C}\right)\end{array}$ \\
\hline K-SMA-QUAL & $0.4 \mathrm{~T}-\mathrm{CT}$ & E1820 & 308 & E-117 & SMA & BM-1 & X-Weld & Air & 1000 & 50000 & 100 \\
\hline K-SMA-QUAL & $0.4 \mathrm{~T}-\mathrm{CT}$ & E1820 & 309 & E-117 & SMA & BM-1 & X-Weld & Air & 1000 & 50000 & 100 \\
\hline K-SMA-QUAL & $0.4 \mathrm{~T}-\mathrm{CT}$ & E1820 & 310 & E-117 & SMA & BM-1 & X-Weld & Air & 1000 & 50000 & 950 \\
\hline K-SMA-QUAL & $0.4 \mathrm{~T}-\mathrm{CT}$ & E1820 & 311 & E-117 & SMA & BM-1 & X-Weld & Air & 1000 & 50000 & 950 \\
\hline K-SMA-QUAL & $0.4 \mathrm{~T}-\mathrm{CT}$ & E1820 & 312 & E-117 & SMA & BM-1 & X-Weld & Air & 1000 & 50000 & 950 \\
\hline K-SMA-QUAL & $0.4 \mathrm{~T}-\mathrm{CT}$ & E1820 & 313 & E-117 & SMA & NA & Deposited & Air & 750 & 76000 & 0 \\
\hline K-SMA-QUAL & $0.4 \mathrm{~T}-\mathrm{CT}$ & E1820 & 314 & E-117 & SMA & NA & Deposited & Air & 750 & 76000 & 0 \\
\hline K-SMA-QUAL & $0.4 \mathrm{~T}-\mathrm{CT}$ & E1820 & 315 & E-117 & SMA & NA & Deposited & Air & 750 & 76000 & 0 \\
\hline K-SMA-QUAL & $0.4 \mathrm{~T}-\mathrm{CT}$ & E1820 & 316 & E-117 & SMA & NA & Deposited & Air & 750 & 76000 & 100 \\
\hline K-SMA-QUAL & $0.4 \mathrm{~T}-\mathrm{CT}$ & E1820 & 317 & E-117 & SMA & NA & Deposited & Air & 750 & 76000 & 100 \\
\hline K-SMA-QUAL & $0.4 \mathrm{~T}-\mathrm{CT}$ & E1820 & 318 & E-117 & SMA & NA & Deposited & Air & 750 & 76000 & 100 \\
\hline K-SMA-QUAL & $0.4 \mathrm{~T}-\mathrm{CT}$ & E1820 & 319 & E-117 & SMA & NA & Deposited & Air & 750 & 76000 & 950 \\
\hline K-SMA-QUAL & $0.4 \mathrm{~T}-\mathrm{CT}$ & E1820 & 320 & E-117 & SMA & NA & Deposited & Air & 750 & 76000 & 950 \\
\hline K-SMA-QUAL & $0.4 \mathrm{~T}-\mathrm{CT}$ & E1820 & 321 & E-117 & SMA & NA & Deposited & Air & 750 & 76000 & 950 \\
\hline K-SMA-QUAL & $0.4 \mathrm{~T}-\mathrm{CT}$ & E1820 & 322 & E-117 & SMA & BM-1 & X-Weld & Air & 750 & 76000 & 0 \\
\hline K-SMA-QUAL & $0.4 \mathrm{~T}-\mathrm{CT}$ & E1820 & 323 & E-117 & SMA & BM-1 & X-Weld & Air & 750 & 76000 & 0 \\
\hline K-SMA-QUAL & $0.4 \mathrm{~T}-\mathrm{CT}$ & E1820 & 324 & E-117 & SMA & BM-1 & X-Weld & Air & 750 & 76000 & 0 \\
\hline K-SMA-QUAL & $0.4 \mathrm{~T}-\mathrm{CT}$ & E1820 & 325 & E-117 & SMA & BM-1 & X-Weld & Air & 750 & 76000 & 100 \\
\hline K-SMA-QUAL & $0.4 \mathrm{~T}-\mathrm{CT}$ & E1820 & 326 & E-117 & SMA & BM-1 & X-Weld & Air & 750 & 76000 & 100 \\
\hline K-SMA-QUAL & $0.4 \mathrm{~T}-\mathrm{CT}$ & E1820 & 327 & E-117 & SMA & BM-1 & X-Weld & Air & 750 & 76000 & 100 \\
\hline K-SMA-QUAL & $0.4 \mathrm{~T}-\mathrm{CT}$ & E1820 & 328 & E-117 & SMA & BM-1 & X-Weld & Air & 750 & 76000 & 950 \\
\hline K-SMA-QUAL & $0.4 \mathrm{~T}-\mathrm{CT}$ & E1820 & 329 & E-117 & SMA & BM-1 & X-Weld & Air & 750 & 76000 & 950 \\
\hline K-SMA-QUAL & $0.4 \mathrm{~T}-\mathrm{CT}$ & E1820 & 330 & E-117 & SMA & BM-1 & X-Weld & Air & 750 & 76000 & 950 \\
\hline K-SMA-QUAL & $0.4 \mathrm{~T}-\mathrm{CT}$ & E1820 & 331 & E-117 & SMA & NA & Deposited & Air & 1000 & 76000 & 0 \\
\hline K-SMA-QUAL & $0.4 \mathrm{~T}-\mathrm{CT}$ & E1820 & 332 & E-117 & SMA & NA & Deposited & Air & 1000 & 76000 & 0 \\
\hline K-SMA-QUAL & $0.4 \mathrm{~T}-\mathrm{CT}$ & E1820 & 333 & E-117 & SMA & NA & Deposited & Air & 1000 & 76000 & 0 \\
\hline K-SMA-QUAL & $0.4 \mathrm{~T}-\mathrm{CT}$ & E1820 & 334 & E-117 & SMA & NA & Deposited & Air & 1000 & 76000 & 100 \\
\hline K-SMA-QUAL & $0.4 \mathrm{~T}-\mathrm{CT}$ & E1820 & 335 & E-117 & SMA & NA & Deposited & Air & 1000 & 76000 & 100 \\
\hline
\end{tabular}




Idaho National Laboratory
\begin{tabular}{|c|lll|}
\hline NEXT GENERATION NUCLEAR PLANT & Identifier: & PLN-2804 & \\
INTERMEDIATE HEAT EXCHANGER & Revision: & 0 & \\
MATERIALS RESEARCH & Effective Date: & $04 / 30 / 08$ & Page: A-53 of A-114 \\
AND DEVELOPMENT PLAN &
\end{tabular}

Table A4(c). Aging Effects on Fracture Toughness of SMA Weld from Weld Electrode 117

\begin{tabular}{|c|c|c|c|c|c|c|c|c|c|c|c|}
\hline Test Prgm & $\begin{array}{l}\text { Spec. } \\
\text { Type }\end{array}$ & $\begin{array}{c}\text { Test } \\
\text { Method }\end{array}$ & $\begin{array}{c}\text { Spec. } \\
\#\end{array}$ & $\begin{array}{c}\text { Weld } \\
\text { Electrode }\end{array}$ & $\begin{array}{l}\text { Weld } \\
\text { Process }\end{array}$ & $\begin{array}{c}\text { A617 Plate } \\
\text { Heat \# }\end{array}$ & $\begin{array}{l}\text { Weld to be } \\
\text { Tested }\end{array}$ & Env. & $\begin{array}{c}\text { Exposure } \\
\text { Temp. }\left({ }^{\circ} \mathrm{C}\right)\end{array}$ & $\begin{array}{l}\text { Exposure } \\
\text { Time (h) }\end{array}$ & $\begin{array}{c}\text { Test Temp. } \\
\left({ }^{\circ} \mathrm{C}\right)\end{array}$ \\
\hline K-SMA-QUAL & $0.4 \mathrm{~T}-\mathrm{CT}$ & E1820 & 336 & E-117 & SMA & NA & Deposited & Air & 1000 & 76000 & 100 \\
\hline K-SMA-QUAL & $0.4 \mathrm{~T}-\mathrm{CT}$ & E1820 & 337 & E-117 & SMA & NA & Deposited & Air & 1000 & 76000 & 950 \\
\hline K-SMA-QUAL & $0.4 \mathrm{~T}-\mathrm{CT}$ & E1820 & 338 & E-117 & SMA & NA & Deposited & Air & 1000 & 76000 & 950 \\
\hline K-SMA-QUAL & $0.4 \mathrm{~T}-\mathrm{CT}$ & E1820 & 339 & E-117 & SMA & NA & Deposited & Air & 1000 & 76000 & 950 \\
\hline K-SMA-QUAL & $0.4 \mathrm{~T}-\mathrm{CT}$ & E1820 & 340 & E-117 & SMA & BM-1 & X-Weld & Air & 1000 & 76000 & 0 \\
\hline K-SMA-QUAL & $0.4 \mathrm{~T}-\mathrm{CT}$ & E1820 & 341 & E-117 & SMA & BM-1 & X-Weld & Air & 1000 & 76000 & 0 \\
\hline K-SMA-QUAL & $0.4 \mathrm{~T}-\mathrm{CT}$ & E1820 & 342 & E-117 & SMA & BM-1 & X-Weld & Air & 1000 & 76000 & 0 \\
\hline K-SMA-QUAL & $0.4 \mathrm{~T}-\mathrm{CT}$ & E1820 & 343 & E-117 & SMA & BM-1 & X-Weld & Air & 1000 & 76000 & 100 \\
\hline K-SMA-QUAL & $0.4 \mathrm{~T}-\mathrm{CT}$ & E1820 & 344 & E-117 & SMA & BM-1 & X-Weld & Air & 1000 & 76000 & 100 \\
\hline K-SMA-QUAL & $0.4 \mathrm{~T}-\mathrm{CT}$ & E1820 & 345 & E-117 & SMA & BM-1 & X-Weld & Air & 1000 & 76000 & 100 \\
\hline K-SMA-QUAL & $0.4 \mathrm{~T}-\mathrm{CT}$ & E1820 & 346 & E-117 & SMA & BM-1 & X-Weld & Air & 1000 & 76000 & 950 \\
\hline K-SMA-QUAL & $0.4 \mathrm{~T}-\mathrm{CT}$ & E1820 & 347 & E-117 & SMA & BM-1 & X-Weld & Air & 1000 & 76000 & 950 \\
\hline K-SMA-QUAL & $0.4 \mathrm{~T}-\mathrm{CT}$ & E1820 & 348 & E-117 & SMA & BM-1 & X-Weld & Air & 1000 & 76000 & 950 \\
\hline K-SMA-QUAL & $0.4 \mathrm{~T}-\mathrm{CT}$ & E1820 & 349 & E-117 & SMA & NA & Deposited & Air & 750 & 120000 & 0 \\
\hline K-SMA-QUAL & $0.4 \mathrm{~T}-\mathrm{CT}$ & E1820 & 350 & E-117 & SMA & NA & Deposited & Air & 750 & 120000 & 0 \\
\hline K-SMA-QUAL & $0.4 \mathrm{~T}-\mathrm{CT}$ & E1820 & 351 & E-117 & SMA & NA & Deposited & Air & 750 & 120000 & 0 \\
\hline K-SMA-QUAL & $0.4 \mathrm{~T}-\mathrm{CT}$ & E1820 & 352 & E-117 & SMA & NA & Deposited & Air & 750 & 120000 & 100 \\
\hline K-SMA-QUAL & $0.4 \mathrm{~T}-\mathrm{CT}$ & E1820 & 353 & E-117 & SMA & NA & Deposited & Air & 750 & 120000 & 100 \\
\hline K-SMA-QUAL & $0.4 \mathrm{~T}-\mathrm{CT}$ & E1820 & 354 & E-117 & SMA & NA & Deposited & Air & 750 & 120000 & 100 \\
\hline K-SMA-QUAL & $0.4 \mathrm{~T}-\mathrm{CT}$ & E1820 & 355 & E-117 & SMA & NA & Deposited & Air & 750 & 120000 & 950 \\
\hline K-SMA-QUAL & $0.4 \mathrm{~T}-\mathrm{CT}$ & E1820 & 356 & E-117 & SMA & NA & Deposited & Air & 750 & 120000 & 950 \\
\hline K-SMA-QUAL & $0.4 \mathrm{~T}-\mathrm{CT}$ & E1820 & 357 & E-117 & SMA & NA & Deposited & Air & 750 & 120000 & 950 \\
\hline K-SMA-QUAL & $0.4 \mathrm{~T}-\mathrm{CT}$ & E1820 & 358 & E-117 & SMA & BM-1 & X-Weld & Air & 750 & 120000 & 0 \\
\hline K-SMA-QUAL & $0.4 \mathrm{~T}-\mathrm{CT}$ & E1820 & 359 & E-117 & SMA & BM-1 & X-Weld & Air & 750 & 120000 & 0 \\
\hline K-SMA-QUAL & $0.4 \mathrm{~T}-\mathrm{CT}$ & E1820 & 360 & E-117 & SMA & BM-1 & X-Weld & Air & 750 & 120000 & 0 \\
\hline K-SMA-QUAL & $0.4 \mathrm{~T}-\mathrm{CT}$ & E1820 & 361 & E-117 & SMA & BM-1 & X-Weld & Air & 750 & 120000 & 100 \\
\hline K-SMA-QUAL & $0.4 \mathrm{~T}-\mathrm{CT}$ & E1820 & 362 & E-117 & SMA & BM-1 & X-Weld & Air & 750 & 120000 & 100 \\
\hline K-SMA-QUAL & $0.4 \mathrm{~T}-\mathrm{CT}$ & E1820 & 363 & E-117 & SMA & BM-1 & X-Weld & Air & 750 & 120000 & 100 \\
\hline
\end{tabular}


Idaho National Laboratory

\begin{tabular}{|c|c|c|c|}
\hline $\begin{array}{l}\text { NEXT GENERATION NUCLEAR PLANT } \\
\text { INTERMEDIATE HEAT EXCHANGER } \\
\text { MATERIALS RESEARCH } \\
\text { AND DEVELOPMENT PLAN }\end{array}$ & $\begin{array}{l}\text { Identifier: } \\
\text { Revision: } \\
\text { Effective Date: }\end{array}$ & $\begin{array}{l}\text { PLN-2804 } \\
0 \\
04 / 30 / 08\end{array}$ & A-114 \\
\hline
\end{tabular}

Table A4(c). Aging Effects on Fracture Toughness of SMA Weld from Weld Electrode 117

\begin{tabular}{|c|c|c|c|c|c|c|c|c|c|c|c|}
\hline Test Prgm & $\begin{array}{l}\text { Spec. } \\
\text { Type }\end{array}$ & $\begin{array}{c}\text { Test } \\
\text { Method }\end{array}$ & $\begin{array}{c}\text { Spec. } \\
\#\end{array}$ & $\begin{array}{c}\text { Weld } \\
\text { Electrode }\end{array}$ & $\begin{array}{c}\text { Weld } \\
\text { Process }\end{array}$ & $\begin{array}{c}\text { A617 Plate } \\
\text { Heat \# }\end{array}$ & $\begin{array}{c}\text { Weld to be } \\
\text { Tested }\end{array}$ & Env. & $\begin{array}{c}\text { Exposure } \\
\text { Temp. }\left({ }^{\circ} \mathrm{C}\right)\end{array}$ & $\begin{array}{l}\text { Exposure } \\
\text { Time (h) }\end{array}$ & $\begin{array}{c}\text { Test Temp. } \\
\left({ }^{\circ} \mathrm{C}\right)\end{array}$ \\
\hline K-SMA-QUAL & $0.4 \mathrm{~T}-\mathrm{CT}$ & E1820 & 364 & E-117 & SMA & BM-1 & X-Weld & Air & 750 & 120000 & 950 \\
\hline K-SMA-QUAL & $0.4 \mathrm{~T}-\mathrm{CT}$ & E1820 & 365 & E-117 & SMA & BM-1 & X-Weld & Air & 750 & 120000 & 950 \\
\hline K-SMA-QUAL & $0.4 \mathrm{~T}-\mathrm{CT}$ & $\mathrm{E} 1820$ & 366 & E-117 & SMA & BM-1 & X-Weld & Air & 750 & 120000 & 950 \\
\hline K-SMA-QUAL & $0.4 \mathrm{~T}-\mathrm{CT}$ & E1820 & 367 & E-117 & SMA & NA & Deposited & Air & 1000 & 120000 & 0 \\
\hline K-SMA-QUAL & $0.4 \mathrm{~T}-\mathrm{CT}$ & $\mathrm{E} 1820$ & 368 & E-117 & SMA & NA & Deposited & Air & 1000 & 120000 & 0 \\
\hline K-SMA-QUAL & $0.4 \mathrm{~T}-\mathrm{CT}$ & E1820 & 369 & E-117 & SMA & NA & Deposited & Air & 1000 & 120000 & 0 \\
\hline K-SMA-QUAL & $0.4 \mathrm{~T}-\mathrm{CT}$ & E1820 & 370 & E-117 & SMA & NA & Deposited & Air & 1000 & 120000 & 100 \\
\hline K-SMA-QUAL & $0.4 \mathrm{~T}-\mathrm{CT}$ & E1820 & 371 & E-117 & SMA & NA & Deposited & Air & 1000 & 120000 & 100 \\
\hline K-SMA-QUAL & $0.4 \mathrm{~T}-\mathrm{CT}$ & E1820 & 372 & E-117 & SMA & NA & Deposited & Air & 1000 & 120000 & 100 \\
\hline K-SMA-QUAL & $0.4 \mathrm{~T}-\mathrm{CT}$ & E1820 & 373 & E-117 & SMA & NA & Deposited & Air & 1000 & 120000 & 950 \\
\hline K-SMA-QUAL & $0.4 \mathrm{~T}-\mathrm{CT}$ & $\mathrm{E} 1820$ & 374 & E-117 & SMA & NA & Deposited & Air & 1000 & 120000 & 950 \\
\hline K-SMA-QUAL & $0.4 \mathrm{~T}-\mathrm{CT}$ & E1820 & 375 & E-117 & SMA & NA & Deposited & Air & 1000 & 120000 & 950 \\
\hline K-SMA-QUAL & $0.4 \mathrm{~T}-\mathrm{CT}$ & E1820 & 376 & E-117 & SMA & BM-1 & X-Weld & Air & 1000 & 120000 & 0 \\
\hline K-SMA-QUAL & $0.4 \mathrm{~T}-\mathrm{CT}$ & E1820 & 377 & E-117 & SMA & BM-1 & X-Weld & Air & 1000 & 120000 & 0 \\
\hline K-SMA-QUAL & $0.4 \mathrm{~T}-\mathrm{CT}$ & E1820 & 378 & E-117 & SMA & BM-1 & X-Weld & Air & 1000 & 120000 & 0 \\
\hline K-SMA-QUAL & $0.4 \mathrm{~T}-\mathrm{CT}$ & E1820 & 379 & E-117 & SMA & BM-1 & X-Weld & Air & 1000 & 120000 & 100 \\
\hline K-SMA-QUAL & $0.4 \mathrm{~T}-\mathrm{CT}$ & E1820 & 380 & E-117 & SMA & BM-1 & X-Weld & Air & 1000 & 120000 & 100 \\
\hline K-SMA-QUAL & $0.4 \mathrm{~T}-\mathrm{CT}$ & E1820 & 381 & E-117 & SMA & BM-1 & X-Weld & Air & 1000 & 120000 & 100 \\
\hline K-SMA-QUAL & $0.4 \mathrm{~T}-\mathrm{CT}$ & E1820 & 382 & E-117 & SMA & BM-1 & X-Weld & Air & 1000 & 120000 & 950 \\
\hline K-SMA-QUAL & $0.4 \mathrm{~T}-\mathrm{CT}$ & E1820 & 383 & E-117 & SMA & BM-1 & X-Weld & Air & 1000 & 120000 & 950 \\
\hline K-SMA-QUAL & $0.4 \mathrm{~T}-\mathrm{CT}$ & E1820 & 384 & E-117 & SMA & BM-1 & X-Weld & Air & 1000 & 120000 & 950 \\
\hline
\end{tabular}




Idaho National Laboratory
\begin{tabular}{|c|lll|}
\hline NEXT GENERATION NUCLEAR PLANT & Identifier: & PLN-2804 & \\
INTERMEDIATE HEAT EXCHANGER & Revision: & 0 & \\
MATERIALS RESEARCH & Effective Date: & $04 / 30 / 08$ & Page: A-55 of A-114 \\
AND DEVELOPMENT PLAN & &
\end{tabular}

\begin{tabular}{|c|c|c|c|c|c|c|c|}
\hline \multicolumn{8}{|c|}{ Table A5. Tensile Test Matrix to Determine Strain Rate Sensitivity in Support of Unified Constitutive Model } \\
\hline Specimen Type & Specimen \# & Material & Product Form & Heat & Environment & Temp $\left({ }^{\circ} \mathrm{C}\right)$ & Total Strain $(\%)$ \\
\hline Tensile & 1 & Alloy 617 & Plate & xyz-CF & air & 20 & 2.5 \\
\hline Tensile & 2 & Alloy 617 & Plate & xyz-CF & air & 20 & 2.5 \\
\hline Tensile & 3 & Alloy 617 & Plate & xyz-CF & air & 20 & 2.5 \\
\hline Tensile & 4 & Alloy 617 & Plate & xyz-CF & air & 100 & 2.5 \\
\hline Tensile & 5 & Alloy 617 & Plate & xyz-CF & air & 100 & 2.5 \\
\hline Tensile & 6 & Alloy 617 & Plate & xyz-CF & air & 100 & 2.5 \\
\hline Tensile & 7 & Alloy 617 & Plate & xyz-CF & air & 200 & 2.5 \\
\hline Tensile & 8 & Alloy 617 & Plate & xyz-CF & air & 200 & 2.5 \\
\hline Tensile & 9 & Alloy 617 & Plate & xyz-CF & air & 200 & 2.5 \\
\hline Tensile & 10 & Alloy 617 & Plate & xyz-CF & air & 300 & 2.5 \\
\hline Tensile & 11 & Alloy 617 & Plate & xyz-CF & air & 300 & 2.5 \\
\hline Tensile & 12 & Alloy 617 & Plate & xyz-CF & air & 300 & 2.5 \\
\hline Tensile & 13 & Alloy 617 & Plate & xyz-CF & air & 400 & 2.5 \\
\hline Tensile & 14 & Alloy 617 & Plate & xyz-CF & air & 400 & 2.5 \\
\hline Tensile & 15 & Alloy 617 & Plate & xyz-CF & air & 400 & 2.5 \\
\hline Tensile & 16 & Alloy 617 & Plate & xyz-CF & air & 500 & 2.5 \\
\hline Tensile & 17 & Alloy 617 & Plate & xyz-CF & air & 500 & 2.5 \\
\hline Tensile & 18 & Alloy 617 & Plate & xyz-CF & air & 500 & 2.5 \\
\hline Tensile & 19 & Alloy 617 & Plate & xyz-CF & air & 600 & 2.5 \\
\hline Tensile & 20 & Alloy 617 & Plate & xyz-CF & air & 600 & 2.5 \\
\hline Tensile & 21 & Alloy 617 & Plate & xyz-CF & air & 600 & 2.5 \\
\hline Tensile & 22 & Alloy 617 & Plate & xyz-CF & air & 650 & 2.5 \\
\hline Tensile & 23 & Alloy 617 & Plate & xyz-CF & air & 650 & 2.5 \\
\hline Tensile & 24 & Alloy 617 & Plate & xyz-CF & air & 650 & 2.5 \\
\hline Tensile & 25 & Alloy 617 & Plate & xyz-CF & air & 700 & 2.5 \\
\hline Tensile & 26 & Alloy 617 & Plate & xyz-CF & air & 700 & 2.5 \\
\hline Tensile & 27 & Alloy 617 & Plate & xyz-CF & air & 700 & 2.5 \\
\hline Tensile & 28 & Alloy 617 & Plate & xyz-CF & air & 750 & 2.5 \\
\hline
\end{tabular}


Form 412.09 (Rev. 10)

Idaho National Laboratory

NEXT GENERATION NUCLEAR PLANT

INTERMEDIATE HEAT EXCHANGER

MATERIALS RESEARCH

AND DEVELOPMENT PLAN

\begin{tabular}{|lll|} 
Identifier: & PLN-2804 & \\
Revision: & 0 & \\
Effective Date: & $04 / 30 / 08$ & Page: A-56 of A-114 \\
\hline
\end{tabular}

Table A5. Tensile Test Matrix to Determine Strain Rate Sensitivity in Support of Unified Constitutive Model

\begin{tabular}{|c|c|c|c|c|c|c|c|}
\hline Specimen Type & Specimen \# & Material & Product Form & Heat & Environment & Temp $\left({ }^{\circ} \mathrm{C}\right)$ & Total Strain $(\%)$ \\
\hline Tensile & 29 & Alloy 617 & Plate & xyz-CF & air & 750 & 2.5 \\
\hline Tensile & 30 & Alloy 617 & Plate & xyz-CF & air & 750 & 2.5 \\
\hline Tensile & 31 & Alloy 617 & Plate & xyz-CF & air & 800 & 2.5 \\
\hline Tensile & 32 & Alloy 617 & Plate & xyz-CF & air & 800 & 2.5 \\
\hline Tensile & 33 & Alloy 617 & Plate & xyz-CF & air & 800 & 2.5 \\
\hline Tensile & 34 & Alloy 617 & Plate & xyz-CF & air & 850 & 2.5 \\
\hline Tensile & 35 & Alloy 617 & Plate & xyz-CF & air & 850 & 2.5 \\
\hline Tensile & 36 & Alloy 617 & Plate & xyz-CF & air & 850 & 2.5 \\
\hline Tensile & 37 & Alloy 617 & Plate & xyz-CF & air & 900 & 2.5 \\
\hline Tensile & 38 & Alloy 617 & Plate & xyz-CF & air & 900 & 2.5 \\
\hline Tensile & 39 & Alloy 617 & Plate & xyz-CF & air & 900 & 2.5 \\
\hline Tensile & 40 & Alloy 617 & Plate & xyz-CF & air & 950 & 2.5 \\
\hline Tensile & 41 & Alloy 617 & Plate & xyz-CF & air & 950 & 2.5 \\
\hline Tensile & 42 & Alloy 617 & Plate & xyz-CF & air & 950 & 2.5 \\
\hline Tensile & 43 & Alloy 617 & Plate & xyz-CF & air & 1000 & 2.5 \\
\hline Tensile & 44 & Alloy 617 & Plate & xyz-CF & air & 1000 & 2.5 \\
\hline Tensile & 45 & Alloy 617 & Plate & xyz-CF & air & 1000 & 2.5 \\
\hline
\end{tabular}


Form 412.09 (Rev. 10)

Idaho National Laboratory
\begin{tabular}{|c|lll|}
\hline NEXT GENERATION NUCLEAR PLANT & Identifier: & PLN-2804 \\
INTERMEDIATE HEAT EXCHANGER & Revision: & 0 & \\
MATERIALS RESEARCH & Effective Date: & $04 / 30 / 08$ & Page: A-57 of A-114 \\
AND DEVELOPMENT PLAN &
\end{tabular}

\begin{tabular}{|c|c|c|c|c|c|c|}
\hline \multicolumn{7}{|c|}{ Table A6. Torsion Test Matrix for Validating Von Mises Criterion to Support Unified Constitutive Model } \\
\hline Specimen Type & Specimen \# & Material & Product Form & Heat & Environment & Temp $\left({ }^{\circ} \mathrm{C}\right)$ \\
\hline Tubular & 1 & Alloy 617 & Plate & xyz-CF & air & 600 \\
\hline Tubular & 2 & Alloy 617 & Plate & xyz-CF & air & 600 \\
\hline Tubular & 3 & Alloy 617 & Plate & xyz-CF & air & 600 \\
\hline Tubular & 4 & Alloy 617 & Plate & xyz-CF & air & 700 \\
\hline Tubular & 5 & Alloy 617 & Plate & xyz-CF & air & 700 \\
\hline Tubular & 6 & Alloy 617 & Plate & xyz-CF & air & 700 \\
\hline Tubular & 7 & Alloy 617 & Plate & xyz-CF & air & 800 \\
\hline Tubular & 8 & Alloy 617 & Plate & xyz-CF & air & 800 \\
\hline Tubular & 9 & Alloy 617 & Plate & xyz-CF & air & 800 \\
\hline Tubular & 10 & Alloy 617 & Plate & xyz-CF & air & 900 \\
\hline Tubular & 11 & Alloy 617 & Plate & xyz-CF & air & 900 \\
\hline Tubular & 12 & Alloy 617 & Plate & xyz-CF & air & 900 \\
\hline Tubular & 13 & Alloy 617 & Plate & xyz-CF & air & 1000 \\
\hline Tubular & 14 & Alloy 617 & Plate & xyz-CF & air & 1000 \\
\hline Tubular & 15 & Alloy 617 & Plate & xyz-CF & air & 1000 \\
\hline
\end{tabular}




Idaho National Laboratory
\begin{tabular}{|c|lll|}
\hline NEXT GENERATION NUCLEAR PLANT & Identifier: & PLN-2804 & \\
INTERMEDIATE HEAT EXCHANGER & Revision: & 0 & \\
MATERIALS RESEARCH & Effective Date: & $04 / 30 / 08$ & Page: A-58 of A-114 \\
AND DEVELOPMENT PLAN & &
\end{tabular}

\begin{tabular}{|c|c|c|c|c|c|c|}
\hline Specimen Type & Specimen \# & Material & Product Form & Heat & Environment & Temp $\left({ }^{\circ} \mathrm{C}\right)$ \\
\hline Tensile & 1 & Alloy 617 & Plate & $\mathrm{xyz}-\mathrm{CF}$ & air & 600 \\
\hline Tensile & 2 & Alloy 617 & Plate & xyz - CF & air & 600 \\
\hline Tensile & 3 & Alloy 617 & Plate & xyz - CF & air & 600 \\
\hline Tensile & 4 & Alloy 617 & Plate & xyz - CF & air & 650 \\
\hline Tensile & 5 & Alloy 617 & Plate & $\mathrm{xyz}-\mathrm{CF}$ & air & 650 \\
\hline Tensile & 6 & Alloy 617 & Plate & xyz - CF & air & 650 \\
\hline Tensile & 7 & Alloy 617 & Plate & xyz - CF & air & 700 \\
\hline Tensile & 8 & Alloy 617 & Plate & xyz - CF & air & 700 \\
\hline Tensile & 9 & Alloy 617 & Plate & $\mathrm{xyz}-\mathrm{CF}$ & air & 700 \\
\hline Tensile & 10 & Alloy 617 & Plate & $\mathrm{xyz}-\mathrm{CF}$ & air & 750 \\
\hline Tensile & 11 & Alloy 617 & Plate & xyz - CF & air & 750 \\
\hline Tensile & 12 & Alloy 617 & Plate & $\mathrm{xyz}-\mathrm{CF}$ & air & 750 \\
\hline Tensile & 13 & Alloy 617 & Plate & xyz - CF & air & 800 \\
\hline Tensile & 14 & Alloy 617 & Plate & $\mathrm{xyz}-\mathrm{CF}$ & air & 800 \\
\hline Tensile & 15 & Alloy 617 & Plate & $\mathrm{xyz}-\mathrm{CF}$ & air & 800 \\
\hline Tensile & 16 & Alloy 617 & Plate & $\mathrm{xyz}-\mathrm{CF}$ & air & 850 \\
\hline Tensile & 17 & Alloy 617 & Plate & xyz - CF & air & 850 \\
\hline Tensile & 18 & Alloy 617 & Plate & $\mathrm{xyz}-\mathrm{CF}$ & air & 850 \\
\hline Tensile & 19 & Alloy 617 & Plate & $\mathrm{xyz}-\mathrm{CF}$ & air & 900 \\
\hline Tensile & 20 & Alloy 617 & Plate & xyz - CF & air & 900 \\
\hline Tensile & 21 & Alloy 617 & Plate & $\mathrm{xyz}-\mathrm{CF}$ & air & 900 \\
\hline Tensile & 22 & Alloy 617 & Plate & xyz - CF & air & 950 \\
\hline Tensile & 23 & Alloy 617 & Plate & $\mathrm{xyz}-\mathrm{CF}$ & air & 950 \\
\hline Tensile & 24 & Alloy 617 & Plate & xyz - CF & air & 950 \\
\hline Tensile & 25 & Alloy 617 & Plate & xyz - CF & air & 1000 \\
\hline Tensile & 26 & Alloy 617 & Plate & $\mathrm{xyz}-\mathrm{CF}$ & air & 1000 \\
\hline Tensile & 27 & Alloy 617 & Plate & xyz - CF & air & 1000 \\
\hline
\end{tabular}




Idaho National Laboratory
\begin{tabular}{|c|lll|}
\hline NEXT GENERATION NUCLEAR PLANT & Identifier: & PLN-2804 & \\
INTERMEDIATE HEAT EXCHANGER & Revision: & 0 & \\
MATERIALS RESEARCH & Effective Date: & $04 / 30 / 08$ & Page: A-59 of A-114 \\
AND DEVELOPMENT PLAN & &
\end{tabular}

\begin{tabular}{|c|c|c|c|c|c|c|}
\hline Specimen Type & Specimen \# & Material & Product Form & Heat & Environment & Temp $\left({ }^{\circ} \mathrm{C}\right)$ \\
\hline Tensile & 1 & Alloy 617 & Plate & $\mathrm{xyz}-\mathrm{CF}$ & air & 600 \\
\hline Tensile & 2 & Alloy 617 & Plate & xyz - CF & air & 600 \\
\hline Tensile & 3 & Alloy 617 & Plate & xyz - CF & air & 600 \\
\hline Tensile & 4 & Alloy 617 & Plate & $\mathrm{xyz}-\mathrm{CF}$ & air & 650 \\
\hline Tensile & 5 & Alloy 617 & Plate & $\mathrm{xyz}-\mathrm{CF}$ & air & 650 \\
\hline Tensile & 6 & Alloy 617 & Plate & $\mathrm{xyz}-\mathrm{CF}$ & air & 650 \\
\hline Tensile & 7 & Alloy 617 & Plate & $\mathrm{xyz}-\mathrm{CF}$ & air & 700 \\
\hline Tensile & 8 & Alloy 617 & Plate & xyz - CF & air & 700 \\
\hline Tensile & 9 & Alloy 617 & Plate & $\mathrm{xyz}-\mathrm{CF}$ & air & 700 \\
\hline Tensile & 10 & Alloy 617 & Plate & $\mathrm{xyz}-\mathrm{CF}$ & air & 750 \\
\hline Tensile & 11 & Alloy 617 & Plate & $\mathrm{xyz}-\mathrm{CF}$ & air & 750 \\
\hline Tensile & 12 & Alloy 617 & Plate & $\mathrm{xyz}-\mathrm{CF}$ & air & 750 \\
\hline Tensile & 13 & Alloy 617 & Plate & $\mathrm{xyz}-\mathrm{CF}$ & air & 800 \\
\hline Tensile & 14 & Alloy 617 & Plate & $\mathrm{xyz}-\mathrm{CF}$ & air & 800 \\
\hline Tensile & 15 & Alloy 617 & Plate & $\mathrm{xyz}-\mathrm{CF}$ & air & 800 \\
\hline Tensile & 16 & Alloy 617 & Plate & $\mathrm{xyz}-\mathrm{CF}$ & air & 850 \\
\hline Tensile & 17 & Alloy 617 & Plate & $\mathrm{xyz}-\mathrm{CF}$ & air & 850 \\
\hline Tensile & 18 & Alloy 617 & Plate & $\mathrm{xyz}-\mathrm{CF}$ & air & 850 \\
\hline Tensile & 19 & Alloy 617 & Plate & $\mathrm{xyz}-\mathrm{CF}$ & air & 900 \\
\hline Tensile & 20 & Alloy 617 & Plate & $\mathrm{xyz}-\mathrm{CF}$ & air & 900 \\
\hline Tensile & 21 & Alloy 617 & Plate & $\mathrm{xyz}-\mathrm{CF}$ & air & 900 \\
\hline Tensile & 22 & Alloy 617 & Plate & $\mathrm{xyz}-\mathrm{CF}$ & air & 950 \\
\hline Tensile & 23 & Alloy 617 & Plate & $\mathrm{xyz}-\mathrm{CF}$ & air & 950 \\
\hline Tensile & 24 & Alloy 617 & Plate & $\mathrm{xyz}-\mathrm{CF}$ & air & 950 \\
\hline Tensile & 25 & Alloy 617 & Plate & $\mathrm{xyz}-\mathrm{CF}$ & air & 1000 \\
\hline Tensile & 26 & Alloy 617 & Plate & $\mathrm{xyz}-\mathrm{CF}$ & air & 1000 \\
\hline Tensile & 27 & Alloy 617 & Plate & $\mathrm{xyz}-\mathrm{CF}$ & air & 1000 \\
\hline
\end{tabular}




Idaho National Laboratory
\begin{tabular}{|c|lll|}
\hline NEXT GENERATION NUCLEAR PLANT & Identifier: & PLN-2804 & \\
INTERMEDIATE HEAT EXCHANGER & Revision: & 0 & \\
MATERIALS RESEARCH & Effective Date: & $04 / 30 / 08$ & Page: A-60 of A-114 \\
AND DEVELOPMENT PLAN & &
\end{tabular}

\begin{tabular}{|c|c|c|c|c|c|c|}
\hline Specimen Type & Specimen \# & Material & Product Form & Heat & Environment & Temp $\left({ }^{\circ} \mathrm{C}\right)$ \\
\hline Tensile & 1 & Alloy 617 & Plate & $\mathrm{xyz}-\mathrm{CF}$ & air & 600 \\
\hline Tensile & 2 & Alloy 617 & Plate & $\mathrm{xyz}-\mathrm{CF}$ & air & 600 \\
\hline Tensile & 3 & Alloy 617 & Plate & $\mathrm{xyz}-\mathrm{CF}$ & air & 600 \\
\hline Tensile & 4 & Alloy 617 & Plate & xyz - CF & air & 650 \\
\hline Tensile & 5 & Alloy 617 & Plate & $\mathrm{xyz}-\mathrm{CF}$ & air & 650 \\
\hline Tensile & 6 & Alloy 617 & Plate & xyz - CF & air & 650 \\
\hline Tensile & 7 & Alloy 617 & Plate & $\mathrm{xyz}-\mathrm{CF}$ & air & 700 \\
\hline Tensile & 8 & Alloy 617 & Plate & xyz - CF & air & 700 \\
\hline Tensile & 9 & Alloy 617 & Plate & $\mathrm{xyz}-\mathrm{CF}$ & air & 700 \\
\hline Tensile & 10 & Alloy 617 & Plate & xyz - CF & air & 750 \\
\hline Tensile & 11 & Alloy 617 & Plate & $\mathrm{xyz}-\mathrm{CF}$ & air & 750 \\
\hline Tensile & 12 & Alloy 617 & Plate & xyz - CF & air & 750 \\
\hline Tensile & 13 & Alloy 617 & Plate & xyz - CF & air & 800 \\
\hline Tensile & 14 & Alloy 617 & Plate & $\mathrm{xyz}-\mathrm{CF}$ & air & 800 \\
\hline Tensile & 15 & Alloy 617 & Plate & $\mathrm{xyz}-\mathrm{CF}$ & air & 800 \\
\hline Tensile & 16 & Alloy 617 & Plate & xyz - CF & air & 850 \\
\hline Tensile & 17 & Alloy 617 & Plate & xyz - CF & air & 850 \\
\hline Tensile & 18 & Alloy 617 & Plate & xyz - CF & air & 850 \\
\hline Tensile & 19 & Alloy 617 & Plate & $\mathrm{xyz}-\mathrm{CF}$ & air & 900 \\
\hline Tensile & 20 & Alloy 617 & Plate & $\mathrm{xyz}-\mathrm{CF}$ & air & 900 \\
\hline Tensile & 21 & Alloy 617 & Plate & xyz - CF & air & 900 \\
\hline Tensile & 22 & Alloy 617 & Plate & xyz - CF & air & 950 \\
\hline Tensile & 23 & Alloy 617 & Plate & xyz - CF & air & 950 \\
\hline Tensile & 24 & Alloy 617 & Plate & $\mathrm{xyz}-\mathrm{CF}$ & air & 950 \\
\hline Tensile & 25 & Alloy 617 & Plate & xyz - CF & air & 1000 \\
\hline Tensile & 26 & Alloy 617 & Plate & xyz - CF & air & 1000 \\
\hline Tensile & 27 & Alloy 617 & Plate & xyz - CF & air & 1000 \\
\hline
\end{tabular}




Idaho National Laboratory
\begin{tabular}{|c|lll|}
\hline NEXT GENERATION NUCLEAR PLANT & Identifier: & PLN-2804 & \\
INTERMEDIATE HEAT EXCHANGER & Revision: & 0 & \\
MATERIALS RESEARCH & Effective Date: & $04 / 30 / 08$ & Page: A-61 of A-114 \\
AND DEVELOPMENT PLAN & &
\end{tabular}

\begin{tabular}{|c|c|c|c|c|c|c|c|c|}
\hline Specimen Type & Specimen \# & Material & Product Form & Heat & Environment & Temp $\left({ }^{\circ} \mathrm{C}\right)$ & $\begin{array}{l}\text { Shear Strain } \\
\text { Rate }(\mathrm{m} / \mathrm{m} / \mathrm{s})\end{array}$ & $\begin{array}{c}\text { Axial Strain } \\
(\%)\end{array}$ \\
\hline Tubular & 1 & Alloy 617 & Plate & xyz-CF & air & 850 & $\pm 1 \mathrm{E}-03$ & 0.00 \\
\hline Tubular & 2 & Alloy 617 & Plate & xyz-CF & air & 850 & $\pm 1 \mathrm{E}-03$ & 0.00 \\
\hline Tubular & 3 & Alloy 617 & Plate & xyz-CF & air & 850 & $\pm 1 \mathrm{E}-03$ & 0.00 \\
\hline Tubular & 4 & Alloy 617 & Plate & xyz-CF & air & 950 & $\pm 1 \mathrm{E}-03$ & 0.00 \\
\hline Tubular & 5 & Alloy 617 & Plate & xyz-CF & air & 950 & $\pm 1 \mathrm{E}-03$ & 0.00 \\
\hline Tubular & 6 & Alloy 617 & Plate & xyz-CF & air & 950 & $\pm 1 \mathrm{E}-03$ & 0.00 \\
\hline Tubular & 7 & Alloy 617 & Plate & xyz-CF & air & 850 & $\pm 1 \mathrm{E}-03$ & 0.15 \\
\hline Tubular & 8 & Alloy 617 & Plate & xyz-CF & air & 850 & $\pm 1 \mathrm{E}-03$ & 0.15 \\
\hline Tubular & 9 & Alloy 617 & Plate & xyz-CF & air & 850 & $\pm 1 \mathrm{E}-03$ & 0.15 \\
\hline Tubular & 10 & Alloy 617 & Plate & xyz-CF & air & 950 & $\pm 1 \mathrm{E}-03$ & 0.15 \\
\hline Tubular & 11 & Alloy 617 & Plate & xyz-CF & air & 950 & $\pm 1 \mathrm{E}-03$ & 0.15 \\
\hline Tubular & 12 & Alloy 617 & Plate & xyz-CF & air & 950 & $\pm 1 \mathrm{E}-03$ & 0.15 \\
\hline Tubular & 13 & Alloy 617 & Plate & xyz-CF & air & 850 & $\pm 1 \mathrm{E}-03$ & 0.30 \\
\hline Tubular & 14 & Alloy 617 & Plate & xyz-CF & air & 850 & $\pm 1 \mathrm{E}-03$ & 0.30 \\
\hline Tubular & 15 & Alloy 617 & Plate & xyz-CF & air & 850 & $\pm 1 \mathrm{E}-03$ & 0.30 \\
\hline Tubular & 16 & Alloy 617 & Plate & xyz-CF & air & 950 & $\pm 1 \mathrm{E}-03$ & 0.30 \\
\hline Tubular & 17 & Alloy 617 & Plate & xyz-CF & air & 950 & $\pm 1 \mathrm{E}-03$ & 0.30 \\
\hline Tubular & 18 & Alloy 617 & Plate & xyz-CF & air & 950 & $\pm 1 \mathrm{E}-03$ & 0.30 \\
\hline & & & & & & & & \\
\hline Tubular & 19 & Alloy 617 & Plate & xyz-CF & air & 850 & $\pm 1 \mathrm{E}-05$ & 0.00 \\
\hline Tubular & 20 & Alloy 617 & Plate & xyz-CF & air & 850 & $\pm 1 \mathrm{E}-05$ & 0.00 \\
\hline Tubular & 21 & Alloy 617 & Plate & xyz-CF & air & 850 & $\pm 1 \mathrm{E}-05$ & 0.00 \\
\hline Tubular & 22 & Alloy 617 & Plate & xyz-CF & air & 950 & $\pm 1 \mathrm{E}-05$ & 0.00 \\
\hline Tubular & 23 & Alloy 617 & Plate & xyz-CF & air & 950 & $\pm 1 \mathrm{E}-05$ & 0.00 \\
\hline Tubular & 24 & Alloy 617 & Plate & xyz-CF & air & 950 & $\pm 1 \mathrm{E}-05$ & 0.00 \\
\hline Tubular & 25 & Alloy 617 & Plate & xyz-CF & air & 850 & $\pm 1 \mathrm{E}-05$ & 0.15 \\
\hline
\end{tabular}


Idaho National Laboratory

\begin{tabular}{|c|c|c|c|}
\hline $\begin{array}{l}\text { NEXT GENERATION NUCLEAR PLANT } \\
\text { INTERMEDIATE HEAT EXCHANGER } \\
\text { MATERIALS RESEARCH } \\
\text { AND DEVELOPMENT PLAN }\end{array}$ & $\begin{array}{l}\text { Identifier: } \\
\text { Revision: } \\
\text { Effective Date: }\end{array}$ & $\begin{array}{l}\text { PLN-2804 } \\
0 \\
04 / 30 / 08\end{array}$ & Page: A-62 of A-114 \\
\hline
\end{tabular}

Table A10. Test Matrix for Torsional Cycling with Constant Axial Strain to Support Unified Constitutive Model

\begin{tabular}{|c|c|c|c|c|c|c|c|c|}
\hline Specimen Type & Specimen \# & Material & Product Form & Heat & Environment & Temp $\left({ }^{\circ} \mathrm{C}\right)$ & $\begin{array}{l}\text { Shear Strain } \\
\text { Rate }(\mathrm{m} / \mathrm{m} / \mathrm{s})\end{array}$ & $\begin{array}{c}\text { Axial Strain } \\
(\%)\end{array}$ \\
\hline Tubular & 26 & Alloy 617 & Plate & $\mathrm{xyz}-\mathrm{CF}$ & air & 850 & $\pm 1 \mathrm{E}-05$ & 0.15 \\
\hline Tubular & 27 & Alloy 617 & Plate & xyz-CF & air & 850 & $\pm 1 \mathrm{E}-05$ & 0.15 \\
\hline Tubular & 28 & Alloy 617 & Plate & xyz-CF & air & 950 & $\pm 1 \mathrm{E}-05$ & 0.15 \\
\hline Tubular & 29 & Alloy 617 & Plate & xyz-CF & air & 950 & $\pm 1 \mathrm{E}-05$ & 0.15 \\
\hline Tubular & 30 & Alloy 617 & Plate & xyz-CF & air & 950 & $\pm 1 \mathrm{E}-05$ & 0.15 \\
\hline Tubular & 31 & Alloy 617 & Plate & xyz-CF & air & 850 & $\pm 1 \mathrm{E}-05$ & 0.30 \\
\hline Tubular & 32 & Alloy 617 & Plate & xyz-CF & air & 850 & $\pm 1 \mathrm{E}-05$ & 0.30 \\
\hline Tubular & 33 & Alloy 617 & Plate & xyz-CF & air & 850 & $\pm 1 \mathrm{E}-05$ & 0.30 \\
\hline Tubular & 34 & Alloy 617 & Plate & xyz-CF & air & 950 & $\pm 1 \mathrm{E}-05$ & 0.30 \\
\hline Tubular & 35 & Alloy 617 & Plate & xyz-CF & air & 950 & $\pm 1 \mathrm{E}-05$ & 0.30 \\
\hline Tubular & 36 & Alloy 617 & Plate & xyz-CF & air & 950 & $\pm 1 \mathrm{E}-05$ & 0.30 \\
\hline
\end{tabular}




Idaho National Laboratory
\begin{tabular}{|c|lll|}
\hline NEXT GENERATION NUCLEAR PLANT & Identifier: & PLN-2804 & \\
INTERMEDIATE HEAT EXCHANGER & Revision: & 0 & \\
MATERIALS RESEARCH & Effective Date: & $04 / 30 / 08$ & Page: A- 63 of A-114 \\
AND DEVELOPMENT PLAN & &
\end{tabular}

\begin{tabular}{|c|c|c|c|c|c|c|c|}
\hline Specimen Type & Specimen \# & Material & Product Form & Heat & Environment & Temp. $\left({ }^{\circ} \mathrm{C}\right)$ & $\begin{array}{c}\text { Mag. of Loading-Unloading } \\
\text { Rate }(\mathrm{MPa} / \mathrm{s})\end{array}$ \\
\hline Tensile & 1 & Alloy 617 & Plate & xyz-CF & air & 600 & $1 \mathrm{E}-02$ \\
\hline Tensile & 2 & Alloy 617 & Plate & xyz-CF & air & 600 & $1 \mathrm{E}-02$ \\
\hline Tensile & 3 & Alloy 617 & Plate & xyz-CF & air & 600 & $1 \mathrm{E}-02$ \\
\hline Tensile & 4 & Alloy 617 & Plate & xyz-CF & air & 700 & $1 \mathrm{E}-02$ \\
\hline Tensile & 5 & Alloy 617 & Plate & xyz-CF & air & 700 & $1 \mathrm{E}-02$ \\
\hline Tensile & 6 & Alloy 617 & Plate & xyz-CF & air & 700 & $1 \mathrm{E}-02$ \\
\hline Tensile & 7 & Alloy 617 & Plate & xyz-CF & air & 800 & $1 \mathrm{E}-02$ \\
\hline Tensile & 8 & Alloy 617 & Plate & xyz-CF & air & 800 & $1 \mathrm{E}-02$ \\
\hline Tensile & 9 & Alloy 617 & Plate & xyz-CF & air & 800 & $1 \mathrm{E}-02$ \\
\hline Tensile & 10 & Alloy 617 & Plate & xyz-CF & air & 900 & $1 \mathrm{E}-02$ \\
\hline Tensile & 11 & Alloy 617 & Plate & xyz-CF & air & 900 & $1 \mathrm{E}-02$ \\
\hline Tensile & 12 & Alloy 617 & Plate & xyz-CF & air & 900 & $1 \mathrm{E}-02$ \\
\hline Tensile & 13 & Alloy 617 & Plate & xyz-CF & air & 1000 & $1 \mathrm{E}-02$ \\
\hline Tensile & 14 & Alloy 617 & Plate & xyz-CF & air & 1000 & $1 \mathrm{E}-02$ \\
\hline Tensile & 15 & Alloy 617 & Plate & xyz-CF & air & 1000 & $1 \mathrm{E}-02$ \\
\hline & & & & & & & \\
\hline Tensile & 16 & Alloy 617 & Plate & xyz-CF & air & 600 & $1 \mathrm{E}-01$ \\
\hline Tensile & 17 & Alloy 617 & Plate & xyz-CF & air & 600 & $1 \mathrm{E}-01$ \\
\hline Tensile & 18 & Alloy 617 & Plate & xyz-CF & air & 600 & $1 \mathrm{E}-01$ \\
\hline Tensile & 19 & Alloy 617 & Plate & xyz-CF & air & 700 & $1 \mathrm{E}-01$ \\
\hline Tensile & 20 & Alloy 617 & Plate & xyz-CF & air & 700 & $1 \mathrm{E}-01$ \\
\hline Tensile & 21 & Alloy 617 & Plate & xyz-CF & air & 700 & $1 \mathrm{E}-01$ \\
\hline Tensile & 22 & Alloy 617 & Plate & xyz-CF & air & 800 & $1 \mathrm{E}-01$ \\
\hline Tensile & 23 & Alloy 617 & Plate & xyz-CF & air & 800 & $1 \mathrm{E}-01$ \\
\hline Tensile & 24 & Alloy 617 & Plate & xyz-CF & air & 800 & $1 \mathrm{E}-01$ \\
\hline Tensile & 25 & Alloy 617 & Plate & xyz-CF & air & 900 & $1 \mathrm{E}-01$ \\
\hline Tensile & 26 & Alloy 617 & Plate & xyz-CF & air & 900 & $1 \mathrm{E}-01$ \\
\hline
\end{tabular}


Form 412.09 (Rev. 10)

Idaho National Laboratory

\begin{tabular}{|c|c|c|c|}
\hline $\begin{array}{l}\text { NEXT GENERATION NUCLEAR PLANT } \\
\text { INTERMEDIATE HEAT EXCHANGER } \\
\text { MATERIALS RESEARCH } \\
\text { AND DEVELOPMENT PLAN }\end{array}$ & $\begin{array}{l}\text { Identifier: } \\
\text { Revision: } \\
\text { Effective Date: }\end{array}$ & $\begin{array}{l}\text { PLN-2804 } \\
0 \\
04 / 30 / 08\end{array}$ & Page: \\
\hline
\end{tabular}

Table A11. Test Matrix for Loading-Unloading-Creep Sequence to Support Unified Constitutive Model

\begin{tabular}{|c|c|c|c|c|c|c|c|}
\hline Specimen Type & Specimen \# & Material & Product Form & Heat & Environment & Temp. $\left({ }^{\circ} \mathrm{C}\right)$ & $\begin{array}{c}\text { Mag. of Loading-Unloading } \\
\text { Rate }(\mathrm{MPa} / \mathrm{s})\end{array}$ \\
\hline Tensile & 27 & Alloy 617 & Plate & xyz-CF & air & 900 & $1 \mathrm{E}-01$ \\
\hline Tensile & 28 & Alloy 617 & Plate & xyz-CF & air & 1000 & $1 \mathrm{E}-01$ \\
\hline Tensile & 29 & Alloy 617 & Plate & xyz-CF & air & 1000 & $1 \mathrm{E}-01$ \\
\hline Tensile & 30 & Alloy 617 & Plate & xyz-CF & air & 1000 & $1 \mathrm{E}-01$ \\
\hline Tensile & 31 & Alloy 617 & Plate & xyz-CF & air & 600 & $1 \mathrm{E}+00$ \\
\hline Tensile & 32 & Alloy 617 & Plate & xyz-CF & air & 600 & $1 \mathrm{E}+00$ \\
\hline Tensile & 33 & Alloy 617 & Plate & xyz-CF & air & 600 & $1 \mathrm{E}+00$ \\
\hline Tensile & 34 & Alloy 617 & Plate & xyz-CF & air & 700 & $1 \mathrm{E}+00$ \\
\hline Tensile & 35 & Alloy 617 & Plate & xyz-CF & air & 700 & $1 \mathrm{E}+00$ \\
\hline Tensile & 36 & Alloy 617 & Plate & xyz-CF & air & 700 & $1 \mathrm{E}+00$ \\
\hline Tensile & 37 & Alloy 617 & Plate & xyz-CF & air & 800 & $1 \mathrm{E}+00$ \\
\hline Tensile & 38 & Alloy 617 & Plate & xyz-CF & air & 800 & $1 \mathrm{E}+00$ \\
\hline Tensile & 39 & Alloy 617 & Plate & xyz-CF & air & 800 & $1 \mathrm{E}+00$ \\
\hline Tensile & 40 & Alloy 617 & Plate & xyz-CF & air & 900 & $1 \mathrm{E}+00$ \\
\hline Tensile & 41 & Alloy 617 & Plate & xyz-CF & air & 900 & $1 \mathrm{E}+00$ \\
\hline Tensile & 42 & Alloy 617 & Plate & xyz-CF & air & 900 & $1 \mathrm{E}+00$ \\
\hline Tensile & 43 & Alloy 617 & Plate & xyz-CF & air & 1000 & $1 \mathrm{E}+00$ \\
\hline Tensile & 44 & Alloy 617 & Plate & xyz-CF & air & 1000 & $1 \mathrm{E}+00$ \\
\hline Tensile & 45 & Alloy 617 & Plate & xyz-CF & air & 1000 & $1 \mathrm{E}+00$ \\
\hline
\end{tabular}




Idaho National Laboratory
\begin{tabular}{|c|lll|}
\hline NEXT GENERATION NUCLEAR PLANT & Identifier: & PLN-2804 & \\
INTERMEDIATE HEAT EXCHANGER & Revision: & 0 & \\
MATERIALS RESEARCH & Effective Date: & $04 / 30 / 08$ & Page: A-65 of A-114 \\
AND DEVELOPMENT PLAN &
\end{tabular}

\begin{tabular}{|c|c|c|c|c|c|c|c|c|c|}
\hline Specimen Type & Specimen \# & Material & $\begin{array}{c}\text { Product } \\
\text { Form }\end{array}$ & Heat & Environment & Condition & $\begin{array}{l}\text { Temp. } \\
\left({ }^{\circ} \mathrm{C}\right)\end{array}$ & $\begin{array}{l}\text { Strain Rate } \\
(\mathrm{m} / \mathrm{m} / \mathrm{s})\end{array}$ & $\begin{array}{c}\text { Strain Range } \\
(\%)\end{array}$ \\
\hline Fatigue & 1 & Alloy 617 & Plate & xyz-CF & air & isothermal & 600 & $1 \mathrm{E}-05$ & 0.6 \\
\hline Fatigue & 2 & Alloy 617 & Plate & xyz-CF & air & isothermal & 600 & $1 \mathrm{E}-05$ & 0.6 \\
\hline Fatigue & 3 & Alloy 617 & Plate & xyz-CF & air & isothermal & 600 & $1 \mathrm{E}-05$ & 1.2 \\
\hline Fatigue & 4 & Alloy 617 & Plate & xyz-CF & air & isothermal & 600 & $1 \mathrm{E}-05$ & 1.2 \\
\hline Fatigue & 5 & Alloy 617 & Plate & xyz-CF & air & isothermal & 600 & $1 \mathrm{E}-05$ & 1.8 \\
\hline Fatigue & 6 & Alloy 617 & Plate & xyz-CF & air & isothermal & 600 & $1 \mathrm{E}-05$ & 1.8 \\
\hline Fatigue & 7 & Alloy 617 & Plate & xyz-CF & air & isothermal & 1000 & $1 \mathrm{E}-05$ & 0.6 \\
\hline Fatigue & 8 & Alloy 617 & Plate & xyz-CF & air & isothermal & 1000 & $1 \mathrm{E}-05$ & 0.6 \\
\hline Fatigue & 9 & Alloy 617 & Plate & xyz-CF & air & isothermal & 1000 & $1 \mathrm{E}-05$ & 1.2 \\
\hline Fatigue & 10 & Alloy 617 & Plate & xyz-CF & air & isothermal & 1000 & $1 \mathrm{E}-05$ & 1.2 \\
\hline Fatigue & 11 & Alloy 617 & Plate & $\mathrm{xyz}-\mathrm{CF}$ & air & isothermal & 1000 & $1 \mathrm{E}-05$ & 1.8 \\
\hline Fatigue & 12 & Alloy 617 & Plate & xyz-CF & air & isothermal & 1000 & $1 \mathrm{E}-05$ & 1.8 \\
\hline & & & & & & & & & \\
\hline Fatigue & 13 & Alloy 617 & Plate & xyz-CF & air & Non-isothermal & $600 / 1000$ & $1 \mathrm{E}-05$ & 0.6 \\
\hline Fatigue & 14 & Alloy 617 & Plate & xyz-CF & air & Non-isothermal & $600 / 1000$ & $1 \mathrm{E}-05$ & 0.6 \\
\hline Fatigue & 15 & Alloy 617 & Plate & xyz-CF & air & Non-isothermal & $600 / 1000$ & $1 \mathrm{E}-05$ & 1.2 \\
\hline Fatigue & 16 & Alloy 617 & Plate & xyz-CF & air & Non-isothermal & $600 / 1000$ & $1 \mathrm{E}-05$ & 1.2 \\
\hline Fatigue & 17 & Alloy 617 & Plate & xyz-CF & air & Non-isothermal & $600 / 1000$ & $1 \mathrm{E}-05$ & 1.8 \\
\hline Fatigue & 18 & Alloy 617 & Plate & $\mathrm{xyz}-\mathrm{CF}$ & air & Non-isothermal & $600 / 1000$ & $1 \mathrm{E}-05$ & 1.8 \\
\hline
\end{tabular}




Idaho National Laboratory
\begin{tabular}{|c|lll|}
\hline NEXT GENERATION NUCLEAR PLANT & Identifier: & PLN-2804 & \\
INTERMEDIATE HEAT EXCHANGER & Revision: & 0 & \\
MATERIALS RESEARCH & Effective Date: & $04 / 30 / 08$ & Page: A-66 of A-114 \\
AND DEVELOPMENT PLAN &
\end{tabular}

\begin{tabular}{|c|c|c|c|c|c|c|c|c|c|c|}
\hline $\begin{array}{c}\text { Specimen } \\
\text { Type }\end{array}$ & $\begin{array}{c}\text { Specimen } \\
\# \\
\end{array}$ & Material & $\begin{array}{l}\text { Product } \\
\text { Form }\end{array}$ & Heat & $\begin{array}{c}\text { Environ- } \\
\text { ment }\end{array}$ & $\begin{array}{l}\text { Temp. } \\
\left({ }^{\circ} \mathrm{C}\right)\end{array}$ & $\begin{array}{l}\text { Applied } \\
\text { Stress } \\
(\mathrm{MPa})\end{array}$ & $\begin{array}{l}\text { Estimated } \\
\text { Rupture } \\
\text { Time (h) } \\
\end{array}$ & $\begin{array}{c}\text { Estimated 95\% } \\
\text { Lower Bound } \\
\text { Rupture Time (h) }\end{array}$ & $\begin{array}{c}\text { Estimated } 95 \% \\
\text { Upper Bound } \\
\text { Rupture Time (h) }\end{array}$ \\
\hline Tensile & 1 & Alloy 617 & Plate & xyz-CF & air & 800 & 60 & 31615 & 8126 & 55104 \\
\hline Tensile & 2 & Alloy 617 & Plate & xyz-CF & air & 800 & 60 & 31615 & 8126 & 55104 \\
\hline Tensile & 3 & Alloy 617 & Plate & xyz-CF & air & 800 & 65 & 19789 & 5087 & 34492 \\
\hline Tensile & 4 & Alloy 617 & Plate & xyz-CF & air & 800 & 65 & 19789 & 5087 & 34492 \\
\hline Tensile & 5 & Alloy 617 & Plate & xyz-CF & air & 800 & 70 & 12825 & 3296 & 22353 \\
\hline Tensile & 6 & Alloy 617 & Plate & xyz-CF & air & 800 & 70 & 12825 & 3296 & 22353 \\
\hline Tensile & 7 & Alloy 617 & Plate & xyz-CF & air & 800 & 80 & 5870 & 1509 & 10231 \\
\hline Tensile & 8 & Alloy 617 & Plate & xyz-CF & air & 800 & 80 & 5870 & 1509 & 10231 \\
\hline Tensile & 9 & Alloy 617 & Plate & xyz-CF & air & 900 & 26 & 31227 & 8027 & 54428 \\
\hline Tensile & 10 & Alloy 617 & Plate & xyz-CF & air & 900 & 26 & 31227 & 8027 & 54428 \\
\hline Tensile & 11 & Alloy 617 & Plate & xyz-CF & air & 900 & 28 & 21159 & 5439 & 36880 \\
\hline Tensile & 12 & Alloy 617 & Plate & xyz-CF & air & 900 & 28 & 21159 & 5439 & 36880 \\
\hline Tensile & 13 & Alloy 617 & Plate & xyz-CF & air & 900 & 31 & 12398 & 3187 & 21609 \\
\hline Tensile & 14 & Alloy 617 & Plate & xyz-CF & air & 900 & 31 & 12398 & 3187 & 21609 \\
\hline Tensile & 15 & Alloy 617 & Plate & xyz-CF & air & 900 & 36 & 5653 & 1453 & 9853 \\
\hline Tensile & 16 & Alloy 617 & Plate & xyz-CF & air & 900 & 36 & 5653 & 1453 & 9853 \\
\hline Tensile & 17 & Alloy 617 & Plate & xyz-CF & air & 1000 & 11 & 29574 & 7602 & 51546 \\
\hline Tensile & 18 & Alloy 617 & Plate & xyz-CF & air & 1000 & 11 & 29574 & 7602 & 51546 \\
\hline Tensile & 19 & Alloy 617 & Plate & xyz-CF & air & 1000 & 12 & 19570 & 5030 & 34110 \\
\hline Tensile & 20 & Alloy 617 & Plate & xyz-CF & air & 1000 & 12 & 19570 & 5030 & 34110 \\
\hline Tensile & 21 & Alloy 617 & Plate & xyz-CF & air & 1000 & 13 & 13386 & 3441 & 23331 \\
\hline Tensile & 22 & Alloy 617 & Plate & xyz-CF & air & 1000 & 13 & 13386 & 3441 & 23331 \\
\hline Tensile & 23 & Alloy 617 & Plate & xyz-CF & air & 1000 & 16 & 4998 & 1285 & 8711 \\
\hline Tensile & 24 & Alloy 617 & Plate & xyz-CF & air & 1000 & 16 & 4998 & 1285 & 8711 \\
\hline
\end{tabular}




Idaho National Laboratory
\begin{tabular}{|c|lll|}
\hline NEXT GENERATION NUCLEAR PLANT & Identifier: & PLN-2804 & \\
INTERMEDIATE HEAT EXCHANGER & Revision: & 0 & \\
MATERIALS RESEARCH & Effective Date: & $04 / 30 / 08$ & Page: A-67 of A-114 \\
AND DEVELOPMENT PLAN & &
\end{tabular}

\begin{tabular}{|c|c|c|c|c|c|c|c|c|}
\hline Specimen Type & Specimen \# & Material & $\begin{array}{c}\text { Product } \\
\text { Form }\end{array}$ & Heat & Environment & Temp. $\left({ }^{\circ} \mathrm{C}\right)$ & $\begin{array}{c}\text { Initial Stress } \\
(\mathrm{MPa})\end{array}$ & $\begin{array}{l}\text { Relaxation Time } \\
\text { (h) }\end{array}$ \\
\hline Tensile & 1 & Alloy 617 & Plate & xyz-CF & air & 800 & 60 & 20000 \\
\hline Tensile & 2 & Alloy 617 & Plate & xyz-CF & air & 800 & 60 & 20000 \\
\hline Tensile & 3 & Alloy 617 & Plate & xyz-CF & air & 800 & 65 & 10000 \\
\hline Tensile & 4 & Alloy 617 & Plate & xyz-CF & air & 800 & 65 & 10000 \\
\hline Tensile & 5 & Alloy 617 & Plate & xyz-CF & air & 800 & 70 & 10000 \\
\hline Tensile & 6 & Alloy 617 & Plate & xyz-CF & air & 800 & 70 & 10000 \\
\hline Tensile & 7 & Alloy 617 & Plate & xyz-CF & air & 800 & 80 & 10000 \\
\hline Tensile & 8 & Alloy 617 & Plate & xyz-CF & air & 800 & 80 & 10000 \\
\hline Tensile & 9 & Alloy 617 & Plate & xyz-CF & air & 900 & 26 & 10000 \\
\hline Tensile & 10 & Alloy 617 & Plate & xyz-CF & air & 900 & 26 & 10000 \\
\hline Tensile & 11 & Alloy 617 & Plate & xyz-CF & air & 900 & 28 & 8000 \\
\hline Tensile & 12 & Alloy 617 & Plate & xyz-CF & air & 900 & 28 & 8000 \\
\hline Tensile & 13 & Alloy 617 & Plate & xyz-CF & air & 900 & 31 & 8000 \\
\hline Tensile & 14 & Alloy 617 & Plate & xyz-CF & air & 900 & 31 & 8000 \\
\hline Tensile & 15 & Alloy 617 & Plate & xyz-CF & air & 900 & 36 & 8000 \\
\hline Tensile & 16 & Alloy 617 & Plate & xyz-CF & air & 900 & 36 & 8000 \\
\hline Tensile & 17 & Alloy 617 & Plate & xyz-CF & air & 1000 & 11 & 8000 \\
\hline Tensile & 18 & Alloy 617 & Plate & xyz-CF & air & 1000 & 11 & 8000 \\
\hline Tensile & 19 & Alloy 617 & Plate & xyz-CF & air & 1000 & 12 & 6000 \\
\hline Tensile & 20 & Alloy 617 & Plate & xyz-CF & air & 1000 & 12 & 6000 \\
\hline Tensile & 21 & Alloy 617 & Plate & xyz-CF & air & 1000 & 13 & 6000 \\
\hline Tensile & 22 & Alloy 617 & Plate & xyz-CF & air & 1000 & 13 & 6000 \\
\hline Tensile & 23 & Alloy 617 & Plate & xyz-CF & air & 1000 & 16 & 6000 \\
\hline Tensile & 24 & Alloy 617 & Plate & xyz-CF & air & 1000 & 16 & 6000 \\
\hline
\end{tabular}




Idaho National Laboratory
\begin{tabular}{|c|lll|}
\hline NEXT GENERATION NUCLEAR PLANT & Identifier: & PLN-2804 & \\
INTERMEDIATE HEAT EXCHANGER & Revision: & 0 & \\
MATERIALS RESEARCH & Effective Date: & $04 / 30 / 08$ & Page: A-68 of A-114 \\
AND DEVELOPMENT PLAN &
\end{tabular}

\begin{tabular}{|c|c|c|c|c|c|c|c|c|c|}
\hline Test Type & Spec. Type & Spec. \# & Material & $\begin{array}{l}\text { Product } \\
\text { Form }\end{array}$ & Heat \# & Env. & $\begin{array}{l}\text { Exposure } \\
\text { Temp. }\left({ }^{\circ} \mathrm{C}\right)\end{array}$ & $\begin{array}{l}\text { Exposure } \\
\text { Time (h) }\end{array}$ & $\begin{array}{c}\text { Test Temp. } \\
\left({ }^{\circ} \mathrm{C}\right)\end{array}$ \\
\hline Strain Rate Change & Tensile & 1 & Alloy 617 & Plate & xyz-CF & Air & 750 & 200 & 750 \\
\hline Stress Dip & Tensile & 2 & Alloy 617 & Plate & xyz-CF & Air & 750 & 200 & 750 \\
\hline Loading/Unloading/Creep & Tensile & 3 & Alloy 617 & Plate & xyz-CF & Air & 750 & 200 & 750 \\
\hline Strain Rate Change & Tensile & 4 & Alloy 617 & Plate & xyz-CF & Air & 850 & 200 & 850 \\
\hline Stress Dip & Tensile & 5 & Alloy 617 & Plate & xyz-CF & Air & 850 & 200 & 850 \\
\hline Loading/Unloading/Creep & Tensile & 6 & Alloy 617 & Plate & xyz-CF & Air & 850 & 200 & 850 \\
\hline Strain Rate Change & Tensile & 7 & Alloy 617 & Plate & xyz-CF & Air & 950 & 200 & 950 \\
\hline Stress Dip & Tensile & 8 & Alloy 617 & Plate & xyz-CF & Air & 950 & 200 & 950 \\
\hline Loading/Unloading/Creep & Tensile & 9 & Alloy 617 & Plate & xyz-CF & Air & 950 & 200 & 950 \\
\hline Strain Rate Change & Tensile & 10 & Alloy 617 & Plate & xyz-CF & Air & 1000 & 200 & 1000 \\
\hline Stress Dip & Tensile & 11 & Alloy 617 & Plate & xyz-CF & Air & 1000 & 200 & 1000 \\
\hline Loading/Unloading/Creep & Tensile & 12 & Alloy 617 & Plate & xyz-CF & Air & 1000 & 200 & 1000 \\
\hline Strain Rate Change & Tensile & 13 & Alloy 617 & Plate & xyz-CF & Air & 750 & 650 & 750 \\
\hline Stress Dip & Tensile & 14 & Alloy 617 & Plate & xyz-CF & Air & 750 & 650 & 750 \\
\hline Loading/Unloading/Creep & Tensile & 15 & Alloy 617 & Plate & xyz-CF & Air & 750 & 650 & 750 \\
\hline Strain Rate Change & Tensile & 16 & Alloy 617 & Plate & xyz-CF & Air & 850 & 650 & 850 \\
\hline Stress Dip & Tensile & 17 & Alloy 617 & Plate & xyz-CF & Air & 850 & 650 & 850 \\
\hline Loading/Unloading/Creep & Tensile & 18 & Alloy 617 & Plate & xyz-CF & Air & 850 & 650 & 850 \\
\hline Strain Rate Change & Tensile & 19 & Alloy 617 & Plate & xyz-CF & Air & 950 & 650 & 950 \\
\hline Stress Dip & Tensile & 20 & Alloy 617 & Plate & xyz-CF & Air & 950 & 650 & 950 \\
\hline Loading/Unloading/Creep & Tensile & 21 & Alloy 617 & Plate & xyz-CF & Air & 950 & 650 & 950 \\
\hline Strain Rate Change & Tensile & 22 & Alloy 617 & Plate & xyz-CF & Air & 1000 & 650 & 1000 \\
\hline Stress Dip & Tensile & 23 & Alloy 617 & Plate & xyz-CF & Air & 1000 & 650 & 1000 \\
\hline Loading/Unloading/Creep & Tensile & 24 & Alloy 617 & Plate & xyz-CF & Air & 1000 & 650 & 1000 \\
\hline Strain Rate Change & Tensile & 25 & Alloy 617 & Plate & xyz-CF & Air & 750 & 2000 & 750 \\
\hline Stress Dip & Tensile & 26 & Alloy 617 & Plate & xyz-CF & Air & 750 & 2000 & 750 \\
\hline Loading/Unloading/Creep & Tensile & 27 & Alloy 617 & Plate & xyz-CF & Air & 750 & 2000 & 750 \\
\hline
\end{tabular}


Idaho National Laboratory

\section{NEXT GENERATION NUCLEAR PLANT INTERMEDIATE HEAT EXCHANGER MATERIALS RESEARCH} AND DEVELOPMENT PLAN

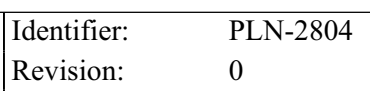

\begin{tabular}{|c|c|c|c|c|c|c|c|c|c|}
\hline \multicolumn{10}{|c|}{ Table A14. Uniaxial Tests on Thermally Aged Alloy 617 to Support Unifed Constitutive Model } \\
\hline Test Type & Spec. Type & Spec. \# & Material & $\begin{array}{l}\text { Product } \\
\text { Form }\end{array}$ & Heat \# & Env. & $\begin{array}{c}\text { Exposure } \\
\text { Temp. }\left({ }^{\circ} \mathrm{C}\right)\end{array}$ & $\begin{array}{l}\text { Exposure } \\
\text { Time (h) }\end{array}$ & $\begin{array}{c}\text { Test Temp. } \\
\left({ }^{\circ} \mathrm{C}\right)\end{array}$ \\
\hline Strain Rate Change & Tensile & 28 & Alloy 617 & Plate & xyz-CF & Air & 850 & 2000 & 850 \\
\hline Stress Dip & Tensile & 29 & Alloy 617 & Plate & xyz-CF & Air & 850 & 2000 & 850 \\
\hline Loading/Unloading/Creep & Tensile & 30 & Alloy 617 & Plate & xyz-CF & Air & 850 & 2000 & 850 \\
\hline Strain Rate Change & Tensile & 31 & Alloy 617 & Plate & xyz-CF & Air & 950 & 2000 & 950 \\
\hline Stress Dip & Tensile & 32 & Alloy 617 & Plate & xyz-CF & Air & 950 & 2000 & 950 \\
\hline Loading/Unloading/Creep & Tensile & 33 & Alloy 617 & Plate & $\mathrm{xyz}-\mathrm{CF}$ & Air & 950 & 2000 & 950 \\
\hline Strain Rate Change & Tensile & 34 & Alloy 617 & Plate & xyz-CF & Air & 1000 & 2000 & 1000 \\
\hline Stress Dip & Tensile & 35 & Alloy 617 & Plate & xyz-CF & Air & 1000 & 2000 & 1000 \\
\hline Loading/Unloading/Creep & Tensile & 36 & Alloy 617 & Plate & $\mathrm{xyz}-\mathrm{CF}$ & Air & 1000 & 2000 & 1000 \\
\hline Strain Rate Change & Tensile & 37 & Alloy 617 & Plate & xyz-CF & Air & 750 & 5300 & 750 \\
\hline Stress Dip & Tensile & 38 & Alloy 617 & Plate & xyz-CF & Air & 750 & 5300 & 750 \\
\hline Loading/Unloading/Creep & Tensile & 39 & Alloy 617 & Plate & xyz-CF & Air & 750 & 5300 & 750 \\
\hline Strain Rate Change & Tensile & 40 & Alloy 617 & Plate & $\mathrm{xyz}-\mathrm{CF}$ & Air & 850 & 5300 & 850 \\
\hline Stress Dip & Tensile & 41 & Alloy 617 & Plate & $\mathrm{xyz}-\mathrm{CF}$ & Air & 850 & 5300 & 850 \\
\hline Loading/Unloading/Creep & Tensile & 42 & Alloy 617 & Plate & xyz-CF & Air & 850 & 5300 & 850 \\
\hline Strain Rate Change & Tensile & 43 & Alloy 617 & Plate & $\mathrm{xyz}-\mathrm{CF}$ & Air & 950 & 5300 & 950 \\
\hline Stress Dip & Tensile & 44 & Alloy 617 & Plate & xyz-CF & Air & 950 & 5300 & 950 \\
\hline Loading/Unloading/Creep & Tensile & 45 & Alloy 617 & Plate & xyz-CF & Air & 950 & 5300 & 950 \\
\hline Strain Rate Change & Tensile & 46 & Alloy 617 & Plate & $\mathrm{xyz}-\mathrm{CF}$ & Air & 1000 & 5300 & 1000 \\
\hline Stress Dip & Tensile & 47 & Alloy 617 & Plate & xyz-CF & Air & 1000 & 5300 & 1000 \\
\hline Loading/Unloading/Creep & Tensile & 48 & Alloy 617 & Plate & xyz-CF & Air & 1000 & 5300 & 1000 \\
\hline Strain Rate Change & Tensile & 49 & Alloy 617 & Plate & xyz-CF & Air & 750 & 20000 & 750 \\
\hline Stress Dip & Tensile & 50 & Alloy 617 & Plate & xyz-CF & Air & 750 & 20000 & 750 \\
\hline Loading/Unloading/Creep & Tensile & 51 & Alloy 617 & Plate & xyz-CF & Air & 750 & 20000 & 750 \\
\hline Strain Rate Change & Tensile & 52 & Alloy 617 & Plate & xyz-CF & Air & 850 & 20000 & 850 \\
\hline Stress Dip & Tensile & 53 & Alloy 617 & Plate & xyz-CF & Air & 850 & 20000 & 850 \\
\hline Loading/Unloading/Creep & Tensile & 54 & Alloy 617 & Plate & $\mathrm{xyz}-\mathrm{CF}$ & Air & 850 & 20000 & 850 \\
\hline Strain Rate Change & Tensile & 55 & Alloy 617 & Plate & xyz-CF & Air & 950 & 20000 & 950 \\
\hline
\end{tabular}


Idaho National Laboratory

\section{NEXT GENERATION NUCLEAR PLANT INTERMEDIATE HEAT EXCHANGER MATERIALS RESEARCH} AND DEVELOPMENT PLAN

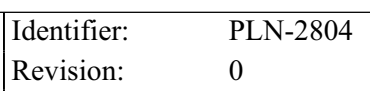

\begin{tabular}{|c|c|c|c|c|c|c|c|c|c|}
\hline \multicolumn{10}{|c|}{ Table A14. Uniaxial Tests on Thermally Aged Alloy 617 to Support Unifed Constitutive Model } \\
\hline Test Type & Spec. Type & Spec. \# & Material & $\begin{array}{l}\text { Product } \\
\text { Form }\end{array}$ & Heat \# & Env. & $\begin{array}{c}\text { Exposure } \\
\text { Temp. }\left({ }^{\circ} \mathrm{C}\right)\end{array}$ & $\begin{array}{l}\text { Exposure } \\
\text { Time (h) }\end{array}$ & $\begin{array}{c}\text { Test Temp. } \\
\left({ }^{\circ} \mathrm{C}\right)\end{array}$ \\
\hline Stress Dip & Tensile & 56 & Alloy 617 & Plate & xyz-CF & Air & 950 & 20000 & 950 \\
\hline Loading/Unloading/Creep & Tensile & 57 & Alloy 617 & Plate & xyz-CF & Air & 950 & 20000 & 950 \\
\hline Strain Rate Change & Tensile & 58 & Alloy 617 & Plate & xyz-CF & Air & 1000 & 20000 & 1000 \\
\hline Stress Dip & Tensile & 59 & Alloy 617 & Plate & xyz-CF & Air & 1000 & 20000 & 1000 \\
\hline Loading/Unloading/Creep & Tensile & 60 & Alloy 617 & Plate & xyz-CF & Air & 1000 & 20000 & 1000 \\
\hline Strain Rate Change & Tensile & 61 & Alloy 617 & Plate & $\mathrm{xyz}-\mathrm{CF}$ & Air & 750 & 32000 & 750 \\
\hline Stress Dip & Tensile & 62 & Alloy 617 & Plate & xyz-CF & Air & 750 & 32000 & 750 \\
\hline Loading/Unloading/Creep & Tensile & 63 & Alloy 617 & Plate & xyz-CF & Air & 750 & 32000 & 750 \\
\hline Strain Rate Change & Tensile & 64 & Alloy 617 & Plate & $\mathrm{xyz}-\mathrm{CF}$ & Air & 850 & 32000 & 850 \\
\hline Stress Dip & Tensile & 65 & Alloy 617 & Plate & xyz-CF & Air & 850 & 32000 & 850 \\
\hline Loading/Unloading/Creep & Tensile & 66 & Alloy 617 & Plate & xyz-CF & Air & 850 & 32000 & 850 \\
\hline Strain Rate Change & Tensile & 67 & Alloy 617 & Plate & xyz-CF & Air & 950 & 32000 & 950 \\
\hline Stress Dip & Tensile & 68 & Alloy 617 & Plate & $\mathrm{xyz}-\mathrm{CF}$ & Air & 950 & 32000 & 950 \\
\hline Loading/Unloading/Creep & Tensile & 69 & Alloy 617 & Plate & $\mathrm{xyz}-\mathrm{CF}$ & Air & 950 & 32000 & 950 \\
\hline Strain Rate Change & Tensile & 70 & Alloy 617 & Plate & xyz-CF & Air & 1000 & 32000 & 1000 \\
\hline Stress Dip & Tensile & 71 & Alloy 617 & Plate & $\mathrm{xyz}-\mathrm{CF}$ & Air & 1000 & 32000 & 1000 \\
\hline Loading/Unloading/Creep & Tensile & 72 & Alloy 617 & Plate & xyz-CF & Air & 1000 & 32000 & 1000 \\
\hline Strain Rate Change & Tensile & 73 & Alloy 617 & Plate & xyz-CF & Air & 750 & 50000 & 750 \\
\hline Stress Dip & Tensile & 74 & Alloy 617 & Plate & $\mathrm{xyz}-\mathrm{CF}$ & Air & 750 & 50000 & 750 \\
\hline Loading/Unloading/Creep & Tensile & 75 & Alloy 617 & Plate & $\mathrm{xyz}-\mathrm{CF}$ & Air & 750 & 50000 & 750 \\
\hline Strain Rate Change & Tensile & 76 & Alloy 617 & Plate & xyz-CF & Air & 850 & 50000 & 850 \\
\hline Stress Dip & Tensile & 77 & Alloy 617 & Plate & xyz-CF & Air & 850 & 50000 & 850 \\
\hline Loading/Unloading/Creep & Tensile & 78 & Alloy 617 & Plate & $\mathrm{xyz}-\mathrm{CF}$ & Air & 850 & 50000 & 850 \\
\hline Strain Rate Change & Tensile & 79 & Alloy 617 & Plate & xyz-CF & Air & 950 & 50000 & 950 \\
\hline Stress Dip & Tensile & 80 & Alloy 617 & Plate & xyz-CF & Air & 950 & 50000 & 950 \\
\hline Loading/Unloading/Creep & Tensile & 81 & Alloy 617 & Plate & $\mathrm{xyz}-\mathrm{CF}$ & Air & 950 & 50000 & 950 \\
\hline Strain Rate Change & Tensile & 82 & Alloy 617 & Plate & $\mathrm{xyz}-\mathrm{CF}$ & Air & 1000 & 50000 & 1000 \\
\hline Stress Dip & Tensile & 83 & Alloy 617 & Plate & xyz-CF & Air & 1000 & 50000 & 1000 \\
\hline
\end{tabular}


Idaho National Laboratory

\section{NEXT GENERATION NUCLEAR PLANT INTERMEDIATE HEAT EXCHANGER MATERIALS RESEARCH} AND DEVELOPMENT PLAN
Identifier: $\quad$ PLN-2804

Revision: $\quad 0$

Effective Date: $\quad 04 / 30 / 08 \quad$ Page: A-71 of A-114

\begin{tabular}{|c|c|c|c|c|c|c|c|c|c|}
\hline \multicolumn{10}{|c|}{ Table A14. Uniaxial Tests on Thermally Aged Alloy 617 to Support Unifed Constitutive Model } \\
\hline Test Type & Spec. Type & Spec. \# & Material & $\begin{array}{l}\text { Product } \\
\text { Form }\end{array}$ & Heat \# & Env. & $\begin{array}{c}\text { Exposure } \\
\text { Temp. }\left({ }^{\circ} \mathrm{C}\right)\end{array}$ & $\begin{array}{l}\text { Exposure } \\
\text { Time (h) }\end{array}$ & $\begin{array}{c}\text { Test Temp. } \\
\left({ }^{\circ} \mathrm{C}\right)\end{array}$ \\
\hline Loading/Unloading/Creep & Tensile & 84 & Alloy 617 & Plate & xyz-CF & Air & 1000 & 50000 & 1000 \\
\hline Strain Rate Change & Tensile & 85 & Alloy 617 & Plate & xyz-CF & Air & 750 & 76000 & 750 \\
\hline Stress Dip & Tensile & 86 & Alloy 617 & Plate & xyz-CF & Air & 750 & 76000 & 750 \\
\hline Loading/Unloading/Creep & Tensile & 87 & Alloy 617 & Plate & xyz-CF & Air & 750 & 76000 & 750 \\
\hline Strain Rate Change & Tensile & 88 & Alloy 617 & Plate & xyz-CF & Air & 850 & 76000 & 850 \\
\hline Stress Dip & Tensile & 89 & Alloy 617 & Plate & $\mathrm{xyz}-\mathrm{CF}$ & Air & 850 & 76000 & 850 \\
\hline Loading/Unloading/Creep & Tensile & 90 & Alloy 617 & Plate & $\mathrm{xyz}-\mathrm{CF}$ & Air & 850 & 76000 & 850 \\
\hline Strain Rate Change & Tensile & 91 & Alloy 617 & Plate & xyz-CF & Air & 950 & 76000 & 950 \\
\hline Stress Dip & Tensile & 92 & Alloy 617 & Plate & $\mathrm{xyz}-\mathrm{CF}$ & Air & 950 & 76000 & 950 \\
\hline Loading/Unloading/Creep & Tensile & 93 & Alloy 617 & Plate & xyz-CF & Air & 950 & 76000 & 950 \\
\hline Strain Rate Change & Tensile & 94 & Alloy 617 & Plate & xyz-CF & Air & 1000 & 76000 & 1000 \\
\hline Stress Dip & Tensile & 95 & Alloy 617 & Plate & xyz-CF & Air & 1000 & 76000 & 1000 \\
\hline Loading/Unloading/Creep & Tensile & 96 & Alloy 617 & Plate & $\mathrm{xyz}-\mathrm{CF}$ & Air & 1000 & 76000 & 1000 \\
\hline Strain Rate Change & Tensile & 97 & Alloy 617 & Plate & $\mathrm{xyz}-\mathrm{CF}$ & Air & 750 & 120000 & 750 \\
\hline Stress Dip & Tensile & 98 & Alloy 617 & Plate & xyz-CF & Air & 750 & 120000 & 750 \\
\hline Loading/Unloading/Creep & Tensile & 99 & Alloy 617 & Plate & $\mathrm{xyz}-\mathrm{CF}$ & Air & 750 & 120000 & 750 \\
\hline Strain Rate Change & Tensile & 100 & Alloy 617 & Plate & xyz-CF & Air & 850 & 120000 & 850 \\
\hline Stress Dip & Tensile & 101 & Alloy 617 & Plate & xyz-CF & Air & 850 & 120000 & 850 \\
\hline Loading/Unloading/Creep & Tensile & 102 & Alloy 617 & Plate & $\mathrm{xyz}-\mathrm{CF}$ & Air & 850 & 120000 & 850 \\
\hline Strain Rate Change & Tensile & 103 & Alloy 617 & Plate & $\mathrm{xyz}-\mathrm{CF}$ & Air & 950 & 120000 & 950 \\
\hline Stress Dip & Tensile & 104 & Alloy 617 & Plate & xyz-CF & Air & 950 & 120000 & 950 \\
\hline Loading/Unloading/Creep & Tensile & 105 & Alloy 617 & Plate & xyz-CF & Air & 950 & 120000 & 950 \\
\hline Strain Rate Change & Tensile & 106 & Alloy 617 & Plate & xyz-CF & Air & 1000 & 120000 & 1000 \\
\hline Stress Dip & Tensile & 107 & Alloy 617 & Plate & xyz-CF & Air & 1000 & 120000 & 1000 \\
\hline Loading/Unloading/Creep & Tensile & 108 & Alloy 617 & Plate & xyz-CF & Air & 1000 & 120000 & 1000 \\
\hline
\end{tabular}




Idaho National Laboratory
\begin{tabular}{|c|lll|}
\hline NEXT GENERATION NUCLEAR PLANT & Identifier: & PLN-2804 & \\
INTERMEDIATE HEAT EXCHANGER & Revision: & 0 & \\
MATERIALS RESEARCH & Effective Date: & $04 / 30 / 08$ & Page: A-72 of A-114 \\
AND DEVELOPMENT PLAN & &
\end{tabular}

\begin{tabular}{|c|c|c|c|c|c|}
\hline \multicolumn{6}{|c|}{ Table A15. Tube Burst Tests for Alloy 617 and Alloy $800 \mathrm{H}$} \\
\hline Material & $\begin{array}{l}\text { Internal } \\
\text { Pressure }\end{array}$ & $\begin{array}{l}\text { Temp. } \\
\left({ }^{\circ} \mathrm{C}\right)\end{array}$ & $\begin{array}{c}\text { Structure } \\
(\mathrm{T}=\text { pressurized tube, } \mathrm{W}=\text { high stressed } \\
\text { welds, Crack }=\text { crack-like surface slot } \\
\text { machined by EDM })\end{array}$ & $\begin{array}{l}\text { Pre-Conditioning of Structure } \\
\text { (Thermally-aged }=\text { aged at test } \\
\text { temp. for } 15,000 \mathrm{~h} \text { ) }\end{array}$ & Environmen \\
\hline Alloy 617 & P1 (TBD) & 950 & $\mathrm{~T}$ & Un-aged & Air \\
\hline Alloy 617 & P1 (TBD) & 950 & $\mathrm{~T}$ & Un-aged & Air \\
\hline Alloy 617 & $\mathrm{P} 2$ (TBD) & 950 & $\mathrm{~T}$ & Un-aged & Air \\
\hline Alloy 617 & P2 (TBD) & 950 & $\mathrm{~T}$ & Un-aged & Air \\
\hline Alloy 617 & P1 (TBD) & 950 & $\mathrm{~T}+\mathrm{W}$ & Un-aged & Air \\
\hline Alloy 617 & P1 (TBD) & 950 & $\mathrm{~T}+\mathrm{W}$ & Un-aged & Air \\
\hline Alloy 617 & P2 (TBD) & 950 & $\mathrm{~T}+\mathrm{W}$ & Un-aged & Air \\
\hline Alloy 617 & P2 (TBD) & 950 & $\mathrm{~T}+\mathrm{W}$ & Un-aged & Air \\
\hline Alloy 617 & P1 (TBD) & 950 & $\mathrm{~T}+\mathrm{W}+$ Crack & Un-aged & Air \\
\hline Alloy 617 & P1 (TBD) & 950 & $\mathrm{~T}+\mathrm{W}+$ Crack & Un-aged & Air \\
\hline Alloy 617 & P2 (TBD) & 950 & $\mathrm{~T}+\mathrm{W}+$ Crack & Un-aged & Air \\
\hline Alloy 617 & P2 (TBD) & 950 & $\mathrm{~T}+\mathrm{W}+$ Crack & Un-aged & Air \\
\hline Alloy 617 & P1 (TBD) & 950 & $\mathrm{~T}$ & Thermally-aged & Air \\
\hline Alloy 617 & P1 (TBD) & 950 & $\mathrm{~T}$ & Thermally-aged & Air \\
\hline Alloy 617 & P2 (TBD) & 950 & $\mathrm{~T}$ & Thermally-aged & Air \\
\hline Alloy 617 & P2 (TBD) & 950 & $\mathrm{~T}$ & Thermally-aged & Air \\
\hline Alloy 617 & P1 (TBD) & 950 & $\mathrm{~T}+\mathrm{W}$ & Thermally-aged & Air \\
\hline Alloy 617 & P1 (TBD) & 950 & $\mathrm{~T}+\mathrm{W}$ & Thermally-aged & Air \\
\hline Alloy 617 & P2 (TBD) & 950 & $\mathrm{~T}+\mathrm{W}$ & Thermally-aged & Air \\
\hline Alloy 617 & P2 (TBD) & 950 & $\mathrm{~T}+\mathrm{W}$ & Thermally-aged & Air \\
\hline Alloy 617 & P1 (TBD) & 950 & $\mathrm{~T}+\mathrm{W}+$ Crack & Thermally-aged & Air \\
\hline Alloy 617 & $\mathrm{P} 1$ (TBD) & 950 & $\mathrm{~T}+\mathrm{W}+$ Crack & Thermally-aged & Air \\
\hline Alloy 617 & P2 (TBD) & 950 & $\mathrm{~T}+\mathrm{W}+$ Crack & Thermally-aged & Air \\
\hline Alloy 617 & P2 (TBD) & 950 & $\mathrm{~T}+\mathrm{W}+$ Crack & Thermally-aged & Air \\
\hline
\end{tabular}


Idaho National Laboratory

\begin{tabular}{|c|c|c|c|}
\hline $\begin{array}{l}\text { NEXT GENERATION NUCLEAR PLANT } \\
\text { INTERMEDIATE HEAT EXCHANGER } \\
\text { MATERIALS RESEARCH } \\
\text { AND DEVELOPMENT PLAN }\end{array}$ & $\begin{array}{l}\text { Identifier: } \\
\text { Revision: } \\
\text { Effective Date: }\end{array}$ & $\begin{array}{l}\text { PLN-2804 } \\
0 \\
04 / 30 / 08\end{array}$ & Page: \\
\hline
\end{tabular}

\begin{tabular}{|c|c|c|c|c|c|}
\hline \multicolumn{6}{|c|}{ Table A15. Tube Burst Tests for Alloy 617 and Alloy $800 \mathrm{H}$} \\
\hline Material & $\begin{array}{l}\text { Internal } \\
\text { Pressure }\end{array}$ & $\begin{array}{c}\text { Temp. } \\
\left({ }^{\circ} \mathrm{C}\right)\end{array}$ & $\begin{array}{c}\text { Structure } \\
(\mathrm{T}=\text { pressurized tube, } \mathrm{W}=\text { high stressed } \\
\text { welds, Crack }=\text { crack-like surface slot } \\
\text { machined by EDM) }\end{array}$ & $\begin{array}{l}\text { Pre-Conditioning of Structure } \\
\text { (Thermally-aged }=\text { aged at test } \\
\text { temp. for } 15,000 \mathrm{~h} \text { ) }\end{array}$ & Environment \\
\hline Alloy $800 \mathrm{H}$ & P3 (TBD) & 760 & $\mathrm{~T}$ & Un-aged & Air \\
\hline Alloy $800 \mathrm{H}$ & P3 (TBD) & 760 & $\mathrm{~T}$ & Un-aged & Air \\
\hline Alloy $800 \mathrm{H}$ & P3 (TBD) & 760 & $\mathrm{~T}+\mathrm{W}$ & Un-aged & Air \\
\hline Alloy $800 \mathrm{H}$ & P3 (TBD) & 760 & $\mathrm{~T}+\mathrm{W}$ & Un-aged & Air \\
\hline Alloy $800 \mathrm{H}$ & P3 (TBD) & 760 & $\mathrm{~T}+\mathrm{W}+\mathrm{Crack}$ & Un-aged & Air \\
\hline Alloy $800 \mathrm{H}$ & P3 (TBD) & 760 & $\mathrm{~T}+\mathrm{W}+$ Crack & Un-aged & Air \\
\hline Alloy $800 \mathrm{H}$ & P3 (TBD) & 760 & $\mathrm{~T}$ & Thermally-aged & Air \\
\hline Alloy $800 \mathrm{H}$ & P3 (TBD) & 760 & $\mathrm{~T}$ & Thermally-aged & Air \\
\hline Alloy $800 \mathrm{H}$ & P3 (TBD) & 760 & $\mathrm{~T}+\mathrm{W}$ & Thermally-aged & Air \\
\hline Alloy $800 \mathrm{H}$ & P3 (TBD) & 760 & $\mathrm{~T}+\mathrm{W}$ & Thermally-aged & Air \\
\hline Alloy $800 \mathrm{H}$ & P3 (TBD) & 760 & $\mathrm{~T}+\mathrm{W}+$ Crack & Thermally-aged & Air \\
\hline Alloy $800 \mathrm{H}$ & P3 (TBD) & 760 & $\mathrm{~T}+\mathrm{W}+\mathrm{Crack}$ & Thermally-aged & Air \\
\hline
\end{tabular}




Idaho National Laboratory
\begin{tabular}{|c|lll|}
\hline NEXT GENERATION NUCLEAR PLANT & Identifier: & PLN-2804 & \\
INTERMEDIATE HEAT EXCHANGER & Revision: & 0 & \\
MATERIALS RESEARCH & Effective Date: & $04 / 30 / 08$ & Page: A-74 of A-114 \\
AND DEVELOPMENT PLAN & &
\end{tabular}

\begin{tabular}{|c|c|c|c|c|c|c|c|c|c|c|}
\hline Specimen \# & Material & $\begin{array}{l}\text { Product } \\
\text { Form }\end{array}$ & Heat & $\begin{array}{l}\text { Strain Rate } \\
\text { Magnitude } \\
(\mathrm{m} / \mathrm{m} / \mathrm{s})\end{array}$ & Env. & $\begin{array}{l}\text { Hold time } \\
\text { in } \mathrm{T} \text { or } \mathrm{C}\end{array}$ & $\begin{array}{l}\text { Temp. } \\
\left({ }^{\circ} \mathrm{C}\right)\end{array}$ & $\Delta \varepsilon_{e}$ & $\begin{array}{l}\text { Internal } \\
\text { Pressure }\end{array}$ & Hold Time (min) \\
\hline 1 & Alloy 617 & Plate & xyz-CF & S1 (TBD) & air & tension & 950 & 0.3 & 0 & 0 \\
\hline 2 & Alloy 617 & Plate & xyz-CF & $\mathrm{S} 1$ (TBD) & air & tension & 950 & 0.3 & 0 & 0 \\
\hline 3 & Alloy 617 & Plate & xyz-CF & S1 (TBD) & air & tension & 950 & 0.3 & 0 & 10 \\
\hline 4 & Alloy 617 & Plate & xyz-CF & $\mathrm{S} 1$ (TBD) & air & tension & 950 & 0.3 & 0 & 10 \\
\hline 5 & Alloy 617 & Plate & xyz-CF & S1 (TBD) & air & tension & 950 & 0.3 & 0 & 30 \\
\hline 6 & Alloy 617 & Plate & xyz-CF & S1 (TBD) & air & tension & 950 & 0.3 & 0 & 30 \\
\hline 7 & Alloy 617 & Plate & xyz-CF & $\mathrm{S} 1$ (TBD) & air & tension & 950 & 0.6 & 0 & 0 \\
\hline 8 & Alloy 617 & Plate & xyz-CF & $\mathrm{S} 1$ (TBD) & air & tension & 950 & 0.6 & 0 & 0 \\
\hline 9 & Alloy 617 & Plate & xyz-CF & S1 (TBD) & air & tension & 950 & 0.6 & 0 & 10 \\
\hline 10 & Alloy 617 & Plate & xyz-CF & S1 (TBD) & air & tension & 950 & 0.6 & 0 & 10 \\
\hline 11 & Alloy 617 & Plate & xyz-CF & $\mathrm{S} 1$ (TBD) & air & tension & 950 & 0.6 & 0 & 30 \\
\hline 12 & Alloy 617 & Plate & xyz-CF & $\mathrm{S} 1$ (TBD) & air & tension & 950 & 0.6 & 0 & 30 \\
\hline 13 & Alloy 617 & Plate & xyz-CF & $\mathrm{S} 1$ (TBD) & air & tension & 950 & 0.3 & 0 & 150 \\
\hline 14 & Alloy 617 & Plate & xyz-CF & S1 (TBD) & air & tension & 950 & 0.3 & 0 & 150 \\
\hline 15 & Alloy 617 & Plate & xyz-CF & S1 (TBD) & air & tension & 950 & 0.3 & 0 & 600 \\
\hline 16 & Alloy 617 & Plate & xyz-CF & $\mathrm{S} 1$ (TBD) & air & tension & 950 & 0.3 & 0 & 600 \\
\hline 17 & Alloy 617 & Plate & xyz-CF & S1 (TBD) & air & tension & 950 & 0.3 & $\mathrm{p} 1$ (TBD) & 10 \\
\hline 18 & Alloy 617 & Plate & xyz-CF & S1 (TBD) & air & tension & 950 & 0.3 & p1 (TBD) & 10 \\
\hline 19 & Alloy 617 & Plate & xyz-CF & S1 (TBD) & air & tension & 950 & 0.3 & p1 (TBD) & 30 \\
\hline 20 & Alloy 617 & Plate & xyz-CF & S1 (TBD) & air & tension & 950 & 0.3 & p1 (TBD) & 30 \\
\hline 21 & Alloy 617 & Plate & xyz-CF & $\mathrm{S} 1$ (TBD) & air & tension & 950 & 0.6 & $\mathrm{p} 1$ (TBD) & 10 \\
\hline 22 & Alloy 617 & Plate & xyz-CF & S1 (TBD) & air & tension & 950 & 0.6 & p1 (TBD) & 10 \\
\hline 23 & Alloy 617 & Plate & xyz-CF & S1 (TBD) & air & tension & 950 & 0.6 & p1 (TBD) & 30 \\
\hline 24 & Alloy 617 & Plate & xyz-CF & S1 (TBD) & air & tension & 950 & 0.6 & $\mathrm{p} 1$ (TBD) & 30 \\
\hline
\end{tabular}


Idaho National Laboratory

\begin{tabular}{|c|c|c|c|}
\hline $\begin{array}{l}\text { NEXT GENERATION NUCLEAR PLANT } \\
\text { INTERMEDIATE HEAT EXCHANGER } \\
\text { MATERIALS RESEARCH } \\
\text { AND DEVELOPMENT PLAN }\end{array}$ & $\begin{array}{l}\text { Identifier: } \\
\text { Revision: } \\
\text { Effective Date: }\end{array}$ & $\begin{array}{l}\text { PLN-2804 } \\
0 \\
04 / 30 / 08\end{array}$ & Page: A \\
\hline
\end{tabular}

\begin{tabular}{|c|c|c|c|c|c|c|c|c|c|c|}
\hline Specimen \# & Material & $\begin{array}{c}\text { Product } \\
\text { Form }\end{array}$ & Heat & $\begin{array}{c}\text { Strain Rate } \\
\text { Magnitude } \\
(\mathrm{m} / \mathrm{m} / \mathrm{s})\end{array}$ & Env. & $\begin{array}{l}\text { Hold time } \\
\text { in } \mathrm{T} \text { or } \mathrm{C}\end{array}$ & $\begin{array}{c}\text { Temp. } \\
\left({ }^{\circ} \mathrm{C}\right)\end{array}$ & $\Delta \varepsilon_{e}$ & $\begin{array}{l}\text { Internal } \\
\text { Pressure }\end{array}$ & Hold Time (min) \\
\hline 25 & Alloy 617 & Plate & $\mathrm{xyz}-\mathrm{CF}$ & $\mathrm{S} 1$ (TBD) & NGNP He & tension & 950 & 0.3 & 0 & 0 \\
\hline 26 & Alloy 617 & Plate & xyz-CF & $\mathrm{S} 1$ (TBD) & NGNP He & tension & 950 & 0.3 & 0 & 0 \\
\hline 27 & Alloy 617 & Plate & xyz-CF & $\mathrm{S} 1$ (TBD) & NGNP He & tension & 950 & 0.3 & 0 & 10 \\
\hline 28 & Alloy 617 & Plate & xyz-CF & $\mathrm{S} 1$ (TBD) & NGNP He & tension & 950 & 0.3 & 0 & 10 \\
\hline 29 & Alloy 617 & Plate & xyz-CF & $\mathrm{S} 1$ (TBD) & NGNP He & tension & 950 & 0.3 & 0 & 30 \\
\hline 30 & Alloy 617 & Plate & xyz-CF & $\mathrm{S} 1$ (TBD) & NGNP He & tension & 950 & 0.3 & 0 & 30 \\
\hline 31 & Alloy 617 & Plate & xyz-CF & $\mathrm{S} 1$ (TBD) & NGNP He & tension & 950 & 0.6 & 0 & 0 \\
\hline 32 & Alloy 617 & Plate & xyz-CF & $\mathrm{S} 1$ (TBD) & NGNP He & tension & 950 & 0.6 & 0 & 0 \\
\hline 33 & Alloy 617 & Plate & $\mathrm{xyz}-\mathrm{CF}$ & $\mathrm{S} 1$ (TBD) & NGNP He & tension & 950 & 0.6 & 0 & 10 \\
\hline 34 & Alloy 617 & Plate & xyz-CF & $\mathrm{S} 1$ (TBD) & NGNP He & tension & 950 & 0.6 & 0 & 10 \\
\hline 35 & Alloy 617 & Plate & xyz-CF & S1 (TBD) & NGNP He & tension & 950 & 0.6 & 0 & 30 \\
\hline 36 & Alloy 617 & Plate & xyz-CF & $\mathrm{S} 1$ (TBD) & NGNP He & tension & 950 & 0.6 & 0 & 30 \\
\hline 37 & Alloy 617 & Plate & xyz-CF & $\mathrm{S} 1$ (TBD) & NGNP He & tension & 950 & 0.3 & 0 & 150 \\
\hline 38 & Alloy 617 & Plate & xyz-CF & $\mathrm{S} 1$ (TBD) & NGNP He & tension & 950 & 0.3 & 0 & 150 \\
\hline 39 & Alloy 617 & Plate & xyz-CF & $\mathrm{S} 1$ (TBD) & NGNP He & tension & 950 & 0.3 & 0 & 600 \\
\hline 40 & Alloy 617 & Plate & $\mathrm{xyz}-\mathrm{CF}$ & $\mathrm{S} 1$ (TBD) & NGNP He & tension & 950 & 0.3 & 0 & 600 \\
\hline
\end{tabular}

Tests 41 to 48 deleted (too difficult to test with internal pressure and $\mathrm{He}$ 
Form 412.09 (Rev. 10)

Idaho National Laboratory
\begin{tabular}{|c|lll|}
\hline NEXT GENERATION NUCLEAR PLANT & Identifier: & PLN-2804 & \\
INTERMEDIATE HEAT EXCHANGER & Revision: & 0 & \\
MATERIALS RESEARCH & Effective Date: & $04 / 30 / 08$ & Page: A-76 of A-114 \\
AND DEVELOPMENT PLAN &
\end{tabular}

\begin{tabular}{|c|c|c|c|c|c|c|c|c|c|c|c|}
\hline \multicolumn{10}{|c|}{ Table A17. Long Term Alloy 617 Creep Rupture Tests for Qualification } \\
\hline & $\begin{array}{c}\text { Spec. } \\
\text { Type }\end{array}$ & $\begin{array}{c}\text { Test } \\
\text { Type }\end{array}$ & $\begin{array}{c}\text { Spec. } \\
\#\end{array}$ & Material & $\begin{array}{c}\text { Product } \\
\text { Form }\end{array}$ & Heat \# & Env. & $\begin{array}{c}\text { Temp. } \\
\left({ }^{\circ} \text { C) }\right.\end{array}$ & $\begin{array}{c}\text { Applied } \\
\text { Stress } \\
(\mathrm{MPa})\end{array}$ & $\begin{array}{c}\text { Est. 95\% Lower } \\
\text { Bound Rupture } \\
\text { Time (h) }\end{array}$ & $\begin{array}{c}\text { Est. 95\% Lower } \\
\text { Bound Rupture } \\
\text { Time (yrs) }\end{array}$ \\
\hline Rupture-QUAL & Tensile & Creep & 1 & Alloy 617 & Plate & xyz-CF & air & 850 & 27.5 & 61335 & 7.0 \\
\hline Rupture-QUAL & Tensile & Creep & 2 & Alloy 617 & Plate & xyz-CF & air & 850 & 27.5 & 61335 & 7.0 \\
\hline Rupture-QUAL & Tensile & Creep & 3 & Alloy 617 & Plate & xyz-CF & air & 850 & 23.5 & 146498 & 16.7 \\
\hline Rupture-QUAL & Tensile & Creep & 4 & Alloy 617 & Plate & xyz-CF & air & 850 & 23.5 & 146498 & 16.7 \\
\hline Rupture-QUAL & Tensile & Creep & 5 & Alloy 617 & Plate & xyz-CF & air & 950 & 11.5 & 54554 & 6.2 \\
\hline Rupture-QUAL & Tensile & Creep & 6 & Alloy 617 & Plate & xyz-CF & air & 950 & 11.5 & 54554 & 6.2 \\
\hline Rupture-QUAL & Tensile & Creep & 7 & Alloy 617 & Plate & xyz-CF & air & 950 & 9.5 & 141484 & 16.2 \\
\hline Rupture-QUAL & Tensile & Creep & 8 & Alloy 617 & Plate & xyz-CF & air & 950 & 9.5 & 141484 & 16.2 \\
\hline
\end{tabular}




Idaho National Laboratory
\begin{tabular}{|c|lll|}
\hline NEXT GENERATION NUCLEAR PLANT & Identifier: & PLN-2804 & \\
INTERMEDIATE HEAT EXCHANGER & Revision: & 0 & \\
MATERIALS RESEARCH & Effective Date: & $04 / 30 / 08$ & Page: A-77 of A-114 \\
AND DEVELOPMENT PLAN & &
\end{tabular}

\begin{tabular}{|c|c|c|c|c|c|c|c|c|c|}
\hline Test Program & $\begin{array}{l}\text { Specimen } \\
\text { Type }\end{array}$ & Specimen \# & Material & $\begin{array}{l}\text { Product } \\
\text { Form }\end{array}$ & Heat \# & Env. & $\begin{array}{l}\text { Exposure } \\
\text { Temp. }\left({ }^{\circ} \mathrm{C}\right)\end{array}$ & $\begin{array}{l}\text { Exposure } \\
\text { Time (h) }\end{array}$ & $\begin{array}{l}\text { Tensile Test } \\
\text { Temp. }\left({ }^{\circ} \mathrm{C}\right)\end{array}$ \\
\hline YT-SRF & Tensile & 1 & Alloy 617 & Plate & Aged-3 & Air & None & None & 20 \\
\hline YT-SRF & Tensile & 2 & Alloy 617 & Plate & Aged-3 & Air & None & None & 20 \\
\hline YT-SRF & Tensile & 3 & Alloy 617 & Plate & Aged-3 & Air & None & None & 950 \\
\hline YT-SRF & Tensile & 4 & Alloy 617 & Plate & Aged-3 & Air & None & None & 950 \\
\hline YT-SRF & Tensile & 5 & Alloy 617 & Plate & Aged-4 & Air & None & None & 20 \\
\hline YT-SRF & Tensile & 6 & Alloy 617 & Plate & Aged-4 & Air & None & None & 20 \\
\hline YT-SRF & Tensile & 7 & Alloy 617 & Plate & Aged-4 & Air & None & None & 950 \\
\hline YT-SRF & Tensile & 8 & Alloy 617 & Plate & Aged-4 & Air & None & None & 950 \\
\hline YT-SRF & Tensile & 9 & Alloy 617 & Plate & Aged-3 & Air & 750 & 200 & 20 \\
\hline YT-SRF & Tensile & 10 & Alloy 617 & Plate & Aged-3 & Air & 750 & 200 & 20 \\
\hline YT-SRF & Tensile & 11 & Alloy 617 & Plate & Aged-3 & Air & 750 & 200 & 950 \\
\hline YT-SRF & Tensile & 12 & Alloy 617 & Plate & Aged-3 & Air & 750 & 200 & 950 \\
\hline YT-SRF & Tensile & 13 & Alloy 617 & Plate & Aged-4 & Air & 750 & 200 & 20 \\
\hline YT-SRF & Tensile & 14 & Alloy 617 & Plate & Aged-4 & Air & 750 & 200 & 20 \\
\hline YT-SRF & Tensile & 15 & Alloy 617 & Plate & Aged-4 & Air & 750 & 200 & 950 \\
\hline YT-SRF & Tensile & 16 & Alloy 617 & Plate & Aged-4 & Air & 750 & 200 & 950 \\
\hline YT-SRF & Tensile & 17 & Alloy 617 & Plate & Aged-3 & Air & 850 & 200 & 20 \\
\hline YT-SRF & Tensile & 18 & Alloy 617 & Plate & Aged-3 & Air & 850 & 200 & 20 \\
\hline YT-SRF & Tensile & 19 & Alloy 617 & Plate & Aged-3 & Air & 850 & 200 & 950 \\
\hline YT-SRF & Tensile & 20 & Alloy 617 & Plate & Aged-3 & Air & 850 & 200 & 950 \\
\hline YT-SRF & Tensile & 21 & Alloy 617 & Plate & Aged-4 & Air & 850 & 200 & 20 \\
\hline YT-SRF & Tensile & 22 & Alloy 617 & Plate & Aged-4 & Air & 850 & 200 & 20 \\
\hline YT-SRF & Tensile & 23 & Alloy 617 & Plate & Aged-4 & Air & 850 & 200 & 950 \\
\hline YT-SRF & Tensile & 24 & Alloy 617 & Plate & Aged-4 & Air & 850 & 200 & 950 \\
\hline YT-SRF & Tensile & 25 & Alloy 617 & Plate & Aged-3 & Air & 950 & 200 & 20 \\
\hline YT-SRF & Tensile & 26 & Alloy 617 & Plate & Aged-3 & Air & 950 & 200 & 20 \\
\hline
\end{tabular}


Idaho National Laboratory

\section{NEXT GENERATION NUCLEAR PLANT INTERMEDIATE HEAT EXCHANGER MATERIALS RESEARCH} AND DEVELOPMENT PLAN

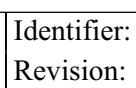

\begin{tabular}{|c|c|c|c|c|c|c|c|c|c|}
\hline \multicolumn{10}{|c|}{ Table A18. Thermal Aging Test Matrix for Strength Reduction Factors } \\
\hline Test Program & $\begin{array}{c}\text { Specimen } \\
\text { Type }\end{array}$ & Specimen \# & Material & $\begin{array}{l}\text { Product } \\
\text { Form }\end{array}$ & Heat \# & Env. & $\begin{array}{c}\text { Exposure } \\
\text { Temp. }\left({ }^{\circ} \mathrm{C}\right)\end{array}$ & $\begin{array}{c}\text { Exposure } \\
\text { Time (h) }\end{array}$ & $\begin{array}{l}\text { Tensile Test } \\
\text { Temp. }\left({ }^{\circ} \mathrm{C}\right)\end{array}$ \\
\hline YT-SRF & Tensile & 27 & Alloy 617 & Plate & Aged-3 & Air & 950 & 200 & 950 \\
\hline YT-SRF & Tensile & 28 & Alloy 617 & Plate & Aged-3 & Air & 950 & 200 & 950 \\
\hline YT-SRF & Tensile & 29 & Alloy 617 & Plate & Aged-4 & Air & 950 & 200 & 20 \\
\hline YT-SRF & Tensile & 30 & Alloy 617 & Plate & Aged-4 & Air & 950 & 200 & 20 \\
\hline YT-SRF & Tensile & 31 & Alloy 617 & Plate & Aged-4 & Air & 950 & 200 & 950 \\
\hline YT-SRF & Tensile & 32 & Alloy 617 & Plate & Aged-4 & Air & 950 & 200 & 950 \\
\hline YT-SRF & Tensile & 33 & Alloy 617 & Plate & Aged-3 & Air & 1000 & 200 & 20 \\
\hline YT-SRF & Tensile & 34 & Alloy 617 & Plate & Aged-3 & Air & 1000 & 200 & 20 \\
\hline YT-SRF & Tensile & 35 & Alloy 617 & Plate & Aged-3 & Air & 1000 & 200 & 950 \\
\hline YT-SRF & Tensile & 36 & Alloy 617 & Plate & Aged-3 & Air & 1000 & 200 & 950 \\
\hline YT-SRF & Tensile & 37 & Alloy 617 & Plate & Aged-4 & Air & 1000 & 200 & 20 \\
\hline YT-SRF & Tensile & 38 & Alloy 617 & Plate & Aged-4 & Air & 1000 & 200 & 20 \\
\hline YT-SRF & Tensile & 39 & Alloy 617 & Plate & Aged-4 & Air & 1000 & 200 & 950 \\
\hline YT-SRF & Tensile & 40 & Alloy 617 & Plate & Aged-4 & Air & 1000 & 200 & 950 \\
\hline YT-SRF & Tensile & 41 & Alloy 617 & Plate & Aged-3 & Air & 750 & 650 & 20 \\
\hline YT-SRF & Tensile & 42 & Alloy 617 & Plate & Aged-3 & Air & 750 & 650 & 20 \\
\hline YT-SRF & Tensile & 43 & Alloy 617 & Plate & Aged-3 & Air & 750 & 650 & 950 \\
\hline YT-SRF & Tensile & 44 & Alloy 617 & Plate & Aged-3 & Air & 750 & 650 & 950 \\
\hline YT-SRF & Tensile & 45 & Alloy 617 & Plate & Aged-4 & Air & 750 & 650 & 20 \\
\hline YT-SRF & Tensile & 46 & Alloy 617 & Plate & Aged-4 & Air & 750 & 650 & 20 \\
\hline YT-SRF & Tensile & 47 & Alloy 617 & Plate & Aged-4 & Air & 750 & 650 & 950 \\
\hline YT-SRF & Tensile & 48 & Alloy 617 & Plate & Aged-4 & Air & 750 & 650 & 950 \\
\hline YT-SRF & Tensile & 49 & Alloy 617 & Plate & Aged-3 & Air & 850 & 650 & 20 \\
\hline YT-SRF & Tensile & 50 & Alloy 617 & Plate & Aged-3 & Air & 850 & 650 & 20 \\
\hline YT-SRF & Tensile & 51 & Alloy 617 & Plate & Aged-3 & Air & 850 & 650 & 950 \\
\hline YT-SRF & Tensile & 52 & Alloy 617 & Plate & Aged-3 & Air & 850 & 650 & 950 \\
\hline YT-SRF & Tensile & 53 & Alloy 617 & Plate & Aged-4 & Air & 850 & 650 & 20 \\
\hline
\end{tabular}


Idaho National Laboratory

\begin{tabular}{|c|c|c|c|}
\hline $\begin{array}{l}\text { NEXT GENERATION NUCLEAR PLANT } \\
\text { INTERMEDIATE HEAT EXCHANGER } \\
\text { MATERIALS RESEARCH } \\
\text { AND DEVELOPMENT PLAN }\end{array}$ & $\begin{array}{l}\text { Identifier: } \\
\text { Revision: } \\
\text { Effective Date: }\end{array}$ & $\begin{array}{l}\text { PLN-2804 } \\
0 \\
04 / 30 / 08\end{array}$ & Page: A \\
\hline
\end{tabular}

\begin{tabular}{|c|c|c|c|c|c|c|c|c|c|}
\hline \multicolumn{10}{|c|}{ Table A18. Thermal Aging Test Matrix for Strength Reduction Factors } \\
\hline Test Program & $\begin{array}{c}\text { Specimen } \\
\text { Type }\end{array}$ & Specimen \# & Material & $\begin{array}{l}\text { Product } \\
\text { Form }\end{array}$ & Heat \# & Env. & $\begin{array}{c}\text { Exposure } \\
\text { Temp. }\left({ }^{\circ} \mathrm{C}\right)\end{array}$ & $\begin{array}{c}\text { Exposure } \\
\text { Time (h) }\end{array}$ & $\begin{array}{l}\text { Tensile Test } \\
\text { Temp. }\left({ }^{\circ} \mathrm{C}\right)\end{array}$ \\
\hline YT-SRF & Tensile & 54 & Alloy 617 & Plate & Aged-4 & Air & 850 & 650 & 20 \\
\hline YT-SRF & Tensile & 55 & Alloy 617 & Plate & Aged-4 & Air & 850 & 650 & 950 \\
\hline YT-SRF & Tensile & 56 & Alloy 617 & Plate & Aged-4 & Air & 850 & 650 & 950 \\
\hline YT-SRF & Tensile & 57 & Alloy 617 & Plate & Aged-3 & Air & 950 & 650 & 20 \\
\hline YT-SRF & Tensile & 58 & Alloy 617 & Plate & Aged-3 & Air & 950 & 650 & 20 \\
\hline YT-SRF & Tensile & 59 & Alloy 617 & Plate & Aged-3 & Air & 950 & 650 & 950 \\
\hline YT-SRF & Tensile & 60 & Alloy 617 & Plate & Aged-3 & Air & 950 & 650 & 950 \\
\hline YT-SRF & Tensile & 61 & Alloy 617 & Plate & Aged-4 & Air & 950 & 650 & 20 \\
\hline YT-SRF & Tensile & 62 & Alloy 617 & Plate & Aged-4 & Air & 950 & 650 & 20 \\
\hline YT-SRF & Tensile & 63 & Alloy 617 & Plate & Aged-4 & Air & 950 & 650 & 950 \\
\hline YT-SRF & Tensile & 64 & Alloy 617 & Plate & Aged-4 & Air & 950 & 650 & 950 \\
\hline YT-SRF & Tensile & 65 & Alloy 617 & Plate & Aged-3 & Air & 1000 & 650 & 20 \\
\hline YT-SRF & Tensile & 66 & Alloy 617 & Plate & Aged-3 & Air & 1000 & 650 & 20 \\
\hline YT-SRF & Tensile & 67 & Alloy 617 & Plate & Aged-3 & Air & 1000 & 650 & 950 \\
\hline YT-SRF & Tensile & 68 & Alloy 617 & Plate & Aged-3 & Air & 1000 & 650 & 950 \\
\hline YT-SRF & Tensile & 69 & Alloy 617 & Plate & Aged-4 & Air & 1000 & 650 & 20 \\
\hline YT-SRF & Tensile & 70 & Alloy 617 & Plate & Aged-4 & Air & 1000 & 650 & 20 \\
\hline YT-SRF & Tensile & 71 & Alloy 617 & Plate & Aged-4 & Air & 1000 & 650 & 950 \\
\hline YT-SRF & Tensile & 72 & Alloy 617 & Plate & Aged-4 & Air & 1000 & 650 & 950 \\
\hline YT-SRF & Tensile & 73 & Alloy 617 & Plate & Aged-3 & Air & 750 & 2000 & 20 \\
\hline YT-SRF & Tensile & 74 & Alloy 617 & Plate & Aged-3 & Air & 750 & 2000 & 20 \\
\hline YT-SRF & Tensile & 75 & Alloy 617 & Plate & Aged-3 & Air & 750 & 2000 & 950 \\
\hline YT-SRF & Tensile & 76 & Alloy 617 & Plate & Aged-3 & Air & 750 & 2000 & 950 \\
\hline YT-SRF & Tensile & 77 & Alloy 617 & Plate & Aged-4 & Air & 750 & 2000 & 20 \\
\hline YT-SRF & Tensile & 78 & Alloy 617 & Plate & Aged-4 & Air & 750 & 2000 & 20 \\
\hline YT-SRF & Tensile & 79 & Alloy 617 & Plate & Aged-4 & Air & 750 & 2000 & 950 \\
\hline YT-SRF & Tensile & 80 & Alloy 617 & Plate & Aged-4 & Air & 750 & 2000 & 950 \\
\hline
\end{tabular}


Idaho National Laboratory

\section{NEXT GENERATION NUCLEAR PLANT INTERMEDIATE HEAT EXCHANGER MATERIALS RESEARCH} AND DEVELOPMENT PLAN

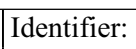

\begin{tabular}{|c|c|c|c|c|c|c|c|c|c|}
\hline \multicolumn{10}{|c|}{ Table A18. Thermal Aging Test Matrix for Strength Reduction Factors } \\
\hline Test Program & $\begin{array}{c}\text { Specimen } \\
\text { Type }\end{array}$ & Specimen \# & Material & $\begin{array}{l}\text { Product } \\
\text { Form }\end{array}$ & Heat \# & Env. & $\begin{array}{c}\text { Exposure } \\
\text { Temp. }\left({ }^{\circ} \mathrm{C}\right)\end{array}$ & $\begin{array}{c}\text { Exposure } \\
\text { Time (h) }\end{array}$ & $\begin{array}{l}\text { Tensile Test } \\
\text { Temp. }\left({ }^{\circ} \mathrm{C}\right)\end{array}$ \\
\hline YT-SRF & Tensile & 81 & Alloy 617 & Plate & Aged-3 & Air & 850 & 2000 & 20 \\
\hline YT-SRF & Tensile & 82 & Alloy 617 & Plate & Aged-3 & Air & 850 & 2000 & 20 \\
\hline YT-SRF & Tensile & 83 & Alloy 617 & Plate & Aged-3 & Air & 850 & 2000 & 950 \\
\hline YT-SRF & Tensile & 84 & Alloy 617 & Plate & Aged-3 & Air & 850 & 2000 & 950 \\
\hline YT-SRF & Tensile & 85 & Alloy 617 & Plate & Aged-4 & Air & 850 & 2000 & 20 \\
\hline YT-SRF & Tensile & 86 & Alloy 617 & Plate & Aged-4 & Air & 850 & 2000 & 20 \\
\hline YT-SRF & Tensile & 87 & Alloy 617 & Plate & Aged-4 & Air & 850 & 2000 & 950 \\
\hline YT-SRF & Tensile & 88 & Alloy 617 & Plate & Aged-4 & Air & 850 & 2000 & 950 \\
\hline YT-SRF & Tensile & 89 & Alloy 617 & Plate & Aged-3 & Air & 950 & 2000 & 20 \\
\hline YT-SRF & Tensile & 90 & Alloy 617 & Plate & Aged-3 & Air & 950 & 2000 & 20 \\
\hline YT-SRF & Tensile & 91 & Alloy 617 & Plate & Aged-3 & Air & 950 & 2000 & 950 \\
\hline YT-SRF & Tensile & 92 & Alloy 617 & Plate & Aged-3 & Air & 950 & 2000 & 950 \\
\hline YT-SRF & Tensile & 93 & Alloy 617 & Plate & Aged-4 & Air & 950 & 2000 & 20 \\
\hline YT-SRF & Tensile & 94 & Alloy 617 & Plate & Aged-4 & Air & 950 & 2000 & 20 \\
\hline YT-SRF & Tensile & 95 & Alloy 617 & Plate & Aged-4 & Air & 950 & 2000 & 950 \\
\hline YT-SRF & Tensile & 96 & Alloy 617 & Plate & Aged-4 & Air & 950 & 2000 & 950 \\
\hline YT-SRF & Tensile & 97 & Alloy 617 & Plate & Aged-3 & Air & 1000 & 2000 & 20 \\
\hline YT-SRF & Tensile & 98 & Alloy 617 & Plate & Aged-3 & Air & 1000 & 2000 & 20 \\
\hline YT-SRF & Tensile & 99 & Alloy 617 & Plate & Aged-3 & Air & 1000 & 2000 & 950 \\
\hline YT-SRF & Tensile & 100 & Alloy 617 & Plate & Aged-3 & Air & 1000 & 2000 & 950 \\
\hline YT-SRF & Tensile & 101 & Alloy 617 & Plate & Aged-4 & Air & 1000 & 2000 & 20 \\
\hline YT-SRF & Tensile & 102 & Alloy 617 & Plate & Aged-4 & Air & 1000 & 2000 & 20 \\
\hline YT-SRF & Tensile & 103 & Alloy 617 & Plate & Aged-4 & Air & 1000 & 2000 & 950 \\
\hline YT-SRF & Tensile & 104 & Alloy 617 & Plate & Aged-4 & Air & 1000 & 2000 & 950 \\
\hline YT-SRF & Tensile & 105 & Alloy 617 & Plate & Aged-3 & Air & 750 & 5300 & 20 \\
\hline YT-SRF & Tensile & 106 & Alloy 617 & Plate & Aged-3 & Air & 750 & 5300 & 20 \\
\hline YT-SRF & Tensile & 107 & Alloy 617 & Plate & Aged-3 & Air & 750 & 5300 & 950 \\
\hline
\end{tabular}


Idaho National Laboratory

\section{NEXT GENERATION NUCLEAR PLANT INTERMEDIATE HEAT EXCHANGER MATERIALS RESEARCH} AND DEVELOPMENT PLAN

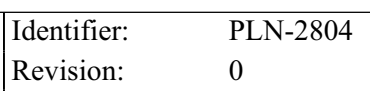

\begin{tabular}{|c|c|c|c|c|c|c|c|c|c|}
\hline \multicolumn{10}{|c|}{ Table A18. Thermal Aging Test Matrix for Strength Reduction Factors } \\
\hline Test Program & $\begin{array}{c}\text { Specimen } \\
\text { Type }\end{array}$ & Specimen \# & Material & $\begin{array}{l}\text { Product } \\
\text { Form }\end{array}$ & Heat \# & Env. & $\begin{array}{c}\text { Exposure } \\
\text { Temp. }\left({ }^{\circ} \mathrm{C}\right)\end{array}$ & $\begin{array}{c}\text { Exposure } \\
\text { Time (h) }\end{array}$ & $\begin{array}{l}\text { Tensile Test } \\
\text { Temp. }\left({ }^{\circ} \mathrm{C}\right)\end{array}$ \\
\hline YT-SRF & Tensile & 108 & Alloy 617 & Plate & Aged-3 & Air & 750 & 5300 & 950 \\
\hline YT-SRF & Tensile & 109 & Alloy 617 & Plate & Aged-4 & Air & 750 & 5300 & 20 \\
\hline YT-SRF & Tensile & 110 & Alloy 617 & Plate & Aged-4 & Air & 750 & 5300 & 20 \\
\hline YT-SRF & Tensile & 111 & Alloy 617 & Plate & Aged-4 & Air & 750 & 5300 & 950 \\
\hline YT-SRF & Tensile & 112 & Alloy 617 & Plate & Aged-4 & Air & 750 & 5300 & 950 \\
\hline YT-SRF & Tensile & 113 & Alloy 617 & Plate & Aged-3 & Air & 850 & 5300 & 20 \\
\hline YT-SRF & Tensile & 114 & Alloy 617 & Plate & Aged-3 & Air & 850 & 5300 & 20 \\
\hline YT-SRF & Tensile & 115 & Alloy 617 & Plate & Aged-3 & Air & 850 & 5300 & 950 \\
\hline YT-SRF & Tensile & 116 & Alloy 617 & Plate & Aged-3 & Air & 850 & 5300 & 950 \\
\hline YT-SRF & Tensile & 117 & Alloy 617 & Plate & Aged-4 & Air & 850 & 5300 & 20 \\
\hline YT-SRF & Tensile & 118 & Alloy 617 & Plate & Aged-4 & Air & 850 & 5300 & 20 \\
\hline YT-SRF & Tensile & 119 & Alloy 617 & Plate & Aged-4 & Air & 850 & 5300 & 950 \\
\hline YT-SRF & Tensile & 120 & Alloy 617 & Plate & Aged-4 & Air & 850 & 5300 & 950 \\
\hline YT-SRF & Tensile & 121 & Alloy 617 & Plate & Aged-3 & Air & 950 & 5300 & 20 \\
\hline YT-SRF & Tensile & 122 & Alloy 617 & Plate & Aged-3 & Air & 950 & 5300 & 20 \\
\hline YT-SRF & Tensile & 123 & Alloy 617 & Plate & Aged-3 & Air & 950 & 5300 & 950 \\
\hline YT-SRF & Tensile & 124 & Alloy 617 & Plate & Aged-3 & Air & 950 & 5300 & 950 \\
\hline YT-SRF & Tensile & 125 & Alloy 617 & Plate & Aged-4 & Air & 950 & 5300 & 20 \\
\hline YT-SRF & Tensile & 126 & Alloy 617 & Plate & Aged-4 & Air & 950 & 5300 & 20 \\
\hline YT-SRF & Tensile & 127 & Alloy 617 & Plate & Aged-4 & Air & 950 & 5300 & 950 \\
\hline YT-SRF & Tensile & 128 & Alloy 617 & Plate & Aged-4 & Air & 950 & 5300 & 950 \\
\hline YT-SRF & Tensile & 129 & Alloy 617 & Plate & Aged-3 & Air & 1000 & 5300 & 20 \\
\hline YT-SRF & Tensile & 130 & Alloy 617 & Plate & Aged-3 & Air & 1000 & 5300 & 20 \\
\hline YT-SRF & Tensile & 131 & Alloy 617 & Plate & Aged-3 & Air & 1000 & 5300 & 950 \\
\hline YT-SRF & Tensile & 132 & Alloy 617 & Plate & Aged-3 & Air & 1000 & 5300 & 950 \\
\hline YT-SRF & Tensile & 133 & Alloy 617 & Plate & Aged-4 & Air & 1000 & 5300 & 20 \\
\hline YT-SRF & Tensile & 134 & Alloy 617 & Plate & Aged-4 & Air & 1000 & 5300 & 20 \\
\hline
\end{tabular}


Idaho National Laboratory

\section{NEXT GENERATION NUCLEAR PLANT INTERMEDIATE HEAT EXCHANGER MATERIALS RESEARCH} AND DEVELOPMENT PLAN

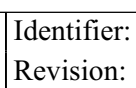

\begin{tabular}{|c|c|c|c|c|c|c|c|c|c|}
\hline \multicolumn{10}{|c|}{ Table A18. Thermal Aging Test Matrix for Strength Reduction Factors } \\
\hline Test Program & $\begin{array}{c}\text { Specimen } \\
\text { Type }\end{array}$ & Specimen \# & Material & $\begin{array}{l}\text { Product } \\
\text { Form }\end{array}$ & Heat \# & Env. & $\begin{array}{c}\text { Exposure } \\
\text { Temp. }\left({ }^{\circ} \mathrm{C}\right)\end{array}$ & $\begin{array}{c}\text { Exposure } \\
\text { Time (h) }\end{array}$ & $\begin{array}{l}\text { Tensile Test } \\
\text { Temp. }\left({ }^{\circ} \mathrm{C}\right)\end{array}$ \\
\hline YT-SRF & Tensile & 135 & Alloy 617 & Plate & Aged-4 & Air & 1000 & 5300 & 950 \\
\hline YT-SRF & Tensile & 136 & Alloy 617 & Plate & Aged-4 & Air & 1000 & 5300 & 950 \\
\hline YT-SRF & Tensile & 137 & Alloy 617 & Plate & Aged-3 & Air & 750 & 20000 & 20 \\
\hline YT-SRF & Tensile & 138 & Alloy 617 & Plate & Aged-3 & Air & 750 & 20000 & 20 \\
\hline YT-SRF & Tensile & 139 & Alloy 617 & Plate & Aged-3 & Air & 750 & 20000 & 950 \\
\hline YT-SRF & Tensile & 140 & Alloy 617 & Plate & Aged-3 & Air & 750 & 20000 & 950 \\
\hline YT-SRF & Tensile & 141 & Alloy 617 & Plate & Aged-4 & Air & 750 & 20000 & 20 \\
\hline YT-SRF & Tensile & 142 & Alloy 617 & Plate & Aged-4 & Air & 750 & 20000 & 20 \\
\hline YT-SRF & Tensile & 143 & Alloy 617 & Plate & Aged-4 & Air & 750 & 20000 & 950 \\
\hline YT-SRF & Tensile & 144 & Alloy 617 & Plate & Aged-4 & Air & 750 & 20000 & 950 \\
\hline YT-SRF & Tensile & 145 & Alloy 617 & Plate & Aged-3 & Air & 850 & 20000 & 20 \\
\hline YT-SRF & Tensile & 146 & Alloy 617 & Plate & Aged-3 & Air & 850 & 20000 & 20 \\
\hline YT-SRF & Tensile & 147 & Alloy 617 & Plate & Aged-3 & Air & 850 & 20000 & 950 \\
\hline YT-SRF & Tensile & 148 & Alloy 617 & Plate & Aged-3 & Air & 850 & 20000 & 950 \\
\hline YT-SRF & Tensile & 149 & Alloy 617 & Plate & Aged-4 & Air & 850 & 20000 & 20 \\
\hline YT-SRF & Tensile & 150 & Alloy 617 & Plate & Aged-4 & Air & 850 & 20000 & 20 \\
\hline YT-SRF & Tensile & 151 & Alloy 617 & Plate & Aged-4 & Air & 850 & 20000 & 950 \\
\hline YT-SRF & Tensile & 152 & Alloy 617 & Plate & Aged-4 & Air & 850 & 20000 & 950 \\
\hline YT-SRF & Tensile & 153 & Alloy 617 & Plate & Aged-3 & Air & 950 & 20000 & 20 \\
\hline YT-SRF & Tensile & 154 & Alloy 617 & Plate & Aged-3 & Air & 950 & 20000 & 20 \\
\hline YT-SRF & Tensile & 155 & Alloy 617 & Plate & Aged-3 & Air & 950 & 20000 & 950 \\
\hline YT-SRF & Tensile & 156 & Alloy 617 & Plate & Aged-3 & Air & 950 & 20000 & 950 \\
\hline YT-SRF & Tensile & 157 & Alloy 617 & Plate & Aged-4 & Air & 950 & 20000 & 20 \\
\hline YT-SRF & Tensile & 158 & Alloy 617 & Plate & Aged-4 & Air & 950 & 20000 & 20 \\
\hline YT-SRF & Tensile & 159 & Alloy 617 & Plate & Aged-4 & Air & 950 & 20000 & 950 \\
\hline YT-SRF & Tensile & 160 & Alloy 617 & Plate & Aged-4 & Air & 950 & 20000 & 950 \\
\hline YT-SRF & Tensile & 161 & Alloy 617 & Plate & Aged-3 & Air & 1000 & 20000 & 20 \\
\hline
\end{tabular}


Idaho National Laboratory

\section{NEXT GENERATION NUCLEAR PLANT INTERMEDIATE HEAT EXCHANGER MATERIALS RESEARCH} AND DEVELOPMENT PLAN

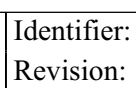

\begin{tabular}{|c|c|c|c|c|c|c|c|c|c|}
\hline \multicolumn{10}{|c|}{ Table A18. Thermal Aging Test Matrix for Strength Reduction Factors } \\
\hline Test Program & $\begin{array}{c}\text { Specimen } \\
\text { Type }\end{array}$ & Specimen \# & Material & $\begin{array}{l}\text { Product } \\
\text { Form }\end{array}$ & Heat \# & Env. & $\begin{array}{c}\text { Exposure } \\
\text { Temp. }\left({ }^{\circ} \mathrm{C}\right)\end{array}$ & $\begin{array}{c}\text { Exposure } \\
\text { Time (h) }\end{array}$ & $\begin{array}{l}\text { Tensile Test } \\
\text { Temp. }\left({ }^{\circ} \mathrm{C}\right)\end{array}$ \\
\hline YT-SRF & Tensile & 162 & Alloy 617 & Plate & Aged-3 & Air & 1000 & 20000 & 20 \\
\hline YT-SRF & Tensile & 163 & Alloy 617 & Plate & Aged-3 & Air & 1000 & 20000 & 950 \\
\hline YT-SRF & Tensile & 164 & Alloy 617 & Plate & Aged-3 & Air & 1000 & 20000 & 950 \\
\hline YT-SRF & Tensile & 165 & Alloy 617 & Plate & Aged-4 & Air & 1000 & 20000 & 20 \\
\hline YT-SRF & Tensile & 166 & Alloy 617 & Plate & Aged-4 & Air & 1000 & 20000 & 20 \\
\hline YT-SRF & Tensile & 167 & Alloy 617 & Plate & Aged-4 & Air & 1000 & 20000 & 950 \\
\hline YT-SRF & Tensile & 168 & Alloy 617 & Plate & Aged-4 & Air & 1000 & 20000 & 950 \\
\hline YT-QUAL & Tensile & 169 & Alloy 617 & Plate & Aged-3 & Air & 750 & 32000 & 20 \\
\hline YT-QUAL & Tensile & 170 & Alloy 617 & Plate & Aged-3 & Air & 750 & 32000 & 20 \\
\hline YT-QUAL & Tensile & 171 & Alloy 617 & Plate & Aged-3 & Air & 750 & 32000 & 950 \\
\hline YT-QUAL & Tensile & 172 & Alloy 617 & Plate & Aged-3 & Air & 750 & 32000 & 950 \\
\hline YT-QUAL & Tensile & 173 & Alloy 617 & Plate & Aged-4 & Air & 750 & 32000 & 20 \\
\hline YT-QUAL & Tensile & 174 & Alloy 617 & Plate & Aged-4 & Air & 750 & 32000 & 20 \\
\hline YT-QUAL & Tensile & 175 & Alloy 617 & Plate & Aged-4 & Air & 750 & 32000 & 950 \\
\hline YT-QUAL & Tensile & 176 & Alloy 617 & Plate & Aged-4 & Air & 750 & 32000 & 950 \\
\hline YT-QUAL & Tensile & 177 & Alloy 617 & Plate & Aged-3 & Air & 850 & 32000 & 20 \\
\hline YT-QUAL & Tensile & 178 & Alloy 617 & Plate & Aged-3 & Air & 850 & 32000 & 20 \\
\hline YT-QUAL & Tensile & 179 & Alloy 617 & Plate & Aged-3 & Air & 850 & 32000 & 950 \\
\hline YT-QUAL & Tensile & 180 & Alloy 617 & Plate & Aged-3 & Air & 850 & 32000 & 950 \\
\hline YT-QUAL & Tensile & 181 & Alloy 617 & Plate & Aged-4 & Air & 850 & 32000 & 20 \\
\hline YT-QUAL & Tensile & 182 & Alloy 617 & Plate & Aged-4 & Air & 850 & 32000 & 20 \\
\hline YT-QUAL & Tensile & 183 & Alloy 617 & Plate & Aged-4 & Air & 850 & 32000 & 950 \\
\hline YT-QUAL & Tensile & 184 & Alloy 617 & Plate & Aged-4 & Air & 850 & 32000 & 950 \\
\hline YT-QUAL & Tensile & 185 & Alloy 617 & Plate & Aged-3 & Air & 950 & 32000 & 20 \\
\hline YT-QUAL & Tensile & 186 & Alloy 617 & Plate & Aged-3 & Air & 950 & 32000 & 20 \\
\hline YT-QUAL & Tensile & 187 & Alloy 617 & Plate & Aged-3 & Air & 950 & 32000 & 950 \\
\hline YT-QUAL & Tensile & 188 & Alloy 617 & Plate & Aged-3 & Air & 950 & 32000 & 950 \\
\hline
\end{tabular}




Idaho National Laboratory
\begin{tabular}{|c|lll|}
\hline NEXT GENERATION NUCLEAR PLANT & Identifier: & PLN-2804 & \\
INTERMEDIATE HEAT EXCHANGER & Revision: & 0 & \\
MATERIALS RESEARCH & Effective Date: & $04 / 30 / 08$ & Page: A-84 of A-114 \\
AND DEVELOPMENT PLAN &
\end{tabular}

\begin{tabular}{|c|c|c|c|c|c|c|c|c|c|}
\hline Test Program & $\begin{array}{c}\text { Specimen } \\
\text { Type }\end{array}$ & Specimen \# & Material & $\begin{array}{l}\text { Product } \\
\text { Form }\end{array}$ & Heat \# & Env. & $\begin{array}{c}\text { Exposure } \\
\text { Temp. }\left({ }^{\circ} \mathrm{C}\right)\end{array}$ & $\begin{array}{c}\text { Exposure } \\
\text { Time (h) }\end{array}$ & $\begin{array}{l}\text { Tensile Test } \\
\text { Temp. }\left({ }^{\circ} \mathrm{C}\right)\end{array}$ \\
\hline YT-QUAL & Tensile & 189 & Alloy 617 & Plate & Aged-4 & Air & 950 & 32000 & 20 \\
\hline YT-QUAL & Tensile & 190 & Alloy 617 & Plate & Aged-4 & Air & 950 & 32000 & 20 \\
\hline YT-QUAL & Tensile & 191 & Alloy 617 & Plate & Aged-4 & Air & 950 & 32000 & 950 \\
\hline YT-QUAL & Tensile & 192 & Alloy 617 & Plate & Aged-4 & Air & 950 & 32000 & 950 \\
\hline YT-QUAL & Tensile & 193 & Alloy 617 & Plate & Aged-3 & Air & 1000 & 32000 & 20 \\
\hline YT-QUAL & Tensile & 194 & Alloy 617 & Plate & Aged-3 & Air & 1000 & 32000 & 20 \\
\hline YT-QUAL & Tensile & 195 & Alloy 617 & Plate & Aged-3 & Air & 1000 & 32000 & 950 \\
\hline YT-QUAL & Tensile & 196 & Alloy 617 & Plate & Aged-3 & Air & 1000 & 32000 & 950 \\
\hline YT-QUAL & Tensile & 197 & Alloy 617 & Plate & Aged-4 & Air & 1000 & 32000 & 20 \\
\hline YT-QUAL & Tensile & 198 & Alloy 617 & Plate & Aged-4 & Air & 1000 & 32000 & 20 \\
\hline YT-QUAL & Tensile & 199 & Alloy 617 & Plate & Aged-4 & Air & 1000 & 32000 & 950 \\
\hline YT-QUAL & Tensile & 200 & Alloy 617 & Plate & Aged-4 & Air & 1000 & 32000 & 950 \\
\hline YT-QUAL & Tensile & 201 & Alloy 617 & Plate & Aged-3 & Air & 750 & 50000 & 20 \\
\hline YT-QUAL & Tensile & 202 & Alloy 617 & Plate & Aged-3 & Air & 750 & 50000 & 20 \\
\hline YT-QUAL & Tensile & 203 & Alloy 617 & Plate & Aged-3 & Air & 750 & 50000 & 950 \\
\hline YT-QUAL & Tensile & 204 & Alloy 617 & Plate & Aged-3 & Air & 750 & 50000 & 950 \\
\hline YT-QUAL & Tensile & 205 & Alloy 617 & Plate & Aged-4 & Air & 750 & 50000 & 20 \\
\hline YT-QUAL & Tensile & 206 & Alloy 617 & Plate & Aged-4 & Air & 750 & 50000 & 20 \\
\hline YT-QUAL & Tensile & 207 & Alloy 617 & Plate & Aged-4 & Air & 750 & 50000 & 950 \\
\hline YT-QUAL & Tensile & 208 & Alloy 617 & Plate & Aged-4 & Air & 750 & 50000 & 950 \\
\hline YT-QUAL & Tensile & 209 & Alloy 617 & Plate & Aged-3 & Air & 850 & 50000 & 20 \\
\hline YT-QUAL & Tensile & 210 & Alloy 617 & Plate & Aged-3 & Air & 850 & 50000 & 20 \\
\hline YT-QUAL & Tensile & 211 & Alloy 617 & Plate & Aged-3 & Air & 850 & 50000 & 950 \\
\hline YT-QUAL & Tensile & 212 & Alloy 617 & Plate & Aged-3 & Air & 850 & 50000 & 950 \\
\hline YT-QUAL & Tensile & 213 & Alloy 617 & Plate & Aged-4 & Air & 850 & 50000 & 20 \\
\hline YT-QUAL & Tensile & 214 & Alloy 617 & Plate & Aged-4 & Air & 850 & 50000 & 20 \\
\hline YT-QUAL & Tensile & 215 & Alloy 617 & Plate & Aged-4 & Air & 850 & 50000 & 950 \\
\hline
\end{tabular}




Idaho National Laboratory
\begin{tabular}{|c|lll|}
\hline NEXT GENERATION NUCLEAR PLANT & Identifier: & PLN-2804 & \\
INTERMEDIATE HEAT EXCHANGER & Revision: & 0 & \\
MATERIALS RESEARCH & Effective Date: & $04 / 30 / 08$ & Page: A-85 of A-114 \\
AND DEVELOPMENT PLAN &
\end{tabular}

\begin{tabular}{|c|c|c|c|c|c|c|c|c|c|}
\hline Test Program & $\begin{array}{c}\text { Specimen } \\
\text { Type }\end{array}$ & Specimen \# & Material & $\begin{array}{l}\text { Product } \\
\text { Form }\end{array}$ & Heat \# & Env. & $\begin{array}{c}\text { Exposure } \\
\text { Temp. }\left({ }^{\circ} \mathrm{C}\right)\end{array}$ & $\begin{array}{l}\text { Exposure } \\
\text { Time (h) }\end{array}$ & $\begin{array}{l}\text { Tensile Test } \\
\text { Temp. }\left({ }^{\circ} \mathrm{C}\right)\end{array}$ \\
\hline YT-QUAL & Tensile & 216 & Alloy 617 & Plate & Aged-4 & Air & 850 & 50000 & 950 \\
\hline YT-QUAL & Tensile & 217 & Alloy 617 & Plate & Aged-3 & Air & 950 & 50000 & 20 \\
\hline YT-QUAL & Tensile & 218 & Alloy 617 & Plate & Aged-3 & Air & 950 & 50000 & 20 \\
\hline YT-QUAL & Tensile & 219 & Alloy 617 & Plate & Aged-3 & Air & 950 & 50000 & 950 \\
\hline YT-QUAL & Tensile & 220 & Alloy 617 & Plate & Aged-3 & Air & 950 & 50000 & 950 \\
\hline YT-QUAL & Tensile & 221 & Alloy 617 & Plate & Aged-4 & Air & 950 & 50000 & 20 \\
\hline YT-QUAL & Tensile & 222 & Alloy 617 & Plate & Aged-4 & Air & 950 & 50000 & 20 \\
\hline YT-QUAL & Tensile & 223 & Alloy 617 & Plate & Aged-4 & Air & 950 & 50000 & 950 \\
\hline YT-QUAL & Tensile & 224 & Alloy 617 & Plate & Aged-4 & Air & 950 & 50000 & 950 \\
\hline YT-QUAL & Tensile & 225 & Alloy 617 & Plate & Aged-3 & Air & 1000 & 50000 & 20 \\
\hline YT-QUAL & Tensile & 226 & Alloy 617 & Plate & Aged-3 & Air & 1000 & 50000 & 20 \\
\hline YT-QUAL & Tensile & 227 & Alloy 617 & Plate & Aged-3 & Air & 1000 & 50000 & 950 \\
\hline YT-QUAL & Tensile & 228 & Alloy 617 & Plate & Aged-3 & Air & 1000 & 50000 & 950 \\
\hline YT-QUAL & Tensile & 229 & Alloy 617 & Plate & Aged-4 & Air & 1000 & 50000 & 20 \\
\hline YT-QUAL & Tensile & 230 & Alloy 617 & Plate & Aged-4 & Air & 1000 & 50000 & 20 \\
\hline YT-QUAL & Tensile & 231 & Alloy 617 & Plate & Aged-4 & Air & 1000 & 50000 & 950 \\
\hline YT-QUAL & Tensile & 232 & Alloy 617 & Plate & Aged-4 & Air & 1000 & 50000 & 950 \\
\hline YT-QUAL & Tensile & 233 & Alloy 617 & Plate & Aged-3 & Air & 750 & 76000 & 20 \\
\hline YT-QUAL & Tensile & 234 & Alloy 617 & Plate & Aged-3 & Air & 750 & 76000 & 20 \\
\hline YT-QUAL & Tensile & 235 & Alloy 617 & Plate & Aged-3 & Air & 750 & 76000 & 950 \\
\hline YT-QUAL & Tensile & 236 & Alloy 617 & Plate & Aged-3 & Air & 750 & 76000 & 950 \\
\hline YT-QUAL & Tensile & 237 & Alloy 617 & Plate & Aged-4 & Air & 750 & 76000 & 20 \\
\hline YT-QUAL & Tensile & 238 & Alloy 617 & Plate & Aged-4 & Air & 750 & 76000 & 20 \\
\hline YT-QUAL & Tensile & 239 & Alloy 617 & Plate & Aged-4 & Air & 750 & 76000 & 950 \\
\hline YT-QUAL & Tensile & 240 & Alloy 617 & Plate & Aged-4 & Air & 750 & 76000 & 950 \\
\hline YT-QUAL & Tensile & 241 & Alloy 617 & Plate & Aged-3 & Air & 850 & 76000 & 20 \\
\hline YT-QUAL & Tensile & 242 & Alloy 617 & Plate & Aged-3 & Air & 850 & 76000 & 20 \\
\hline
\end{tabular}




Idaho National Laboratory
\begin{tabular}{|c|lll|}
\hline NEXT GENERATION NUCLEAR PLANT & Identifier: & PLN-2804 & \\
INTERMEDIATE HEAT EXCHANGER & Revision: & 0 & \\
MATERIALS RESEARCH & Effective Date: & $04 / 30 / 08$ & Page: A-86 of A-114 \\
AND DEVELOPMENT PLAN &
\end{tabular}

\begin{tabular}{|c|c|c|c|c|c|c|c|c|c|}
\hline Test Program & $\begin{array}{c}\text { Specimen } \\
\text { Type }\end{array}$ & Specimen \# & Material & $\begin{array}{c}\text { Product } \\
\text { Form }\end{array}$ & Heat \# & Env. & $\begin{array}{c}\text { Exposure } \\
\text { Temp. }\left({ }^{\circ} \mathrm{C}\right)\end{array}$ & $\begin{array}{l}\text { Exposure } \\
\text { Time (h) }\end{array}$ & $\begin{array}{l}\text { Tensile Test } \\
\text { Temp. }\left({ }^{\circ} \mathrm{C}\right)\end{array}$ \\
\hline YT-QUAL & Tensile & 243 & Alloy 617 & Plate & Aged-3 & Air & 850 & 76000 & 950 \\
\hline YT-QUAL & Tensile & 244 & Alloy 617 & Plate & Aged-3 & Air & 850 & 76000 & 950 \\
\hline YT-QUAL & Tensile & 245 & Alloy 617 & Plate & Aged-4 & Air & 850 & 76000 & 20 \\
\hline YT-QUAL & Tensile & 246 & Alloy 617 & Plate & Aged-4 & Air & 850 & 76000 & 20 \\
\hline YT-QUAL & Tensile & 247 & Alloy 617 & Plate & Aged-4 & Air & 850 & 76000 & 950 \\
\hline YT-QUAL & Tensile & 248 & Alloy 617 & Plate & Aged-4 & Air & 850 & 76000 & 950 \\
\hline YT-QUAL & Tensile & 249 & Alloy 617 & Plate & Aged-3 & Air & 950 & 76000 & 20 \\
\hline YT-QUAL & Tensile & 250 & Alloy 617 & Plate & Aged-3 & Air & 950 & 76000 & 20 \\
\hline YT-QUAL & Tensile & 251 & Alloy 617 & Plate & Aged-3 & Air & 950 & 76000 & 950 \\
\hline YT-QUAL & Tensile & 252 & Alloy 617 & Plate & Aged-3 & Air & 950 & 76000 & 950 \\
\hline YT-QUAL & Tensile & 253 & Alloy 617 & Plate & Aged-4 & Air & 950 & 76000 & 20 \\
\hline YT-QUAL & Tensile & 254 & Alloy 617 & Plate & Aged-4 & Air & 950 & 76000 & 20 \\
\hline YT-QUAL & Tensile & 255 & Alloy 617 & Plate & Aged-4 & Air & 950 & 76000 & 950 \\
\hline YT-QUAL & Tensile & 256 & Alloy 617 & Plate & Aged-4 & Air & 950 & 76000 & 950 \\
\hline YT-QUAL & Tensile & 257 & Alloy 617 & Plate & Aged-3 & Air & 1000 & 76000 & 20 \\
\hline YT-QUAL & Tensile & 258 & Alloy 617 & Plate & Aged-3 & Air & 1000 & 76000 & 20 \\
\hline YT-QUAL & Tensile & 259 & Alloy 617 & Plate & Aged-3 & Air & 1000 & 76000 & 950 \\
\hline YT-QUAL & Tensile & 260 & Alloy 617 & Plate & Aged-3 & Air & 1000 & 76000 & 950 \\
\hline YT-QUAL & Tensile & 261 & Alloy 617 & Plate & Aged-4 & Air & 1000 & 76000 & 20 \\
\hline YT-QUAL & Tensile & 262 & Alloy 617 & Plate & Aged-4 & Air & 1000 & 76000 & 20 \\
\hline YT-QUAL & Tensile & 263 & Alloy 617 & Plate & Aged-4 & Air & 1000 & 76000 & 950 \\
\hline YT-QUAL & Tensile & 264 & Alloy 617 & Plate & Aged-4 & Air & 1000 & 76000 & 950 \\
\hline YT-QUAL & Tensile & 265 & Alloy 617 & Plate & Aged-3 & Air & 750 & 120000 & 20 \\
\hline YT-QUAL & Tensile & 266 & Alloy 617 & Plate & Aged-3 & Air & 750 & 120000 & 20 \\
\hline YT-QUAL & Tensile & 267 & Alloy 617 & Plate & Aged-3 & Air & 750 & 120000 & 950 \\
\hline YT-QUAL & Tensile & 268 & Alloy 617 & Plate & Aged-3 & Air & 750 & 120000 & 950 \\
\hline YT-QUAL & Tensile & 269 & Alloy 617 & Plate & Aged-4 & Air & 750 & 120000 & 20 \\
\hline
\end{tabular}


Idaho National Laboratory

\section{NEXT GENERATION NUCLEAR PLANT INTERMEDIATE HEAT EXCHANGER MATERIALS RESEARCH} AND DEVELOPMENT PLAN

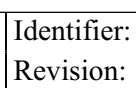

\begin{tabular}{|c|c|c|c|c|c|c|c|c|c|}
\hline Test Program & $\begin{array}{c}\text { Specimen } \\
\text { Type }\end{array}$ & Specimen \# & Material & $\begin{array}{l}\text { Product } \\
\text { Form }\end{array}$ & Heat \# & Env. & $\begin{array}{c}\text { Exposure } \\
\text { Temp. }\left({ }^{\circ} \mathrm{C}\right)\end{array}$ & $\begin{array}{c}\text { Exposure } \\
\text { Time (h) }\end{array}$ & $\begin{array}{l}\text { Tensile Test } \\
\text { Temp. }\left({ }^{\circ} \mathrm{C}\right)\end{array}$ \\
\hline YT-QUAL & Tensile & 270 & Alloy 617 & Plate & Aged-4 & Air & 750 & 120000 & 20 \\
\hline YT-QUAL & Tensile & 271 & Alloy 617 & Plate & Aged-4 & Air & 750 & 120000 & 950 \\
\hline YT-QUAL & Tensile & 272 & Alloy 617 & Plate & Aged-4 & Air & 750 & 120000 & 950 \\
\hline YT-QUAL & Tensile & 273 & Alloy 617 & Plate & Aged-3 & Air & 850 & 120000 & 20 \\
\hline YT-QUAL & Tensile & 274 & Alloy 617 & Plate & Aged-3 & Air & 850 & 120000 & 20 \\
\hline YT-QUAL & Tensile & 275 & Alloy 617 & Plate & Aged-3 & Air & 850 & 120000 & 950 \\
\hline YT-QUAL & Tensile & 276 & Alloy 617 & Plate & Aged-3 & Air & 850 & 120000 & 950 \\
\hline YT-QUAL & Tensile & 277 & Alloy 617 & Plate & Aged-4 & Air & 850 & 120000 & 20 \\
\hline YT-QUAL & Tensile & 278 & Alloy 617 & Plate & Aged-4 & Air & 850 & 120000 & 20 \\
\hline YT-QUAL & Tensile & 279 & Alloy 617 & Plate & Aged-4 & Air & 850 & 120000 & 950 \\
\hline YT-QUAL & Tensile & 280 & Alloy 617 & Plate & Aged-4 & Air & 850 & 120000 & 950 \\
\hline YT-QUAL & Tensile & 281 & Alloy 617 & Plate & Aged-3 & Air & 950 & 120000 & 20 \\
\hline YT-QUAL & Tensile & 282 & Alloy 617 & Plate & Aged-3 & Air & 950 & 120000 & 20 \\
\hline YT-QUAL & Tensile & 283 & Alloy 617 & Plate & Aged-3 & Air & 950 & 120000 & 950 \\
\hline YT-QUAL & Tensile & 284 & Alloy 617 & Plate & Aged-3 & Air & 950 & 120000 & 950 \\
\hline YT-QUAL & Tensile & 285 & Alloy 617 & Plate & Aged-4 & Air & 950 & 120000 & 20 \\
\hline YT-QUAL & Tensile & 286 & Alloy 617 & Plate & Aged-4 & Air & 950 & 120000 & 20 \\
\hline YT-QUAL & Tensile & 287 & Alloy 617 & Plate & Aged-4 & Air & 950 & 120000 & 950 \\
\hline YT-QUAL & Tensile & 288 & Alloy 617 & Plate & Aged-4 & Air & 950 & 120000 & 950 \\
\hline YT-QUAL & Tensile & 289 & Alloy 617 & Plate & Aged-3 & Air & 1000 & 120000 & 20 \\
\hline YT-QUAL & Tensile & 290 & Alloy 617 & Plate & Aged-3 & Air & 1000 & 120000 & 20 \\
\hline YT-QUAL & Tensile & 291 & Alloy 617 & Plate & Aged-3 & Air & 1000 & 120000 & 950 \\
\hline YT-QUAL & Tensile & 292 & Alloy 617 & Plate & Aged-3 & Air & 1000 & 120000 & 950 \\
\hline YT-QUAL & Tensile & 293 & Alloy 617 & Plate & Aged-4 & Air & 1000 & 120000 & 20 \\
\hline YT-QUAL & Tensile & 294 & Alloy 617 & Plate & Aged-4 & Air & 1000 & 120000 & 20 \\
\hline YT-QUAL & Tensile & 295 & Alloy 617 & Plate & Aged-4 & Air & 1000 & 120000 & 950 \\
\hline YT-QUAL & Tensile & 296 & Alloy 617 & Plate & Aged-4 & Air & 1000 & 120000 & 950 \\
\hline
\end{tabular}




Idaho National Laboratory
\begin{tabular}{|c|lll|}
\hline NEXT GENERATION NUCLEAR PLANT & Identifier: & PLN-2804 & \\
INTERMEDIATE HEAT EXCHANGER & Revision: & 0 & \\
MATERIALS RESEARCH & Effective Date: & $04 / 30 / 08$ & Page: A-88 of A-114 \\
AND DEVELOPMENT PLAN &
\end{tabular}

\begin{tabular}{|c|c|c|c|c|c|c|c|c|c|}
\hline Test Program & $\begin{array}{c}\text { Specimen } \\
\text { Type }\end{array}$ & Specimen \# & Material & $\begin{array}{c}\text { Product } \\
\text { Form }\end{array}$ & Heat & $\begin{array}{c}\text { Environ- } \\
\text { ment }\end{array}$ & $\begin{array}{c}\text { Temp. } \\
\left({ }^{\circ} \mathrm{C}\right)\end{array}$ & $\begin{array}{c}\text { Strain Rate } \\
\text { Magnitude } \\
(\mathrm{m} / \mathrm{m} / \mathrm{s})\end{array}$ & $\begin{array}{c}\text { Strain Range } \\
(\%)\end{array}$ \\
\hline Strain Rate Effect & Fatigue & 1 & Alloy 617 & Plate & xyz-CF & air & 950 & $1 \mathrm{E}-02$ & 2.00 \\
\hline Strain Rate Effect & Fatigue & 2 & Alloy 617 & Plate & xyz-CF & air & 950 & $1 \mathrm{E}-02$ & 2.00 \\
\hline Strain Rate Effect & Fatigue & 3 & Alloy 617 & Plate & xyz-CF & air & 950 & $1 \mathrm{E}-02$ & 2.00 \\
\hline Strain Rate Effect & Fatigue & 4 & Alloy 617 & Plate & xyz-CF & air & 950 & $1 \mathrm{E}-03$ & 2.00 \\
\hline Strain Rate Effect & Fatigue & 5 & Alloy 617 & Plate & xyz-CF & air & 950 & $1 \mathrm{E}-03$ & 2.00 \\
\hline Strain Rate Effect & Fatigue & 6 & Alloy 617 & Plate & xyz-CF & air & 950 & $1 \mathrm{E}-03$ & 2.00 \\
\hline Strain Rate Effect & Fatigue & 7 & Alloy 617 & Plate & xyz-CF & air & 950 & $1 \mathrm{E}-04$ & 2.00 \\
\hline Strain Rate Effect & Fatigue & 8 & Alloy 617 & Plate & xyz-CF & air & 950 & $1 \mathrm{E}-04$ & 2.00 \\
\hline Strain Rate Effect & Fatigue & 9 & Alloy 617 & Plate & xyz-CF & air & 950 & $1 \mathrm{E}-04$ & 2.00 \\
\hline Strain Rate Effect & Fatigue & 10 & Alloy 617 & Plate & xyz-CF & air & 950 & $1 \mathrm{E}-05$ & 2.00 \\
\hline Strain Rate Effect & Fatigue & 11 & Alloy 617 & Plate & xyz-CF & air & 950 & $1 \mathrm{E}-05$ & 2.00 \\
\hline Strain Rate Effect & Fatigue & 12 & Alloy 617 & Plate & xyz-CF & air & 950 & $1 \mathrm{E}-05$ & 2.00 \\
\hline Design Curve & Fatioue & 13 & Allov 617 & Plate & $\mathrm{YYZ}-\mathrm{CF}$ & air & 850 & S1(TRD) & 015 \\
\hline Design Curve & Fatigue & 14 & Alloy 617 & Plate & $\mathrm{xyz}-\mathrm{CF}$ & air & 850 & S1 (TBD) & 0.15 \\
\hline Design Curve & Fatigue & 15 & Alloy 617 & Plate & xyz-CF & air & 850 & $\mathrm{~S} 1$ (TBD) & 0.15 \\
\hline Design Curve & Fatigue & 16 & Alloy 617 & Plate & xyz-CF & air & 850 & $\mathrm{~S} 1$ (TBD) & 0.25 \\
\hline Design Curve & Fatigue & 17 & Alloy 617 & Plate & xyz-CF & air & 850 & $\mathrm{~S} 1$ (TBD) & 0.25 \\
\hline Design Curve & Fatigue & 18 & Alloy 617 & Plate & xyz-CF & air & 850 & $\mathrm{~S} 1$ (TBD) & 0.25 \\
\hline Design Curve & Fatigue & 19 & Alloy 617 & Plate & xyz-CF & air & 850 & $\mathrm{~S} 1$ (TBD) & 0.40 \\
\hline Design Curve & Fatigue & 20 & Alloy 617 & Plate & xyz-CF & air & 850 & $\mathrm{~S} 1$ (TBD) & 0.40 \\
\hline Design Curve & Fatigue & 21 & Alloy 617 & Plate & xyz-CF & air & 850 & S1 (TBD) & 0.40 \\
\hline Design Curve & Fatigue & 22 & Alloy 617 & Plate & xyz-CF & air & 850 & $\mathrm{~S} 1$ (TBD) & 0.60 \\
\hline Design Curve & Fatigue & 23 & Alloy 617 & Plate & xyz-CF & air & 850 & $\mathrm{~S} 1$ (TBD) & 0.60 \\
\hline Design Curve & Fatigue & 24 & Alloy 617 & Plate & xyz-CF & air & 850 & $\mathrm{~S} 1$ (TBD) & 0.60 \\
\hline Design Curve & Fatigue & 25 & Alloy 617 & Plate & xyz-CF & air & 850 & $\mathrm{~S} 1$ (TBD) & 1.00 \\
\hline
\end{tabular}


Idaho National Laboratory

\begin{tabular}{|c|c|c|c|}
\hline $\begin{array}{l}\text { NEXT GENERATION NUCLEAR PLANT } \\
\text { INTERMEDIATE HEAT EXCHANGER } \\
\text { MATERIALS RESEARCH } \\
\text { AND DEVELOPMENT PLAN }\end{array}$ & $\begin{array}{l}\text { Identifier: } \\
\text { Revision: } \\
\text { Effective Date: }\end{array}$ & $\begin{array}{l}\text { PLN-2804 } \\
0 \\
04 / 30 / 08\end{array}$ & Page: A-89 of A-114 \\
\hline
\end{tabular}

Table A19. Fatigue Tests to Support Design Curve Development in Alloy 617 Code Case

\begin{tabular}{|c|c|c|c|c|c|c|c|c|c|}
\hline Test Program & $\begin{array}{c}\text { Specimen } \\
\text { Type }\end{array}$ & Specimen \# & Material & $\begin{array}{c}\text { Product } \\
\text { Form }\end{array}$ & Heat & $\begin{array}{c}\text { Environ- } \\
\text { ment }\end{array}$ & $\begin{array}{c}\text { Temp. } \\
\left({ }^{\circ} \mathrm{C}\right)\end{array}$ & $\begin{array}{c}\text { Strain Rate } \\
\text { Magnitude } \\
(\mathrm{m} / \mathrm{m} / \mathrm{s})\end{array}$ & $\begin{array}{c}\text { Strain Range } \\
(\%)\end{array}$ \\
\hline Design Curve & Fatigue & 26 & Alloy 617 & Plate & xyz-CF & air & 850 & S1 (TBD) & 1.00 \\
\hline Design Curve & Fatigue & 27 & Alloy 617 & Plate & xyz-CF & air & 850 & $\mathrm{~S} 1$ (TBD) & 1.00 \\
\hline Design Curve & Fatigue & 28 & Alloy 617 & Plate & xyz-CF & air & 850 & $\mathrm{~S} 1$ (TBD) & 2.00 \\
\hline Design Curve & Fatigue & 29 & Alloy 617 & Plate & xyz-CF & air & 850 & $\mathrm{~S} 1$ (TBD) & 2.00 \\
\hline Design Curve & Fatigue & 30 & Alloy 617 & Plate & xyz-CF & air & 850 & $\mathrm{~S} 1$ (TBD) & 2.00 \\
\hline Design Curve & Fatigue & 31 & Alloy 617 & Plate & xyz-CF & air & 950 & $\mathrm{~S} 1$ (TBD) & 0.15 \\
\hline Design Curve & Fatigue & 32 & Alloy 617 & Plate & xyz-CF & air & 950 & $\mathrm{~S} 1$ (TBD) & 0.15 \\
\hline Design Curve & Fatigue & 33 & Alloy 617 & Plate & xyz-CF & air & 950 & $\mathrm{~S} 1$ (TBD) & 0.15 \\
\hline Design Curve & Fatigue & 34 & Alloy 617 & Plate & xyz-CF & air & 950 & $\mathrm{~S} 1$ (TBD) & 0.25 \\
\hline Design Curve & Fatigue & 35 & Alloy 617 & Plate & xyz-CF & air & 950 & $\mathrm{~S} 1$ (TBD) & 0.25 \\
\hline Design Curve & Fatigue & 36 & Alloy 617 & Plate & xyz-CF & air & 950 & $\mathrm{~S} 1$ (TBD) & 0.25 \\
\hline Design Curve & Fatigue & 37 & Alloy 617 & Plate & xyz-CF & air & 950 & $\mathrm{~S} 1$ (TBD) & 0.40 \\
\hline Design Curve & Fatigue & 38 & Alloy 617 & Plate & xyz-CF & air & 950 & $\mathrm{~S} 1$ (TBD) & 0.40 \\
\hline Design Curve & Fatigue & 39 & Alloy 617 & Plate & xyz-CF & air & 950 & $\mathrm{~S} 1$ (TBD) & 0.40 \\
\hline Design Curve & Fatigue & 40 & Alloy 617 & Plate & xyz-CF & air & 950 & $\mathrm{~S} 1$ (TBD) & 0.60 \\
\hline Design Curve & Fatigue & 41 & Alloy 617 & Plate & xyz-CF & air & 950 & S1 (TBD) & 0.60 \\
\hline Design Curve & Fatigue & 42 & Alloy 617 & Plate & xyz-CF & air & 950 & $\mathrm{~S} 1$ (TBD) & 0.60 \\
\hline Design Curve & Fatigue & 43 & Alloy 617 & Plate & xyz-CF & air & 950 & $\mathrm{~S} 1$ (TBD) & 1.00 \\
\hline Design Curve & Fatigue & 44 & Alloy 617 & Plate & $\mathrm{xyz}-\mathrm{CF}$ & air & 950 & $\mathrm{~S} 1$ (TBD) & 1.00 \\
\hline Design Curve & Fatigue & 45 & Alloy 617 & Plate & xyz-CF & air & 950 & $\mathrm{~S} 1$ (TBD) & 1.00 \\
\hline Design Curve & Fatigue & 46 & Alloy 617 & Plate & xyz-CF & air & 950 & $\mathrm{~S} 1$ (TBD) & 2.00 \\
\hline Design Curve & Fatigue & 47 & Alloy 617 & Plate & xyz-CF & air & 950 & $\mathrm{~S} 1$ (TBD) & 2.00 \\
\hline Design Curve & Fatigue & 48 & Alloy 617 & Plate & xyz-CF & air & 950 & $\mathrm{~S} 1$ (TBD) & 2.00 \\
\hline Strain Rate Effect & Fatigue & 49 & Alloy 617 & Plate & xyz-CF & NGNP He & 950 & $1 \mathrm{E}-02$ & 2.00 \\
\hline Strain Rate Effect & Fatigue & 50 & Alloy 617 & Plate & $\mathrm{xyz}-\mathrm{CF}$ & NGNP He & 950 & $1 \mathrm{E}-02$ & 2.00 \\
\hline Strain Rate Effect & Fatigue & 51 & Alloy 617 & Plate & xyz-CF & NGNP He & 950 & $1 \mathrm{E}-02$ & 2.00 \\
\hline
\end{tabular}


Idaho National Laboratory

\begin{tabular}{|c|c|c|c|}
\hline $\begin{array}{l}\text { NEXT GENERATION NUCLEAR PLANT } \\
\text { INTERMEDIATE HEAT EXCHANGER } \\
\text { MATERIALS RESEARCH } \\
\text { AND DEVELOPMENT PLAN }\end{array}$ & $\begin{array}{l}\text { Identifier: } \\
\text { Revision: } \\
\text { Effective Date: }\end{array}$ & $\begin{array}{l}\text { PLN-2804 } \\
0 \\
04 / 30 / 08\end{array}$ & Page: A \\
\hline
\end{tabular}

Table A19. Fatigue Tests to Support Design Curve Development in Alloy 617 Code Case

\begin{tabular}{|c|c|c|c|c|c|c|c|c|c|}
\hline Test Program & $\begin{array}{c}\text { Specimen } \\
\text { Type }\end{array}$ & Specimen \# & Material & $\begin{array}{c}\text { Product } \\
\text { Form }\end{array}$ & Heat & $\begin{array}{c}\text { Environ- } \\
\text { ment }\end{array}$ & $\begin{array}{c}\text { Temp. } \\
\left({ }^{\circ} \mathrm{C}\right)\end{array}$ & $\begin{array}{c}\text { Strain Rate } \\
\text { Magnitude } \\
(\mathrm{m} / \mathrm{m} / \mathrm{s})\end{array}$ & $\begin{array}{c}\text { Strain Range } \\
(\%)\end{array}$ \\
\hline Strain Rate Effect & Fatigue & 52 & Alloy 617 & Plate & xyz-CF & NGNP He & 950 & $1 \mathrm{E}-03$ & 2.00 \\
\hline Strain Rate Effect & Fatigue & 53 & Alloy 617 & Plate & xyz-CF & NGNP He & 950 & $1 \mathrm{E}-03$ & 2.00 \\
\hline Strain Rate Effect & Fatigue & 54 & Alloy 617 & Plate & xyz-CF & NGNP He & 950 & $1 \mathrm{E}-03$ & 2.00 \\
\hline Strain Rate Effect & Fatigue & 55 & Alloy 617 & Plate & xyz-CF & NGNP He & 950 & $1 \mathrm{E}-04$ & 2.00 \\
\hline Strain Rate Effect & Fatigue & 56 & Alloy 617 & Plate & xyz-CF & NGNP He & 950 & $1 \mathrm{E}-04$ & 2.00 \\
\hline Strain Rate Effect & Fatigue & 57 & Alloy 617 & Plate & $\mathrm{xyz}-\mathrm{CF}$ & NGNP He & 950 & $1 \mathrm{E}-04$ & 2.00 \\
\hline Strain Rate Effect & Fatigue & 58 & Alloy 617 & Plate & $\mathrm{xyz}-\mathrm{CF}$ & NGNP He & 950 & $1 \mathrm{E}-05$ & 2.00 \\
\hline Strain Rate Effect & Fatigue & 59 & Alloy 617 & Plate & xyz-CF & NGNP He & 950 & $1 \mathrm{E}-05$ & 2.00 \\
\hline Strain Rate Effect & Fatigue & 60 & Alloy 617 & Plate & xyz-CF & NGNP He & 950 & $1 \mathrm{E}-05$ & 2.00 \\
\hline Design Curve & Fatigue & 61 & Alloy 617 & Plate & $\mathrm{xyz}-\mathrm{CF}$ & NGNP He & 850 & $\mathrm{~S} 2$ (TBD) & 0.15 \\
\hline Design Curve & Fatigue & 62 & Alloy 617 & Plate & xyz-CF & NGNP He & 850 & $\mathrm{~S} 2$ (TBD) & 0.15 \\
\hline Design Curve & Fatigue & 63 & Alloy 617 & Plate & xyz-CF & NGNP He & 850 & $\mathrm{~S} 2$ (TBD) & 0.15 \\
\hline Design Curve & Fatigue & 64 & Alloy 617 & Plate & xyz-CF & NGNP He & 850 & S2 (TBD) & 0.25 \\
\hline Design Curve & Fatigue & 65 & Alloy 617 & Plate & xyz-CF & NGNP He & 850 & S2 (TBD) & 0.25 \\
\hline Design Curve & Fatigue & 66 & Alloy 617 & Plate & $\mathrm{xyz}-\mathrm{CF}$ & NGNP He & 850 & $\mathrm{~S} 2$ (TBD) & 0.25 \\
\hline Design Curve & Fatigue & 67 & Alloy 617 & Plate & $\mathrm{xyz}-\mathrm{CF}$ & NGNP He & 850 & $\mathrm{~S} 2$ (TBD) & 0.40 \\
\hline Design Curve & Fatigue & 68 & Alloy 617 & Plate & xyz-CF & NGNP He & 850 & $\mathrm{~S} 2$ (TBD) & 0.40 \\
\hline Design Curve & Fatigue & 69 & Alloy 617 & Plate & $\mathrm{xyz}-\mathrm{CF}$ & NGNP He & 850 & $\mathrm{~S} 2$ (TBD) & 0.40 \\
\hline Design Curve & Fatigue & 70 & Alloy 617 & Plate & $\mathrm{xyz}-\mathrm{CF}$ & NGNP He & 850 & $\mathrm{~S} 2$ (TBD) & 0.60 \\
\hline Design Curve & Fatigue & 71 & Alloy 617 & Plate & xyz-CF & NGNP He & 850 & $\mathrm{~S} 2$ (TBD) & 0.60 \\
\hline Design Curve & Fatigue & 72 & Alloy 617 & Plate & xyz-CF & NGNP He & 850 & S2 (TBD) & 0.60 \\
\hline Design Curve & Fatigue & 73 & Alloy 617 & Plate & xyz-CF & NGNP He & 850 & S2 (TBD) & 1.00 \\
\hline Design Curve & Fatigue & 74 & Alloy 617 & Plate & xyz-CF & NGNP He & 850 & $\mathrm{~S} 2$ (TBD) & 1.00 \\
\hline Design Curve & Fatigue & 75 & Alloy 617 & Plate & xyz-CF & NGNP He & 850 & S2 (TBD) & 1.00 \\
\hline Design Curve & Fatigue & 76 & Alloy 617 & Plate & $\mathrm{xyz}-\mathrm{CF}$ & NGNP He & 850 & $\mathrm{~S} 2$ (TBD) & 2.00 \\
\hline Design Curve & Fatigue & 77 & Alloy 617 & Plate & xyz-CF & NGNP He & 850 & S2 (TBD) & 2.00 \\
\hline
\end{tabular}


Idaho National Laboratory

\begin{tabular}{|c|c|c|c|}
\hline $\begin{array}{l}\text { NEXT GENERATION NUCLEAR PLANT } \\
\text { INTERMEDIATE HEAT EXCHANGER } \\
\text { MATERIALS RESEARCH } \\
\text { AND DEVELOPMENT PLAN }\end{array}$ & $\begin{array}{l}\text { Identifier: } \\
\text { Revision: } \\
\text { Effective Date: }\end{array}$ & $\begin{array}{l}\text { PLN-2804 } \\
0 \\
04 / 30 / 08\end{array}$ & Page: A \\
\hline
\end{tabular}

\begin{tabular}{|c|c|c|c|c|c|c|c|c|c|}
\hline \multicolumn{10}{|c|}{ Table A19. Fatigue Tests to Support Design Curve Development in Alloy 617 Code Case } \\
\hline Test Program & $\begin{array}{l}\text { Specimen } \\
\text { Type }\end{array}$ & Specimen \# & Material & $\begin{array}{c}\text { Product } \\
\text { Form }\end{array}$ & Heat & $\begin{array}{c}\text { Environ- } \\
\text { ment }\end{array}$ & $\begin{array}{c}\text { Temp. } \\
\left({ }^{\circ} \mathrm{C}\right)\end{array}$ & $\begin{array}{c}\text { Strain Rate } \\
\text { Magnitude } \\
(\mathrm{m} / \mathrm{m} / \mathrm{s})\end{array}$ & $\begin{array}{c}\text { Strain Range } \\
(\%)\end{array}$ \\
\hline Design Curve & Fatigue & 78 & Alloy 617 & Plate & xyz-CF & NGNP He & 850 & $\mathrm{~S} 2$ (TBD) & 2.00 \\
\hline Design Curve & Fatigue & 79 & Alloy 617 & Plate & xyz-CF & NGNP He & 950 & $\mathrm{~S} 2$ (TBD) & 0.15 \\
\hline Design Curve & Fatigue & 80 & Alloy 617 & Plate & xyz-CF & NGNP He & 950 & S2 (TBD) & 0.15 \\
\hline Design Curve & Fatigue & 81 & Alloy 617 & Plate & xyz-CF & NGNP He & 950 & S2 (TBD) & 0.15 \\
\hline Design Curve & Fatigue & 82 & Alloy 617 & Plate & xyz-CF & NGNP He & 950 & S2 (TBD) & 0.25 \\
\hline Design Curve & Fatigue & 83 & Alloy 617 & Plate & $\mathrm{xyz}-\mathrm{CF}$ & NGNP He & 950 & S2 (TBD) & 0.25 \\
\hline Design Curve & Fatigue & 84 & Alloy 617 & Plate & xyz-CF & NGNP He & 950 & S2 (TBD) & 0.25 \\
\hline Design Curve & Fatigue & 85 & Alloy 617 & Plate & xyz-CF & NGNP He & 950 & S2 (TBD) & 0.40 \\
\hline Design Curve & Fatigue & 86 & Alloy 617 & Plate & xyz-CF & NGNP He & 950 & S2 (TBD) & 0.40 \\
\hline Design Curve & Fatigue & 87 & Alloy 617 & Plate & xyz-CF & NGNP He & 950 & S2 (TBD) & 0.40 \\
\hline Design Curve & Fatigue & 88 & Alloy 617 & Plate & xyz-CF & NGNP He & 950 & S2 (TBD) & 0.60 \\
\hline Design Curve & Fatigue & 89 & Alloy 617 & Plate & xyz-CF & NGNP He & 950 & S2 (TBD) & 0.60 \\
\hline Design Curve & Fatigue & 90 & Alloy 617 & Plate & xyz-CF & NGNP He & 950 & S2 (TBD) & 0.60 \\
\hline Design Curve & Fatigue & 91 & Alloy 617 & Plate & xyz-CF & NGNP He & 950 & S2 (TBD) & 1.00 \\
\hline Design Curve & Fatigue & 92 & Alloy 617 & Plate & xyz-CF & NGNP He & 950 & S2 (TBD) & 1.00 \\
\hline Design Curve & Fatigue & 93 & Alloy 617 & Plate & xyz-CF & NGNP He & 950 & $\mathrm{~S} 2$ (TBD) & 1.00 \\
\hline Design Curve & Fatigue & 94 & Alloy 617 & Plate & xyz-CF & NGNP He & 950 & S2 (TBD) & 2.00 \\
\hline Design Curve & Fatigue & 95 & Alloy 617 & Plate & xyz-CF & NGNP He & 950 & S2 (TBD) & 2.00 \\
\hline Design Curve & Fatigue & 96 & Alloy 617 & Plate & xyz-CF & NGNP He & 950 & S2 (TBD) & 2.00 \\
\hline
\end{tabular}




Idaho National Laboratory
\begin{tabular}{|c|lll|}
\hline NEXT GENERATION NUCLEAR PLANT & Identifier: & PLN-2804 & \\
INTERMEDIATE HEAT EXCHANGER & Revision: & 0 & \\
MATERIALS RESEARCH & Effective Date: & $04 / 30 / 08$ & Page: A-92 of A-114 \\
AND DEVELOPMENT PLAN & &
\end{tabular}

\begin{tabular}{|c|c|c|c|c|c|c|c|c|c|}
\hline $\begin{array}{c}\text { Specimen } \\
\#\end{array}$ & Material & $\begin{array}{l}\text { Product } \\
\text { Form }\end{array}$ & Heat & $\begin{array}{c}\text { Strain Rate } \\
\text { Magnitude } \\
(\mathrm{m} / \mathrm{m} / \mathrm{s})\end{array}$ & Env. & $\begin{array}{c}\text { Hold Time in } \\
\mathrm{T} \text { or } \mathrm{C}\end{array}$ & Temp $\left({ }^{\circ} \mathrm{C}\right)$ & $\begin{array}{c}\text { Strain Range } \\
(\%)\end{array}$ & $\begin{array}{l}\text { Hold Time } \\
\quad(\mathrm{min})\end{array}$ \\
\hline 1 & Alloy 617 & Plate & xyz-CF & $1 \mathrm{E}-03$ & air & tension & 950 & 0.3 & 0 \\
\hline 2 & Alloy 617 & Plate & xyz-CF & $1 \mathrm{E}-03$ & air & tension & 950 & 0.3 & 0 \\
\hline 3 & Alloy 617 & Plate & $\mathrm{xyz}-\mathrm{CF}$ & $1 \mathrm{E}-03$ & air & tension & 950 & 0.3 & 0 \\
\hline 4 & Alloy 617 & Plate & xyz-CF & $1 \mathrm{E}-03$ & air & tension & 950 & 0.3 & 3 \\
\hline 5 & Alloy 617 & Plate & xyz-CF & $1 \mathrm{E}-03$ & air & tension & 950 & 0.3 & 3 \\
\hline 6 & Alloy 617 & Plate & xyz-CF & $1 \mathrm{E}-03$ & air & tension & 950 & 0.3 & 3 \\
\hline 7 & Alloy 617 & Plate & xyz-CF & $1 \mathrm{E}-03$ & air & tension & 950 & 0.3 & 10 \\
\hline 8 & Alloy 617 & Plate & xyz-CF & $1 \mathrm{E}-03$ & air & tension & 950 & 0.3 & 10 \\
\hline 9 & Alloy 617 & Plate & xyz-CF & $1 \mathrm{E}-03$ & air & tension & 950 & 0.3 & 10 \\
\hline 10 & Alloy 617 & Plate & xyz-CF & $1 \mathrm{E}-03$ & air & tension & 950 & 0.3 & 30 \\
\hline 11 & Alloy 617 & Plate & xyz-CF & $1 \mathrm{E}-03$ & air & tension & 950 & 0.3 & 30 \\
\hline 12 & Alloy 617 & Plate & xyz-CF & $1 \mathrm{E}-03$ & air & tension & 950 & 0.3 & 30 \\
\hline 13 & Alloy 617 & Plate & xyz-CF & $1 \mathrm{E}-03$ & air & tension & 950 & 0.6 & 0 \\
\hline 14 & Alloy 617 & Plate & xyz-CF & $1 \mathrm{E}-03$ & air & tension & 950 & 0.6 & 0 \\
\hline 15 & Alloy 617 & Plate & xyz-CF & $1 \mathrm{E}-03$ & air & tension & 950 & 0.6 & 0 \\
\hline 16 & Alloy 617 & Plate & $\mathrm{xyz}-\mathrm{CF}$ & $1 \mathrm{E}-03$ & air & tension & 950 & 0.6 & 3 \\
\hline 17 & Alloy 617 & Plate & xyz-CF & $1 \mathrm{E}-03$ & air & tension & 950 & 0.6 & 3 \\
\hline 18 & Alloy 617 & Plate & xyz-CF & $1 \mathrm{E}-03$ & air & tension & 950 & 0.6 & 3 \\
\hline 19 & Alloy 617 & Plate & xyz-CF & $1 \mathrm{E}-03$ & air & tension & 950 & 0.6 & 10 \\
\hline 20 & Alloy 617 & Plate & xyz-CF & $1 \mathrm{E}-03$ & air & tension & 950 & 0.6 & 10 \\
\hline 21 & Alloy 617 & Plate & xyz-CF & $1 \mathrm{E}-03$ & air & tension & 950 & 0.6 & 10 \\
\hline 22 & Alloy 617 & Plate & xyz-CF & $1 \mathrm{E}-03$ & air & tension & 950 & 0.6 & 30 \\
\hline 23 & Alloy 617 & Plate & xyz-CF & $1 \mathrm{E}-03$ & air & tension & 950 & 0.6 & 30 \\
\hline 24 & Alloy 617 & Plate & xyz-CF & $1 \mathrm{E}-03$ & air & tension & 950 & 0.6 & 30 \\
\hline 25 & Alloy 617 & Plate & xyz-CF & $1 \mathrm{E}-03$ & air & tension & 950 & 1.0 & 0 \\
\hline 26 & Alloy 617 & Plate & xyz-CF & $1 \mathrm{E}-03$ & air & tension & 950 & 1.0 & 0 \\
\hline
\end{tabular}




Idaho National Laboratory
\begin{tabular}{|c|lll|}
\hline NEXT GENERATION NUCLEAR PLANT & Identifier: & PLN-2804 & \\
INTERMEDIATE HEAT EXCHANGER & Revision: & 0 & \\
MATERIALS RESEARCH & Effective Date: & $04 / 30 / 08$ & Page: A-93 of A-114 \\
AND DEVELOPMENT PLAN &
\end{tabular}

\begin{tabular}{|c|c|c|c|c|c|c|c|c|c|}
\hline $\begin{array}{c}\text { Specimen } \\
\#\end{array}$ & Material & $\begin{array}{l}\text { Product } \\
\text { Form }\end{array}$ & Heat & $\begin{array}{l}\text { Strain Rate } \\
\text { Magnitude } \\
(\mathrm{m} / \mathrm{m} / \mathrm{s})\end{array}$ & Env. & $\begin{array}{c}\text { Hold Time in } \\
\mathrm{T} \text { or } \mathrm{C}\end{array}$ & Temp $\left({ }^{\circ} \mathrm{C}\right)$ & $\begin{array}{c}\text { Strain Range } \\
(\%)\end{array}$ & $\begin{array}{l}\text { Hold Time } \\
\quad(\min )\end{array}$ \\
\hline 27 & Alloy 617 & Plate & xyz-CF & $1 \mathrm{E}-03$ & air & tension & 950 & 1.0 & 0 \\
\hline 28 & Alloy 617 & Plate & xyz-CF & $1 \mathrm{E}-03$ & air & tension & 950 & 1.0 & 3 \\
\hline 29 & Alloy 617 & Plate & xyz-CF & $1 \mathrm{E}-03$ & air & tension & 950 & 1.0 & 3 \\
\hline 30 & Alloy 617 & Plate & xyz-CF & $1 \mathrm{E}-03$ & air & tension & 950 & 1.0 & 3 \\
\hline 31 & Alloy 617 & Plate & xyz-CF & $1 \mathrm{E}-03$ & air & tension & 950 & 1.0 & 10 \\
\hline 32 & Alloy 617 & Plate & xyz-CF & $1 \mathrm{E}-03$ & air & tension & 950 & 1.0 & 10 \\
\hline 33 & Alloy 617 & Plate & xyz-CF & $1 \mathrm{E}-03$ & air & tension & 950 & 1.0 & 10 \\
\hline 34 & Alloy 617 & Plate & xyz-CF & $1 \mathrm{E}-03$ & air & tension & 950 & 1.0 & 30 \\
\hline 35 & Alloy 617 & Plate & xyz-CF & $1 \mathrm{E}-03$ & air & tension & 950 & 1.0 & 30 \\
\hline 36 & Alloy 617 & Plate & xyz-CF & $1 \mathrm{E}-03$ & air & tension & 950 & 1.0 & 30 \\
\hline 37 & Alloy 617 & Plate & xyz-CF & $1 \mathrm{E}-03$ & air & tension & 950 & 0.3 & 150 \\
\hline 38 & Alloy 617 & Plate & xyz-CF & $1 \mathrm{E}-03$ & air & tension & 950 & 0.3 & 150 \\
\hline 39 & Alloy 617 & Plate & xyz-CF & $1 \mathrm{E}-03$ & air & tension & 950 & 0.3 & 150 \\
\hline 40 & Alloy 617 & Plate & xyz-CF & $1 \mathrm{E}-03$ & air & tension & 950 & 0.3 & 600 \\
\hline 41 & Alloy 617 & Plate & xyz-CF & $1 \mathrm{E}-03$ & air & tension & 950 & 0.3 & 600 \\
\hline 42 & Alloy 617 & Plate & xyz-CF & $1 \mathrm{E}-03$ & air & tension & 950 & 0.3 & 600 \\
\hline 43 & Alloy 617 & Plate & xyz-CF & $1 \mathrm{E}-03$ & air & tension & 950 & 1.0 & 150 \\
\hline 44 & Alloy 617 & Plate & xyz-CF & $1 \mathrm{E}-03$ & air & tension & 950 & 1.0 & 150 \\
\hline 45 & Alloy 617 & Plate & xyz-CF & $1 \mathrm{E}-03$ & air & tension & 950 & 1.0 & 150 \\
\hline 46 & Alloy 617 & Plate & xyz-CF & $1 \mathrm{E}-03$ & air & tension & 950 & 1.0 & 600 \\
\hline 47 & Alloy 617 & Plate & xyz-CF & $1 \mathrm{E}-03$ & air & tension & 950 & 1.0 & 600 \\
\hline 48 & Alloy 617 & Plate & xyz-CF & $1 \mathrm{E}-03$ & air & tension & 950 & 1.0 & 600 \\
\hline & & & & & & & & & \\
\hline 49 & Alloy 617 & Plate & xyz-CF & $1 \mathrm{E}-03$ & NGNP He & tension & 950 & 0.3 & 0 \\
\hline 50 & Alloy 617 & Plate & xyz-CF & $1 \mathrm{E}-03$ & NGNP He & tension & 950 & 0.3 & 0 \\
\hline 51 & Alloy 617 & Plate & xyz-CF & $1 \mathrm{E}-03$ & NGNP He & tension & 950 & 0.3 & 0 \\
\hline 52 & Alloy 617 & Plate & xyz-CF & $1 \mathrm{E}-03$ & NGNP He & tension & 950 & 0.3 & 3 \\
\hline
\end{tabular}




Idaho National Laboratory
\begin{tabular}{|c|lll|}
\hline NEXT GENERATION NUCLEAR PLANT & Identifier: & PLN-2804 & \\
INTERMEDIATE HEAT EXCHANGER & Revision: & 0 & \\
MATERIALS RESEARCH & Effective Date: & $04 / 30 / 08$ & Page: A-94 of A-114 \\
AND DEVELOPMENT PLAN &
\end{tabular}

\begin{tabular}{|c|c|c|c|c|c|c|c|c|c|}
\hline $\begin{array}{c}\text { Specimen } \\
\#\end{array}$ & Material & $\begin{array}{l}\text { Product } \\
\text { Form }\end{array}$ & Heat & $\begin{array}{l}\text { Strain Rate } \\
\text { Magnitude } \\
(\mathrm{m} / \mathrm{m} / \mathrm{s})\end{array}$ & Env. & $\begin{array}{c}\text { Hold Time in } \\
\mathrm{T} \text { or } \mathrm{C}\end{array}$ & Temp $\left({ }^{\circ} \mathrm{C}\right)$ & $\begin{array}{c}\text { Strain Range } \\
(\%)\end{array}$ & $\begin{array}{l}\text { Hold Time } \\
\quad(\min )\end{array}$ \\
\hline 53 & Alloy 617 & Plate & xyz-CF & $1 \mathrm{E}-03$ & NGNP He & tension & 950 & 0.3 & 3 \\
\hline 54 & Alloy 617 & Plate & xyz-CF & $1 \mathrm{E}-03$ & NGNP He & tension & 950 & 0.3 & 3 \\
\hline 55 & Alloy 617 & Plate & xyz-CF & $1 \mathrm{E}-03$ & NGNP He & tension & 950 & 0.3 & 10 \\
\hline 56 & Alloy 617 & Plate & xyz-CF & $1 \mathrm{E}-03$ & NGNP He & tension & 950 & 0.3 & 10 \\
\hline 57 & Alloy 617 & Plate & xyz-CF & $1 \mathrm{E}-03$ & NGNP He & tension & 950 & 0.3 & 10 \\
\hline 58 & Alloy 617 & Plate & xyz-CF & 1E-03 & NGNP He & tension & 950 & 0.3 & 30 \\
\hline 59 & Alloy 617 & Plate & xyz-CF & $1 \mathrm{E}-03$ & NGNP He & tension & 950 & 0.3 & 30 \\
\hline 60 & Alloy 617 & Plate & xyz-CF & $1 \mathrm{E}-03$ & NGNP He & tension & 950 & 0.3 & 30 \\
\hline 61 & Alloy 617 & Plate & xyz-CF & $1 \mathrm{E}-03$ & NGNP He & tension & 950 & 0.6 & 0 \\
\hline 62 & Alloy 617 & Plate & xyz-CF & $1 \mathrm{E}-03$ & NGNP He & tension & 950 & 0.6 & 0 \\
\hline 63 & Alloy 617 & Plate & xyz-CF & $1 \mathrm{E}-03$ & NGNP He & tension & 950 & 0.6 & 0 \\
\hline 64 & Alloy 617 & Plate & xyz-CF & $1 \mathrm{E}-03$ & NGNP He & tension & 950 & 0.6 & 3 \\
\hline 65 & Alloy 617 & Plate & xyz-CF & $1 \mathrm{E}-03$ & NGNP He & tension & 950 & 0.6 & 3 \\
\hline 66 & Alloy 617 & Plate & xyz-CF & $1 \mathrm{E}-03$ & NGNP He & tension & 950 & 0.6 & 3 \\
\hline 67 & Alloy 617 & Plate & xyz-CF & $1 \mathrm{E}-03$ & NGNP He & tension & 950 & 0.6 & 10 \\
\hline 68 & Alloy 617 & Plate & xyz-CF & $1 \mathrm{E}-03$ & NGNP He & tension & 950 & 0.6 & 10 \\
\hline 69 & Alloy 617 & Plate & xyz-CF & $1 \mathrm{E}-03$ & NGNP He & tension & 950 & 0.6 & 10 \\
\hline 70 & Alloy 617 & Plate & xyz-CF & $1 \mathrm{E}-03$ & NGNP He & tension & 950 & 0.6 & 30 \\
\hline 71 & Alloy 617 & Plate & xyz-CF & $1 \mathrm{E}-03$ & NGNP He & tension & 950 & 0.6 & 30 \\
\hline 72 & Alloy 617 & Plate & xyz-CF & $1 \mathrm{E}-03$ & NGNP He & tension & 950 & 0.6 & 30 \\
\hline 73 & Alloy 617 & Plate & xyz-CF & $1 \mathrm{E}-03$ & NGNP He & tension & 950 & 1.0 & 0 \\
\hline 74 & Alloy 617 & Plate & xyz-CF & $1 \mathrm{E}-03$ & NGNP He & tension & 950 & 1.0 & 0 \\
\hline 75 & Alloy 617 & Plate & xyz-CF & $1 \mathrm{E}-03$ & NGNP He & tension & 950 & 1.0 & 0 \\
\hline 76 & Alloy 617 & Plate & xyz-CF & $1 \mathrm{E}-03$ & NGNP He & tension & 950 & 1.0 & 3 \\
\hline 77 & Alloy 617 & Plate & xyz-CF & $1 \mathrm{E}-03$ & NGNP He & tension & 950 & 1.0 & 3 \\
\hline 78 & Alloy 617 & Plate & xyz-CF & $1 \mathrm{E}-03$ & NGNP He & tension & 950 & 1.0 & 3 \\
\hline 79 & Alloy 617 & Plate & xyz-CF & $1 \mathrm{E}-03$ & NGNP He & tension & 950 & 1.0 & 10 \\
\hline
\end{tabular}


Idaho National Laboratory

\begin{tabular}{|c|c|c|c|}
\hline $\begin{array}{l}\text { NEXT GENERATION NUCLEAR PLANT } \\
\text { INTERMEDIATE HEAT EXCHANGER } \\
\text { MATERIALS RESEARCH } \\
\text { AND DEVELOPMENT PLAN }\end{array}$ & $\begin{array}{l}\text { Identifier: } \\
\text { Revision: } \\
\text { Effective Date: }\end{array}$ & $\begin{array}{l}\text { PLN-2804 } \\
0 \\
04 / 30 / 08\end{array}$ & Page: A-95 \\
\hline
\end{tabular}

Table A20. Creep-fatigue Test Matrix to Support Determination of Creep-Fatigue Interaction Diagram

\begin{tabular}{|c|c|c|c|c|c|c|c|c|c|}
\hline $\begin{array}{c}\text { Specimen } \\
\#\end{array}$ & Material & $\begin{array}{c}\text { Product } \\
\text { Form }\end{array}$ & Heat & $\begin{array}{c}\text { Strain Rate } \\
\text { Magnitude } \\
(\mathrm{m} / \mathrm{m} / \mathrm{s})\end{array}$ & Env. & $\begin{array}{c}\text { Hold Time in } \\
\mathrm{T} \text { or } \mathrm{C}\end{array}$ & Temp $\left({ }^{\circ} \mathrm{C}\right)$ & $\begin{array}{c}\text { Strain Range } \\
(\%)\end{array}$ & $\begin{array}{l}\text { Hold Time } \\
(\mathrm{min})\end{array}$ \\
\hline 80 & Alloy 617 & Plate & xyz-CF & $1 \mathrm{E}-03$ & NGNP He & tension & 950 & 1.0 & 10 \\
\hline 81 & Alloy 617 & Plate & xyz-CF & $1 \mathrm{E}-03$ & NGNP He & tension & 950 & 1.0 & 10 \\
\hline 82 & Alloy 617 & Plate & $\mathrm{xyz}-\mathrm{CF}$ & $1 \mathrm{E}-03$ & NGNP He & tension & 950 & 1.0 & 30 \\
\hline 83 & Alloy 617 & Plate & xyz-CF & $1 \mathrm{E}-03$ & NGNP He & tension & 950 & 1.0 & 30 \\
\hline 84 & Alloy 617 & Plate & xyz-CF & $1 \mathrm{E}-03$ & NGNP He & tension & 950 & 1.0 & 30 \\
\hline 85 & Alloy 617 & Plate & xyz-CF & $1 \mathrm{E}-03$ & NGNP He & tension & 950 & 0.3 & 150 \\
\hline 86 & Alloy 617 & Plate & xyz-CF & $1 \mathrm{E}-03$ & NGNP He & tension & 950 & 0.3 & 150 \\
\hline 87 & Alloy 617 & Plate & xyz-CF & $1 \mathrm{E}-03$ & NGNP He & tension & 950 & 0.3 & 150 \\
\hline 88 & Alloy 617 & Plate & xyz-CF & $1 \mathrm{E}-03$ & NGNP He & tension & 950 & 0.3 & 600 \\
\hline 89 & Alloy 617 & Plate & xyz-CF & $1 \mathrm{E}-03$ & NGNP He & tension & 950 & 0.3 & 600 \\
\hline 90 & Alloy 617 & Plate & xyz-CF & $1 \mathrm{E}-03$ & NGNP He & tension & 950 & 0.3 & 600 \\
\hline 91 & Alloy 617 & Plate & xyz-CF & $1 \mathrm{E}-03$ & NGNP He & tension & 950 & 1.0 & 150 \\
\hline 92 & Alloy 617 & Plate & xyz-CF & $1 \mathrm{E}-03$ & NGNP He & tension & 950 & 1.0 & 150 \\
\hline 93 & Alloy 617 & Plate & xyz-CF & $1 \mathrm{E}-03$ & NGNP He & tension & 950 & 1.0 & 150 \\
\hline 94 & Alloy 617 & Plate & xyz-CF & $1 \mathrm{E}-03$ & NGNP He & tension & 950 & 1.0 & 600 \\
\hline 95 & Alloy 617 & Plate & xyz-CF & $1 \mathrm{E}-03$ & NGNP He & tension & 950 & 1.0 & 600 \\
\hline 96 & Alloy 617 & Plate & xyz-CF & $1 \mathrm{E}-03$ & NGNP He & tension & 950 & 1.0 & 600 \\
\hline
\end{tabular}




Idaho National Laboratory
\begin{tabular}{|c|lll|}
\hline NEXT GENERATION NUCLEAR PLANT & Identifier: & PLN-2804 & \\
INTERMEDIATE HEAT EXCHANGER & Revision: & 0 & \\
MATERIALS RESEARCH & Effective Date: & $04 / 30 / 08$ & Page: A-96 of A-114 \\
AND DEVELOPMENT PLAN &
\end{tabular}

\begin{tabular}{|c|c|c|c|c|c|c|c|c|c|c|}
\hline $\begin{array}{l}\text { Specimen } \\
\text { Type }\end{array}$ & Test Type & Spec. \# & Material & Heat & Env. & $\begin{array}{c}\text { Temp } \\
\left({ }^{\circ} \mathrm{C}\right)\end{array}$ & $\begin{array}{c}\text { Spec. Loading } \\
\text { Mode }\end{array}$ & Load & $\begin{array}{c}\text { Biaxial Stress } \\
\text { Ratio }\end{array}$ & $\begin{array}{c}\text { Estimated } \\
\text { Rupture Time (h) }\end{array}$ \\
\hline Prz Tube & Creep Rupture & 1 & Alloy 617 & Heat-abc & air & 950 & Pressure & TBD & 2.0 & TBD \\
\hline Prz Tube & Creep Rupture & 2 & Alloy 617 & Heat-abc & air & 950 & Pressure & TBD & 2.0 & TBD \\
\hline Prz Tube & Creep Rupture & 3 & Alloy 617 & Heat-abc & air & 950 & Pressure & TBD & 2.0 & TBD \\
\hline Tubular & Creep Rupture & 4 & Alloy 617 & Heat-abc & air & 950 & Pressure+Axial & TBD & 1.0 & TBD \\
\hline Tubular & Creep Rupture & 5 & Alloy 617 & Heat-abc & air & 950 & Pressure+Axial & TBD & 1.0 & TBD \\
\hline Tubular & Creep Rupture & 6 & Alloy 617 & Heat-abc & air & 950 & Pressure + Axial & TBD & 1.0 & TBD \\
\hline Tubular & Creep Rupture & 7 & Alloy 617 & Heat-abc & air & 950 & Pressure+Axial & TBD & 0.5 & TBD \\
\hline Tubular & Creep Rupture & 8 & Alloy 617 & Heat-abc & air & 950 & Pressure+Axial & TBD & 0.5 & TBD \\
\hline Tubular & Creep Rupture & 9 & Alloy 617 & Heat-abc & air & 950 & Pressure+Axial & TBD & 0.5 & TBD \\
\hline Bar & Creep Rupture & 10 & Alloy 617 & Heat-abc & air & 950 & Axial & TBD & 0 & TBD \\
\hline Bar & Creep Rupture & 11 & Alloy 617 & Heat-abc & air & 950 & Axial & TBD & 0 & TBD \\
\hline Bar & Creep Rupture & 12 & Alloy 617 & Heat-abc & air & 950 & Axial & TBD & 0 & TBD \\
\hline Tubular & Creep Rupture & 13 & Alloy 617 & Heat-abc & air & 950 & Axial+Torsion & TBD & -0.5 & TBD \\
\hline Tubular & Creep Rupture & 14 & Alloy 617 & Heat-abc & air & 950 & Axial+Torsion & TBD & -0.5 & TBD \\
\hline Tubular & Creep Rupture & 15 & Alloy 617 & Heat-abc & air & 950 & Axial+Torsion & TBD & -0.5 & TBD \\
\hline Tubular & Creep Rupture & 16 & Alloy 617 & Heat-abc & air & 950 & Torsion & TBD & -1 & TBD \\
\hline Tubular & Creep Rupture & 17 & Alloy 617 & Heat-abc & air & 950 & Torsion & TBD & -1 & TBD \\
\hline Tubular & Creep Rupture & 18 & Alloy 617 & Heat-abc & air & 950 & Torsion & TBD & -1 & TBD \\
\hline
\end{tabular}




Idaho National Laboratory
\begin{tabular}{|c|lll|}
\hline NEXT GENERATION NUCLEAR PLANT & Identifier: & PLN-2804 & \\
INTERMEDIATE HEAT EXCHANGER & Revision: & 0 & \\
MATERIALS RESEARCH & Effective Date: & $04 / 30 / 08$ & Page: A-97 of A-114 \\
AND DEVELOPMENT PLAN &
\end{tabular}

\begin{tabular}{|c|c|c|c|c|c|c|c|c|c|c|c|}
\hline \multicolumn{12}{|c|}{ Table A22. Test Matrix for Interrupted Creep Tests } \\
\hline $\begin{array}{c}\text { Specimen } \\
\text { Type }\end{array}$ & $\begin{array}{l}\text { Test } \\
\text { Type }\end{array}$ & $\begin{array}{l}\text { Speci- } \\
\text { men \# }\end{array}$ & Material & $\begin{array}{l}\text { Product } \\
\text { Form }\end{array}$ & Heat & $\begin{array}{c}\text { Environ- } \\
\text { ment }\end{array}$ & $\begin{array}{c}\text { Temp. } \\
{ }^{\circ} \mathrm{C}\end{array}$ & $\begin{array}{l}\text { Applied } \\
\text { Stress } \\
\text { (MPa) }\end{array}$ & $\begin{array}{c}\text { Est. } \\
\text { Rupture } \\
\text { Time (h) }\end{array}$ & $\begin{array}{c}\text { Est. 95\% } \\
\text { Lower Bound } \\
\text { Rupture Time } \\
\text { (h) }\end{array}$ & $\begin{array}{c}\text { Est. 95\% Upper } \\
\text { Bound Rupture } \\
\text { Time (h) }\end{array}$ \\
\hline Tensile & Creep & 1 & Alloy 617 & Plate & xyz-CF & air & 750 & 121 & 5110 & 1313 & 8906 \\
\hline Tensile & Creep & 2 & Alloy 617 & Plate & xyz-CF & air & 750 & 121 & 5110 & 1313 & 8906 \\
\hline Tensile & Creep & 3 & Alloy 617 & Plate & xyz-CF & air & 750 & 121 & 5110 & 1313 & 8906 \\
\hline Tensile & Creep & 4 & Alloy 617 & Plate & xyz-CF & air & 750 & 121 & 5110 & 1313 & 8906 \\
\hline Tensile & Creep & 5 & Alloy 617 & Plate & xyz-CF & air & 750 & 121 & 5110 & 1313 & 8906 \\
\hline Tensile & Creep & 6 & Alloy 617 & Plate & xyz-CF & air & 750 & 121 & 5110 & 1313 & 8906 \\
\hline Tensile & Creep & 7 & Alloy 617 & Plate & xyz-CF & air & 750 & 121 & 5110 & 1313 & 8906 \\
\hline Tensile & Creep & 8 & Alloy 617 & Plate & xyz-CF & air & 750 & 121 & 5110 & 1313 & 8906 \\
\hline Tensile & Creep & 9 & Alloy 617 & Plate & xyz-CF & air & 750 & 121 & 5110 & 1313 & 8906 \\
\hline Tensile & Creep & 10 & Alloy 617 & Plate & xyz-CF & air & 750 & 121 & 5110 & 1313 & 8906 \\
\hline Tensile & Creep & 11 & Alloy 617 & Plate & xyz-CF & air & 750 & 145 & 1665 & 428 & 2902 \\
\hline Tensile & Creep & 12 & Alloy 617 & Plate & xyz-CF & air & 750 & 145 & 1665 & 428 & 2902 \\
\hline Tensile & Creep & 13 & Alloy 617 & Plate & xyz-CF & air & 750 & 145 & 1665 & 428 & 2902 \\
\hline Tensile & Creep & 14 & Alloy 617 & Plate & xyz-CF & air & 750 & 145 & 1665 & 428 & 2902 \\
\hline Tensile & Creep & 15 & Alloy 617 & Plate & xyz-CF & air & 750 & 145 & 1665 & 428 & 2902 \\
\hline Tensile & Creep & 16 & Alloy 617 & Plate & xyz-CF & air & 750 & 145 & 1665 & 428 & 2902 \\
\hline Tensile & Creep & 17 & Alloy 617 & Plate & xyz-CF & air & 750 & 145 & 1665 & 428 & 2902 \\
\hline Tensile & Creep & 18 & Alloy 617 & Plate & xyz-CF & air & 750 & 145 & 1665 & 428 & 2902 \\
\hline Tensile & Creep & 19 & Alloy 617 & Plate & xyz-CF & air & 750 & 145 & 1665 & 428 & 2902 \\
\hline Tensile & Creep & 20 & Alloy 617 & Plate & xyz-CF & air & 750 & 145 & 1665 & 428 & 2902 \\
\hline & & & & & & & & & & & \\
\hline Tensile & Creep & 21 & Alloy 617 & Plate & xyz-CF & air & 1000 & 16 & 5000 & 1285 & 8715 \\
\hline Tensile & Creep & 22 & Alloy 617 & Plate & xyz-CF & air & 1000 & 16 & 5000 & 1285 & 8715 \\
\hline Tensile & Creep & 23 & Alloy 617 & Plate & xyz-CF & air & 1000 & 16 & 5000 & 1285 & 8715 \\
\hline Tensile & Creep & 24 & Alloy 617 & Plate & xyz-CF & air & 1000 & 16 & 5000 & 1285 & 8715 \\
\hline
\end{tabular}


Idaho National Laboratory

\begin{tabular}{|c|c|c|c|}
\hline $\begin{array}{l}\text { NEXT GENERATION NUCLEAR PLANT } \\
\text { INTERMEDIATE HEAT EXCHANGER } \\
\text { MATERIALS RESEARCH } \\
\text { AND DEVELOPMENT PLAN }\end{array}$ & $\begin{array}{l}\text { Identifier: } \\
\text { Revision: } \\
\text { Effective Date: }\end{array}$ & $\begin{array}{l}\text { PLN-2804 } \\
0 \\
04 / 30 / 08\end{array}$ & Page: A-98 of \\
\hline
\end{tabular}

\begin{tabular}{|c|c|c|c|c|c|c|c|c|c|c|c|}
\hline \multicolumn{12}{|c|}{ Table A22. Test Matrix for Interrupted Creep Tests } \\
\hline $\begin{array}{c}\text { Specimen } \\
\text { Type }\end{array}$ & $\begin{array}{c}\text { Test } \\
\text { Type }\end{array}$ & $\begin{array}{l}\text { Speci- } \\
\text { men \# }\end{array}$ & Material & $\begin{array}{c}\text { Product } \\
\text { Form }\end{array}$ & Heat & $\begin{array}{c}\text { Environ- } \\
\text { ment }\end{array}$ & $\begin{array}{l}\text { Temp. } \\
{ }^{\circ} \mathrm{C}\end{array}$ & $\begin{array}{l}\text { Applied } \\
\text { Stress } \\
(\mathrm{MPa})\end{array}$ & $\begin{array}{c}\text { Est. } \\
\text { Rupture } \\
\text { Time (h) }\end{array}$ & $\begin{array}{c}\text { Est. 95\% } \\
\text { Lower Bound } \\
\text { Rupture Time } \\
\text { (h) }\end{array}$ & $\begin{array}{c}\text { Est. } 95 \% \text { Upper } \\
\text { Bound Rupture } \\
\text { Time }(\mathrm{h})\end{array}$ \\
\hline Tensile & Creep & 25 & Alloy 617 & Plate & xyz-CF & air & 1000 & 16 & 5000 & 1285 & 8715 \\
\hline Tensile & Creep & 26 & Alloy 617 & Plate & xyz-CF & air & 1000 & 16 & 5000 & 1285 & 8715 \\
\hline Tensile & Creep & 27 & Alloy 617 & Plate & xyz-CF & air & 1000 & 16 & 5000 & 1285 & 8715 \\
\hline Tensile & Creep & 28 & Alloy 617 & Plate & xyz-CF & air & 1000 & 16 & 5000 & 1285 & 8715 \\
\hline Tensile & Creep & 29 & Alloy 617 & Plate & xyz-CF & air & 1000 & 16 & 5000 & 1285 & 8715 \\
\hline Tensile & Creep & 30 & Alloy 617 & Plate & xyz-CF & air & 1000 & 16 & 5000 & 1285 & 8715 \\
\hline Tensile & Creep & 31 & Alloy 617 & Plate & xyz-CF & air & 1000 & 20 & 1733 & 446 & 3021 \\
\hline Tensile & Creep & 32 & Alloy 617 & Plate & xyz-CF & air & 1000 & 20 & 1733 & 446 & 3021 \\
\hline Tensile & Creep & 33 & Alloy 617 & Plate & xyz-CF & air & 1000 & 20 & 1733 & 446 & 3021 \\
\hline Tensile & Creep & 34 & Alloy 617 & Plate & xyz-CF & air & 1000 & 20 & 1733 & 446 & 3021 \\
\hline Tensile & Creep & 35 & Alloy 617 & Plate & xyz-CF & air & 1000 & 20 & 1733 & 446 & 3021 \\
\hline Tensile & Creep & 36 & Alloy 617 & Plate & xyz-CF & air & 1000 & 20 & 1733 & 446 & 3021 \\
\hline Tensile & Creep & 37 & Alloy 617 & Plate & xyz-CF & air & 1000 & 20 & 1733 & 446 & 3021 \\
\hline Tensile & Creep & 38 & Alloy 617 & Plate & xyz-CF & air & 1000 & 20 & 1733 & 446 & 3021 \\
\hline Tensile & Creep & 39 & Alloy 617 & Plate & xyz-CF & air & 1000 & 20 & 1733 & 446 & 3021 \\
\hline Tensile & Creep & 40 & Alloy 617 & Plate & xyz-CF & air & 1000 & 20 & 1733 & 446 & 3021 \\
\hline
\end{tabular}




Idaho National Laboratory
\begin{tabular}{|c|lll|}
\hline NEXT GENERATION NUCLEAR PLANT & Identifier: & PLN-2804 & \\
INTERMEDIATE HEAT EXCHANGER & Revision: & 0 & \\
MATERIALS RESEARCH & Effective Date: & $04 / 30 / 08$ & Page: A-99 of A-114 \\
AND DEVELOPMENT PLAN &
\end{tabular}

\begin{tabular}{|c|c|c|c|c|c|c|c|c|c|}
\hline \multicolumn{10}{|c|}{ Table A23. Test Matrix to Address Creep-Fatigue Saturation with Hold Time } \\
\hline $\begin{array}{c}\text { Specimen } \\
\#\end{array}$ & Material & $\begin{array}{l}\text { Product } \\
\text { Form }\end{array}$ & Heat & $\begin{array}{c}\text { Strain Rate } \\
(\mathrm{m} / \mathrm{m} / \mathrm{s})\end{array}$ & Environment & $\begin{array}{c}\text { Hold Time in } \\
\mathrm{T} \text { or } \mathrm{C}\end{array}$ & $\begin{array}{l}\text { Temp } \\
\left({ }^{\circ} \mathrm{C}\right)\end{array}$ & $\begin{array}{c}\text { Strain } \\
\text { Range (\%) }\end{array}$ & $\begin{array}{l}\text { Hold Time } \\
(\mathrm{min})\end{array}$ \\
\hline 1 & Alloy 617 & Plate & xyz-CF & $1 \mathrm{E}-03$ & air & tension & 1000 & 0.3 & 0 \\
\hline 2 & Alloy 617 & Plate & xyz-CF & $1 \mathrm{E}-03$ & air & tension & 1000 & 0.3 & 0 \\
\hline 3 & Alloy 617 & Plate & xyz-CF & $1 \mathrm{E}-03$ & air & tension & 1000 & 0.3 & 0 \\
\hline 4 & Alloy 617 & Plate & xyz-CF & $1 \mathrm{E}-03$ & air & tension & 1000 & 0.3 & 150 \\
\hline 5 & Alloy 617 & Plate & xyz-CF & $1 \mathrm{E}-03$ & air & tension & 1000 & 0.3 & 150 \\
\hline 6 & Alloy 617 & Plate & xyz-CF & $1 \mathrm{E}-03$ & air & tension & 1000 & 0.3 & 150 \\
\hline 7 & Alloy 617 & Plate & xyz-CF & $1 \mathrm{E}-03$ & air & tension & 1000 & 0.3 & 600 \\
\hline 8 & Alloy 617 & Plate & xyz-CF & $1 \mathrm{E}-03$ & air & tension & 1000 & 0.3 & 600 \\
\hline 9 & Alloy 617 & Plate & xyz-CF & $1 \mathrm{E}-03$ & air & tension & 1000 & 0.3 & 600 \\
\hline 10 & Alloy 617 & Plate & xyz-CF & $1 \mathrm{E}-03$ & air & tension & 1000 & 1.0 & 0 \\
\hline 11 & Alloy 617 & Plate & xyz-CF & $1 \mathrm{E}-03$ & air & tension & 1000 & 1.0 & 0 \\
\hline 12 & Alloy 617 & Plate & xyz-CF & $1 \mathrm{E}-03$ & air & tension & 1000 & 1.0 & 0 \\
\hline 13 & Alloy 617 & Plate & xyz-CF & $1 \mathrm{E}-03$ & air & tension & 1000 & 1.0 & 150 \\
\hline 14 & Alloy 617 & Plate & xyz-CF & $1 \mathrm{E}-03$ & air & tension & 1000 & 1.0 & 150 \\
\hline 15 & Alloy 617 & Plate & xyz-CF & $1 \mathrm{E}-03$ & air & tension & 1000 & 1.0 & 150 \\
\hline 16 & Alloy 617 & Plate & xyz-CF & $1 \mathrm{E}-03$ & air & tension & 1000 & 1.0 & 600 \\
\hline 17 & Alloy 617 & Plate & xyz-CF & $1 \mathrm{E}-03$ & air & tension & 1000 & 1.0 & 600 \\
\hline 18 & Alloy 617 & Plate & xyz-CF & $1 \mathrm{E}-03$ & air & tension & 1000 & 1.0 & 600 \\
\hline
\end{tabular}




Idaho National Laboratory
\begin{tabular}{|c|lll|}
\hline NEXT GENERATION NUCLEAR PLANT & Identifier: & PLN-2804 & \\
INTERMEDIATE HEAT EXCHANGER & Revision: & 0 & \\
MATERIALS RESEARCH & Effective Date: & $04 / 30 / 08$ & Page: A-100 of A-114 \\
AND DEVELOPMENT PLAN & &
\end{tabular}

\begin{tabular}{|c|c|c|c|c|c|c|c|}
\hline Spec. Type & Test Type & Spec. \# & Material & ASTM GS \# & Temp. ${ }^{\circ} \mathrm{C}$ & Stress (MPa) & Creep Duration (h) \\
\hline Tensile & Creep & 1 & Alloy 617 & 0 to 1 & 850 & 10 & 100 \\
\hline Tensile & Creep & 2 & Alloy 617 & 0 to 1 & 950 & 10 & 100 \\
\hline Tensile & Creep & 3 & Alloy 617 & 0 to 1 & 1050 & 10 & 100 \\
\hline Tensile & Creep & 4 & Alloy 617 & 0 to 1 & 850 & 5 & 1000 \\
\hline Tensile & Creep & 5 & Alloy 617 & 0 to 1 & 950 & 5 & 500 \\
\hline Tensile & Creep & 6 & Alloy 617 & 0 to 1 & 1050 & 5 & 300 \\
\hline Tensile & Creep & 7 & Alloy 617 & 2 to 3 & 850 & 10 & 100 \\
\hline Tensile & Creep & 8 & Alloy 617 & 2 to 3 & 950 & 10 & 100 \\
\hline Tensile & Creep & 9 & Alloy 617 & 2 to 3 & 1050 & 10 & 100 \\
\hline Tensile & Creep & 10 & Alloy 617 & 2 to 3 & 850 & 5 & 1000 \\
\hline Tensile & Creep & 11 & Alloy 617 & 2 to 3 & 950 & 5 & 500 \\
\hline Tensile & Creep & 12 & Alloy 617 & 2 to 3 & 1050 & 5 & 300 \\
\hline Tensile & Creep & 13 & Alloy 617 & 4.5 & 850 & 10 & 100 \\
\hline Tensile & Creep & 14 & Alloy 617 & 4.5 & 950 & 10 & 100 \\
\hline Tensile & Creep & 15 & Alloy 617 & 4.5 & 1050 & 10 & 100 \\
\hline Tensile & Creep & 16 & Alloy 617 & 4.5 & 850 & 5 & 1000 \\
\hline Tensile & Creep & 17 & Alloy 617 & 4.5 & 950 & 5 & 500 \\
\hline Tensile & Creep & 18 & Alloy 617 & 4.5 & 1050 & 5 & 300 \\
\hline Tensile & Creep & 19 & Alloy 617 & 8 & 850 & 10 & 100 \\
\hline Tensile & Creep & 20 & Alloy 617 & 8 & 950 & 10 & 100 \\
\hline Tensile & Creep & 21 & Alloy 617 & 8 & 1050 & 10 & 100 \\
\hline Tensile & Creep & 22 & Alloy 617 & 8 & 850 & 5 & 1000 \\
\hline Tensile & Creep & 23 & Alloy 617 & 8 & 950 & 5 & 500 \\
\hline Tensile & Creep & 24 & Alloy 617 & 8 & 1050 & 5 & 300 \\
\hline Tensile & Creep/Stress Jump/Creep & 25 & Alloy 617 & 2 to 3 & 850 & $5 / 10 / 15 / 20$ & 1000 to 1000 \\
\hline Tensile & Creep/Stress Jump/Creep & 26 & Alloy 617 & 2 to 3 & 1050 & $5 / 10 / 15 / 20$ & 500 to 100 \\
\hline Tensile & Creep/Stress Jump/Creep & 27 & Alloy 617 & 8 & 850 & $5 / 10 / 15 / 20$ & 500 to 100 \\
\hline Tensile & Creep/Stress Jump/Creep & 28 & Alloy 617 & 8 & 1050 & $5 / 10 / 15 / 20$ & 300 to 100 \\
\hline
\end{tabular}




Idaho National Laboratory
\begin{tabular}{|c|lll|}
\hline NEXT GENERATION NUCLEAR PLANT & Identifier: & PLN-2804 & \\
INTERMEDIATE HEAT EXCHANGER & Revision: & 0 & \\
MATERIALS RESEARCH & Effective Date: & $04 / 30 / 08$ & Page: A-101 of A-114 \\
AND DEVELOPMENT PLAN &
\end{tabular}

\begin{tabular}{|c|c|c|c|c|c|c|c|c|c|c|c|c|c|c|}
\hline $\begin{array}{c}\text { Test } \\
\text { Prgm } \\
\end{array}$ & $\begin{array}{l}\text { Spec. } \\
\text { Type }\end{array}$ & Test Type & $\begin{array}{c}\text { Spec } \\
\#\end{array}$ & Matl & Heat & Env. & $\begin{array}{c}\text { ASTM } \\
\text { GS } \\
\text { No. }\end{array}$ & $\begin{array}{c}\text { Avg } \\
\text { GS } \\
(\mu \mathrm{m})\end{array}$ & $\begin{array}{l}\text { Temp. } \\
\left({ }^{\circ} \mathrm{C}\right)\end{array}$ & $\begin{array}{l}\text { App. } \\
\text { Stress } \\
\text { (MPa) }\end{array}$ & $\begin{array}{c}\text { Assumed } \\
\text { GS } \\
\text { Rupture } \\
\text { Factor } \\
\end{array}$ & $\begin{array}{l}\text { Est. 95\% } \\
\text { Lower } \\
\text { Bound } \\
\text { Rupture } \\
\text { Time (h) } \\
\end{array}$ & $\begin{array}{l}\text { Best Est. } \\
\text { Rupture } \\
\text { Time (h) }\end{array}$ & $\begin{array}{c}\text { Est. 95\% } \\
\text { Upper } \\
\text { Bound } \\
\text { Rupture } \\
\text { Time (h) }\end{array}$ \\
\hline GS & Tensile & Crp Rupture & 1 & A617 & pqr & air & 1.5 & 200 & 800 & 80.0 & 1.00 & 814 & 5870 & 10925 \\
\hline GS & Tensile & Crp Rupture & 2 & A617 & $\mathrm{pqr}$ & air & 1.5 & 200 & 800 & 80.0 & 1.00 & 814 & 5870 & 10925 \\
\hline GS & Tensile & Crp Rupture & 3 & A617 & pqr & air & 1.5 & 200 & 800 & 73.0 & 1.00 & 1392 & 10032 & 18672 \\
\hline GS & Tensile & Crp Rupture & 4 & A617 & pqr & air & 1.5 & 200 & 800 & 73.0 & 1.00 & 1392 & 10032 & 18672 \\
\hline GS & Tensile & Crp Rupture & 5 & A617 & $\mathrm{pqr}$ & air & 1.5 & 200 & 800 & 67.0 & 1.00 & 2299 & 16573 & 30846 \\
\hline GS & Tensile & Crp Rupture & 6 & A617 & pqr & air & 1.5 & 200 & 800 & 67.0 & 1.00 & 2299 & 16573 & 30846 \\
\hline GS & Tensile & Crp Rupture & 7 & A617 & $\mathrm{pqr}$ & air & 1.5 & 200 & 900 & 36.0 & 1.00 & 836 & 5653 & 10471 \\
\hline GS & Tensile & Crp Rupture & 8 & A617 & $\mathrm{pqr}$ & air & 1.5 & 200 & 900 & 36.0 & 1.00 & 836 & 5653 & 10471 \\
\hline GS & Tensile & Crp Rupture & 9 & A617 & pqr & air & 1.5 & 200 & 900 & 32.0 & 1.00 & 1551 & 10494 & 19437 \\
\hline GS & Tensile & Crp Rupture & 10 & A617 & $\mathrm{pqr}$ & air & 1.5 & 200 & 900 & 32.0 & 1.00 & 1551 & 10494 & 19437 \\
\hline GS & Tensile & Crp Rupture & 11 & A617 & pqr & air & 1.5 & 200 & 900 & 29.0 & 1.00 & 2601 & 17598 & 32595 \\
\hline GS & Tensile & Crp Rupture & 12 & A617 & pqr & air & 1.5 & 200 & 900 & 29.0 & 1.00 & 2601 & 17598 & 32595 \\
\hline GS & Tensile & Crp Rupture & 13 & A617 & $\mathrm{pqr}$ & air & 1.5 & 200 & 1000 & 16.0 & 1.00 & 779 & 4998 & 9216 \\
\hline GS & Tensile & Crp Rupture & 14 & A617 & $\mathrm{pqr}$ & air & 1.5 & 200 & 1000 & 16.0 & 1.00 & 779 & 4998 & 9216 \\
\hline GS & Tensile & Crp Rupture & 15 & A617 & $\mathrm{pqr}$ & air & 1.5 & 200 & 1000 & 14.0 & 1.00 & 1468 & 9417 & 17367 \\
\hline GS & Tensile & Crp Rupture & 16 & $\mathrm{~A} 617$ & $\mathrm{pqr}$ & air & 1.5 & 200 & 1000 & 14.0 & 1.00 & 1468 & 9417 & 17367 \\
\hline GS & Tensile & Crp Rupture & 17 & A617 & pqr & air & 1.5 & 200 & 1000 & 12.0 & 1.00 & 3051 & 19570 & 36089 \\
\hline GS & Tensile & Crp Rupture & 18 & A617 & $\mathrm{pqr}$ & air & 1.5 & 200 & 1000 & 12.0 & 1.00 & 3051 & 19570 & 36089 \\
\hline GS & Strip & Crp Rupture & 19 & A617 & $\mathrm{pqr}$ & air & 3.5 & 110 & 800 & 80.0 & 0.90 & 814 & 3168 & 5522 \\
\hline GS & Strip & Crp Rupture & 20 & A617 & pqr & air & 3.5 & 110 & 800 & 80.0 & 0.90 & 814 & 3168 & 5522 \\
\hline GS & Strip & Crp Rupture & 21 & A617 & $\mathrm{pqr}$ & air & 3.5 & 110 & 800 & 73.0 & 0.90 & 1392 & 5414 & 9437 \\
\hline GS & Strip & Crp Rupture & 22 & A617 & $\mathrm{pqr}$ & air & 3.5 & 110 & 800 & 73.0 & 0.90 & 1392 & 5414 & 9437 \\
\hline GS & Strip & Crp Rupture & 23 & A617 & $\mathrm{pqr}$ & air & 3.5 & 110 & 800 & 67.0 & 0.90 & 2299 & 8945 & 15590 \\
\hline GS & Strip & Crp Rupture & 24 & A617 & pqr & air & 3.5 & 110 & 800 & 67.0 & 0.90 & 2299 & 8945 & 15590 \\
\hline
\end{tabular}


Idaho National Laboratory

\begin{tabular}{|c|c|c|c|}
\hline $\begin{array}{l}\text { NEXT GENERATION NUCLEAR PLANT } \\
\text { INTERMEDIATE HEAT EXCHANGER } \\
\text { MATERIALS RESEARCH } \\
\text { AND DEVELOPMENT PLAN }\end{array}$ & $\begin{array}{l}\text { Identifier: } \\
\text { Revision: } \\
\text { Effective Date: }\end{array}$ & $\begin{array}{l}\text { PLN-2804 } \\
0 \\
04 / 30 / 08\end{array}$ & Page: A \\
\hline
\end{tabular}

Table A25. Test Matrix for Determining Grain Size Rupture Factors for Alloy 617

\begin{tabular}{|c|c|c|c|c|c|c|c|c|c|c|c|c|c|c|}
\hline $\begin{array}{c}\text { Test } \\
\text { Prgm }\end{array}$ & $\begin{array}{l}\text { Spec. } \\
\text { Type }\end{array}$ & Test Type & $\begin{array}{c}\text { Spec } \\
\# \\
\end{array}$ & Matl & Heat & Env. & $\begin{array}{c}\text { ASTM } \\
\text { GS } \\
\text { No. }\end{array}$ & $\begin{array}{c}\text { Avg } \\
\text { GS } \\
(\mu \mathrm{m})\end{array}$ & $\begin{array}{c}\text { Temp. } \\
\left({ }^{\circ} \mathrm{C}\right)\end{array}$ & $\begin{array}{c}\text { App. } \\
\text { Stress } \\
(\mathrm{MPa})\end{array}$ & $\begin{array}{c}\text { Assumed } \\
\text { GS } \\
\text { Rupture } \\
\text { Factor }\end{array}$ & $\begin{array}{c}\text { Est. } 95 \% \\
\text { Lower } \\
\text { Bound } \\
\text { Rupture } \\
\text { Time (h) }\end{array}$ & $\begin{array}{l}\text { Best Est. } \\
\text { Rupture } \\
\text { Time (h) }\end{array}$ & $\begin{array}{c}\text { Est. 95\% } \\
\text { Upper } \\
\text { Bound } \\
\text { Rupture } \\
\text { Time (h) }\end{array}$ \\
\hline GS & Strip & Crp Rupture & 25 & A617 & pqr & air & 3.5 & 110 & 900 & 36.0 & 0.90 & 836 & 3251 & 5666 \\
\hline GS & Strip & Crp Rupture & 26 & A617 & pqr & air & 3.5 & 110 & 900 & 36.0 & 0.90 & 836 & 3251 & 5666 \\
\hline GS & Strip & Crp Rupture & 27 & A617 & pqr & air & 3.5 & 110 & 900 & 32.0 & 0.90 & 1551 & 6034 & 10518 \\
\hline GS & Strip & Crp Rupture & 28 & A617 & pqr & air & 3.5 & 110 & 900 & 32.0 & 0.90 & 1551 & 6034 & 10518 \\
\hline GS & Strip & Crp Rupture & 29 & A617 & $\mathrm{pqr}$ & air & 3.5 & 110 & 900 & 29.0 & 0.90 & 2601 & 10119 & 17638 \\
\hline GS & Strip & Crp Rupture & 30 & A617 & $\mathrm{pqr}$ & air & 3.5 & 110 & 900 & 29.0 & 0.90 & 2601 & 10119 & 17638 \\
\hline GS & Strip & Crp Rupture & 31 & A617 & pqr & air & 3.5 & 110 & 1000 & 16.0 & 0.90 & 779 & 3031 & 5284 \\
\hline GS & Strip & Crp Rupture & 32 & A617 & pqr & air & 3.5 & 110 & 1000 & 16.0 & 0.90 & 779 & 3031 & 5284 \\
\hline GS & Strip & Crp Rupture & 33 & A617 & pqr & air & 3.5 & 110 & 1000 & 14.0 & 0.90 & 1468 & 5712 & 9956 \\
\hline GS & Strip & Crp Rupture & 34 & A617 & pqr & air & 3.5 & 110 & 1000 & 14.0 & 0.90 & 1468 & 5712 & 9956 \\
\hline GS & Strip & Crp Rupture & 35 & A617 & $\mathrm{pqr}$ & air & 3.5 & 110 & 1000 & 12.0 & 0.90 & 3051 & 11871 & 20690 \\
\hline GS & Strip & Crp Rupture & 36 & A617 & pqr & air & 3.5 & 110 & 1000 & 12.0 & 0.90 & 3051 & 11871 & 20690 \\
\hline GS & Strip & Crp Rupture & 37 & A617 & pqr & air & 4.5 & 75 & 800 & 80.0 & 0.80 & 121 & 1590 & 3059 \\
\hline GS & Strip & Crp Rupture & 38 & A617 & pqr & air & 4.5 & 75 & 800 & 80.0 & 0.80 & 121 & 1590 & 3059 \\
\hline GS & Strip & Crp Rupture & 39 & A617 & pqr & air & 4.5 & 75 & 800 & 73.0 & 0.80 & 207 & 2717 & 5228 \\
\hline GS & Strip & Crp Rupture & 40 & A617 & pqr & air & 4.5 & 75 & 800 & 73.0 & 0.80 & 207 & 2717 & 5228 \\
\hline GS & Strip & Crp Rupture & 41 & A617 & $\mathrm{pqr}$ & air & 4.5 & 75 & 800 & 67.0 & 0.80 & 342 & 4489 & 8636 \\
\hline GS & Strip & Crp Rupture & 42 & A617 & $\mathrm{pqr}$ & air & 4.5 & 75 & 800 & 67.0 & 0.80 & 342 & 4489 & 8636 \\
\hline GS & Strip & Crp Rupture & 43 & A617 & pqr & air & 4.5 & 75 & 900 & 36.0 & 0.80 & 151 & 1751 & 3351 \\
\hline GS & Strip & Crp Rupture & 44 & A617 & pqr & air & 4.5 & 75 & 900 & 36.0 & 0.80 & 151 & 1751 & 3351 \\
\hline GS & Strip & Crp Rupture & 45 & A617 & pqr & air & 4.5 & 75 & 900 & 32.0 & 0.80 & 281 & 3251 & 6221 \\
\hline GS & Strip & Crp Rupture & 46 & A617 & pqr & air & 4.5 & 75 & 900 & 32.0 & 0.80 & 281 & 3251 & 6221 \\
\hline GS & Strip & Crp Rupture & 47 & A617 & pqr & air & 4.5 & 75 & 900 & 29.0 & 0.80 & 471 & 5451 & 10432 \\
\hline GS & Strip & Crp Rupture & 48 & A617 & pqr & air & 4.5 & 75 & 900 & 29.0 & 0.80 & 471 & 5451 & 10432 \\
\hline GS & Strip & Crp Rupture & 49 & A617 & pqr & air & 4.5 & 75 & 1000 & 16.0 & 0.80 & 166 & 1733 & 3301 \\
\hline
\end{tabular}


Idaho National Laboratory

\begin{tabular}{|c|c|c|c|}
\hline $\begin{array}{l}\text { NEXT GENERATION NUCLEAR PLANT } \\
\text { INTERMEDIATE HEAT EXCHANGER } \\
\text { MATERIALS RESEARCH } \\
\text { AND DEVELOPMENT PLAN }\end{array}$ & $\begin{array}{l}\text { Identifier: } \\
\text { Revision: } \\
\text { Effective Date: }\end{array}$ & $\begin{array}{l}\text { PLN-2804 } \\
0 \\
04 / 30 / 08\end{array}$ & Page: A-103 \\
\hline
\end{tabular}

\begin{tabular}{|c|c|c|c|c|c|c|c|c|c|c|c|c|c|c|}
\hline $\begin{array}{c}\text { Test } \\
\text { Prgm }\end{array}$ & $\begin{array}{l}\text { Spec. } \\
\text { Type }\end{array}$ & Test Type & $\begin{array}{c}\text { Spec } \\
\#\end{array}$ & Matl & Heat & Env. & $\begin{array}{c}\text { ASTM } \\
\text { GS } \\
\text { No. }\end{array}$ & $\begin{array}{c}\text { Avg } \\
\text { GS } \\
(\mu \mathrm{m})\end{array}$ & $\begin{array}{c}\text { Temp. } \\
\left({ }^{\circ} \mathrm{C}\right)\end{array}$ & $\begin{array}{l}\text { App. } \\
\text { Stress } \\
(\mathrm{MPa})\end{array}$ & $\begin{array}{c}\text { Assumed } \\
\text { GS } \\
\text { Rupture } \\
\text { Factor }\end{array}$ & $\begin{array}{c}\text { Est. 95\% } \\
\text { Lower } \\
\text { Bound } \\
\text { Rupture } \\
\text { Time (h) }\end{array}$ & $\begin{array}{l}\text { Best Est. } \\
\text { Rupture } \\
\text { Time (h) }\end{array}$ & $\begin{array}{c}\text { Est. 95\% } \\
\text { Upper } \\
\text { Bound } \\
\text { Rupture } \\
\text { Time (h) }\end{array}$ \\
\hline GS & Strip & Crp Rupture & 50 & A617 & pqr & air & 4.5 & 75 & 1000 & 16.0 & 0.80 & 166 & 1733 & 3301 \\
\hline GS & Strip & Crp Rupture & 51 & A617 & pqr & air & 4.5 & 75 & 1000 & 14.0 & 0.80 & 313 & 3267 & 6220 \\
\hline GS & Strip & Crp Rupture & 52 & A617 & pqr & air & 4.5 & 75 & 1000 & 14.0 & 0.80 & 313 & 3267 & 6220 \\
\hline GS & Strip & Crp Rupture & 53 & A617 & pqr & air & 4.5 & 75 & 1000 & 12.0 & 0.80 & 651 & 6788 & 12925 \\
\hline GS & strip & Crp Rupture & 54 & A617 & pqr & air & 4.5 & 75 & 1000 & 12.0 & 0.80 & 651 & 6788 & 12925 \\
\hline GS & Foil & Crp Rupture & 55 & A617 & pqr & air & 8 & 22 & 800 & 80.0 & 0.65 & 121 & 472 & 822 \\
\hline GS & Foil & Crp Rupture & 56 & A617 & pqr & air & 8 & 22 & 800 & 80.0 & 0.65 & 121 & 472 & 822 \\
\hline GS & Foil & Crp Rupture & 57 & A617 & pqr & air & 8 & 22 & 800 & 73.0 & 0.65 & 207 & 806 & 1405 \\
\hline GS & Foil & Crp Rupture & 58 & A617 & pqr & air & 8 & 22 & 800 & 73.0 & 0.65 & 207 & 806 & 1405 \\
\hline GS & Foil & Crp Rupture & 59 & A617 & pqr & air & 8 & 22 & 800 & 67.0 & 0.65 & 342 & 1332 & 2321 \\
\hline GS & Foil & Crp Rupture & 60 & A617 & pqr & air & 8 & 22 & 800 & 67.0 & 0.65 & 342 & 1332 & 2321 \\
\hline GS & Foil & Crp Rupture & 61 & A617 & pqr & air & 8 & 22 & 900 & 36.0 & 0.65 & 151 & 589 & 1026 \\
\hline GS & Foil & Crp Rupture & 62 & A617 & pqr & air & 8 & 22 & 900 & 36.0 & 0.65 & 151 & 589 & 1026 \\
\hline GS & Foil & Crp Rupture & 63 & A617 & pqr & air & 8 & 22 & 900 & 32.0 & 0.65 & 281 & 1092 & 1904 \\
\hline GS & Foil & Crp Rupture & 64 & A617 & pqr & air & 8 & 22 & 900 & 32.0 & 0.65 & 281 & 1092 & 1904 \\
\hline GS & Foil & Crp Rupture & 65 & A617 & pqr & air & 8 & 22 & 900 & 29.0 & 0.65 & 471 & 1832 & 3193 \\
\hline GS & Foil & Crp Rupture & 66 & A617 & pqr & air & 8 & 22 & 900 & 29.0 & 0.65 & 471 & 1832 & 3193 \\
\hline GS & Foil & Crp Rupture & 67 & A617 & pqr & air & 8 & 22 & 1000 & 16.0 & 0.65 & 166 & 647 & 1128 \\
\hline GS & Foil & Crp Rupture & 68 & A617 & pqr & air & 8 & 22 & 1000 & 16.0 & 0.65 & 166 & 647 & 1128 \\
\hline GS & Foil & Crp Rupture & 69 & A617 & pqr & air & 8 & 22 & 1000 & 14.0 & 0.65 & 313 & 1220 & 2126 \\
\hline GS & Foil & Crp Rupture & 70 & A617 & pqr & air & 8 & 22 & 1000 & 14.0 & 0.65 & 313 & 1220 & 2126 \\
\hline GS & Foil & Crp Rupture & 71 & A617 & pqr & air & 8 & 22 & 1000 & 12.0 & 0.65 & 651 & 2534 & 4417 \\
\hline GS & Foil & Crp Rupture & 72 & A617 & pqr & air & 8 & 22 & 1000 & 12.0 & 0.65 & 651 & 2534 & 4417 \\
\hline
\end{tabular}




Idaho National Laboratory
\begin{tabular}{|c|lll|}
\hline NEXT GENERATION NUCLEAR PLANT & Identifier: & PLN-2804 & \\
INTERMEDIATE HEAT EXCHANGER & Revision: & 0 & \\
MATERIALS RESEARCH & Effective Date: & $04 / 30 / 08$ & Page: A-104 of A-114 \\
AND DEVELOPMENT PLAN & &
\end{tabular}

\begin{tabular}{|c|c|c|c|c|c|c|c|}
\hline \multicolumn{8}{|c|}{ Table A26. Tensile Tests Supporting Unified Constitutive Model for Alloy $800 \mathrm{H}$} \\
\hline Test Type & Spec. Type & Spec. \# & Material & Product Form & Heat \# & Env. & Test Temp. $\left({ }^{\circ} \mathrm{C}\right)$ \\
\hline Strain Rate Change & Tensile & 1 & Alloy $800 \mathrm{H}$ & Plate & heat-1 & Air & 550 \\
\hline Strain Rate Change & Tensile & 2 & Alloy $800 \mathrm{H}$ & Plate & heat-1 & Air & 550 \\
\hline Stress Dip & Tensile & 3 & Alloy $800 \mathrm{H}$ & Plate & heat-1 & Air & 550 \\
\hline Stress Dip & Tensile & 4 & Alloy $800 \mathrm{H}$ & Plate & heat-1 & Air & 550 \\
\hline Loading/Unloading/Creep & Tensile & 5 & Alloy $800 \mathrm{H}$ & Plate & heat-1 & Air & 550 \\
\hline Loading/Unloading/Creep & Tensile & 6 & Alloy $800 \mathrm{H}$ & Plate & heat-1 & Air & 550 \\
\hline Uniaxial Ratchetting & Tensile & 7 & Alloy $800 \mathrm{H}$ & Plate & heat-1 & Air & 550 \\
\hline Uniaxial Ratchetting & Tensile & 8 & Alloy $800 \mathrm{H}$ & Plate & heat-1 & Air & 550 \\
\hline Strain Rate Change & Tensile & 9 & Alloy $800 \mathrm{H}$ & Plate & heat-1 & Air & 650 \\
\hline Strain Rate Change & Tensile & 10 & Alloy $800 \mathrm{H}$ & Plate & heat-1 & Air & 650 \\
\hline Stress Dip & Tensile & 11 & Alloy $800 \mathrm{H}$ & Plate & heat-1 & Air & 650 \\
\hline Stress Dip & Tensile & 12 & Alloy $800 \mathrm{H}$ & Plate & heat-1 & Air & 650 \\
\hline Loading/Unloading/Creep & Tensile & 13 & Alloy $800 \mathrm{H}$ & Plate & heat-1 & Air & 650 \\
\hline Loading/Unloading/Creep & Tensile & 14 & Alloy $800 \mathrm{H}$ & Plate & heat-1 & Air & 650 \\
\hline Uniaxial Ratchetting & Tensile & 15 & Alloy $800 \mathrm{H}$ & Plate & heat-1 & Air & 650 \\
\hline Uniaxial Ratchetting & Tensile & 16 & Alloy $800 \mathrm{H}$ & Plate & heat-1 & Air & 650 \\
\hline Strain Rate Change & Tensile & 17 & Alloy $800 \mathrm{H}$ & Plate & heat-1 & Air & 750 \\
\hline Strain Rate Change & Tensile & 18 & Alloy $800 \mathrm{H}$ & Plate & heat-1 & Air & 750 \\
\hline Stress Dip & Tensile & 19 & Alloy $800 \mathrm{H}$ & Plate & heat-1 & Air & 750 \\
\hline Stress Dip & Tensile & 20 & Alloy $800 \mathrm{H}$ & Plate & heat-1 & Air & 750 \\
\hline Loading/Unloading/Creep & Tensile & 21 & Alloy $800 \mathrm{H}$ & Plate & heat-1 & Air & 750 \\
\hline Loading/Unloading/Creep & Tensile & 22 & Alloy $800 \mathrm{H}$ & Plate & heat-1 & Air & 750 \\
\hline Uniaxial Ratchetting & Tensile & 23 & Alloy $800 \mathrm{H}$ & Plate & heat-1 & Air & 750 \\
\hline Uniaxial Ratchetting & Tensile & 24 & Alloy $800 \mathrm{H}$ & Plate & heat-1 & Air & 750 \\
\hline Strain Rate Change & Tensile & 25 & Alloy $800 \mathrm{H}$ & Plate & heat-1 & Air & 850 \\
\hline Strain Rate Change & Tensile & 26 & Alloy $800 \mathrm{H}$ & Plate & heat-1 & Air & 850 \\
\hline
\end{tabular}


Idaho National Laboratory

NEXT GENERATION NUCLEAR PLANT

INTERMEDIATE HEAT EXCHANGER

MATERIALS RESEARCH

AND DEVELOPMENT PLAN

$\begin{array}{ll}\text { Identifier: } & \text { PLN-2804 } \\ \text { Revision: } & 0 \\ \text { Effective Date: } & 04 / 30 / 08\end{array}$

Effective Date: $\quad 04 / 30 / 08 \quad$ Page: A-105 of A-114

Table A26. Tensile Tests Supporting Unified Constitutive Model for Alloy $800 \mathrm{H}$

\begin{tabular}{|c|c|c|c|c|c|c|c|}
\hline Test Type & Spec. Type & Spec. \# & Material & Product Form & Heat \# & Env. & Test Temp. $\left({ }^{\circ} \mathrm{C}\right)$ \\
\hline Stress Dip & Tensile & 27 & Alloy $800 \mathrm{H}$ & Plate & heat-1 & Air & 850 \\
\hline Stress Dip & Tensile & 28 & Alloy $800 \mathrm{H}$ & Plate & heat-1 & Air & 850 \\
\hline Loading/Unloading/Creep & Tensile & 29 & Alloy $800 \mathrm{H}$ & Plate & heat-1 & Air & 850 \\
\hline Loading/Unloading/Creep & Tensile & 30 & Alloy $800 \mathrm{H}$ & Plate & heat-1 & Air & 850 \\
\hline Uniaxial Ratchetting & Tensile & 31 & Alloy $800 \mathrm{H}$ & Plate & heat-1 & Air & 850 \\
\hline Uniaxial Ratchetting & Tensile & 32 & Alloy $800 \mathrm{H}$ & Plate & heat-1 & Air & 850 \\
\hline
\end{tabular}




Idaho National Laboratory
\begin{tabular}{|c|lll|}
\hline NEXT GENERATION NUCLEAR PLANT & Identifier: & PLN-2804 & \\
INTERMEDIATE HEAT EXCHANGER & Revision: & 0 & \\
MATERIALS RESEARCH & Effective Date: & $04 / 30 / 08$ & Page: A-106 of A-114 \\
AND DEVELOPMENT PLAN &
\end{tabular}

\begin{tabular}{|c|c|c|c|c|c|c|c|c|c|c|}
\hline Test Program & Test Type & Spec. \# & Weld Consumable & $\begin{array}{c}\text { Weld } \\
\text { Process }\end{array}$ & $\begin{array}{l}\text { Base } \\
\text { Metal }\end{array}$ & $\begin{array}{c}\text { Weld to be } \\
\text { Tested }\end{array}$ & Env. & $\begin{array}{c}\text { Temp. } \\
{ }^{\circ} \mathrm{C}\end{array}$ & $\begin{array}{l}\text { Applied } \\
\text { Stress } \\
\text { (MPa) }\end{array}$ & $\begin{array}{c}\text { Estimated } \\
\text { Rupture } \\
\text { Time (h) } \\
\end{array}$ \\
\hline WSRF-800H & Creep & 1 & 82 (ERNiCr-3) & GTA & A $800 \mathrm{H}$ & X-Weld & air & 900 & 12 & 4000 \\
\hline WSRF-800H & Creep & 2 & 82 (ERNiCr-3) & GTA & A $800 \mathrm{H}$ & X-Weld & air & 900 & 12 & 4000 \\
\hline WSRF-800H & Creep & 3 & 82 (ERNiCr-3) & GTA & A $800 \mathrm{H}$ & X-Weld & air & 900 & 8 & 20000 \\
\hline WSRF-800H & Creep & 4 & 82 (ERNiCr-3) & GTA & A $800 \mathrm{H}$ & X-Weld & air & 900 & 8 & 20000 \\
\hline WSRF-800H & Creep & 5 & 82 (ERNiCr-3) & GTA & A $800 \mathrm{H}$ & X-Weld & air & 925 & 12 & 2000 \\
\hline WSRF- $800 \mathrm{H}$ & Creep & 6 & 82 (ERNiCr-3) & GTA & A $800 \mathrm{H}$ & X-Weld & air & 925 & 12 & 2000 \\
\hline WSRF-800H & Creep & 7 & 82 (ERNiCr-3) & GTA & A $800 \mathrm{H}$ & X-Weld & air & 925 & 8 & 10000 \\
\hline WSRF-800H & Creep & 8 & 82 (ERNiCr-3) & GTA & A $800 \mathrm{H}$ & X-Weld & air & 925 & 8 & 10000 \\
\hline WSRF- $800 \mathrm{H}$ & Creep & 9 & 82 (ERNiCr-3) & GTA & A $800 \mathrm{H}$ & X-Weld & air & 950 & 8 & 4000 \\
\hline WSRF-800H & Creep & 10 & 82 (ERNiCr-3) & GTA & A $800 \mathrm{H}$ & X-Weld & air & 950 & 8 & 4000 \\
\hline WSRF-800H & Creep & 11 & 82 (ERNiCr-3) & GTA & A $800 \mathrm{H}$ & X-Weld & air & 950 & 5 & 15000 \\
\hline WSRF-800H & Creep & 12 & 82 (ERNiCr-3) & GTA & A $800 \mathrm{H}$ & X-Weld & air & 950 & 5 & 15000 \\
\hline WSRF-800H & Creep & 13 & 82 (ERNiCr-3) & GTA & A $800 \mathrm{H}$ & X-Weld & air & 975 & 8 & 2000 \\
\hline WSRF-800H & Creep & 14 & 82 (ERNiCr-3) & GTA & A $800 \mathrm{H}$ & X-Weld & air & 975 & 8 & 2000 \\
\hline WSRF-800H & Creep & 15 & 82 (ERNiCr-3) & GTA & A $800 \mathrm{H}$ & X-Weld & air & 975 & 5 & 7000 \\
\hline WSRF-800H & Creep & 16 & 82 (ERNiCr-3) & GTA & A $800 \mathrm{H}$ & X-Weld & air & 975 & 5 & 7000 \\
\hline WSRF- $800 \mathrm{H}$ & Creep & 17 & 82 (ERNiCr-3) & GTA & A $800 \mathrm{H}$ & X-Weld & air & 1000 & 5 & 3000 \\
\hline WSRF-800H & Creep & 18 & 82 (ERNiCr-3) & GTA & A $800 \mathrm{H}$ & X-Weld & air & 1000 & 5 & 3000 \\
\hline WSRF- $800 \mathrm{H}$ & Creep & 19 & 82 (ERNiCr-3) & GTA & A $800 \mathrm{H}$ & X-Weld & air & 1000 & 3 & 12000 \\
\hline WSRF-800H & Creep & 20 & 82 (ERNiCr-3) & GTA & A $800 \mathrm{H}$ & X-Weld & air & 1000 & 3 & 12000 \\
\hline WSRF-800H & Creep & 21 & 82 (ERNiCr-3) & GTA & NA & Deposited & air & 900 & 12 & 4000 \\
\hline WSRF- $800 \mathrm{H}$ & Creep & 22 & 82 (ERNiCr-3) & GTA & NA & Deposited & air & 900 & 12 & 4000 \\
\hline WSRF-800H & Creep & 23 & 82 (ERNiCr-3) & GTA & NA & Deposited & air & 950 & 8 & 4000 \\
\hline WSRF-800H & Creep & 24 & 82 (ERNiCr-3) & GTA & NA & Deposited & air & 950 & 8 & 4000 \\
\hline WSRF- $800 \mathrm{H}$ & Creep & 25 & 82 (ERNiCr-3) & GTA & NA & Deposited & air & 1000 & 5 & 3000 \\
\hline WSRF-800H & Creep & 26 & 82 (ERNiCr-3) & GTA & NA & Deposited & air & 1000 & 5 & 3000 \\
\hline
\end{tabular}


Idaho National Laboratory

\begin{tabular}{|c|c|c|c|}
\hline $\begin{array}{l}\text { NEXT GENERATION NUCLEAR PLANT } \\
\text { INTERMEDIATE HEAT EXCHANGER } \\
\text { MATERIALS RESEARCH } \\
\text { AND DEVELOPMENT PLAN }\end{array}$ & $\begin{array}{l}\text { Identifier: } \\
\text { Revision: } \\
\text { Effective Date: }\end{array}$ & $\begin{array}{l}\text { PLN-2804 } \\
0 \\
04 / 30 / 08\end{array}$ & Page: A \\
\hline
\end{tabular}

\begin{tabular}{|c|c|c|c|c|c|c|c|c|c|c|}
\hline Test Program & Test Type & Spec. \# & Weld Consumable & $\begin{array}{c}\text { Weld } \\
\text { Process }\end{array}$ & $\begin{array}{l}\text { Base } \\
\text { Metal } \\
\end{array}$ & $\begin{array}{c}\text { Weld to be } \\
\text { Tested }\end{array}$ & Env. & $\begin{array}{c}\text { Temp. } \\
{ }^{\circ} \mathrm{C}\end{array}$ & $\begin{array}{c}\text { Applied } \\
\text { Stress } \\
(\mathrm{MPa})\end{array}$ & $\begin{array}{c}\text { Estimated } \\
\text { Rupture } \\
\text { Time (h) }\end{array}$ \\
\hline WSRF-800H & Creep & 27 & $\mathrm{~A}(\mathrm{ENiCrFe}-2)$ & SMA & $\mathrm{A} 800 \mathrm{H}$ & X-Weld & air & 900 & 12 & 4000 \\
\hline WSRF-800H & Creep & 28 & $\mathrm{~A}(\mathrm{ENiCrFe}-2)$ & SMA & A $800 \mathrm{H}$ & X-Weld & air & 900 & 12 & 4000 \\
\hline WSRF-800H & Creep & 29 & $\mathrm{~A}(\mathrm{ENiCrFe}-2)$ & SMA & A $800 \mathrm{H}$ & X-Weld & air & 900 & 8 & 20000 \\
\hline WSRF-800H & Creep & 30 & $\mathrm{~A}(\mathrm{ENiCrFe}-2)$ & SMA & $\mathrm{A} 800 \mathrm{H}$ & X-Weld & air & 900 & 8 & 20000 \\
\hline WSRF-800H & Creep & 31 & $\mathrm{~A}(\mathrm{ENiCrFe}-2)$ & SMA & A $800 \mathrm{H}$ & X-Weld & air & 925 & 12 & 2000 \\
\hline WSRF-800H & Creep & 32 & $\mathrm{~A}(\mathrm{ENiCrFe}-2)$ & SMA & A $800 \mathrm{H}$ & X-Weld & air & 925 & 12 & 2000 \\
\hline WSRF-800H & Creep & 33 & $\mathrm{~A}(\mathrm{ENiCrFe}-2)$ & SMA & A $800 \mathrm{H}$ & X-Weld & air & 925 & 8 & 10000 \\
\hline WSRF-800H & Creep & 34 & $\mathrm{~A}(\mathrm{ENiCrFe}-2)$ & SMA & A $800 \mathrm{H}$ & X-Weld & air & 925 & 8 & 10000 \\
\hline WSRF-800H & Creep & 35 & $\mathrm{~A}(\mathrm{ENiCrFe}-2)$ & SMA & A $800 \mathrm{H}$ & X-Weld & air & 950 & 8 & 4000 \\
\hline WSRF-800H & Creep & 36 & $\mathrm{~A}(\mathrm{ENiCrFe}-2)$ & SMA & A $800 \mathrm{H}$ & X-Weld & air & 950 & 8 & 4000 \\
\hline WSRF-800H & Creep & 37 & $\mathrm{~A}(\mathrm{ENiCrFe}-2)$ & SMA & A $800 \mathrm{H}$ & X-Weld & air & 950 & 5 & 15000 \\
\hline WSRF-800H & Creep & 38 & $\mathrm{~A}(\mathrm{ENiCrFe}-2)$ & SMA & A $800 \mathrm{H}$ & X-Weld & air & 950 & 5 & 15000 \\
\hline WSRF-800H & Creep & 39 & $\mathrm{~A}(\mathrm{ENiCrFe}-2)$ & SMA & A $800 \mathrm{H}$ & X-Weld & air & 975 & 8 & 2000 \\
\hline WSRF-800H & Creep & 40 & $\mathrm{~A}(\mathrm{ENiCrFe}-2)$ & SMA & A $800 \mathrm{H}$ & X-Weld & air & 975 & 8 & 2000 \\
\hline WSRF-800H & Creep & 41 & $\mathrm{~A}(\mathrm{ENiCrFe}-2)$ & SMA & A $800 \mathrm{H}$ & X-Weld & air & 975 & 5 & 7000 \\
\hline WSRF-800H & Creep & 42 & $\mathrm{~A}(\mathrm{ENiCrFe}-2)$ & SMA & A $800 \mathrm{H}$ & X-Weld & air & 975 & 5 & 7000 \\
\hline WSRF-800H & Creep & 43 & $\mathrm{~A}(\mathrm{ENiCrFe}-2)$ & SMA & A $800 \mathrm{H}$ & X-Weld & air & 1000 & 5 & 3000 \\
\hline WSRF-800H & Creep & 44 & $\mathrm{~A}(\mathrm{ENiCrFe}-2)$ & SMA & A $800 \mathrm{H}$ & X-Weld & air & 1000 & 5 & 3000 \\
\hline WSRF-800H & Creep & 45 & $\mathrm{~A}(\mathrm{ENiCrFe}-2)$ & SMA & $\mathrm{A} 800 \mathrm{H}$ & X-Weld & air & 1000 & 3 & 12000 \\
\hline WSRF-800H & Creep & 46 & $\mathrm{~A}(\mathrm{ENiCrFe}-2)$ & SMA & A $800 \mathrm{H}$ & X-Weld & air & 1000 & 3 & 12000 \\
\hline WSRF-800H & Creep & 47 & $\mathrm{~A}(\mathrm{ENiCrFe}-2)$ & SMA & NA & Deposited & air & 900 & 12 & 4000 \\
\hline WSRF-800H & Creep & 48 & $\mathrm{~A}(\mathrm{ENiCrFe}-2)$ & SMA & $\mathrm{NA}$ & Deposited & air & 900 & 12 & 4000 \\
\hline WSRF-800H & Creep & 49 & $\mathrm{~A}(\mathrm{ENiCrFe}-2)$ & SMA & NA & Deposited & air & 950 & 8 & 4000 \\
\hline WSRF-800H & Creep & 50 & $\mathrm{~A}(\mathrm{ENiCrFe}-2)$ & SMA & NA & Deposited & air & 950 & 8 & 4000 \\
\hline WSRF-800H & Creep & 51 & $\mathrm{~A}(\mathrm{ENiCrFe}-2)$ & SMA & NA & Deposited & air & 1000 & 5 & 3000 \\
\hline WSRF-800H & Creep & 52 & $\mathrm{~A}(\mathrm{ENiCrFe}-2)$ & SMA & NA & Deposited & air & 1000 & 5 & 3000 \\
\hline Strength mismatch & Creep & 53 & 617 (ERNiCrCoMo-1) & GTA & A $800 \mathrm{H}$ & X-Weld & air & 900 & 60 & 1000 \\
\hline
\end{tabular}


Idaho National Laboratory

\begin{tabular}{|c|c|c|c|}
\hline $\begin{array}{l}\text { NEXT GENERATION NUCLEAR PLANT } \\
\text { INTERMEDIATE HEAT EXCHANGER } \\
\text { MATERIALS RESEARCH } \\
\text { AND DEVELOPMENT PLAN }\end{array}$ & $\begin{array}{l}\text { Identifier: } \\
\text { Revision: } \\
\text { Effective Date: }\end{array}$ & $\begin{array}{l}\text { PLN-2804 } \\
0 \\
04 / 30 / 08\end{array}$ & Page: A-108 of A-114 \\
\hline
\end{tabular}

\begin{tabular}{|c|c|c|c|c|c|c|c|c|c|c|}
\hline \multicolumn{11}{|c|}{ Table A27. Test Matrix for Weld Strength Rupture Factor for Alloy $800 \mathrm{H}$ Weldments } \\
\hline Test Program & Test Type & Spec. \# & Weld Consumable & $\begin{array}{c}\text { Weld } \\
\text { Process }\end{array}$ & $\begin{array}{c}\text { Base } \\
\text { Metal }\end{array}$ & $\begin{array}{c}\text { Weld to be } \\
\text { Tested }\end{array}$ & Env. & $\begin{array}{c}\text { Temp. } \\
{ }^{\circ} \mathrm{C}\end{array}$ & $\begin{array}{c}\text { Applied } \\
\text { Stress } \\
(\mathrm{MPa})\end{array}$ & $\begin{array}{c}\text { Estimated } \\
\text { Rupture } \\
\text { Time (h) }\end{array}$ \\
\hline Strength mismatch & Creep & 54 & $617($ ERNiCrCoMo-1) & GTA & $\mathrm{A} 800 \mathrm{H}$ & X-Weld & air & 900 & 30 & 10000 \\
\hline Strength mismatch & Creep & 55 & 617 (ERNiCrCoMo-1) & GTA & A $800 \mathrm{H}$ & X-Weld & air & 950 & 30 & 1000 \\
\hline Strength mismatch & Creep & 56 & 617 (ERNiCrCoMo-1) & GTA & A $800 \mathrm{H}$ & X-Weld & air & 950 & 18 & 10000 \\
\hline Strength mismatch & Creep & 57 & 617 (ERNiCrCoMo-1) & GTA & $\mathrm{A} 800 \mathrm{H}$ & X-Weld & air & 1000 & 11 & 1000 \\
\hline Strength mismatch & Creep & 58 & 617 (ERNiCrCoMo-1) & GTA & A $800 \mathrm{H}$ & X-Weld & air & 1000 & 7 & 10000 \\
\hline Strength mismatch & Creep & 59 & 117 (ENiCrCoMo-1) & SMA & A $800 \mathrm{H}$ & X-Weld & air & 900 & 60 & 1000 \\
\hline Strength mismatch & Creep & 60 & 117 (ENiCrCoMo-1) & SMA & A $800 \mathrm{H}$ & X-Weld & air & 900 & 30 & 10000 \\
\hline Strength mismatch & Creep & 61 & 117 (ENiCrCoMo-1) & SMA & A $800 \mathrm{H}$ & X-Weld & air & 950 & 30 & 1000 \\
\hline Strength mismatch & Creep & 62 & 117 (ENiCrCoMo-1) & SMA & $\mathrm{A} 800 \mathrm{H}$ & X-Weld & air & 950 & 18 & 10000 \\
\hline Strength mismatch & Creep & 63 & 117 (ENiCrCoMo-1) & SMA & A $800 \mathrm{H}$ & X-Weld & air & 1000 & 11 & 1000 \\
\hline Strength mismatch & Creep & 64 & 117 (ENiCrCoMo-1) & SMA & A $800 \mathrm{H}$ & X-Weld & air & 1000 & 7 & 10000 \\
\hline Evaluation & Creep & 65 & $21 / 33 \mathrm{Nb}$ & GTA & NA & Deposited & air & 900 & 30 & 1000 \\
\hline Evaluation & Creep & 66 & $21 / 33 \mathrm{Nb}$ & GTA & NA & Deposited & air & 900 & 16 & 10000 \\
\hline Evaluation & Creep & 67 & $21 / 33 \mathrm{Nb}$ & GTA & NA & Deposited & air & 950 & 20 & 1000 \\
\hline Evaluation & Creep & 68 & $21 / 33 \mathrm{Nb}$ & GTA & NA & Deposited & air & 950 & 12 & 10000 \\
\hline Evaluation & Creep & 69 & $21 / 33 \mathrm{Nb}$ & GTA & NA & Deposited & air & 1000 & 12 & 1000 \\
\hline Evaluation & Creep & 70 & $21 / 33 \mathrm{Nb}$ & GTA & NA & Deposited & air & 1000 & 7 & 10000 \\
\hline Evaluation & Creep & 71 & $21 / 33 \mathrm{Nb}$ & SMA & NA & Deposited & air & 900 & 30 & 1000 \\
\hline Evaluation & Creep & 72 & $21 / 33 \mathrm{Nb}$ & SMA & NA & Deposited & air & 900 & 16 & 10000 \\
\hline Evaluation & Creep & 73 & $21 / 33 \mathrm{Nb}$ & SMA & NA & Deposited & air & 950 & 20 & 1000 \\
\hline Evaluation & Creep & 74 & $21 / 33 \mathrm{Nb}$ & SMA & NA & Deposited & air & 950 & 12 & 10000 \\
\hline Evaluation & Creep & 75 & $21 / 33 \mathrm{Nb}$ & SMA & NA & Deposited & air & 1000 & 12 & 1000 \\
\hline Evaluation & Creep & 76 & $21 / 33 \mathrm{Nb}$ & SMA & NA & Deposited & air & 1000 & 7 & 10000 \\
\hline
\end{tabular}




Idaho National Laboratory
\begin{tabular}{|c|lll|}
\hline NEXT GENERATION NUCLEAR PLANT & Identifier: & PLN-2804 & \\
INTERMEDIATE HEAT EXCHANGER & Revision: & 0 & \\
MATERIALS RESEARCH & Effective Date: & $04 / 30 / 08$ & Page: A-109 of A-114 \\
AND DEVELOPMENT PLAN &
\end{tabular}

\begin{tabular}{|c|c|c|c|c|c|}
\hline ASTM Grain Size \# & Specimen Type & Specimen \# & Test Temp. $\left({ }^{\circ} \mathrm{C}\right)$ & $\begin{array}{l}\text { Strain rate to } 2 \% \text { strain } \\
(\mathrm{m} / \mathrm{m} / \mathrm{min})\end{array}$ & $\begin{array}{l}\text { Strain rate to ultimate } \\
(\mathrm{m} / \mathrm{m} / \mathrm{min})\end{array}$ \\
\hline 4 to 5 & Tensile & 1 & 23 & 0.05 & 0.5 \\
\hline 4 to 5 & Tensile & 2 & 750 & 0.05 & 0.5 \\
\hline 4 to 5 & Tensile & 3 & 800 & 0.05 & 0.5 \\
\hline 4 to 5 & Tensile & 4 & 850 & 0.05 & 0.5 \\
\hline 4 to 5 & Tensile & 5 & 900 & 0.05 & 0.5 \\
\hline 4 to 5 & Tensile & 6 & 750 & 0.005 & 0.05 \\
\hline 4 to 5 & Tensile & 7 & 800 & 0.005 & 0.05 \\
\hline 4 to 5 & Tensile & 8 & 850 & 0.005 & 0.05 \\
\hline 4 to 5 & Tensile & 9 & 900 & 0.0005 & 0.05 \\
\hline 4 to 5 & Tensile & 10 & 750 & 0.0005 & 0.005 \\
\hline 4 to 5 & Tensile & 11 & 800 & 0.0005 & 0.005 \\
\hline 4 to 5 & Tensile & 12 & 850 & 0.0005 & 0.005 \\
\hline 4 to 5 & Tensile & 13 & 900 & 0.0005 & 0.005 \\
\hline 0 to 1 & Tensile & 14 & 23 & 0.05 & 0.5 \\
\hline 0 to 1 & Tensile & 15 & 750 & 0.05 & 0.5 \\
\hline 0 to 1 & Tensile & 16 & 800 & 0.05 & 0.5 \\
\hline 0 to 1 & Tensile & 17 & 850 & 0.05 & 0.5 \\
\hline 0 to 1 & Tensile & 18 & 900 & 0.05 & 0.5 \\
\hline 0 to 1 & Tensile & 19 & 750 & 0.005 & 0.5 \\
\hline 0 to 1 & Tensile & 20 & 800 & 0.005 & 0.05 \\
\hline 0 to 1 & Tensile & 21 & 850 & 0.005 & 0.05 \\
\hline 0 to 1 & Tensile & 22 & 900 & 0.005 & 0.05 \\
\hline 0 to 1 & Tensile & 23 & 750 & 0.0005 & 0.005 \\
\hline 0 to 1 & Tensile & 24 & 800 & 0.0005 & 0.005 \\
\hline 0 to 1 & Tensile & 25 & 850 & 0.0005 & 0.005 \\
\hline 0 to 1 & Tensile & 26 & 900 & 0.0005 & 0.005 \\
\hline
\end{tabular}


Idaho National Laboratory

\begin{tabular}{|c|c|c|c|}
\hline $\begin{array}{l}\text { NEXT GENERATION NUCLEAR PLANT } \\
\text { INTERMEDIATE HEAT EXCHANGER } \\
\text { MATERIALS RESEARCH } \\
\text { AND DEVELOPMENT PLAN }\end{array}$ & $\begin{array}{l}\text { Identifier: } \\
\text { Revision: } \\
\text { Effective Date: }\end{array}$ & $\begin{array}{l}\text { PLN-2804 } \\
0 \\
04 / 30 / 08\end{array}$ & Page: A \\
\hline
\end{tabular}

\begin{tabular}{|c|c|c|c|c|c|c|c|}
\hline \multicolumn{8}{|c|}{ Table A29. Test Matrix to Explore Creep Mechanisms of Alloy $800 \mathrm{H}$} \\
\hline Spec. Type & Test Type & Spec. \# & Material & ASTM GS \# & Temp. ${ }^{\circ} \mathrm{C}$ & Stress $(\mathrm{MPa})$ & $\begin{array}{c}\text { Creep Duration } \\
\text { (h) }\end{array}$ \\
\hline Tensile & Creep & 1 & Alloy $800 \mathrm{H}$ & 4 to 5 & 850 & 20 & 100 \\
\hline Tensile & Creep & 2 & Alloy $800 \mathrm{H}$ & 4 to 5 & 950 & 20 & 100 \\
\hline Tensile & Creep & 3 & Alloy $800 \mathrm{H}$ & 4 to 5 & 850 & 10 & 1000 \\
\hline Tensile & Creep & 4 & Alloy $800 \mathrm{H}$ & 4 to 5 & 950 & 10 & 500 \\
\hline Tensile & Creep & 5 & Alloy $800 \mathrm{H}$ & 4 to 5 & 850 & 20 & 50 \\
\hline Tensile & Creep & 6 & Alloy $800 \mathrm{H}$ & 4 to 5 & 850 & 10 & 500 \\
\hline Tensile & Creep & 7 & Alloy $800 \mathrm{H}$ & 4 to 5 & 950 & 20 & 50 \\
\hline Tensile & Creep & 8 & Alloy $800 \mathrm{H}$ & 4 to 5 & 950 & 10 & 200 \\
\hline Tensile & Creep & 9 & Alloy $800 \mathrm{H}$ & 0 to 1 or 2 to 3 & 950 & 20 & 1000 \\
\hline Tensile & Creep & 10 & Alloy $800 \mathrm{H}$ & 0 to 1 or 2 to 3 & 950 & 10 & 5000 \\
\hline Tensile & Temp. Change/Creep & 11 & Alloy $800 \mathrm{H}$ & 4 to 5 & $850 / 900 / 950$ & 15 & $200 / 200 / 200$ \\
\hline Tensile & Creep/Stress Jump/Creep & 12 & Alloy $800 \mathrm{H}$ & 4 to 5 & 950 & $5 / 10 / 15 / 20$ & 500 to 100 \\
\hline Tensile & Temp. Change/Creep & 13 & Alloy $800 \mathrm{H}$ & 0 to 1 or 2 to 3 & $850 / 900 / 950$ & 15 & $1000 / 500 / 200$ \\
\hline Tensile & Creep/Stress Jump/Creep & 14 & Alloy $800 \mathrm{H}$ & 0 to 1 or 2 to 3 & 950 & $5 / 10 / 15 / 20$ & 1000 to 100 \\
\hline
\end{tabular}




Idaho National Laboratory
\begin{tabular}{|c|lll|}
\hline NEXT GENERATION NUCLEAR PLANT & Identifier: & PLN-2804 & \\
INTERMEDIATE HEAT EXCHANGER & Revision: & 0 & \\
MATERIALS RESEARCH & Effective Date: & $04 / 30 / 08$ & Page: A-111 of A-114 \\
AND DEVELOPMENT PLAN & &
\end{tabular}

\begin{tabular}{|c|c|c|c|c|c|c|c|c|c|}
\hline Test Program & $\begin{array}{c}\text { Specimen } \\
\text { Type }\end{array}$ & Spec. \# & Material & Product Form & Heat & Env. & $\begin{array}{c}\text { Exposure } \\
\text { Temp. }\left({ }^{\circ} \mathrm{C}\right)\end{array}$ & $\begin{array}{l}\text { Exposure } \\
\text { Time }(\mathrm{h}) \\
\end{array}$ & $\begin{array}{l}\text { Tensile Test } \\
\text { Temp. }\left({ }^{\circ} \mathrm{C}\right)\end{array}$ \\
\hline A800H-SRF-QUAL & Tensile & 1 & Alloy $800 \mathrm{H}$ & Plate & heat-1 & Air & None & None & 650 \\
\hline A800H-SRF-QUAL & Tensile & 2 & Alloy $800 \mathrm{H}$ & Plate & heat-1 & Air & None & None & 650 \\
\hline A800H-SRF-QUAL & Tensile & 3 & Alloy $800 \mathrm{H}$ & Plate & heat-1 & Air & None & None & 750 \\
\hline A800H-SRF-QUAL & Tensile & 4 & Alloy $800 \mathrm{H}$ & Plate & heat-1 & Air & None & None & 750 \\
\hline A800H-SRF-QUAL & Tensile & 5 & Alloy $800 \mathrm{H}$ & Plate & heat-1 & Air & None & None & 850 \\
\hline A800H-SRF-QUAL & Tensile & 6 & Alloy $800 \mathrm{H}$ & Plate & heat-1 & Air & None & None & 850 \\
\hline A800H-SRF-QUAL & Tensile & 7 & Alloy $800 \mathrm{H}$ & Plate & heat -2 & Air & None & None & 650 \\
\hline A800H-SRF-QUAL & Tensile & 8 & Alloy $800 \mathrm{H}$ & Plate & heat-2 & Air & None & None & 650 \\
\hline A800H-SRF-QUAL & Tensile & 9 & Alloy $800 \mathrm{H}$ & Plate & heat-2 & Air & None & None & 750 \\
\hline A800H-SRF-QUAL & Tensile & 10 & Alloy $800 \mathrm{H}$ & Plate & heat- 2 & Air & None & None & 750 \\
\hline A800H-SRF-QUAL & Tensile & 11 & Alloy $800 \mathrm{H}$ & Plate & heat-2 & Air & None & None & 850 \\
\hline A800H-SRF-QUAL & Tensile & 12 & Alloy $800 \mathrm{H}$ & Plate & heat-2 & Air & None & None & 850 \\
\hline A800H-SRF-QUAL & Tensile & 13 & Alloy $800 \mathrm{H}$ & Plate & heat-1 & Air & 750 & 40000 & 650 \\
\hline A800H-SRF-QUAL & Tensile & 14 & Alloy $800 \mathrm{H}$ & Plate & heat-1 & Air & 750 & 40000 & 650 \\
\hline A800H-SRF-QUAL & Tensile & 15 & Alloy $800 \mathrm{H}$ & Plate & heat-1 & Air & 750 & 40000 & 750 \\
\hline A800H-SRF-QUAL & Tensile & 16 & Alloy $800 \mathrm{H}$ & Plate & heat-1 & Air & 750 & 40000 & 750 \\
\hline A800H-SRF-QUAL & Tensile & 17 & Alloy $800 \mathrm{H}$ & Plate & heat-1 & Air & 750 & 40000 & 850 \\
\hline A800H-SRF-QUAL & Tensile & 18 & Alloy $800 \mathrm{H}$ & Plate & heat-1 & Air & 750 & 40000 & 850 \\
\hline A800H-SRF-QUAL & Tensile & 19 & Alloy $800 \mathrm{H}$ & Plate & heat-2 & Air & 750 & 40000 & 650 \\
\hline A800H-SRF-QUAL & Tensile & 20 & Alloy $800 \mathrm{H}$ & Plate & heat-2 & Air & 750 & 40000 & 650 \\
\hline A800H-SRF-QUAL & Tensile & 21 & Alloy $800 \mathrm{H}$ & Plate & heat-2 & Air & 750 & 40000 & 750 \\
\hline A800H-SRF-QUAL & Tensile & 22 & Alloy $800 \mathrm{H}$ & Plate & heat-2 & Air & 750 & 40000 & 750 \\
\hline A800H-SRF-QUAL & Tensile & 23 & Alloy $800 \mathrm{H}$ & Plate & heat- 2 & Air & 750 & 40000 & 850 \\
\hline A800H-SRF-QUAL & Tensile & 24 & Alloy $800 \mathrm{H}$ & Plate & heat-2 & Air & 750 & 40000 & 850 \\
\hline A800H-SRF-QUAL & Tensile & 25 & Alloy $800 \mathrm{H}$ & Plate & heat-1 & Air & 750 & 70000 & 650 \\
\hline A800H-SRF-QUAL & Tensile & 26 & Alloy $800 \mathrm{H}$ & Plate & heat-1 & Air & 750 & 70000 & 650 \\
\hline A800H-SRF-QUAL & Tensile & 27 & Alloy $800 \mathrm{H}$ & Plate & heat-1 & Air & 750 & 70000 & 750 \\
\hline
\end{tabular}




Idaho National Laboratory
\begin{tabular}{|c|lll|}
\hline NEXT GENERATION NUCLEAR PLANT & Identifier: & PLN-2804 & \\
INTERMEDIATE HEAT EXCHANGER & Revision: & 0 & \\
MATERIALS RESEARCH & Effective Date: & $04 / 30 / 08$ & Page: A-112 of A-114 \\
AND DEVELOPMENT PLAN &
\end{tabular}

\begin{tabular}{|c|c|c|c|c|c|c|c|c|c|}
\hline Test Program & $\begin{array}{c}\text { Specimen } \\
\text { Type }\end{array}$ & Spec. \# & Material & Product Form & Heat & Env. & $\begin{array}{c}\text { Exposure } \\
\text { Temp. }\left({ }^{\circ} \mathrm{C}\right)\end{array}$ & $\begin{array}{c}\text { Exposure } \\
\text { Time (h) }\end{array}$ & $\begin{array}{l}\text { Tensile Test } \\
\text { Temp. }\left({ }^{\circ} \mathrm{C}\right)\end{array}$ \\
\hline A800H-SRF-QUAL & Tensile & 28 & Alloy $800 \mathrm{H}$ & Plate & heat-1 & Air & 750 & 70000 & 750 \\
\hline A800H-SRF-QUAL & Tensile & 29 & Alloy $800 \mathrm{H}$ & Plate & heat-1 & Air & 750 & 70000 & 850 \\
\hline A800H-SRF-QUAL & Tensile & 30 & Alloy $800 \mathrm{H}$ & Plate & heat-1 & Air & 750 & 70000 & 850 \\
\hline A800H-SRF-QUAL & Tensile & 31 & Alloy $800 \mathrm{H}$ & Plate & heat-2 & Air & 750 & 70000 & 650 \\
\hline A800H-SRF-QUAL & Tensile & 32 & Alloy $800 \mathrm{H}$ & Plate & heat-2 & Air & 750 & 70000 & 650 \\
\hline A800H-SRF-QUAL & Tensile & 33 & Alloy $800 \mathrm{H}$ & Plate & heat- 2 & Air & 750 & 70000 & 750 \\
\hline A800H-SRF-QUAL & Tensile & 34 & Alloy $800 \mathrm{H}$ & Plate & heat-2 & Air & 750 & 70000 & 750 \\
\hline A800H-SRF-QUAL & Tensile & 35 & Alloy $800 \mathrm{H}$ & Plate & heat-2 & Air & 750 & 70000 & 850 \\
\hline A800H-SRF-QUAL & Tensile & 36 & Alloy $800 \mathrm{H}$ & Plate & heat-2 & Air & 750 & 70000 & 850 \\
\hline A800H-SRF-QUAL & Tensile & 37 & Alloy $800 \mathrm{H}$ & Plate & heat-1 & Air & 850 & 40000 & 650 \\
\hline A800H-SRF-QUAL & Tensile & 38 & Alloy $800 \mathrm{H}$ & Plate & heat-1 & Air & 850 & 40000 & 650 \\
\hline A800H-SRF-QUAL & Tensile & 39 & Alloy $800 \mathrm{H}$ & Plate & heat-1 & Air & 850 & 40000 & 750 \\
\hline A800H-SRF-QUAL & Tensile & 40 & Alloy $800 \mathrm{H}$ & Plate & heat-1 & Air & 850 & 40000 & 750 \\
\hline A800H-SRF-QUAL & Tensile & 41 & Alloy $800 \mathrm{H}$ & Plate & heat-1 & Air & 850 & 40000 & 850 \\
\hline A800H-SRF-QUAL & Tensile & 42 & Alloy $800 \mathrm{H}$ & Plate & heat-1 & Air & 850 & 40000 & 850 \\
\hline A800H-SRF-QUAL & Tensile & 43 & Alloy $800 \mathrm{H}$ & Plate & heat-2 & Air & 850 & 40000 & 650 \\
\hline A800H-SRF-QUAL & Tensile & 44 & Alloy $800 \mathrm{H}$ & Plate & heat-2 & Air & 850 & 40000 & 650 \\
\hline A800H-SRF-QUAL & Tensile & 45 & Alloy $800 \mathrm{H}$ & Plate & heat-2 & Air & 850 & 40000 & 750 \\
\hline A800H-SRF-QUAL & Tensile & 46 & Alloy $800 \mathrm{H}$ & Plate & heat-2 & Air & 850 & 40000 & 750 \\
\hline A800H-SRF-QUAL & Tensile & 47 & Alloy $800 \mathrm{H}$ & Plate & heat-2 & Air & 850 & 40000 & 850 \\
\hline A800H-SRF-QUAL & Tensile & 48 & Alloy $800 \mathrm{H}$ & Plate & heat-2 & Air & 850 & 40000 & 850 \\
\hline A800H-SRF-QUAL & Tensile & 49 & Alloy $800 \mathrm{H}$ & Plate & heat-1 & Air & 850 & 70000 & 650 \\
\hline A800H-SRF-QUAL & Tensile & 50 & Alloy $800 \mathrm{H}$ & Plate & heat-1 & Air & 850 & 70000 & 650 \\
\hline A800H-SRF-QUAL & Tensile & 51 & Alloy $800 \mathrm{H}$ & Plate & heat-1 & Air & 850 & 70000 & 750 \\
\hline A800H-SRF-QUAL & Tensile & 52 & Alloy $800 \mathrm{H}$ & Plate & heat-1 & Air & 850 & 70000 & 750 \\
\hline A800H-SRF-QUAL & Tensile & 53 & Alloy $800 \mathrm{H}$ & Plate & heat-1 & Air & 850 & 70000 & 850 \\
\hline A800H-SRF-QUAL & Tensile & 54 & Alloy $800 \mathrm{H}$ & Plate & heat-1 & Air & 850 & 70000 & 850 \\
\hline A800H-SRF-QUAL & Tensile & 55 & Alloy $800 \mathrm{H}$ & Plate & heat-2 & Air & 850 & 70000 & 650 \\
\hline
\end{tabular}


Idaho National Laboratory

\begin{tabular}{|c|c|c|c|}
\hline $\begin{array}{l}\text { NEXT GENERATION NUCLEAR PLANT } \\
\text { INTERMEDIATE HEAT EXCHANGER } \\
\text { MATERIALS RESEARCH } \\
\text { AND DEVELOPMENT PLAN }\end{array}$ & $\begin{array}{l}\text { Identifier: } \\
\text { Revision: } \\
\text { Effective Date: }\end{array}$ & $\begin{array}{l}\text { PLN-2804 } \\
0 \\
04 / 30 / 08\end{array}$ & Page: A-113 of A-114 \\
\hline
\end{tabular}

Table A30. Test Matrix to Qualify Yield and Tensile Strength Reduction Factors for Alloy 800H Due to Thermal Aging

\begin{tabular}{|c|c|c|c|c|c|c|c|c|c|}
\hline Test Program & $\begin{array}{c}\text { Specimen } \\
\text { Type }\end{array}$ & Spec. \# & Material & Product Form & Heat & Env. & $\begin{array}{c}\text { Exposure } \\
\text { Temp. }\left({ }^{\circ} \mathrm{C}\right)\end{array}$ & $\begin{array}{c}\text { Exposure } \\
\text { Time (h) }\end{array}$ & $\begin{array}{c}\text { Tensile Test } \\
\text { Temp. }\left({ }^{\circ} \mathrm{C}\right)\end{array}$ \\
\hline A800H-SRF-QUAL & Tensile & 56 & Alloy $800 \mathrm{H}$ & Plate & heat-2 & Air & 850 & 70000 & 650 \\
\hline A800H-SRF-QUAL & Tensile & 57 & Alloy $800 \mathrm{H}$ & Plate & heat-2 & Air & 850 & 70000 & 750 \\
\hline A800H-SRF-QUAL & Tensile & 58 & Alloy $800 \mathrm{H}$ & Plate & heat- 2 & Air & 850 & 70000 & 750 \\
\hline A800H-SRF-QUAL & Tensile & 59 & Alloy $800 \mathrm{H}$ & Plate & heat- 2 & Air & 850 & 70000 & 850 \\
\hline A800H-SRF-QUAL & Tensile & 60 & Alloy $800 \mathrm{H}$ & Plate & heat-2 & Air & 850 & 70000 & 850 \\
\hline
\end{tabular}




Idaho National Laboratory
\begin{tabular}{|c|lll|}
\hline NEXT GENERATION NUCLEAR PLANT & Identifier: & PLN-2804 & \\
INTERMEDIATE HEAT EXCHANGER & Revision: & 0 & \\
MATERIALS RESEARCH & Effective Date: & $04 / 30 / 08$ & Page: A-114 of A-114 \\
AND DEVELOPMENT PLAN & &
\end{tabular}

\begin{tabular}{|c|c|c|c|c|c|c|c|c|c|c|}
\hline $\begin{array}{l}\text { Specimen } \\
\text { Type }\end{array}$ & Test Type & $\begin{array}{c}\text { Spec. } \\
\#\end{array}$ & Material & Heat & Env. & $\begin{array}{l}\text { Temp } \\
\left({ }^{\circ} \mathrm{C}\right)\end{array}$ & $\begin{array}{c}\text { Spec. Loading } \\
\text { Mode }\end{array}$ & Load & $\begin{array}{c}\text { Biaxial Stress } \\
\text { Ratio }\end{array}$ & $\begin{array}{c}\text { Estimated } \\
\text { Rupture Time (h) }\end{array}$ \\
\hline Prz Tube & Creep Rupture & 1 & Alloy $800 \mathrm{H}$ & Heat-xyz & air & 850 & Pressure & TBD & 2.0 & TBD \\
\hline Prz Tube & Creep Rupture & 2 & Alloy $800 \mathrm{H}$ & Heat-xyz & air & 850 & Pressure & TBD & 2.0 & TBD \\
\hline Prz Tube & Creep Rupture & 3 & Alloy $800 \mathrm{H}$ & Heat-xyz & air & 850 & Pressure & TBD & 2.0 & TBD \\
\hline Tubular & Creep Rupture & 4 & Alloy $800 \mathrm{H}$ & Heat-xyz & air & 850 & Pressure+Axial & TBD & 1.0 & TBD \\
\hline Tubular & Creep Rupture & 5 & Alloy $800 \mathrm{H}$ & Heat-xyz & air & 850 & Pressure+Axial & TBD & 1.0 & TBD \\
\hline Tubular & Creep Rupture & 6 & Alloy $800 \mathrm{H}$ & Heat-xyz & air & 850 & Pressure+Axial & TBD & 1.0 & TBD \\
\hline Tubular & Creep Rupture & 7 & Alloy $800 \mathrm{H}$ & Heat-xyz & air & 850 & Pressure+Axial & TBD & 0.5 & TBD \\
\hline Tubular & Creep Rupture & 8 & Alloy $800 \mathrm{H}$ & Heat-xyz & air & 850 & Pressure+Axial & TBD & 0.5 & TBD \\
\hline Tubular & Creep Rupture & 9 & Alloy $800 \mathrm{H}$ & Heat-xyz & air & 850 & Pressure + Axial & TBD & 0.5 & TBD \\
\hline Bar & Creep Rupture & 10 & Alloy $800 \mathrm{H}$ & Heat-xyz & air & 850 & Axial & TBD & 0 & TBD \\
\hline Bar & Creep Rupture & 11 & Alloy $800 \mathrm{H}$ & Heat-xyz & air & 850 & Axial & TBD & 0 & TBD \\
\hline Bar & Creep Rupture & 12 & Alloy $800 \mathrm{H}$ & Heat-xyz & air & 850 & Axial & TBD & 0 & TBD \\
\hline Tubular & Creep Rupture & 13 & Alloy $800 \mathrm{H}$ & Heat-xyz & air & 850 & Axial+Torsion & TBD & -0.5 & TBD \\
\hline Tubular & Creep Rupture & 14 & Alloy $800 \mathrm{H}$ & Heat-xyz & air & 850 & Axial+Torsion & TBD & -0.5 & TBD \\
\hline Tubular & Creep Rupture & 15 & Alloy $800 \mathrm{H}$ & Heat-xyz & air & 850 & Axial+Torsion & TBD & -0.5 & TBD \\
\hline Tubular & Creep Rupture & 16 & Alloy $800 \mathrm{H}$ & Heat-xyz & air & 850 & Torsion & TBD & -1 & TBD \\
\hline Tubular & Creep Rupture & 17 & Alloy $800 \mathrm{H}$ & Heat-xyz & air & 850 & Torsion & TBD & -1 & TBD \\
\hline Tubular & Creep Rupture & 18 & Alloy $800 \mathrm{H}$ & Heat-xyz & air & 850 & Torsion & TBD & -1 & TBD \\
\hline
\end{tabular}

